U.S. DEPARTMENT OF THE INTERIOR

U.S. GEOLOGICAL SURVEY

\title{
ANALYSIS OF EARTHQUAKE RECORDINGS OBTAINED FROM THE SEAFLOOR EARTHQUAKE MEASUREMENT SYSTEM (SEMS) INSTRUMENTS \\ DEPLOYED OFF THE COAST OF SOUTHERN CALIFORNIA
}

by

David M. Boore ${ }^{1}$

Open-File Report 97-733

This report is preliminary and has not been reviewed for conformity with U.S. Geological Survey editorial standards or with the North American Stratigraphic Code. Any use of trade, product, or firm names is for descriptive purposes only and does not imply endorsement by the U.S. Government.

$\overline{{ }^{1} \text { U.S. Geological Survey, MS }}$ 977, 345 Middlefield Rd., Menlo Park, CA 94025 


\section{ANALYSIS OF EARTHQUAKE RECORDINGS OBTAINED FROM THE SEAFLOOR EARTHQUAKE MEASUREMENT SYSTEM (SEMS) INSTRUMENTS DEPLOYED OFF THE COAST OF SOUTHERN CALIFORNIA}

INTRODUCTION . . . . . . . . . . . . . . . . . . ....... 1 SHORT HISTORY OF SEMS . . . . . . . . . . . . . . . . . . . . . . . . 4 AVAILABLE DATA AND DATA PROCESSING . . . . . . . . . . . . . . 6

Summary of Data Used . . . . . . . . . . . . . . . . . 6

Processing of Data

DATA INTERPRETATION . . . . . . . . . . . . . . . . . . . . . . . . . . . . . . 9

Preliminary Interpretation . . . . . . . . . . . . . . . . . . . . . . . . 9

Ratio of Vertical to Horizontal Spectral Amplitudes . . . . . . . . . . . . . 11

Effect of record duration on $P S V$. . . . . . . . . . . . . . . . . . . . . . . . 12

$V / H$ from recorded ground motions . . . . . . . . . . . . . . . . . . 13

Comparison of $V / H$ from offshore SEMS recordings and from onshore empirical regression analyses . . . . . . . . . . . . 14

Comparison of $V / H$ from offshore SEMS recordings and from selected onshore recordings . . . . . . . . . . . . . . 16

Peak motions as a function of distance . . . . . . . . . . . . . . . . . . . . 17 COMPARISON OF $V / H$ FROM SEMS RECORDINGS AND FROM THEORY . . 18

Velocity Model . . . . . . . . . . . . . . . . . . . . . . . . . . 18

Water layer . . . . . . . . . . . . . . . . . . . . . . . . . . . . 19

Shallow sediments . . . . . . . . . . . . . . . . . . . . . . . . . . 19

Crust . . . . . . . . . . . . . . . . . . . . . . . . . . 20

Results of Theoretical Analysis . . . . . . . . . . . . . . . . . . . . 21

Effect of water layer . . . . . . . . . . . . . . . . . . . . . . . . . 21

Effect of soil layer . . . . . . . . . . . . . . . . . . . . . . . . 23

Effect of deeper layers . . . . . . . . . . . . . . . . . . . . . . 23

Comparison of observed and theoretical spectral ratios . . . . . . . . . 24 SCALING OBSERVED SEMS RECORDS TO SIMULATE MOTIONS

FROM LARGE EARTHQUAKES . . . . . . . . . . . . . . . . . . . . . 24 CONSTRUCTION OF TIME SERIES FOR STUDIES OF

THE SEISMIC RESPONSE OF OFFSHORE PLATFORMS . . . . . . . . . . . 29 
Velocity Models . . . . . . . . . . . . . . . . . . . . . . . . . . . . . 29

Method . . . . . . . . . . . . . . . . . . . . 30

Results . . . . . . . . . . . . . . . . . . . . . . 31

CONCLUSIONS AND DISCUSSION . . . . . . . . . . . . . . . . . 31

ACKNOWLEDGMENTS . . . . . . . . . . . . . . . . . . . . . . . . 33

REFERENCES . . . . . . . . . . . . . . . . . . . . . . . . . 33

TABLES . . . . . . . . . . . . . . . . . . . . . . . . . 38-51

FIGURES . . . . . . . . . . . . . . . . . . . . . . . . . . . . . . .52-124

APPENDICES

Plots of Three Component Data . . . . . . . . . . . . . . . . . . . . 125

Contents of Subdirectories . . . . . . . . . . . . . . . . . . . . . . . 162

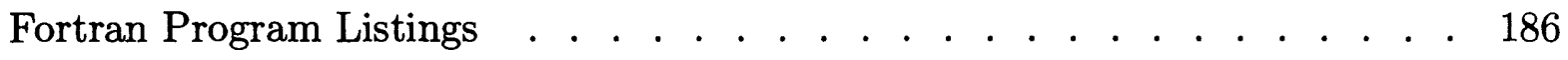




\title{
ANALYSIS OF EARTHQUAKE RECORDINGS OBTAINED FROM THE SEAFLOOR EARTHQUAKE MEASUREMENT SYSTEM (SEMS) INSTRUMENTS DEPLOYED OFF THE COAST OF SOUTHERN CALIFORNIA
}

\author{
by \\ David M. Boore \\ U.S. Geological Survey \\ Menlo Park, California
}

\section{INTRODUCTION}

Under the management and funding of the Minerals Management Service, seismometers have been installed on the ocean floor at various sites off of the coast of southern California. The program is called SEMS, for Seafloor Earthquake Measurement System. The purpose of the program is to characterize the nature of ground shaking from earthquakes for use in the design of offshore platforms used in petroleum drilling and production. I was asked to provide seismological analysis of the data obtained from the various SEMS sites, which I started to do in mid 1992. This report is the documentation of work that I have done on the project.

The following is a brief listing of the tasks accomplished; later sections of the report give full details of the work.

- Data Processing: This involved writing computer programs for reformatting data into standard file formats, correcting some of the data for an inappropriate low-cut filter, plotting time series and Fourier spectra, determining low-cut filter frequencies, applying these filters, and computing velocity and displacement traces, as well as response spectra.

- Data Interpretation: Because of the lack of onshore data for distances comparable to those from the source to the SEMS sites, the empirical interpretation of the data focused on the ratio of response spectra for the vertical and horizontal components $(V / H)$ as a function of period. Comparisons to the few available ratios and to the ratios derived from regression analysis of strong motion data clearly shows the 
offshore ground motions to have anomalously low ratios for short period response. The differences between the average onshore and offshore ratios become smaller as period increases, but still persist at periods as long as 2 sec. A preliminary study suggest that the differences at the longer periods are more a function of the average shear-wave velocities under the site than to whether the site is offshore or onshore. An anomalous $V / H$ does not indicate whether the anomaly is in the vertical or the horizontal components. To study this I plotted the response spectra for a particular period as a function of distance from the earthquake (for the one earthquake with available onshore data at proper distances and azimuth); predictions from the regression analysis of strong motion data were also included in the plots. These plots indicate that the anomalous $V / H$ at short periods is due to very low values for the vertical component, a conclusion reached by Sleefe (1990) by plotting peak accelerations from on- and offshore records.

- Comparison of Observed and Theoretical $V / H$ : Owing to the sparsity of SEMS data available to me in the early stages of the project, I spent considerable effort on theoretical calculations of wave propagation in earth models simulating the offshore environment. This involved deriving velocity models, learning to run the wave propagation codes, doing the runs, writing programs to reformat the data, and making and analyzing plots of the results. Comparisons of observed and theoretical $V / H$ for Fourier spectral amplitudes are in good agreement. The theoretical calculations also allowed parameter studies to aid in understanding the significance of various aspects of the earth model on the ground motions. In particular, I found that the water layer made almost no difference to the horizontal components of the motion, although it did influence the vertical components of the $S$ wave at frequencies related to the depth of water (around $6 \mathrm{~Hz}$ for depths of 60 to $70 \mathrm{~m}$ ); the effect is negligible for periods near the resonant period of the platforms. This is not to say that the water is not an important factor, for it does allow relatively low shear-wave velocities to exist over wide regions. There are onshore locations with comparably low velocities, but they are sometimes fairly restricted in spatial extent.

- Long-Period Waves in Basins: The SEMS unit offshore from Long Beach recorded excellent late arriving waves from the $\mathbf{M}=5.6$ Upland earthquake that occurred in 1990. The path from the source to the station traversed the Los Angeles basin, 
and these waves are quite similar to those passing through the basin from larger earthquakes. I used the $\mathbf{M}=5.6$ recordings as a Green's function and predicted the motions from larger earthquakes using various source scaling relations. The results emphasize the potential importance to seismic design of these long period waves from large earthquakes.

- Construct Time Series for Studies of the Seismic Response of Offshore Platforms: This study was done at the request of Charles Smith of MMS to aid him in his analysis of the structural response of offshore platforms. The motions were computed for a site close to the source, using full wavefield calculations to account for wave propagation along the path and near the site and a stochastic source model to account for source complexities.

This report has sections on each of the tasks discussed above. Unannotated listings of the various working directories for the project are included in the appendix, along with listings of the Fortran programs written for the project.

The results clearly show that the offshore motions have very low vertical motions compared to those from an "average" onshore site, particularly at short periods. To decide whether this is fundamentally due to the presence of the water layer or is simply a result of wave propagation in the low velocity sediments beneath the sea floor requires more extensive analysis of onshore recordings from sites underlain by shear-wave velocities comparable to those beneath the offshore sites. Adequate data to do this were not available during the course of this study, so the study is incomplete in this regard. Just recently I have learned of a number of onshore recordings of the 1990 Upland earthquake that should be very useful for the onshore/offshore comparison discussed above. Studies of these data will be completed as time permits, but any such studies are clearly beyond the scope of the funding provided for this project.

The seafloor environment and the water column exert a strong influence on vertical motions at relatively high frequencies (frequencies near that of the fundamental $P$-wave resonance in the water column, which is about $5.5 \mathrm{~Hz}$ for $70 \mathrm{~m}$ of water) and undoubtedly lead to large differences between onshore and offshore motions. It is easy to get caught up in trying to elucidate and understand these effects, but the importance of these high frequency, "mud-line" motions to the seismic response of offshore platforms may be very 
limited. I have tried to avoid concentrating on these high-frequency motions.

\section{SHORT HISTORY OF SEMS}

The data analyzed in this report were obtained from instrumentation installed on the sea floor by the Seafloor Earthquake Measuring System (SEMS) project. The objective of this system was to obtain ground shaking data on the sea floor that could be used to evaluate the design of offshore oil platforms. The SEMS instrument development, deployment, and data recovery were carried out by Sandia National Laboratory, with funding from the Minerals Management Service. A history of the SEMS is contained in Reece et al. (1981), Ryerson (1981), Sleefe and Engi (1987), Sleefe (1990), Smith (1990), Smith (1991), and Smith (1994). I will give only a brief synopsis of the SEMS project.

The SEMS was developed in a number of stages, although all used digital recording. These are usually referred to as SEMS I, SEMS II, SEMS III, and SEMS IV (in this report I refer to them using standard numbers rather than Roman numerals.... thus, SEMS1, SEMS2, SEMS3, and SEMS4), or more briefly, S1, S2, S3, and S4). I have analyzed data from SEMS1, SEMS2, and SEMS4. Here is a brief summary of each stage of the project.

SEMS1: A 3-axis accelerometer was embedded several meters below the sea floor, and the output from the accelerometer was fed to a self-contained instrument package resting on the sea floor. This package digitized the input at a rate of 100 samples per sec and stored the data on board. Data recovery was via an acoustic uplink to a ship deployed specifically for data recovery. The SEMS was installed at several offshore locations and at one onshore location. I have analyzed data from the onshore location (S1VC) and a nearby offshore location (S1HN) near platform Henry in the Santa Barbara channel (See Tables 1 and 2 for station information, Tables 3 and 4 for earthquake information, and Table 5 for the sites that recorded each earthquake, as well as earthquake-to-station distances).

SEMS2: The system was redesigned to have a longer system life, and was deployed near platforms Elly and Ellen, off of Long Beach. In other respects the system was similar to that of SEMS1 (a triggered system with data storage in a unit on the seafloor, using an acoustic uplink for data retrieval). I use the notation "S2LB" for this system. I have analyzed data for two earthquakes occuring in 1986, the North 
Palm Springs and the Oceanside earthquakes.

SEMS3: The system was again redesigned, using better batteries, electronics, and triggering algorithm. The result was a longer-life, more sensitive system with fewer false triggers. A major improvement was in using data from horizontal as well as the vertical component in the triggering algorithm (the SEMS1 and SEMS2 units used only vertical component, which, as I will show, generally has anomalously low amplitudes of motion). The system was deployed at two locations, one near the SEMS2 package off of Long Beach (S3EE), and another off of Point Pedernales, near platform Irene (S3IR). This latter site used a datalogger on board the platform, connected via a cable to the sensor, which was embedded in the seafloor. Apparently the hole did not slump in, and this, combined with cable drag due to strong currents, limited the usefulness of this installation. The only data from a SEMS3 unit used in this report is that from the 1990 Upland earthquake recorded on S3EE (the recordings for this event, however, are very high quality and useful; their durations and signalto-noise ratios permitted the recording of late arriving long-period surface waves). Unfortunately, recordings of the 1992 Landers earthquake and aftershocks were lost because the seafloor data acquisition system had been dragged away, apparently by a fisherman's net. This is very unfortunate, because that earthquake is the largest to have struck southern California since 1952. The long-period motions of most concern to platform design were very strong for that earthquake, and as a result they were well recorded on conventional strong-motion instruments onshore, thus providing an excellent set of onshore motions against which to check the offshore motions (this has been a problem with most of the SEMS recordings: the earthquakes were far enough away and of low enough magnitude that conventional onshore strong-motion recorders either did not trigger or did not record signals that could yield reliable long-period information; in contrast, the SEMS unit can faithfully record these weak motions). It has just come to my attention (August, 1997) that the Upland earthquake was well recorded by the USC strong-motion network, although it does not appear that the accelerographs recorded for a long enough duration to obtain the largest amplitude, late arriving long-period motions that control the response of long-period oscillators. The records should be useful in understanding the differences in response spectra at shorter periods. Although the data are clearly of relevance, analysis of these data are beyond the scope of the funding provided for this project. In addition, the time 
involved in obtaining these data would significantly delay the completion of this report (which is long overdue anyway).

SEMS4: To address the problem of data recovery from stand-alone sea-floor installations, it was decided to deploy a new system - SEMS4 - using a commercial 24bit datalogger on a platform, with a cable connecting the sensors to the datalogger. The dataloggers also have dialup capability, making it possible to interrogate the units remotely. The loggers are being run at 20 samples per sec. The sensors are force balance accelerometers almost flat to acceleration between 0.4 and $1500 \mathrm{~Hz}$ (the response at $1 \mathrm{~Hz}$ is nominally down by $3 \mathrm{db}$ relative to the $100 \mathrm{~Hz}$ response); the low frequency rolloffs starts at about $0.4 \mathrm{~Hz}$ (see notes in Table 2). Three systems have been deployed, near platforms Eureka (S4EU), Grace (S4GR), and Irene (S4IR). Records of earthquakes in 1995 and 1997, recorded by S4GR and S4IR, are analyzed in this report (to my knowledge, no data have been obtained from S4EU).

It is my understanding that the SEMS4 instruments have been turned over to the California Strong-Motion Program of the California Division of Mines and Geology, who will operate the stations and collect and disseminate the data.

\section{AVAILABLE DATA AND DATA PROCESSING}

Summary of Data Used

The data used in this report included the largest events recorded on the SEMS units. The stations from which data were obtained are listed in Table 1 and Table 2 . Table 1 contains a short summary of basic information for each station, while Table 2 contains various notes that I made while working on the project. The earthquakes used are summarized in Table 3 and 4. As for the station information, the first of the two tables contains basic information for each earthquake, while the second table (Table 4) contains working notes for each event, including references for the earthquake magnitude and focal mechanism. Table 5 is a convenient summary of which stations recorded which earthquakes. The entries in the table are epicentral distances. A map showing the locations of the recording stations and the earthquakes is given in Figure 1. Several important items regarding the data available for this study can be gleaned from Table 5: 
- With one exception, each earthquake was recorded on only one of the offshore SEMS stations. The exception is the first Simi Valley, 1997, aftershock of the 1994 Northridge earthquake. This event was recorded on two SEMS4 stations: S4GR and S4IR. (Note that the SF71 event provided data at two onshore sites but not at any offshore sites; I have included this event in Table 5 because later I compare these data to the S3EE recording of the Upland, 1990, earthquake.) The lack of multiple offshore recordings for a given event limits, to an extent, the interpretation of the data.

- A more important limitation than the lack of multiple offshore recordings is the relative scarcity of onshore data at sites near the offshore sites (by near, I mean along the same general azimuth from the earthquake to the SEMS site, and at distances as close to the SEMS site as the coastal configuration allows; for the earthquakes listed in Table 3 there are usually numerous recordings of ground motion, but at epicentral distances much smaller than the epicentral distances to the SEMS stations). As Tables 3 and 5 show, most of the SEMS records were obtained from moderate size earthquakes at distances in excess of $70 \mathrm{~km}$. The standard analog, onshore accelerographs do not have the sensitivity to provide digitizable data at these distance for the earthquakes recorded on the SEMS sites. The only earthquake for which I was able to obtain onshore and offshore data is the Santa Barbara Island, 1981, earthquake, which was recorded on 3 onshore stations, one of which was a SEMS unit installed onshore, near Vic Trace Reservoir. The other two recordings, SC38 and SC51, were obtained on standard analog accelerometers maintained by the University of Southern California (USC). Only recently have onshore instruments with performance characteristics comparable to those of the SEMS units been installed in the southern California region (the SEMS units were ahead of their time!). As mentioned earlier, I recently found out that numerous onshore analog recordings of the Upland, 1990, earthquake are available. A cursory perusal of a preliminary digitization of these data (using a 300 dpi scanner) indicates that the data will be useful for some aspects of this study. Unfortunately, the instruments did not record for a long enough time to capture the long-period basin waves that are of particular importance to platform response. The data need to be digitized using a scanner with higher resolution. Not knowing when the new digitization will be available, nor what other demands will be placed on my time, I decided to write this report before obtaining these newly digitized data. 
- Several sites recorded different earthquakes, thus allowing a check on the stability of the ratio of motions on the vertical and horizontal components. These sites include S2EE, with 2 recordings, S4GR, with 3 recordings, and S4IR, with 2 recordings. In addition, sites S2EE and S3EE were close to one another, so if counted as one site, 3 recordings are available for these sites.

Other data than those listed in Table 5 have been recorded by the SEMS units. To my knowledge, there have been smaller earthquakes than those used in this study (e.g., Reece et al., 1981, discuss data from a magnitude 3.2 earthquake recorded at S1HN and S1VC), but none of these data have been made available to me. In addition to the SEMS stations, several platforms have been instrumented by the oil company responsible for the platform, and apparently data from these installations have been obtained. For example, Chen et al. (1989) and Mason et al. (1989) discuss records on and beneath platform Grace obtained from the 1987 Whittier Narrows earthquake (this event was not recorded on any SEMS stations). Several of the recordings were obtained at depths down to about $100 \mathrm{~m}$ below the platform; finite element calculations show that these records are little influenced by the platform and therefore can be considered to be free-field records. These data should be very useful in understanding the response of the site to ground shaking.

\section{Processing of Data}

The processing involved several steps:

- Reformatting the data into a common format: I chose the SMC file format used for the strong-motion data produced and disseminated by the U.S. Geological Survey. This format is described in the documentation accompanying the program BAP (Basic Accelerogram Processing) by Converse (1992). The file format of the data provided to me was different for the various generations of SEMS, and therefore I had to write different Fortran programs to reformat each data set. As part of the process of reformatting SEMS4 data, I found that the whole extent of the data could not be used because of artificial steps at the front and back of the time series. I reformatted the data as provided, plotted the time series, and then extracted the good portion of the data (which was almost all of the data; the offsets only affect the beginning and end). The file names I have used for the basic time series data sometimes have "smc" as a file extension, and other times I have used the standard notation used by Seekins 
et al. (1992) in their compilation of strong motion data. For example, 247p51s1.hne is the $e$ horizontal component at station $s 1 \mathrm{hn}$ for the 1981 Santa Barbara Island earthquake. Note that because of file length limitations in DOS, the four character station code is split by the period ( $s 1 \mathrm{hn}$ becomes $s 1 . h n)$. The first three characters of the file name (247) give the Julian day of the earthquake and the next 3 characters ( $p 51)$ are a code related to the origin time of the event.

- Determining Low-Cut Filter Parameters: The first thing I did after reformatting the data was to compute and plot whole-record Fourier spectral amplitudes. Looking at these gave me some indication of what cut-off frequencies $\left(f_{c}\right)$ to use in the processing. This is a subjective process, but various trials with different frequency cut offs showed me that the response spectra are only affected for periods longer than about $0.5 / f_{c}$ (Figure 2). The frequency cut offs used in this report are given in Table 6. In this report I have generally used response spectra for period less than or equal to $2.0 \mathrm{sec}$. With the exception of the two S2EE recordings, the choice of $f_{c}$ should not affect the response spectra used in this report (as Figure 2 shows, the response spectra at $T=2 \mathrm{sec}$ for the two $\mathrm{S} 2 \mathrm{EE}$ recordings are somewhat affected by the cut-off frequency).

- Integrate the Filtered Time Series to Produce Velocity and Displacement Time Series and 5\% Damped Pseudovelocity Response Spectra (PSV): I used the program BAP to filter and integrate the time series. Three-component plots of the acceleration, velocity, and displacement time series for all records used in this report are contained in Appendix A. Plots of individual response spectra and Fourier spectra are not included in this report.

\section{DATA INTERPRETATION}

\section{Preliminary Interpretation}

Visually, the accelerograms recorded on the SEMS units look much like those from onshore sites. As an example, Figure 3 shows three components of motion for the 1990 Upland earthquake; because the units have pre-event buffers, the initial P-wave motion has been captured (unlike the records from analog accelerographs), and the $\mathrm{P}$ wave is followed by a clear $\mathrm{S}$ arrival, which is followed by a slowly decaying coda or tail. The vertical 
component is small relative to horizontal components, but it is possible to find onshore records with comparable relations between the components.

The acceleration, velocity, and displacement time series for the 1990 Upland SEMS recording are shown in Figure 4, 5, and 6. The acceleration traces are largest near the beginning of the record, and they decay to small motions at the time of arrival of the large amplitude long-period waves. The outstanding feature of these figures are the late arriving, long-period $(\approx 6 \mathrm{sec})$ motions on all three components. These motions are not unexpected, for the travel path (Figure 1) traverses the Los Angeles basin, and the waves resemble the surface waves that have been observed to propagate in the basin. In seismological terms, the peak accelerations are probably carried by body waves, while the long-period arrivals are surface waves.

The motions in the displacement traces are low amplitude (peak displacement of about $1 \mathrm{~cm}$ ). The amplitudes of the motions are below the noise threshold of normal analog strong-motion instruments, and it is natural to question whether the motions faithfully reproduce the ground motion or whether they are nothing but long-period noise. A qualitative check on the motions is to compare plots of the time series with those from other, larger events recorded at sites for which the waves have traveled comparable distances through the Los Angeles basin. I have done this for two recordings of the 1971 San Fernando earthquake ( $M=6.6)$, recorded at Costa Mesa $(\mathrm{CM})$ and Palos Verdes (PV). According to Hanks (1975), there is no question that the long-period motions for these earthquakes are signal and not noise. The stations, earthquake location, and paths are shown in Figure 1. Comparative plots of acceleration, velocity, and displacement are shown in Figures 7, 8, and 9 (I have chosen the horizontal component from each record that best matches the various records). I have lined up the records on the $\mathrm{S}$ arrival for the SEMS record and on the beginning of the record for the onshore records (it appears that the onshore records were triggered shortly after the $\mathrm{S}$ arrival; the late triggering will have little affect on the late arriving waves). The comparison shows the records to be in good qualitative agreement: the displacements increase in time, with the largest displacements occurring 45 to $60 \mathrm{sec}$ after the initial $\mathrm{S}$ arrival. The peak displacements are carried by waves with periods near 5 sec. Exact agreement of the waveforms for the various recordings is not expected; the earthquakes were different in magnitude and in travel path. The source duration for the Upland quake was probably shorter than the period of dominant 
displacement motion (making the record a good Green's function...more on this later), but this is not the case for the San Fernando recordings, for which the source duration and period of dominant displacements is comparable. The comparisons in Figures 7, 8, and 9 give confidence that the SEMS long period motions are signal, not noise.

As an aside, I note that recorded durations from instruments triggered on acceleration levels (such as the ubiquitous analog strong-motion accelerographs) might be too short to capture the peak displacements (in fact, it is not clear that the peak motions have in fact been captured on the traces shown in Figure 9; this may be particularly so for the CM recording). If the duration of recording following the initial trigger is set to less than about $60 \mathrm{sec}$, then it is possible that the largest displacements will not be recorded.

\section{Ratio of Vertical to Horizontal Spectral Amplitudes}

Because the earthquakes recorded at the SEMS sites were generally not recorded at nearby onshore sites, it is difficult to make a direct assessment of the agreement between onshore and offshore motions (ground motions depend on many variables, such as earthquake size and style of faulting, distance from the source, propagation path, and local site geology; a comparison of only a few recordings is worthless unless adequate corrections can be made to remove these influences on the amplitudes of the motions). The ratio of vertical to horizontal motions $(V / H)$, however, might be expected to remove all but the effect of local geology, at least to first order. By comparing ratios it would then be possible to compare a few onshore and offshore recordings to see if they were comparable or not. I have done that here. I have also compared the ratios from offshore recordings with those predicted from regression analyses based on hundreds of onshore recordings from many earthquakes; this provides a measure of comparison that represents the average ratio for a typical site and earthquake of a specified magnitude and distance. In addition, I have compared the average $V / H$ for offshore SEMS sites to the $V / H$ from a few onshore recordings for which the shear-wave velocities beneath the recording sites are similar to the velocities I estimate to exist beneath the SEMS offshore sites.

I have studied both ratios of Fourier spectra and ratios of response spectra. The Fourier spectra are more directly related to site transfer functions, but the response spectra have the advantage of having relations available from the analysis of numerous onshore recordings, which provide a well-founded mean expectation for onshore recordings. 
This method of analysis, but using $H / V$ rather than $V / H$, has been applied by a number of seismologists to extract information about site response (Field and Jacob, 1995, and references therein; Atakan and Havskov, 1996). This method is often referred to as "Nakamura's method", after the application by Nakamura (1989) to obtaining site response by using microseismic noise. The basic assumption that makes this method work for extracting site response is that the vertical component motion is little affected by the sediments; as I will show later, this is a poor assumption at frequencies near the resonant frequency of $\mathrm{P}$-waves in the water column, and therefore the method may not work well for offshore recordings. In addition, site response obtained using $H / V$ are sometimes in agreement with those from other methods only at frequencies near the fundamental mode of the soil response (assuming the soil layers have a clearly defined resonance), and then only in the frequency of resonance but not in the amplitude of the response. For these reasons, I have not used the ratios as a means for estimating site response.

Effect of record duration on PSV: As mentioned earlier, it is not clear that the recorded motions have captured all of the long-period motion. I have studied this by computing response spectra for one of the horizontal traces of the S3EE recording of the Upland 1990 earthquake, using progressively shorter durations of the time series. Figure 10 shows the set of time series for acceleration, and Figures 11 and 12 show the velocity and displacement time series. The terminology "T40" (and similarly, "Tcut = 40"), etc., refers to the length of time series before padding with zeros at the front and back of the record; this zero padding is done by the processing program BAP to reduce the effect of the tails of the noncausal filters used in the processing. The displayed time series include the zero pads. The velocity time series (Figure 11) suggests that intermediate periods (around $1 \mathrm{sec}$ ) will be captured on all but the T40 record. In contrast, the displacement time series suggests that the long period motions late in the record will be missing from all but the T90, T80, and possibly the T70 records. A quantitative assessment of this is given in Figure 13, which shows response spectra computed for the set of traces shown in Figure 10. From this comparison it can be seen that for periods longer than about $2 \mathrm{sec}$, durations longer than the T60 duration are required to capture the complete oscillator response. If late arriving basin waves are present (such as control the response for periods greater than 4 secs), durations equal to or exceeding the T80 duration are required. Many analog onshore strong-motion accelerographs do not record for a long enough duration to capture these basin waves, particularly at the large distances for which the basin waves are well formed 
(and for which the peak accelerations, which control the triggering of the film recorder, are small).

The difference in the response around $6 \mathrm{sec}$ between the Tcut $=70$ and the Tcut $=80$ and 90 time series is a bit surprising, for it seems from the displacement traces in Figure 12 that the T70 trace captured at least one cycle of the large amplitude late-arriving energy (note that the peak displacement for T70 is similar to that of T80 and T90, but the response spectra at $6 \mathrm{sec}$ differ by more than a factor of 2). To see why this is so, I show in Figure 14 the input accelerations and 6 sec oscillator response for T70, T80, and T90 (note that each trace in the figure is scaled individually). This comparison clearly shows that the T70 record did not capture the long period response.

The results above show that long-period response is sensitive to record duration. This might be a problem with some of the SEMS records. (The long period response for some of the SEMS units is also problematical because I judge that noise dominates the motions; see the cut-off frequencies in see Table 6). The question then arises as to what periods to use in the analysis. Since I am particularly interested in $V / H$, I show in Figure 15 the $V / H$ ratios for the various record durations. From this it seems that response spectral ratios should be OK for periods less than about $2.0 \mathrm{sec}$ (the biggest difference shows up for the Tcut $=40$ trace, but I judge that most of the SEMS recordings have longer effective durations). This cutoff means that long-period basin waves, such as those in the SEMS recording of the 1990 Upland earthquake, will not be included in the analysis.

$V / H$ from recorded ground motions: With this preliminary work out of the way, I now present the results of forming ratios of vertical to horizontal ground motion. I first show results from recordings of the 1981 Santa Barbara Island earthquake, which was recorded on an offshore station and several onshore stations (Figure 1). The ratios of $5 \%$ damped response spectra and Fourier amplitude spectra are shown in Figures 16 and 17, respectively. In these figures the geometric average of the two horizontal components has been used for the denominator. In both plots it is clear that the offshore recording (S1HN) has a much different $V / H$ than for the onshore recordings. The difference is largest at short periods and tends to decrease at long periods. An explanation for this behavior in terms of wave propagation is given later.

Several events were recorded at the same station (Table 5). It is interesting to compare 
$V / H$ for the multiple earthquakes at a given site to assess the stability of the ratio. Similar ratios for different events might suggest that the ratio is strongly controlled by local site conditions, particularly if the events are different magnitude and have different travel paths to the site. Figures 18, 19, and 20 show such comparisons for three sites: S2EE, S4GR, and S4IR. In general the ratios at a given site are similar to one another. There is also a general trend shared by all sites for the ratio to increase with period, although individual sites have distinct characteristics (in particular, compare S2EE to S4IR).

I compare ratios of response spectra at all offshore sites in Figure 21 and ratios of Fourier spectra for earthquakes through 1990 in Figure 22. These figures show considerable scatter, which the preceding figures suggest is largely due to site-to-site variations in the ratio of vertical to horizontal motion. The differences are larger for short periods than for long periods, which is what I expect in view of possible lateral variations in shear-wave velocity, as well as the influence of the water column on the higher frequency vertical motions. The ratios are similar enough in overall trend, however, to justify computing an average $V / H$ as a function of period for purposes of comparing with average onshore relations. In the next section I compare the average offshore response spectral ratios to regression-based average onshore spectra. Later in the report I compare the ratios of Fourier amplitude spectra to theoretical predictions.

Comparison of $V / H$ from offshore SEMS and from onshore regression analyses: Two recent sets of regression analyses were used to provide onshore ratios of vertical and horizontal components. These are Abrahamson and Silva (1997) and Campbell (1997). The Abrahamson and Silva relations, hereafter referred to as "AS97", were derived from data recorded at distances as large as $200 \mathrm{~km}$; in contrast, the Campbell relations ("C97") only used data for distances less than or equal to $60 \mathrm{~km}$. Both AS97 and C97 give equations for the vertical and horizontal components separately; I formed $V / H$ from the individual components predictions. The regression-based predictions are a function of style of faulting, site condition, magnitude, and distance. For C97 I used a basement depth of $2.0 \mathrm{~km}$. I first show some figures illustrating the variation expected for some of these quantities. In all cases I show results for "soil" sites. By this is meant the average soil site represented by the collection of strong-motion stations. Many of these stations are on stiff soil, and the analysis of velocities from boreholes, many of which are colocated with strong-motion stations, finds that the average shear-wave velocity in the upper $30 \mathrm{~m}\left(V_{30}\right)$ for a typical 
soil site is $310 \mathrm{~m} / \mathrm{s}$ (Boore and Joyner, 1997). As I show later, the shear-wave velocities beneath the SEMS offshore sites are probably lower than at a typical onshore soil site, with $V_{30} \approx 220 \mathrm{~m} / \mathrm{sec}$.

Figures 23 and 24 give the ratios for AS97 for a suite of distances and $\mathbf{M}=5.0$ (Figure 23) and $\mathbf{M}=6.0$ (Figure 24). (Recall that most of the SEMS recordings are for magnitudes between 4.7 and 6.1 and distances from 66 to $309 \mathrm{~km}$ ). It is clear that $V / H$ can have considerable distance variability, depending on oscillator period and magnitude. Figure 25 compares $V / H$ for magnitudes 5 and 6 and a suite of fault types. This figure shows that fault type is not an important factor for $V / H$. Figure 26 is similar to Figure 25 , but it uses the $\mathrm{C} 97$ regression results. In this case, C97 does not distinguish between reverse (Mech 1.0) and oblique (Mech 0.5) faults. As for AS97, Figure 26 shows that fault type is not an important factor. A comparison of $V / H$ for AS97 and C97 is shown in Figure 27 for two magnitudes ( 5 and 6 ) and the greatest distance for which the $\mathrm{C} 97$ results are valid $(60 \mathrm{~km})$. The differences between the results are a crude estimate of the epistemic uncertainty due to lack of data, as well as different assumptions regarding databases and regression procedures.

I turn now to comparisons with the SEMS results. Figure 28 shows ratios from the SEMS and USC recordings for the 1981 Santa Barbara Island earthquake and the regression-based ratios. In this case the regression-based ratios are in much better agreement with the onshore ratios than with the offshore ratio. I judge that with the possible exception of SC38, the onshore sites are underlain by materials with higher shearwave velocities than is the offshore site (SC38 is described to be on dune sand in Anderson et al. (1981), whereas S1VC and SC51 are on marine terrace deposits), and therefore I would expect the spectral ratios for the onshore sites to be more similar to the ratios from regression-based results than for the offshore site.

Figure 29 shows a comparison between the regression-based onshore results and the average of the SEMS offshore results (using two types of averaging - arithmetic and geometric). In view of the distance dependence of $V / H$ shown earlier, it may be argued that I should make the comparisons on an event-by-event basis. This would lead to more figures than necessary, and the basic conclusions can be derived from a comparison with the average ratio. In so doing I use a distance for AS97 of $120 \mathrm{~km}$, which is close to the geometric mean distance of $113 \mathrm{~km}$ for the events used in forming the ratio. The 
regression-based results for C97 were evaluated at the greatest distance- $60 \mathrm{~km}$ - for which his equations are valid. Included in the comparison in Figure 29 are results from analyses of specific earthquakes (Loma Prieta 1989 and Northridge 1994), as well as results from the SMART1 array in Taiwan. In general, the onshore results are above the SEMS offshore results, and the difference is largest at short periods.

The large difference between average onshore sites and the SEMS offshore recordings at short periods is consistent with the findings of Sleefe (1990), who made scatter plots of peak accelerations, with horizontal components on one axis and vertical components on the other. Using different symbols for offshore and onshore recordings, he clearly found two populations separated in the same sense as I found for response spectra and Fourier spectra. In addition, Smith (1990) found that $V / H$ for peak acceleration and peak velocity from offshore sites was smaller than for onshore sites, again in qualitative agreement with the findings from the spectral ratios.

At longer periods a difference between AS97 and C97 and the SEMS results still persists, but the difference is much smaller than at short periods. The C97 results are closer to the SEMS results than are the AS97 predictions, but recall that the C97 results are for $D=60$; the AS97 distance dependence produced an increase of $V / H$ with distance, which if true for C97 would lead to larger values for $D>60 \mathrm{~km}$, and therefore the C97 ratios would be more discordant with SEMS ratios than shown in the figure. Although the AS97 and C97 ratios are higher than the SEMS ratios at all periods, it may be significant that the SMART1 results produce somewhat lower values of $V / H$ than the SEMS values for periods in excess of about $0.6 \mathrm{sec}$ (and if the distance dependence shown in Figures 23 and 24 holds for the SMART1 data, then applying a distance correction to go from the ratios at $50 \mathrm{~km}$ to the average distance from the earthquakes to the SEMS recordings would likely result in SMART1 ratios being in good agreement with the SEMS ratios). The SMART1 site is underlain by low velocity materials and as shown in the comparison of shear-wave velocities in Figure 30, may be a closer analog to the average SEMS offshore site than the average soil class represented by the other regression results. (The estimation of the offshore SEMS velocities is discussed in more detail later in the text.)

Comparison of $V / H$ from offshore SEMS and from selected onshore recordings: The relatively good agreement at longer periods between the spectral ratios from the offshore SEMS recordings and the recordings on the SMART1 array, as well as the agreement in 
velocities, suggests that at longer periods the comparison between offshore and onshore ground motions is more a function of the sediments underlying the sites than it is on the presence or absence of a layer of water above a site. In other words, a hypothesis can be made that the ground motions will be the same if the depth dependence of the shear-wave velocities is the same, regardless of whether the site is an offshore or an onshore site. An obvious test of this hypothesis is to compare $V / H$ for offshore and onshore sites underlain with similar velocities. I have made a limited test of this hypothesis. Figure 30 compares velocities estimated at offshore SEMS sites and velocities from several onshore sites: the LSST site within the SMART1 array, two sites near the edge of San Francisco Bay, and a site in the Imperial Valley. Three-component acceleration time series for recordings at the latter three sites are given in Figure 31, along with the offshore recordings of the 1990 Upland earthquake at S3EE. The general character of the time series is similar, but the S3EE recordings has smaller vertical accelerations relative to the horizontal accelerations. A more precise comparison of the motions is given by the ratios of response spectra, as given in Figure 32 (Figure 32 also contains the regression-based results discussed earlier). It is clear that the spectral ratios at longer periods from onshore sites can be lower than from offshore sites; the apparent bias between the offshore and onshore ratios at longer periods noted in Figure 29 may be due to the fact that the onshore regression-based ratios are from soil sites underlain by shear-wave velocities higher on average than those under the offshore sites. Figure 32 gives some support for the hypothesis that the comparison of the ground motions at longer periods is most strongly controlled by the underlying shearwave velocities. The figure also emphasizes the dramatic difference between offshore and onshore ground motions at shorter periods.

Peak motions as a function of distance: The previous figures show a clear difference in $V / H$ at short periods between the offshore and onshore recordings. Is this due to onshore vs. offshore differences in the vertical or the horizontal components, or both? To investigate this, I plotted response spectral amplitudes for a few selected periods as a function of distance from the earthquake. I considered only the 1981 Santa Barbara Island data, for which both onshore and offshore data are available. Plots for the horizontal components are given in Figures 33 through 37 and for the vertical components in Figures 38 through 42. Included on these plots are the regression-based results of AS97 and C97. From these plots, it is clear that the offshore vertical component is always smaller than the SEMS and USC onshore vertical components (after accounting for the attenuation with distance); 
the difference is greatest at short periods. The same is not always true for the horizontal components. This comparison is strong evidence that the very low values of $V / H$ at short periods are due to small values of $V$, rather than large values of $H$. A similar conclusion was drawn by Smith (1994), who plotted peak accelerations against distance for vertical and horizontal components.

The comparison of the SEMS results with regression-based results in Figures 33 through 42 is less useful; for longer periods both offshore and onshore $V$ and $H$ are below the regression-based results. From this comparison with the empirical results I conclude that it would be meaningless to base a conclusion regarding differences between onshore and offshore motions on a comparison of only an offshore recording with the regressionbased results; onshore and offshore motions from the same event are needed.

\section{COMPARISON OF $V / H$ FROM SEMS RECORDINGS AND FROM THEORY}

It is instructive to compare the observed ratios of vertical and horizontal motions with theoretical computations. Such a comparison helps in understanding the physical mechanism leading to the particular observed ratios and can be used to assess the motions expected in cases for which data are not available.

\section{Velocity Model}

The first step in the procedure is to derive velocities as a function of depth below a typical site (sufficient information was not available to do a site-by-site evaluation; in view of the overall agreement in the spectral ratios for all of the SEMS sites, this should not be an important limitation. Site-specific velocity structures, however, undoubtedly explain some of the site-to-site variations.) I could find no direct measurements of the velocity, and therefore I had to estimate the velocity from available information and from analogs to other onshore sites for which velocity information is available.

I chose to break up the model into three layers: water, $0.1 \mathrm{~km}$ of soft sediments, and underlying crust. I did the calculations using various combinations of these three components to understand the influence of each. 
Water layer: I used a water depth of $60 \mathrm{~m}$, which is appropriate for a number of the SEMS sites that I studied (see Table 1).

Shallow sediments: I obtained lithologic data and standard penetration data for three borings near SEMS station S3EE. The logs indicate that the most of the sites are underlain by sands and silts, with some clay present (the deeper sites may be subject to less current scouring and may be underlain by more clay - logs near platform Eureka near S4EU indicate this to be the case). T. Fumal of the USGS estimated shear-wave velocity from this information, based on his experience with correlations between SPT and shear-wave velocities (e.g., Fumal, 1978). His estimates are labeled "hole 261-1", "hole 261-3", and "hole 262-1" in Figure 43. Also included on this plot are shear-wave velocities from Hamilton (1976a) for ocean-bottom sediments, velocities determined by L. Dorman (written communication, 1997) for a site offshore of southern California, near Camp Pendleton, and velocities for several sites off the coast of Norway for which the water depths are comparable to those for the SEMS stations (Rognlien, 1987). Based on these velocities for ocean-bottom sites on continental shelves, I derived a model of velocities in the upper $100 \mathrm{~m}$; these velocities are shown in the figure.

It is instructive to see how the offshore velocities in Figure 43 compare to those from onshore boreholes close to Long Beach. Figure 44 shows a map of USGS boreholes in the vicinity, and Figure 45 shows the velocities, along with the SEMS model. The velocities separate into two groups, which the map indicates are well correlated with the age of the near-surface sediments: with one exception (BH16), the lower velocities correspond to Holocene sediments, while the higher velocities correspond to the Pleistocene sediments, which are older (for those sites with Holocene sediments at the surface, BH44 is unusual in that the low-velocity Holocene sediments are underlain by much higher-velocity shales). The adopted SEMS model is in good agreement with the Holocene velocities.

Another comparison of the SEMS model was previously given in Figure 30, in which the onshore velocities come from farther afield: the Imperial Valley, sites near San Francisco Bay underlain by clay, and Taiwan. The adopted SEMS model has higher velocities near the surface than the clay sites, and is in reasonable agreement with the Imperial Valley velocities.

The message conveyed by Figures 30 and 45 is that onshore sites do exist with velocities 
similar to those that I have adopted for the offshore sites. It is probably too simplistic to lump sites into simple "offshore" and "onshore" categories. One difference between onshore and offshore sites, however, might be that the subsea depositional environment may lead to less site-to-site variation in the shear-wave velocities near the Earth's surface.

Crust: The travel time through the upper $100 \mathrm{~m}$ of the adopted SEMS model is 0.37 sec. This corresponds to a quarter wavelength period of $1.5 \mathrm{sec}$. Because I want to do computations out to at least $5.0 \mathrm{sec}$, it is necessary to specify the velocity structure at deeper depths. At the time I was doing the theoretical modeling, I was guided by my work in 1986 for velocities in "rock" in California (Boore, 1986), and I simply placed the soil model discussed above on this rock model, with slight modifications. Since then I have become aware of other models that may be more appropriate for the crustal velocities below the sediments (e.g., Magistrale et al., 1996; Boore and Joyner, 1997), and I would use these velocities if I were to redo the theoretical calculations. It should be kept in mind, however, that the calculations will be strongly controlled by the top $100 \mathrm{~m}$ of sediments for frequencies greater than about $0.7 \mathrm{~Hz}$, so limitations of the underlying velocities will not invalidate the theoretical results at these higher frequencies- nor will they invalidate the comparisons I make with models with and without the water layer. As I show later, however, the calculations on a rock site alone, stripped of the low velocity sediments, are suspect, particularly at high frequencies. Various velocity profiles are shown in Figures 46 and 47, for depths of 1 and $5 \mathrm{~km}$, respectively. The models include velocities from the Magistrale et al. (1996) model for the Los Angeles basin. This model provides velocitydepth profiles for any site in the region; at my request, $H$. Magistrale provided velocities for sites corresponding to onshore borehole BH50 at Seal Beach, the onshore strongmotion station Costa Mesa, and offshore SEMS site S3EE (the locations of these sites are plotted on the map in Figure 44). Also included in Figures 46 and 47 are profiles from Swanger's study of offshore ground motions (Swanger, 1981), the model used by Hauksson and Jones (1988) in their study of the 1986 Oceanside earthquake, a model from D. O'Connell (written commun., 1995) for the western Transverse Ranges, and Boore and Joyner's (1997) velocities for "California" rock. The SEMS model that I adopted has a much steeper gradient near the surface than the other models. If I were doing the theoretical calculations again, I would use the Magistrale et al. (1996) model for S3EE.

The model I used in the calculations is given in Table 7 and is plotted in Figure 48. 
Also included in Table 7 are the attenuations used in the calculations. I will show results of calculations for three different velocity models derived from the basic model given in Table 7: 1) the complete model, including the water layer; 2) the model with the water layer removed; and 3) the model stripped of the water layer and the upper $0.1 \mathrm{~km}$ of sediments. Results of Theoretical Analysis

To do the theoretical modeling, I used program HSPEC91 by R. Herrmann. This versatile program uses wavenumber integration to compute the complete wavefield in an earth represented by a stack of laterally-uniform, constant-velocity layers. My procedure was to generate synthetic seismograms for a specified type of faulting for the earth model of interest, and then to treat the synthetic seismogram as I would an observed seismogram. In most case I computed the Fourier amplitude spectrum of the S-wave portion of the seismogram, although in a few cases I studied the P-wave portion. The focal depth used in the model was $10 \mathrm{~km}$. The surface waves resulting from this depth will not be as energetic as the basin waves, which are probably generated by conversion of body waves at basin edges. For this reason, I do not claim that the theoretical modeling includes basin waves. This is consistent with the possible lack of basin waves in the $V / H$ ratios computed from the data (because of the limited duration for some of the SEMS recordings or the presence of noise at long periods).

Effect of water layer: It is instructive to use the theoretical calculations to investigate the expected effect of the water layer. Because shear waves do not propagate through the water layer, the response of vertically incident shear waves should be the same with and without the water layer. For non-vertically incident SV waves, however, conversion of $\mathrm{SV}$ to $\mathrm{P}$ will occur at the water-soil interface, and the $\mathrm{P}$ waves will resonate within the water layer. The converted upgoing $P$ wave will reflect from the ocean surface and travel back down. Some of it will be reflected from the ocean bottom, and some will be converted into downgoing SV waves. A similar process will occur for incident $\mathrm{P}$ waves. The wave propagation code HSPEC91 accounts for all of these interactions; it does not assume incidence of a particular type of plane wave; rather, it computes the motion at a given horizontal distance from a point source for a specified type of faulting embedded in the layered structure.

I show in Figure 49 the ratio of horizontal and vertical S motions at the seafloor for 
the model with a water layer and at the surface of the model obtained by stripping off the water layer. This figure predicts that the water layer exerts almost no influence on the horizontal $\mathrm{S}$ wave motions. The effect of the water layer does show up on the vertical component of the $\mathrm{S}$ wave, as a strong reduction in vertical motion at a particular frequency - an antiresonance. Saying "S wave" is somewhat misleading, for the wavetrain starting around the time of the initial $\mathrm{S}$ wave can have $\mathrm{P}$-wave energy, obtained from conversion of S-wave motion to $\mathrm{P}$-wave motion at interfaces. It is probably this conversion of S-wave motion into $\mathrm{P}$-wave motion at the seafloor which is leading to the reduction in vertical motions compared to the case with no water layer (Bureau, 1986, also did calculations that yielded a reduction in vertical motion for an ocean-bottom site). The frequency at which the reduction in $\mathrm{S}$ energy is greatest is the fundamental resonance mode for $\mathrm{P}$ waves trapped in the water layer, as discussed below. This water-layer effect on the vertical component of the $\mathrm{S}$ wave will lead to different theoretical $V / H$ ratios for onshore and offshore sites underlain by the same materials, but the difference will only be pronounced for frequencies greater than about one-half the water-layer resonance frequency.

As mentioned above, the water layer will have its most pronounced effect on motions dominated by $\mathrm{P}$ waves. Crouse and Quilter (1991) give a simple theory in which they predict the ratio of $\mathrm{P}$-wave motion at the seafloor relative to motion without the overlaying water layer. The largest effect should be at frequencies corresponding to resonance in the water layer. At resonance, a phase change at the water-seafloor interface leads to destructive interference and a relative node in the P-wave motion. Only the fundamental mode is in the frequency range of our data, at least for all but the deepest site, for which I do not have data. The resonant frequency is given by $f_{P}=C /(4 H)$, where $C$ is the velocity of $\mathrm{P}$ waves in water $(1500 \mathrm{~m} / \mathrm{s})$ and $H$ is the water thickness. For a depth of 60 $\mathrm{m}(200 \mathrm{ft})$ this gives $f_{P}=6.25 \mathrm{~Hz}$. I used HSPEC91 to check the model of Crouse and Quilter. The results are shown in Figure 50, from which it can be seen that their simple theory is in good agreement with the calculations. Based on the these results, the water layer itself will not affect sea-floor motions for frequencies lower than about $0.5 f_{P}$. For platforms near the SEMS stations providing the data analyzed in this report, I would not expect the water layer itself to influence directly waves with frequencies less than about 3 $\mathrm{Hz}$. Of course, as the water depth increases the resonant frequency moves to smaller values (but I assume that so does the resonant frequency of a platform), so that for the deepest SEMS site (S4EU) I expect frequencies of $1.7 \mathrm{~Hz}$ and higher to be affected by resonance 
in the water layer. No data are available for S4EU.

Effect of soil layer: Figure 51 shows the ratio of Fourier amplitude spectra of S-wave motions for the soil+rock and the rock only models, along with the empirically determined soil amplifications from Boore et al. $(1993,1994,1997)$ for horizontal-component response spectra. Results for both horizontal and vertical motions are shown. Clearly, the soil layer has a pronounced affect on the motions for the horizontal component. It also shows that the predicted onshore soil amplifications are similar to those observed empirically, and that those amplifications can be substantial at periods as long as 2 sec. The reduction of the soil site response at higher frequencies is due to the attenuation in the soil layers, which more than compensates for the amplification in the layers (and remember, these are linear calculations; nonlinear response might induce more damping of the motions at frequencies of several $\mathrm{Hz}$ ).

Effect of deeper layers: Simulations focused on the effect of the deeper layers were not made, but some comments can be made based on the results in Figure 51. The large peak in the vertical component ratio is most likely due to a reduction in motion in the rock only motion, resulting from the strong gradient in the rock velocities near the surface. For calculations on rock sites (no low-velocity sediments on top), this steep gradient causes high-frequency waves to refract more toward vertical than for low-frequency waves. The frequency effect can be explained in terms of ray propagation, for which the angle of incidence near the surface depends on an effective shear-wave velocity, which is the shearwave velocity averaged over some fraction of a wavelength. The effective velocity for high frequencies will be lower than for low frequencies, and therefore there will be a stronger refraction toward vertical for the high-frequency motions. The refraction will lead to very small vertical S-wave motions and a pronounced dip in the $V / H$ ratio. As mentioned earlier, I am not satisfied with the velocity models used for the deeper layers, and if the computations were to be repeated I would use a model with a less extreme gradient.

As discussed before, for several reasons the periods emphasized in this report are shorter than several seconds. Variations in the deeper parts of the model may have an important effect at longer periods. For example, Swanger and Boore (1978) emphasize the importance of deeper layers for motions with periods of several seconds or longer; they used a model with a less rapid gradient than in the SEMS model (see the model labeled 
"Swanger" in Figure 47), which will give a larger amplification at long periods than will the SEMS model.

Comparison of observed and theoretical spectral ratios: I now turn to comparisons of ratios of vertical- and horizontal-component S-wave Fourier amplitude spectra. Figure 52 show the observed and theoretical ratios for the offshore site, and Figure 53 shows the same for the onshore sites. The comparison for the offshore site is quite good, but the predicted onshore ratio has a strong dip starting at about $2.5 \mathrm{~Hz}$ not seen in the observed ratios. As discussed earlier, this dip is a consequence of the steep gradient in my assumed rock profile.

\section{SCALING OBSERVED SEMS RECORDS TO SIMULATE MOTIONS FROM LARGE EARTHQUAKES}

As shown before, the S3EE record of the 1990 Upland earthquake has long-period late arriving energy similar to that on records from the larger 1971 San Fernando earthquake. This section explores the use of the S3EE record in constructing the motions that would be expected at the site for an earthquake larger than the 1990 Upland earthquake. The procedure for doing this is outlined in Figure 54. The basis of the procedure is to multiply the Fourier spectrum of the recording by the ratio of source spectra for the target earthquake and an earthquake with magnitude equal to the observed earthquake. The earthquake providing the observed motion I call the "basis" event. (The smaller event is often called a "Green function", but in the formal use of the term, this would imply that the source was an impulse and all of the complexity in the record was due to wave propagation. This may be true for frequencies lower than about one-half the corner frequency of the basis event, but for higher frequencies some of the complexity in the recorded motion will be due to source complexity. For this reason I avoid the use of the term "Green function"). I assume that the target event is larger than the basis event. The ratio of source spectra accounts for differences in the amplitude spectrum; differences in duration need also to be considered. I do this by constructing a sequence of Gaussian random numbers with duration equal to the difference in duration between the larger target event and the basis event. As described in Figure 54, this time series is used as a filter to extend the duration of the basis event. The program used to generate the scaled-up time series is BIGEQ.FOR. Two assumptions are made in this analysis: 1) the materials remain linear, even for strong shaking, and 2) all of the path effects are captured by the basis event (this might not be 
true for an extended rupture, for which energy for different parts of the rupture would not be traveling along the same path).

Any suitable source-scaling relation can be used in this procedure; I use two in this study: the single-corner-frequency Brune source and the regression-based source scaling of Atkinson and Silva (1997). I found that the equations for the source spectra in Atkinson and Silva (1997) did not fit their regression-based results in the same paper. For this reason I modified their equations to produce a better fit to their regression results.

Atkinson and Silva (1997) studied Fourier amplitude spectra from strong-motion recordings of California earthquakes. Using regression analysis, they determined parameters describing the attenuation of the motion with distance, a site factor for each site, and "source" spectra for each earthquake. The "source" spectra are actually the spectra at the ground surface, corrected for the site factors and the attenuation with distance to a reference distance of $1 \mathrm{~km}$ and averaged over all recordings for each earthquake. They then fit a quadratic equation in moment magnitude to the corrected spectra. The coefficients are determined frequency-by-frequency, and are given at the bottom of the Appendix in Atkinson and Silva (1997). I refer to these corrected spectra as the regression-based source spectra. These spectra imply a magnitude dependent diminution parameter $\kappa$ and stress parameter $\Delta \sigma$. This is most clearly seen in Figures 55 and 56 , in which the ratio of Fourier amplitude spectra for two magnitudes is plotted against frequency. For a singlecorner-frequency Brune model, the ratio of two spectra at frequencies well above the corner frequency of each spectra is given by

$$
\ln S_{1} / S_{2}=\frac{1}{2}(\ln 10)\left(\mathbf{M}_{1}-\mathbf{M}_{2}\right)+\frac{2}{3} \ln \left(\Delta \sigma_{1} / \Delta \sigma_{2}\right)-\pi\left(\kappa_{1}-\kappa_{2}\right) f .
$$

For equal diminution parameters $\kappa$, there should be no frequency dependence for the spectral ratio at high frequencies. Figures 55 and 56 show that there is a frequency dependence. Fitting a straight line to the high frequency part of the spectra gives the equation

$$
\ln S_{1} / S_{2}=c+s f
$$

from which

$$
\left(\kappa_{1}-\kappa_{2}\right)=-s / \pi
$$

and

$$
\ln \Delta \sigma_{1} / \Delta \sigma_{2}=1.5\left[c-0.5(\ln 10)\left(\mathbf{M}_{1}-\mathbf{M}_{2}\right)\right]
$$


From Figure 55, where $\mathbf{M}_{1}=6.5$ and $\mathbf{M}_{2}=5.5$ this gives $\Delta \sigma_{1} / \Delta \sigma_{2}=0.69$ and $\left(\kappa_{1}-\kappa_{2}\right)=0.008$. From Figure 56 , where $\mathbf{M}_{1}=7.5$ and $\mathbf{M}_{2}=5.5$ this gives $\Delta \sigma_{1} / \Delta \sigma_{2}=0.29$ and $\left(\kappa_{1}-\kappa_{2}\right)=0.01$. The nonconstant stress parameter will lead to a significant change in predicted ground motions relative to those predicted using a constant stress parameter, particularly at high frequencies.

The nonconstant stress parameter implied by the Atkinson and Silva (1997) results is clearly shown in Figure 57, in which ratios of Fourier spectra for a suite of single-cornerfrequency models (with stress parameters of 25, 50, 100, and 200 bars) are compared to the regression-based source spectra. If the stress parameter were constant, the ratio should be 10 at high frequencies; the regression-based source spectra have a ratio between 3 and 4 at high frequency.

For predictions of ground motion using the stochastic model, it is useful to derive a functional form that gives the source spectra as a function of frequency, after removing both the amplification due to velocity changes along the propagation path and the diminution due to $\kappa$. Atkinson and Silva (1997) have done that, assuming the following function for the acceleration source spectrum:

$$
A_{0}(f)=C(2 \pi f)^{2} M_{0}\left\{(1-\epsilon) /\left[1+\left(f / f_{A}\right)^{2}\right]+\epsilon /\left[1+\left(f / f_{B}\right)^{2}\right]\right\}
$$

The corner frequencies and $\epsilon$ determined by Atkinson and Silva (1997) are

$$
\begin{aligned}
& \log f_{A}=2.181-0.496 \mathbf{M}, \\
& \log f_{B}=1.778-0.302 \mathbf{M},
\end{aligned}
$$

and

$$
\log \epsilon=2.764-0.623 \mathbf{M}
$$

I found that this formulation does not quite fit their regression-based source spectra and I have derived an improved version. One indication of the misfit is shown in Figure 57 (the dashed line is based on equation 5). I have altered their equation for $\epsilon$ somewhat to obtain a better fit. The new equation is

$$
\log \epsilon=3.440-0.746 \mathbf{M}
$$


The fit to ratios of Fourier amplitude for magnitudes of 6.5 to 5.5 and 7.5 to 5.5 are shown in Figures 58 and 59, respectively. I have used the altered equation for $\epsilon$ in scaling up the time series and in making predictions of response spectra.

The acceleration time series that results from scaling the observed motion at S3EE for the $M=5.6$ earthquake to what would have been observed at the same site and the same distance for a $\mathbf{M}=7.5$ earthquake are shown in Figure 60 . The velocity and displacement time series obtained from the acceleration trace are shown in Figures 61 and 62. In each figure the basis motion is given at the bottom and the scaled-up motions for the two source scalings are given in the upper two traces. Note the large long-period motions late in the scaled-up motions. This enhanced long-period motion relative to the high-frequency motion at the beginning of the traces is a consequence of source scaling: because of the shift in corner frequencies to lower frequency as the moment increases, the long-period motions have a stronger dependence on moment than do the high-frequency motions, leading to the observed difference in relative frequency content. The difference is less pronounced for the Atkinson and Silva scaling; this is a result of the "sag" in their spectra relative to the single-corner-frequency Brune spectra.

The relative differences in frequency content are easier to see in the response spectra of the motions. These are shown in Figure 63 for the Brune scaling and Figure 64 for the Atkinson and Silva scaling. If the scaled motion is shifted vertically to match the basis motion at short periods, it is clear that the scaled motion is much richer in long periods than the basis motions. (The response spectra shown in Figures 63 and 64 are the geometric means of the individual horizontal components; the individual spectra and the mean for the basis and the Brune scaling are shown in Figure 65, where it is clear that the individual horizontal components are similar to the mean horizontal component. This is not to say that rotating the two components into radial and transverse components would not reveal physically significant differences in the ground motions. I have chosen not to rotate the components for several reasons: the component azimuths were not available for all stations; lateral refraction over long travel paths can introduce $P$ and $S V$ motion onto the transverse component, and vice versa; and the regression results and stochastic model simulations are in terms of the random horizontal component, which is given by the geometric mean of the two horizontal components).

Figures 63 and 64 also contain comparisons with PSV computed in two ways: 1) from 
equations based on the regression analysis of many onshore strong-motion recordings, and 2) from simulations using the stochastic model (Boore, 1983, 1996) and the source scaling models used in the figures.

The parameters used in the stochastic-model simulations are given in Tables 8 and 9, which are copies of the input files used by SMSIM (Boore, 1996), the program used to compute the motions. The motions are intended to represent response spectra for an average soil site (which has $V_{30}=310 \mathrm{~m} / \mathrm{s}$ ). To generate PSV values on a generic soil site, I used different approaches for the Brune and the Atkinson and Silva (1997) scaling.

Brune scaling: I generated response spectra using Boore and Joyner's (1997) amplifications for a generic rock site (with $V_{30}=620 \mathrm{~m} / \mathrm{s}$ ) and simbasg.dat as an input file for SMSIM. I then applied rock $\rightarrow$ soil conversions within program BIGEQ.FOR. The conversions used the site factors of Boore et al. (1994), assuming constant values of the conversion for periods outside the 0.1 to $1.0 \mathrm{sec}$ range (using the Boore et al. factors at $0.1 \mathrm{sec}$ for $T<0.1 \mathrm{sec}$ and at $1.0 \mathrm{sec}$ for $T>1.0 \mathrm{sec}$ ). Note that the assumption for $T>1.0 \mathrm{sec}$ may be conservative, for the conversion factor at $T=1.0 \mathrm{sec}$ is greater than unity (the actual conversion factor will approach unity for long periods). Note that the Boore et al. factors are for response spectra, not Fourier spectra as in Atkinson and Silva (1997).

Atkinson and Silva (1997) scaling: The response spectra were generated using soil amplification factors in the SMSIM calculations. The amplifications were derived in program AS96_CD.FOR by multiplying the rock amplifications of Boore (1986) by the rock $\rightarrow$ soil amplifications of Atkinson and Silva (1997). The resulting amplifications are given in sim_as.dat (Table 9). No additional modifications were made within program BIGEQ.FOR. (The reason for including the rock amplifications is that the Atkinson and Silva (1997) source model was derived by removing the rock amplifications of Boore (1986), so I had to reapply the amplifications; their soil amplifications are relative to rock motions at the Earth's surface.)

The comparisons in Figures 63 and 64 tell a number of things. Note first the relatively good agreement between the PSV from the SEMS unit on the ocean floor and the regression-based results for periods from about 0.2 to $2 \mathrm{sec}$. This suggests that the horizontal-component SEMS motions are not strongly influenced by the presence of the 
water layer. The next thing to note is the relatively good comparison between the simulated and regression-based motions, particularly for the Brune source model (Figure 63). The regression-based relations do not extend to periods as long as those that dominate the S3EE recording, and the good fit at shorter periods gives credibility to using the simulations as a means of extrapolating the regression-based results to longer periods. The good comparison between regression-based and simulated motions suggests that the long period simulations can be considered to be representative of the typical onshore soil site. Focusing on the long periods, observe the large discrepancy for $\mathbf{M}=5.6$ between the observed motion and the predicted motions at long periods. It is this mismatch that carries over to the motions for the M7.5 earthquake and produces the large motions for that earthquake at long periods. The mismatch is a result of the presence of basin waves on the SEMS record for the smaller earthquake. This emphasizes the importance of basin waves in producing large ground motions at the periods of interest to platform design. Finally, comparing Figures 63 and 64 indicates that both the Brune and Atkinson and Silva (1997) source scalings predict motions in relatively good agreement with the regression-based results for the smaller earthquake for periods less than about $1.0 \mathrm{sec}$. For the larger earthquake, however, the Brune scaling is in much better agreement with the regression-based results than is the Atkinson and Silva (1997) scaling. This is worrisome, because the Atkinson and Silva (1997) results are based on analysis of Fourier spectra from a dataset similar to that used to obtain the regression-based PSV. I am not sure how to explain this discrepancy; more work is clearly needed.

\section{CONSTRUCTION OF TIME SERIES FOR STUDIES OF THE SEISMIC RESPONSE OF OFFSHORE PLATFORMS}

At the request of Charles Smith, I constructed three-component time series for a $\mathbf{M}=7.5$ earthquake at $10 \mathrm{~km}$ epicentral distance and $10 \mathrm{~km}$ depth. The motions were computed for several fault orientations and for two sites: site A, a firm-soil onshore site, and site $\mathrm{B}$, an offshore site.

\section{Velocity Models}

The velocity models were developed in conjunction with C. Smith; they are plotted in Figures 66 and 67 (same model, but different depths plotted). The figure also includes 
the SEMS model I used in the theoretical calculations discussed in a previous section. The water layer for the offshore models has not been shown. The SEMS model below $0.1 \mathrm{~km}$ has been used beneath both the site A and site B models.

\section{Method}

As no SEMS data were available to me for these short distances, I could not use the scaling approach discussed in the previous section. Instead, I used full wavefield calculations to obtain the impulse response for the layered earth model, and I convolved the time series with stochastic-model motions. Synthetic time series for a point source in a layered media were calculated using the frequency-wavenumber integration method, as contained in Robert Herrmann's program HSPEC91. These time series are for a simple source with a source time function given by a slightly smoothed step change in slip on the fault. The time series were convolved with the motions obtained using the stochastic model (Boore, 1996) for a magnitude 7.5 earthquake in a whole space. In other words, the stochastic model accounted for the source complexity and the frequency-wavenumber model accounted for the wave propagation. The procedure is illustrated in Figures 68, 69, and 70 for the tranverse, radial, and vertical components of motion at site A, respectively. The top trace in the figures is the same in each case and is the result of the wholespace stochastic model, the middle trace in each figure is the impulse response for the layered earth model, and the bottom trace in each figure is the desired ground motion, obtained by convolving the upper two traces (after accounting for some scaling factors). The details of the convolution are given in computer program MakeTS.FOR. The time series are computed at 40 samples per sec ( $0.025 \mathrm{sec}$ sampling interval), but because of the long HSPEC91 run times required for high-frequency simulations, a cutoff was used such that motions above about $5 \mathrm{~Hz}$ have been artificially reduced in amplitude; the motions should be unaffected for lower frequencies.

Note that most of the duration and complexity of the synthesized records is due to the source and not to the layered structure. This would not be true for greater epicentral distances. Also note that the basin waves discussed earlier will not be included in the simulations at the close distance in this exercise (10 km epicentral distance). 
Figures 71 through 74 show three-component time series for both sites and for two fault orientations. The faults are a vertical strikeslip and a 45-degree reverse fault. For the vertical fault, the motions were rotated into transverse $(T)$, radial $(R)$, and vertical $(Z)$; for the inclined fault the orientations are north $(N)$, east $(E)$, and vertical $(Z)$. Site A (onshore) motions are shown in Figures 71 and 72 ; site B (offshore) motions are shown in Figures 73 and 74. In all cases ground accelerations in units of $\mathrm{cm} / \mathrm{s}$ are shown. Note that the fault mechanisms leads to substantial differences in amplitudes of motion, particularly for the transverse and vertical components; this is a direct result of radiation pattern. Note also that the ratio of vertical to horizontal motion is smaller for the offshore model (site B) than it is for the onshore model, in keeping with regression-based results discussed earlier in this report, in the data analysis section.

\section{CONCLUSIONS AND DISCUSSION}

The Seafloor Earthquake Measuring System (SEMS) is a multiphase instrumentation effort that has been in existence for almost two decades. The SEMS stations are excellent instruments and have produced high-quality data for a number of events. Unfortunately, onshore strong-motion instruments have not generally been of the same high-caliber as the SEMS units, and therefore few data are available from which direct comparisons can be made of onshore and offshore motions from the same earthquake recorded at similar distances and for similar site conditions. For this reason, the analysis of the SEMS data have had to use a combination of somewhat indirect observational studies and theoretical calculations to answer the fundamental question: Are the earthquake ground motions at the seafloor so different from onshore motions that the more numerous onshore recordings cannot be used for platform design?

The answer to the fundamental question is "It depends." It depends on the component of motion and the frequency of ground shaking. The ratio of vertical-to-horizontal motions $(V / H)$ is clearly much smaller than for onshore recordings at relatively high frequencies (above about $3 \mathrm{~Hz}$ ). Studies of the vertical and horizontal motions separately suggest that the anomaly lies with the vertical motions. For lower frequencies the results of this study suggest that both components of the seafloor motions are similar to those from onshore 
recordings at sites underlain by geologic materials similar to those beneath the seafloor sites.

Theoretical studies show that the reduction of vertical motions can be produced by interactions of S-waves in the solid materials below the seafloor and P-waves in the water layer. This interaction is most important at the resonant frequencies of vertically propagating acoustic waves in the water layer. A reduced vertical component can also be produced by refraction of an incoming wave toward the vertical, such as will occur for shear-wave velocities that decrease towards the Earth's surface. $V / H$ computed from a few onshore sites with shear-wave velocity versus depth similar to that estimated to be beneath the SEMS offshore stations are much different at high frequencies than the ratios from the SEMS stations, suggesting that simple upward-refraction plays a small role in the difference between onshore and offshore motions at the higher frequencies.

The water layer indirectly influences motions by allowing low-velocity sediments to exist over a widespread area, and by increasing the pore pressure in the sediments, which will reduce the velocity in sands and silts.

It is easy to get caught up in the complexities at high frequencies, which reflect the water layer as well as very local shear-wave velocities. Although some parts of the platform system are sensitive to high-frequency, vertical-component waves (e.g., Smith, 1994; Brady, 1993), the motions are mudline motions and are far from the horizontal resonance frequencies of the platform. More important for design and analysis of platforms may be periods of motion longer than one second.

Particularly useful recordings for the study of long-period motions were made at a SEMS site offshore of Long Beach. Comparisons of response spectra obtained from the SEMS instruments with onshore regression-based spectra and theoretical calculations, as well as time-domain comparisons with onshore waves that have traveled through the Los Angeles basin, suggest that the seafloor motions at the SEMS site are significantly influenced by late arriving, large amplitude surface waves ("basin waves") at long periods. These waves may be more important for platform analysis and design than the higher frequency waves which are influenced by the water layer. In this sense, the travel path may be more important than the local site conditions. 


\section{ACKNOWLEDGMENTS}

This work would not have been possible without the diligent work of Charles Smith of the Minerals Management Service, who championed the development and deployment of the SEMS stations, conceived of this project, and provided my funding for its completion. I wish to thank the many people who contributed data, information, or criticisms. These include Norm Abrahamson, Gail Atkinson, Yousef Bozorgnia, Hilmar Bungum, C.B. Crouse, Leroy Dorman, Joe Ehasz, Tom Fumal, Jens Havskov, Bob Herrmann, Francois Heuze, Bill Joyner, Harold Magistrale, Farrokh Nadim, Dan O'Connell, Linda Seekins, Gerry Sleefe, Kuo-Liang Wen, and Bob Yerkes. The strong-motion programs of the California Division of Mines and Geology and the U.S. Geological Survey provided accelerograms and borehole velocities.

\section{REFERENCES}

Abrahamson, N.A. and W.J. Silva (1997). Empirical response spectral attenuation relations for shallow crustal earthquakes, Seism. Res. Lett. 68, 94-127.

Anderson, J.G., M.D. Trifunac, T.-L. Teng, A. Amini, and K. Moslem (1981). Los Angeles vicinity strong motion accelerograph network, Civil Engineering Report CE 81-04, Univ. of Southern California, 79 pp.

Atakan, K. and J. Havskov (1996). Local site effects in northern North Sea based on single-station spectral ratios of OBS recordings, Terra Nova, 8, 22-33.

Atkinson, G.M. and W. Silva (1997). An empirical study of earthquake source spectra for California earthquakes, Bull. Seism. Soc. Am. 87, 97-113.

Boore, D. M. (1983). Stochastic simulation of high-frequency ground motions based on seismological models of the radiated spectra, Bull. Seism. Soc. Am. 73, 1865-1894.

Boore, D. M. (1986). Short-period $P$ - and $S$-wave radiation from large earthquakes: implications for spectral scaling relations, Bull. Seism. Soc. Am. 76, 43-64.

Boore, D.M. (1996). SMSIM - Fortran programs for simulating ground motions from earthquakes: version 1.0, U. S. Geol. Surv. Open-File Rept. 96-80-A and 96-80-B, 73 
p.

Boore, D.M. and W.B. Joyner (1997). Site-amplifications for generic rock sites, Bull. Seism. Soc. Am. 87, 327-341.

Boore, D. M., W. B. Joyner, and T. E. Fumal (1993). Estimation of response spectra and peak accelerations from western North American earthquakes: An interim report, $U$. S. Geol. Surv. Open-File Rept. 93-509, 72 pp.

Boore, D. M., W. B. Joyner, and T. E. Fumal (1994). Estimation of response spectra and peak accelerations from western North American earthquakes: An interim report, Part 2 U. S. Geol. Surv. Open-File Rept. 94-127, 40 pp.

Boore, D. M., W. B. Joyner, and T. E. Fumal (1997). Equations for estimating horizontal response spectra and peak acceleration from western North American earthquakes: A summary of recent work, Seism. Res. Lett. 68, 128-153.

Bozorgnia, Y. and M. Niazi (1993). Distance scaling of vertical and horizontal response spectra of the Loma Prieta earthquake, J. of Earthquake Engineering and Structural Dynamics 22, 695-707.

Bozorgnia, Y., M. Niazi, and K.W. Campbell (1994). Vertical ground motion during the 1994 Northridge earthquake, Proceedings of 6th U.S.-Japan Workshop on the Improvement of Building Structural Design and Practices ATC-15-5, Applied Technology Council, Redwood City, California.

Bozorgnia, Y., M. Niazi, and K.W. Campbell (1995). Characteristics of free-field vertical ground motion during the Northridge earthquake, Earthquake Spectra 11, 515-525.

Brady, A.G. (1993). Offshore strong ground motion and onshore surrogates, Proceedings, International WOrkshop on Wind and Earthquake Engineering for Offshore and Coastal Facilities, Yokosuka, Japan, May 12-14.

Bureau, G. (1986). New considerations for offshore seismic response studies, Proceedings of the Third U.S. National Conf. on Earthquake Engineering, Charleston, SC, volume 1, 789-795. 
Campbell, K.W. (1997). Empirical near-source attenuation relationships for horizontal and vertical components of peak ground acceleration, peak ground velocity, and pseudoabsolute acceleration response spectra, Seism. Res. Lett. 68, 154-179.

Chen, J., R.R Ullmann, and A.B. Mason (1989). Measurement of earthquake ground acceleration and structural response of a fixed offshore platform, Proceedings Offshore Technology Conference OTC 6172, 561-568.

Crouse, C.B. and J. Quilter (1991). Seismic hazard analysis and development of design spectra for Maui A platform, Proceedings Pacific Conf. on Earthquake Engineering, New Zealand, vol 3, 137-148.

Converse, A.M. (1992). Basic strong-motion accelerogram processing software - Version 1.0, U. S. Geol. Surv. Open-File Rept. 92-296A,B.

Dorman, L.M. (1997). Propagation in marine sediments, Encyclopedia of Acoustics, edited by M.J. Crocker, John Wiley \& Sons, 409-416.

Field, E.H. and K.H. Jacob (1995). A comparison and test of various site-reponse estimation techniques, including three that are not reference-site dependent, Bull. Seism. Soc. Am. 85, 1127-1143.

Fumal, T.E. (1978). Correlations between seismic wave velocities and physical properties of near-surface geologic materials in the southern San Francisco Bay region, California, U. S. Geol. Surv. Open-File Rept. 78-1067, 114 p.

Hamilton, E.L. (1976a). Shear-wave velocity versus depth in marine sediments: A review, Geophysics 41, 985-996.

Hamilton, E.L. (1976b). Variations of density and porosity with depth in deep-sea sediments, J. Sedimentary Petrology 46, 280-300.

Hamilton, E.L. (1976c). Attenuation of shear waves in marine sediments, J. Acoust. Soc. Am. 60, 334-338.

Hanks, T. C. (1975). Strong ground motion of the San Fernando, California, earthquake: 
ground displacements, Bull. Seism. Soc. Am. 65, 193-225.

Hauksson, E. and L.M. Jones (1988). The July 1986 Oceanside $\left(M_{L}=5.3\right)$ earthquake sequence in the continental borderland, southern California, Bull. Seism. Soc. Am. 78, 1885-1906.

Helmberger, D. and K. McNally (1980). Attenuation of shear waves in marine sediments: Santa Barbara Channel, Woodward Clyde 8 Assoc. Report to Sandia Laboratories.

Liu, H.-P., R.E. Warrick, R.E. Westerlund, and R.E. Kayen (1994). In situ measurement of seismic shear-wave absorption in the San Francisco Holocene Bay Mud by the pulse broadening method, Bull. Seism. Soc. Am. 84, 62-75.

Magistrale, H., K. McLaughlin, and S. Day (1996). A geology based 3D velocity model of the Los Angeles basin sediments, Bull. Seism. Soc. Am. 86, 1161-1166.

Mason, A.B., J.L. Beck, J. Chen, and R.R. Ullmann (1989). Modal parameter identification of an offshore platform from earthquake response records, Seismic engineering: Research and Practice, Proceedings of Structures Congress '89, American Society of Civil Engineers, 217-226.

Nakamura, Y. (1989). A method for dynamic characteristics estimation of subsurface using microtremor on the ground surface, QR Railway Tech. Res. Inst. 30, 1.

Niazi, M. and Y. Bozorgnia (1992). Behavior of near-source vertical and horizontal response spectra at SMART-1 array, Taiwan, J. of Earthquake Engineering and Structural Dynamics 21, 37-50.

Porcella, R.L. (1984). Geotechnical investigations at strong-motion stations in the Imperial Valley, California, U. S. Geol. Surv. Open-File Rept. 84-562, 174 p.

Reece, E.W., D.E. Ryerson, and R.L. McNeill (1981). Long-term measurements of ground motions offshore, International Conf. on Recent Advances in Geotechnical Earthquake Engineering and Soil Dynamics, St. Louis, Missouri, April 26-May 3, 1981, Vol. I, $377-380$. 
Rognlien, B. (1987). Soil reponse on selected sites on the Norwegian continental shelf, ELOCS Report 4-1.

Ryerson, D.E. (1981). Seafloor earthquake measurement system. Volume 1. Overview and physical description, Sandia Report SAND81-1810/1, 66 pp.

Sleefe, G.E. (1990). The long-term measurement of strong-motion earthquakes offshore southern California, Proceedings Offshore Technology Conference OTC 6336, 561568.

Sleefe, G.E. and D. Engi (1987). Seafloor response for two southern California earthquakes, Proceedings 1987 Spring Conf. on Exper. Mech., Houston, Texas, June 14-19, 1987, and Sandia report SAND86-2441C.

Smith, C.E. (1990). Seismic design considerations for offshore oil and gas structures, Proceedings 21st Joint Meeting of the U.S.- Japan Cooperative Program in Natural Resources:Panel on Wind and Seismic Effects, NIST SP 776.

Smith, C.E. (1991). Seafloor seismic network offshore southern California, Proceedings 23rd Joint Meeting of the U.S.-Japan Cooperative Program in Natural Resources:Panel on Wind and Seismic Effects.

Smith, C.E. (1994). Dynamic response of offshore steel-jacket platforms subject to measured seafloor seismic ground motions, Ph.D. thesis, Graduate School of Engineering and Applied Science, George Washington University, 323 pp.

Swanger, H.J. (1981). Surface waves in strong ground motion with applications to offshore environments, Ph.D. thesis, Geophysics Department, Stanford University, 145 pp.

Swanger, H.J and D.M. Boore (1978). Importance of surface waves in strong ground motion in the period range of 1 to 10 seconds, Proceedings of the Second International Conference on Microzonation, San Francisco, CA, November 26-December 1, 1978, 1447-1457. 


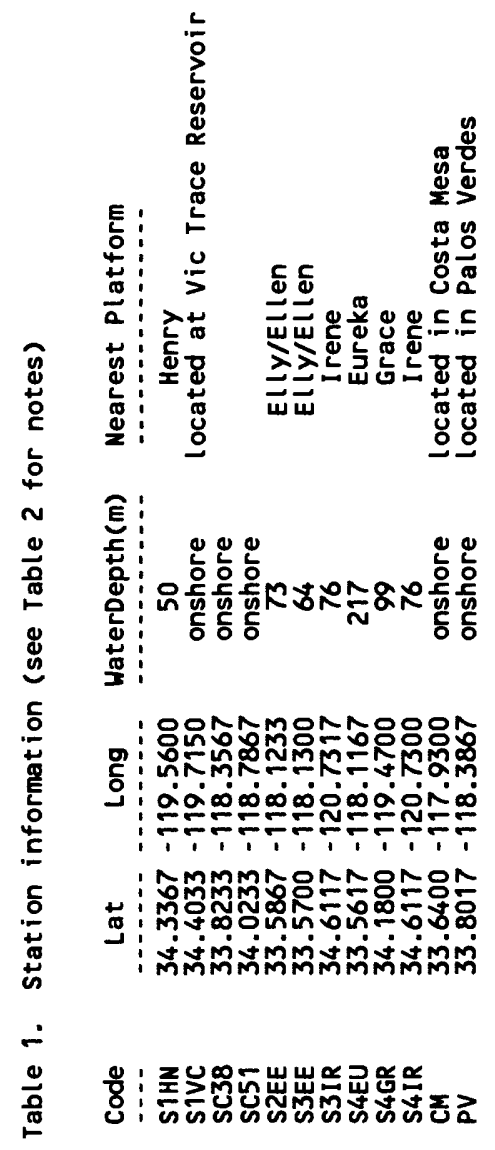




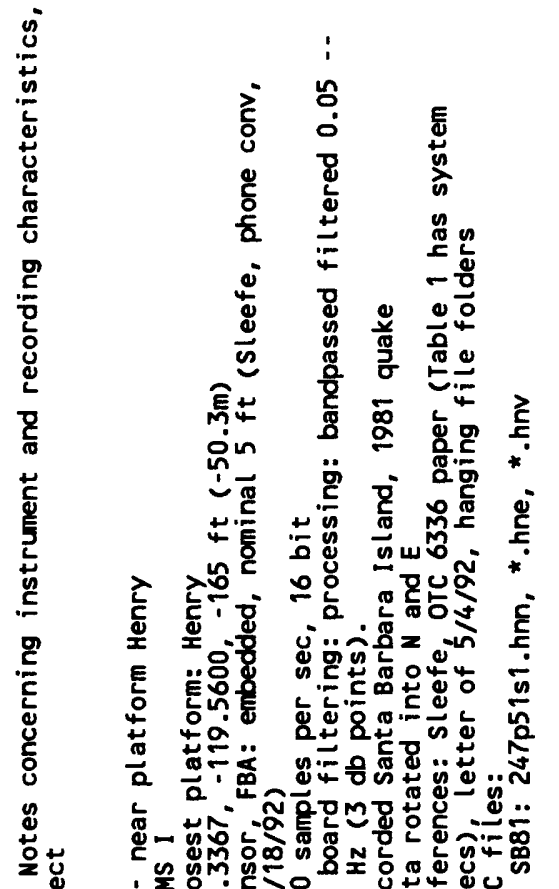

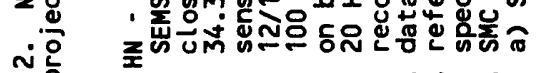

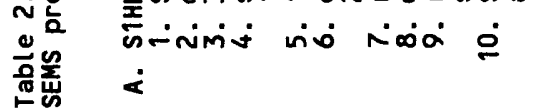

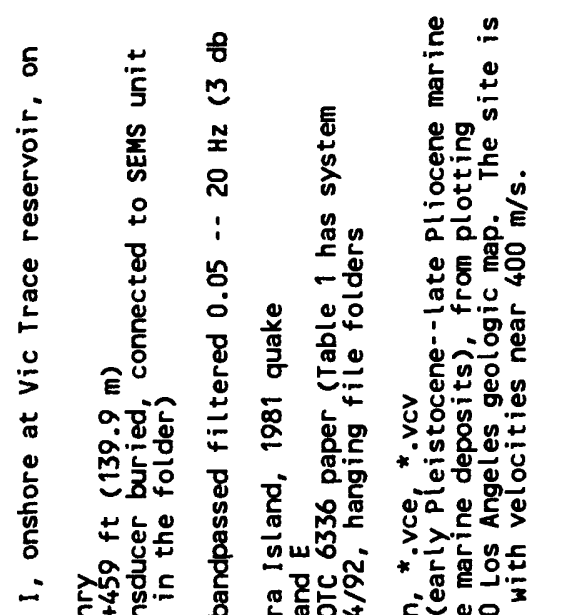

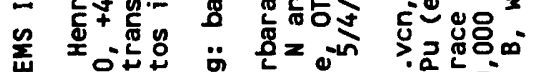

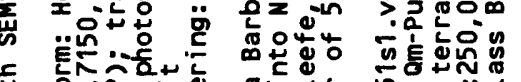
.

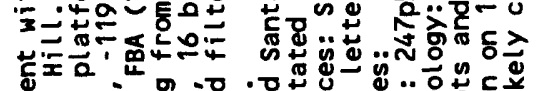

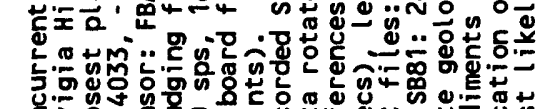

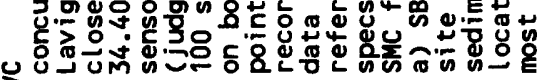

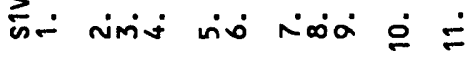
๓

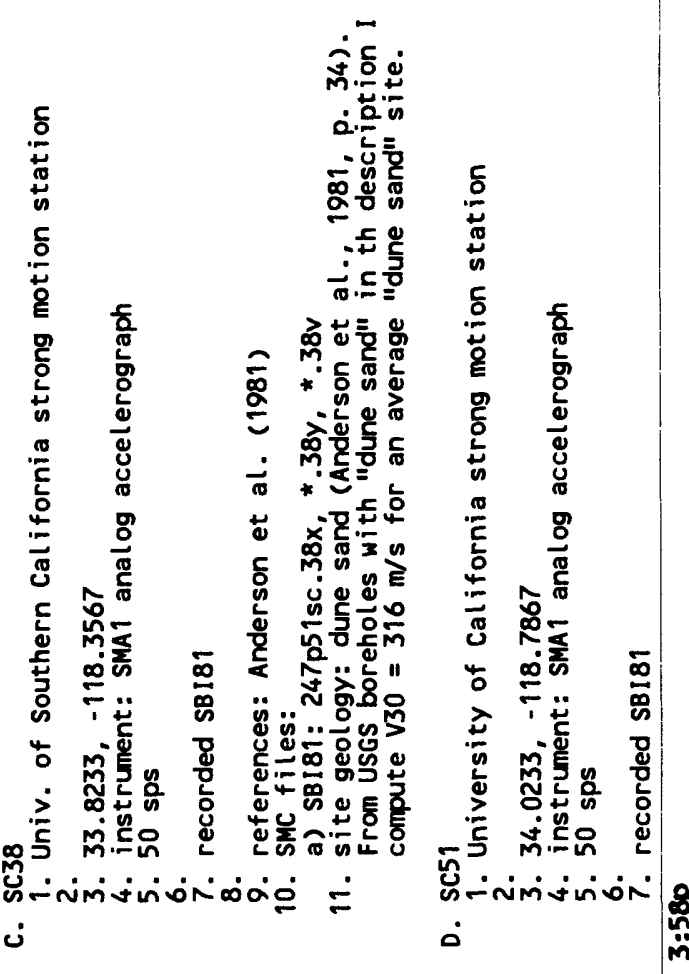

5 


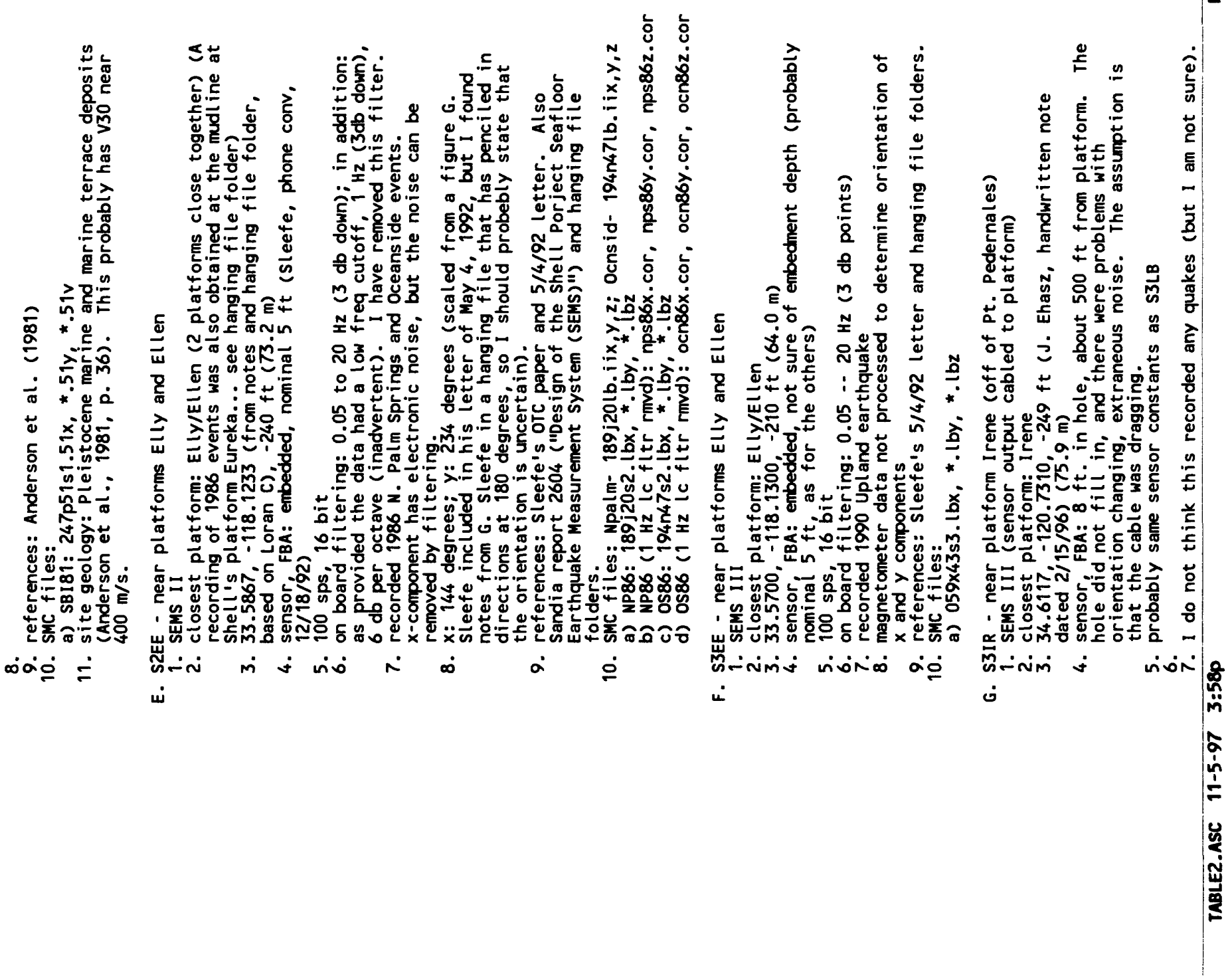




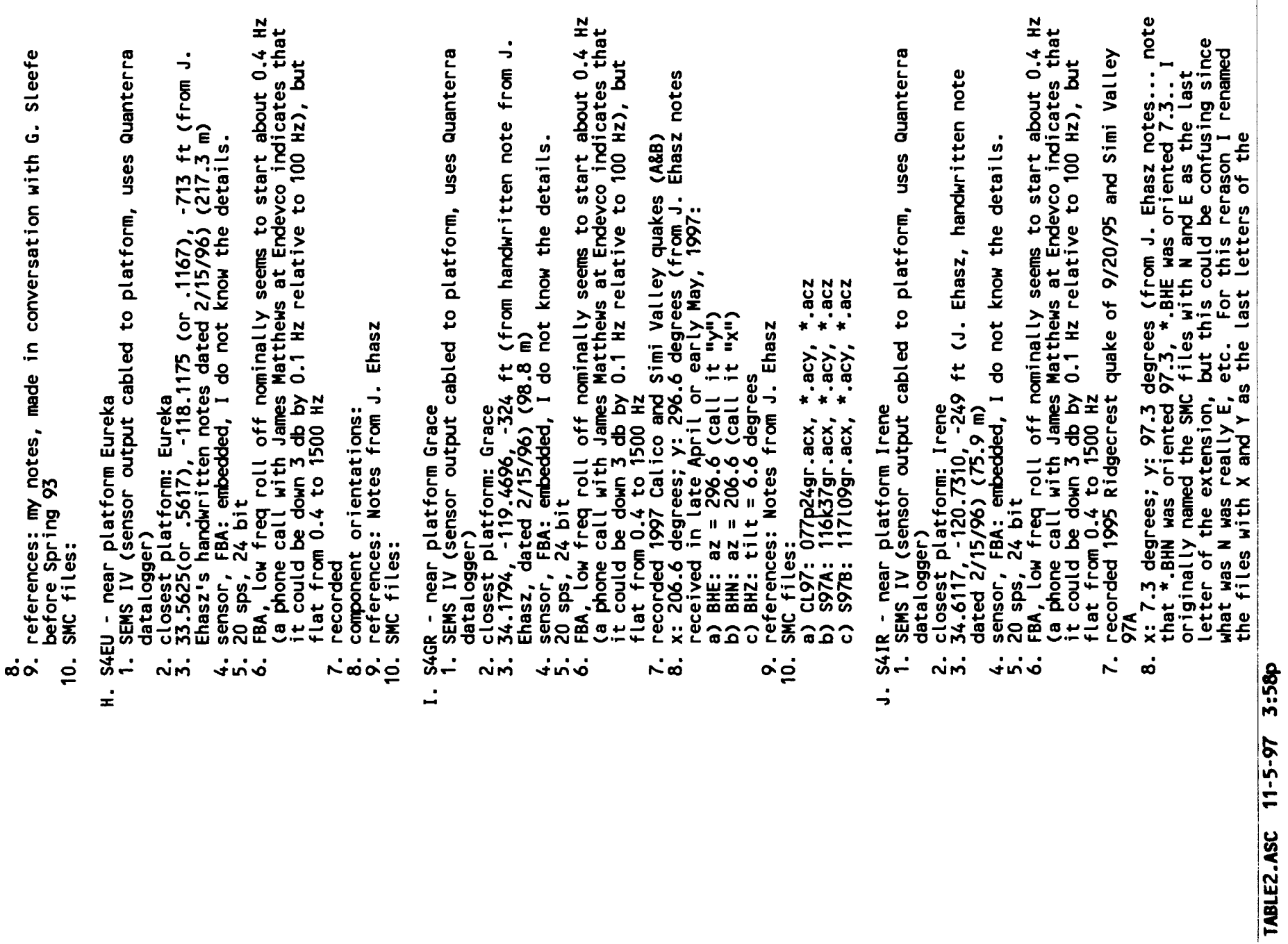




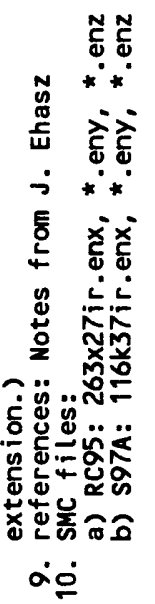




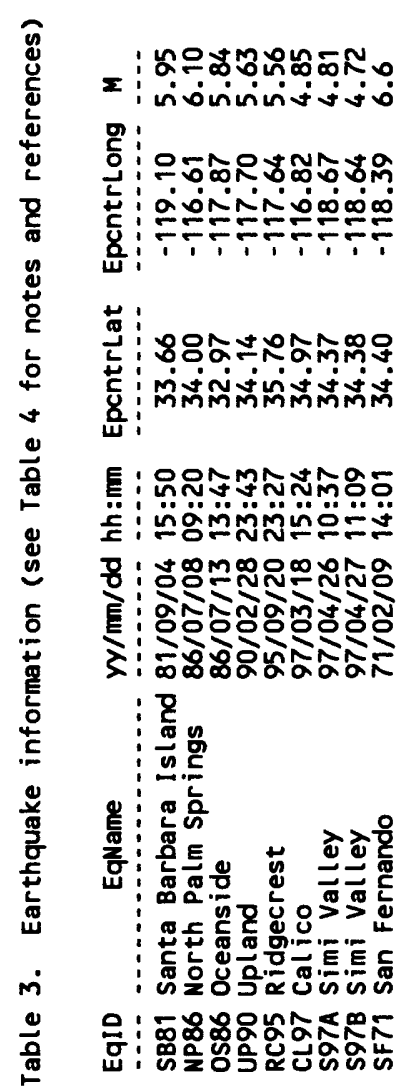




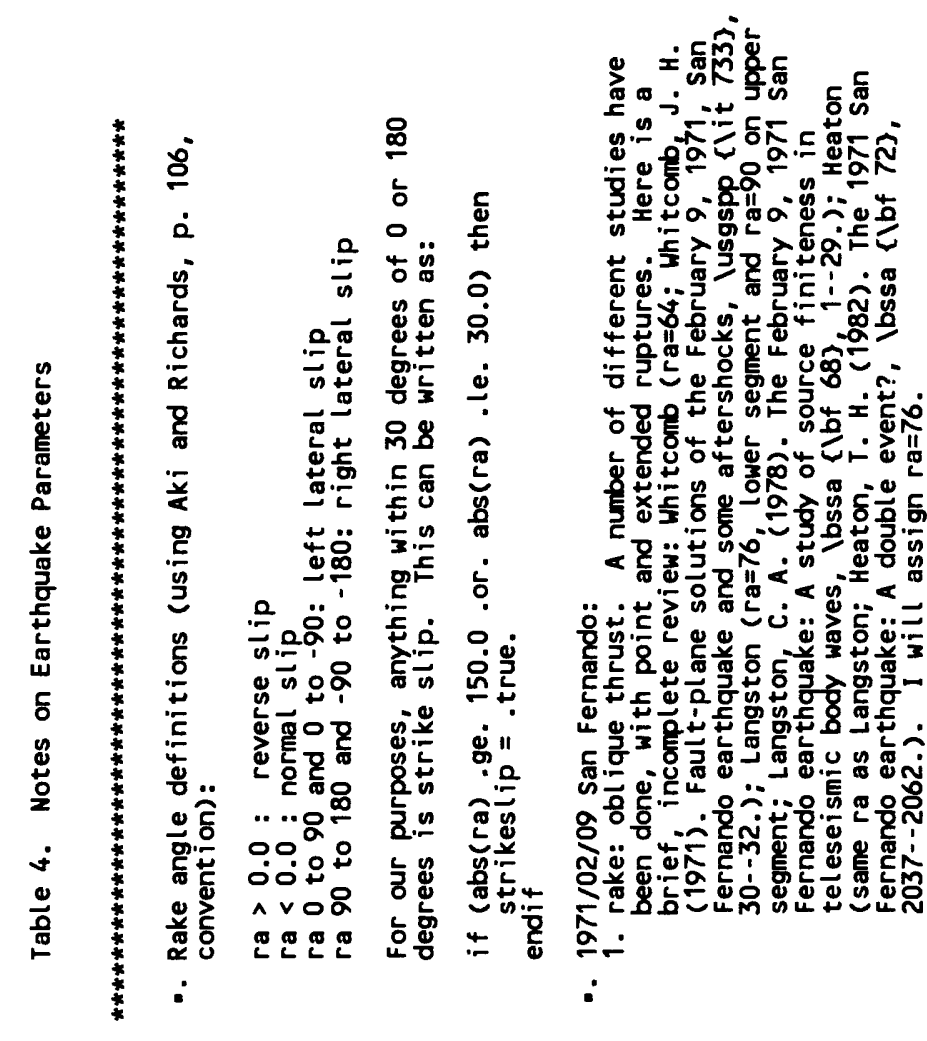

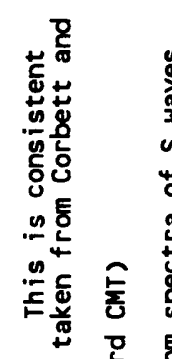

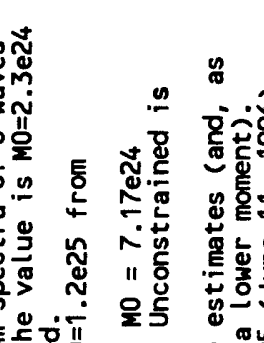

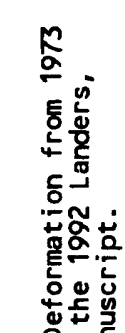

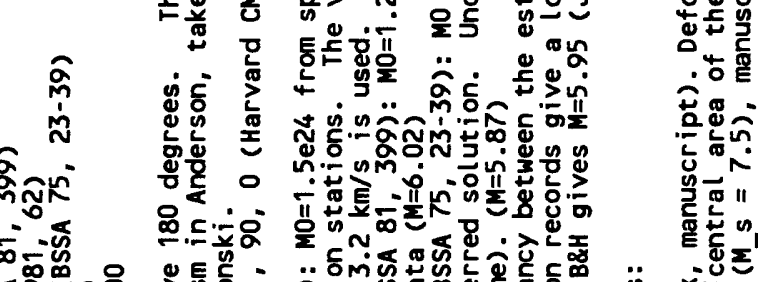

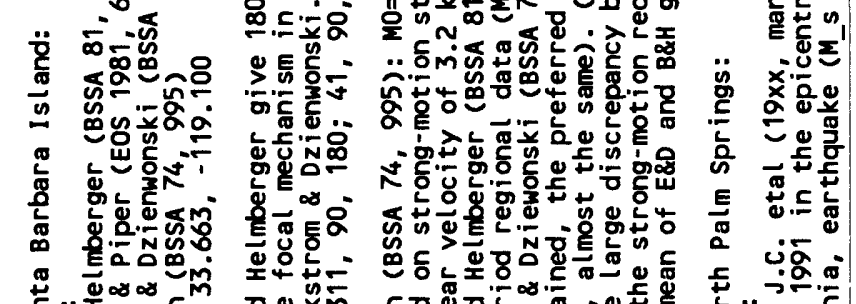

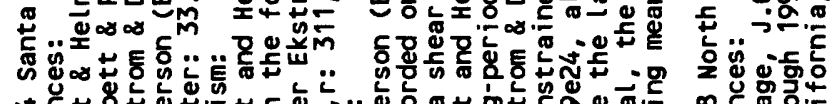

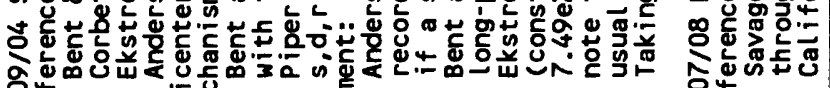
品 Nim 
ล กิ้

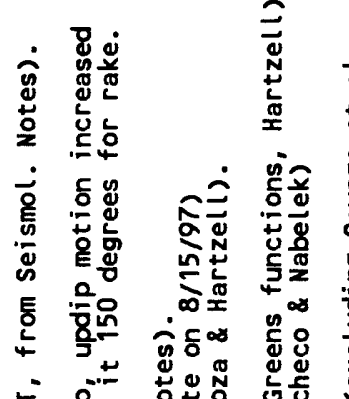

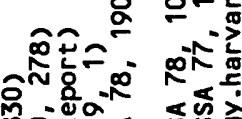

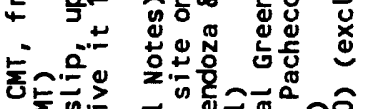

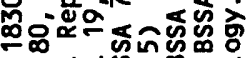

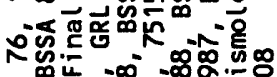

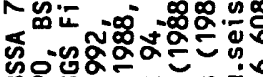

$$
\text { in }
$$




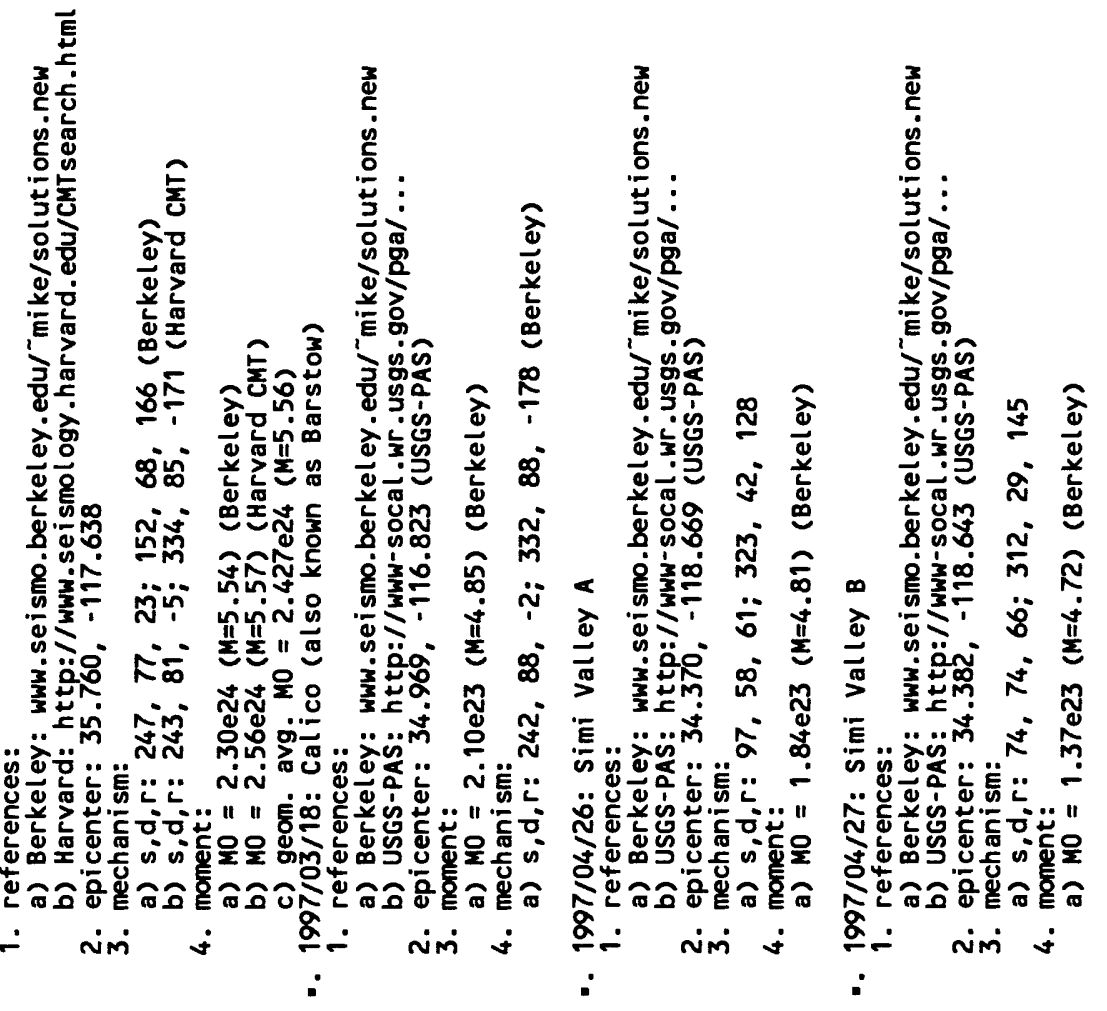




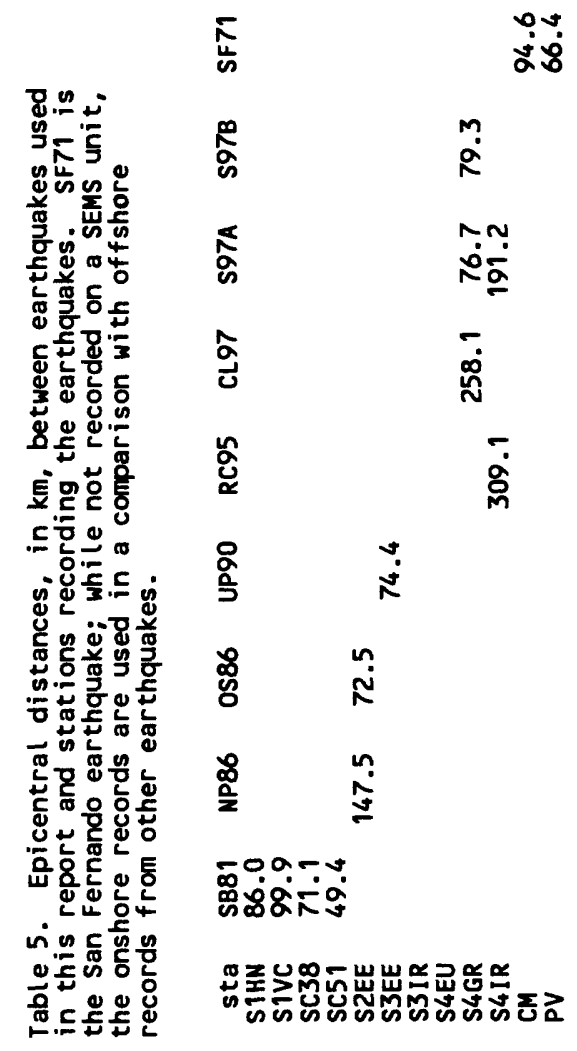




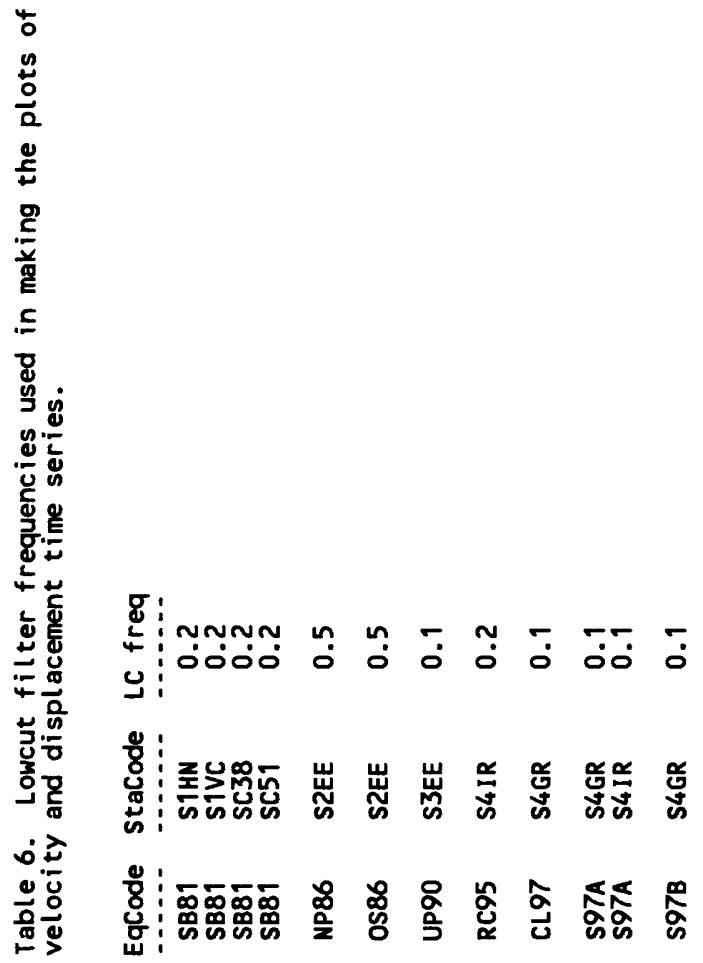


ڤึ

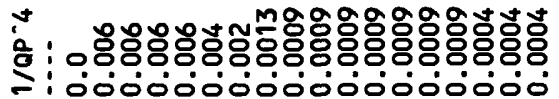

m

ปัن

焉

옻

$\sim$

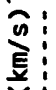

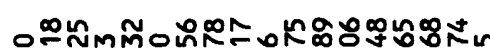

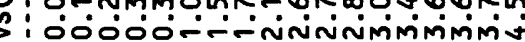

í

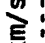

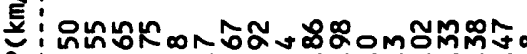

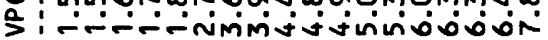

豆:

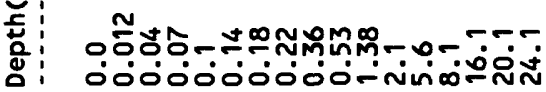

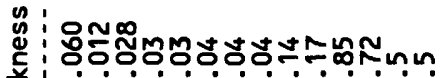

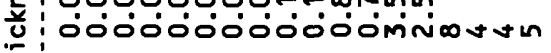

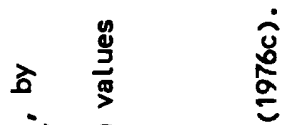

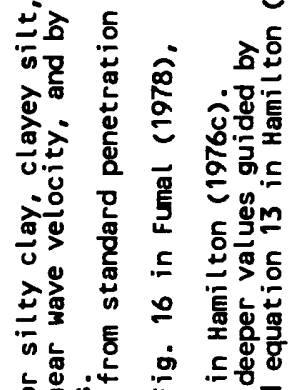

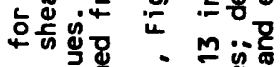

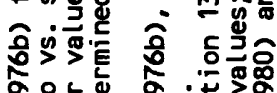

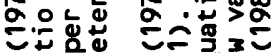

象 웡

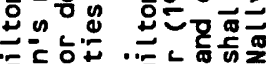

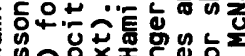

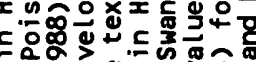

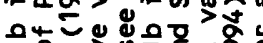

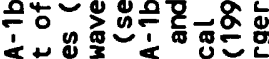
$<+$

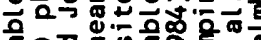

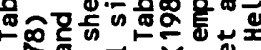

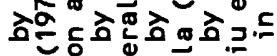

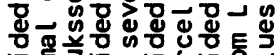

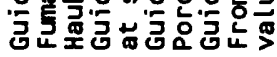

$\because \ddot{\sim} \ddot{\sim} \ddot{ت} \ddot{n}$ 


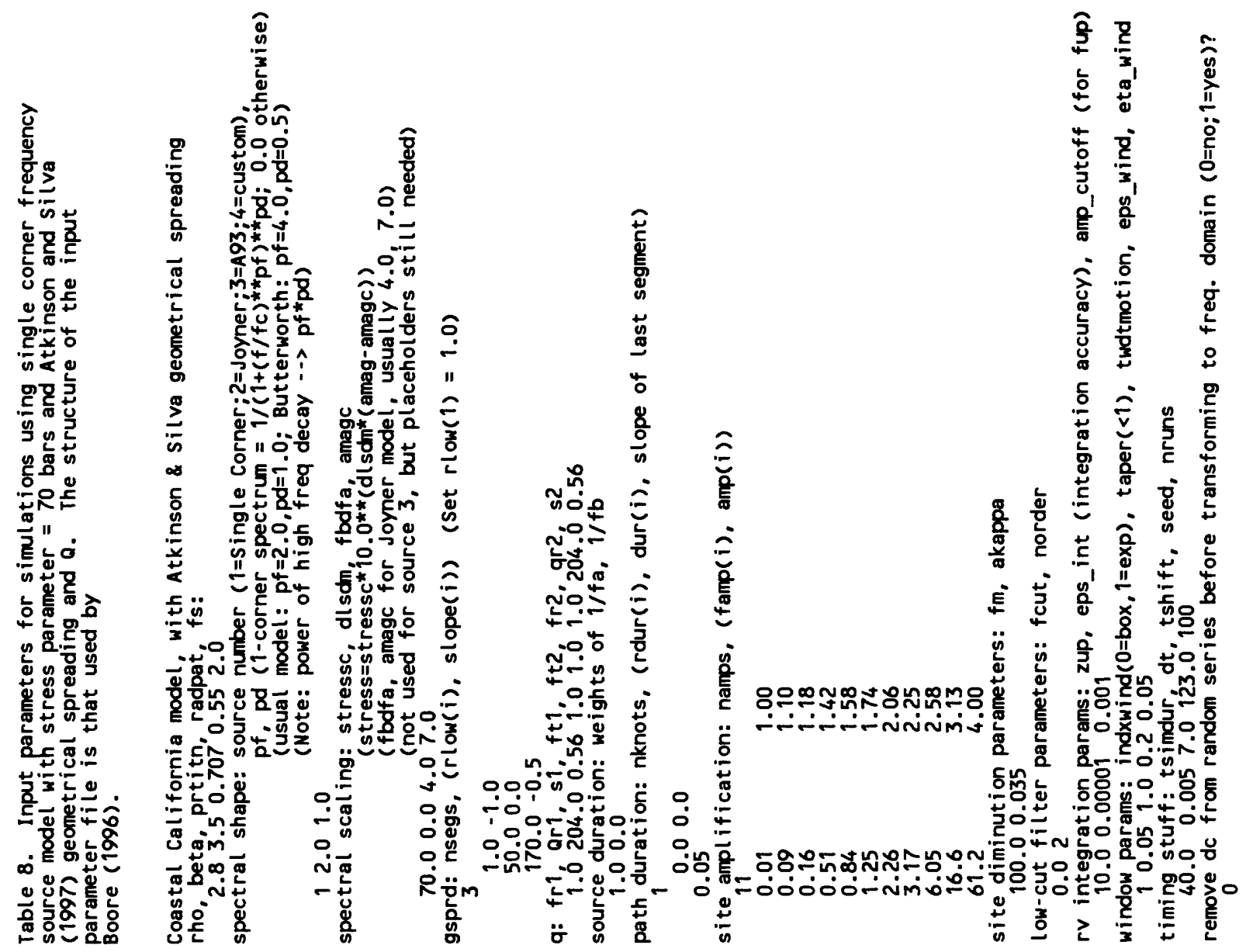




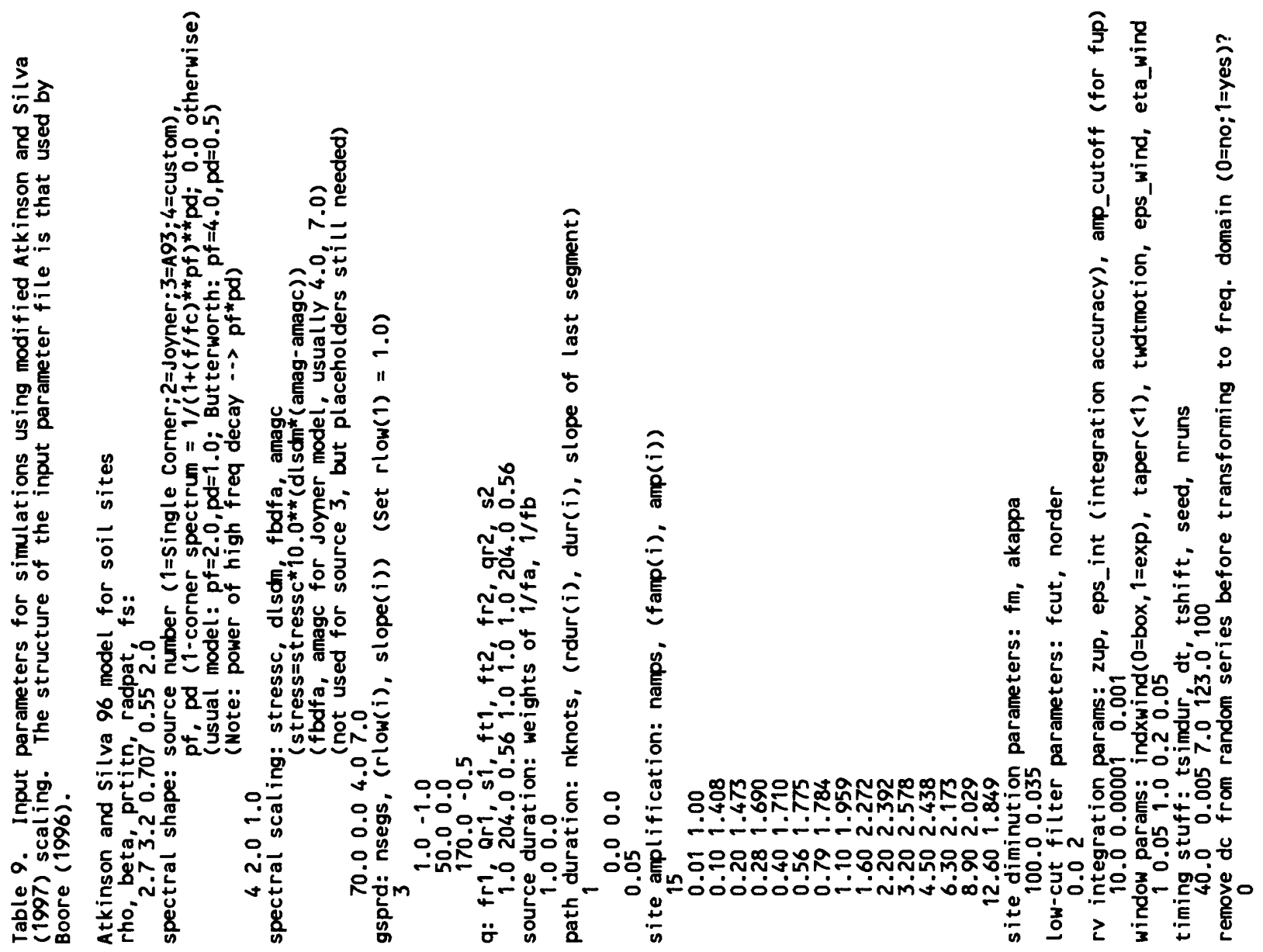




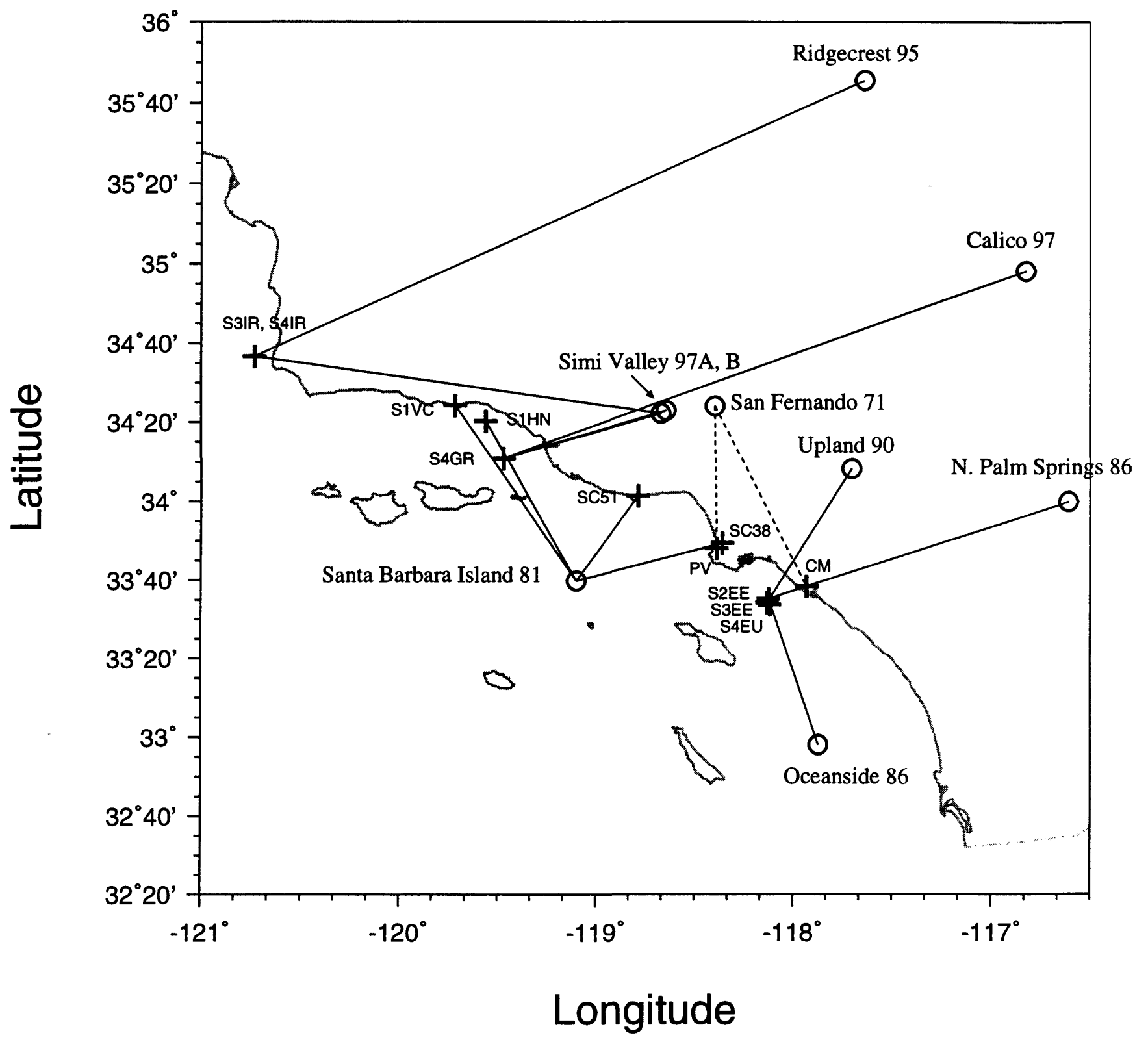

Dec 1, 1997 3:11:20 pm D:ISEMSISEMS_MAP.GRA D:ISEMSICORD4MAP.DT

Figure 1. Map of southern California. Lines connect events (open circles) and stations (pluses) providing data for the corresponding event. The dashed lines show paths for two recordings of the 1971 San Fernando earthquake; these paths cross the Los Angeles basin, as does the path from the Upland 1990 earthquake to SEMS site S3EE. Waveforms of these two events are compared in this report. Although providing no data, station S4EU is shown for completeness. 


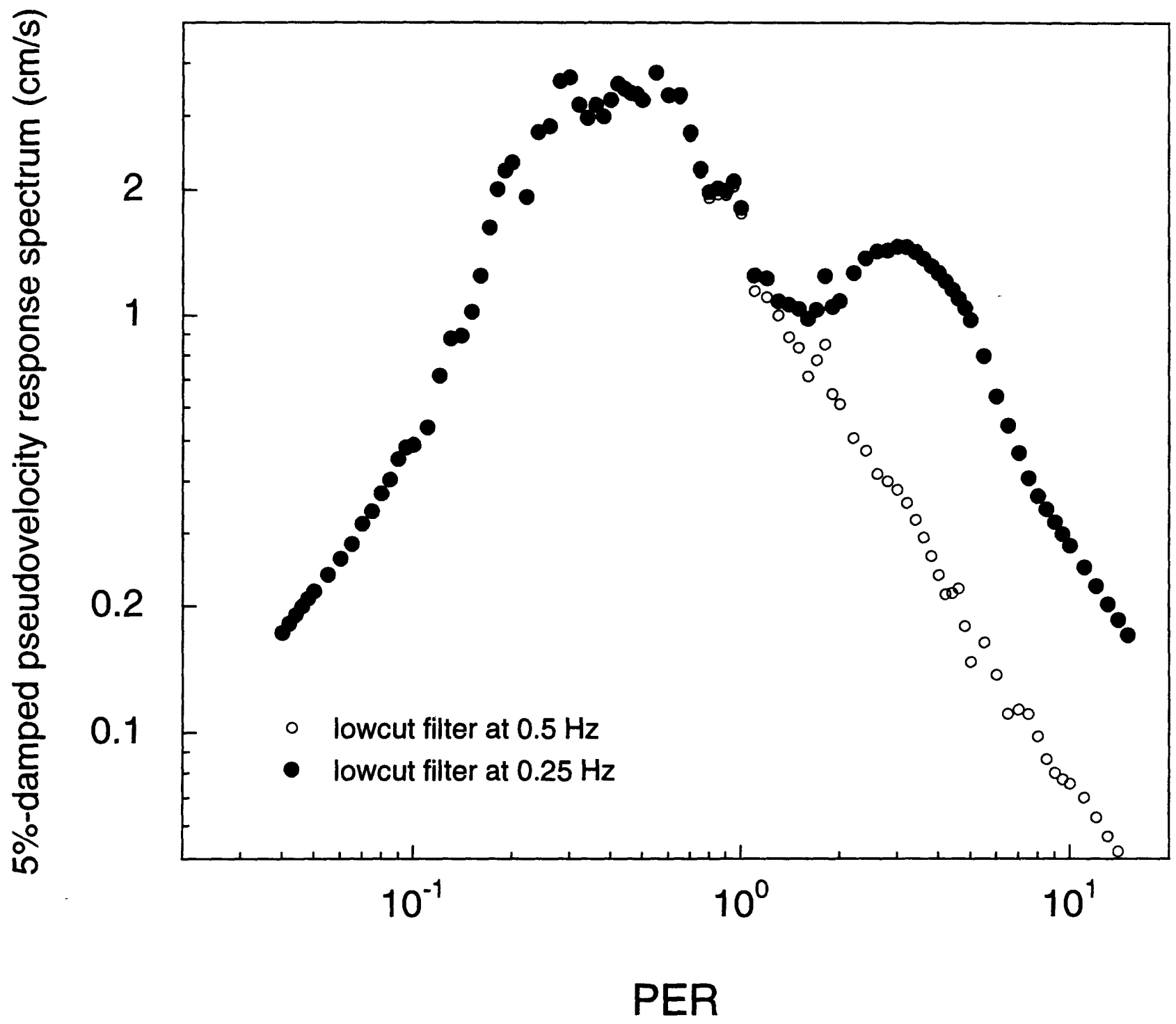

Oct 31, 1997 2:58:36 pm

D:ISEMSWPALM86LCP5P25X.GRA

D:ISEMSWNPALM86LC_P5P25.DT

Figure 2. 5\%-damped response spectra for a horizontal component of the 1986 North Palm Springs earthquake recorded at SEMS site S2EE, showing the effect of the lowfrequency cutoff. 
Upland, 1990, S3EE (horizontal x component)

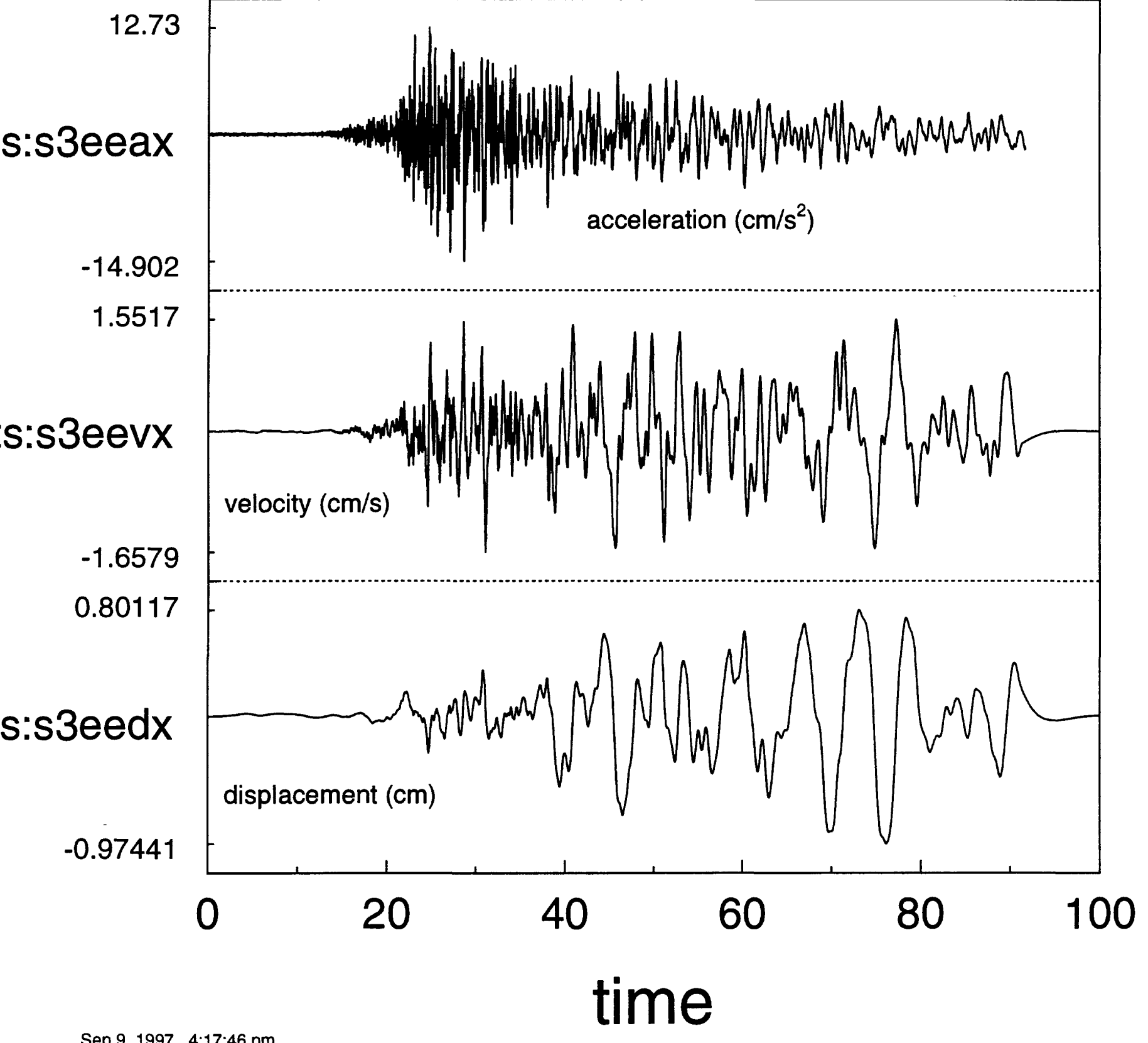

Sep 9, 1997 4:17:46 pm

C:ISEMSIUPLAND9OUVDX4RPT.GRA

C:ISEMSIUPLAND9OIS3EEAVDX.DT

Figure 4. Acceleration $\left(\mathrm{cm} / \mathrm{sec}^{2}\right)$, velocity $(\mathrm{cm} / \mathrm{sec})$, and displacement $(\mathrm{cm})$ time series for the horizontal $x$ component of the S3EE recording of the 1990 Upland earthquake. Note the dominance of late arriving 5 to 6 sec waves on the displacement trace, something not emphasized in the accelerogram. 
Upland, 1990, S3EE (horizontal y component)

\section{s:s3eeay}

s:s3eevy

s:s3eedy

$-1.7931$

velocity $(\mathrm{cm} / \mathrm{s})$

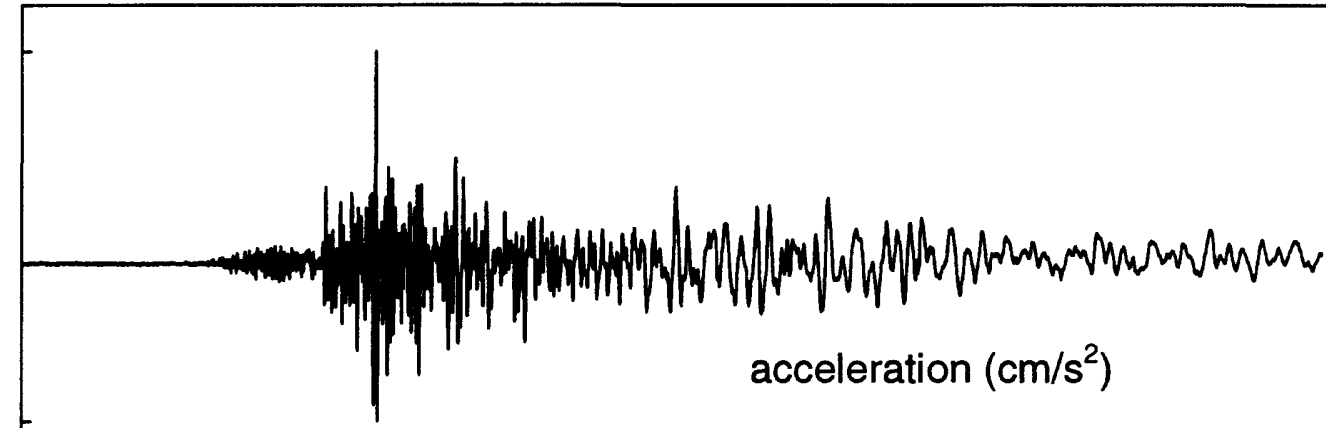

$-20.595$

1.8292

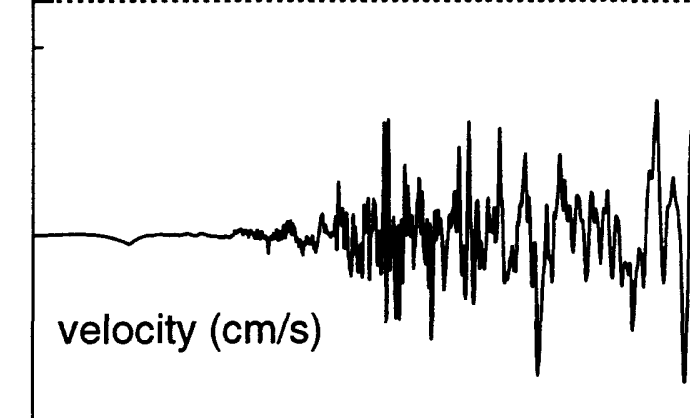

0.9988

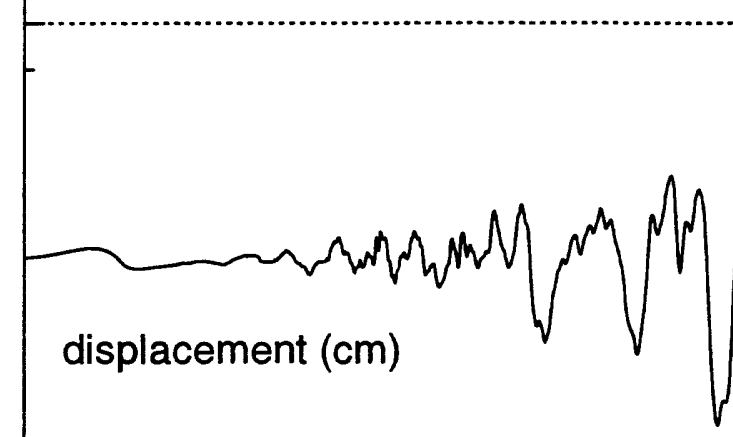

$-0.95156$

Sep 9, 1997 4:19:07 pm

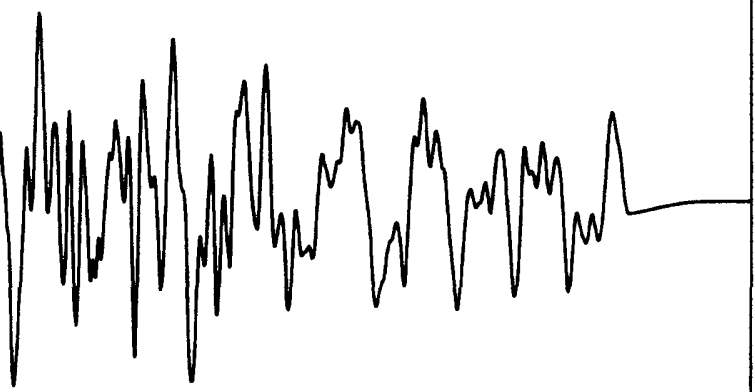

C:ISEMSIUPLAND9OVAVDY4RPT.GRA

C:ISEMSIUPLAND9OIS3EEAVDY.DT

Figure 5. Acceleration $\left(\mathrm{cm} / \mathrm{sec}^{2}\right)$, velocity $(\mathrm{cm} / \mathrm{sec})$, and displacement $(\mathrm{cm})$ time series for the horizontal y component of the S3EE recording of the 1990 Upland earthquake. Note the dominance of late arriving 5 to $6 \mathrm{sec}$ waves on the displacement trace, something not emphasized in the accelerogram. 
Upland, 1990, S3EE (vertical component)

s:s3eeaz

s:s3eevz

$-0.51888$

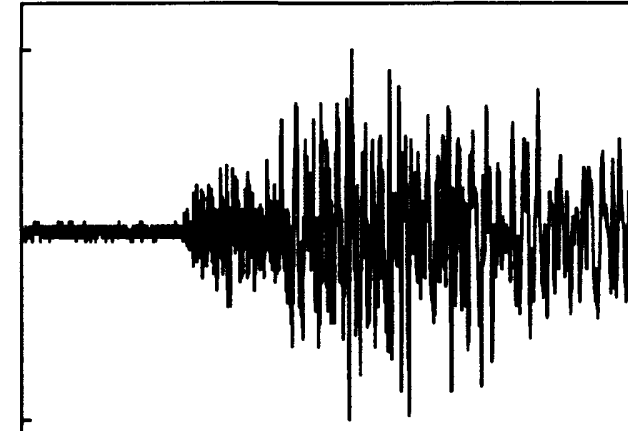

$-3.636$

s:s3eedz

$-0.28049$

0.25195

velocity $(\mathrm{cm} / \mathrm{s})$

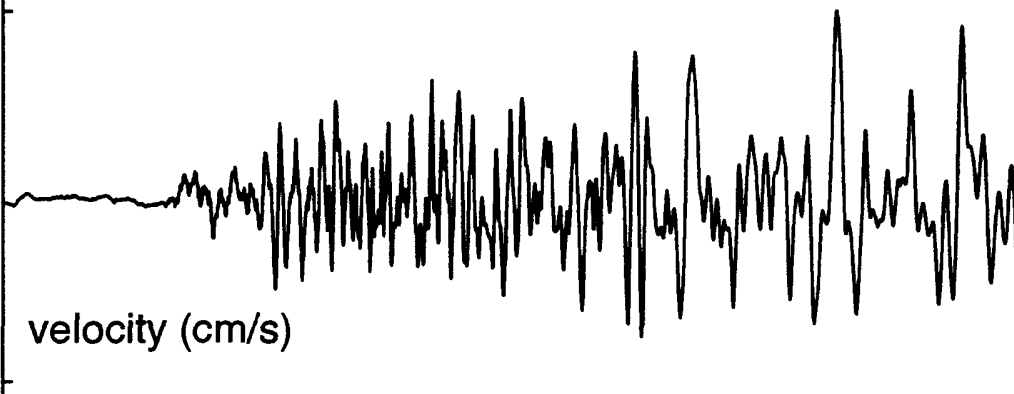

$$
\text { acceleration }\left(\mathrm{cm} / \mathrm{s}^{2}\right)
$$
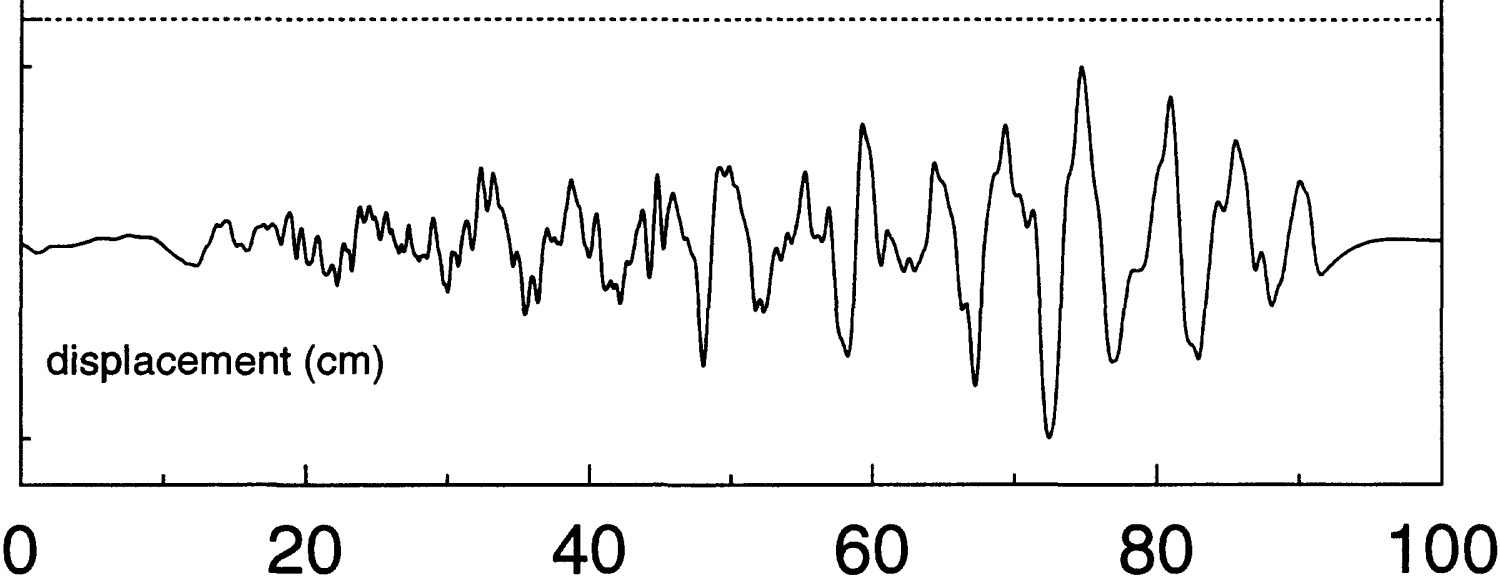

\section{time}

Sep 9, 1997 4:21:26 pm

C:ISEMSIUPLAND9OVAVDZRPT.GRA

C:ISEMSIUPLAND9OIS3EEAVDZ.DT

Figure 6. Acceleration $\left(\mathrm{cm} / \mathrm{sec}^{2}\right)$, velocity $(\mathrm{cm} / \mathrm{sec})$, and displacement $(\mathrm{cm})$ time series for the vertical component of the S3EE recording of the 1990 Upland earthquake. Note the dominance of late arriving 5 to $6 \mathrm{sec}$ waves on the displacement trace, something not emphasized in the accelerogram. Furthermore, note the similarity of the waveforms to those of the horizontal components, something difficult to see in the true amplitude scaling in Figure 3. 
Figure 7. Horizontal-component accelerations $\left(\mathrm{cm} / \mathrm{sec}^{2}\right)$ from the 1990 Upland earthquake recorded offshore at S3EE (top trace) and from the larger 1971 San Fernando earthquake recorded at Palos Verdes and Costa Mesa (middle and bottom traces, respectively). The two 1971 recordings apparently triggered on the $S$ wave, but comparison with the 1990 recording suggests that most of the $S$ energy has been captured. It is unlikely that the response spectra will be affected by the short duration of missing $S$ energy, particularly at the longer periods of most interest in this report. The durations of the accelerograms represent the complete recording, after which the triggered instruments turned off. It is likely that the long-period energy continued for a longer duration.

$$
\underset{-1}{-\infty}
$$

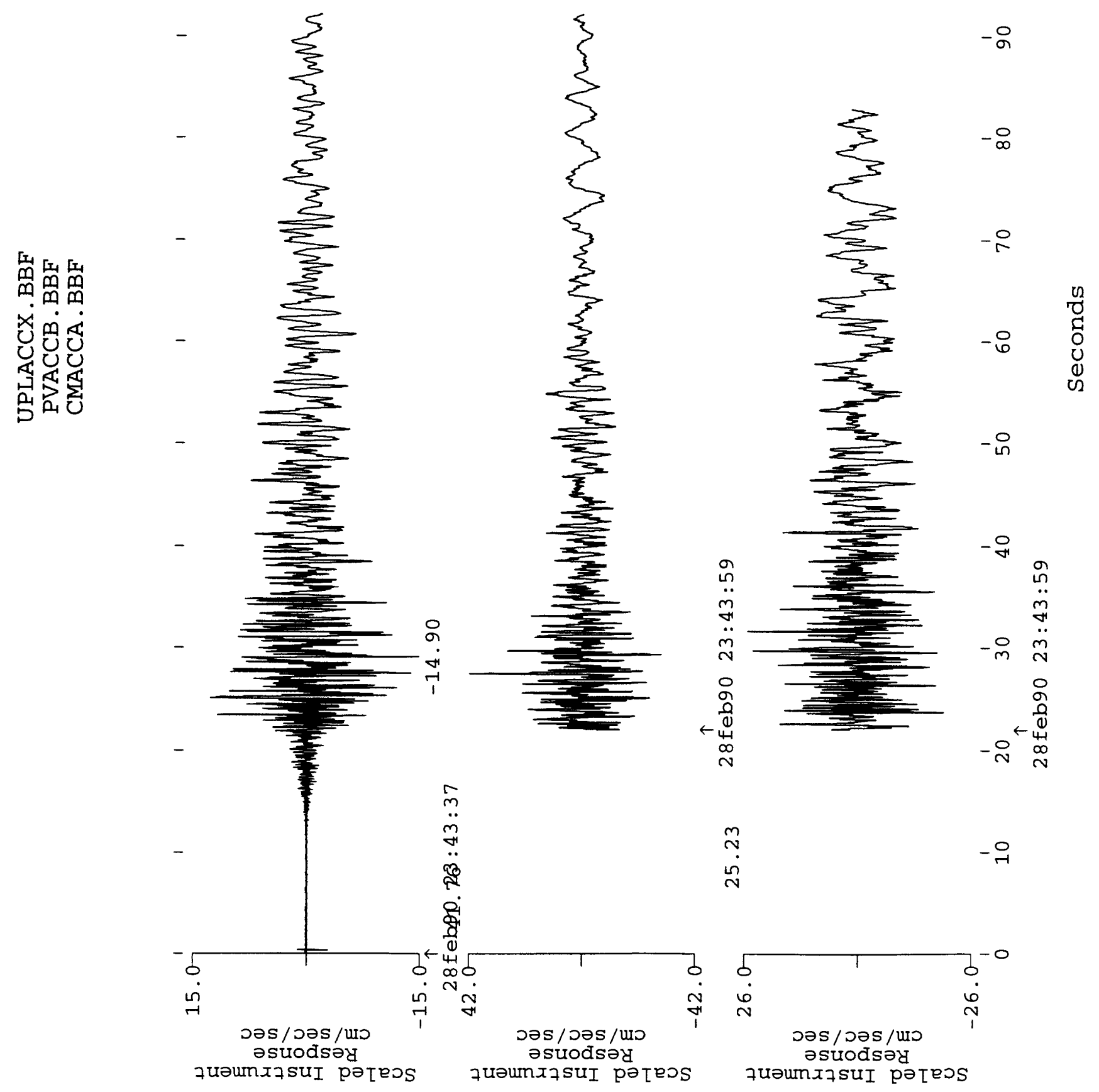


Figure 8. Horizontal-component velocities $(\mathrm{cm} / \mathrm{sec})$ from the 1990 Upland earthquake recorded offshore at S3EE (top trace) and from the larger 1971 San Fernando earthquake recorded at Palos Verdes and Costa Mesa (middle and bottom traces, respectively).

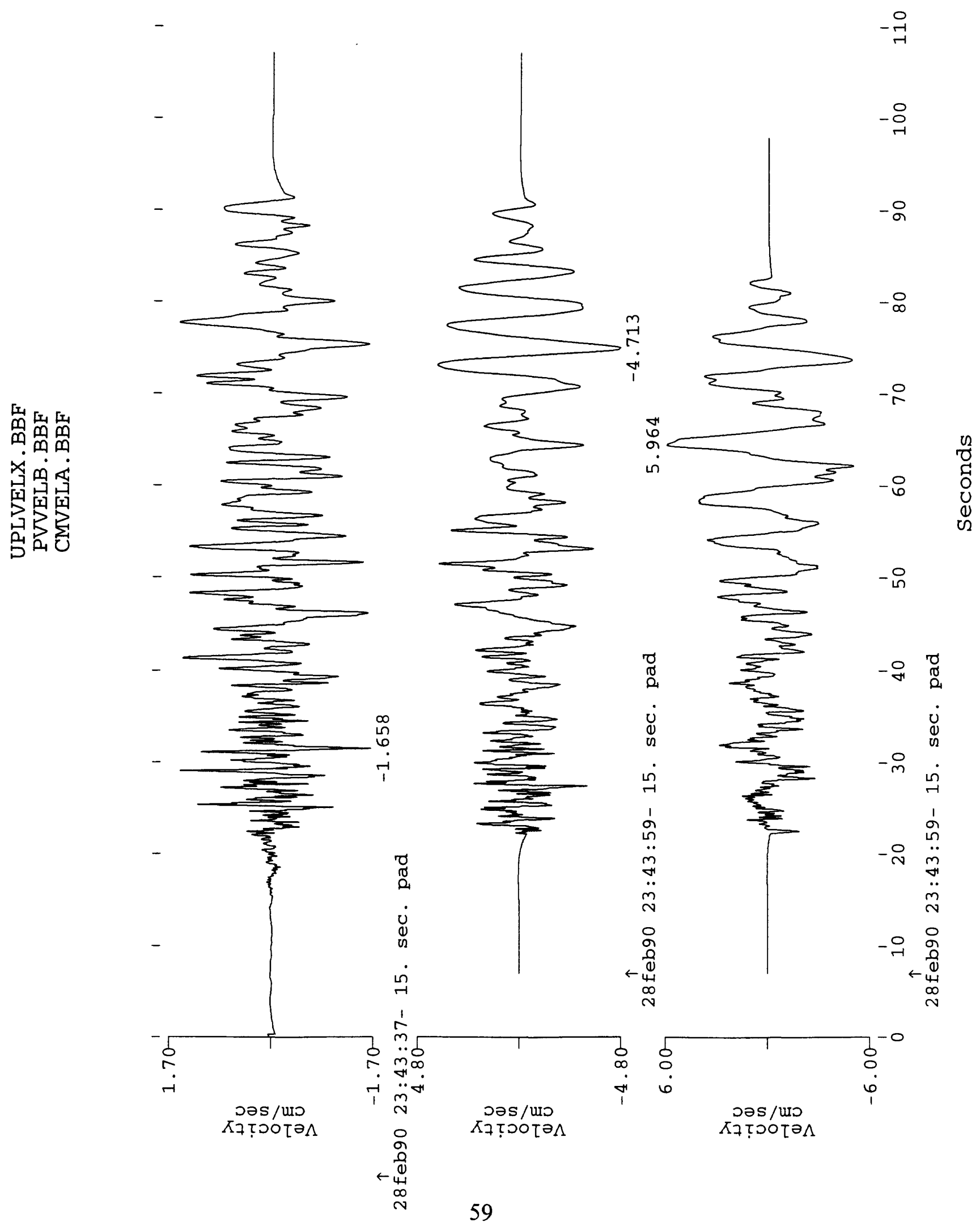


Figure 9. Horizontal-component displacements $(\mathrm{cm})$ of lowcut filtered accelerations from the 1990 Upland earthquake recorded offshore at S3EE (top trace) and from the larger 1971 San Fernando earthquake recorded at Palos Verdes and Costa Mesa (middle and bottom traces, respectively). Note the overall similarity in the waveforms, despite the factor of up to 5 disparity in peak amplitudes. As noted in Figure 7, it is likely that the long-period motions continued for a longer duration than shown.

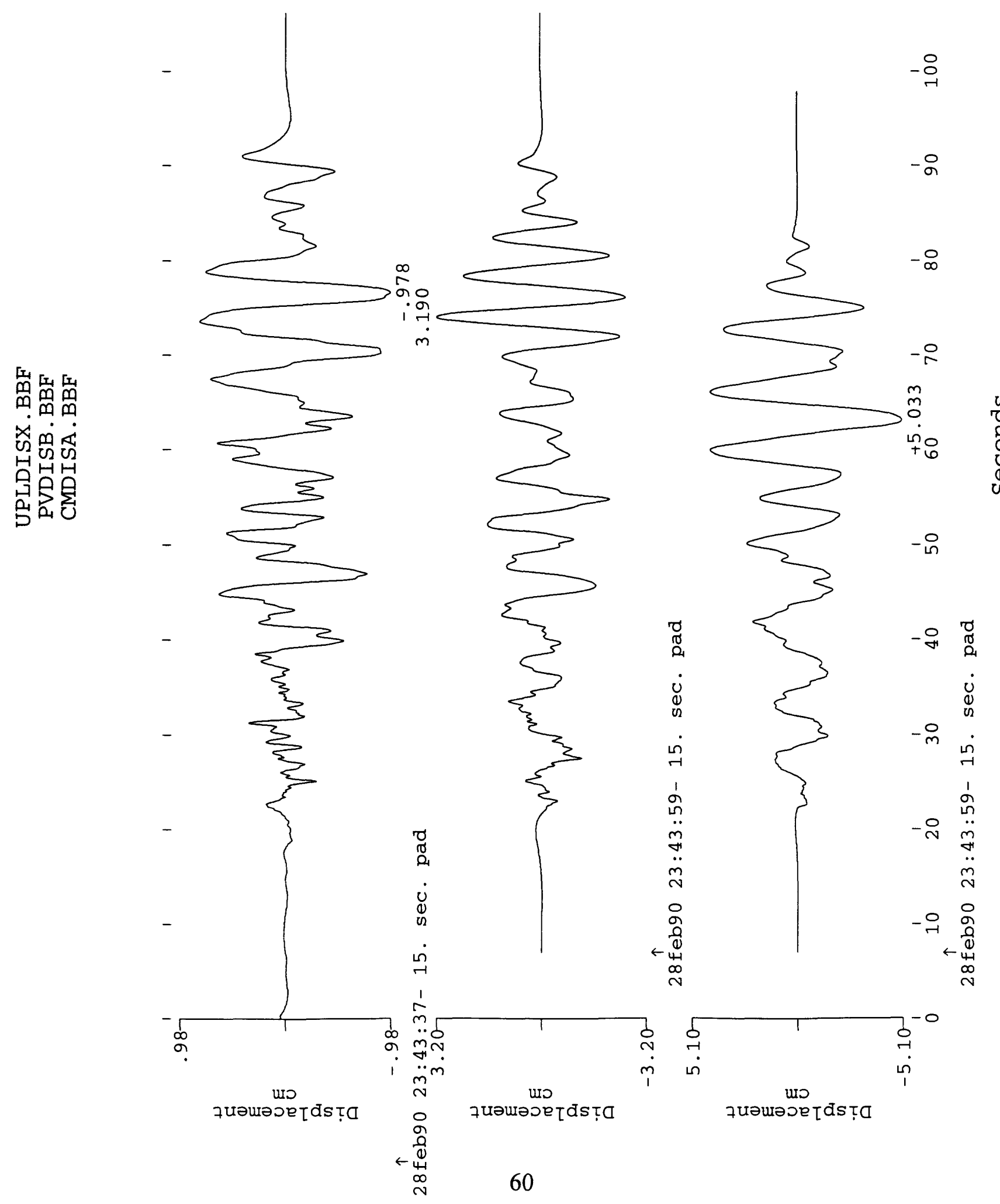


Figure 10. Accelerograms $\left(\mathrm{cm} / \mathrm{sec}^{2}\right)$ shown for various cutoff times (and lowcut filtered at $0.1 \mathrm{~Hz}$ ). These accelerograms were used in a study of the effect of the cutoff time on the computed response spectra (i.e., how important is the late arriving motion that may have been lost due to the limited recording duration of the triggered accelerographs?).

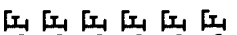

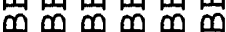

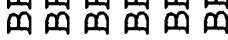
نUنuن

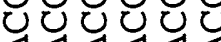
出出出出 OD 06 L
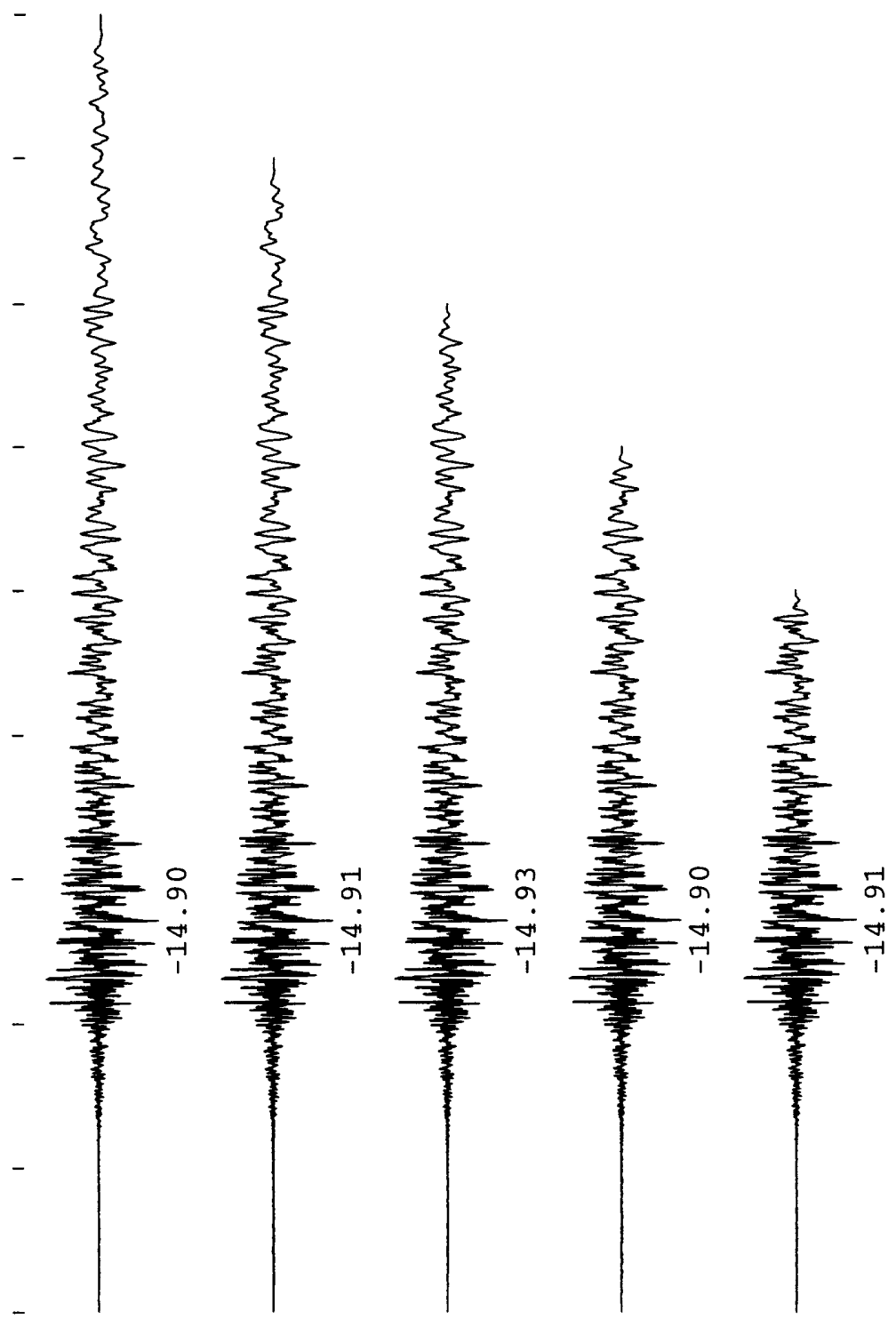

- 웅
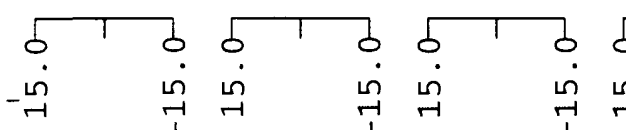

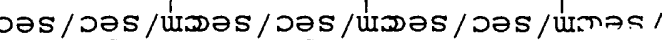
วsuodsəy əsuodsəy əsuodsəy
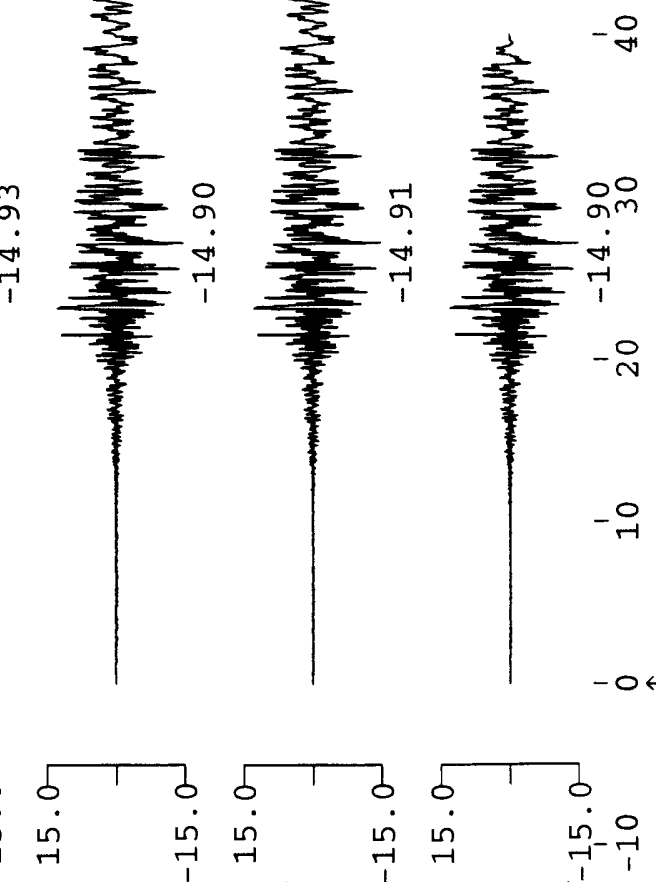

$-0$

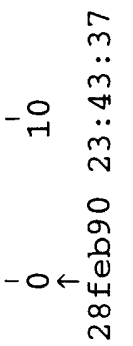

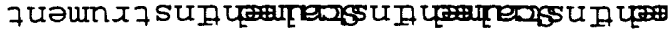
ođsəy əsuodsəy əsuođsəy

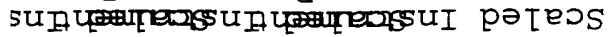


Figure 11. Velocity time series $(\mathrm{cm} / \mathrm{sec})$ computed from the accelerograms shown in Figure 10. Note that intermediate-period energy (with a period of one to several seconds) will be captured on all but the shortest duration record.

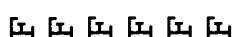
$m M m M$ ต口

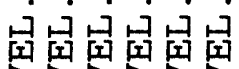
35353 है

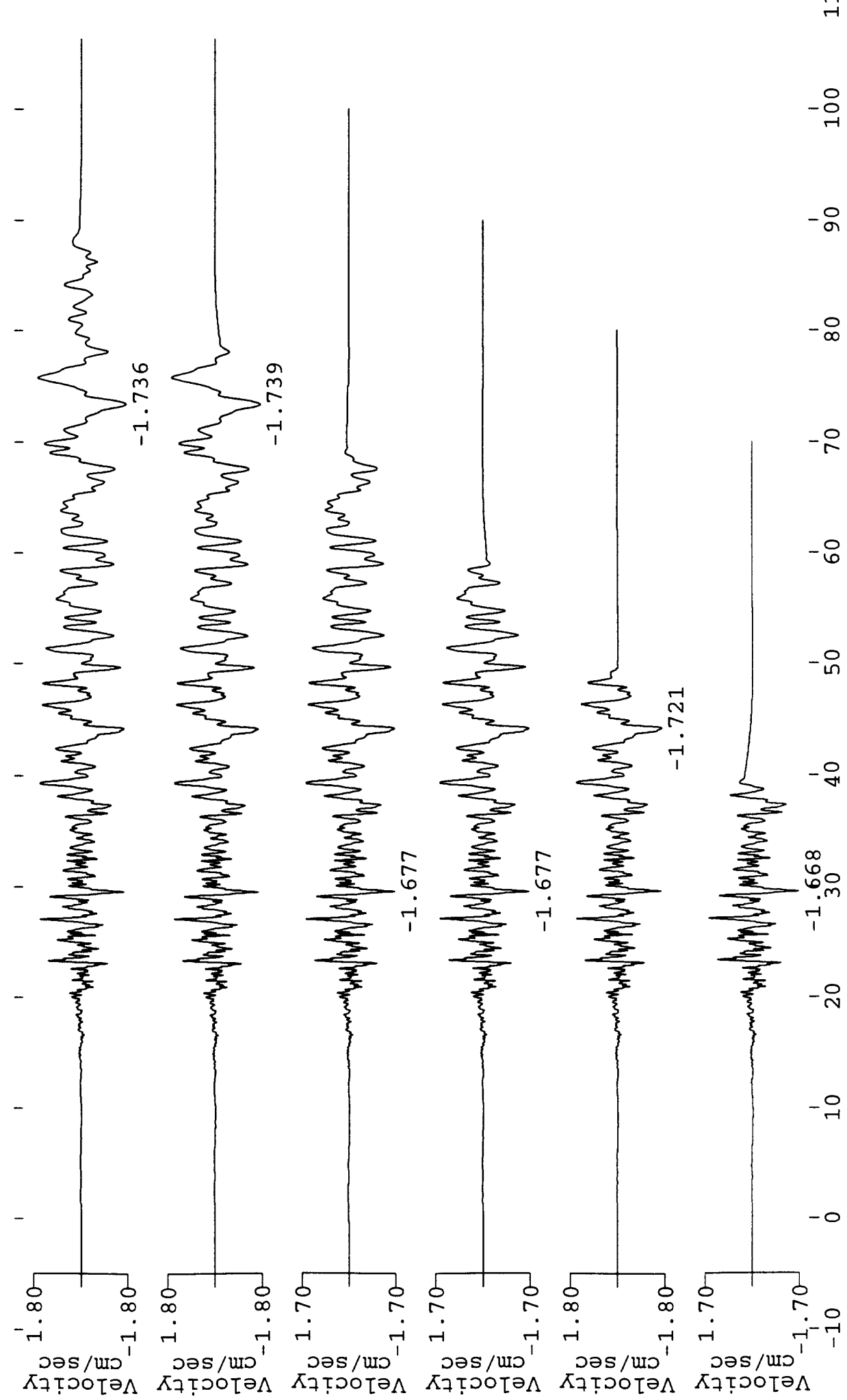


Figure 12. Displacement time series $(\mathrm{cm})$ computed from the accelerograms shown in Figure 10. The 6-7 sec waves are only captured by the two longest records.

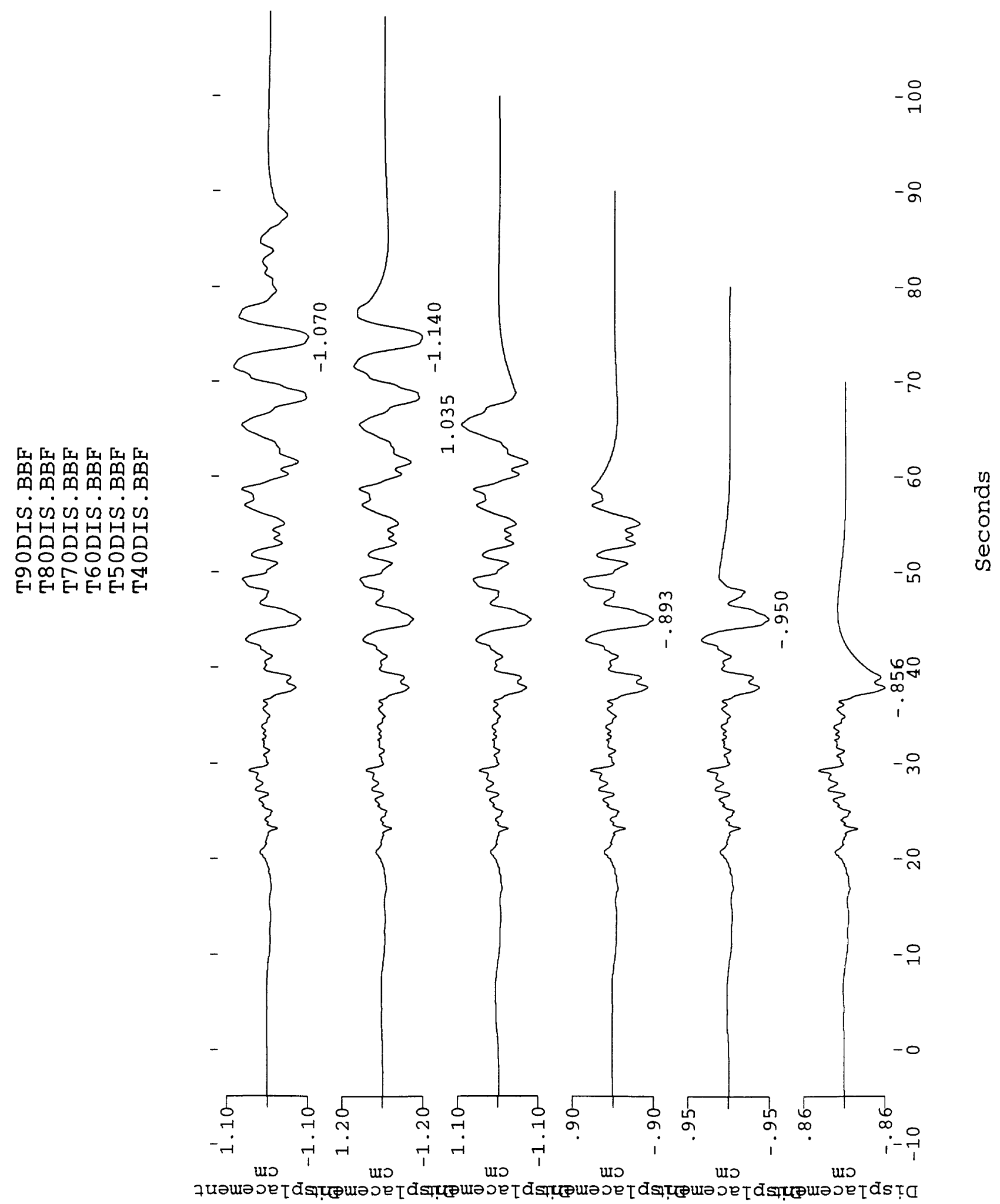




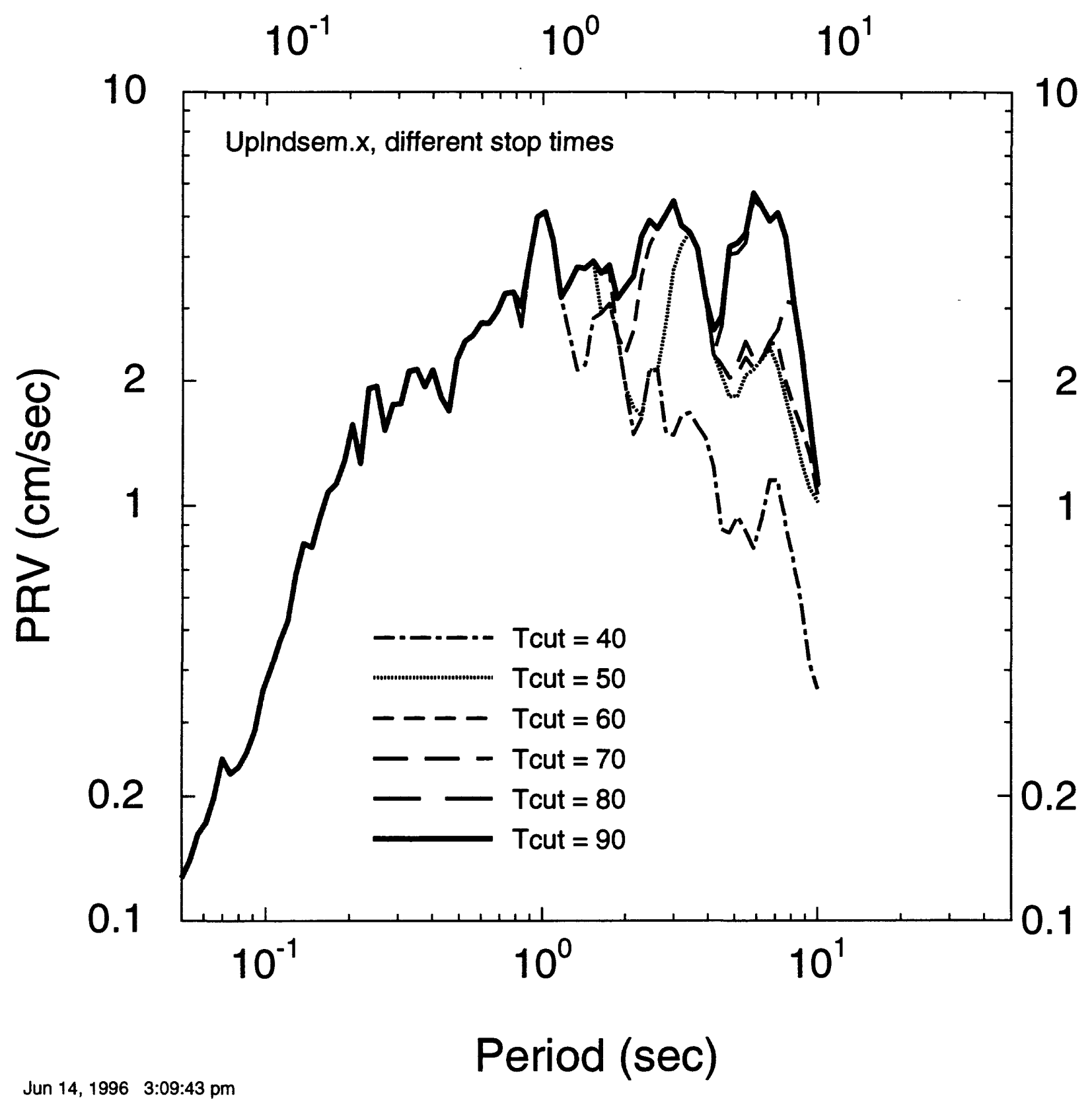

C:ISEMSIBIGEQIRS_VS_T.GRA

C:ISEMSIBIGEQIRS_VS_T.DT

Figure 13. 5\%-damped response spectra for the accelerograms shown in Figure 10, showing the effect of eliminating the late arriving long-period energy if the instrument stops recording at a certain time. Note that only the T80 and T90 accelerograms capture the 6-7 sec waves. 


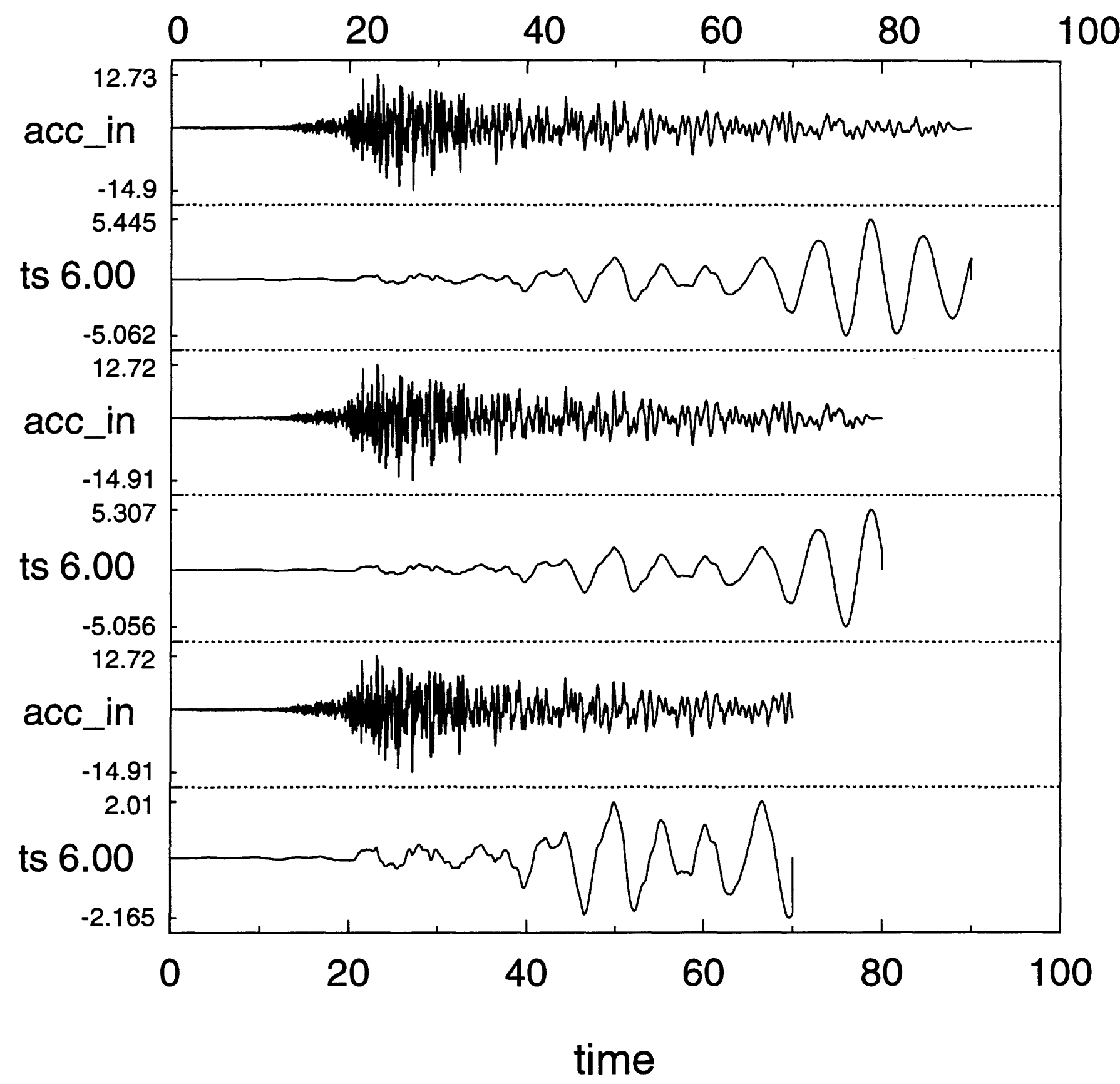

Oct 20, 1997 9:10:20 am D:ISEMSIBIGEQICHKRS.GRA D:ISEMSIBIGEQICHKRS.DT

Figure 14. The accelerogram and corresponding response of a 5\%-damped, 6 sec oscillator for accelerogram cutoffs of 90,80 , and 70 seconds. Unlike the 70 second accelerogram, the accelerograms with 80 and 90 second cutoffs have captured enough of the 6 second response to give the same response spectral amplitudes (Figure 13). 


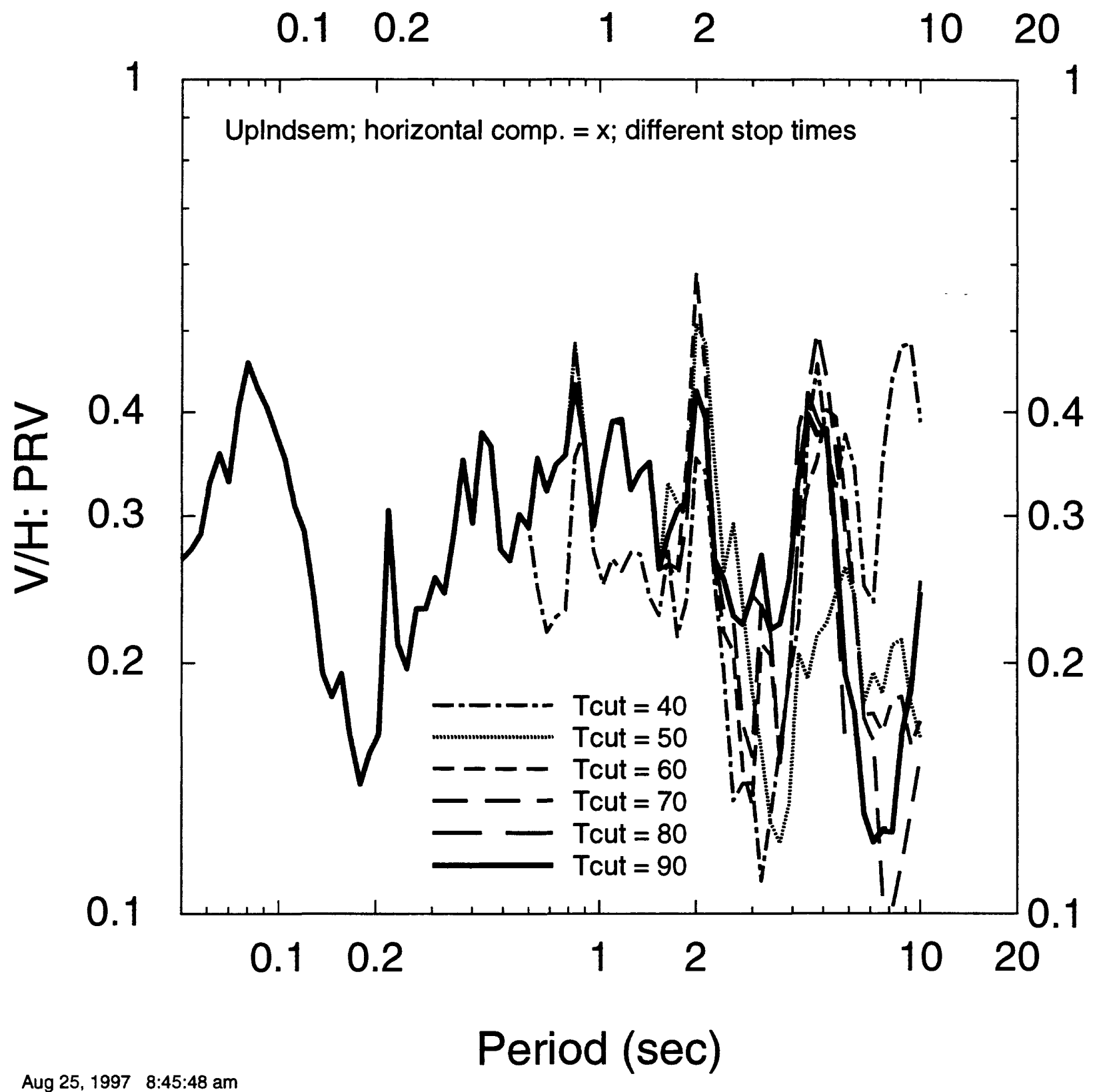

C:ISEMSIBIGEQIRSTCUTVH.GRA

C:ISEMSIBIGEQIRSTCUTVH.DT

Figure 15. $V / H$ ratio of 5\%-damped response spectra computed from accelerograms with different cutoff times. 


\section{SBI81 observations}

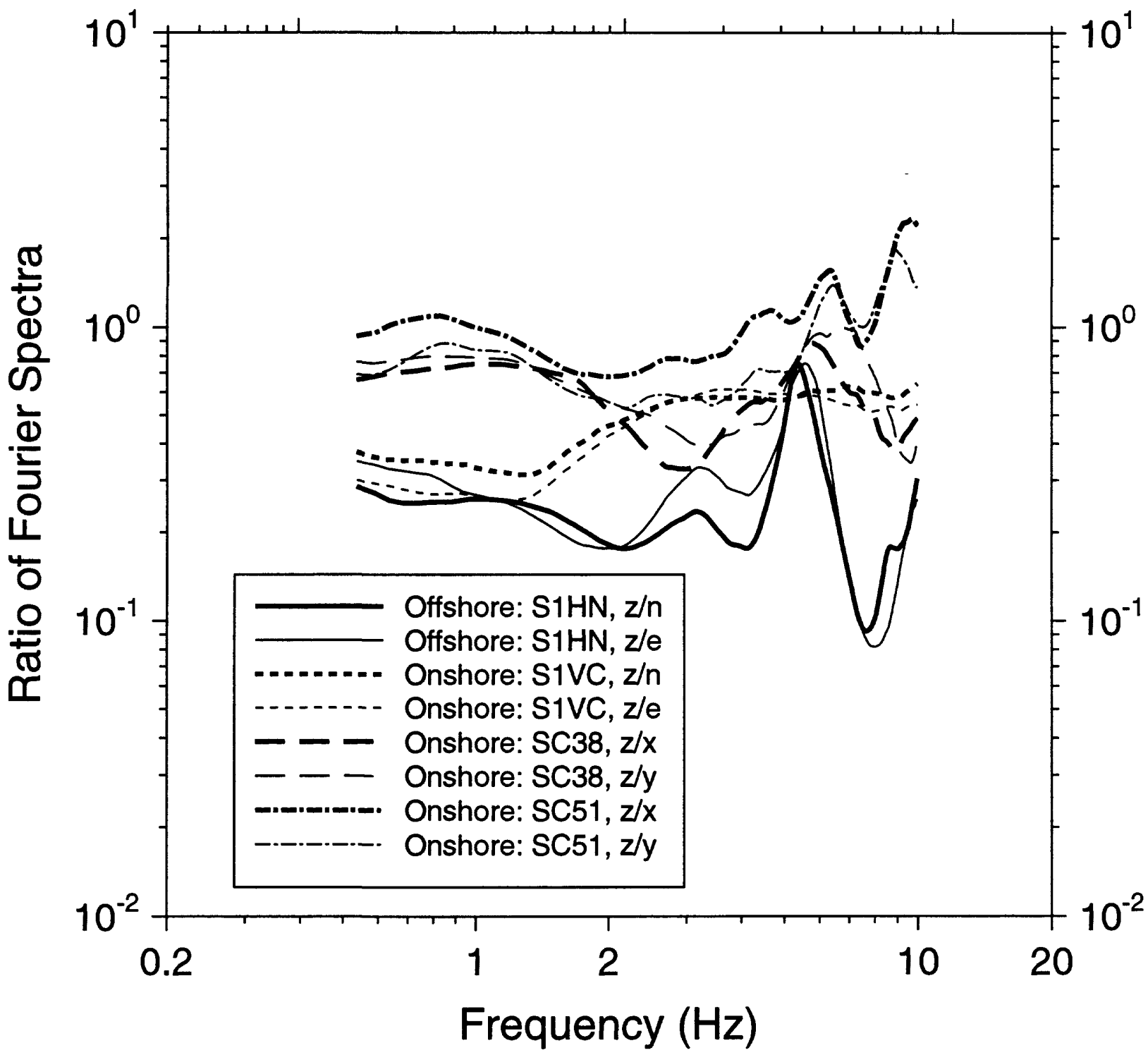

Nov 21, 1997 1:48:53 pm D:ISEMSISBI81ZDH.GRA

D:ISEMSISBI81ISBI81RAT.DT

Figure 16. Comparison of $V / H$ ratios of $5 \%$-damped response spectra for recordings of the 1981 Santa Barbara Island earthquake at offshore and onshore sites. The ratio for the offshore site $(\mathrm{S} 1 \mathrm{HN})$ is much lower at short periods than are the ratios from the onshore sites. 


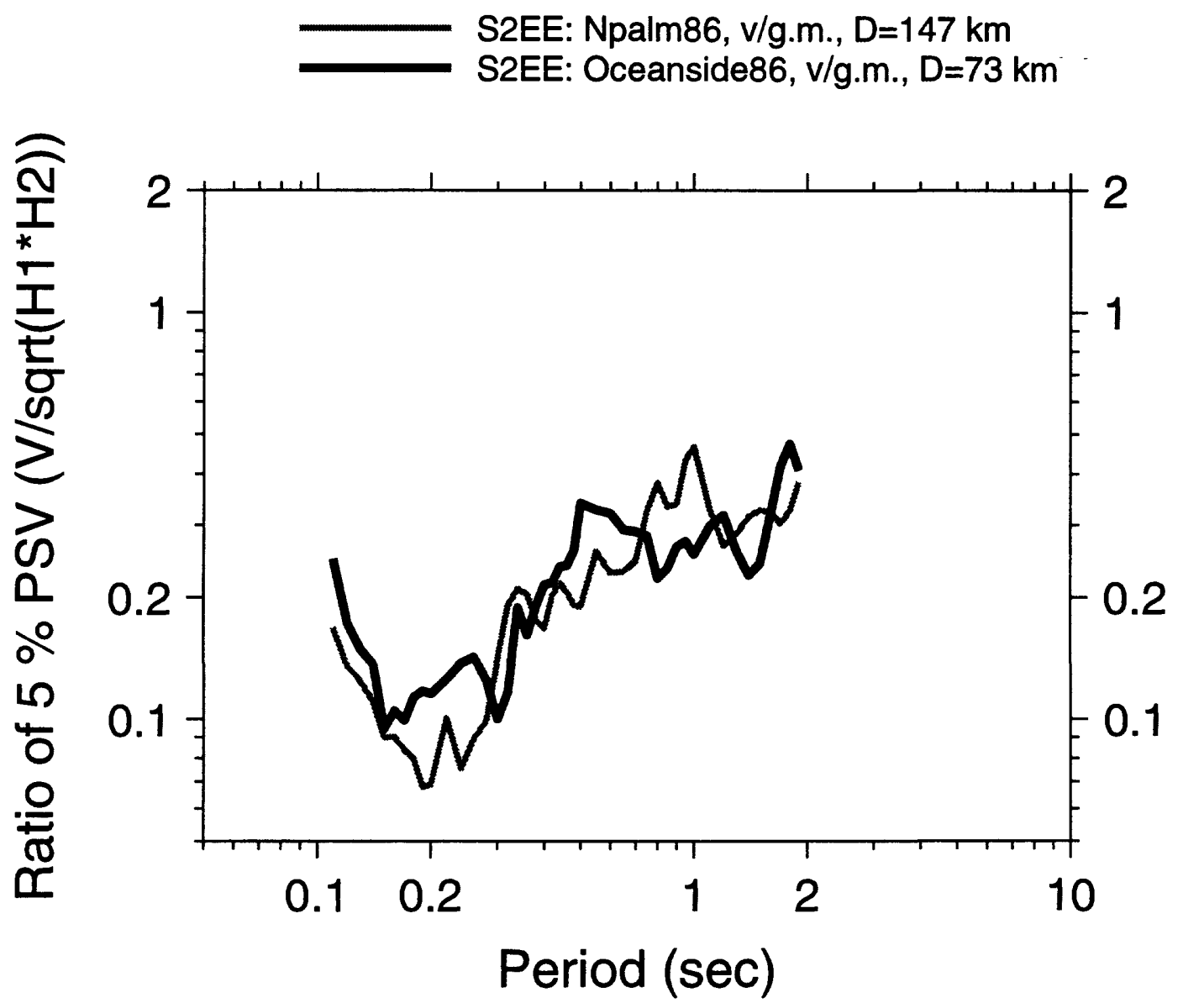

Sep 4, 1997 11:55:42 am C:ISEMSIV_HIS2LB.GRA C:ISEMSIV_HIOBS_V_H.DT

Figure 18. Comparison of $V / H$ ratios of $5 \%$-damped response spectra for recordings at the SEMS site S2EE. Notice the similarity of the ratios for the two events recorded at the same site. 
CL97 @ S4GR: $M=4.8, D=258$ km

S97A @ S4GR: $M=4.8, D=77 \mathrm{~km}$

S97B @ S4GR: $M=4.7, D=79$ km

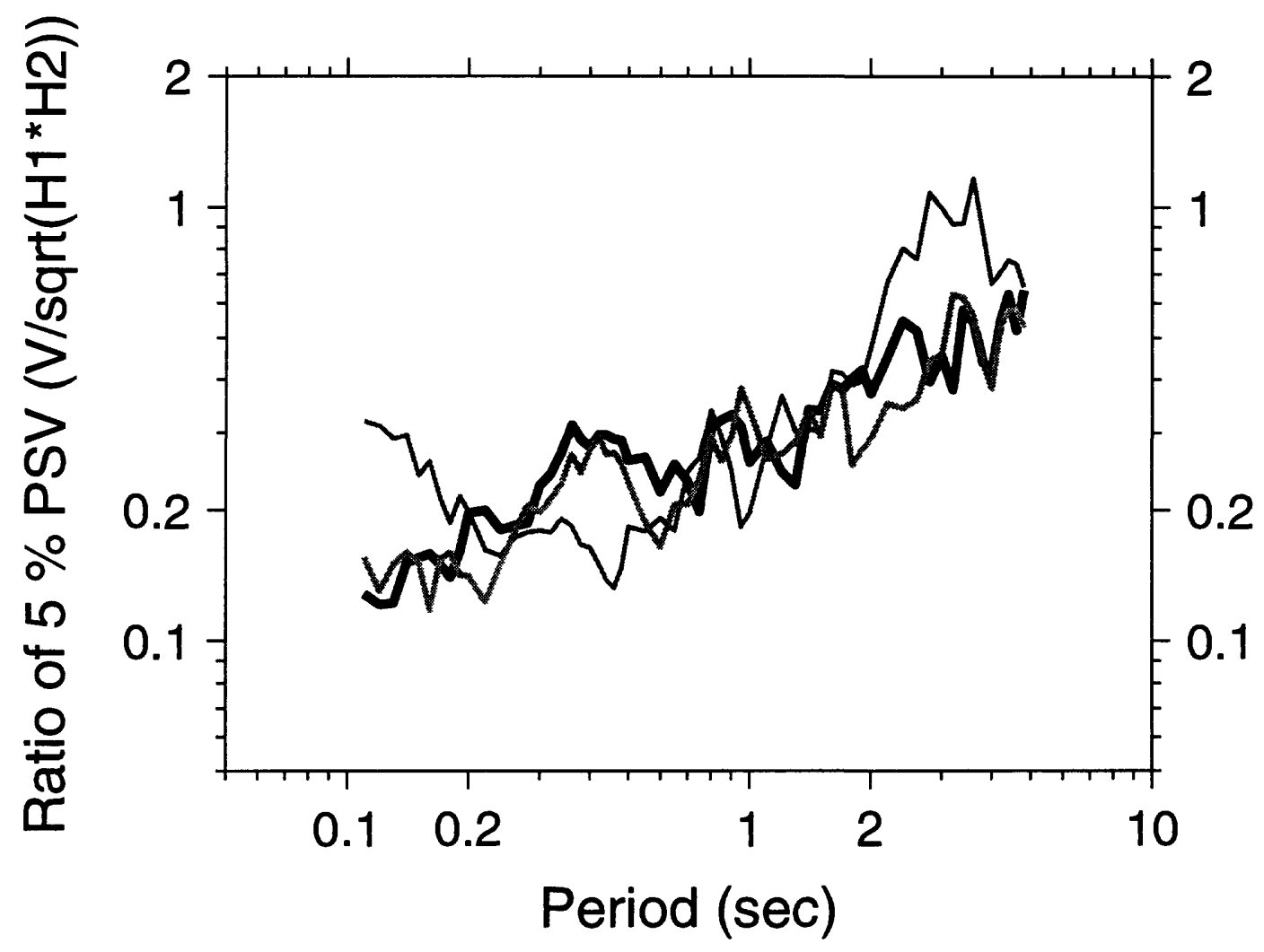

Aug 27, 1997 3:08:09 pm C:ISEMSIV_HIGRACE.GRA C:ISEMSIV_HIOBS_V_H.DT

Figure 19. Comparison of $V / H$ ratios of 5\%-damped response spectra for recordings at the SEMS site S4GR. Notice the similarity of the ratios for the events recorded at the same site, particularly for the two Simi Valley earthquakes, which were located close to one another. 


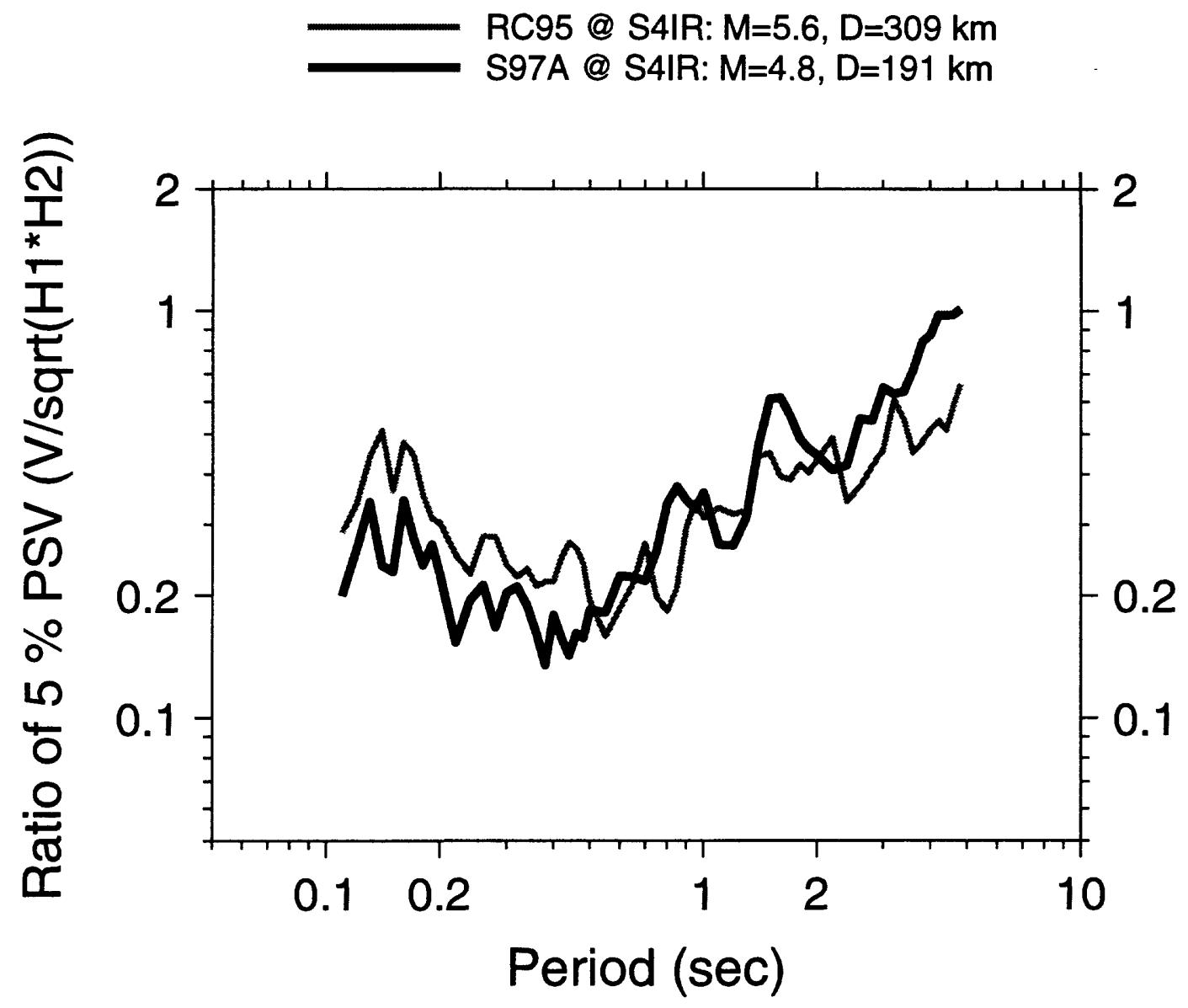

Aug 27, 1997 3:08:28 pm C:ISEMSIV_HIRENE.GRA C:ISEMSIV_HIOBS_V_H.DT

Figure 20. Comparison of $V / H$ ratios of 5\%-damped response spectra for recordings at the SEMS site S4IR. Notice the similarity of the ratios for the two events recorded at the same site. 


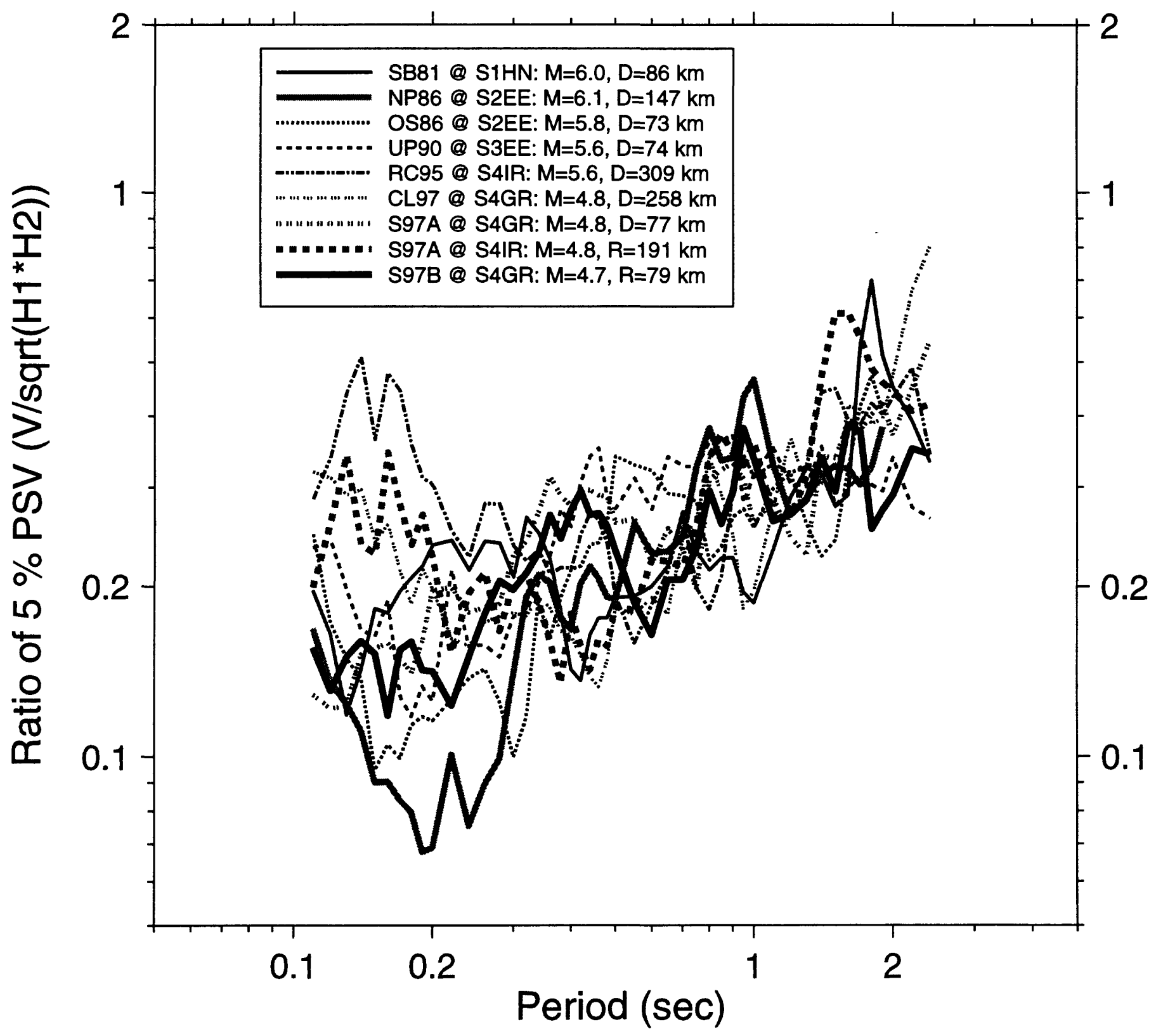

Oct 24, 1997 11:47:59 am D:ISEMSIV_HIMEAN4PLT.DT D:ISEMSIV_HIV_H_OBS.GRA

Figure 21. Comparison of $V / H$ ratios of $5 \%$-damped response spectra for recordings at all of the offshore SEMS sites considered in this report. In view of the widespread distribution of the stations, the ratios are remarkably similar, particularly for the longer periods. Theoretical calculations suggest that the spread in the ratios at short periods may be due to site-to-site variations in water depth and near-surface geological properties. 


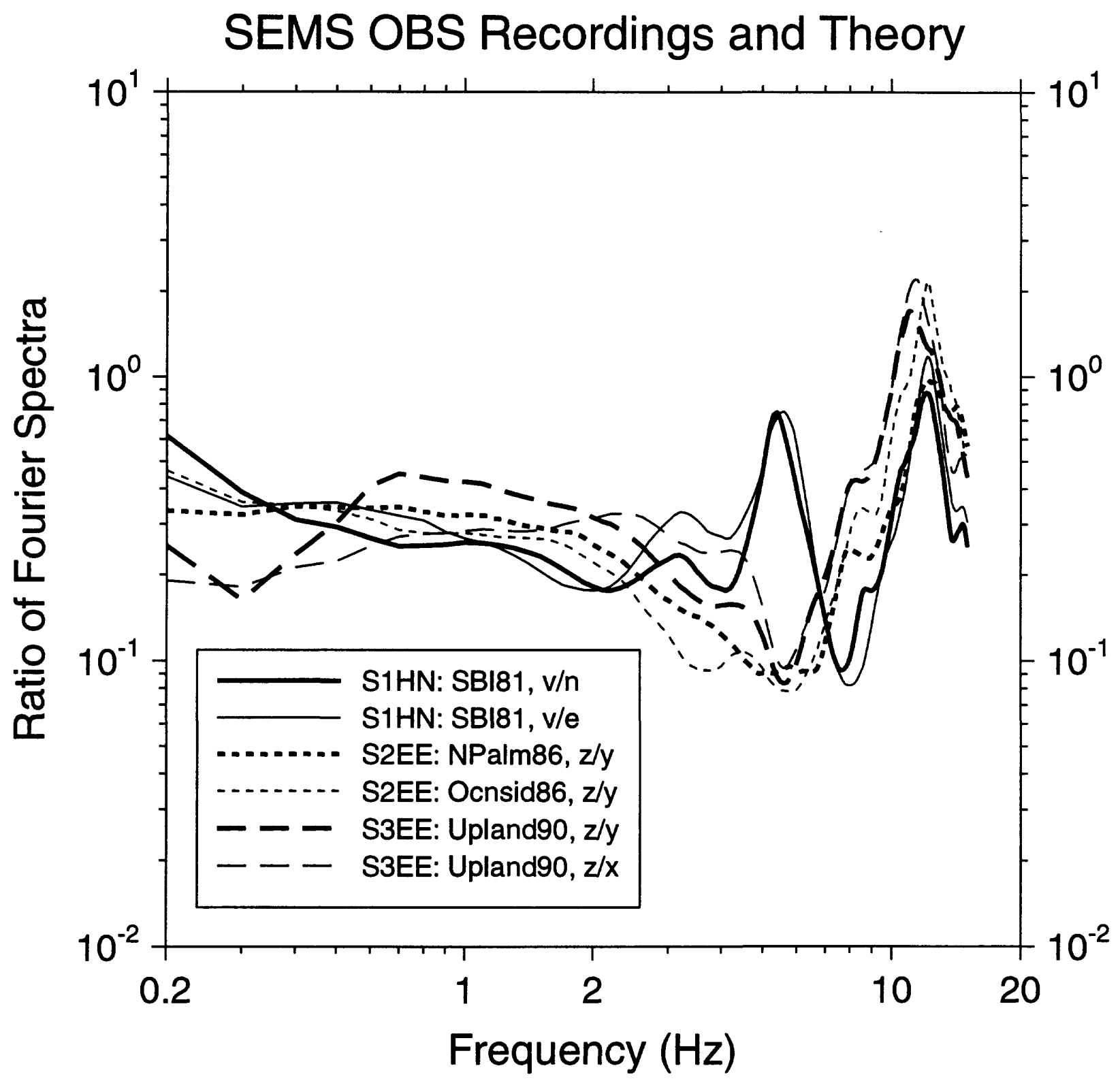

Nov 22, 1997 9:16:26 am zdhoff.grg D:ISEMSIV_HZDH_COR.GRA D:ISEMSIV_HIRAT_CORR.DT

Figure 22. Comparison of $V / H$ ratios of Fourier amplitude spectra for the offshore SEMS recordings through 1990. As in the ratio of response spectra, the ratios are very similar at low frequencies and show some divergence at high frequencies. 


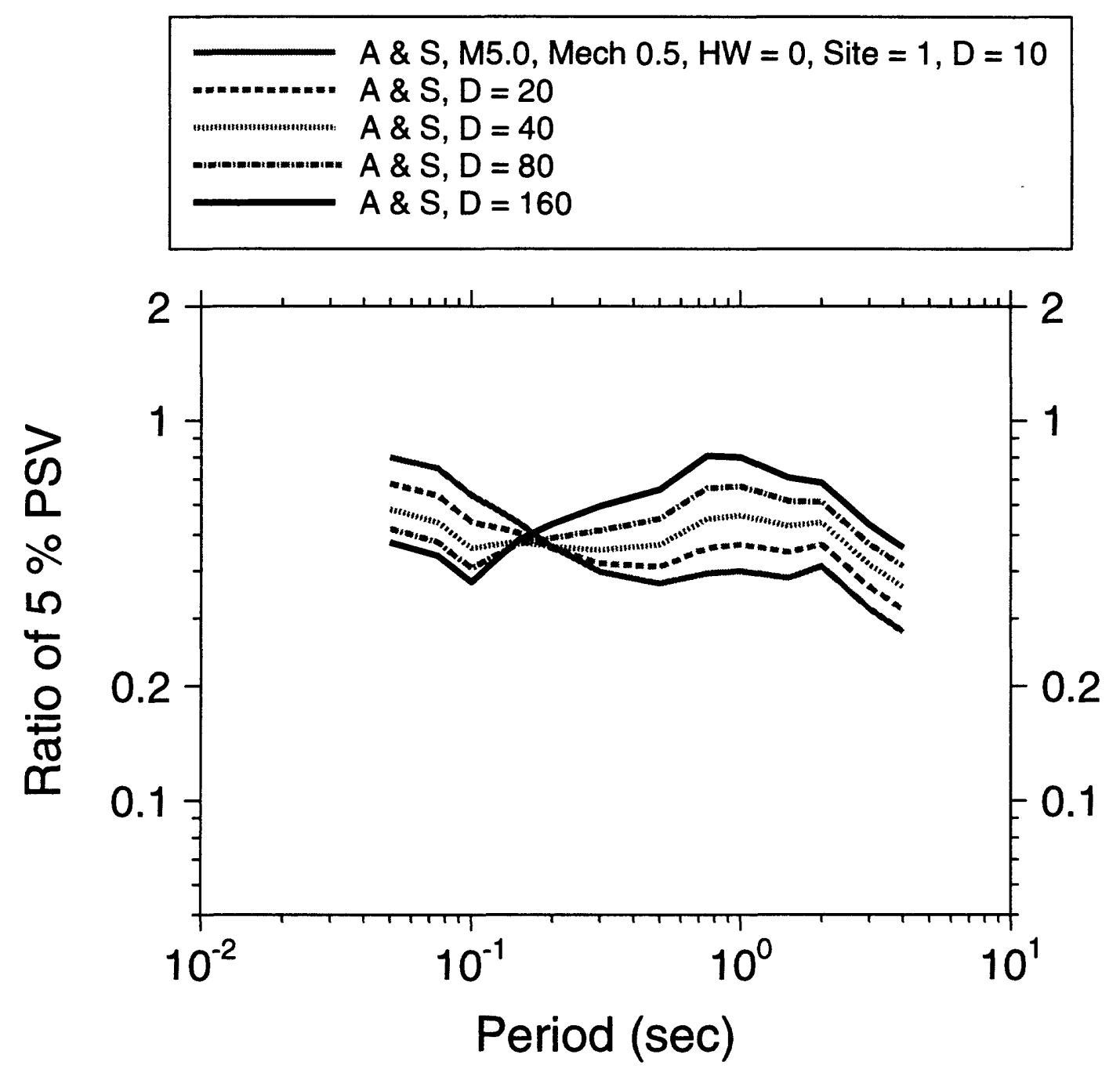

Oct 24, 1997 10:50:26 am D:ISEMSIV_HIV_H5060.DT D:ISEMSIV_HIVHM5DAS.GRA

Figure 23. $\mathrm{V} / \mathrm{H}$ ratios of 5\%-damped response spectra from Abrahamson and Silva's (1997) regression results for $\mathbf{M}=5.0$, oblique slip faulting, soil site, and distances from 10 to $160 \mathrm{~km}$. 


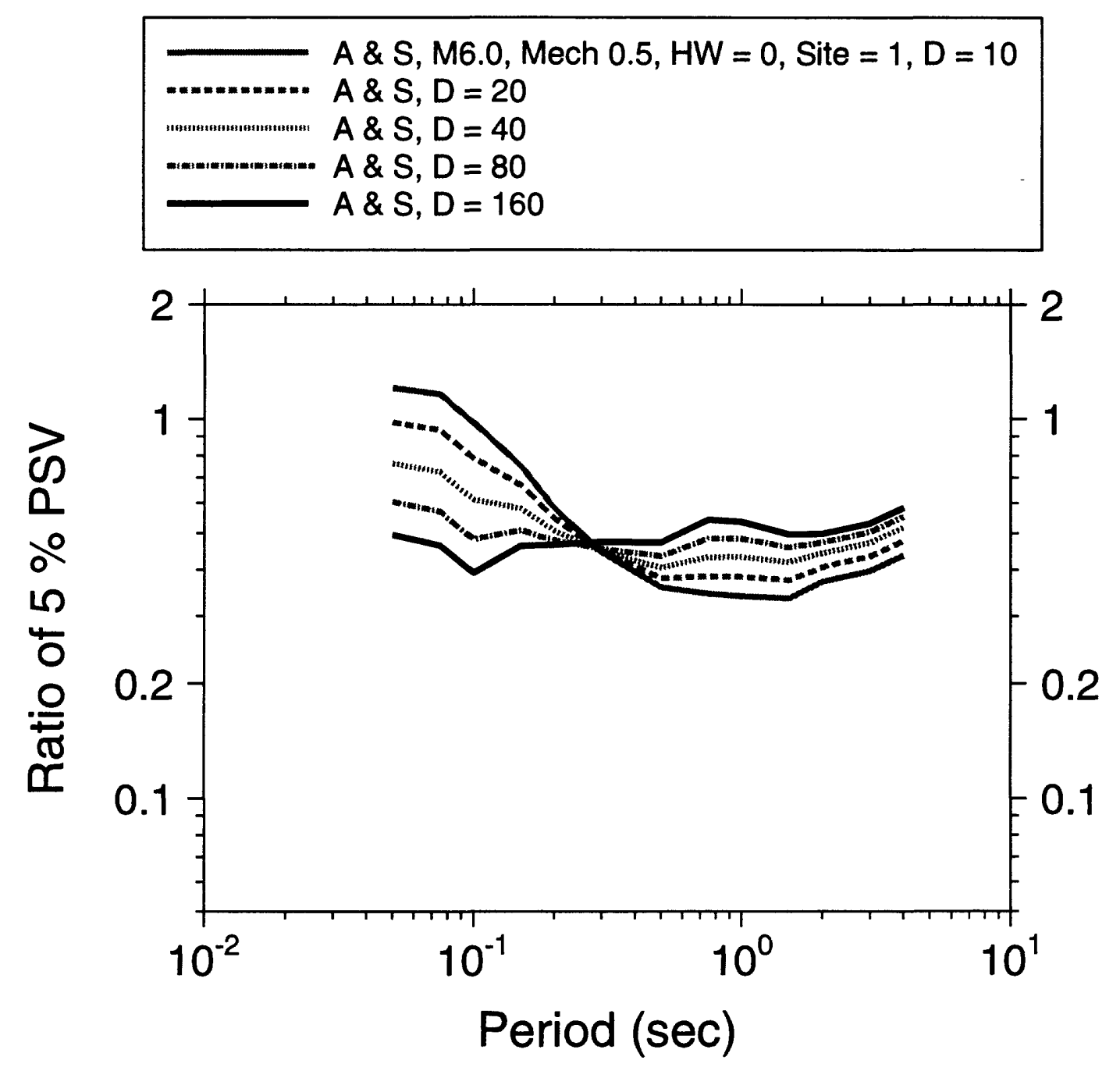

Oct 24, 1997 10:50:09 am D:ISEMSIV_HIV_H5060.DT D:ISEMSIV_HIVHM6DAS.GRA

Figure 24. $V / H$ ratios of 5\%-damped response spectra from Abrahamson and Silva's (1997) regression results for $\mathbf{M}=6.0$, oblique slip faulting, soil site, and distances from 10 to $160 \mathrm{~km}$. 

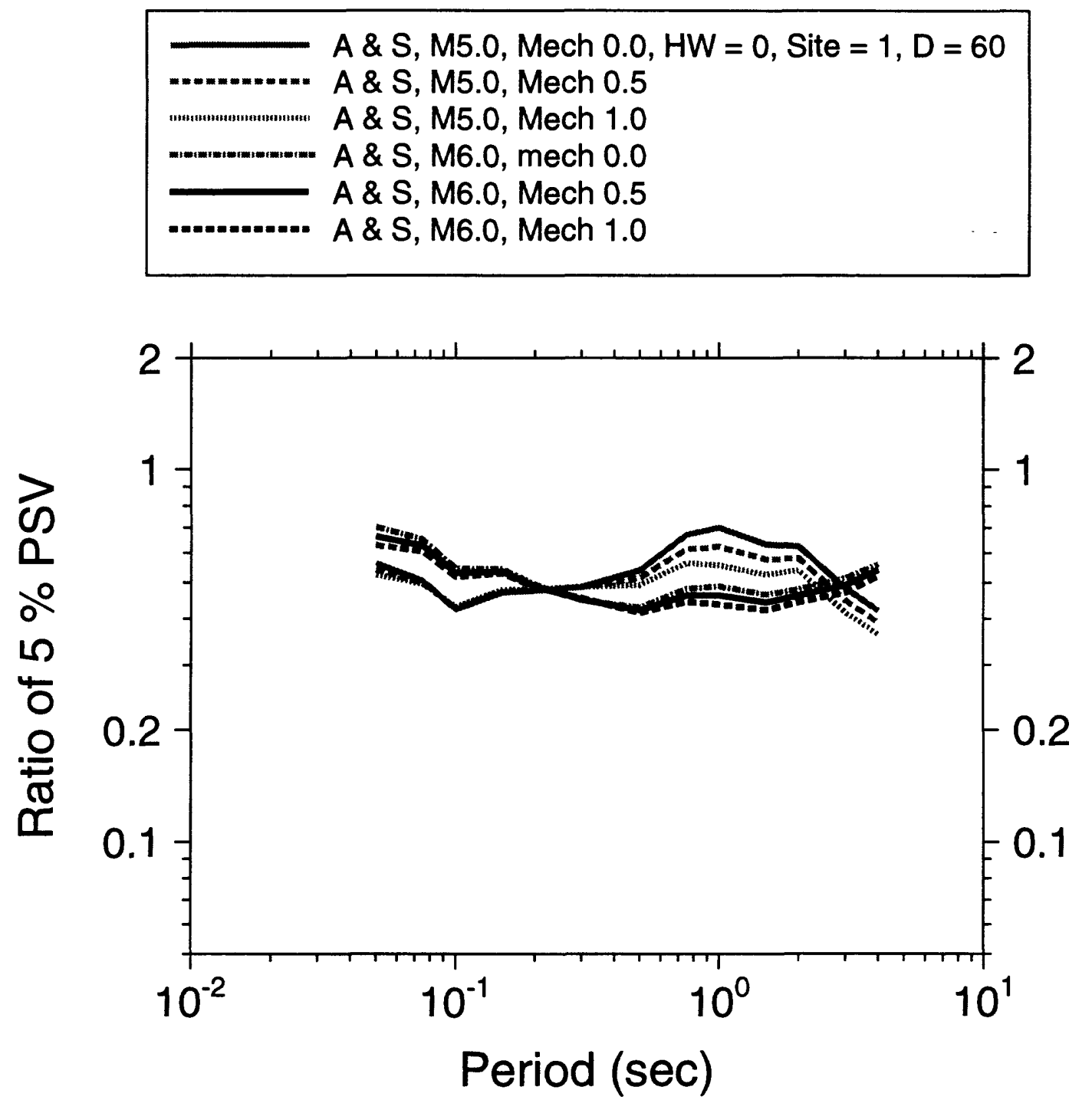

Oct 24, 1997 10:51:18 am D:ISEMSIV_HIV_H5060.DT D:ISEMSIV_HIVHM5M6AS.GRA

Figure 25. $V / H$ ratios of 5\%-damped response spectra from Abrahamson and Silva's (1997) regression results for $\mathbf{M} 5$ and 6 , strikeslip (Mech $=0.0$ ), oblique slip faulting $(\mathrm{Mech}=0.5)$, and reverse slip faulting $(\mathrm{Mech}=1.0)$, a soil site, and a distance of $60 \mathrm{~km}$. 

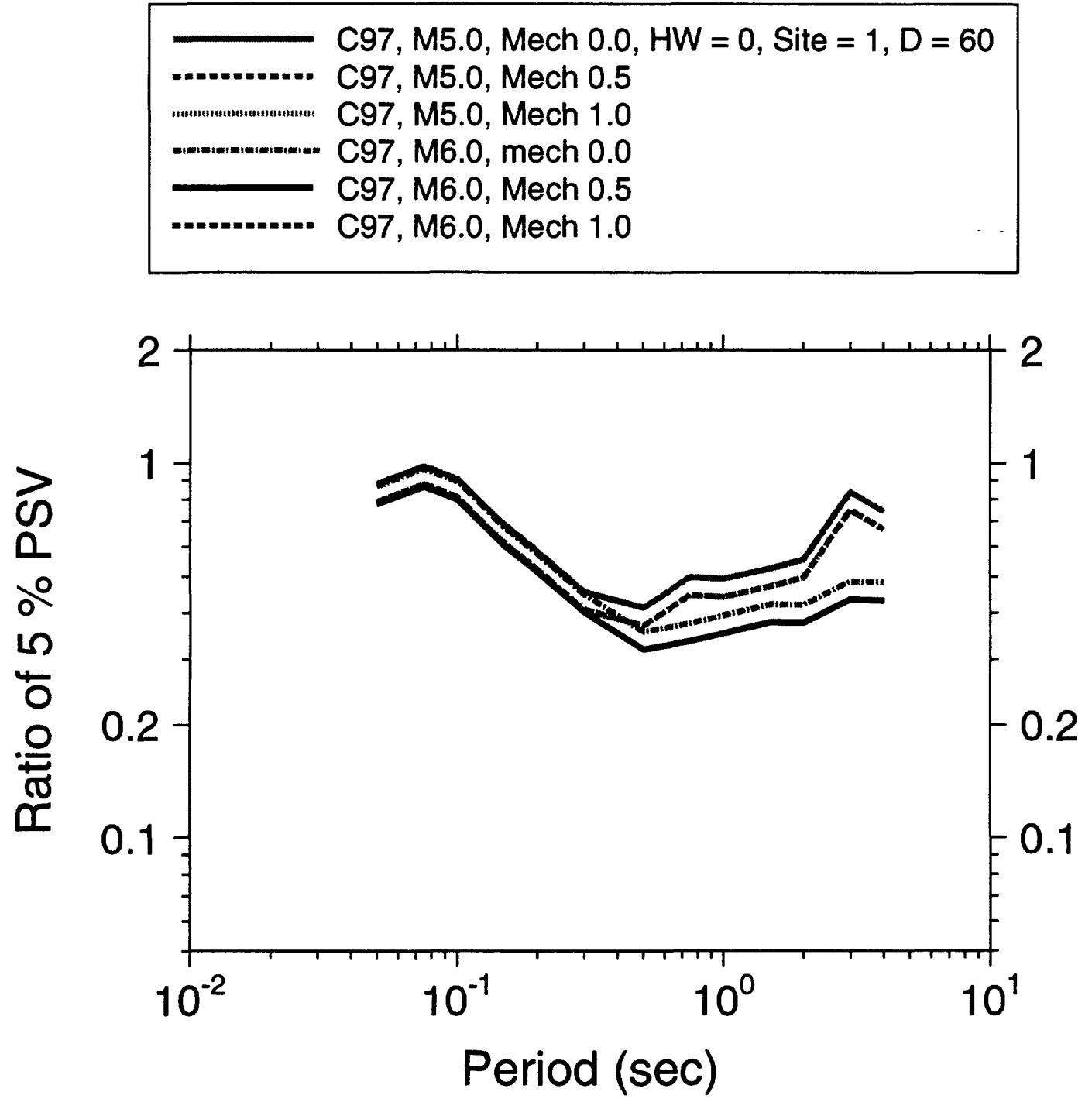

Oct 24, 1997 10:52:11 am D:ISEMSIV_HIV_H5060.DT D:ISEMSIV_HIVHM5M6C.GRA

Figure 26. $\quad V / H$ ratios of 5\%-damped response spectra from Campbell's (1997) regression results for $\mathbf{M} 5$ and 6, strikeslip $(\mathrm{Mech}=0.0)$, oblique slip faulting $(\mathrm{Mech}=0.5)$, and reverse slip faulting $(\mathrm{Mech}=1.0)$, a soil site, and a distance of $60 \mathrm{~km}$. 

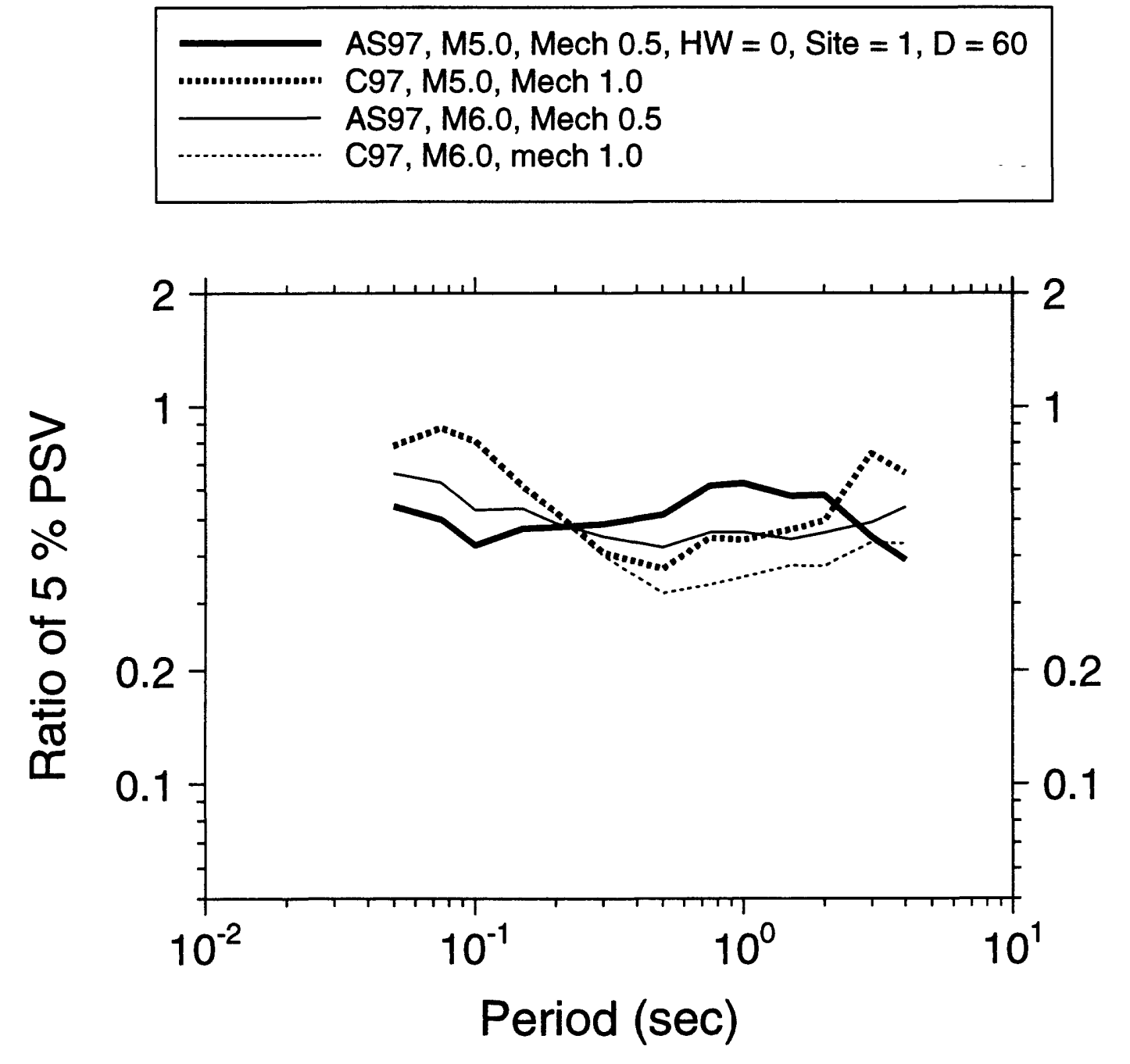

Oct 24, 1997 10:53:02 am D:ISEMSIV_HIV_H5060.DT D:ISEMSIV_HIVHM5M6AC.GRA

Figure 27. $\mathrm{V} / \mathrm{H}$ ratios of 5\%-damped response spectra from Abrahamson and Silva's (1997) and Campbell's (1997) regression results for $\mathbf{M} 5$ and 6 , oblique slip faulting $(\mathrm{Mech}=0.5)$, and reverse slip faulting $(\mathrm{Mech}=1.0)$, a soil site, and a distance of 60 $\mathrm{km}$. 


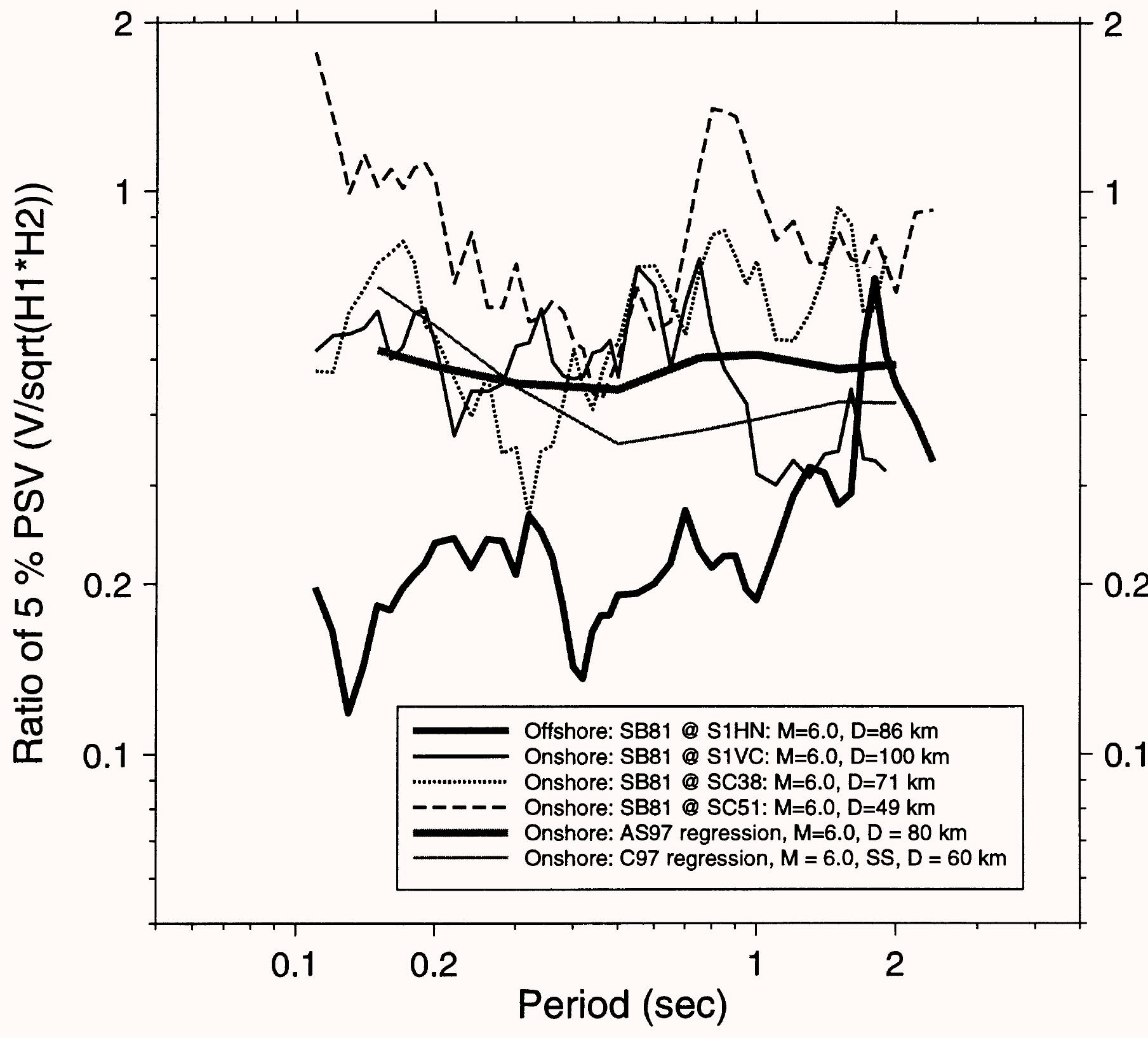

Dec 1, 1997 3:19:00 pm D:ISEMSIV_HISBOBSEMP.GRA D:ISEMSIV_HISB81_V_H.DT

Figure 28. $V / H$ ratios of 5\%-damped response spectra for offshore and onshore recordings of the 1981 Santa Barbara Island earthquake, compared with the regression results of Abrahamson and Silva (1997) (AS97) and Campbell (1997) (C97). 
Dec 2, 1997 3:16:39 pm D:ISEMSIV_HIVHAVGRGR.GRA D:ISEMSIV_HIVVGRGR.DT
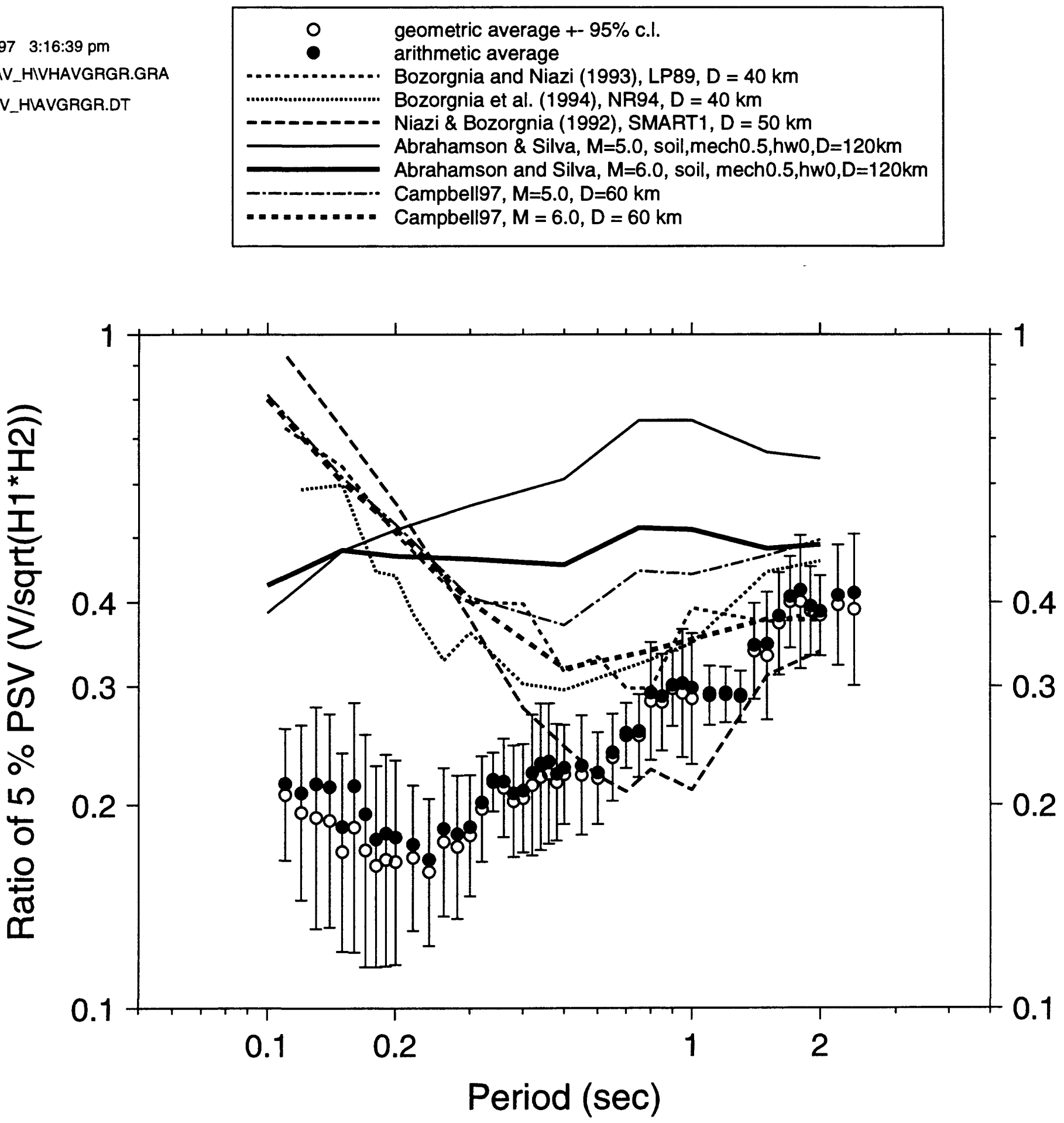

Figure 29. Observed offshore $V / H$ ratios of 5\%-damped response spectra compared with onshore ratios from regression analyses. The results for the Loma Prieta and Northridge earthquakes are indicated in the legend by "LP89" and "NR94", respectively. The Bozorgnia et al. (1994) results for the Northridge earthquake differ slightly from those in the final published study (Bozorgnia et al., 1995). 


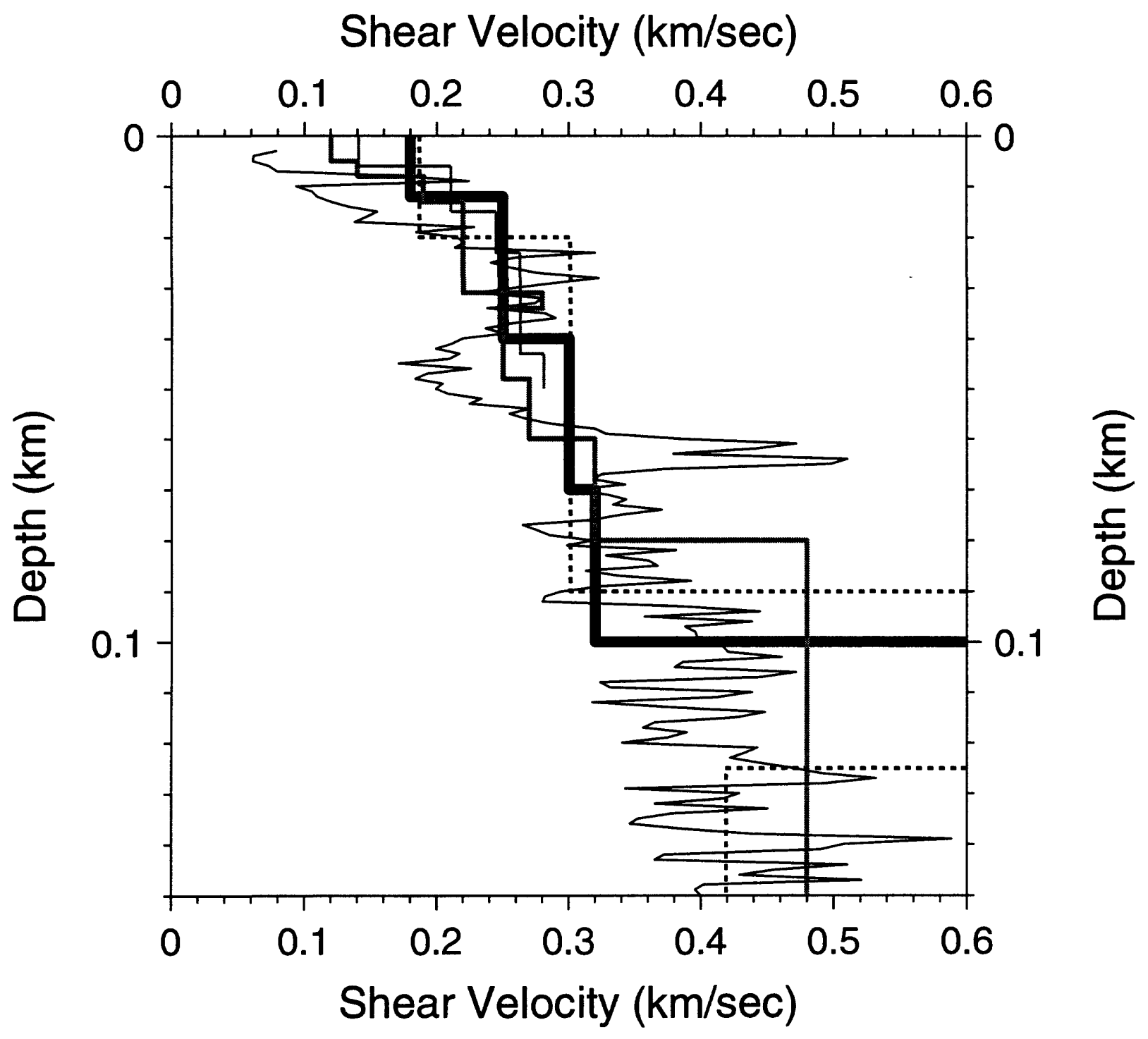

SEMS (sans water layer)

Palo Alto 2-Story (near San Francisco Bay)

El Centro 9 (Imperial Valley)

LSST (within SMART1 array, Taiwan)

Dumbarton west (edge of San Francisco Bay)
Oct 31, 1997 1:35:33 pm

D:ISEMSIVEL_QIVSEM_ON3.GRA

D:ISEMSIVEL_QIVELS2.DT

Figure 30. Shear-wave velocity estimated for an average offshore SEMS site and measured at several onshore sites for which the velocities are comparable to the estimated SEMS velocity. 

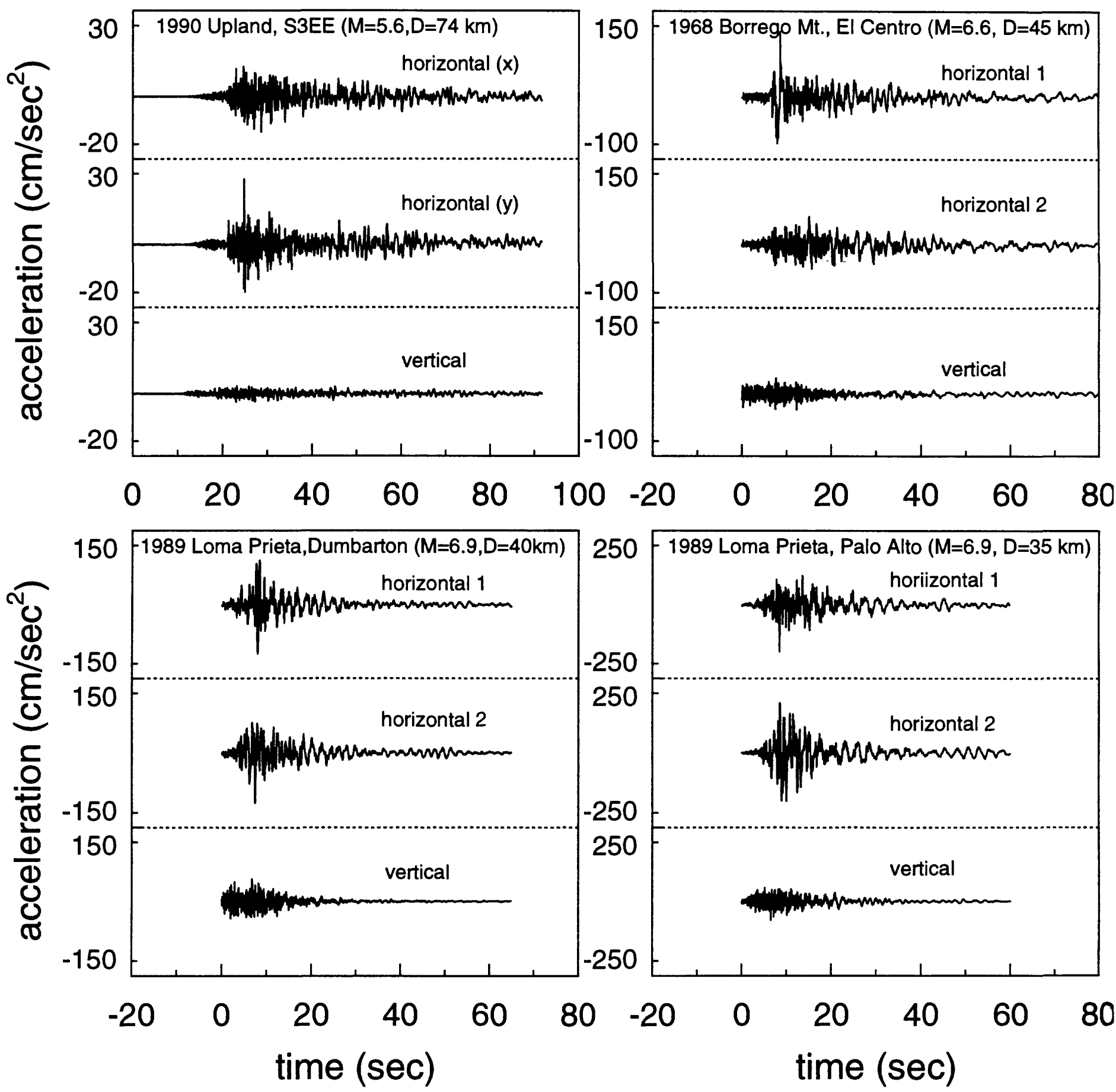

d:Isemsiv_hl3ts_4pnl.grg ct 31,1997 1:55:24 pm

D:ISEMSIUPLAND9013TS_1.GRA D:IPSWBM68I3TS_2.GRA D:IPSWLOMAICSMIPI3TS_3.GRA D:IPSWLOMAICSMIPI3TS_4.GRA

Figure 31. Three-component accelerograms for a SEMS recording (1990 Upland earthquake at $\mathrm{S} 3 \mathrm{EE}$ ) and three recordings made at onshore sites underlain by shear-wave velocities similar to those estimated to be beneath the SEMS sites. 
Dec 2, 1997 3:17:56 pm D:ISEMSIV_HIVH_ALL.GRA D:ISEMSIV_HIAVGRGR.DT
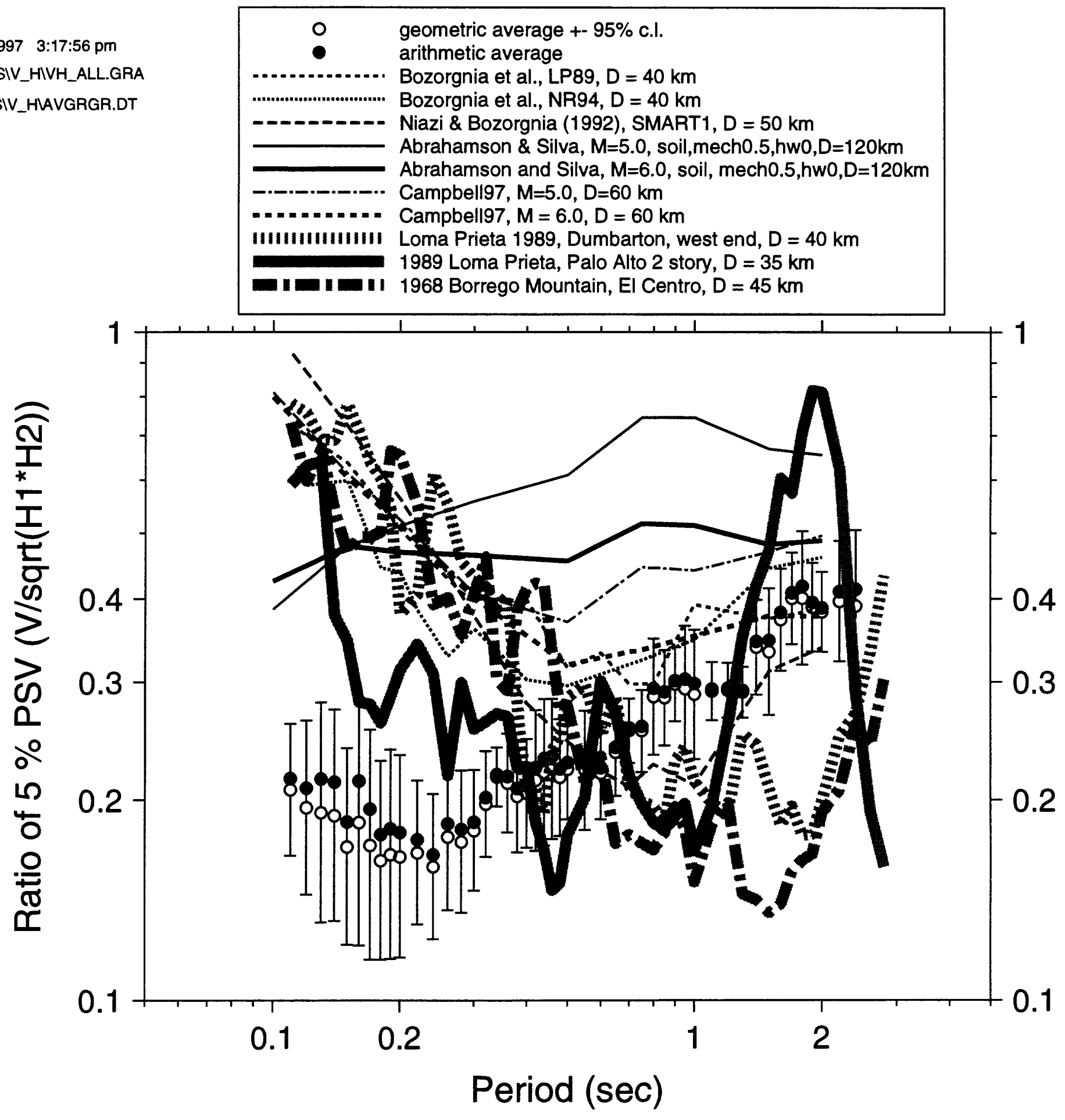

Figure 32. $V / H$ ratios. This is the same as Figure 29, with the addition of $V / H$ from three onshore sites underlain by velocities similar to those estimated to lie beneath the SEMS site. The ratios for these three sites are shown by the wide, grey lines (the bottom three in the legend). 


\section{SBI81 -- Horizontal Motion}

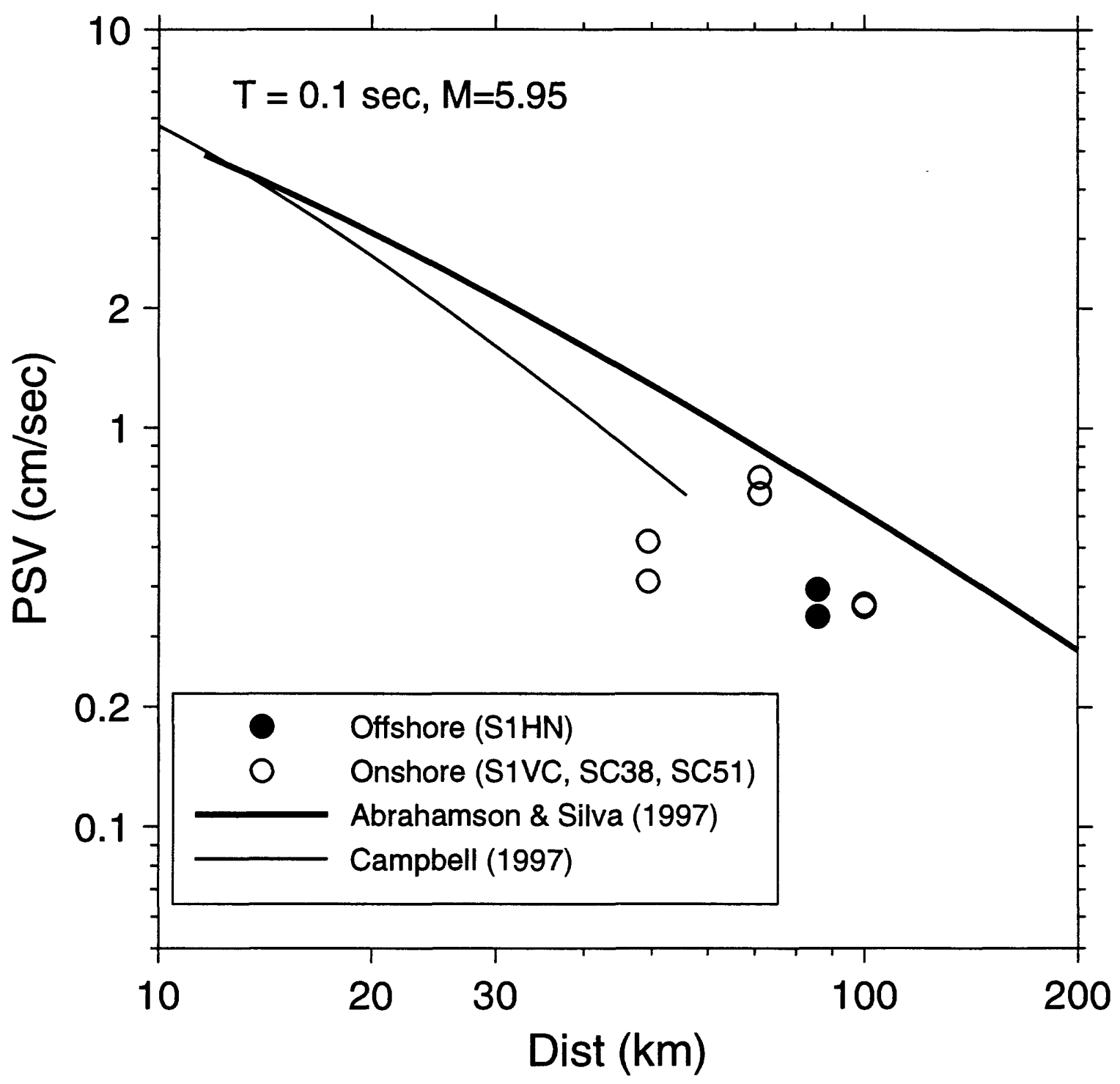

Nov 6, 1997 1:56:27 pm

D:ISEMSISBI81VHTOP1.GRA

D:ISEMSISBI81ISEMSHEMP.DT

Figure 33. Horizontal-component, 5\%-damped pseudo-velocity response spectra for $0.1 \mathrm{sec}$ oscillator period as a function of epicentral distance for the 1981 Santa Barbara Island earthquake, compared with predictions from regression analyses. 


\section{SBI81 -- Horizontal Motion}

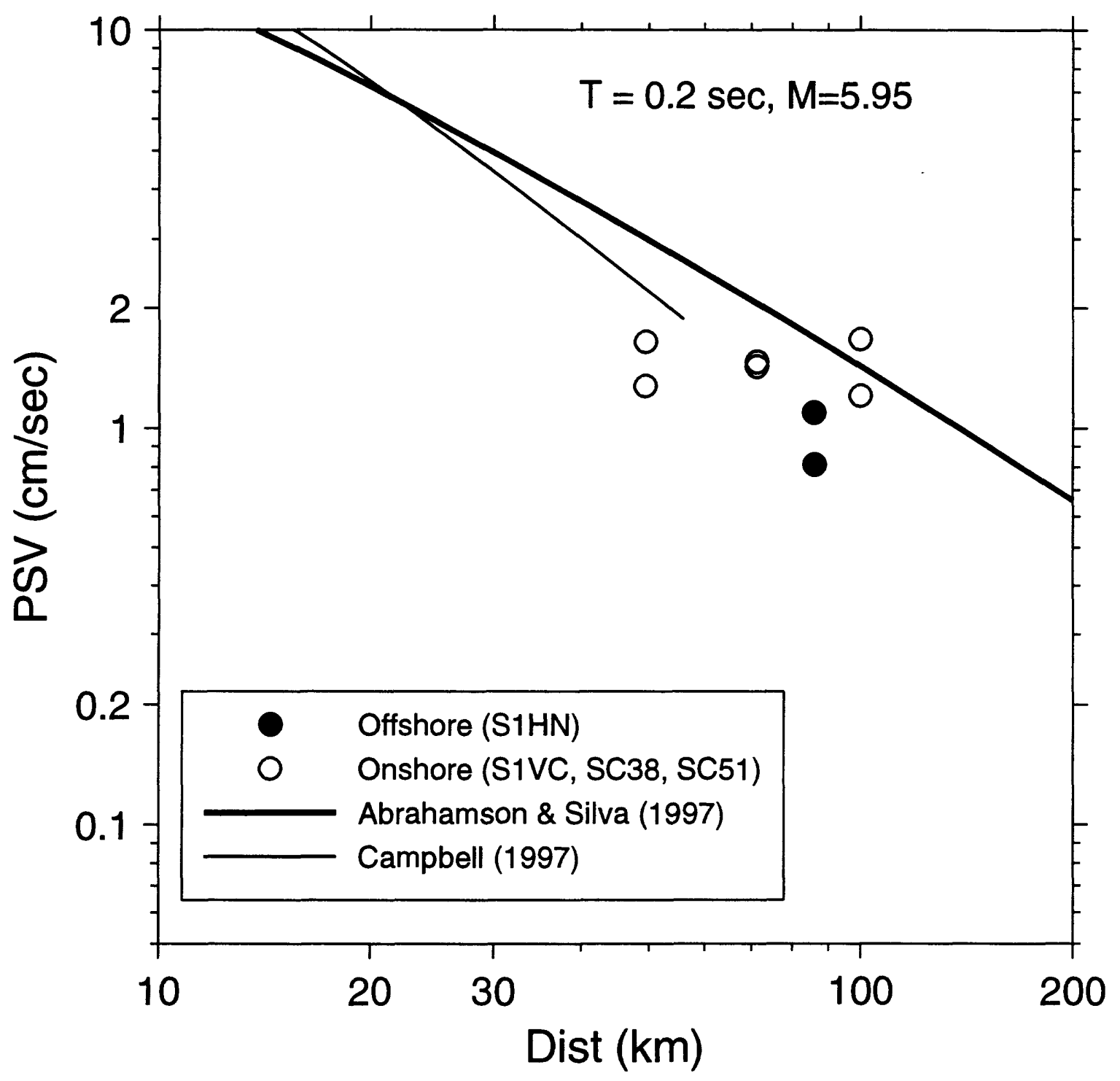

Nov 6, 1997 1:57:30 pm

D:ISEMSISBI81VHTOP2.GRA

D:ISEMSISBI81ISEMSHEMP.DT

Figure 34. Horizontal-component, 5\%-damped pseudo-velocity response spectra for $0.2 \mathrm{sec}$ oscillator period as a function of epicentral distance for the 1981 Santa Barbara Island earthquake, compared with predictions from regression analyses. 


\section{SBI81 -- Horizontal Motion}

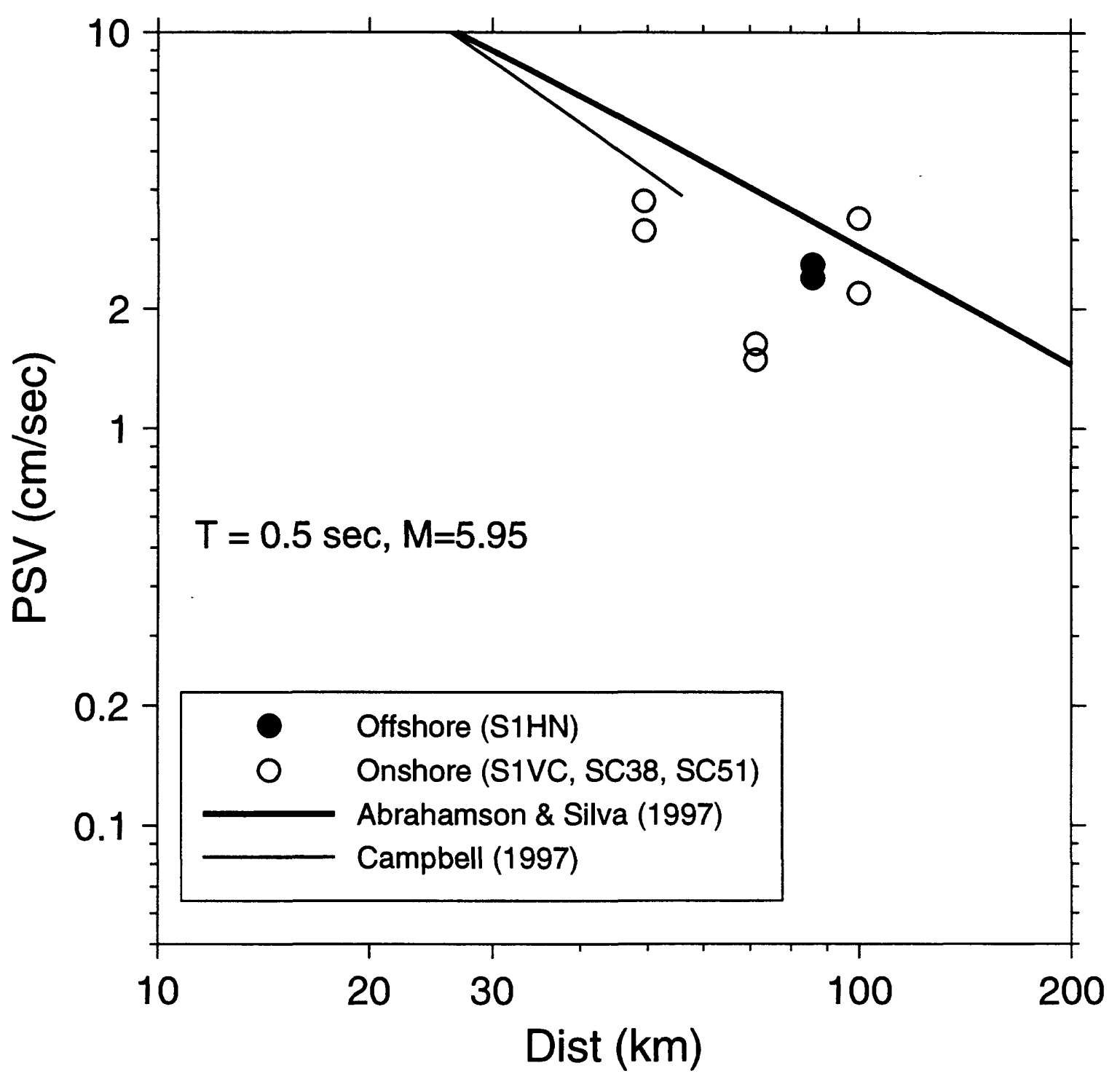

Nov 6, 1997 1:58:03 pm

D:ISEMSISBI81WHTOP5.GRA

D:ISEMSISBI81\SEMSHEMP.DT

Figure 35. Horizontal-component, 5\%-damped pseudo-velocity response spectra for $0.5 \mathrm{sec}$ oscillator period as a function of epicentral distance for the 1981 Santa Barbara Island earthquake, compared with predictions from regression analyses. 


\section{SBI81 -- Horizontal Motion}

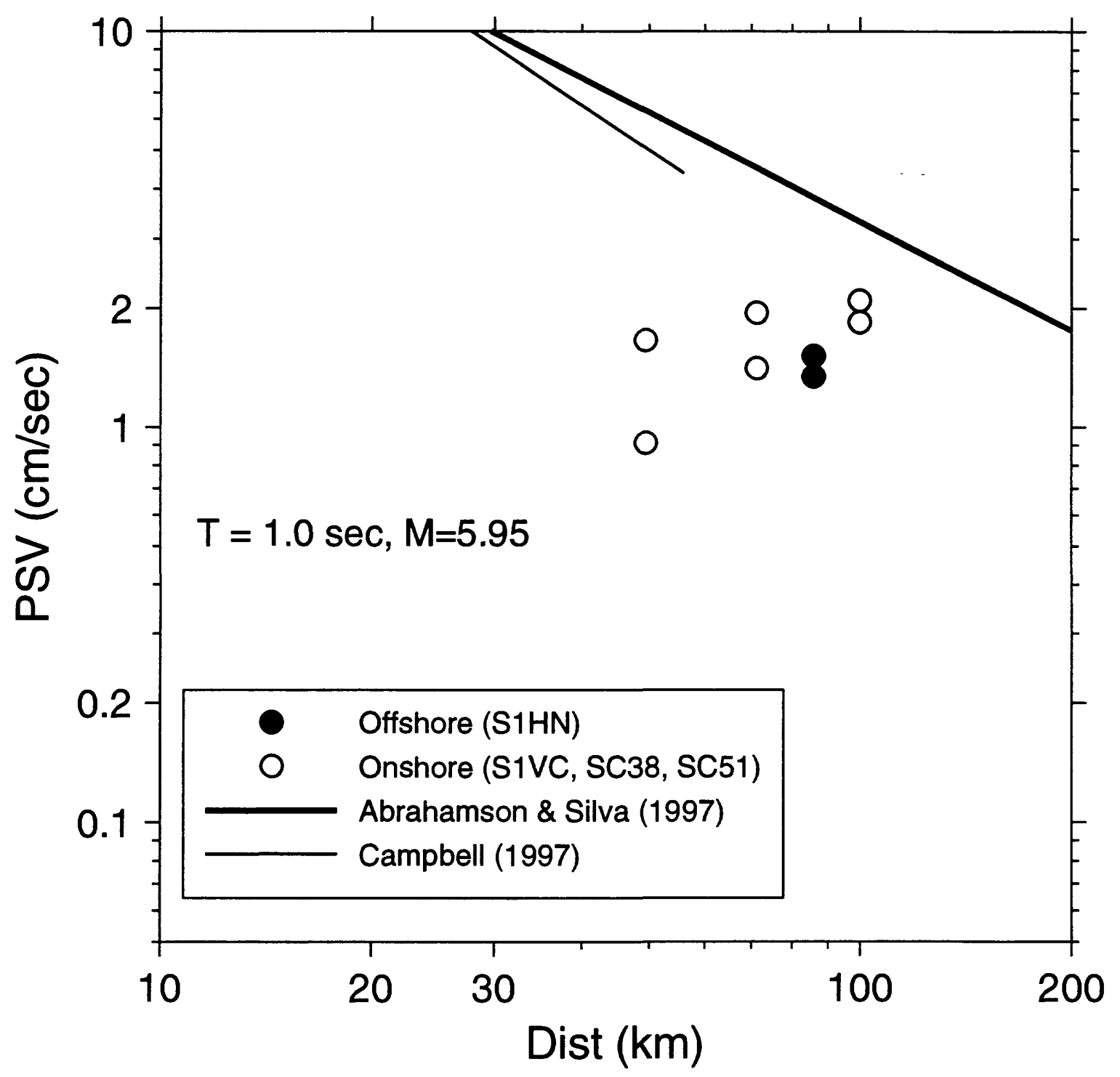

Nov 6, 1997 1:58:50 pm

D:ISEMSISBI81VHTIPO.GRA

D:ISEMSISBI81ISEMSHEMP.DT

Figure 36. Horizontal-component, 5\%-damped pseudo-velocity response spectra for $1.0 \mathrm{sec}$ oscillator period as a function of epicentral distance for the 1981 Santa Barbara Island earthquake, compared with predictions from regression analyses. 


\section{SBI81 -- Horizontal Motion}

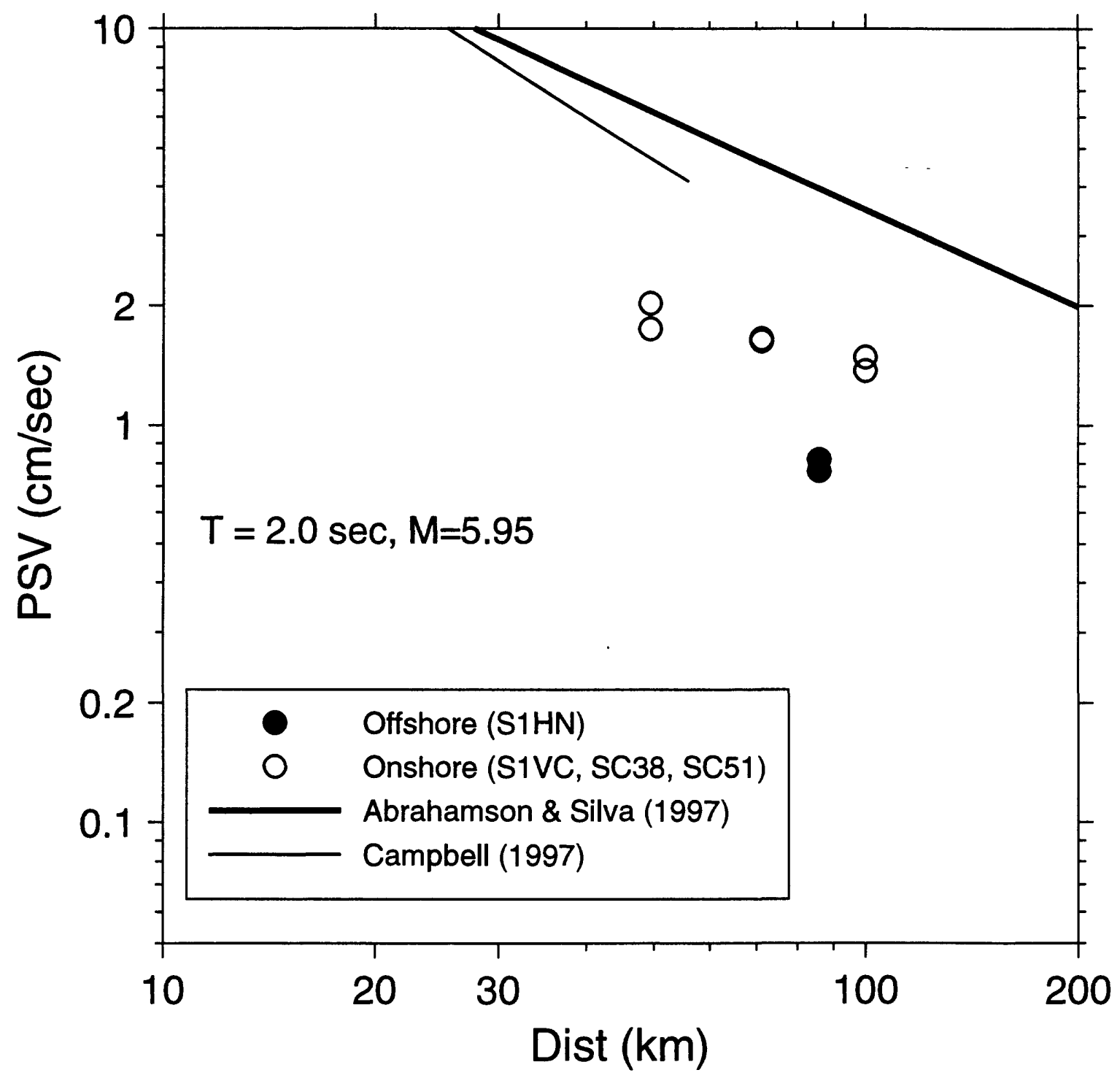

Nov 6, 1997 1:59:38 pm

D:ISEMSISBI81VHT2PO.GRA

D:ISEMSISBI81ISEMSHEMP.DT

Figure 37. Horizontal-component, 5\%-damped pseudo-velocity response spectra for $2.0 \mathrm{sec}$ oscillator period as a function of epicentral distance for the 1981 Santa Barbara Island earthquake, compared with predictions from regression analyses. 


\section{SBI81 -- Vertical Motion}

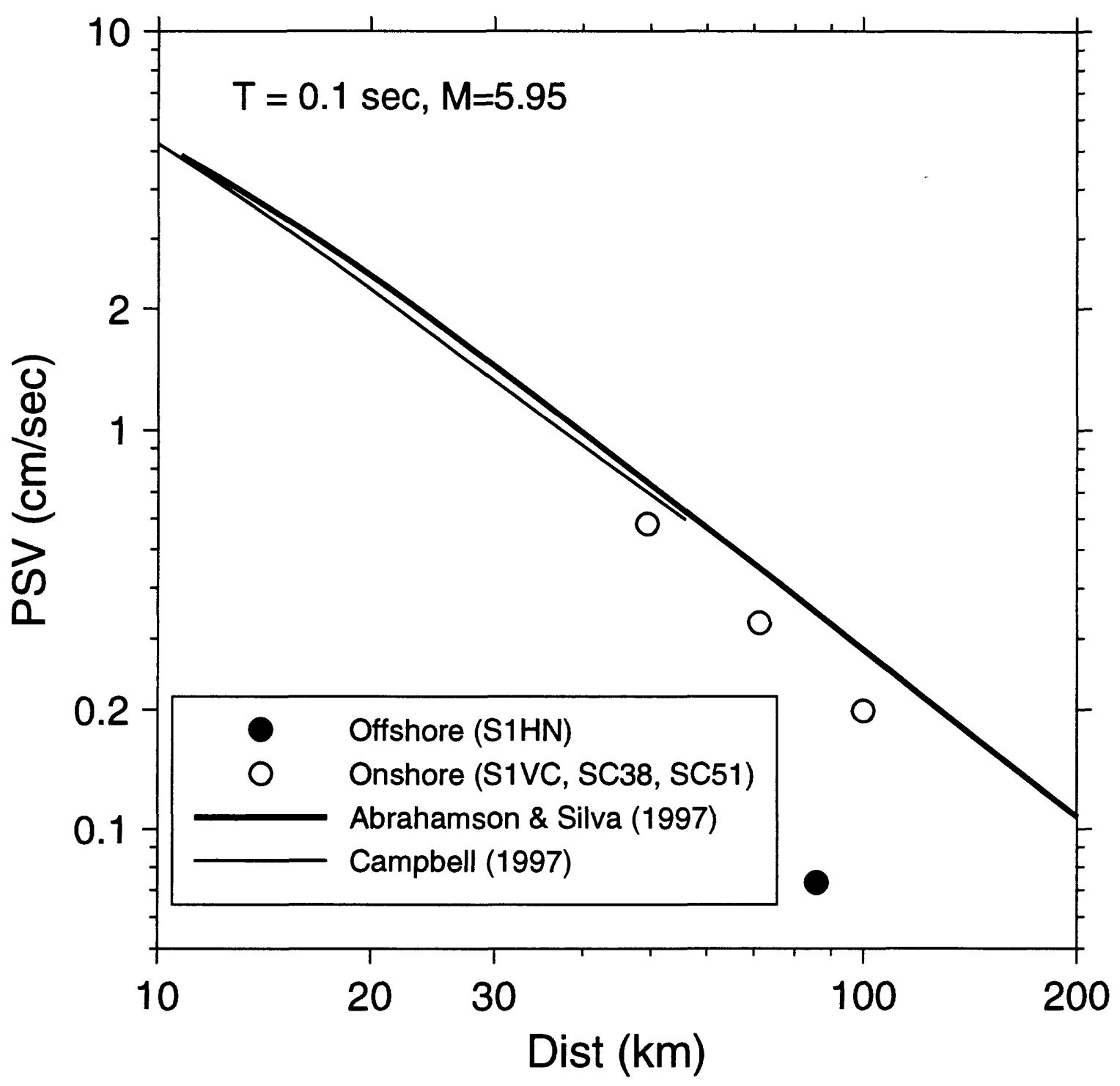

Nov 6, 1997 2:00:59 pm

D:ISEMSISBI81IVTOP1.GRA

D:ISEMSISBI81ISEMSVEMP.DT

Figure 38. Vertical-component, 5\%-damped pseudo-velocity response spectra for 0.1 sec oscillator period as a function of epicentral distance for the 1981 Santa Barbara Island earthquake, compared with predictions from regression analyses. 


\section{SBI81 -- Vertical Motion}

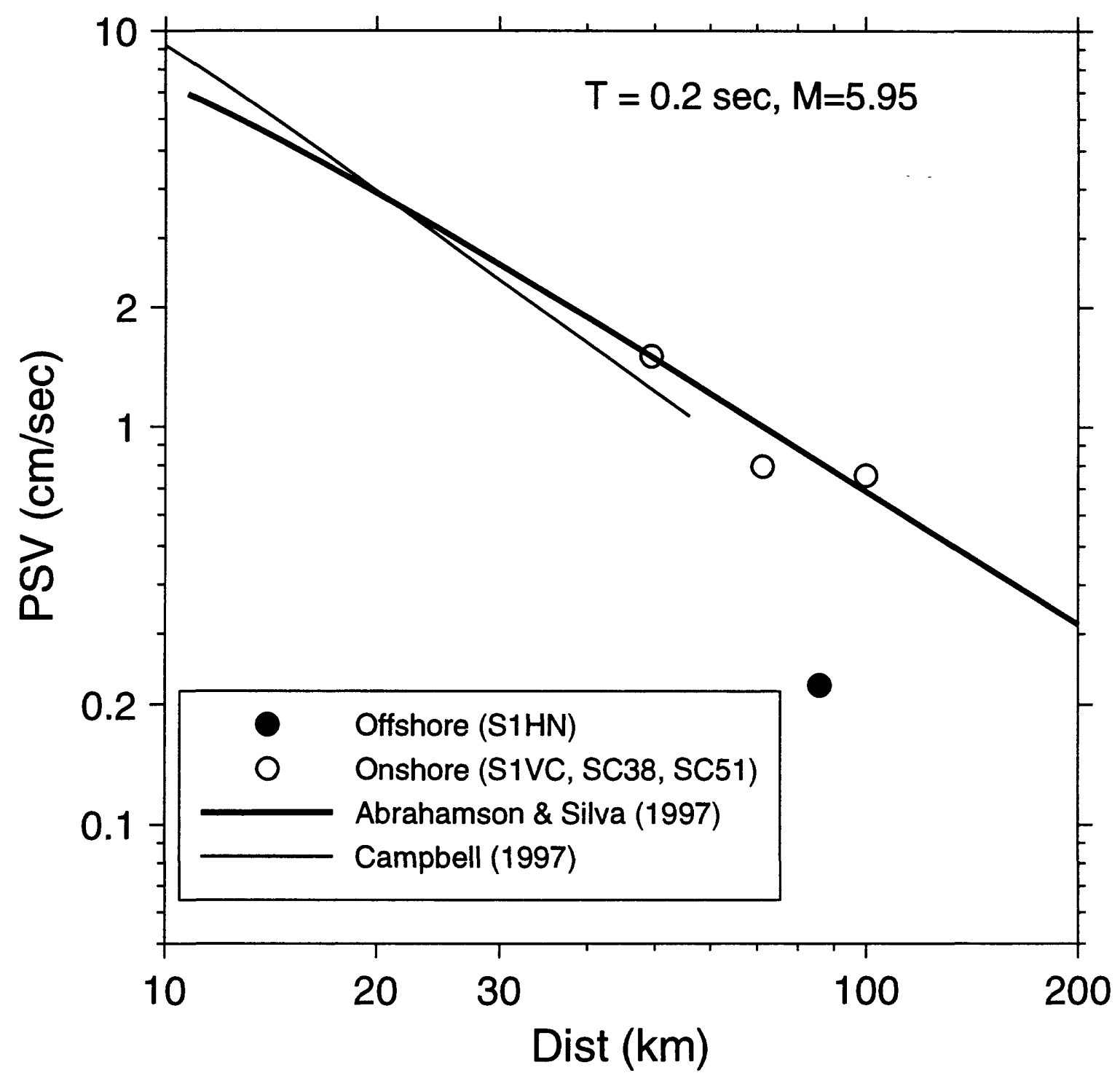

Nov 6, 1997 2:01:22 pm

D:ISEMSISBI81IVTOP2.GRA

D:ISEMSISBI81/SEMSVEMP.DT

Figure 39. Vertical-component, 5\%-damped pseudo-velocity response spectra for 0.2 sec oscillator period as a function of epicentral distance for the 1981 Santa Barbara Island earthquake, compared with predictions from regression analyses. 


\section{SBI81 -- Vertical Motion}

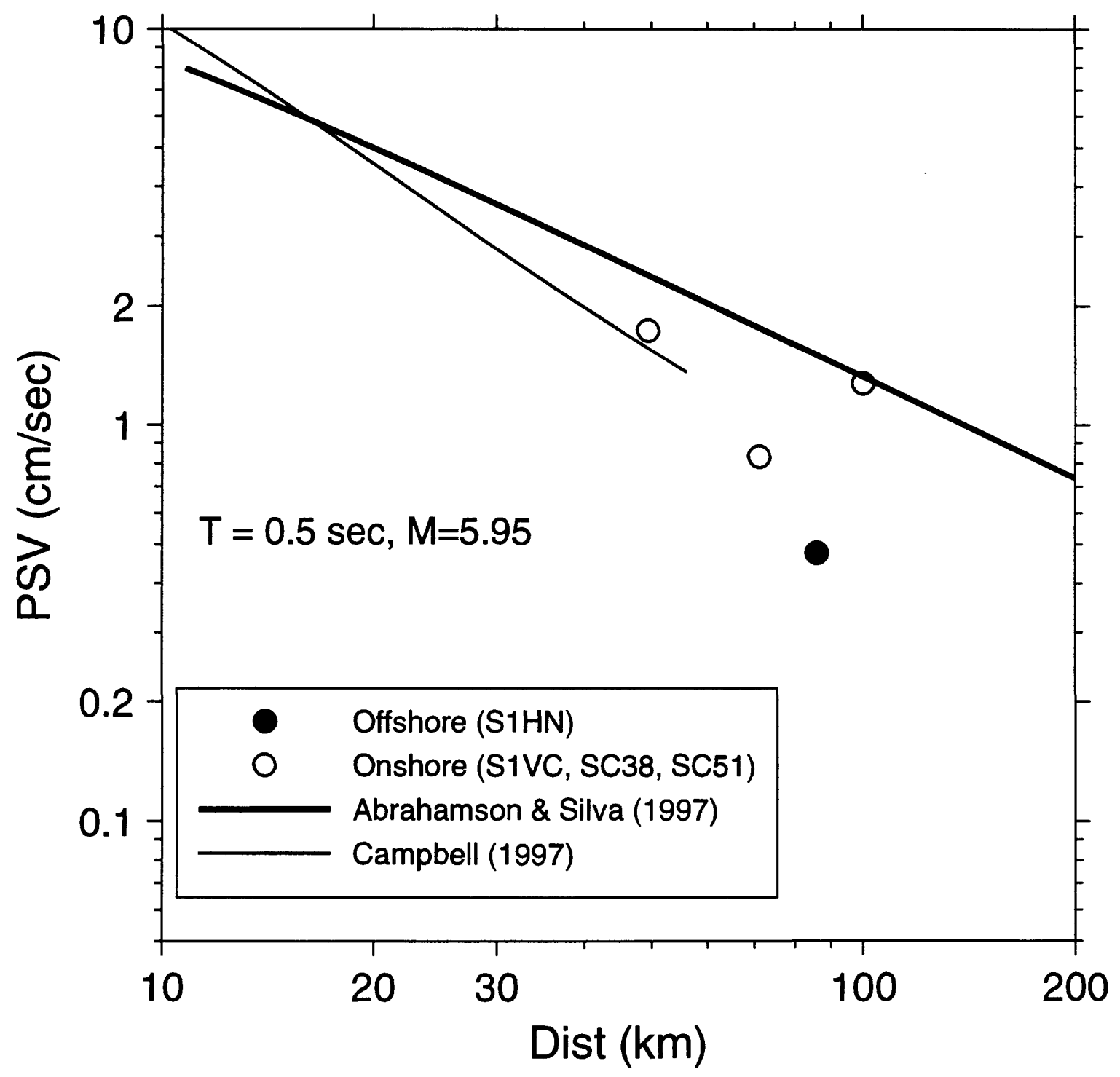

Nov 6, 1997 2:01:45 pm

D:ISEMSISBI81IVTOP5.GRA

D:ISEMSISBI81ISEMSVEMP.DT

Figure 40. Vertical-component, 5\%-damped pseudo-velocity response spectra for 0.5 sec oscillator period as a function of epicentral distance for the 1981 Santa Barbara Island earthquake, compared with predictions from regression analyses. 


\section{SBI81 -- Vertical Motion}

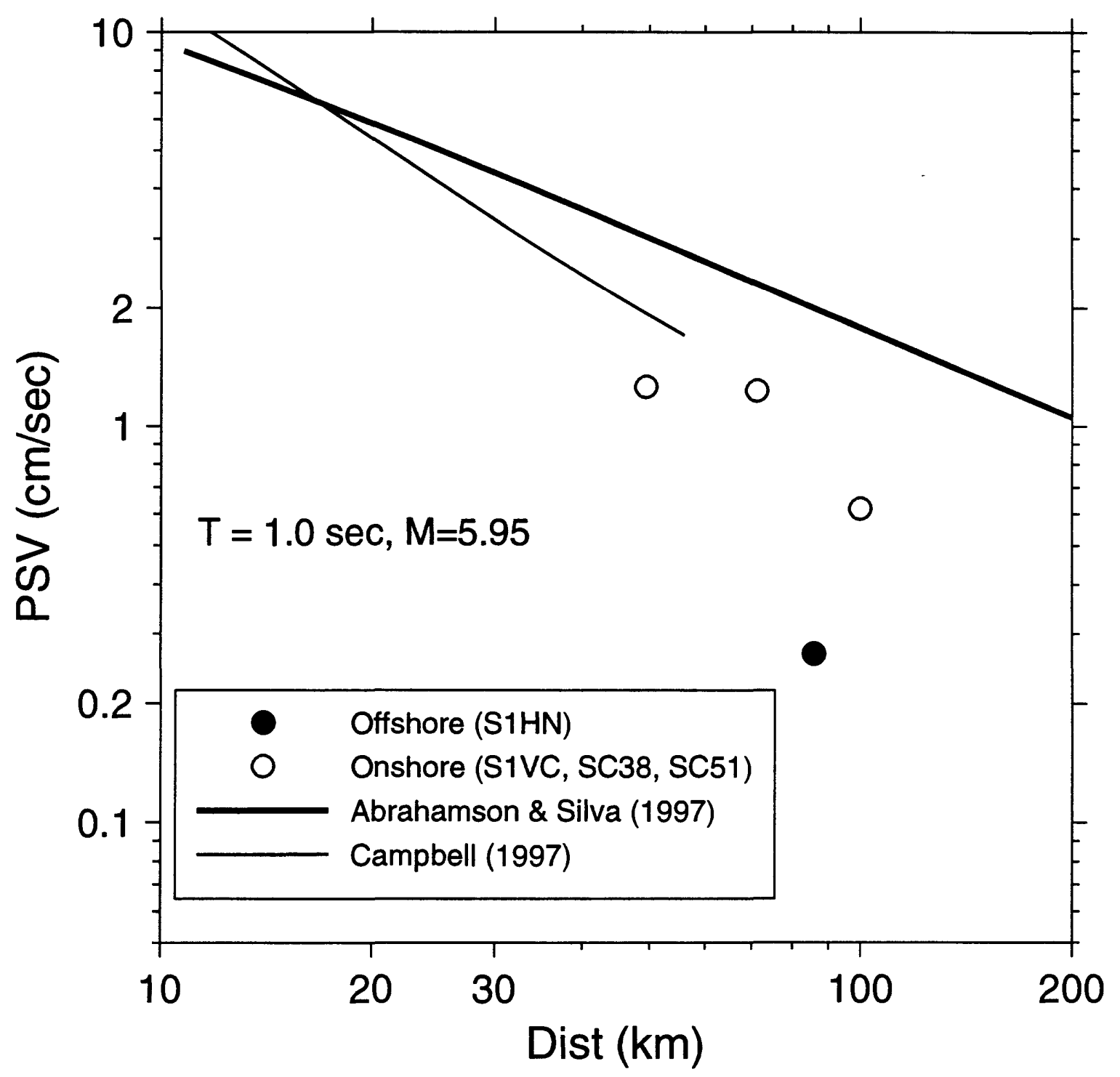

Nov 6, 1997 2:02:09 pm

D:ISEMSISBI81IVT1PO.GRA

D:ISEMSISBI81ISEMSVEMP.DT

Figure 41. Vertical-component, 5\%-damped pseudo-velocity response spectra for 1.0 sec oscillator period as a function of epicentral distance for the 1981 Santa Barbara Island earthquake, compared with predictions from regression analyses. 


\section{SBI81 -- Vertical Motion}

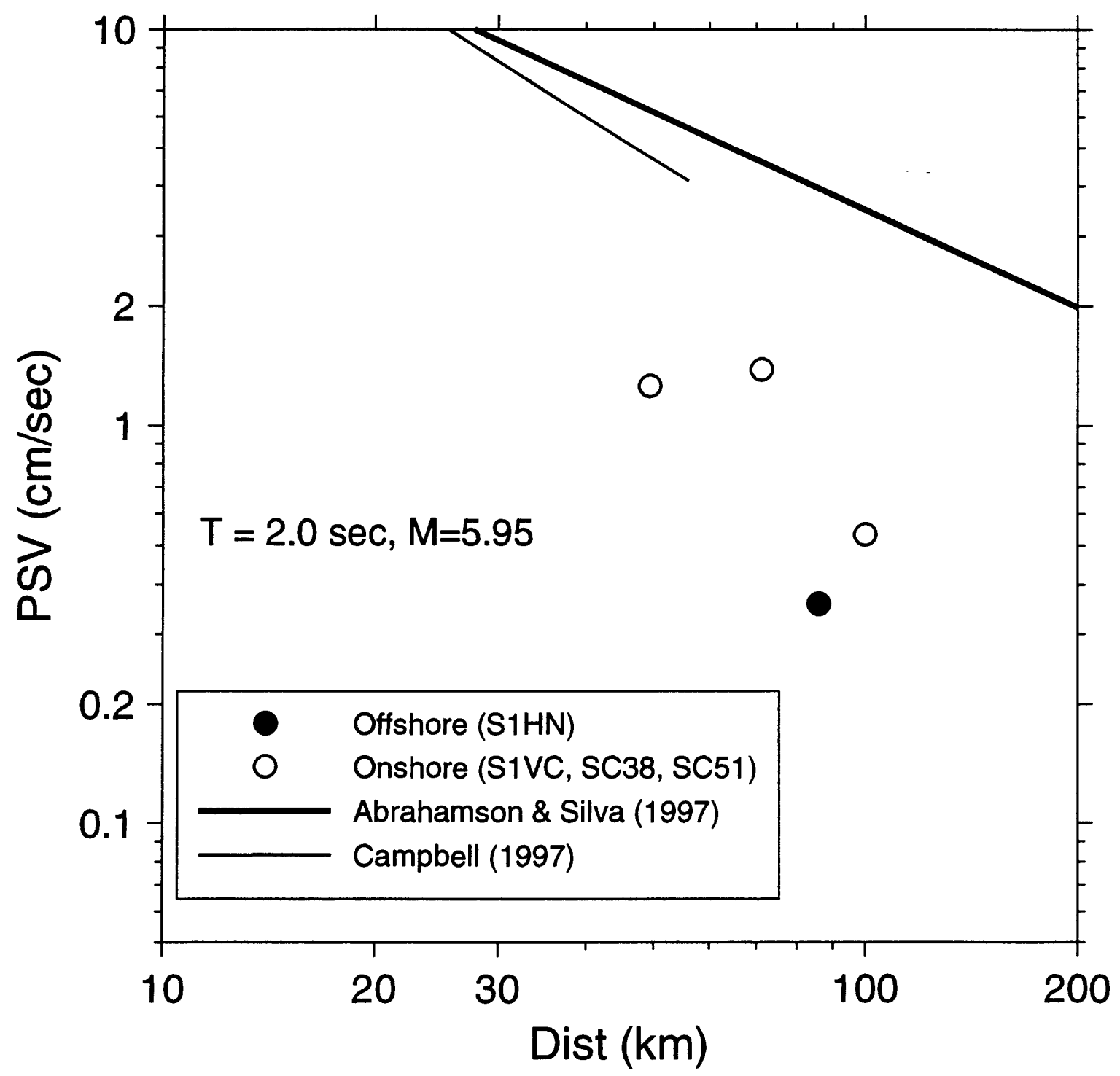

Nov 6, 1997 2:06:09 pm

D:ISEMSISBI81IVT2P0.GRA

D:ISEMSISBI81ISEMSVEMP.DT

Figure 42. Vertical-component, 5\%-damped pseudo-velocity response spectra for 2.0 sec oscillator period as a function of epicentral distance for the 1981 Santa Barbara Island earthquake, compared with predictions from regression analyses. 


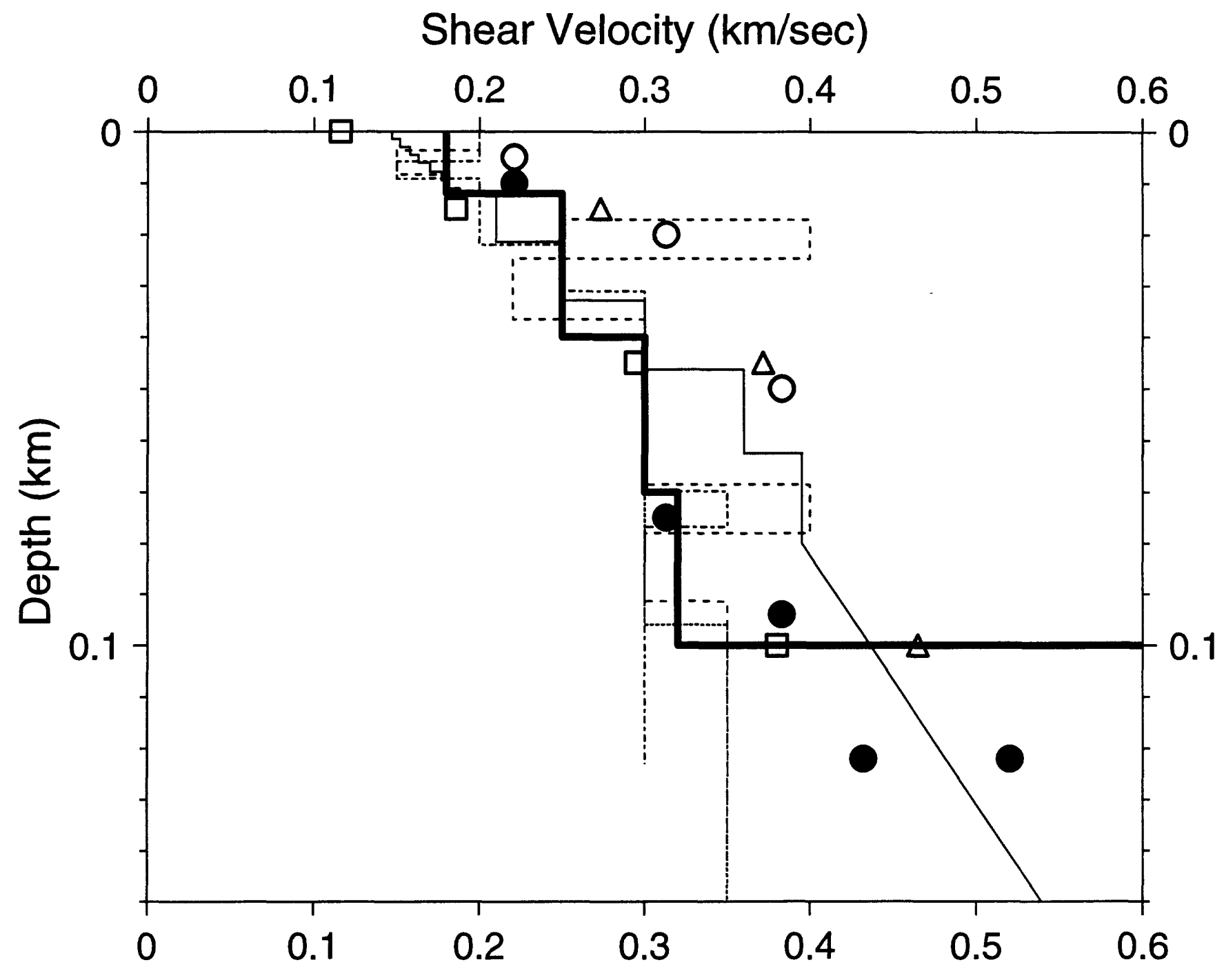

Nov 24, 1997 10:42:40 am D:ISEMSIVEL_QIV_OFF.GRA D:ISEMSIVEL_QIVELS2.DT

\begin{tabular}{|c|c|}
\hline$\Delta$ & $\begin{array}{l}\text { SEMS (sans water layer) } \\
\text { Sand (Hamilton, 1976a) }\end{array}$ \\
\hline & Silt-Clay (Hamilton, 1976a) \\
\hline & hole 261-1 \\
\hline$\cdots+\cdots$ & hole $261-3$ \\
\hline ......... & hole $262-1$ (from 0.06 to $0.15 \mathrm{~km}$ ) \\
\hline & off Camp Pendleton (Dorman, pers. commun., 1997) \\
\hline & Norway continental shelf, profile A (72m water) (Rognlien, 1987) \\
\hline & Norway continental shelf, profile B ( $82 \mathrm{~m}$ water) (Rognlien, 1987) \\
\hline
\end{tabular}

Figure 43. Shear-wave velocity to $0.15 \mathrm{~km}$ from offshore sites and adopted SEMS velocity. The velocities for holes 261-1, 261-3, and 262-1 were estimated from standard penetration values near SEMS site S2EE. The velocities for Norwegian sites are point values for a series of representative depths; the actual profiles are characterized by linear velocity gradients with depth. 


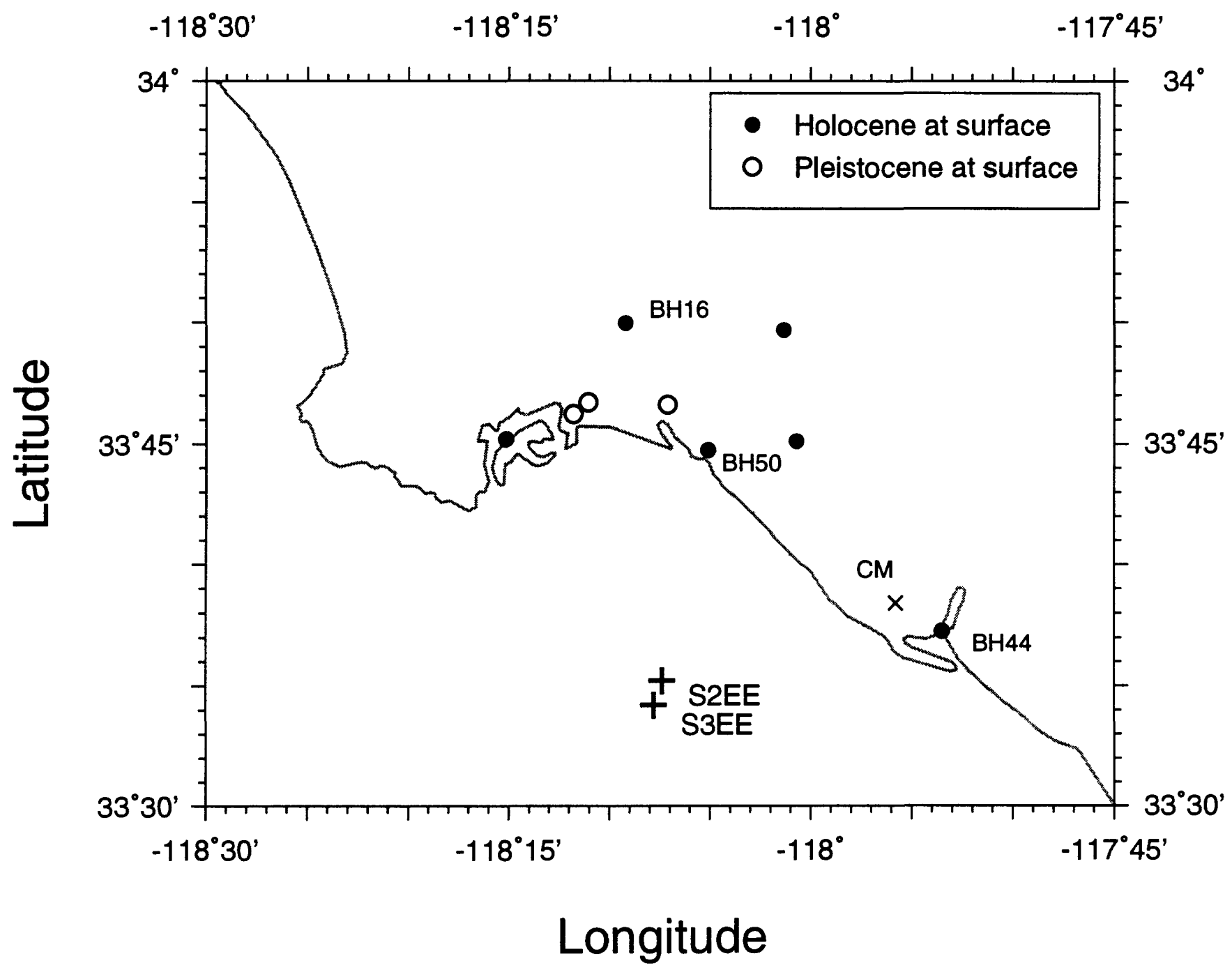

Dec 2, 1997 2:18:17 pm

D:ISEMSIVEL_QIVELMAP.GRA

D:ISEMSIVEL_QIVELMAP.DT

Figure 44. Map of borehole sites (circles) near the SEMS sites offshore of Long Beach (pluses). Boreholes BH16, BH44, and BH50 are discussed in the text; "CM" is the strongmotion station at Costa Mesa (see also Figure 1). 


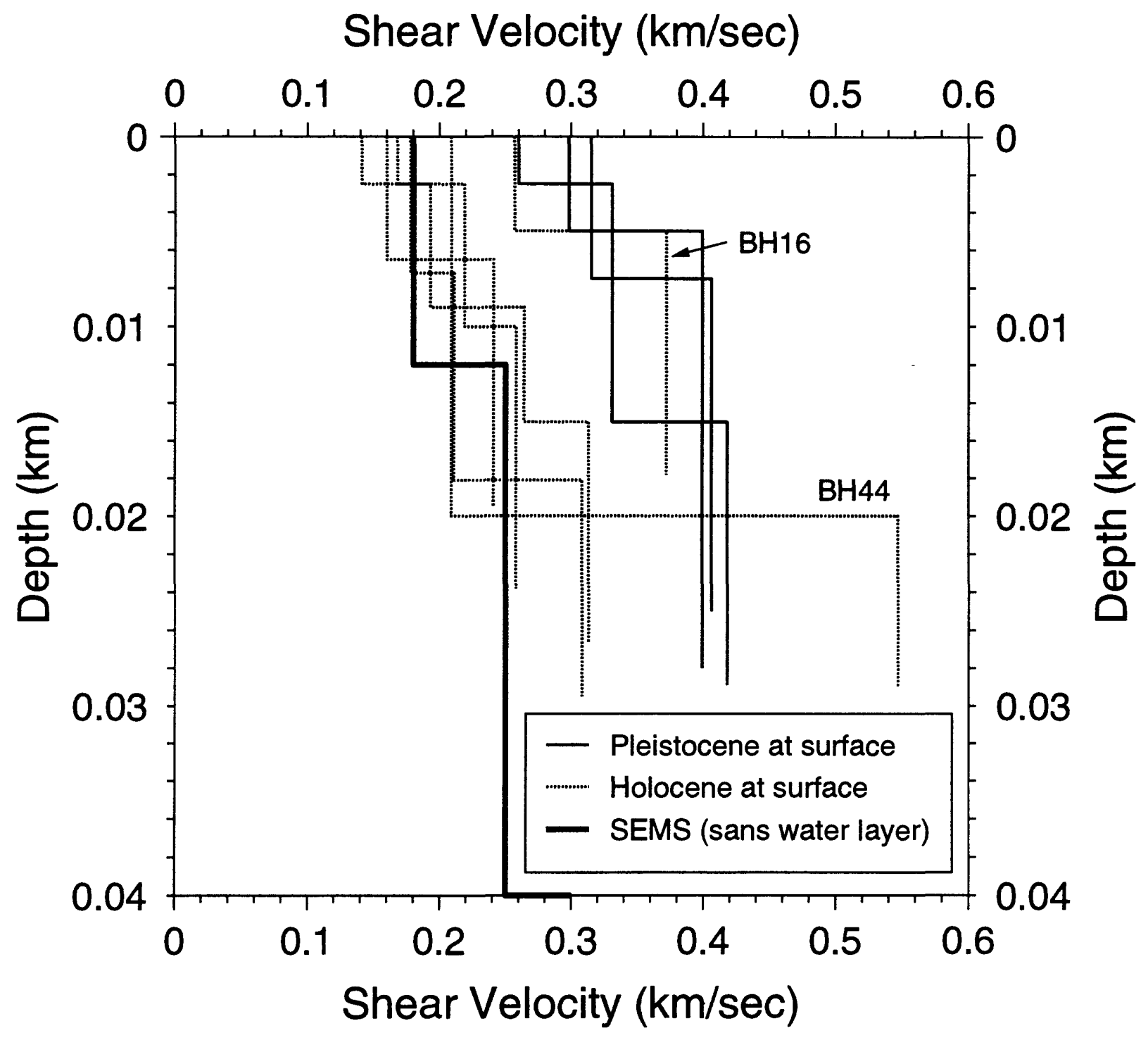

Sep 29, 1997 4:29:33 pm C:ISEMSIVEL_QIVSEM_ON2.GRA C:ISEMSIVEL_QIVELS2.DT

Figure 45. Shear-wave velocity to $0.04 \mathrm{~km}$ from borehole sites near Long Beach and velocity profile adopted for theoretical calculations at the SEMS sites. 


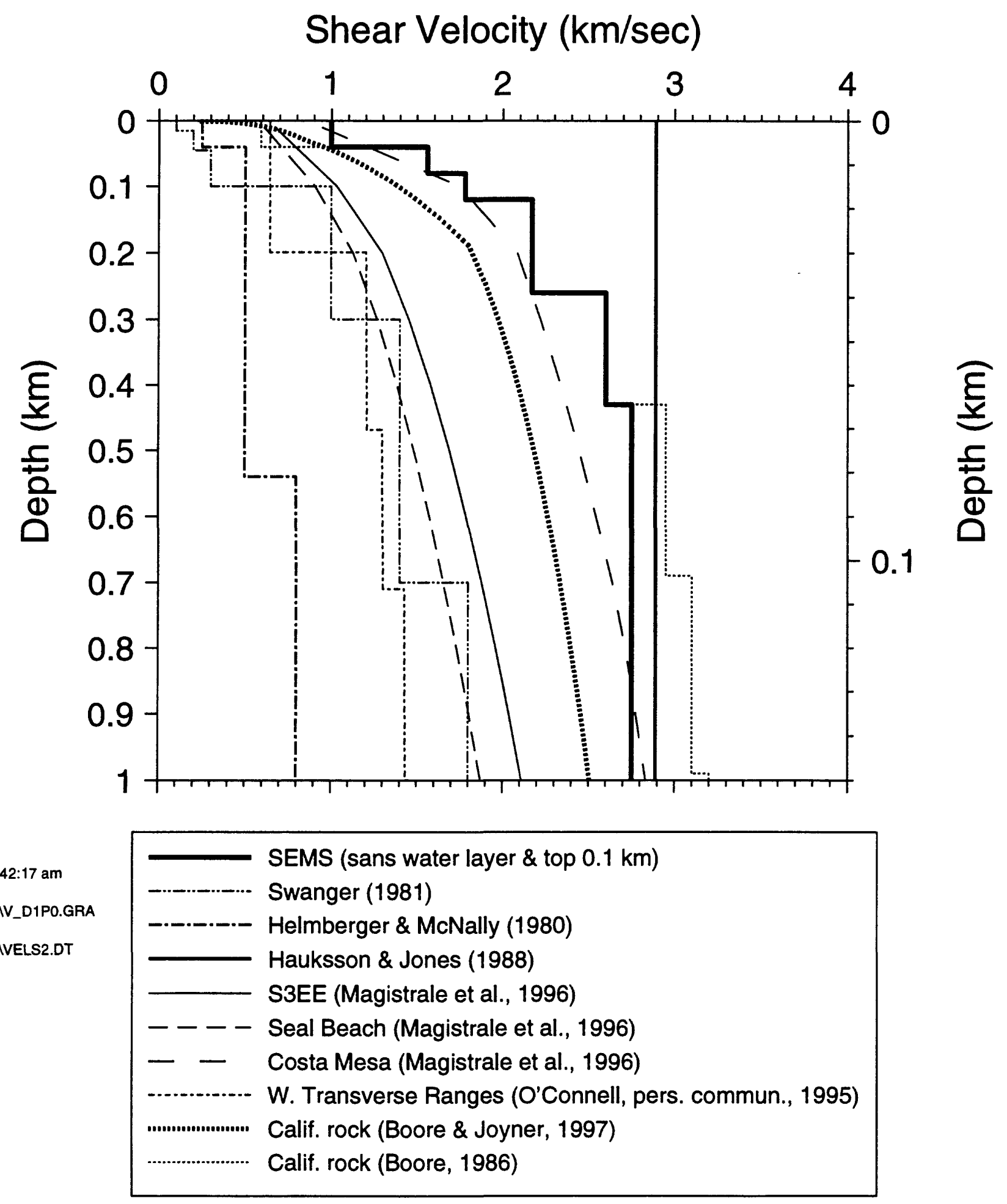

Nov 24, 1997 9:42:17 am D:ISEMSIVEL_QIV_D1PO.GRA D:ISEMSIVEL_QIVELS2.DT

\section{Shear Velocity $(\mathrm{km} / \mathrm{sec})$}

Figure 46. Shear-wave velocity to $1.0 \mathrm{~km}$ from several sources, compared to the adopted SEMS model, stripped of the water layer and the material in the first $0.1 \mathrm{~km}$ beneath the seafloor. The Hauksson and Jones values were derived from their P-wave velocities, assuming a Poisson's ratio of 0.25 . 


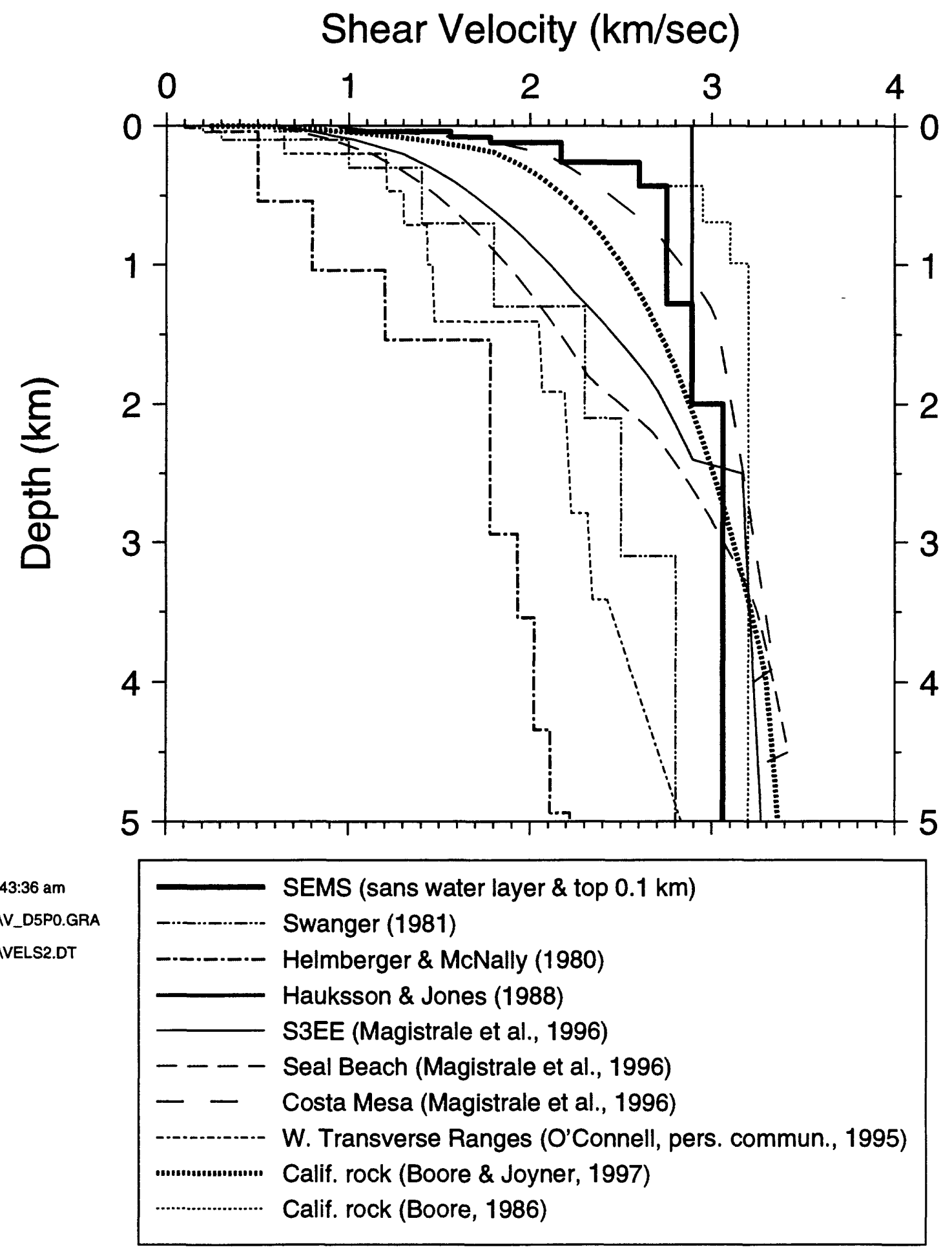

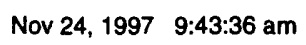
D:ISEMSIVEL_QIV_D5PO.GRA D:ISEMSIVEL_QIVELS2.DT

\begin{tabular}{|c|c|}
\hline & SEMS (sans water layer \& top $0.1 \mathrm{~km}$ ) \\
\hline$\cdots \cdots$ & Swanger (1981) \\
\hline -.--.-- & Helmberger \& McNally (1980) \\
\hline & $\begin{array}{l}\text { Hauksson \& Jones (1988) } \\
\text { S3EE (Magistrale et al., 1996) }\end{array}$ \\
\hline--- & Seal Beach (Magistrale et al., 1996) \\
\hline - - & Costa Mesa (Magistrale et al., 1996) \\
\hline$\cdots$ & W. Transverse Ranges (O'Connell, pers. commun., 1995) \\
\hline ....…………" & Calif. rock (Boore \& Joyner, 1997) \\
\hline$\ldots \ldots \ldots \ldots \ldots \ldots$ & Calif. rock (Boore, 1986) \\
\hline
\end{tabular}

Figure 47. Shear-wave velocity to $5.0 \mathrm{~km}$ from several sources, compared to the adopted SEMS model, stripped of the water layer and the material in the first $0.1 \mathrm{~km}$ beneath the seafloor. The Hauksson and Jones values were derived from their P-wave velocities, assuming a Poisson's ratio of 0.25 . 


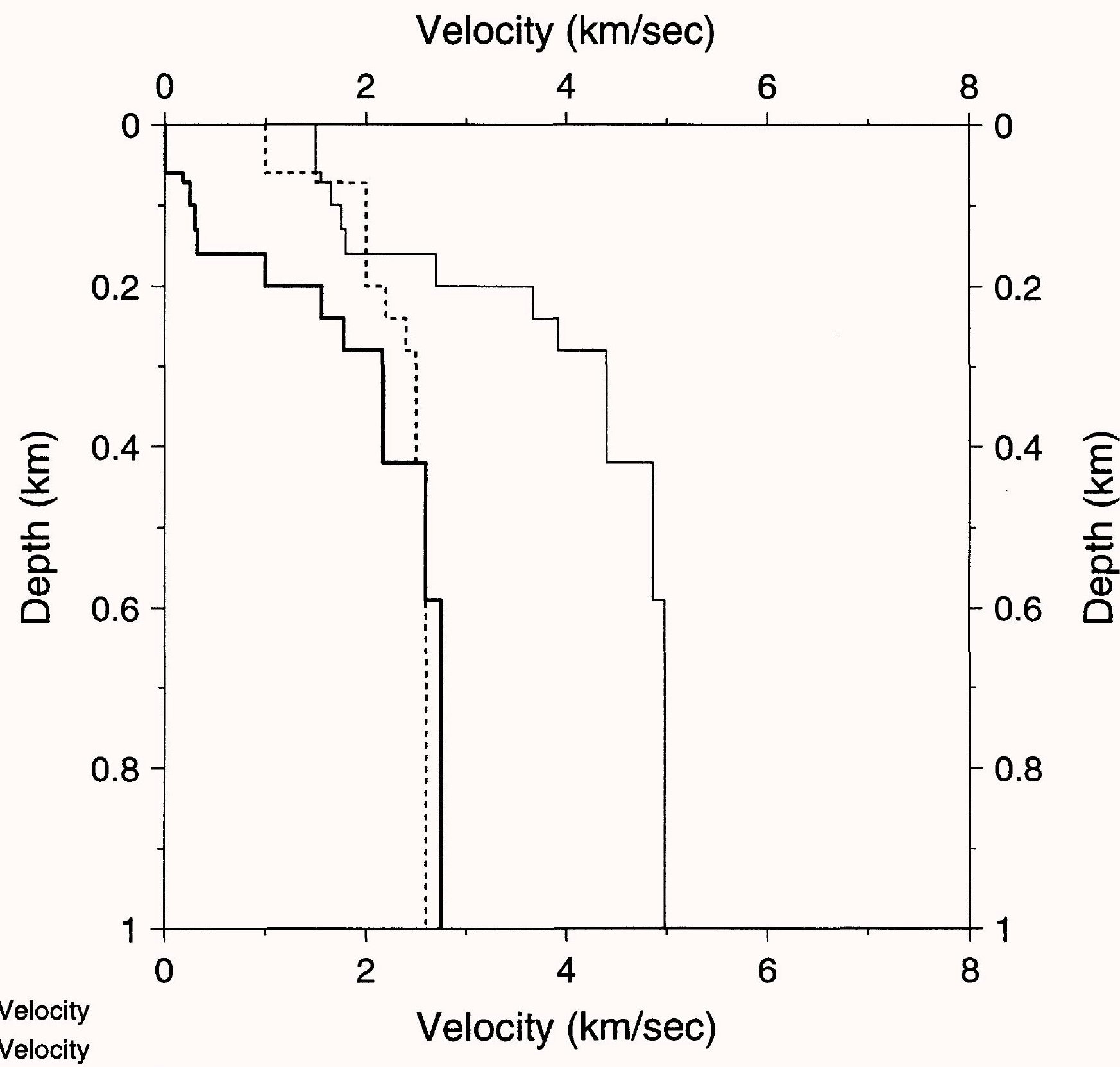

- P Velocity

- S Velocity

-... Density $\left(\mathrm{gm} / \mathrm{cm}^{3}\right)$

Sep 29, $1997 \quad 4: 42: 11 \mathrm{pm}$ C:ISEMSIVEL_OIVELSUM.GRA C:ISEMSIVEL_QIVELSUM.DT

Figure 48. SEMS shear and compressional wave velocity and density used in the theoretical wave propagation calculations. 


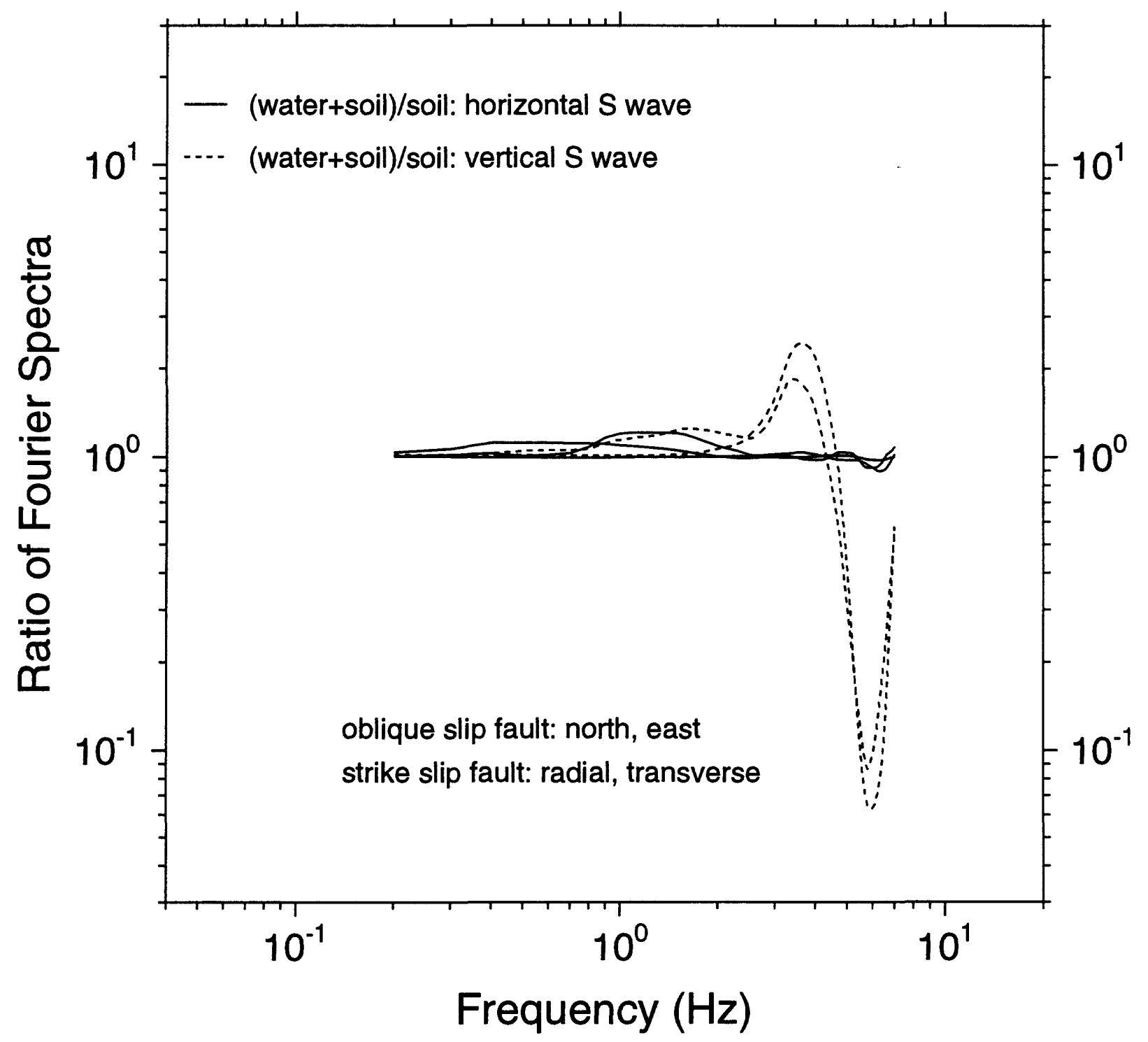

Nov 23, 1997 12:17:47 pm C:ISEMSITHEORYSSTW_S.GRA C:ISEMSITH:AnNMARATDIFF3.DT
Nov 23, 1997 12:17нбцря8, 1997 12:36:20pm23, 1997 12:17:47 pm

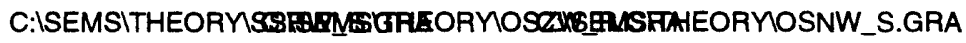

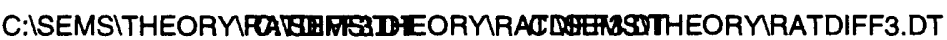

Nov 24, 1997 9:51:40 am D:ISEMSITHEORYOSEW_S.GF D:ISEMSITHEORMRATDIFF3.D

Figure 49. Ratios of Fourier spectra for the S-wave portion of horizontal-component (solid lines) and vertical-component (dashed lines) synthetic seismograms computed for various velocity models and fault orientations (because the results are so similar, the different orientations are not specifically identified). Shown are the ratio of spectra for models with and without the water layer. The figure shows that the water layer only has influence on the vertical-component motions. For the ocean bottom situation and the water depths of most relevance to the SEMS recordings analyzed in this report (about $70 \mathrm{~m}$; see Table 1), the effect of the water layer is only important for frequencies higher than about $2.5 \mathrm{~Hz}$. 


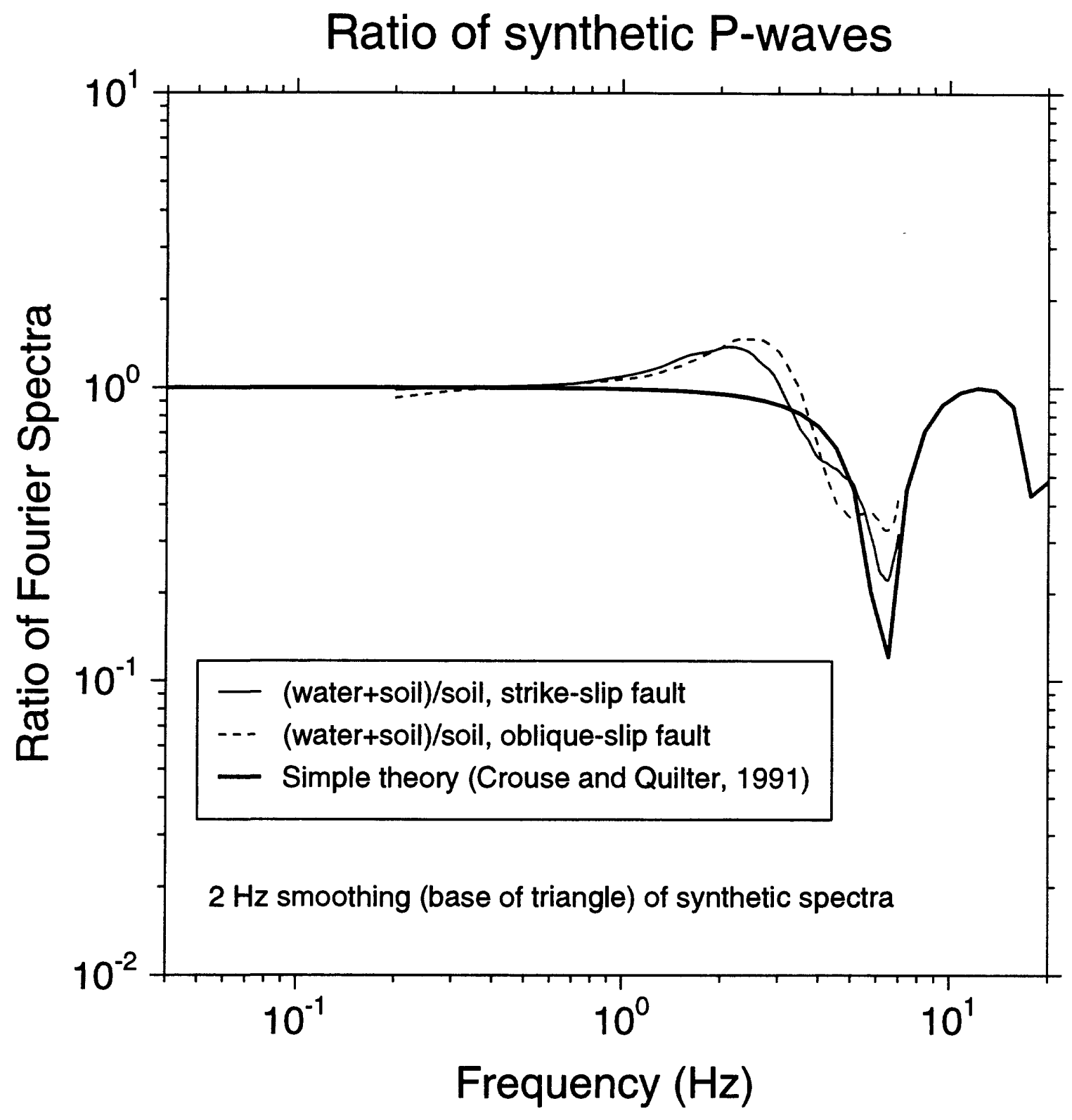

Nov 22, 1997 9:32:58 am

D:ISEMSITHEORYPZRAT.GRA

D:ISEMSITHEORYRAT3P.DT

Figure 50. Ratios of Fourier spectra for the P-wave portion of vertical-component synthetic seismograms computed for various velocity models and fault orientations. Also shown is the prediction from a simple model of a $\mathrm{P}$-wave vertically incident on a water layer overlying an elastic halfspace (Crouse and Quilter, 1991). 


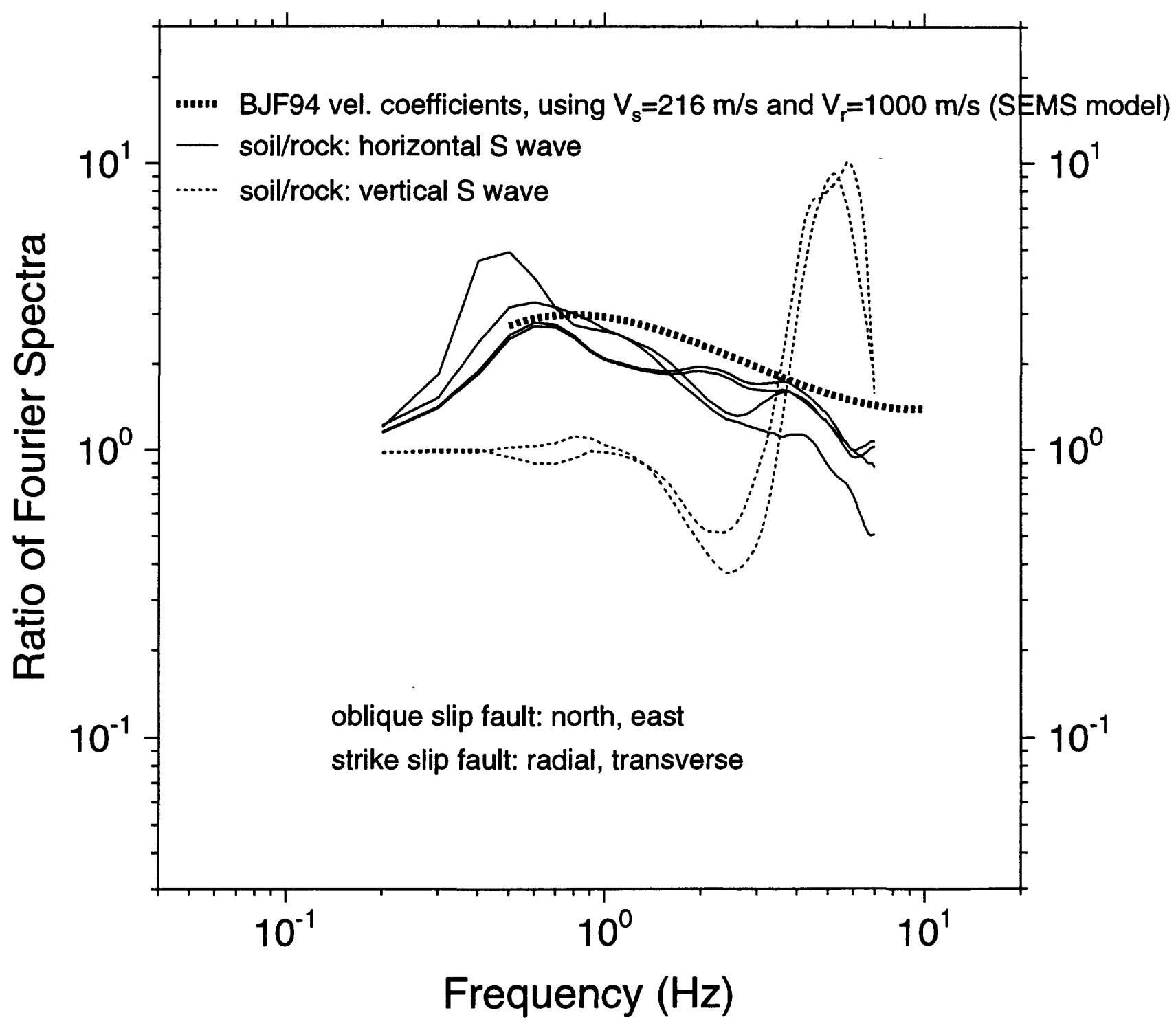

Nov 23, 1997 12:39:32 pm C:ISEMSITHEORYSSTS_R.GRA C:ISEMSITHEORYRATDIFF3.DT
Nov 23, 1997 12:39

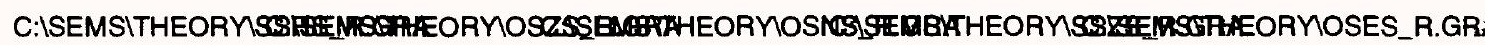

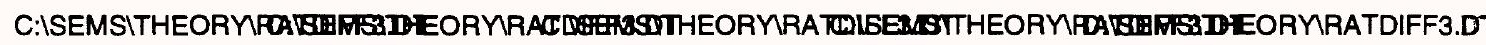

Figure 51. Ratios of Fourier spectra for the S-wave portion of horizontal-component (solid lines) and vertical-component (dashed lines) synthetic seismograms computed for various velocity models and fault orientations (because the results are so similar, the different orientations are not specifically identified). Shown are the ratio of spectra for models with and without the upper $0.1 \mathrm{~km}$ of sediments ("soil" and "rock"). The heavy dashed line is the soil-to-rock coefficients for horizontal-component response spectra found by Boore et al. (1994) from regression analysis. 


\section{SEMS OBS Recordings and Theory}

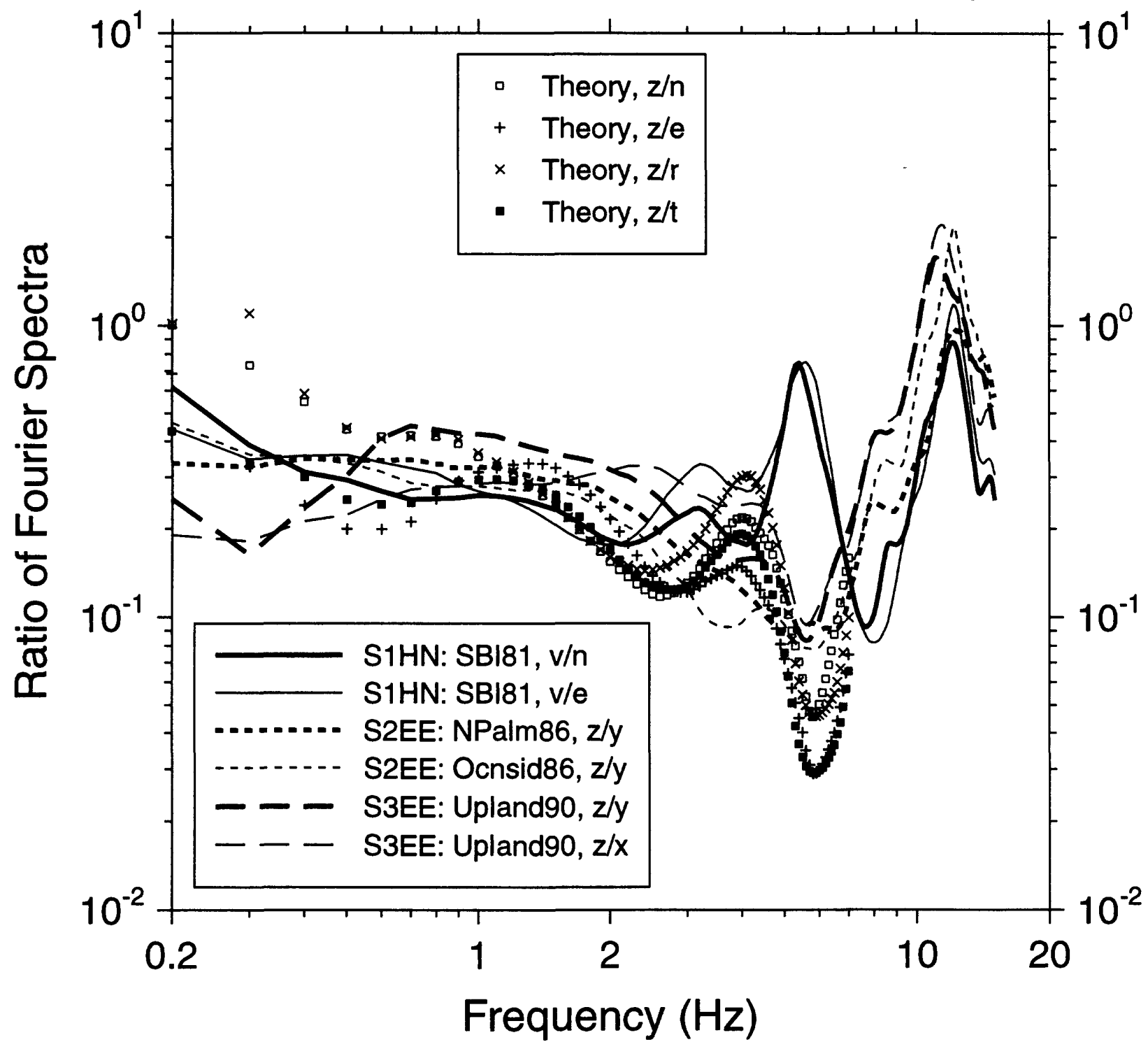

Nov 22, 1997 2:06:53 pm D:ISEMSIV_HIZDH_COR.GRA

Nov 22, 1997 1:46:56 pm

zdhoff.grg

D:ISEMSIV_HIRAT_CORR.DT D:ISEMSIV_HIZDHOFFTH.GRA

D:ISEMSIV_HIZDH3.DT

Figure 52. $V / H$ ratios of Fourier amplitude spectra of the S-wave portion of offshore recordings, compared to theoretical predictions. 


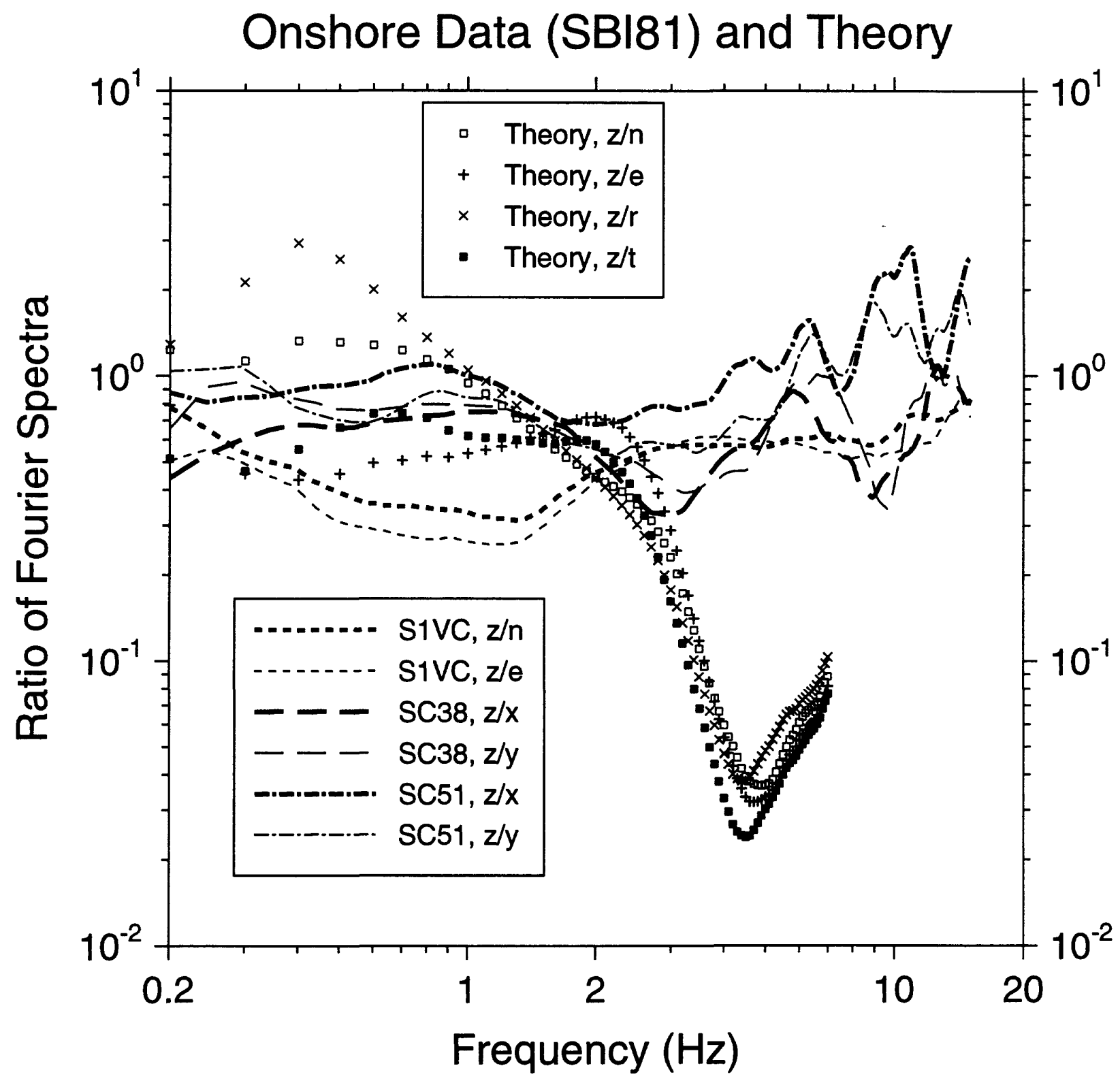

zdhon.grg

D:ISEMSIV_HIZDHON.GRA

D:ISEMSIV_HISBI81RAT.DT
Dev 22,19997 32408t37ppm

D:ISEMSIV_HIZDHONTH.GRA

D:ISEMSIV_HZDH3.DT

Figure 53. $V / H$ ratios of Fourier amplitude spectra of the S-wave portion of onshore recordings, compared to theoretical predictions. As discussed in the text, the model used for the theoretical computations should be changed; it is based on a old assessment of the velocity gradient beneath a generic rock site (Boore, 1986). More recent studies (Boore and Joyner, 1997) suggest that the gradient in this model is too steep, leading to a strong reduction in high-frequency vertical component motion, and consequently a strong dip in the ratio of $V / H$. Furthermore, the appropriate velocity model beneath the near-surface sediments for these onshore sites should probably be different than for a generic rock site. 
Constructing the ground shaking for a large earthquake from the recording of a smaller earthquake

- Construct duration filter (Gaussian random numbers with duration equal to difference in source duration of large and small earthquakes)

- Multiply spectrum of duration filter by source spectral ratios

- Multiply product above by the spectrum of the small earthquake

- Inverse transform to obtain time series of large event.

- Compute velocity, displacement, and response spectra

Figure 54. Basis of scaling method. 


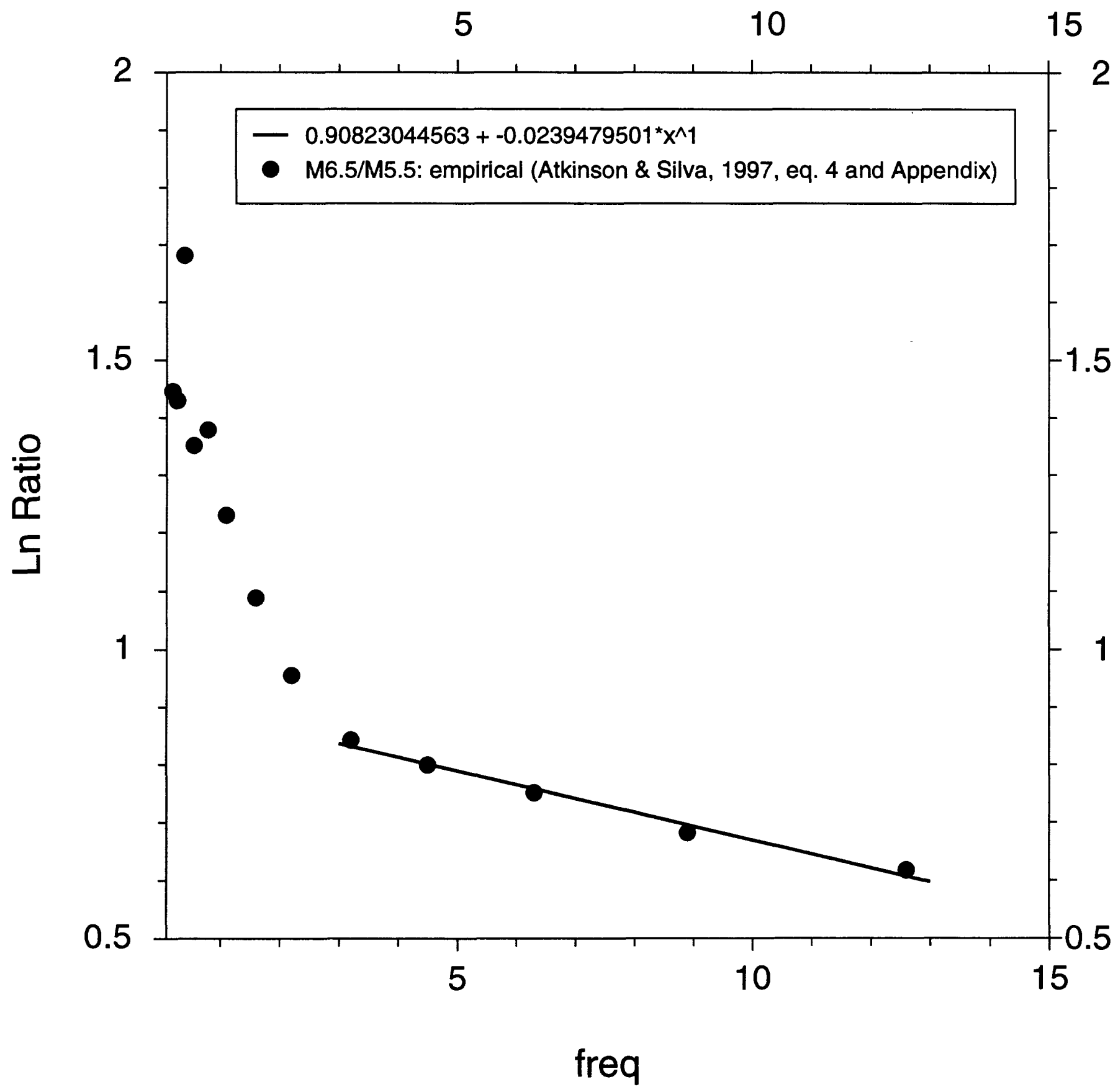

Oct 14, 1997 10:45:30 am

C:ISEMSIBIGEQILNE_5565.GRA

C:ISEMSIBIGEQWNEWE65B.DT

Figure 55. The symbols are the ratio of "source" spectra from Atkinson and Silva (1997) for moment magnitudes 6.5 and $5.5, \ln A_{6.5} / A_{5.5}$, plotted against frequency using semilog scales. The line is a regression fit to the symbols over the range of frequencies indicated by the extent of the line. The slope and intercept of the line give information about the difference in $\kappa$ values and equivalent stress parameters for the two earthquakes (see text). 


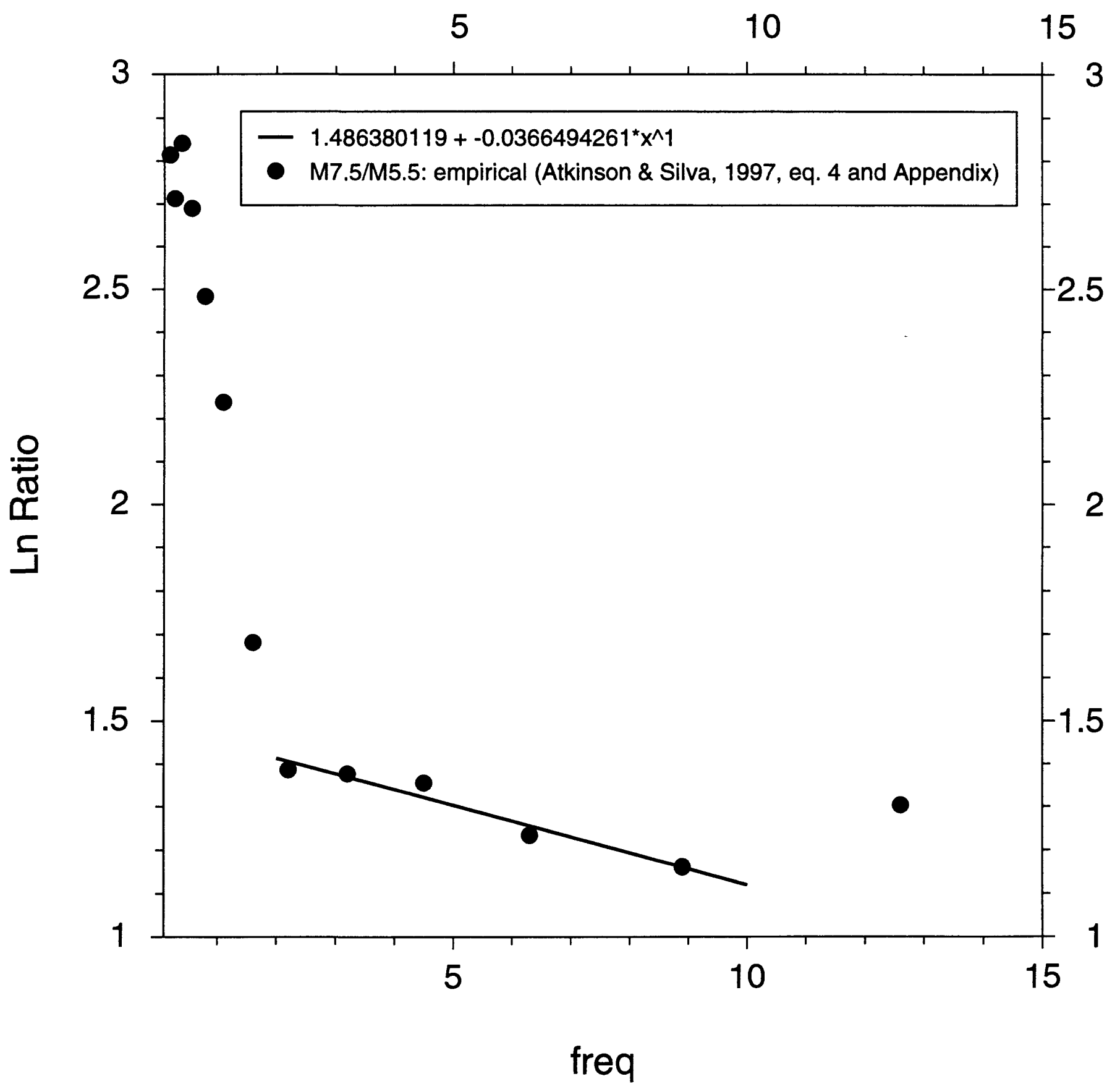

Oct 14, 1997 10:48:26 am

C:ISEMSIBIGEQLNE_5575.GRA

C:ISEMSIBIGEQWEWE75B.DT

Figure 56. The symbols are the ratio of "source" spectra from Atkinson and Silva (1997) regression analysis of Fourier spectral amplitudes from strong motion data in California, for moment magnitudes 7.5 and $5.5, \ln A_{7.5} / A_{5.5}$, plotted against frequency using semilog scales. The line is a regression fit to the symbols over the range of frequencies indicated by the extent of the line. The slope and intercept of the line give information about the difference in $\kappa$ values and equivalent stress parameters for the two earthquakes (see text). 


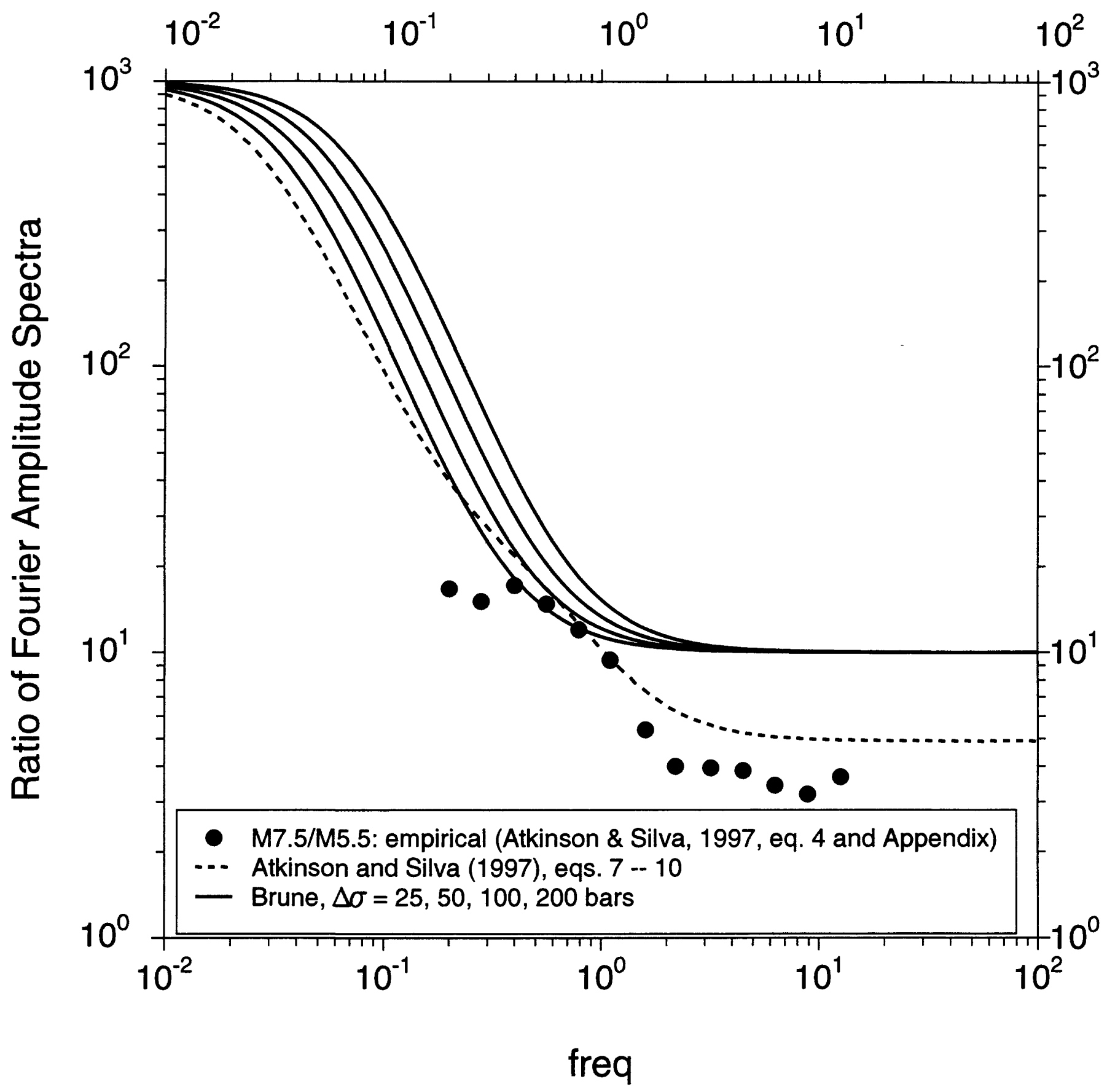

Oct 14, 1997 10:44:19 am

C:ISEMSIBIGEQLBRUNE.GRA

C:ISEMSIBIGEQIBRUNE.DT

Figure 57. Ratio of "source" spectra from Atkinson and Silva (1997) vs. frequency, plotted using log-log scales (symbols). The dashed line is the ratio of amplitudes predicted from the equations in Atkinson and Silva for earthquakes with moment magnitudes of 7.5 and 5.5. The mismatch is an indication of the need to modify the Atkinson and Silva equations, as is done in the text. The solid curves are the ratios expected for a single-corner-frequency, constant-stress-parameter model, which is clearly ruled out by the Atkinson and Silva derived source spectra. 


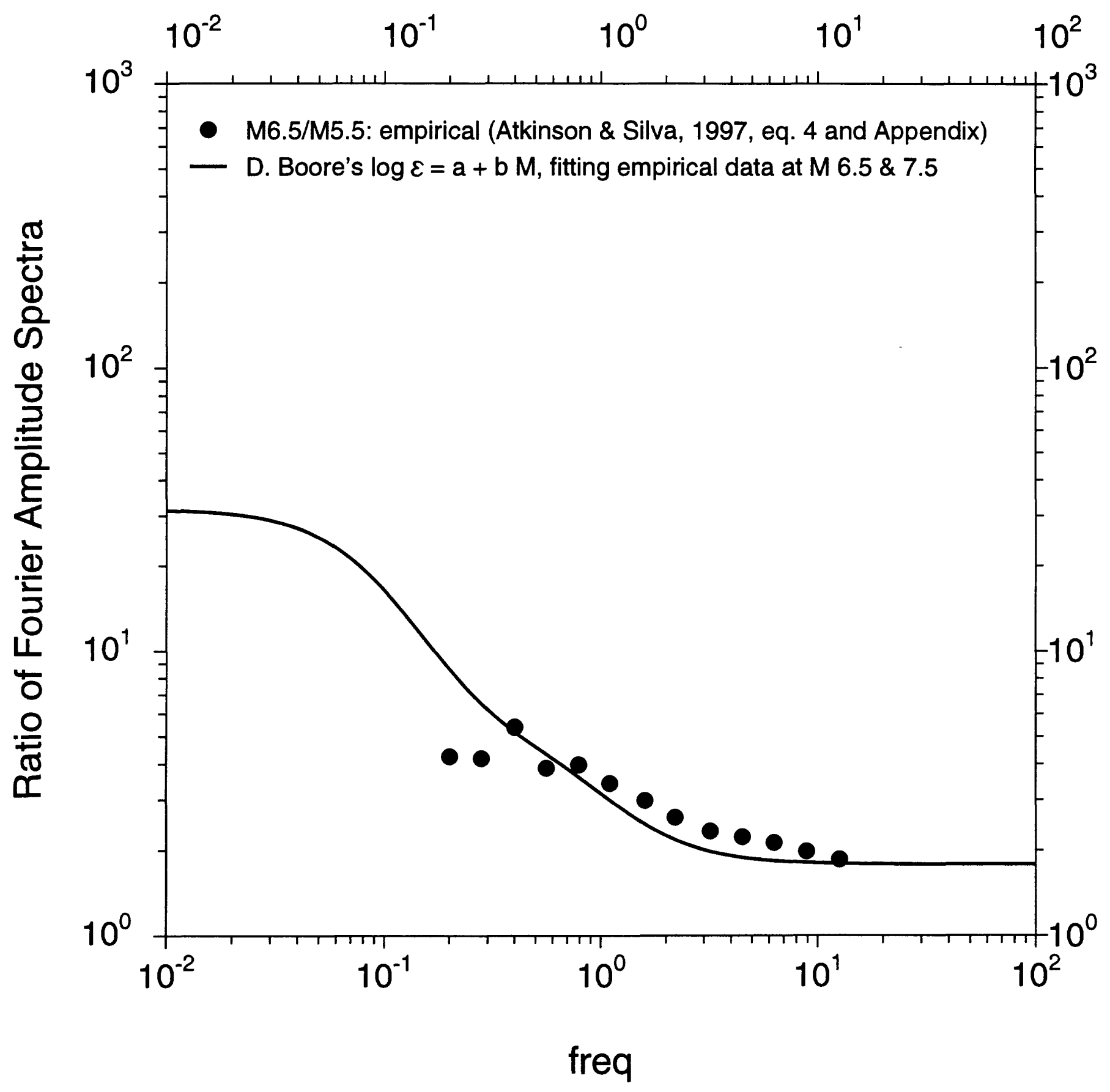

Oct 14, 1997 10:46:26 am

C:ISEMSIBIGEQINEWE65B.GRA

C:ISEMSIBIGEQINEWE65B.DT

Figure 58. Ratio of "source" spectra from Atkinson and Silva (1997) vs. frequency, plotted using log-log scales (symbols). The solid line is the ratio of amplitudes predicted from my modification to the equations in Atkinson and Silva for earthquakes with moment magnitudes of 6.5 and 5.5 . 


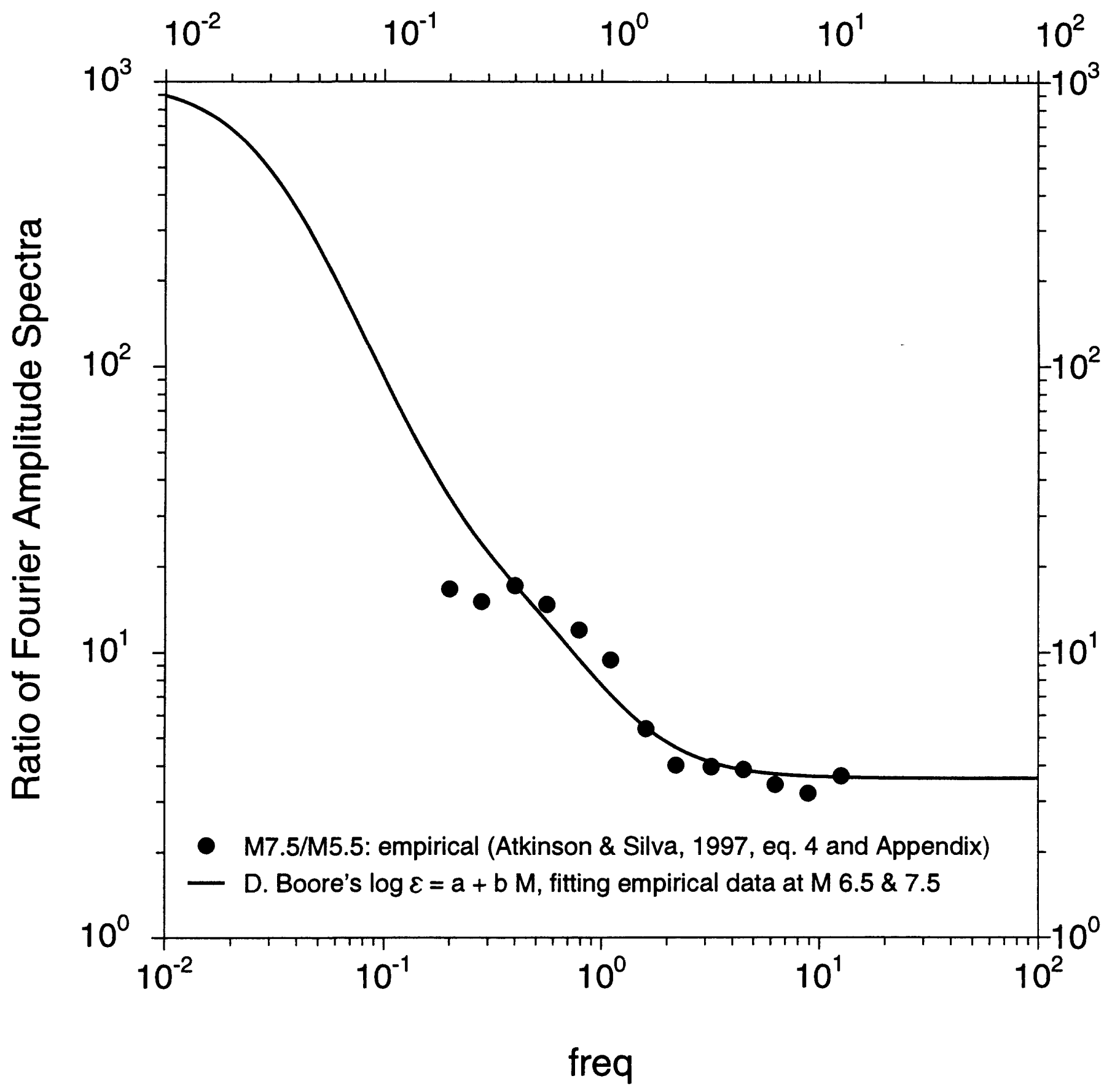

Oct 14, 1997 10:46:55 am

C:ISEMSIBIGEQWNEWE75B.GRA

C:ISEMSIBIGEQWICINF75B.DT

Figure 59. Ratio of "source" spectra from Atkinson and Silva (1997) vs. frequency, plotted using $\log -\log$ scales (symbols). The solid line is the ratio of amplitudes predicted from my modification to the equations in Atkinson and Silva for earthquakes with moment magnitudes of 7.5 and 5.5 . 


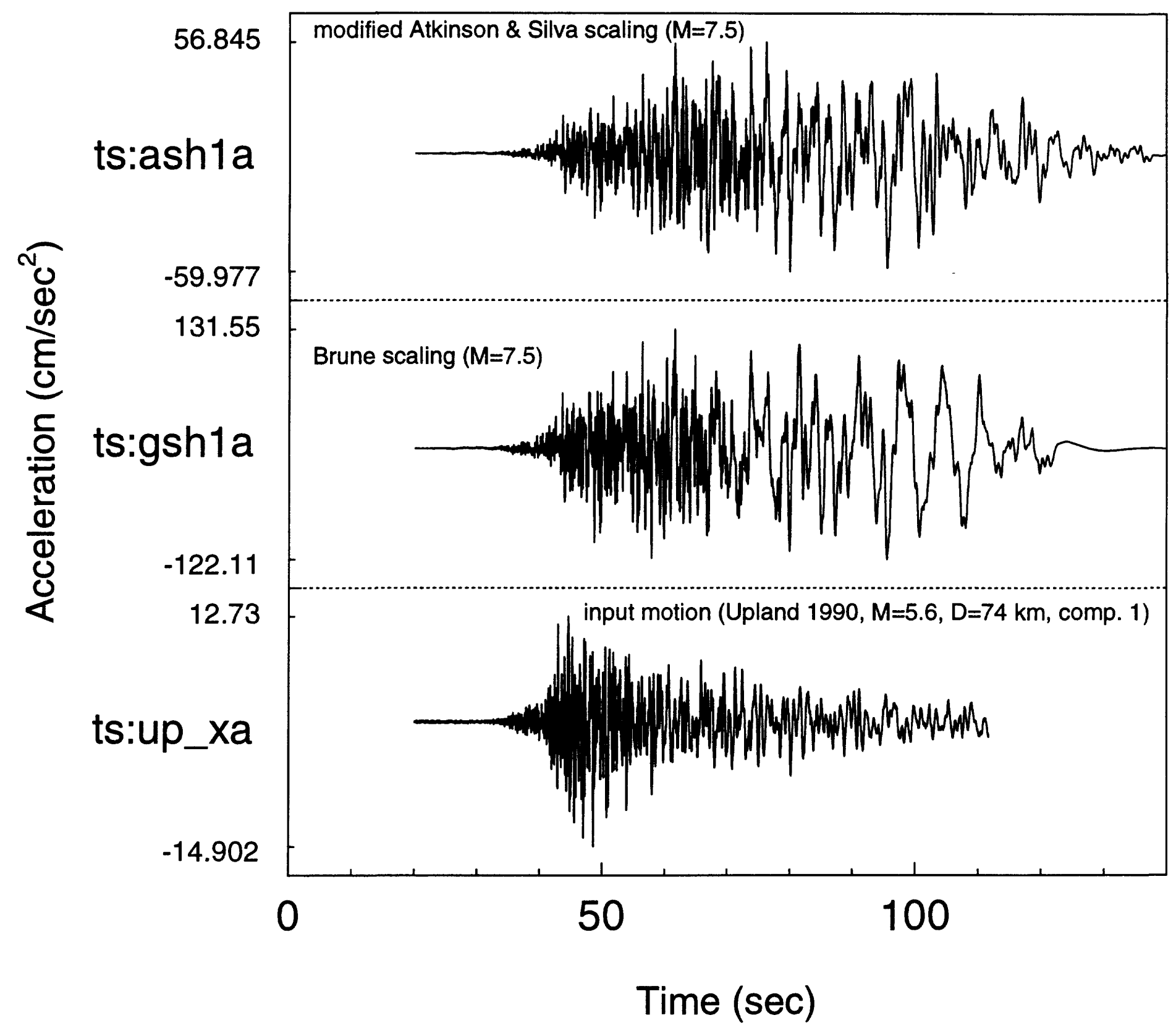

Oct 20, 1997 1:57:21 pm

D:ISEMSIBIGEQVABUP_ACC.GRA

D:ISEMSIBIGEQLABUP_ACC.DT

Figure 60. Scaling of horizontal-component acceleration recorded for a $\mathbf{M}=5.6$ earthquake at SEMS site S3EE up to an earthquake with $\mathbf{M}=7.5$. The bottom trace is the recorded motion, and upper two traces are the motions for the larger earthquake, based on the indicated source-scaling models. 


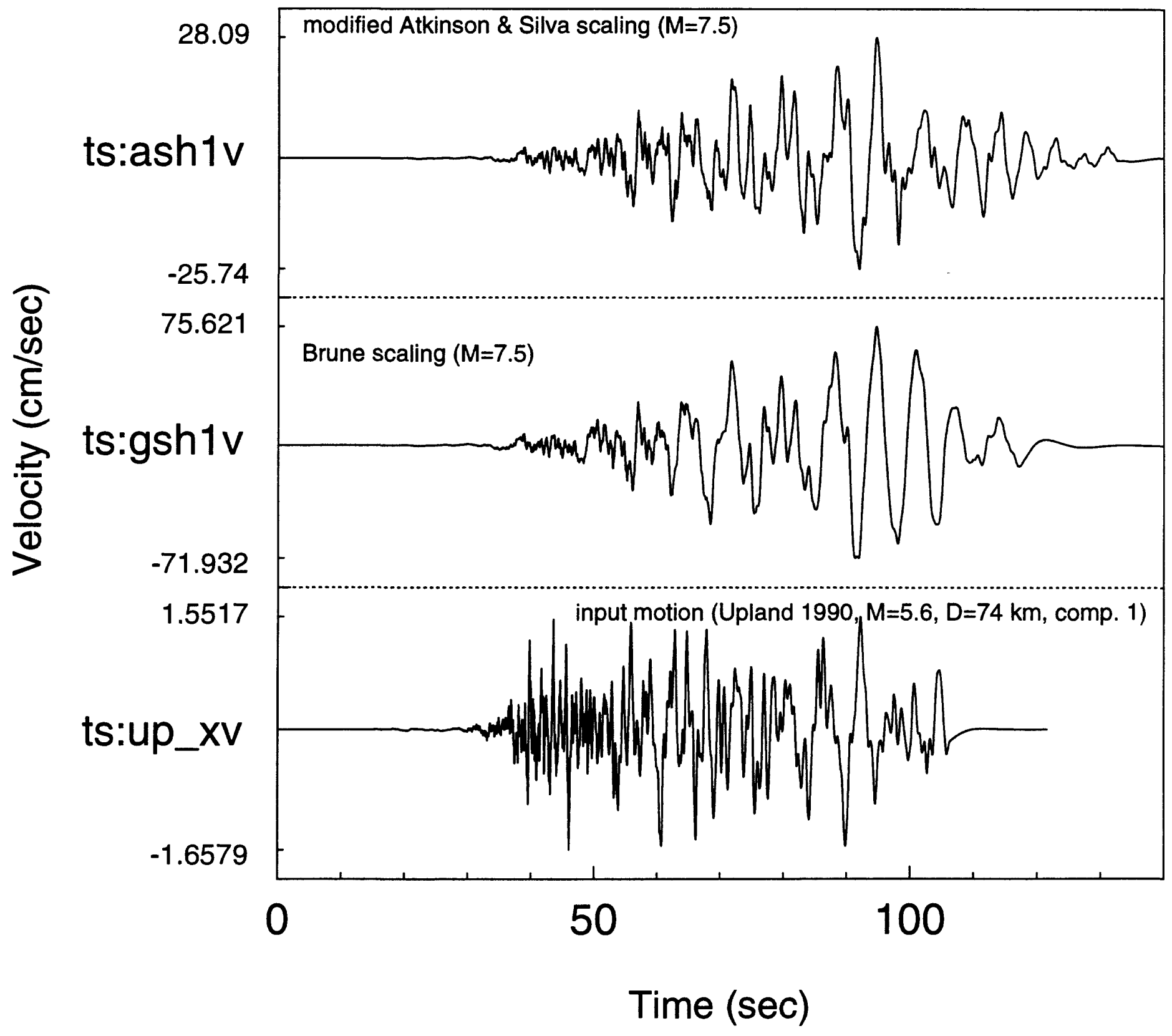

Oct 20, 1997 1:56:41 pm

D:ISEMSIBIGEQVABUP_VEL.GRA

D:ISEMSIBIGEQVABUP_VEL.DT

Figure 61. Scaling of horizontal-component velocity time series for a $\mathbf{M}=5.6$ earthquake at SEMS site S3EE up to an earthquake with $\mathbf{M}=7.5$. The bottom trace is derived from the recorded motion, and upper two traces are the motions for the larger earthquake, based on the indicated source-scaling models. These time series were obtained by integrating the acceleration time series in Figure 60. 


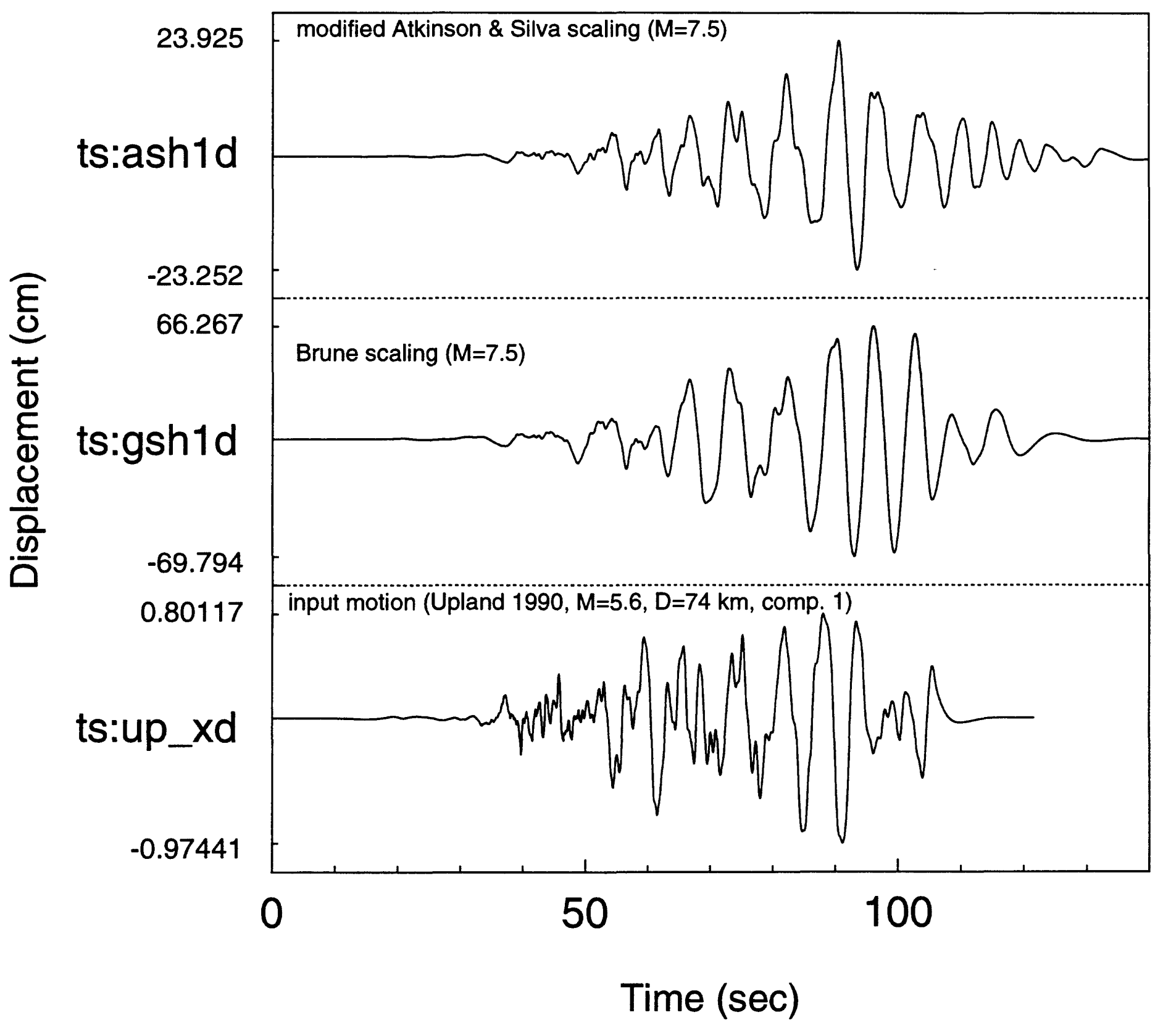

Oct 20, 1997 2:09:31 pm

D:ISEMSIBIGEQVABUP_DIS.GRA

D:ISEMSIBIGEQVABUP_DIS.DT

Figure 62. Scaling of horizontal-component displacement time series for a $\mathbf{M}=5.6$ earthquake at SEMS site S3EE up to an earthquake with $\mathbf{M}=7.5$. The bottom trace is derived from the recorded motion, and upper two traces are the motions for the larger earthquake, based on the indicated source-scaling models. These time series were obtained by integrating the velocity time series in Figure 61. 


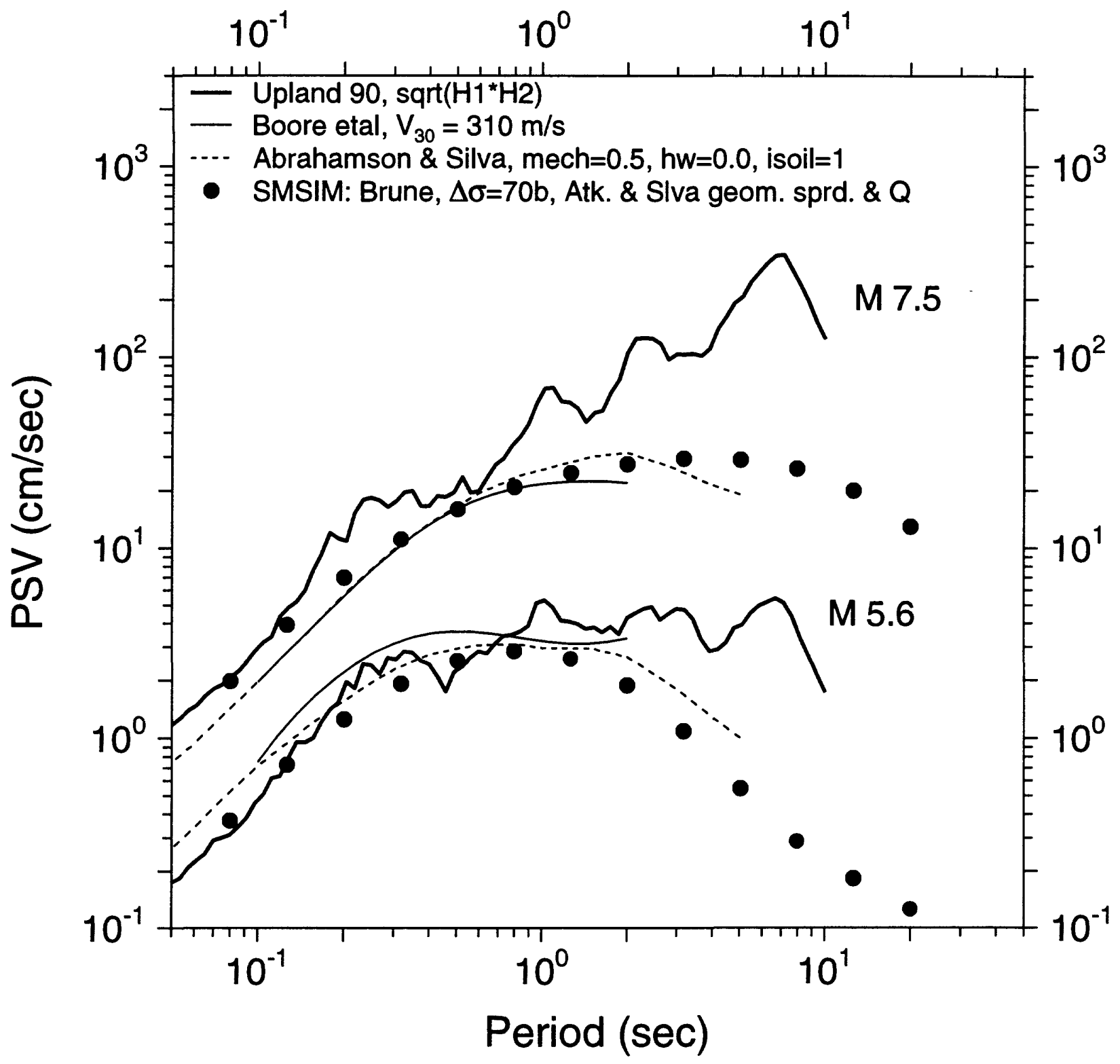

Jun 14, 1996 3:50:47 pm

C:ISEMSIBIGEQIBASGS.GRA

C:ISEMSIBIGEQIBASGS.DT

Figure 63. 5\%-damped, pseudo-velocity response spectra $(P S V)$ for the basis earthquake $(\mathbf{M}=5.6)$ and the target earthquake $(\mathbf{M}=7.5)$ (heavy solid lines). The $P S V$ for the target event has been derived from the basis event assuming single-cornerfrequency scaling with a stress parameter of 70 bars. Also shown are the predictions from two regression analyses (light solid and dashed lines) and from stochastic-model simulations (solid circles). 


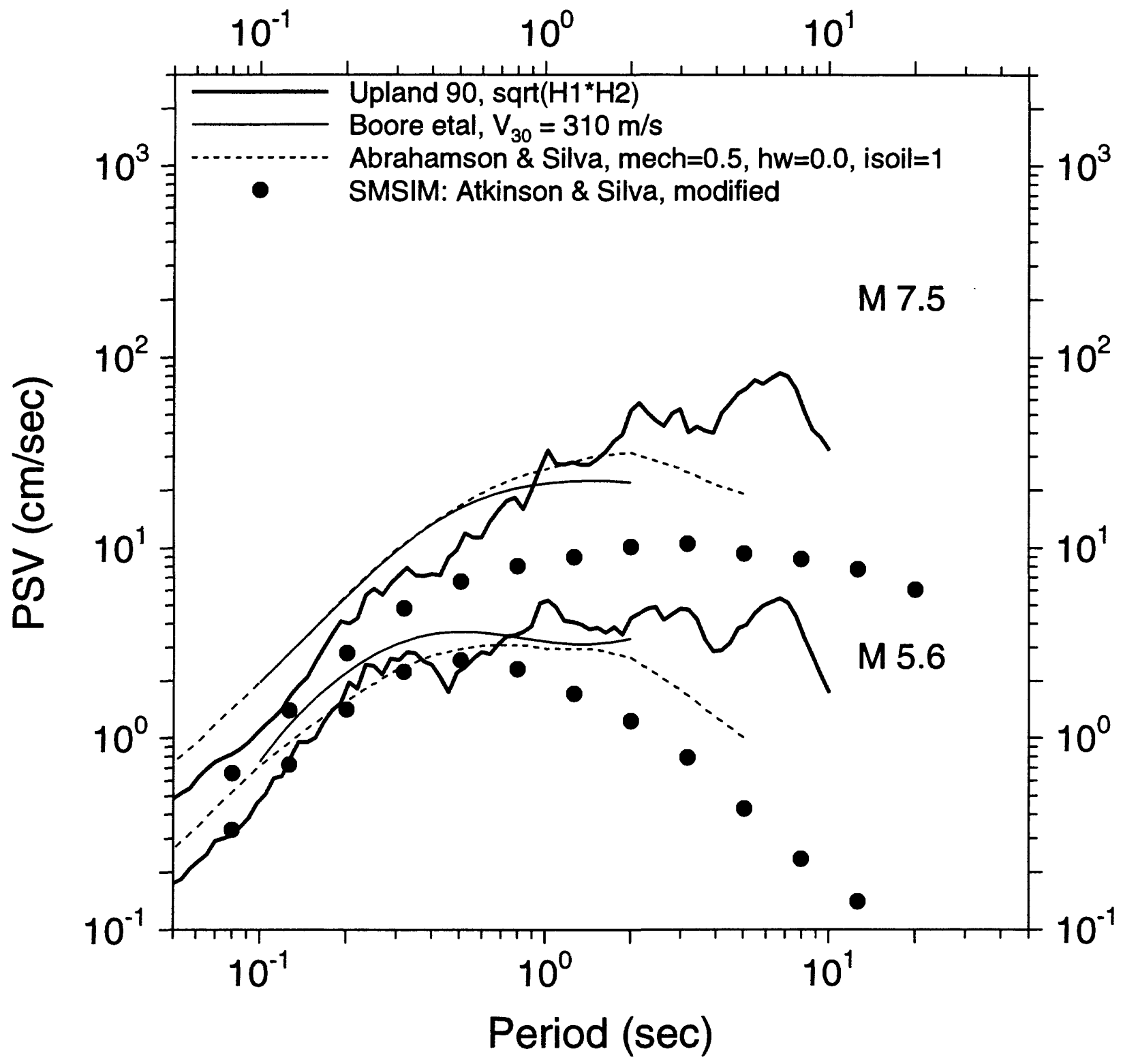

Jun 14, 1996 3:50:33 pm

C:ISEMSIBIGEQLAS.GRA

C:ISEMSIBIGEQVAS.DT

Figure 64. 5\%-damped, pseudo-velocity response spectra $(P S V)$ for the basis earthquake $(\mathbf{M}=5.6)$ and the target earthquake $(\mathbf{M}=7.5)$ (heavy solid lines). The $P S V$ for the target event has been derived from the basis event assuming modified Atkinson and Silva source scaling. Also shown are the predictions from two regression analyses (light solid and dashed lines) and from stochastic-model simulations (solid circles). 


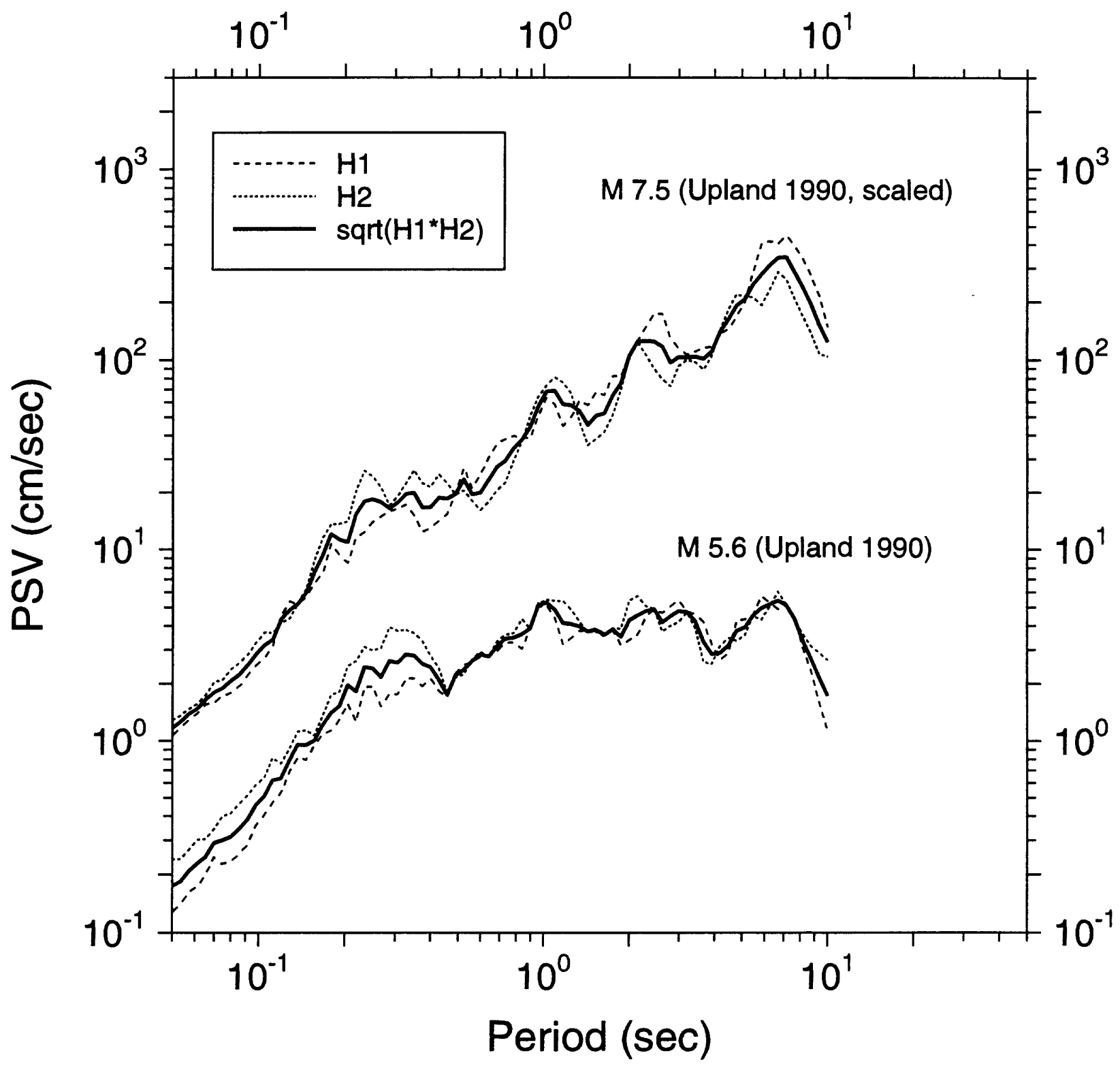

Oct 14, 1997 3:31:33 pm

C:ISEMSIBIGEQIBASGSH12.GRA

C:ISEMSIBIGEQIBASGSOBS.DT

Figure 65. This figure demonstrates the insensitivity of the scaled results to the component of horizontal motion. As in Figure 63, the $P S V$ for the target event has been derived from the basis event assuming single-corner-frequency scaling with a stress parameter of 70 bars. The solid line is the geometric mean of the two horizontal components (dashed lines). 


\section{Shear Velocity $(\mathrm{km} / \mathrm{sec})$}

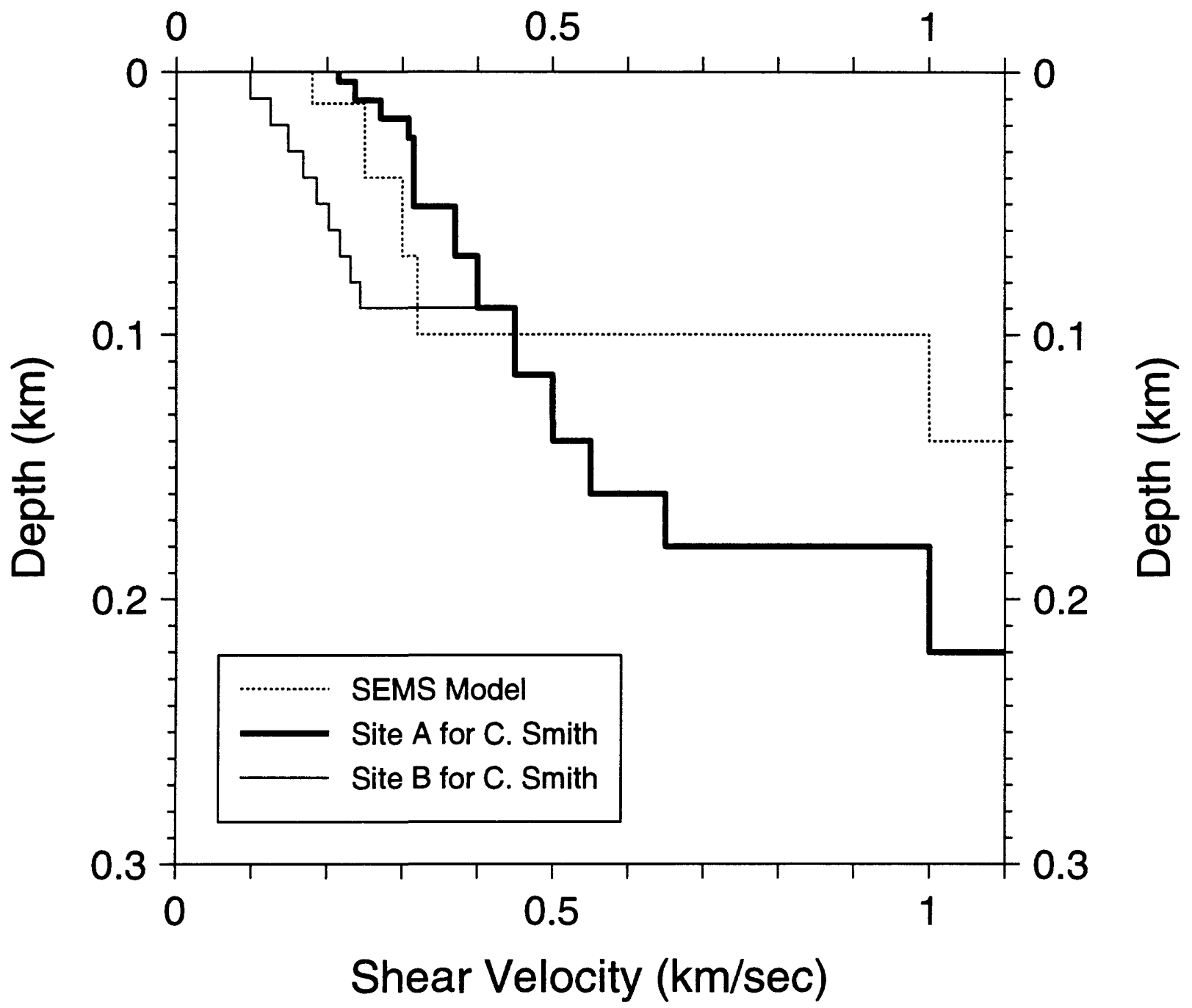

Oct 20, 1997 10:38:30 am

D:ISEMSIVEL_QIVSITEAB.GRA

D:ISEMSIVEL_QIVELS2.DT

Figure 66. Shear-wave velocity for the two sites for which synthetic motions were generated for use in platform response studies by C. Smith, plotted to a depth of $0.3 \mathrm{~km}$. Also shown is the SEMS model used in modeling $V / H$. 


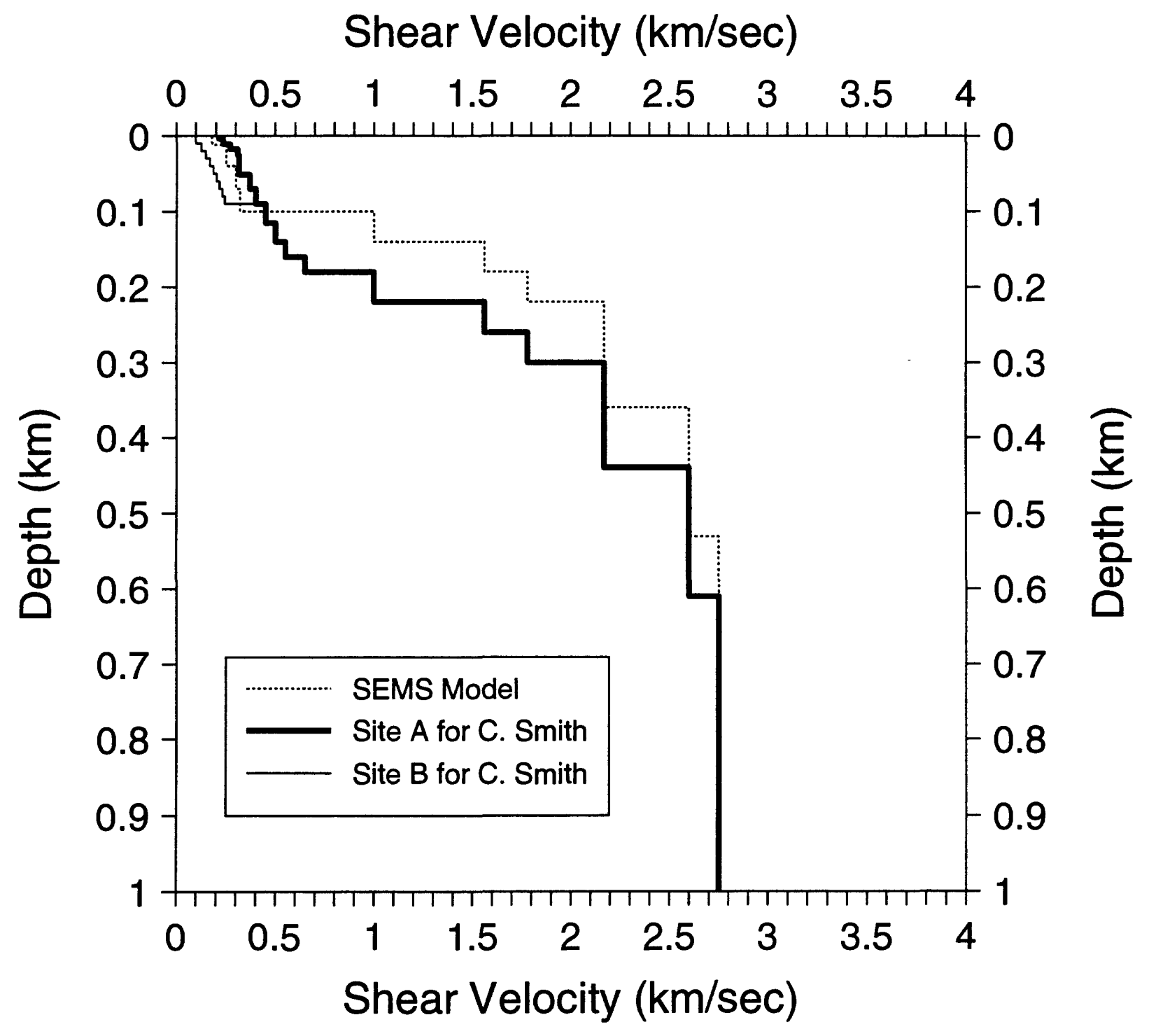

Figure 67. Shear-wave velocity for the two sites for which synthetic motions were generated for use in platform response studies by C. Smith, plotted to a depth of $1.0 \mathrm{~km}$. Also shown is the SEMS model used in modeling $V / H$. 
Site A, Transverse Component

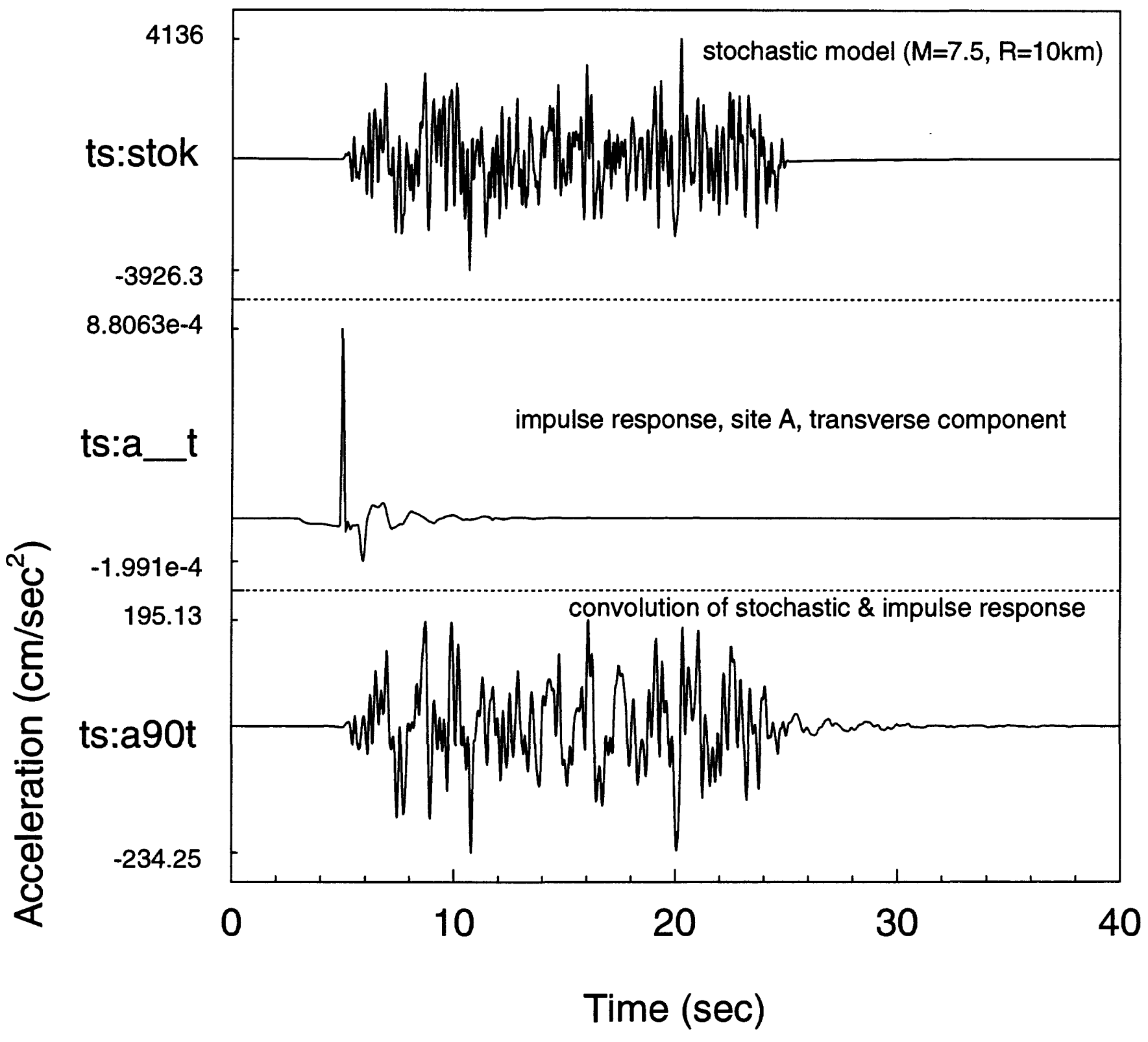

Oct 20, 1997 2:16:50 pm

D:ISEMSISITEABIPROC.FNAT GRA

D:ISEMSISITEABIPRC

Figure 68. Illustrating the procedure for generating the design motions. The top trace shows the output of the stochastic model (Boore, 1996) for a moment magnitude of 7.5 and a distance of $10 \mathrm{~km}$. The complexity in the time series is assumed to be due to source complexity. The middle trace is the impulse response of the layered velocity model, computed using full-wave synthetics (using program HSPEC91, written by R. Herrmann). This time series accounts for site-specific geological complexity (at least that part that can be modeled by a stack of laterally uniform layers). The bottom trace is the final result, obtained by convolving the top two traces. This ground motion corresponds to the transverse component at site $\mathrm{A}$. 


\section{Site A, Radial Component}

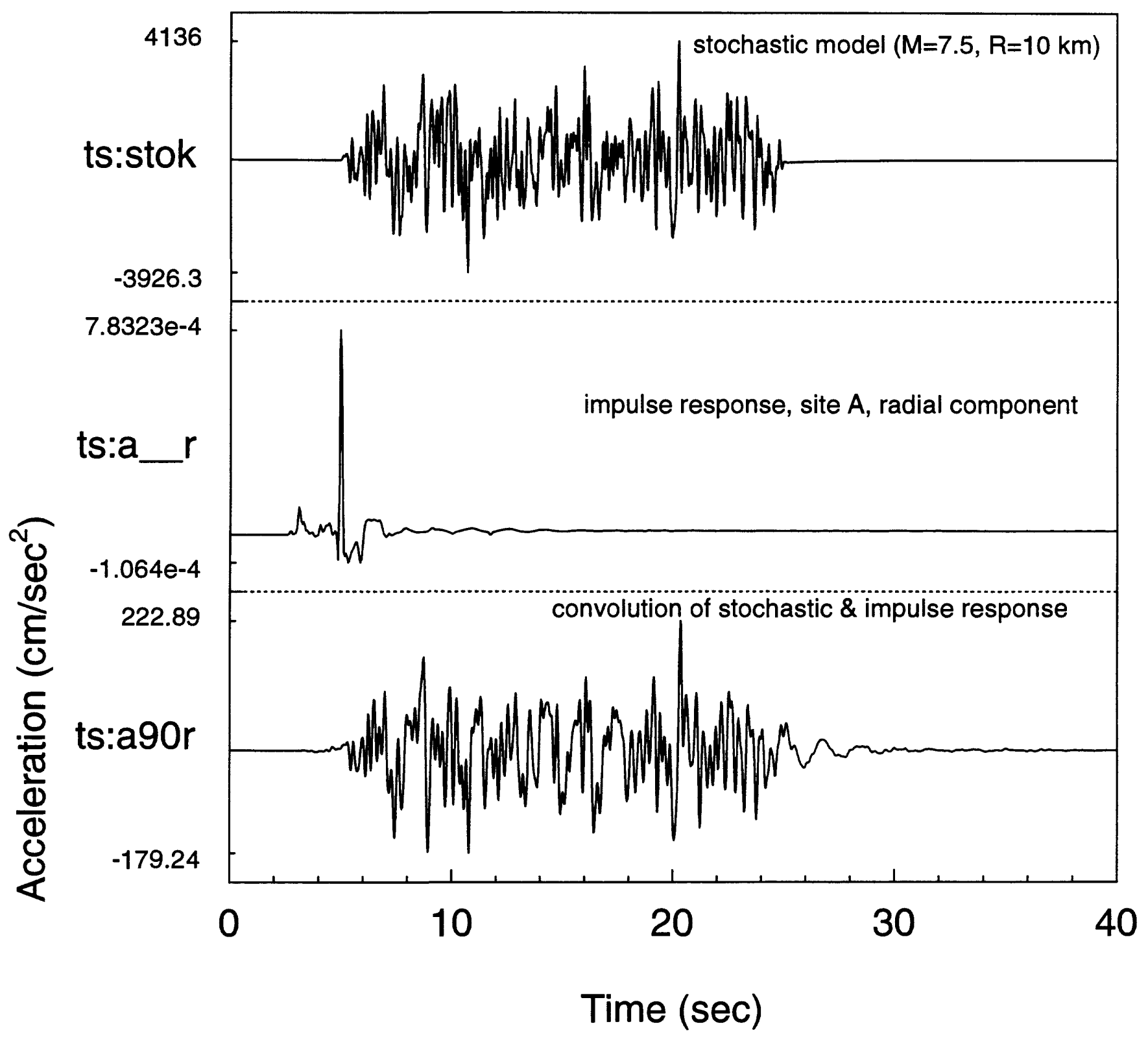

Oct 20, 1997 2:15:59 pm D:ISEMSISITEABIPROCEDAR.GRA

D:ISEMSIE'Tr-Ammnnmrnin nT

Figure 69. Illustrating the procedure for generating the design motions. The top trace shows the output of the stochastic model (Boore, 1996) for a moment magnitude of 7.5 and a distance of $10 \mathrm{~km}$. The complexity in the time series is assumed to be due to source complexity. The middle trace is the impulse response of the layered velocity model, computed using full-wave synthetics (using program HSPEC91, written by R. Herrmann). This time series accounts for site-specific geological complexity (at least that part that can be modeled by a stack of laterally uniform layers). The bottom trace is the final result, obtained by convolving the top two traces. This ground motion corresponds to the radial component at site A. 


\section{Site A, Vertical Component}

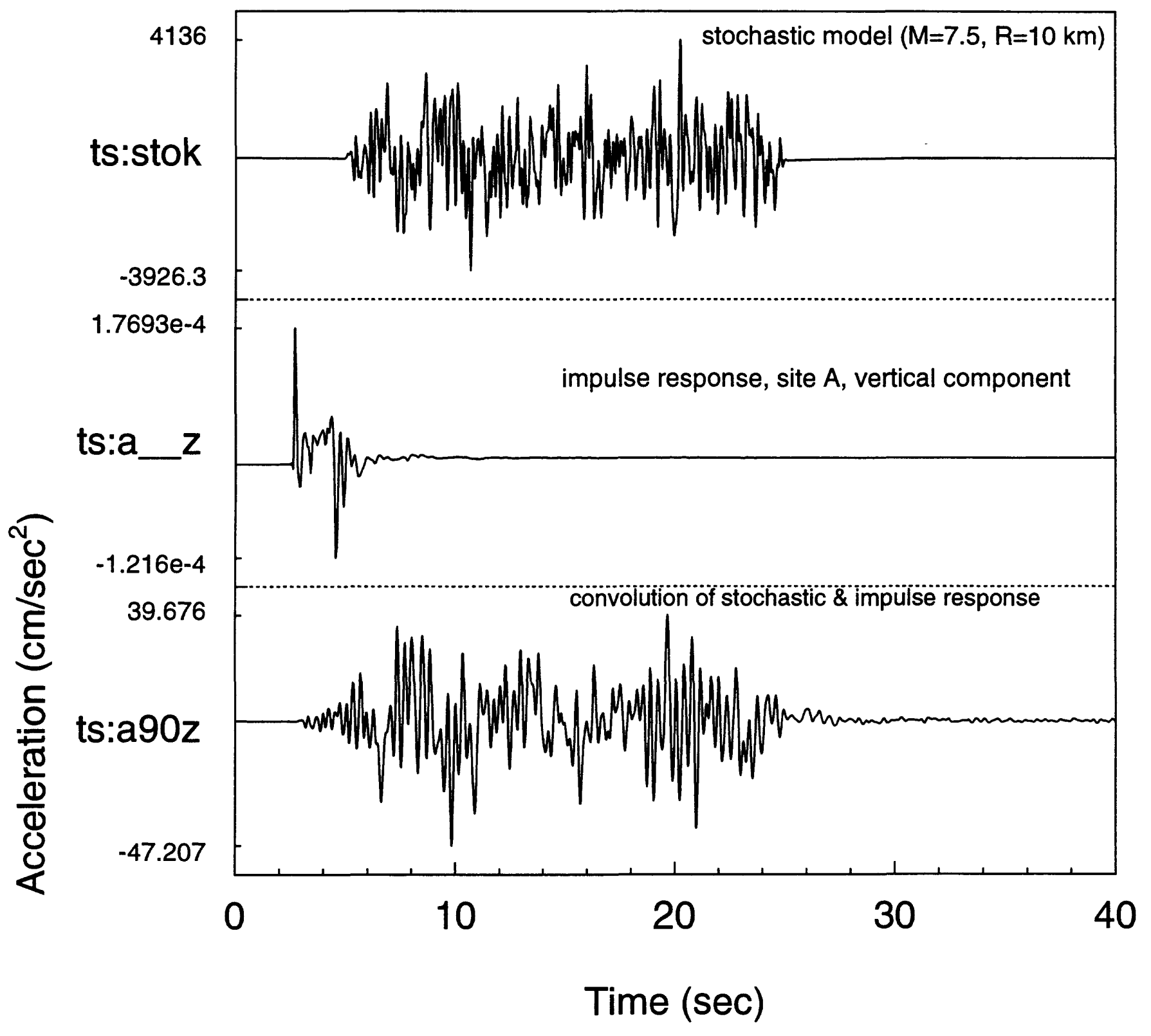

Oct 20, 1997 2:19:35 pm

D:ISEMSISITEABIPROCEDAZ.GRA

D:ISEMSISITEABIPROCEDUR.DT

Figure 70. Illustrating the procedure for generating the design motions. The top trace shows the output of the stochastic model (Boore, 1996) for a moment magnitude of 7.5 and a distance of $10 \mathrm{~km}$. The complexity in the time series is assumed to be due to source complexity. The middle trace is the impulse response of the layered velocity model, computed using full-wave synthetics (using program HSPEC91, written by R. Herrmann). This time series accounts for site-specific geological complexity (at least that part that can be modeled by a stack of laterally uniform layers). The bottom trace is the final result, obtained by convolving the top two traces. This ground motion corresponds to the vertical component at site $\mathrm{A}$. 


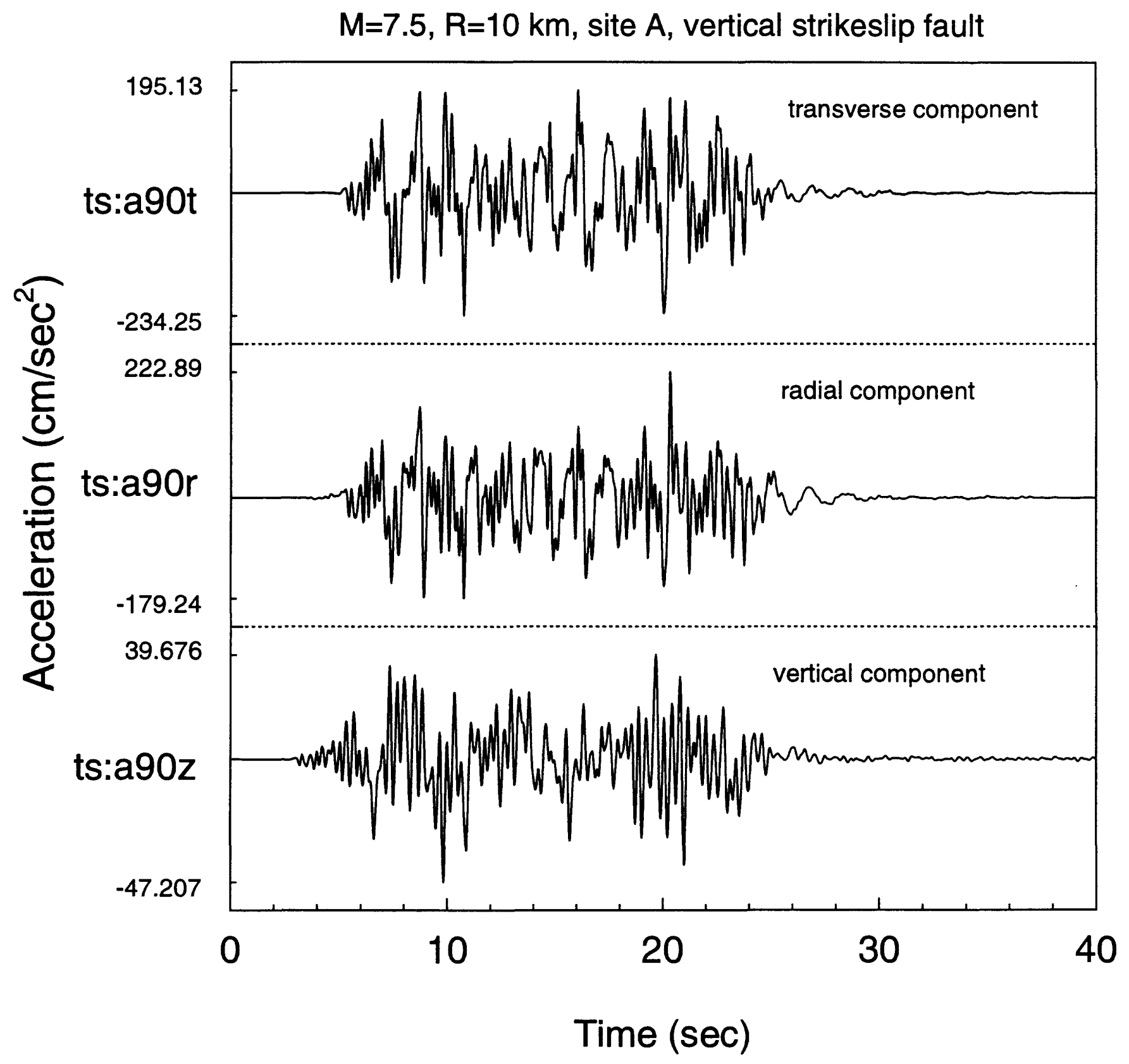

Oct 20, 1997 2:26:24 pm

D:ISEMSISITEABUM75D90A.GRA

D:ISEMSISITEABM75D90A.DT

Figure 71. The three-component simulated motion at site A for a vertical strikeslip fault, at $10 \mathrm{~km}$ from a $\mathbf{M}=7.5$ earthquake. 
$M=7.5, R=10 \mathrm{~km}$, site $A$, dipping reverseslip fault

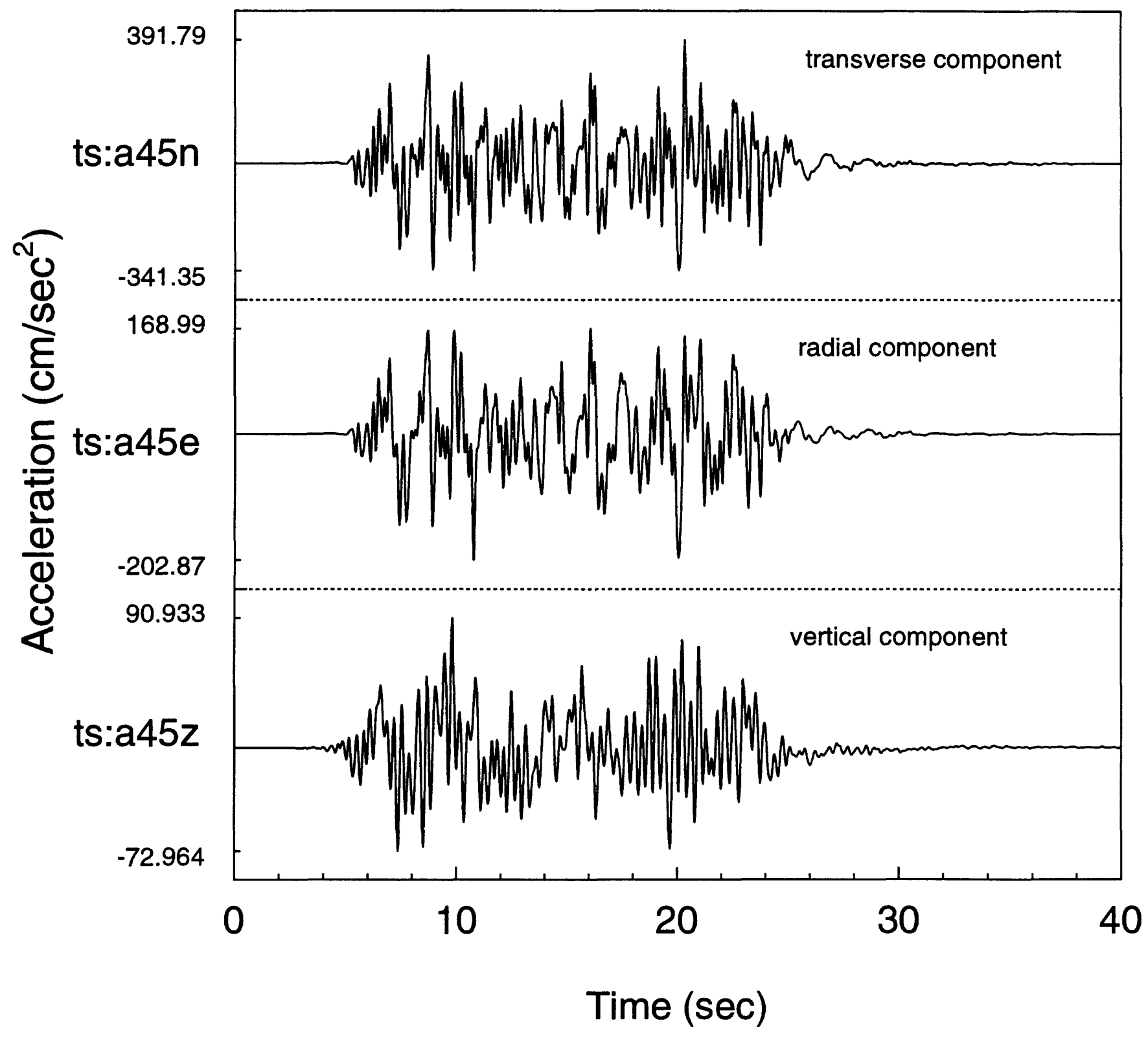

Oct 20, 1997 2:21:01 pm

D:ISEMSISITEABUM75D45A.GRA

D:ISEMSISITEABIM75D45A.DT

Figure 72. The three-component simulated motion at site $\mathrm{A}, 10 \mathrm{~km}$ from a $\mathbf{M}=7.5$ earthquake on a 45 degree reverseslip fault. 


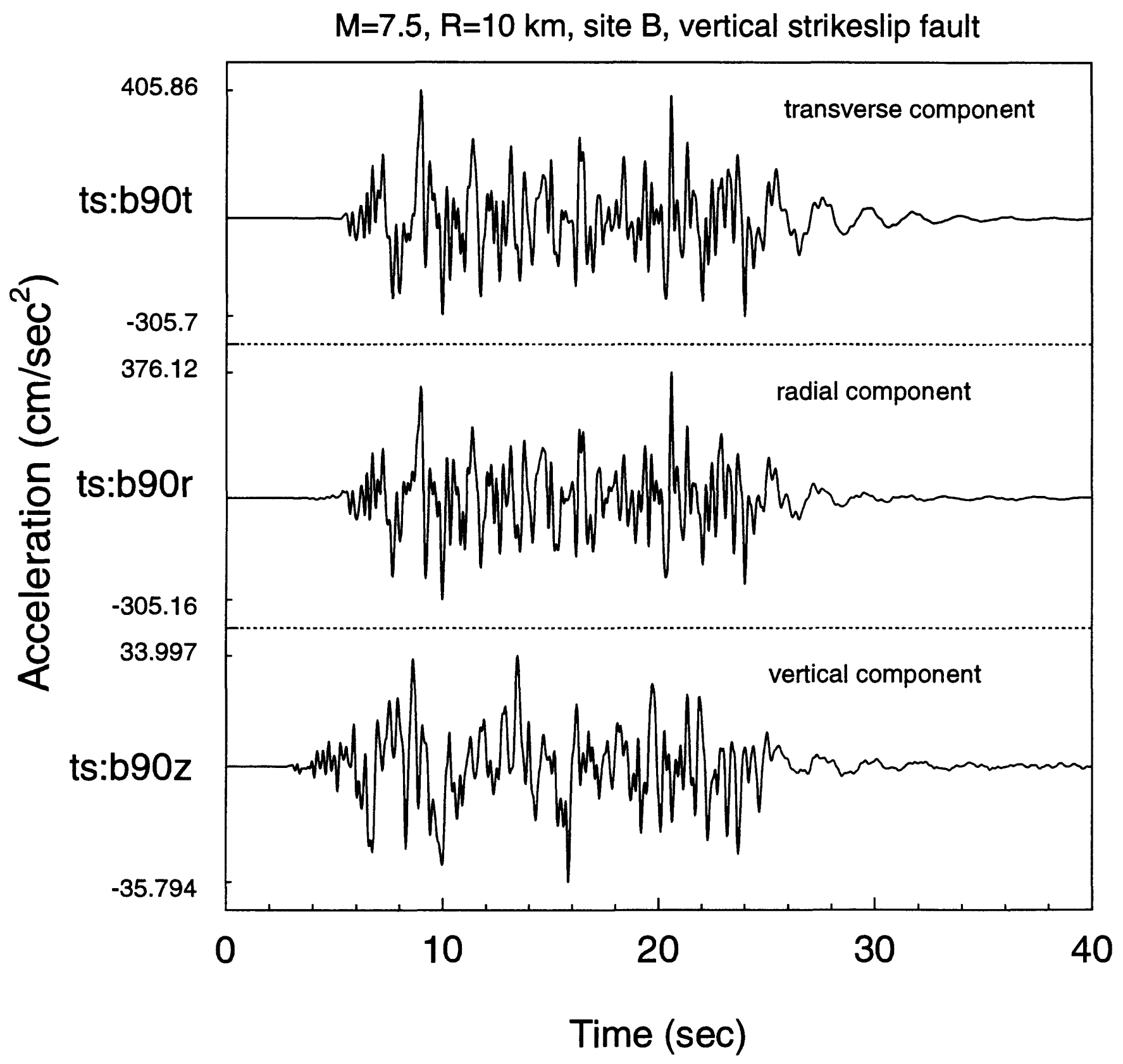

Oct 20, 1997 2:23:15 pm D:ISEMSISITEABM75D90B.GRA D:ISEMSISITEABMM75D90B.DT

Figure 73. The three-component simulated motion at site B for a vertical strikeslip fault, at $10 \mathrm{~km}$ from a $\mathbf{M}=7.5$ earthquake. 


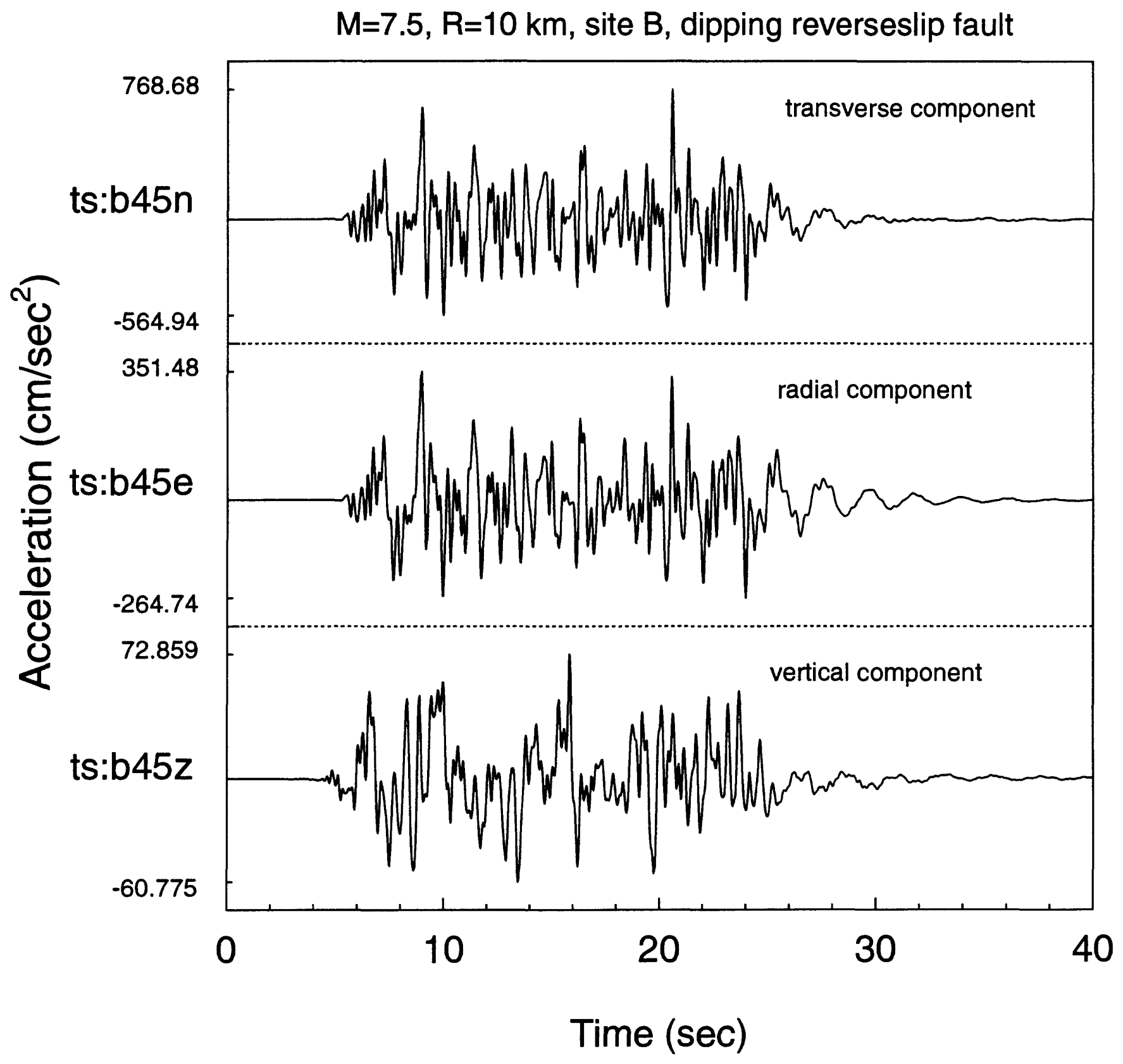

Oct 20, 1997 2:21:42 pm D:ISEMSISITEABW75D45B.GRA D:ISEMSISITEABM75D45B.DT

Figure 74. The three-component simulated motion at site $\mathrm{B}, 10 \mathrm{~km}$ from a $\mathbf{M}=7.5$ earthquake on a 45 degree reverseslip fault. 


\section{APPENDIX A - PLOTS OF SEMS DATA}

The following figures contain plots of acceleration, velocity, and displacement for all of the SEMS recordings. Each figure shows the three components of motion for a given recording, and consecutive figures show acceleration, velocity and displacement for each recording. The identification of each recording can be obtained from the small comment in the lower left of each figure. For example, "C: $\backslash$ SEMS $\backslash$ SBI81 $\backslash$ S1HN_3A.DT" is a plot of the three components of acceleration at station S1HN. Somewhat less obvious are the names for the recordings of the two 1997 Simi Valley earthquakes. In this case,

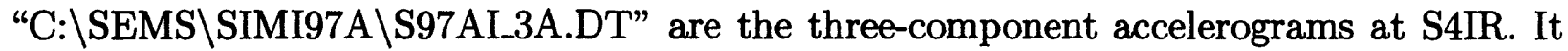
is best to refer to Table 5 to help in deciphering the names. Note that in some cases "LB" has been used as part of a station name; this is the same as station "EE". 


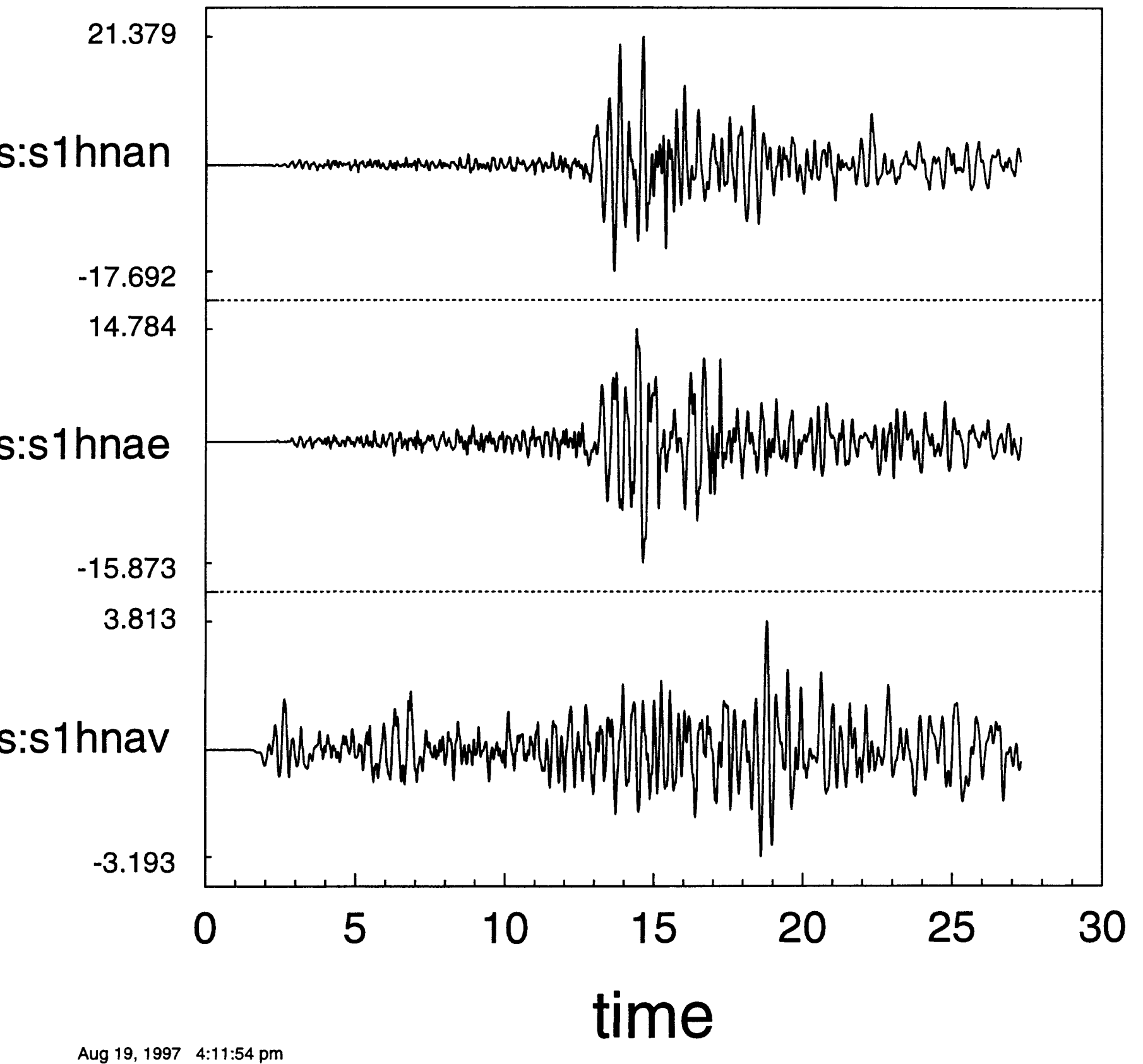

C:ISEMSISBI8113TS.GRA

C:ISEMSISBI81IS1HN_3A.DT 


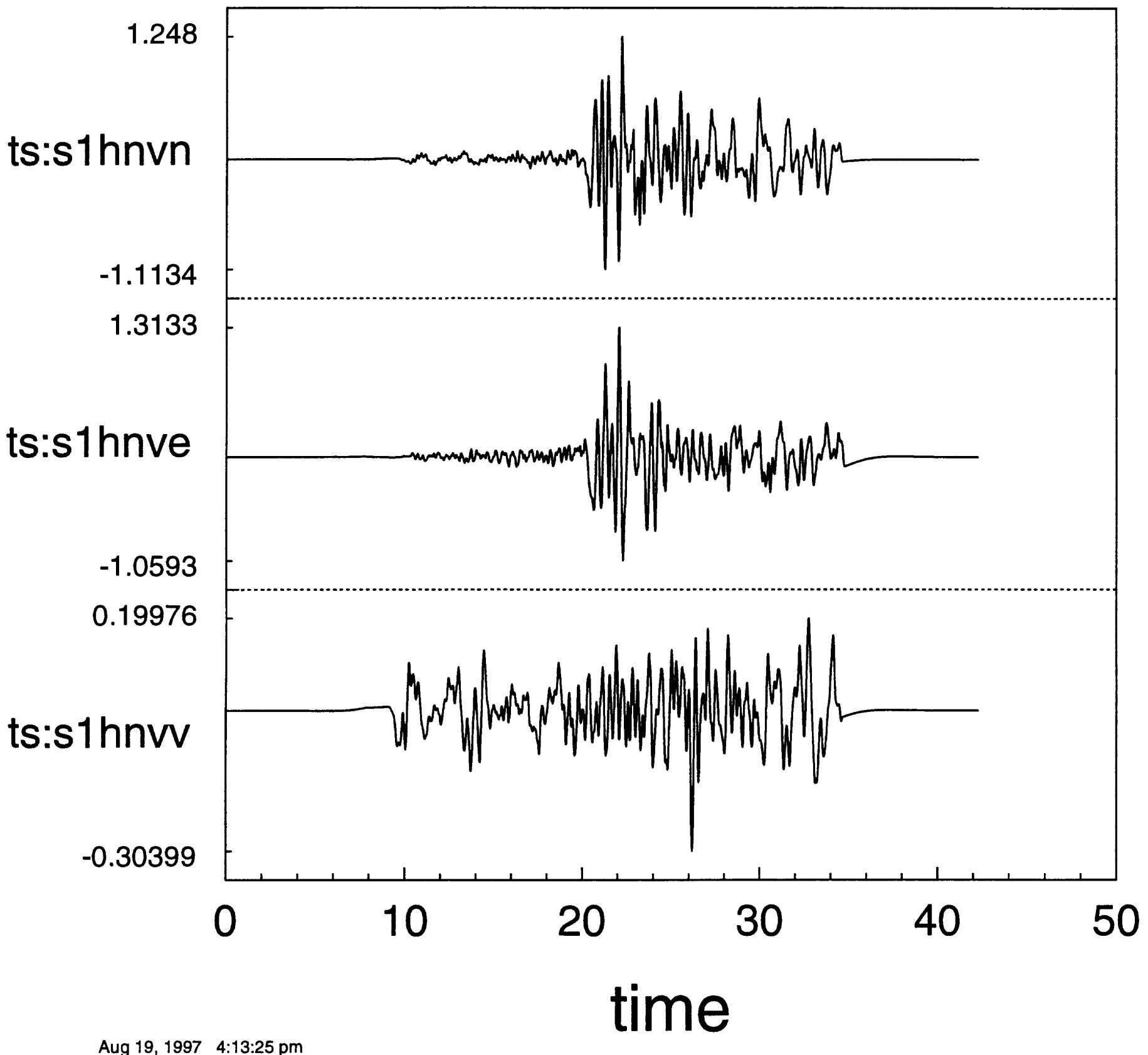

C:ISEMSISBI8113TS.GRA

C:ISEMSISBI811S1HN_3V.DT 


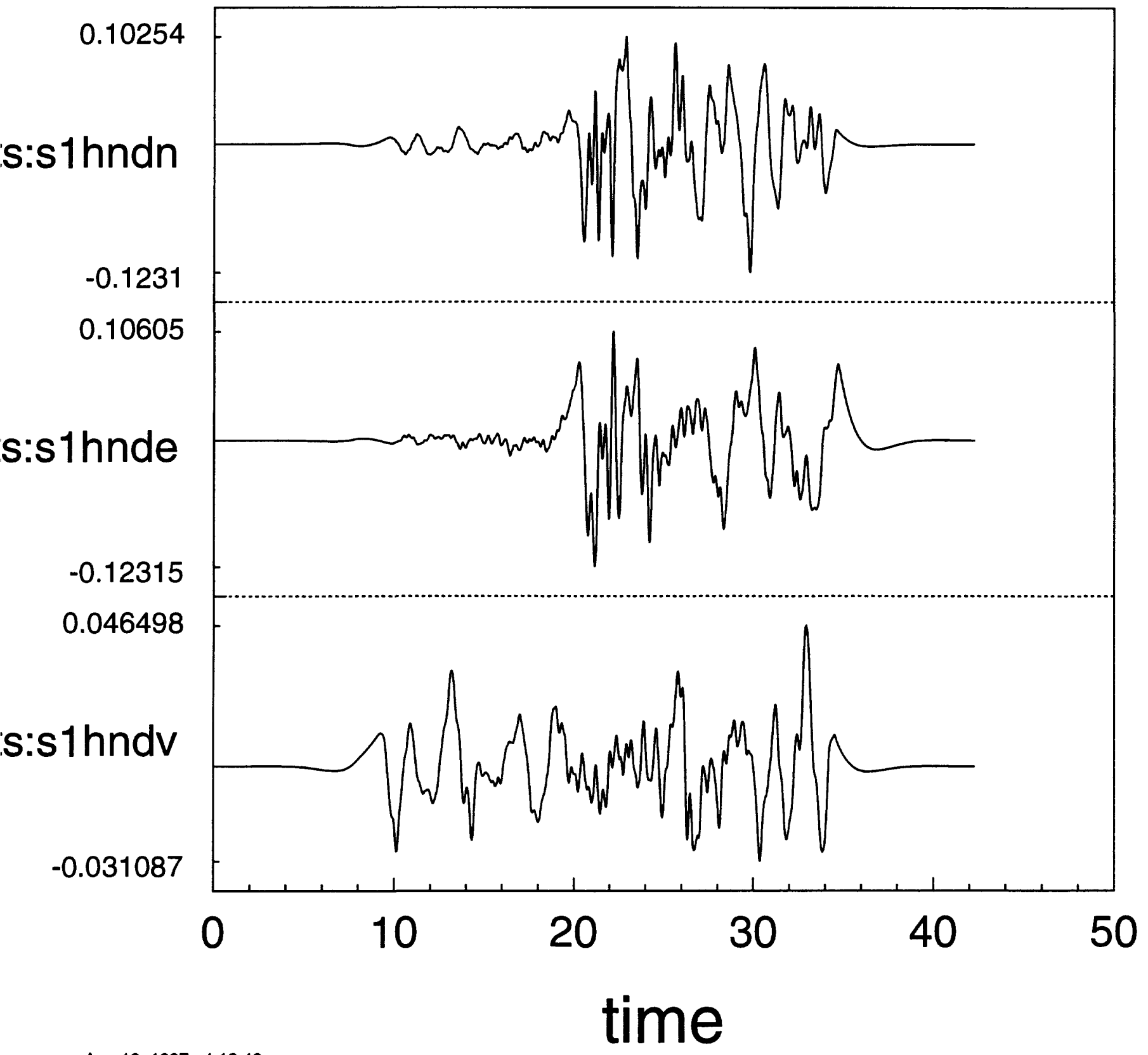

Aug 19, 1997 4:12:49 pm

C:ISEMSISBI8113TS.GRA

C:ISEMSISBI81IS1HN_3D.DT 
ts:s1vcdn

ts:s1vcde

ts:s1vedv

$-0.1214$

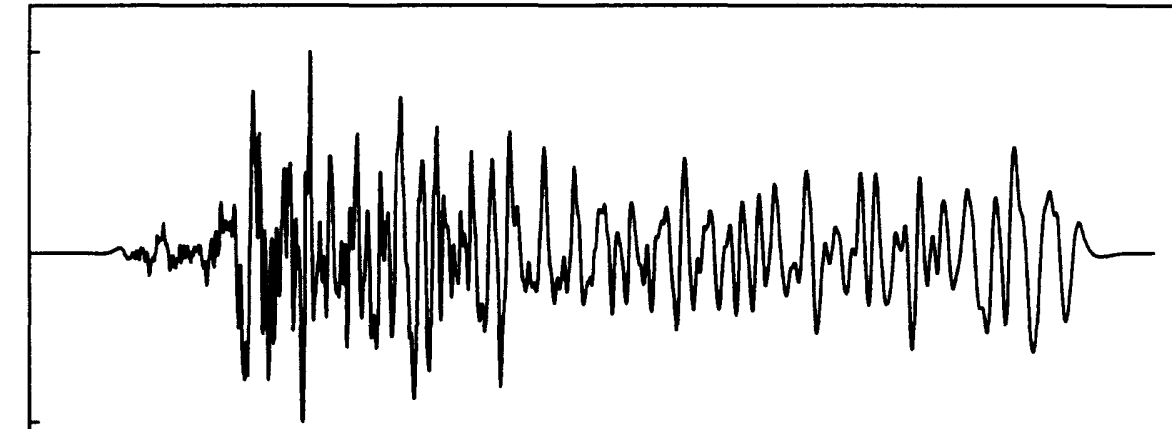

$-0.11764$

0.14735

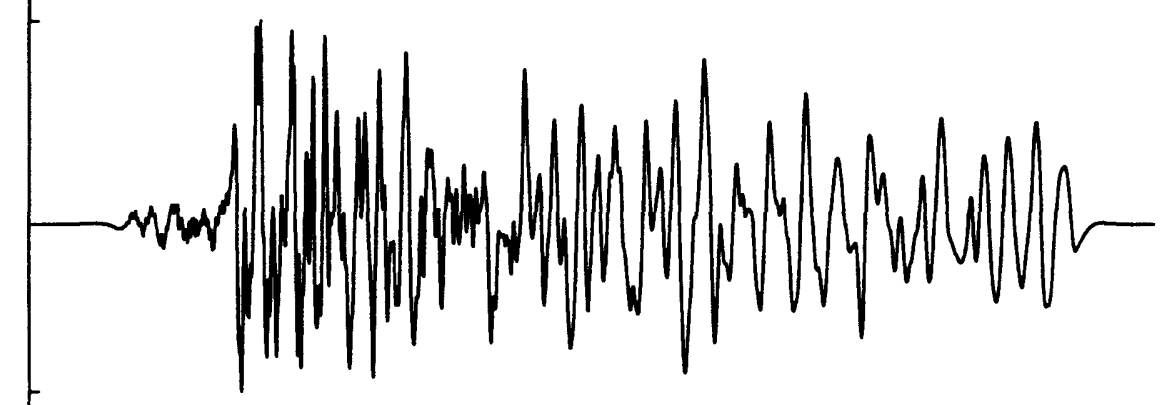

0.066579

....

$-0.054165$

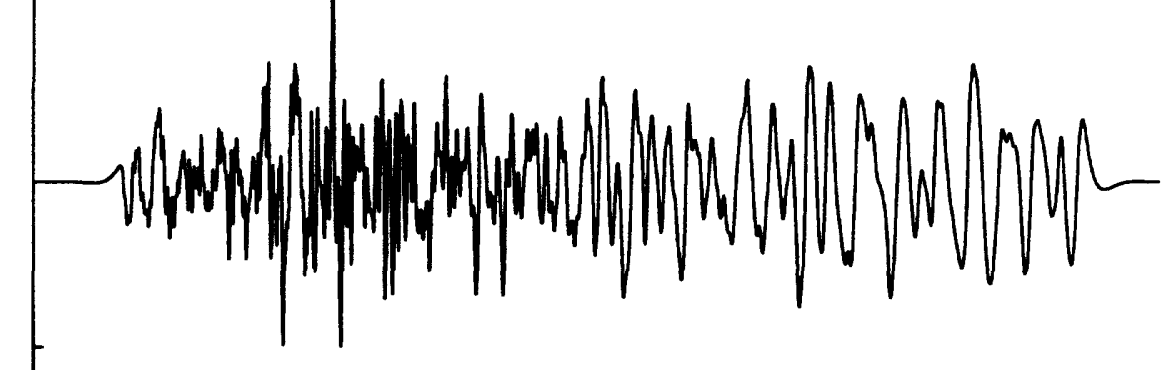

0

50

100

time

Aug 19, 1997 4:14:58 pm

C:ISEMSISBI8113TS.GRA

C:ISEMSISBI81IS1VC_3D.DT 


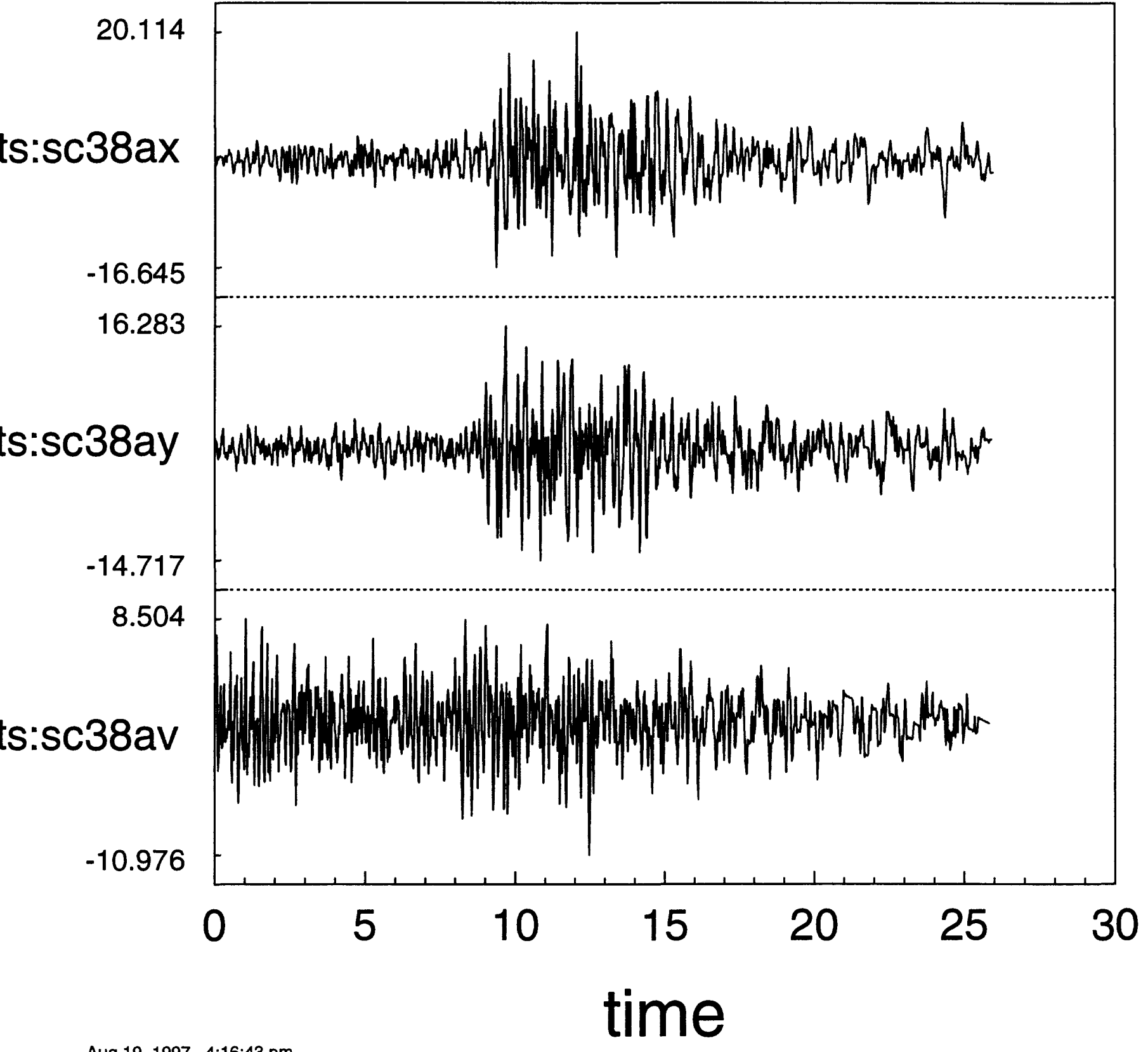

Aug 19, 1997 4:16:43 pm

C:ISEMSISBI8113TS.GRA

C:ISEMSISBI81ISC38_3A.DT 
ts:sc38vx

ts:sc38vy

ts:sc38vv

$-0.8564$

ts:sc38vv

$-0.46861$

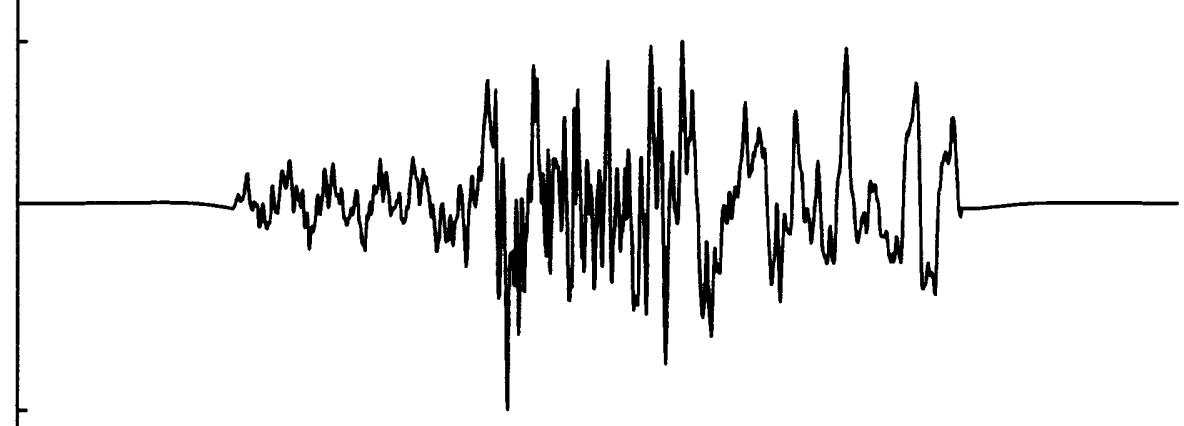

0.61304
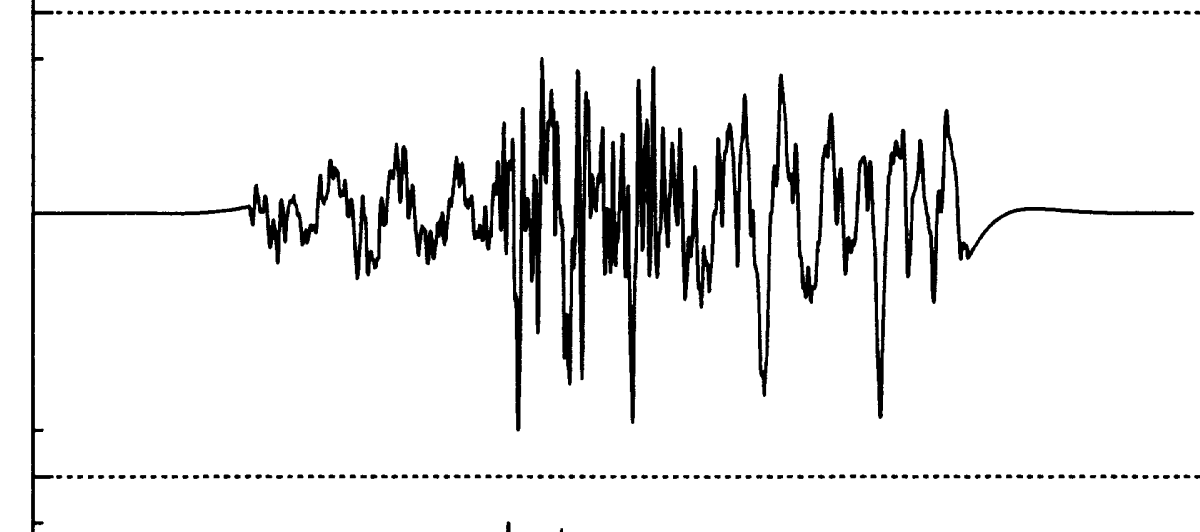


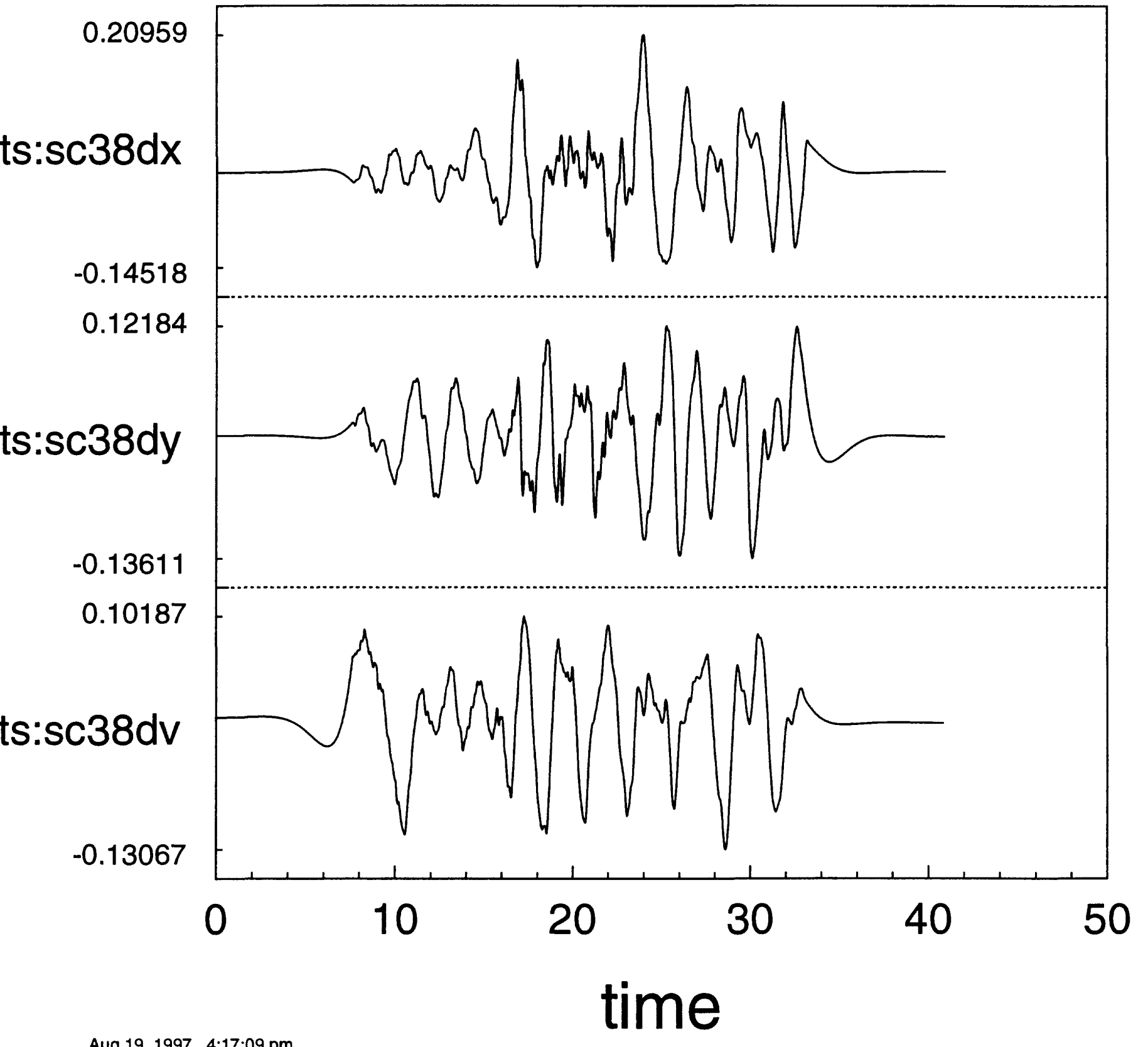

Aug 19, 1997 4:17:09 pm

C:ISEMSISBI8113TS.GRA

C:ISEMSISBI81ISC38_3D.DT 
ts:sc51vx

ts:sc51vy

0.81101
s:sc51 vV

$-1.0809$

0.81101
s:sc51 vV

$-0.71238$

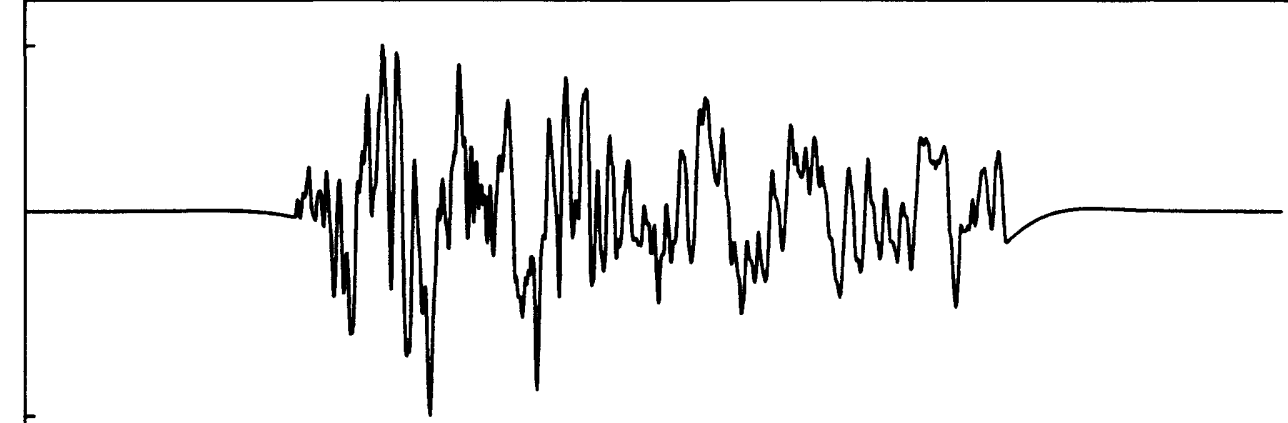

$-1.0324$

1.3241

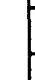

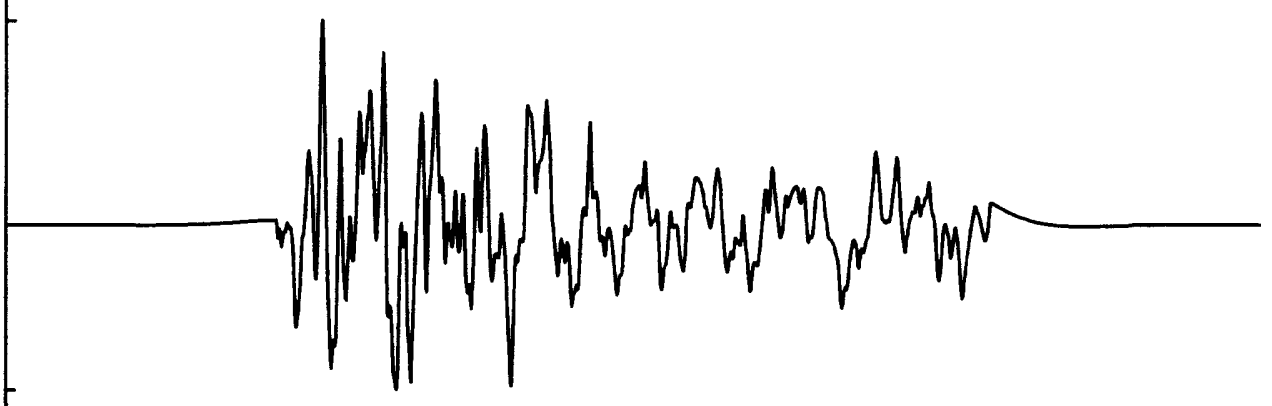

Aug 19, 1997 4:18:21 pm

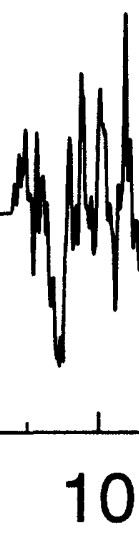

C:ISEMSISBI8113TS.GRA

C:ISEMSISBI811SC51_3V.DT 


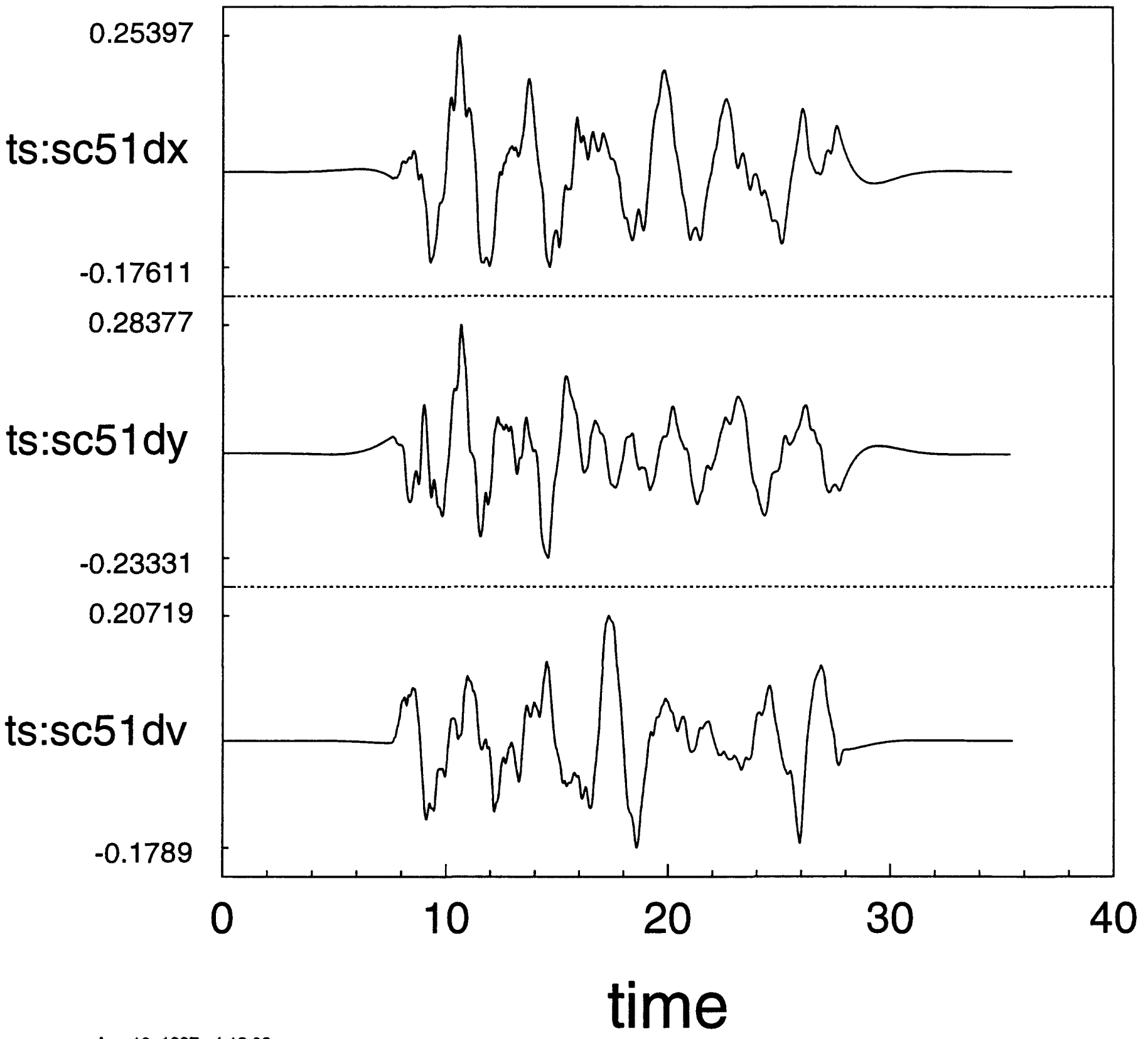

Aug 19, 1997 4:18:02 pm

C:ISEMSISBI8113TS.GRA

C:ISEMSISBI81ISC51_3D.DT 
ts:s2lbvx

ts:s2lbvy

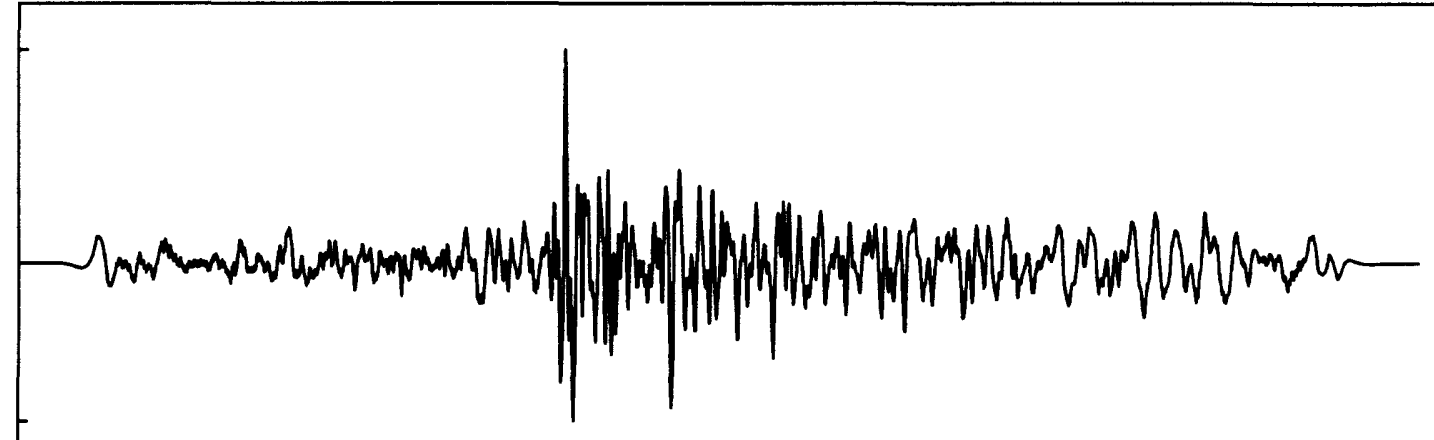

$-1.3014$

0.84291

$-0.9628$

0.2669

ts:s2lbvz

$-0.21839$
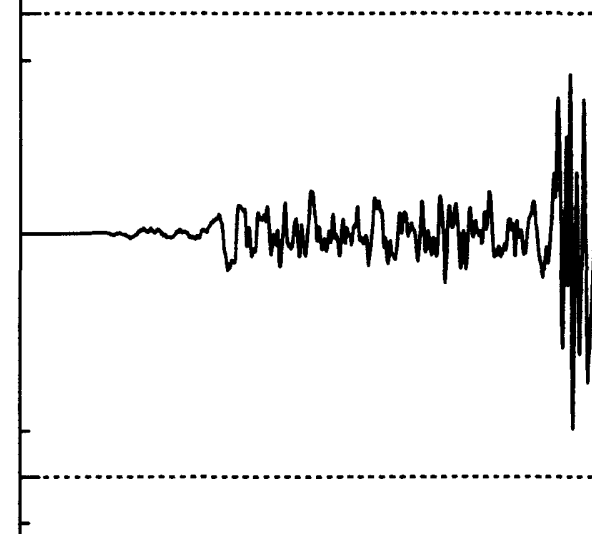

Aug 19, 1997 4:21:26 pm

time

C:ISEMSINPALM8613TS.GRA

C:ISEMSINPALM86IS2LB_3V.DT 


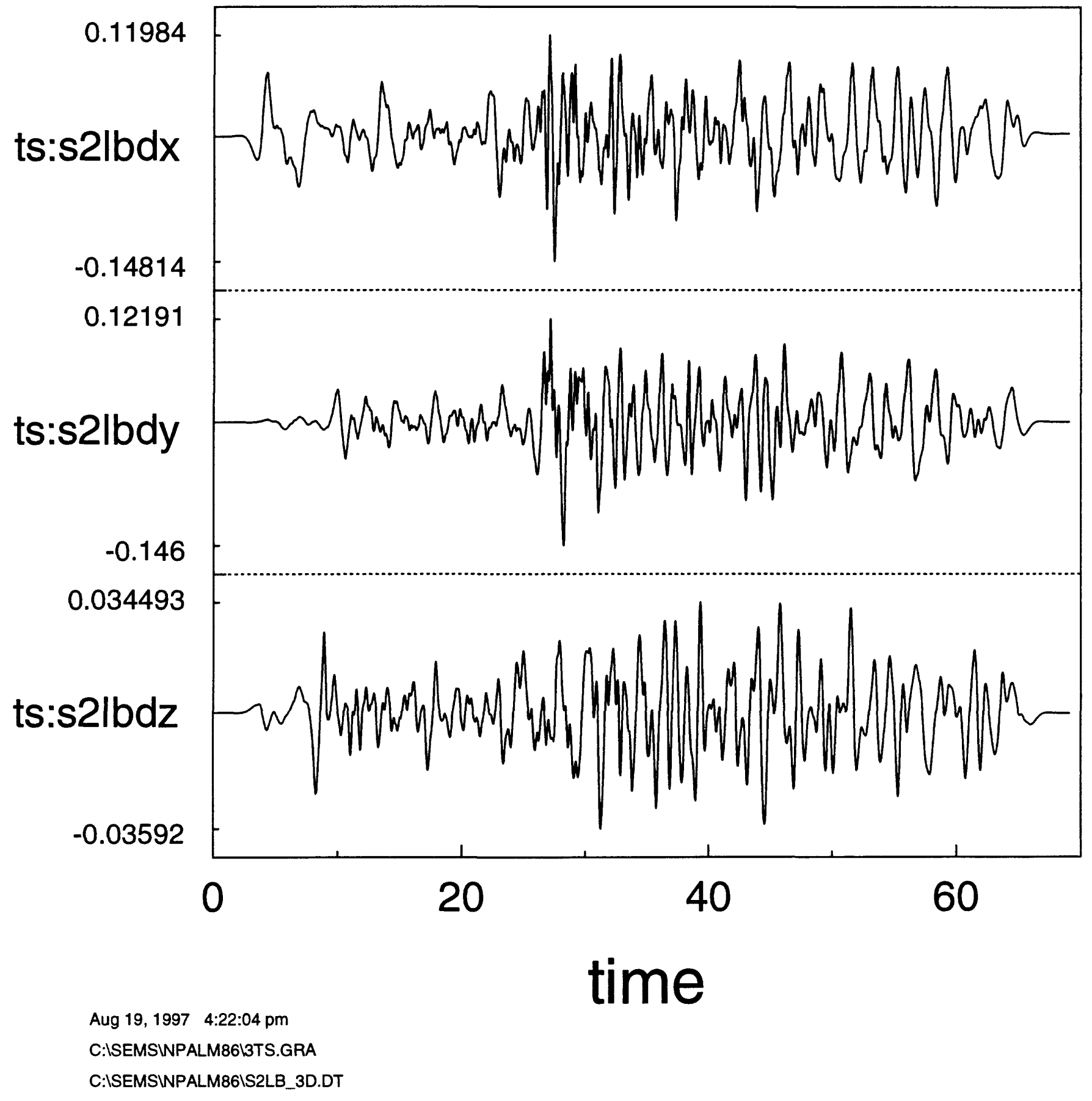




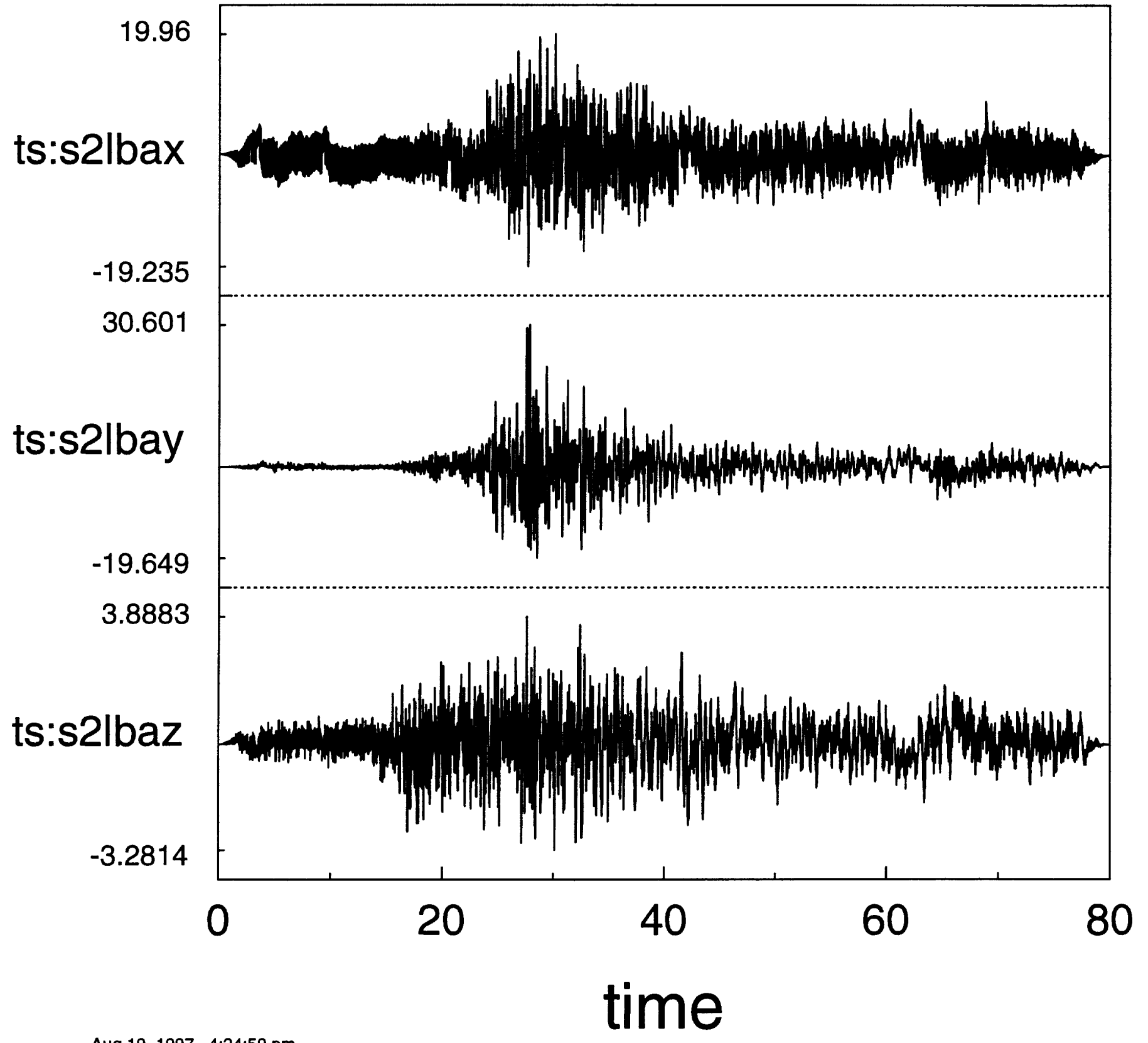

Aug 19, 1997 4:24:59 pm

C:ISEMSIOCNSID8613TS.GRA

C:ISEMSIOCNSID86IS2LB_3A.DT 


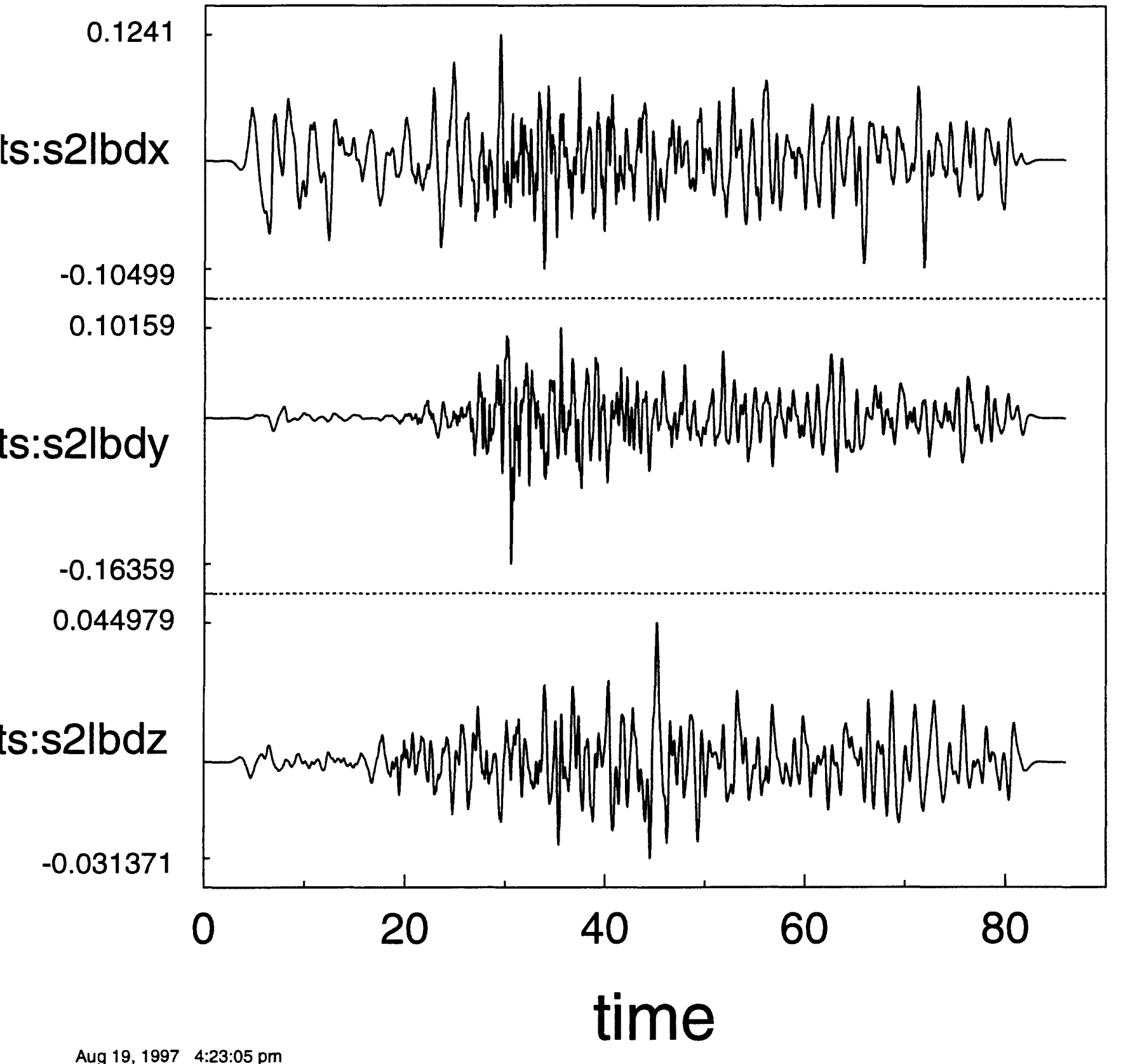

C:ISEMSIOCNSID8613TS.GRA

C:ISEMSIOCNSID86IS2LB_3D.DT 


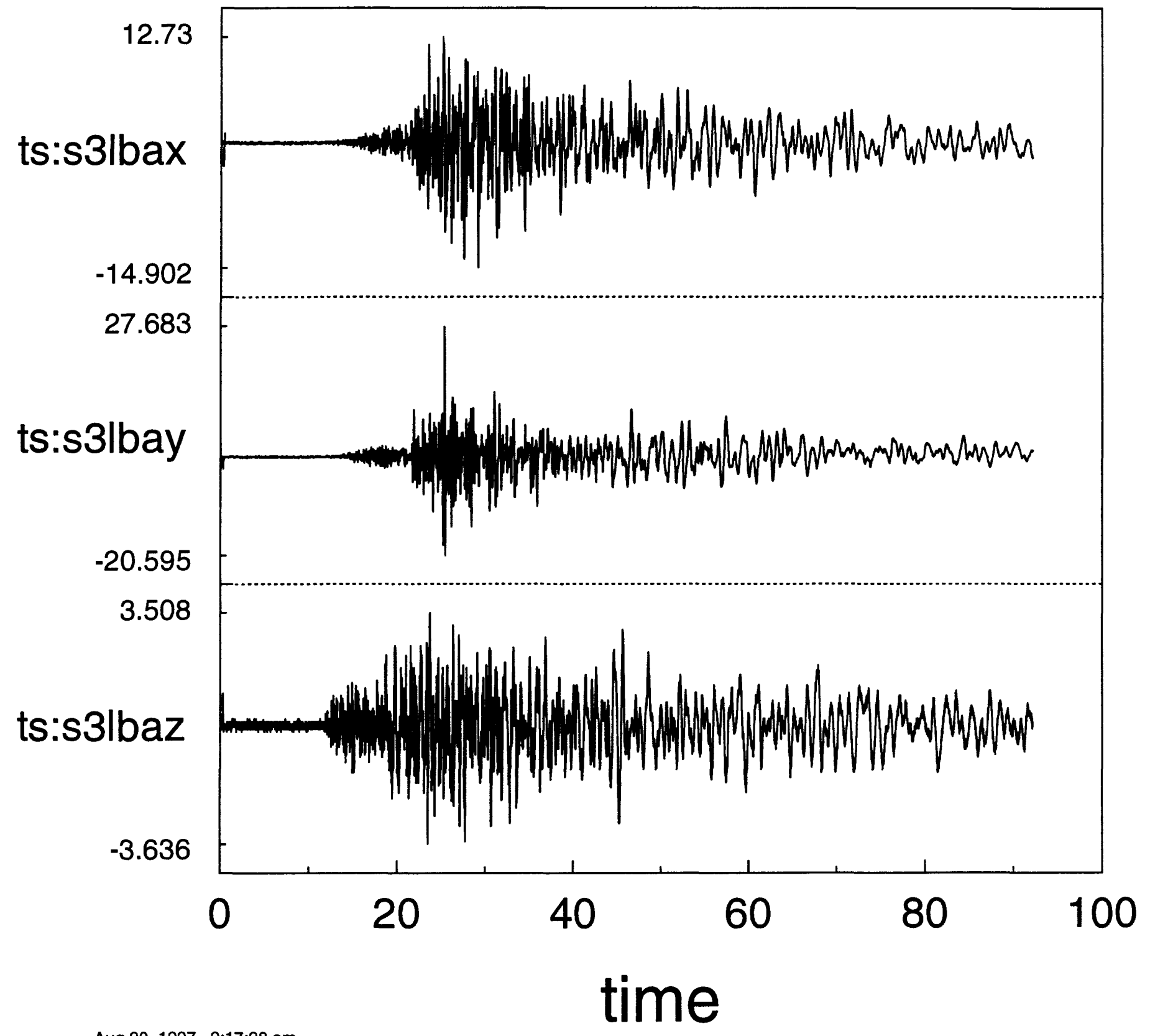

Aug 20, 1997 9:17:28 am

C:ISEMSIUPLAND9013TS.GRA

C:ISEMSIUPLAND90IS3LB_3A.DT 


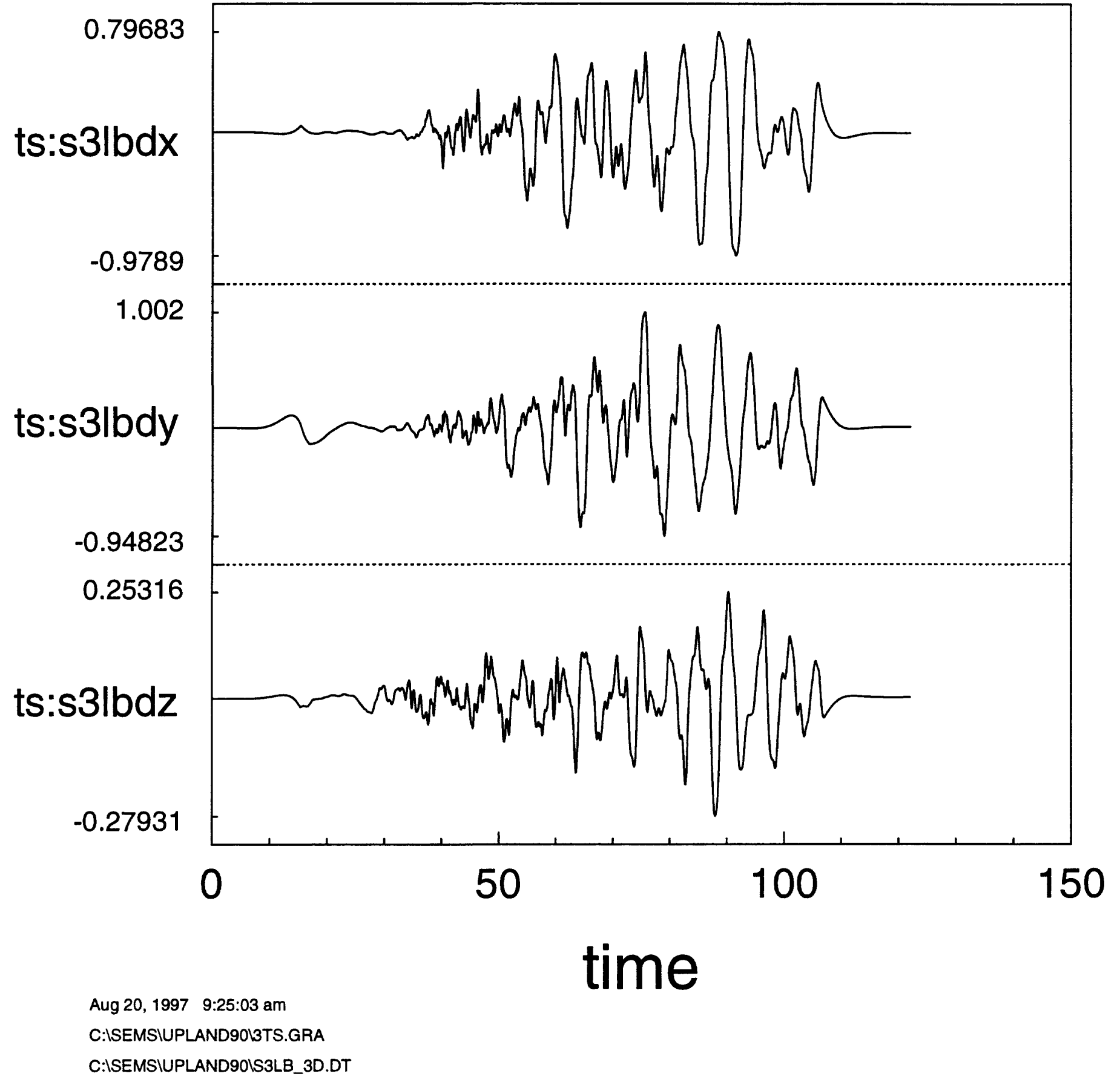




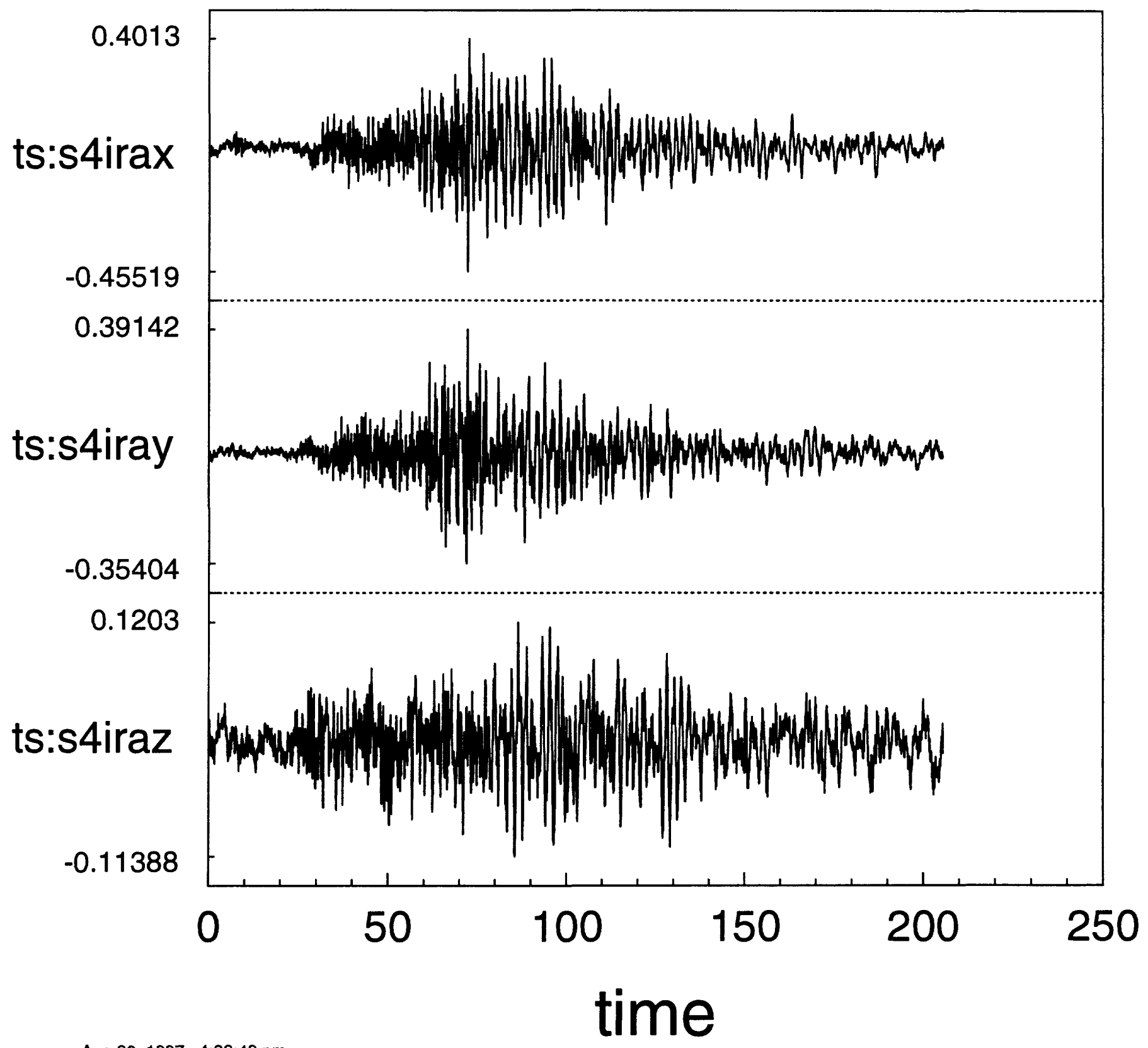

Aug 20, 1997 4:32:49 pm

C:ISEMSIRC95I3TS.GRA

C:ISEMSIRC95IS4IR_3A.DT 


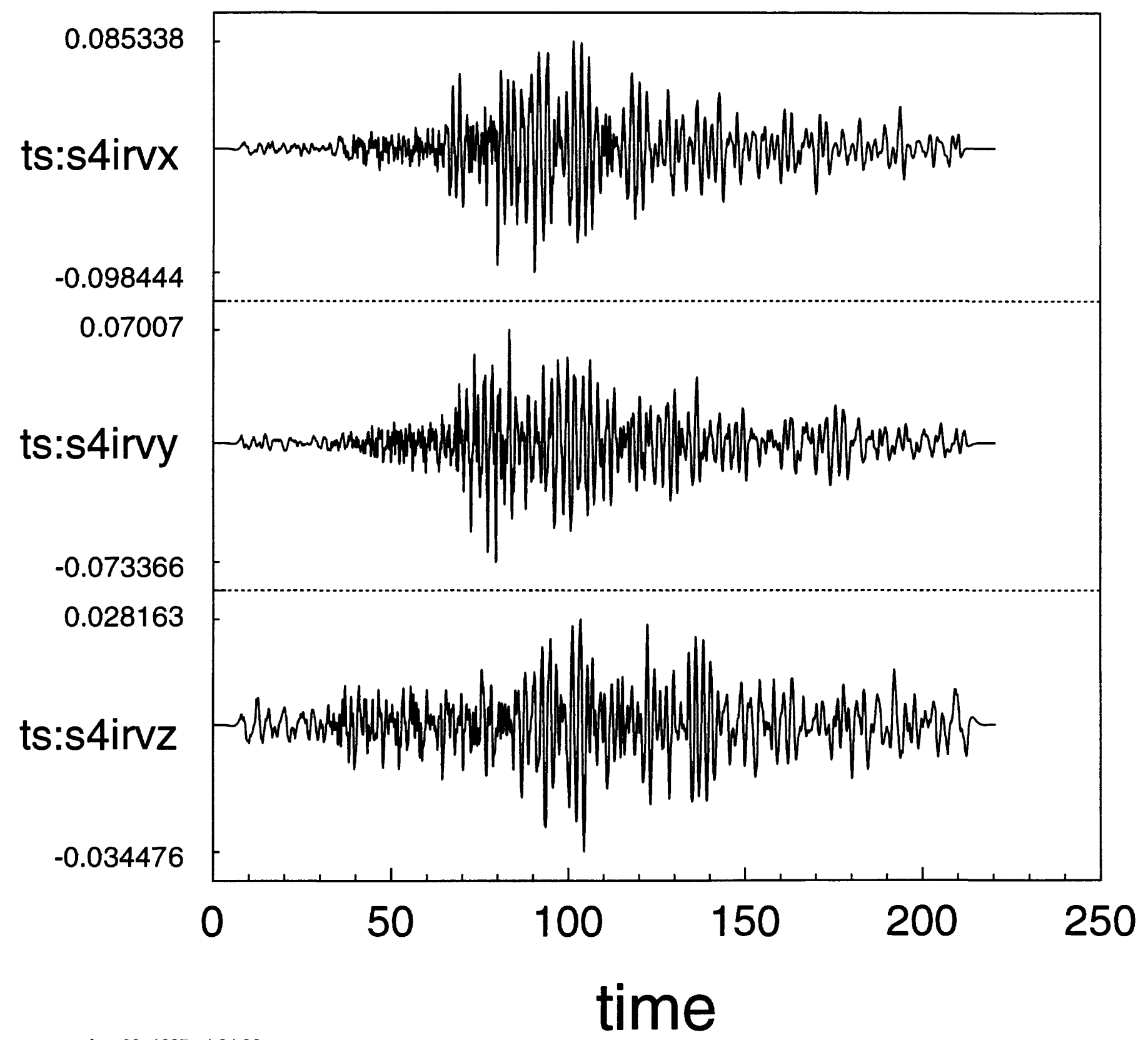

Aug 20, 1997 4:34:09 pm

C:ISEMSIRC95I3TS.GRA

C:ISEMSIRC95IS4IR_3V.DT 


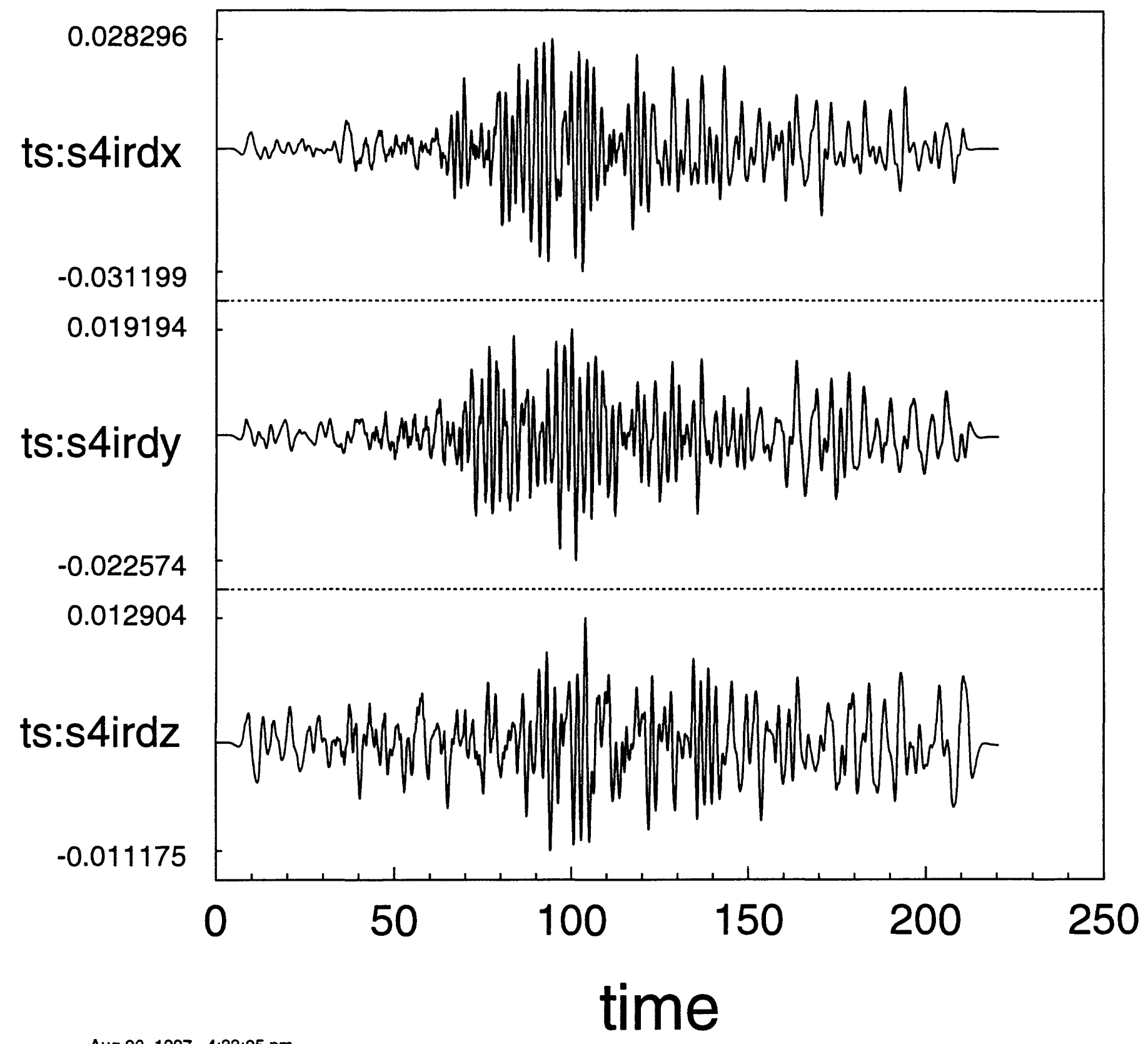

Aug 20, 1997 4:33:25 pm

C:ISEMSIRC95I3TS.GRA

C:ISEMSIRC95IS4IR_3D.DT 

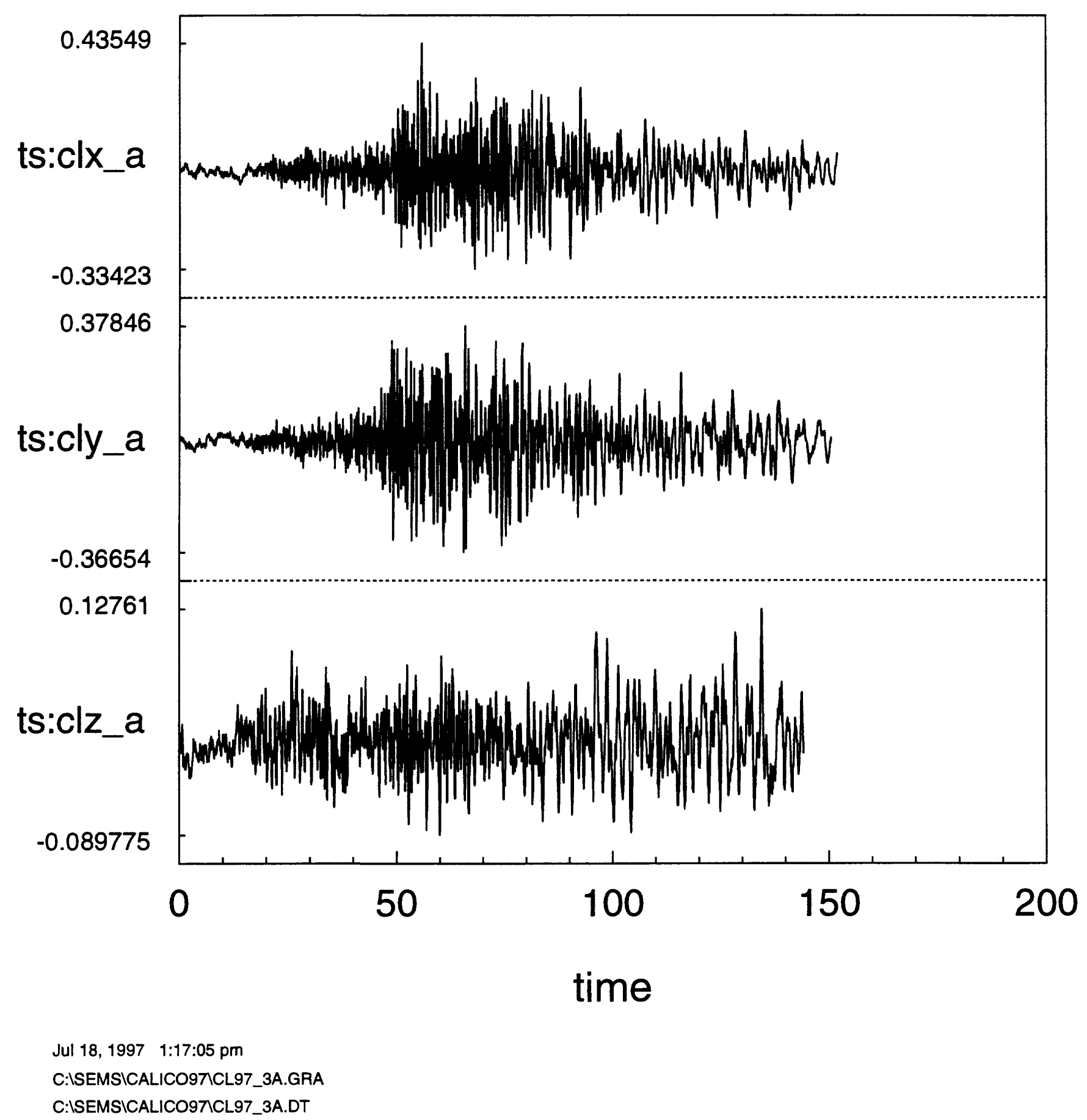


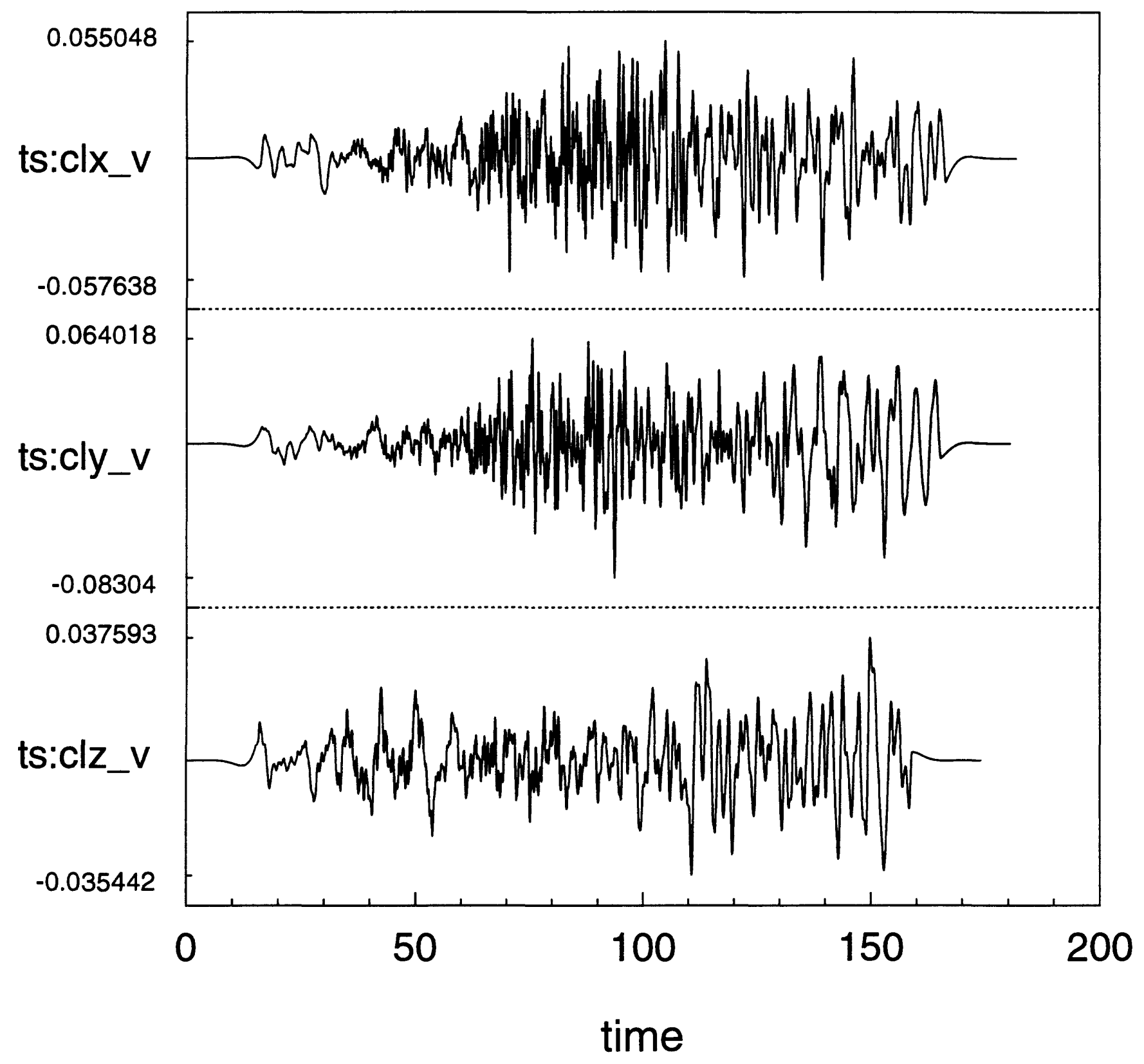

Jul 18, 1997 1:18:17 pm

C:ISEMSICALICO97ICL97_3V.GRA

C:ISEMSICALICO97ICL97_3V.DT 


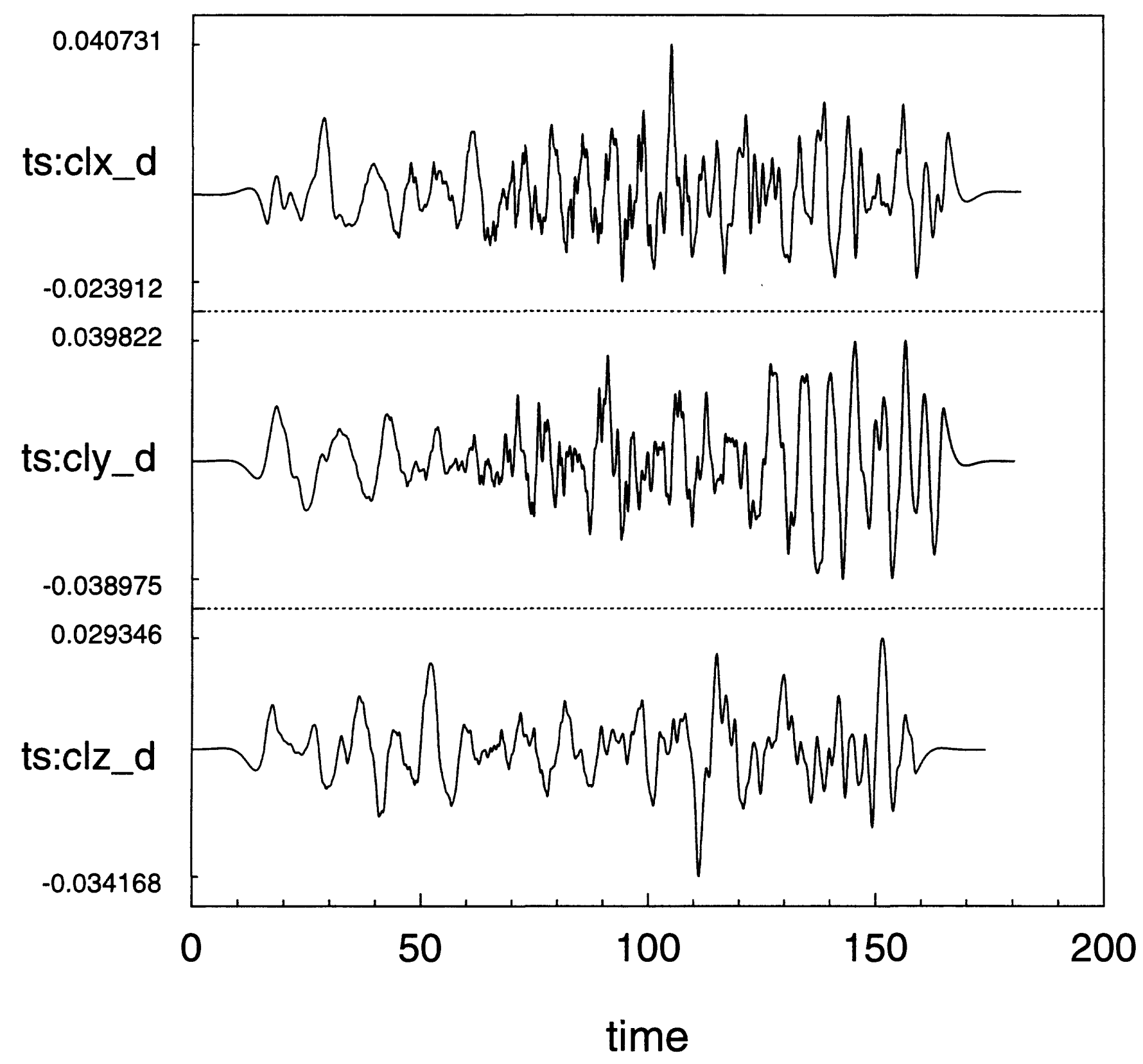

Jul 18, 1997 1:17:32 pm

C:ISEMSICALICO97ICL97_3D.GRA

C:ISEMSICALICO97ICL97_3D.DT 


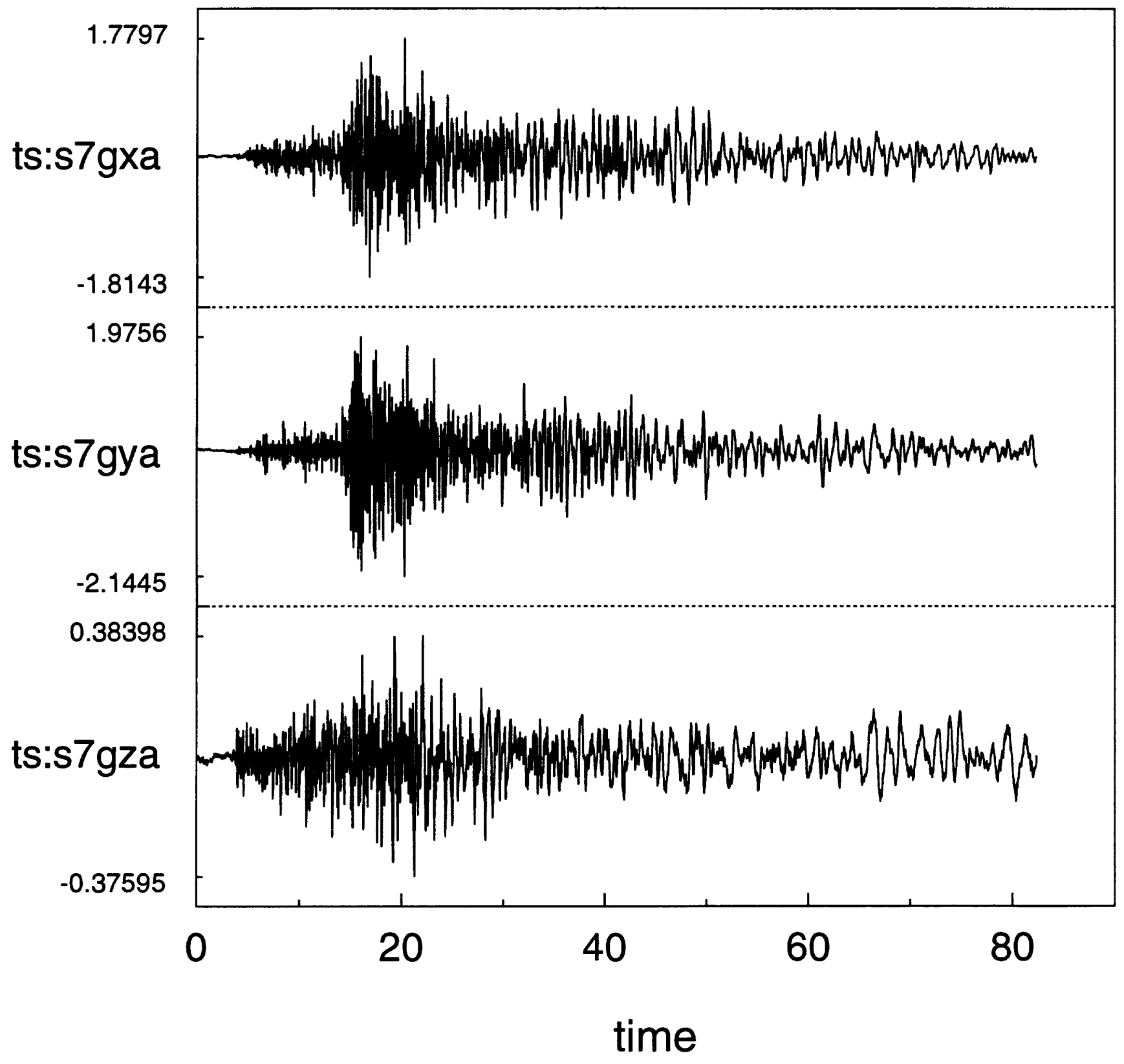

Jul 18, 1997 1:18:53 pm

C:ISEMSISIMI97AIS97A_3AG.GRA

C:ISEMSISIMI97AIS7AG_3A.DT 


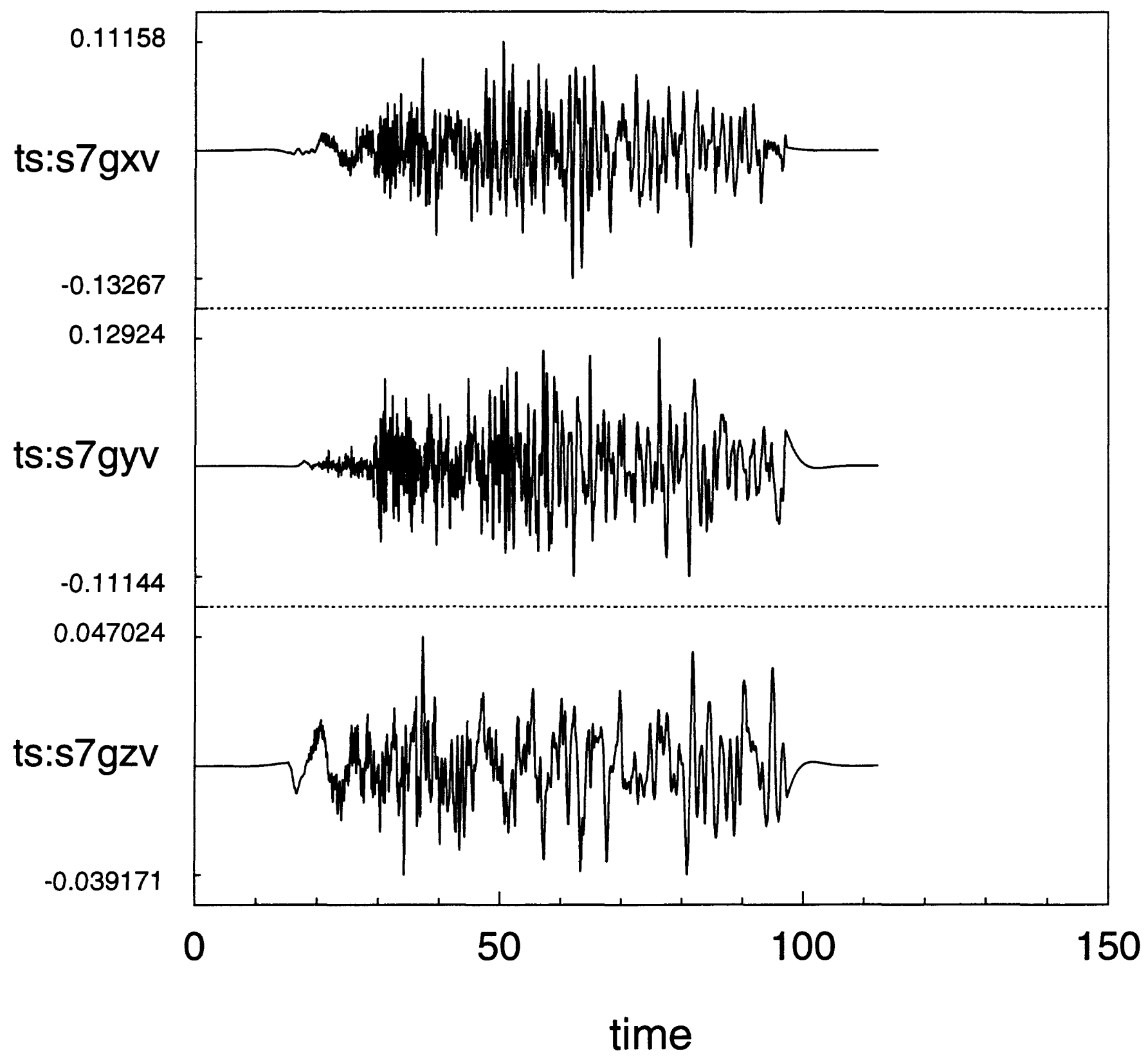

Jul 18, 1997 1:22:23 pm

C:ISEMSISIMI97AIS97A_3VG.GRA

C:ISEMSISIMI97AIS7AG_3V.DT 


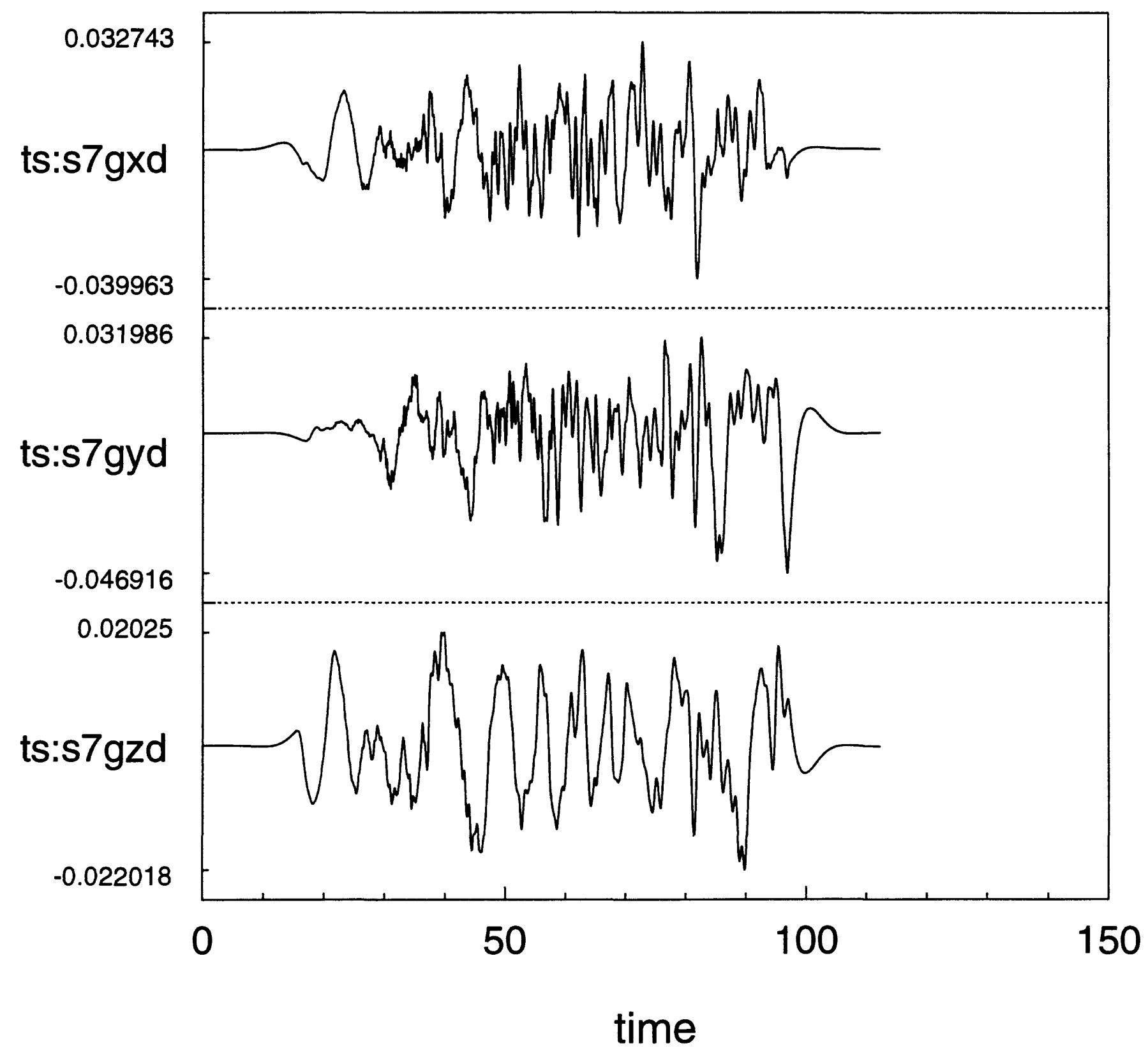

Jul 18, 1997 1:20:06 pm

C:ISEMSISIMI97AIS97A_3DG.GRA

C:ISEMSISIMI97AIS7AG_3D.DT 


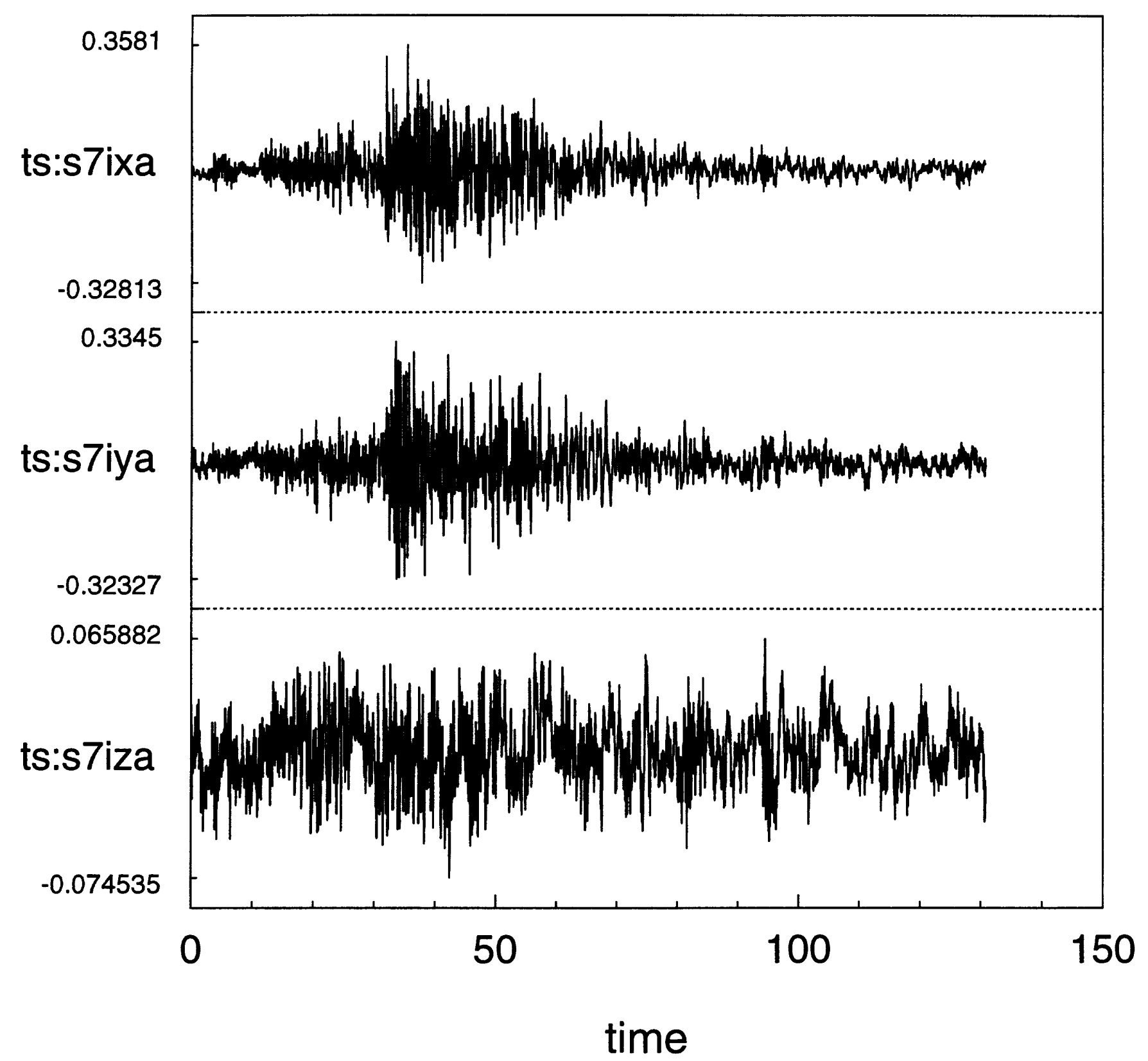

Jul 18, 1997 1:19:25 pm

C:ISEMSISIMI97AIS97A_3AI.GRA

C:ISEMSISIMI97AIS7AI_3A.DT 


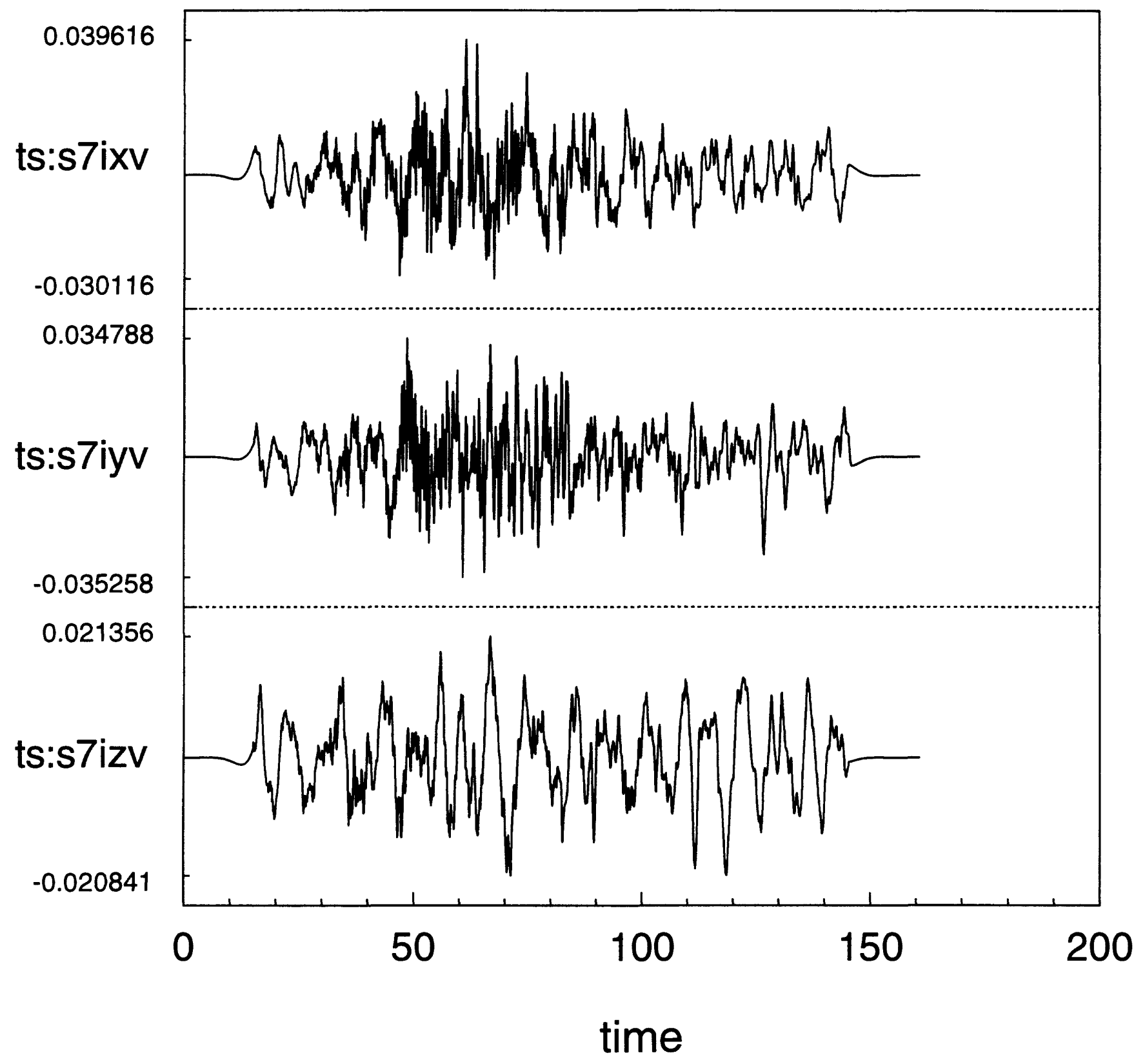

Jul 18, $1997 \quad$ 1:22:59 pm

C:ISEMSISIMI97AIS97A_3VI.GRA

C:ISEMSISIMI97AIS7AI_3V.DT 


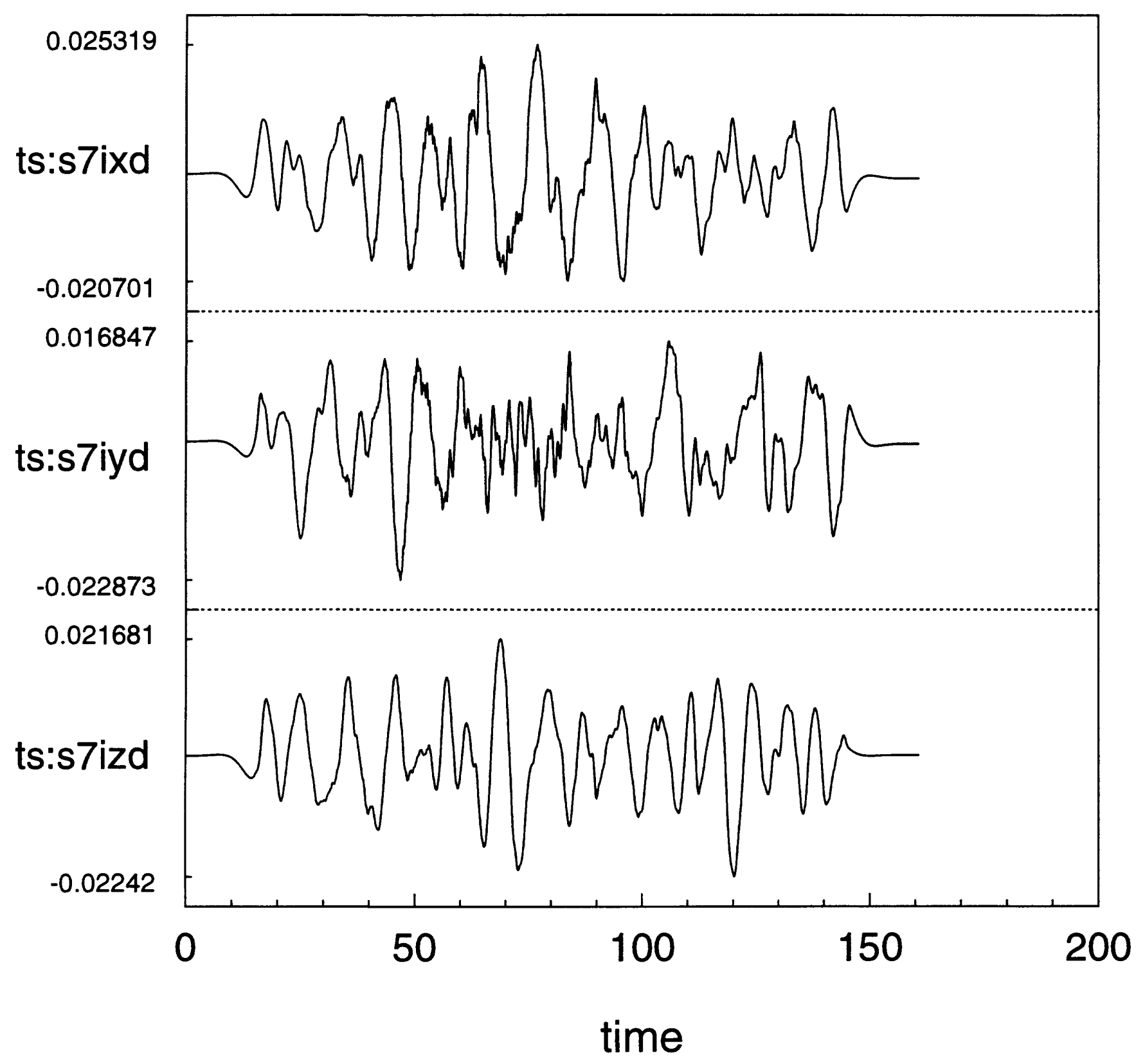

Jul 18, 1997 1:20:45 pm

C:ISEMSISIMI97AIS97A_3DI.GRA

C:ISEMSISIMI97AIS7AI_3D.DT 


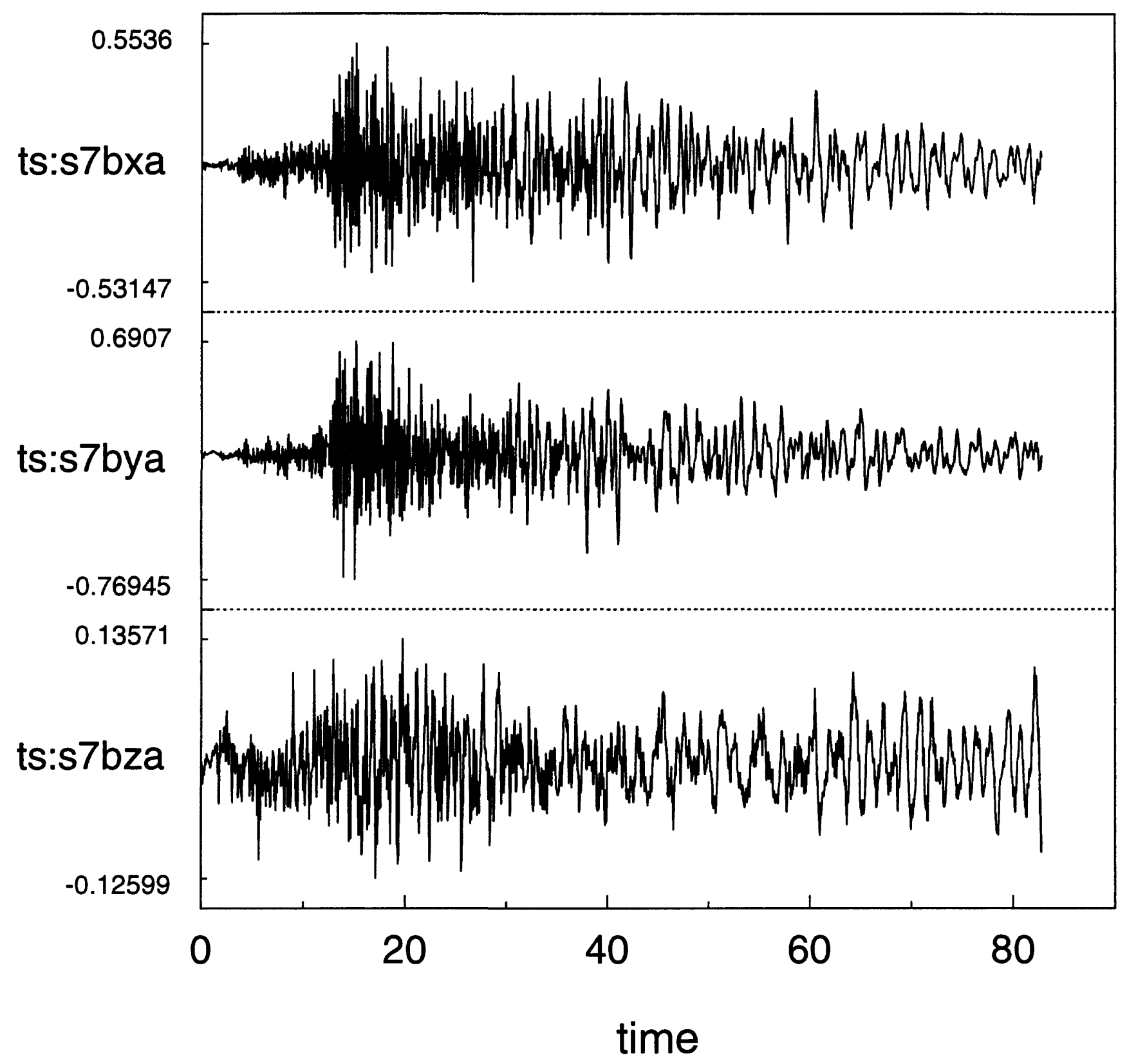

Jul 18, 1997 1:24:02 pm

C:ISEMSISIMI97BIS97B_3A.GRA

C:ISEMSISIMI97BIS97B_3A.DT 


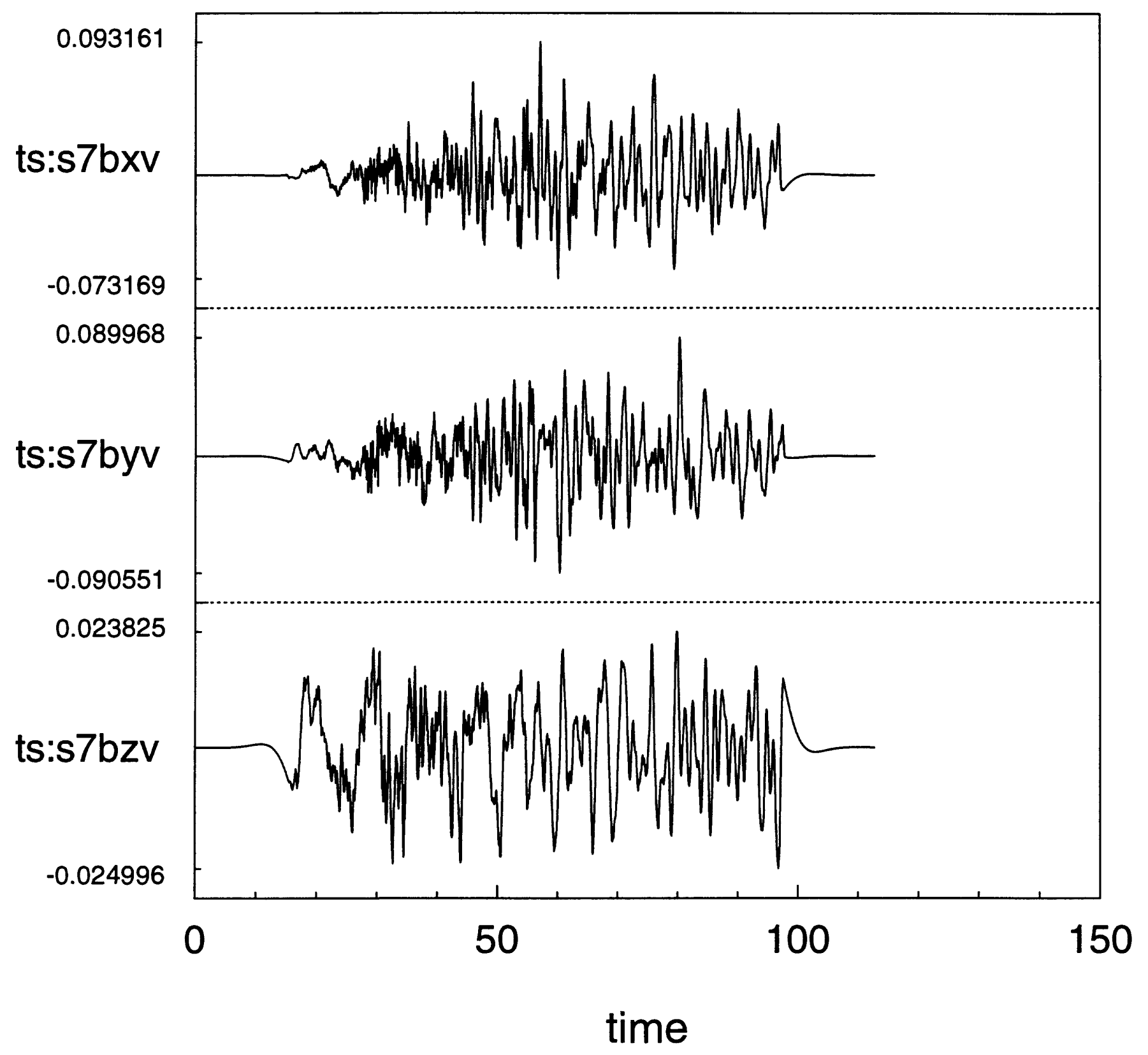

Jul 18, 1997 1:25:03 pm

C:ISEMSISIMI97BIS97B_3V.GRA

C:ISEMSISIMI97BIS97B_3V.DT 


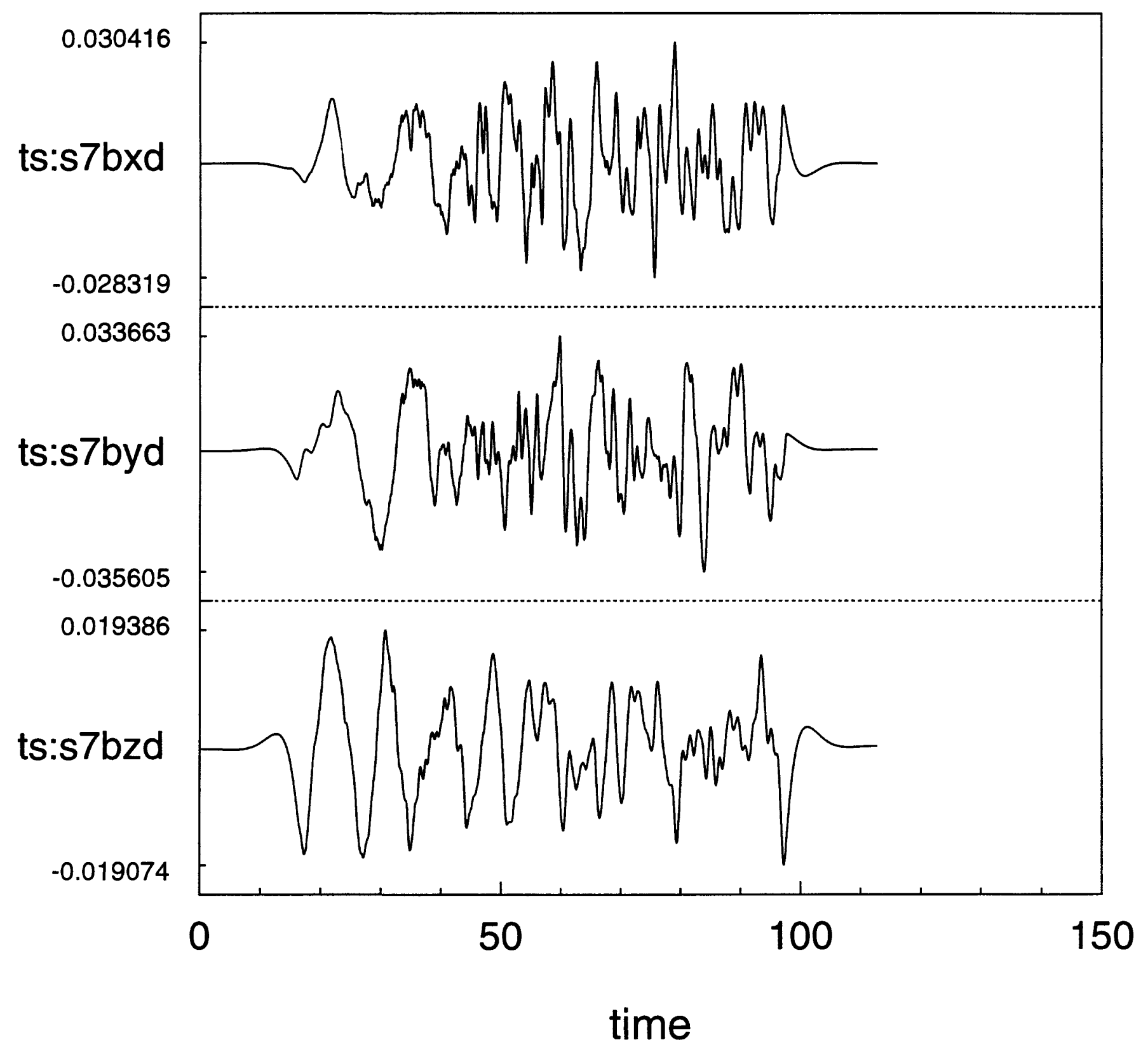

Jul 18, 1997 1:24:21 pm

C:ISEMSISIMI97BIS97B_3D.GRA

C:ISEMSISIMI97BIS97B_3D.DT 


\section{APPENDIX B - LISTINGS OF DIRECTORY CONTENTS}

The following pages contain listings of the contents of the various directories used in this project. The first 2 pages contain the contents of the root directory ( $\backslash$ SEMS) and the

following pages are the contents of the subdirectories, arranged alphabetically. 


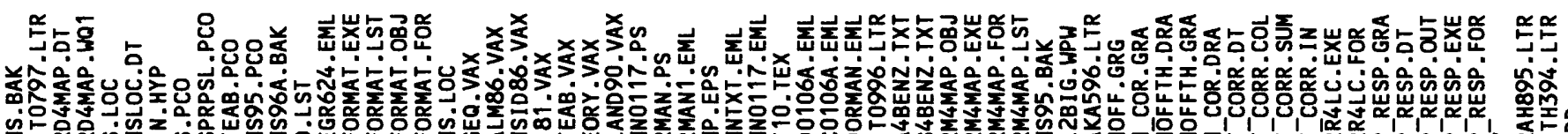

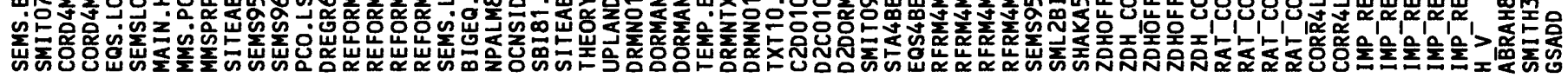

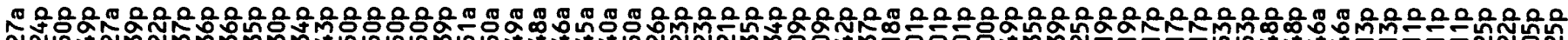
NNn์ Nm Nmmmmm

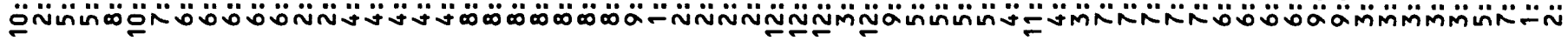

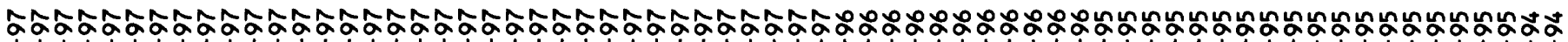

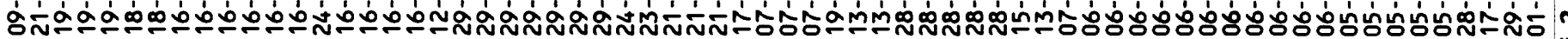

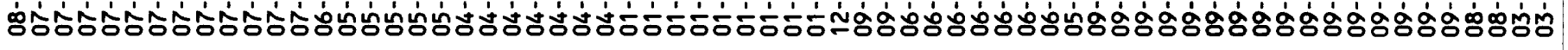

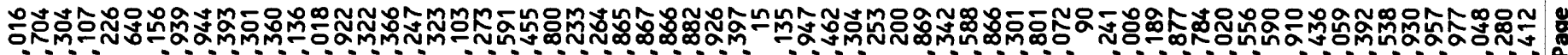

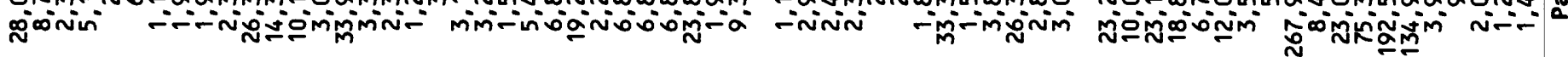

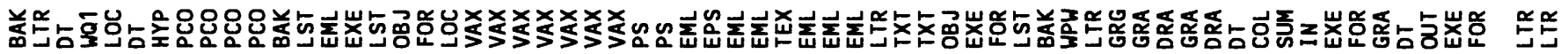

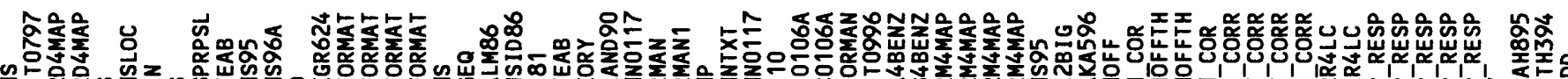
出

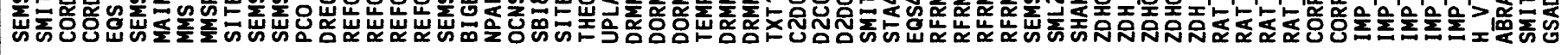

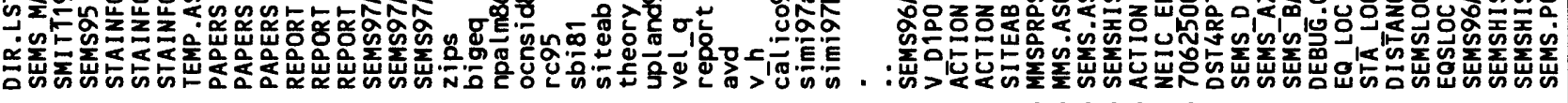

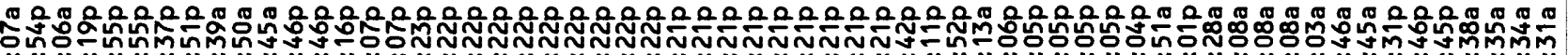

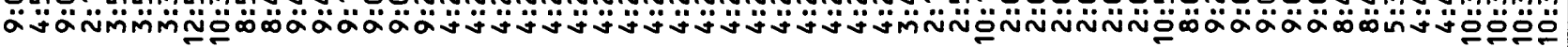

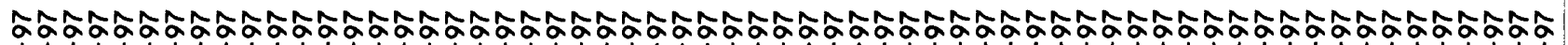

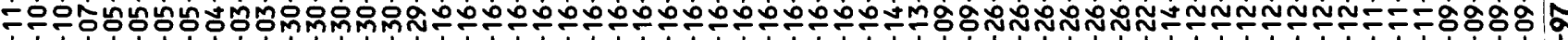

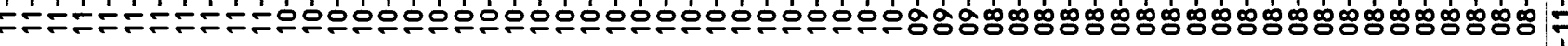

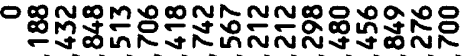

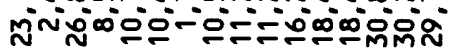

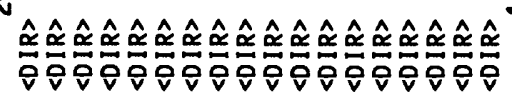

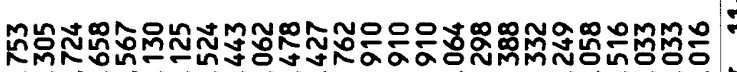

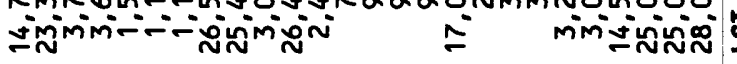

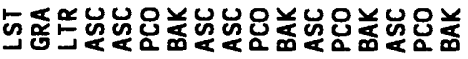

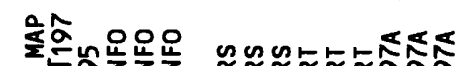

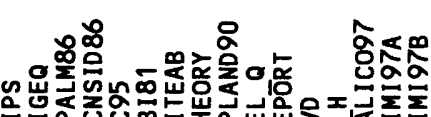

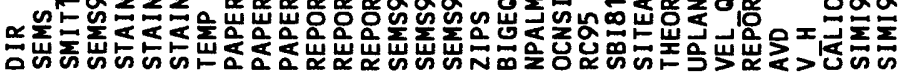

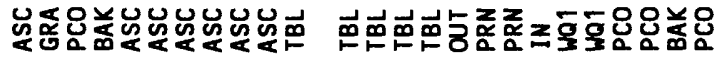

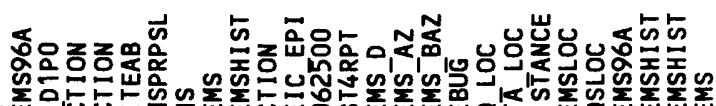

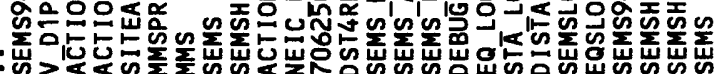




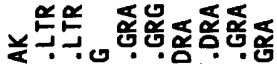

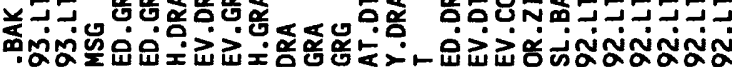

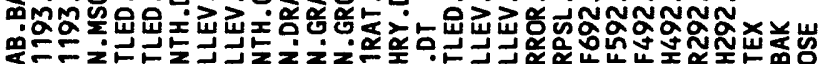

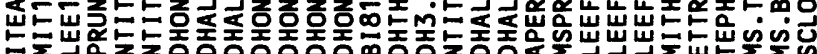

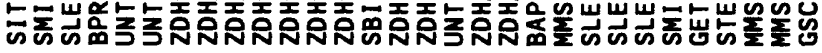

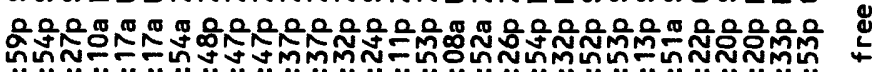

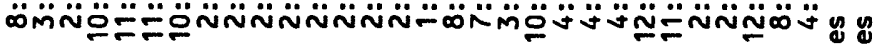

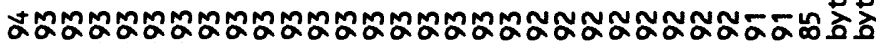

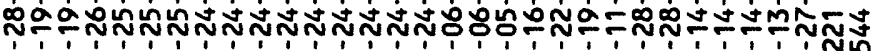

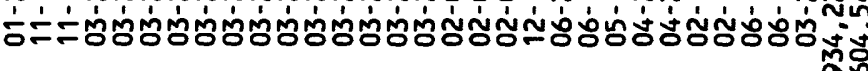

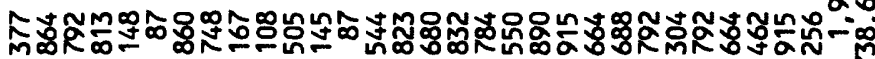

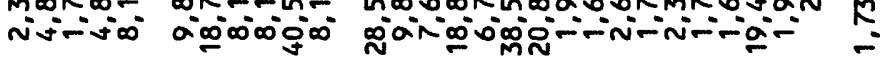

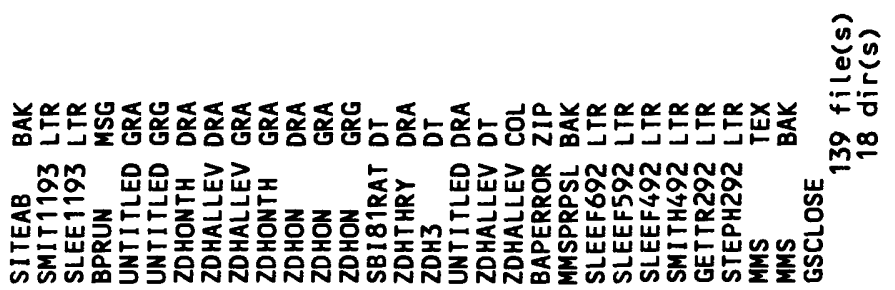




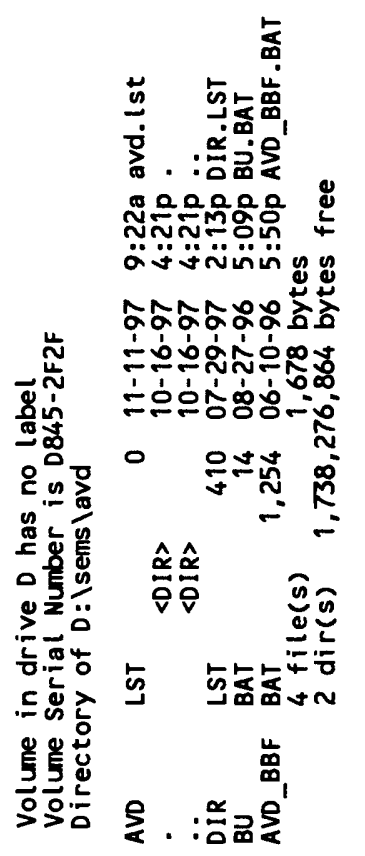




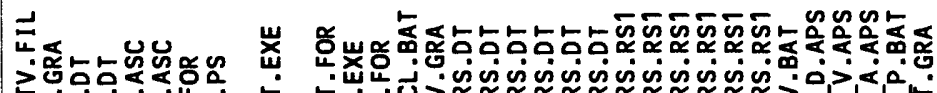

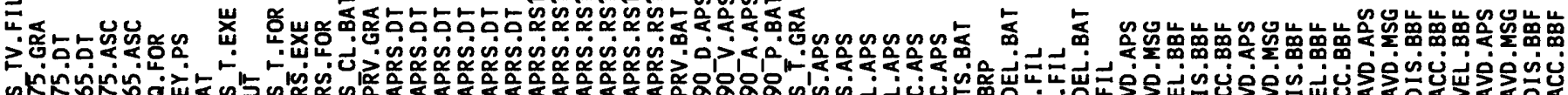

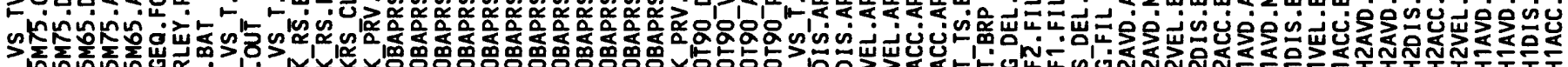

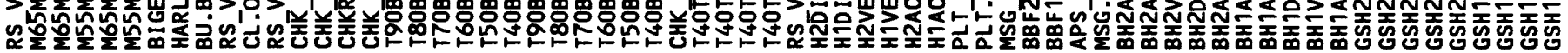

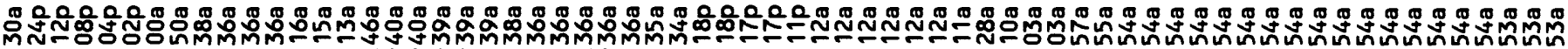

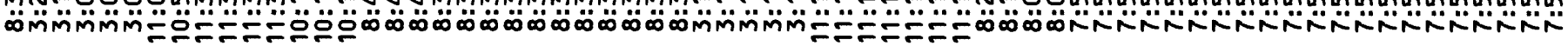

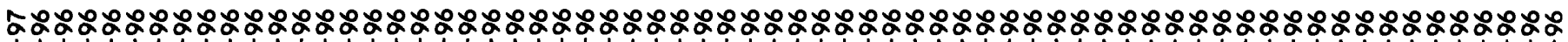

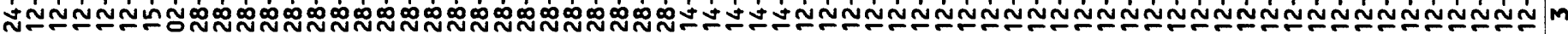

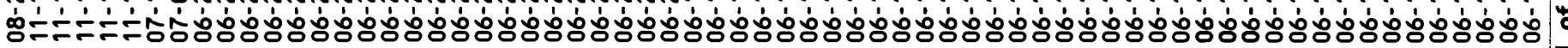

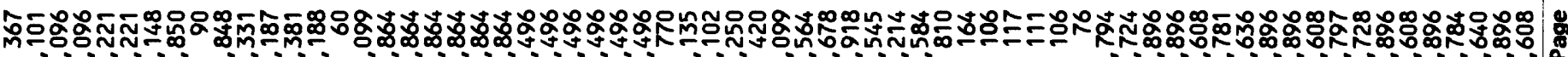
Nivinjo

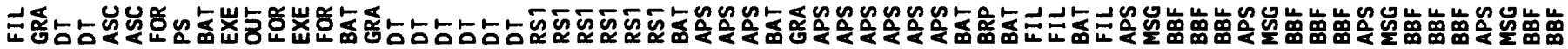

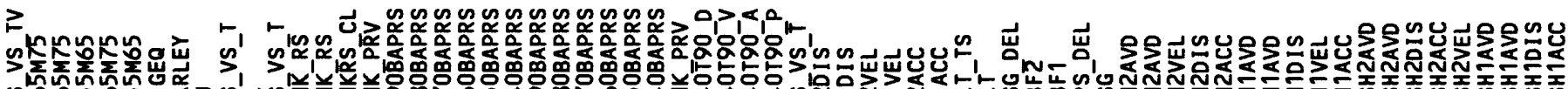

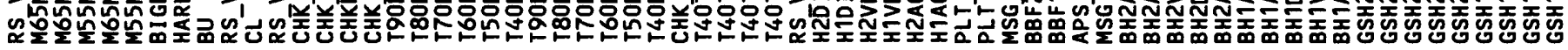

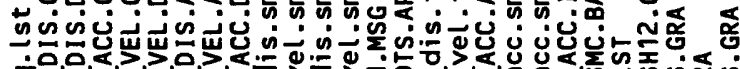
g.

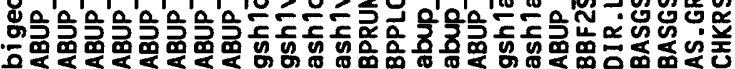

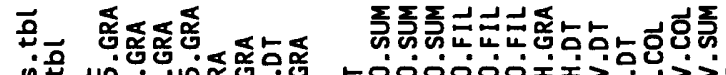

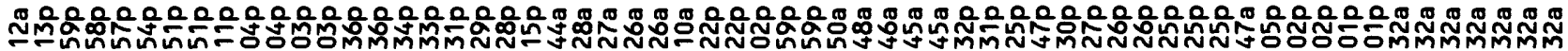

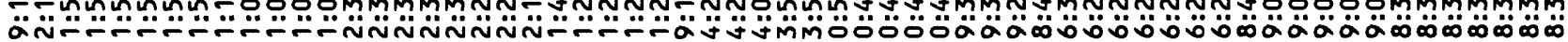

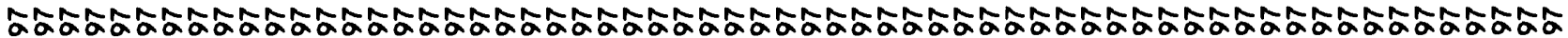

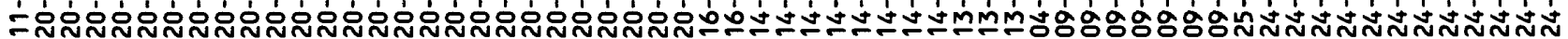

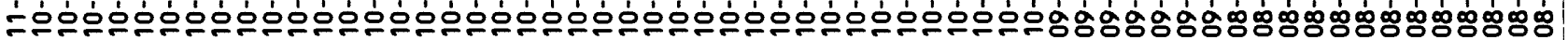

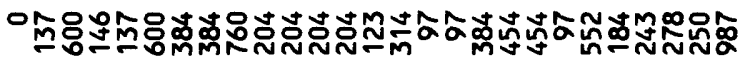

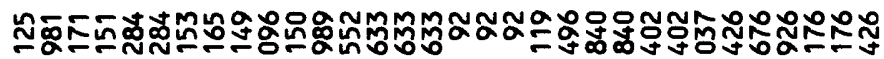

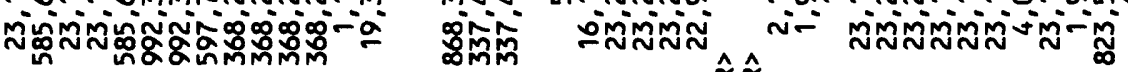
䰷余

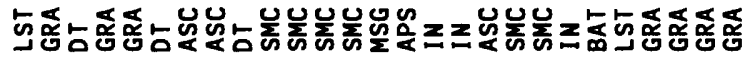

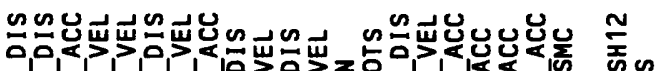

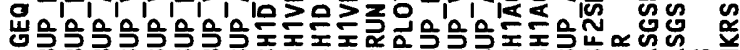

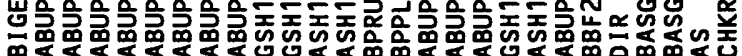

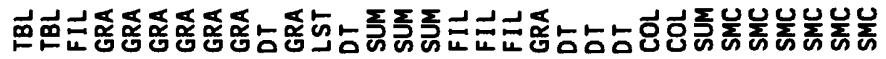

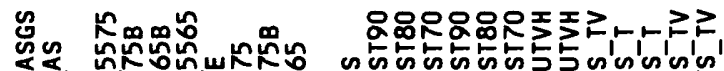

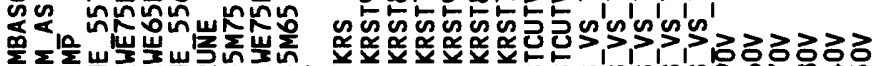




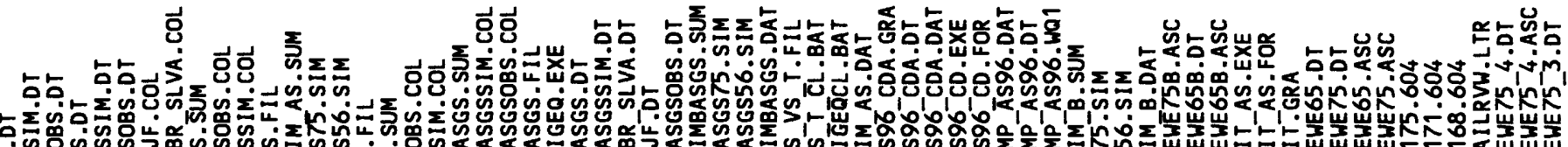

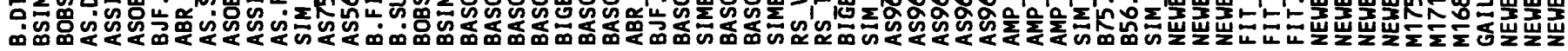

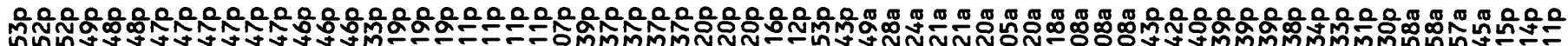

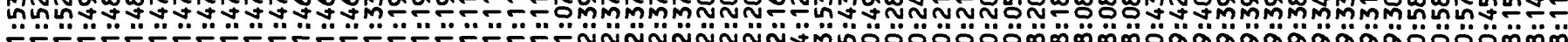

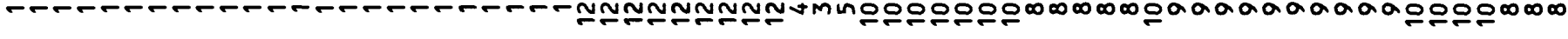

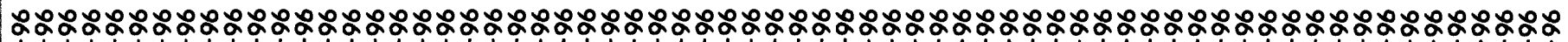

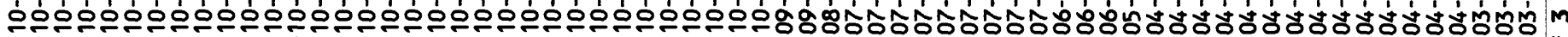

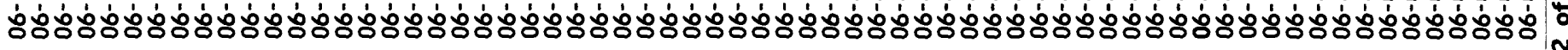

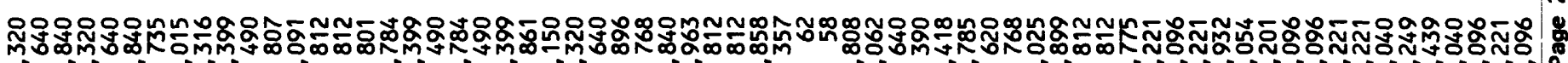

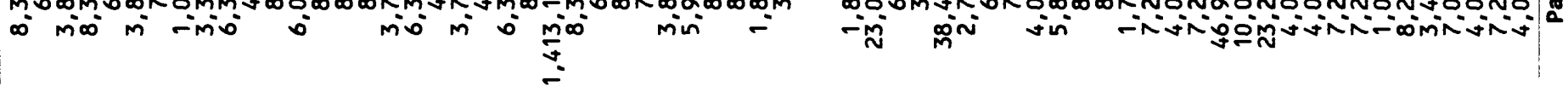

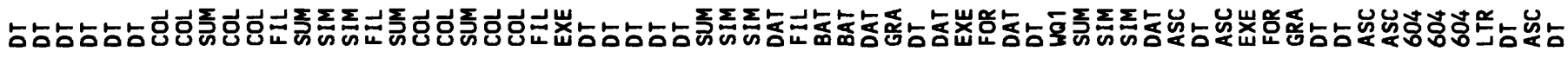

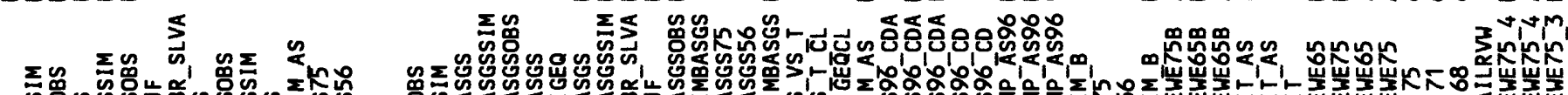

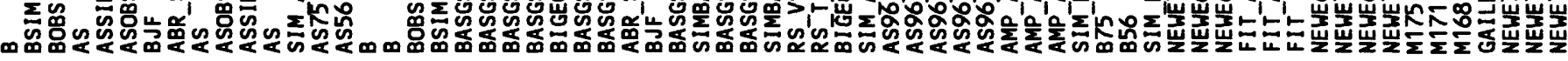

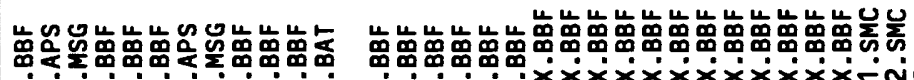
सं९ु

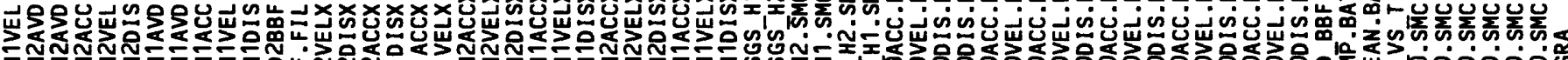

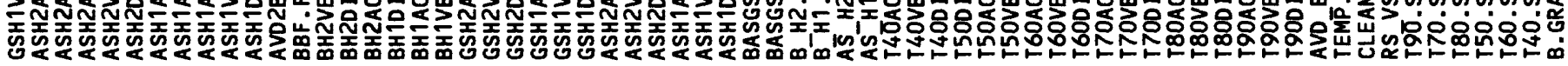

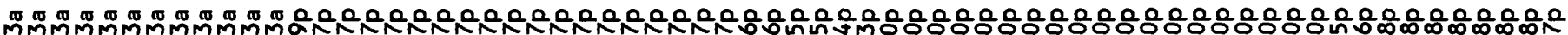

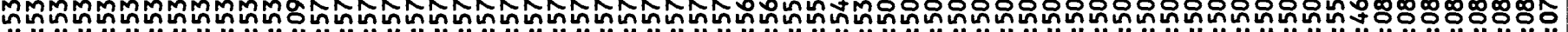

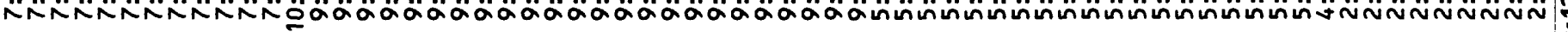

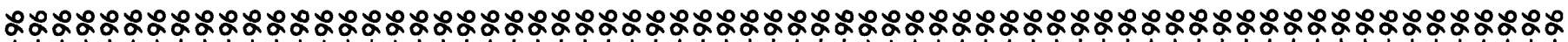

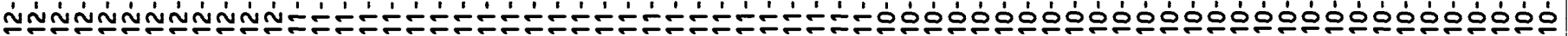

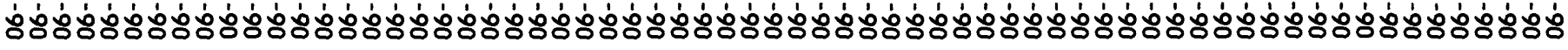

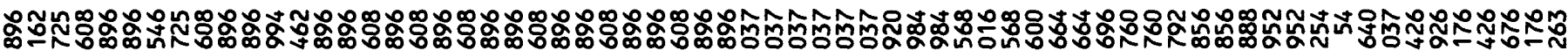

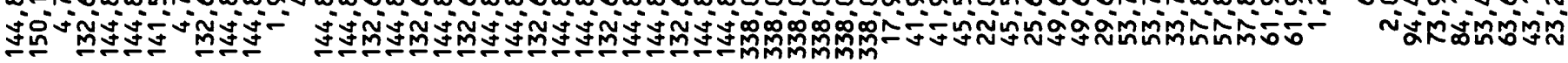

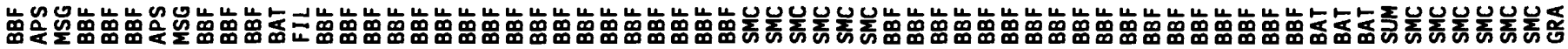

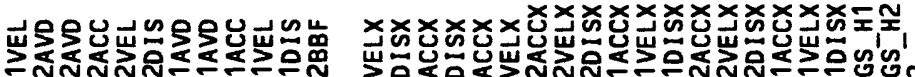

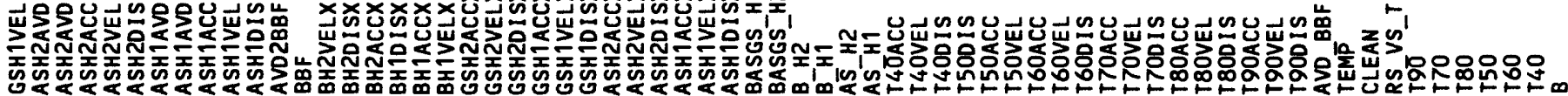




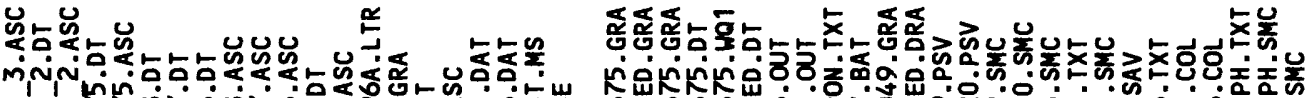

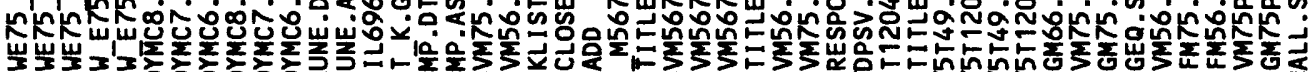

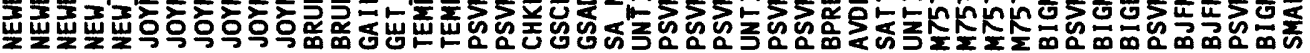

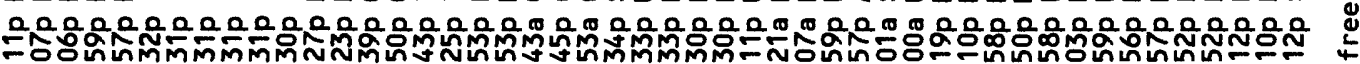

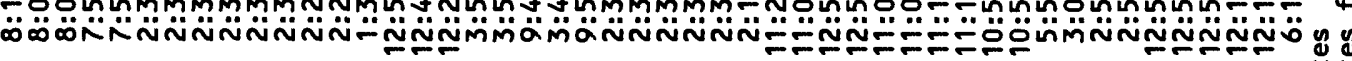

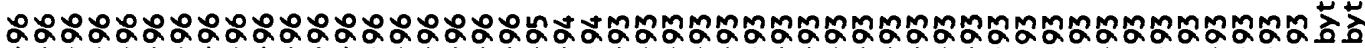

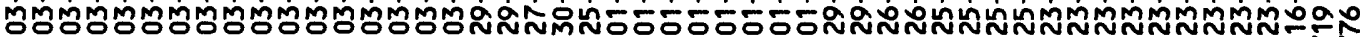

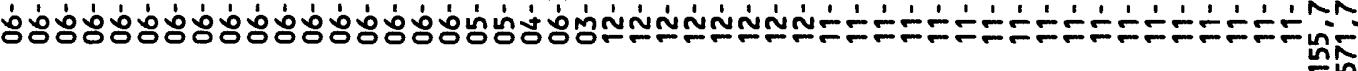
సั้ำสำ:

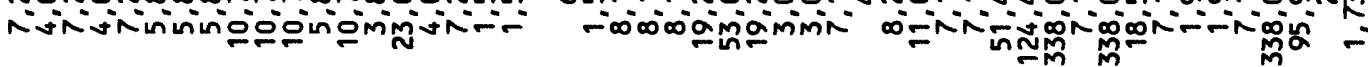

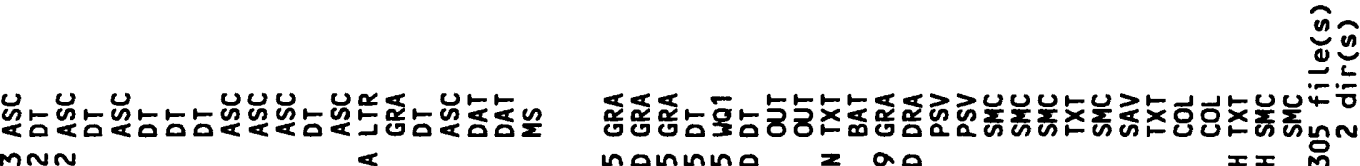

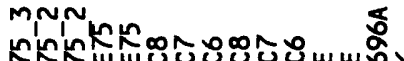

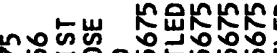

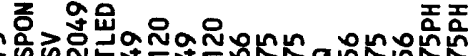

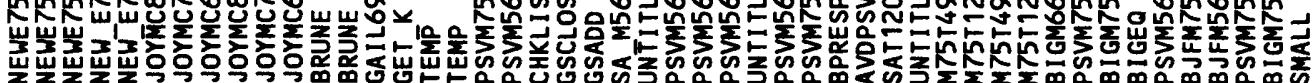




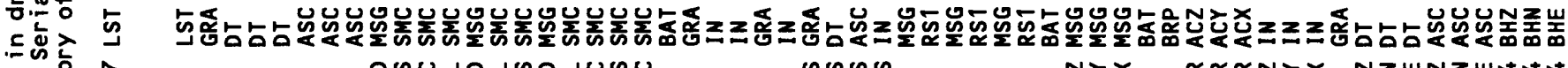




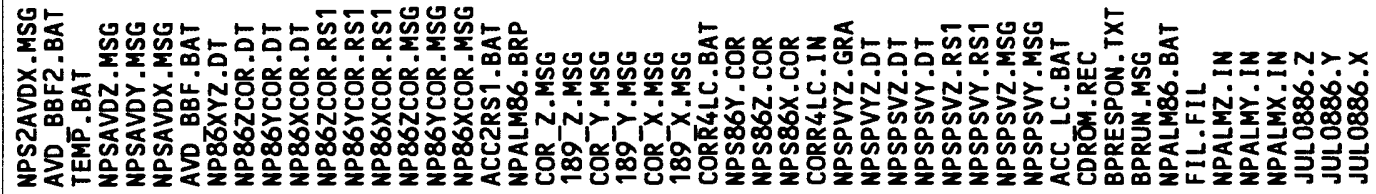

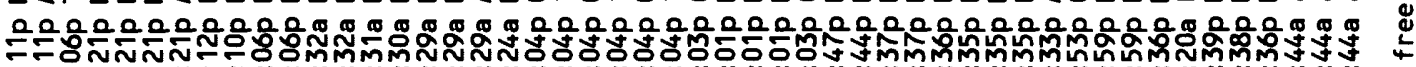

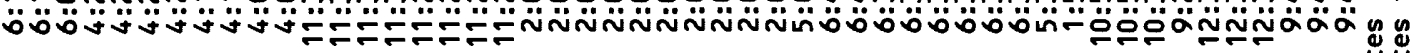

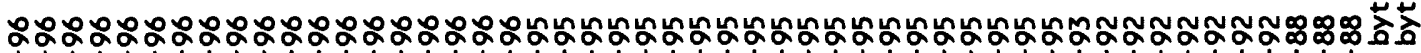

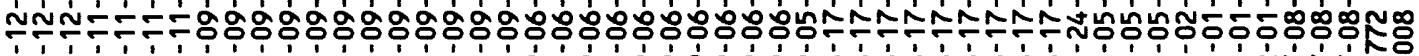

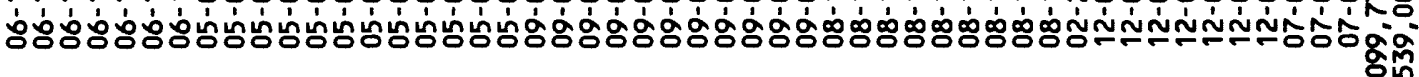

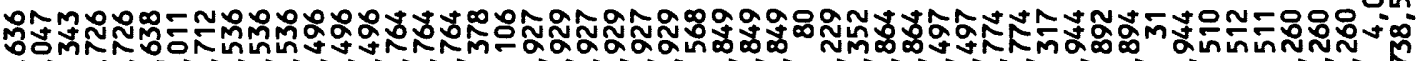
$\therefore$ ivin-Fn-

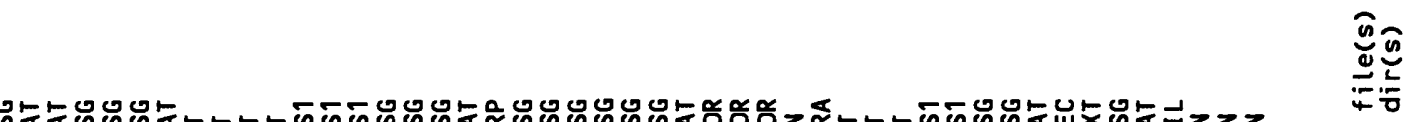

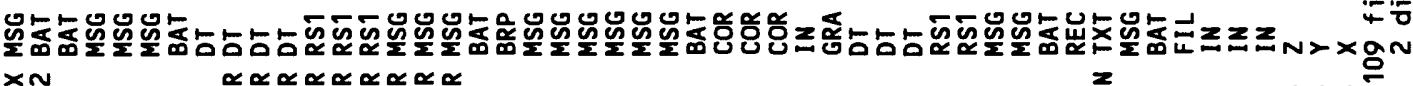

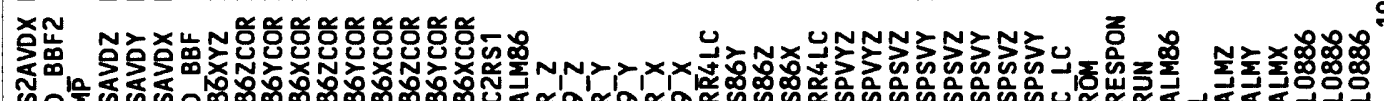

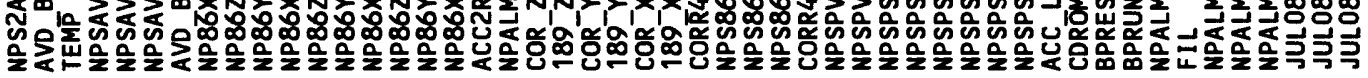

皮

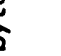




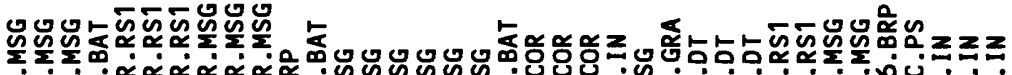

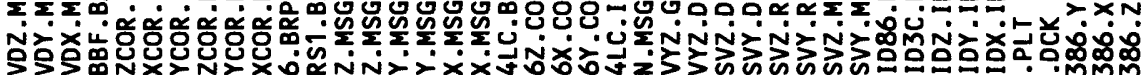

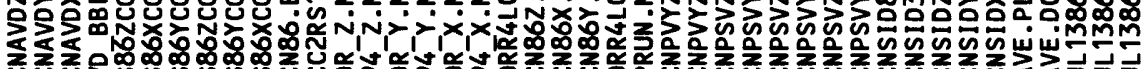
층쳥쳥

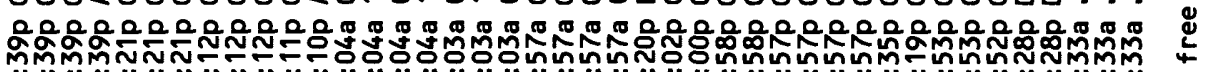

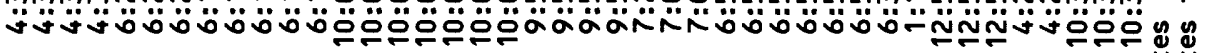

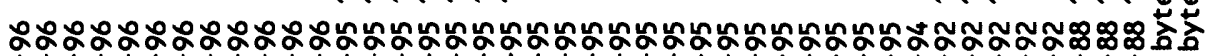

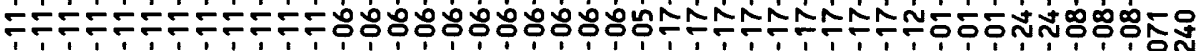

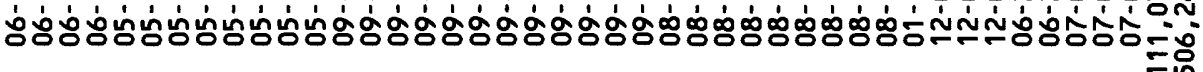

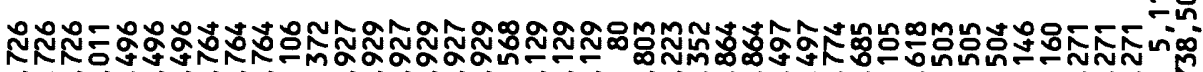

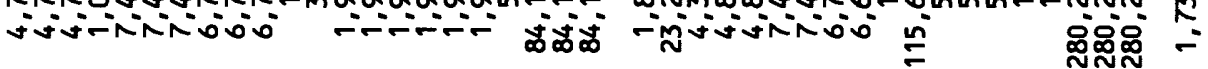

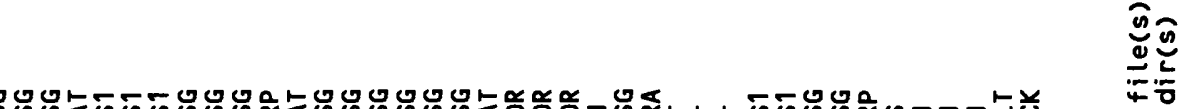

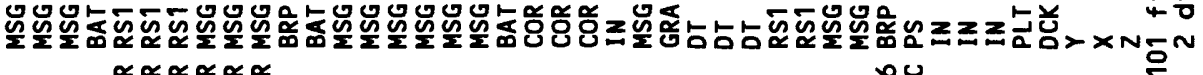

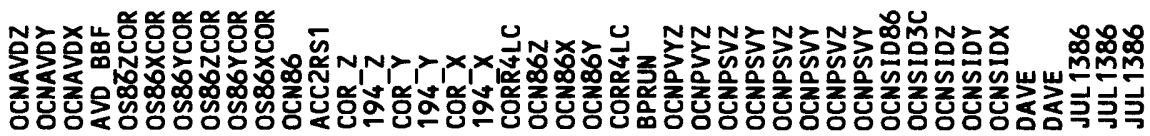

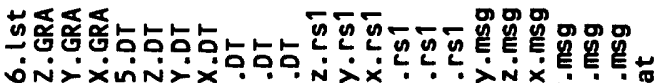
8n்

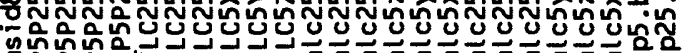

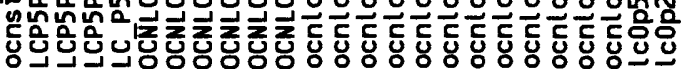

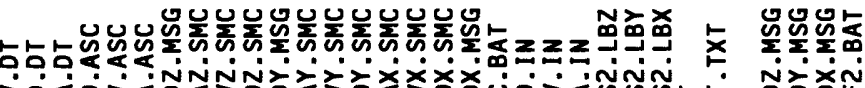

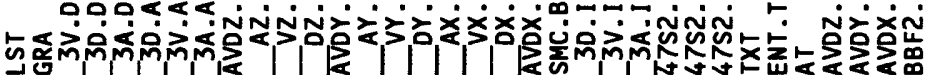

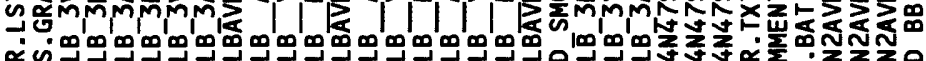

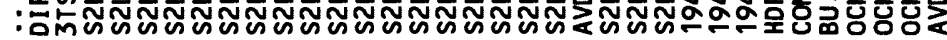

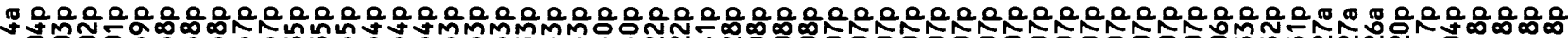

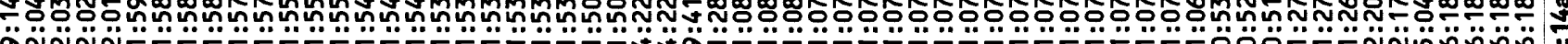

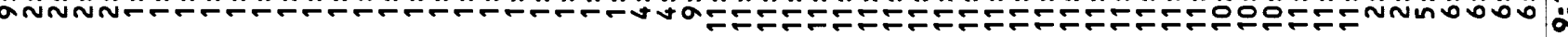

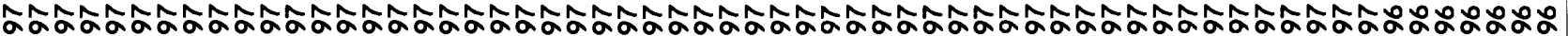
-

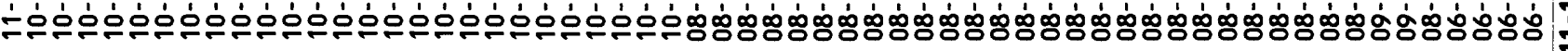

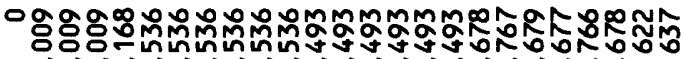

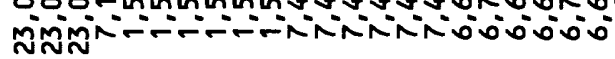
产产

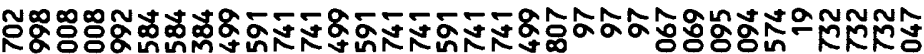

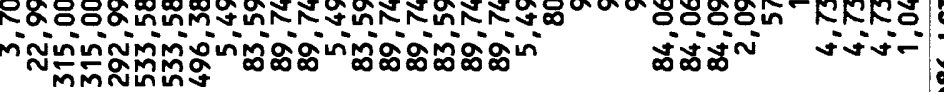

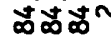

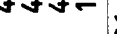

空兽

क्ष

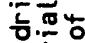

.

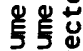

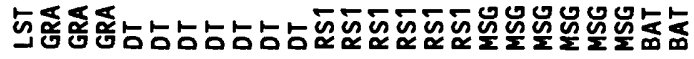

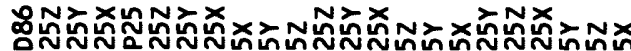

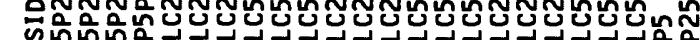

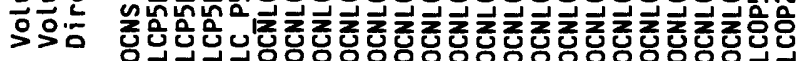

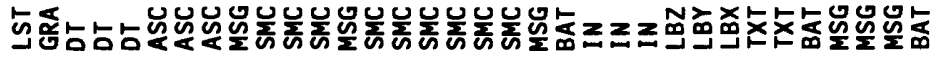

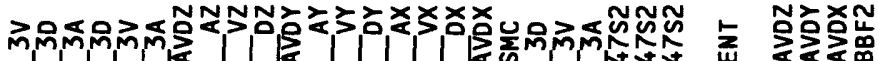
管

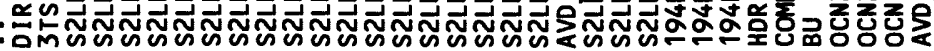




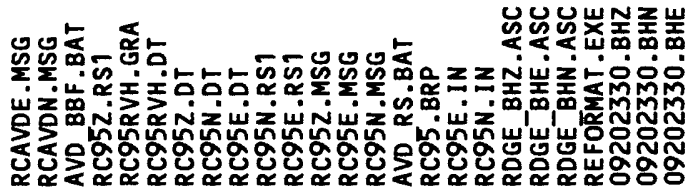

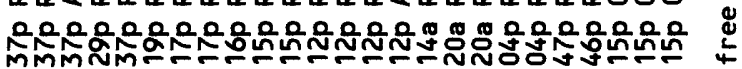

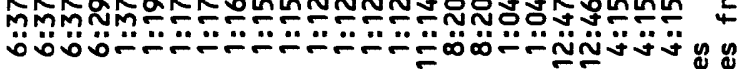

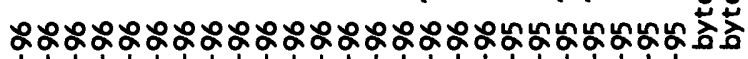

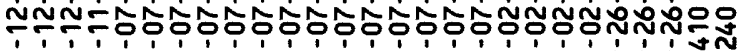

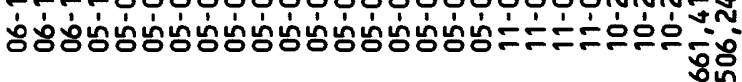

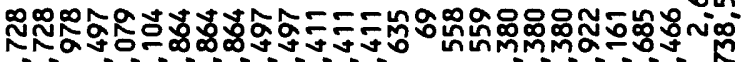

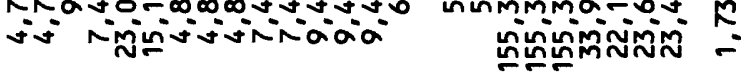

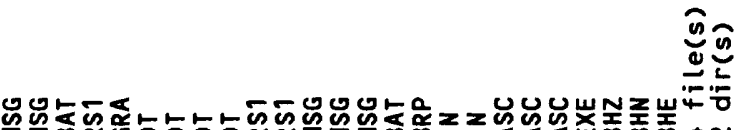

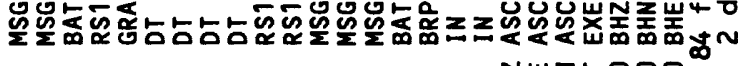

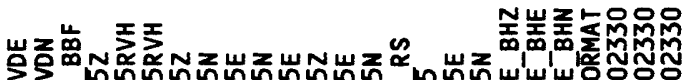

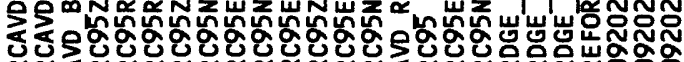

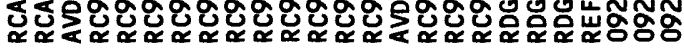

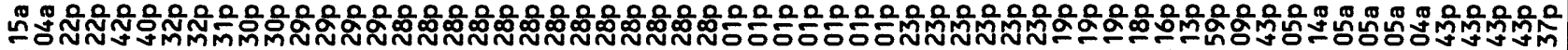

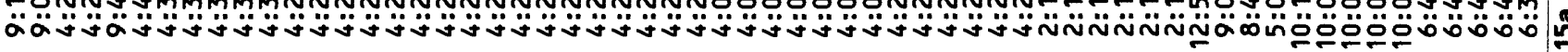

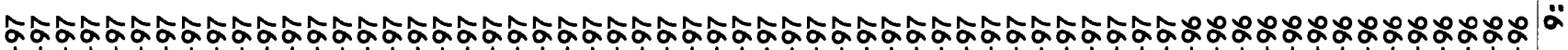

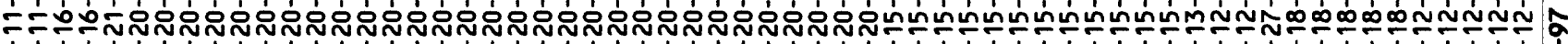

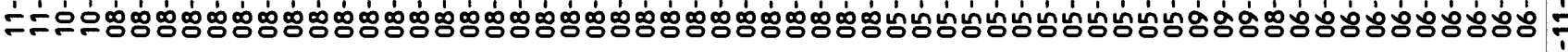

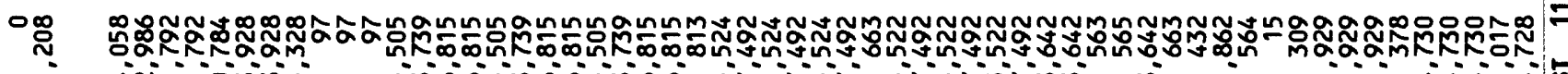

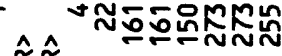

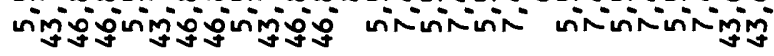
$\therefore=-i+2=0$ $\frac{\alpha}{\nabla} \frac{\alpha}{\nabla}$

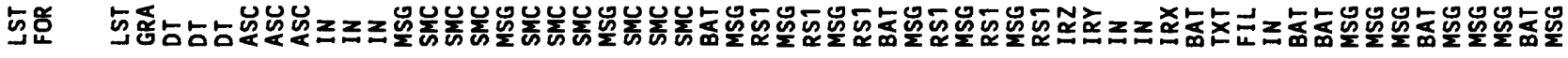

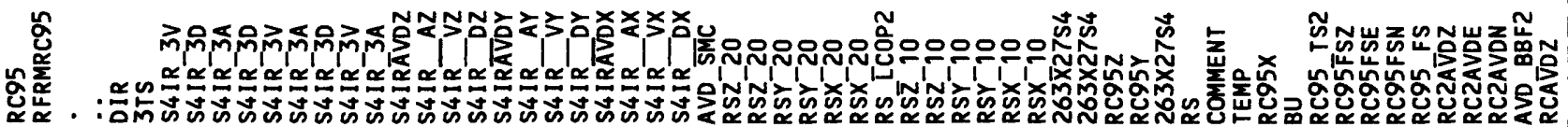




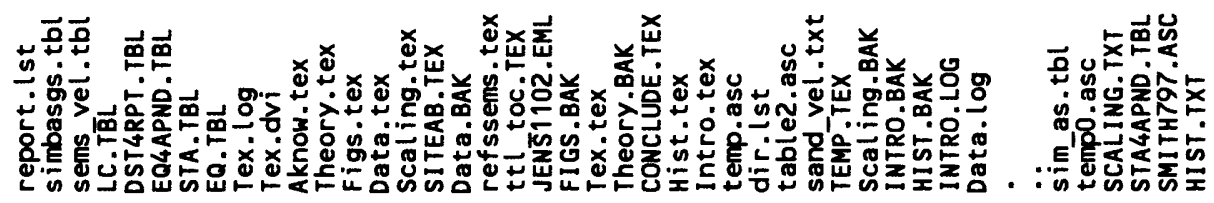

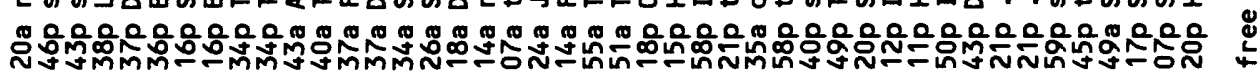

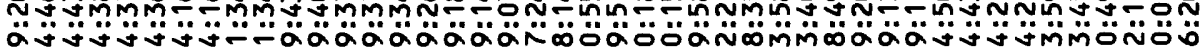
व

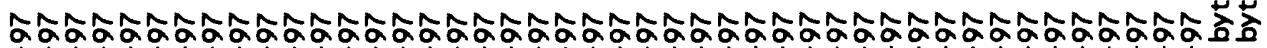

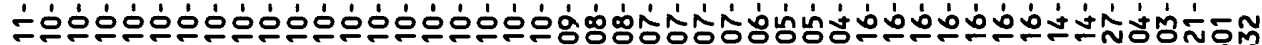

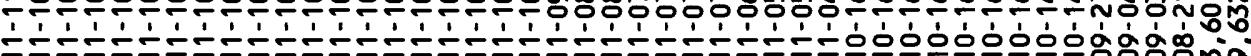

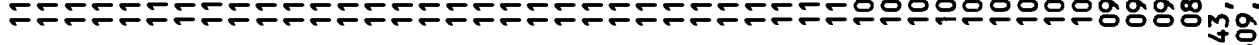

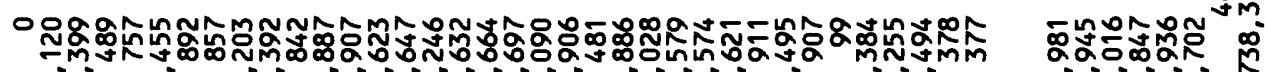

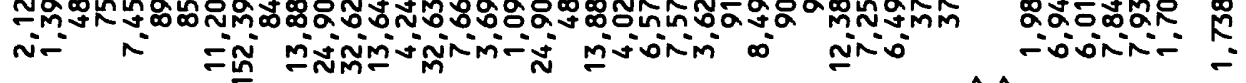

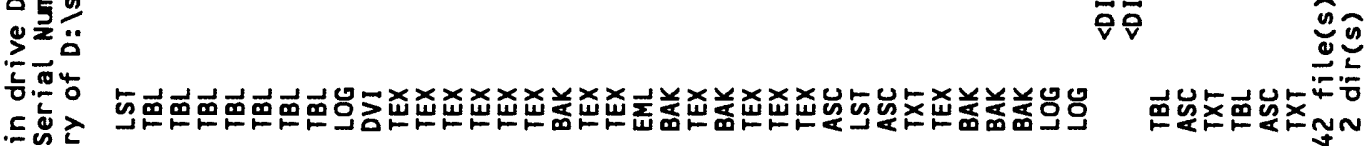

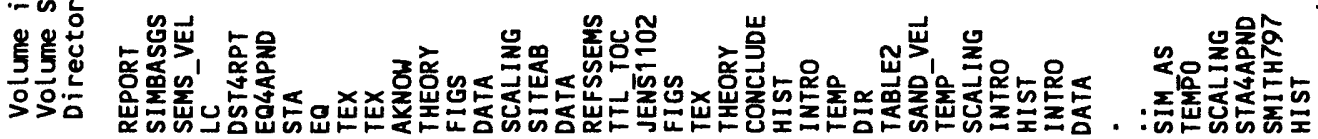




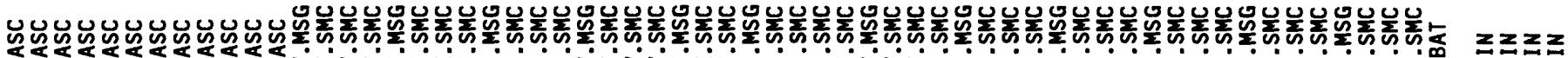

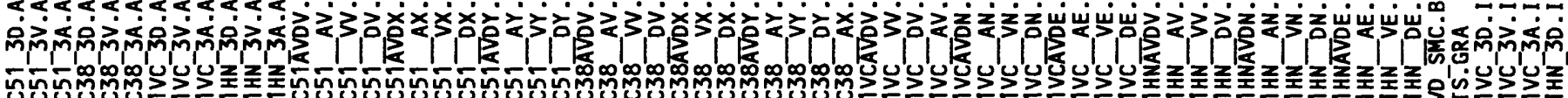

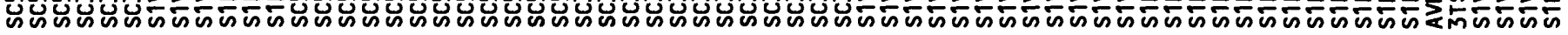

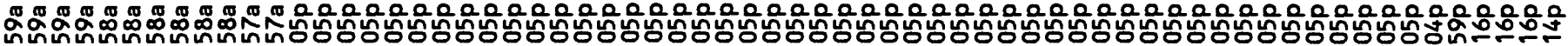

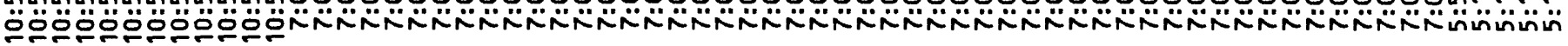

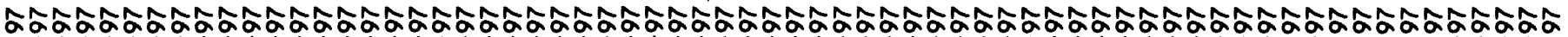

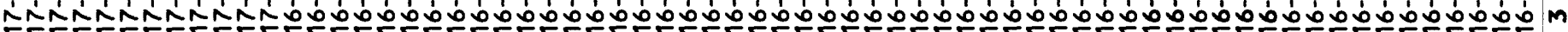

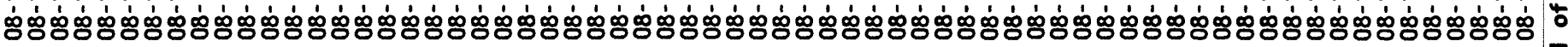

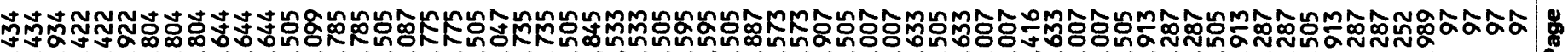

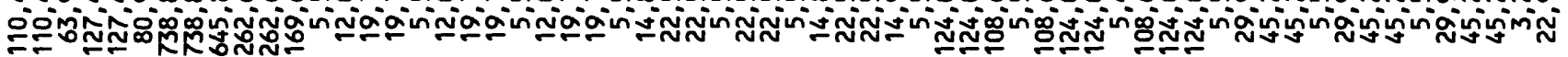

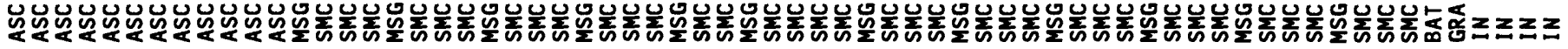

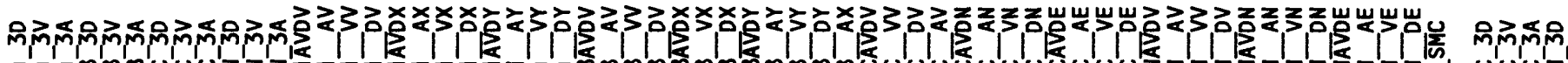
n்

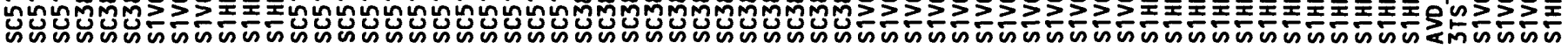

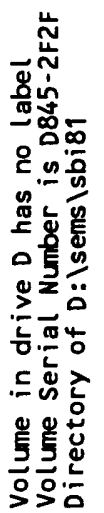

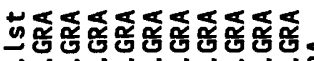

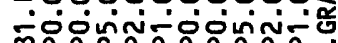

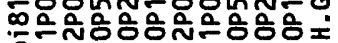

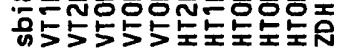

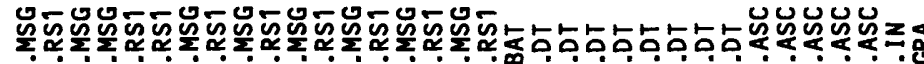

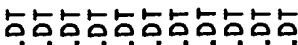

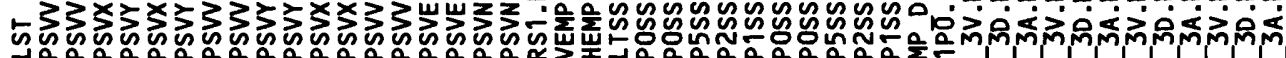
슨음은응

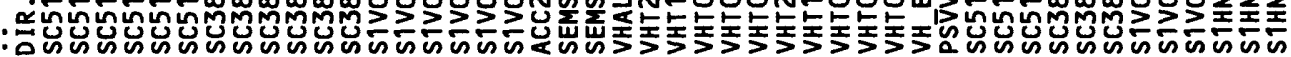

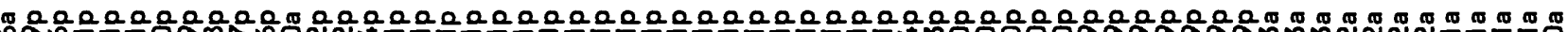

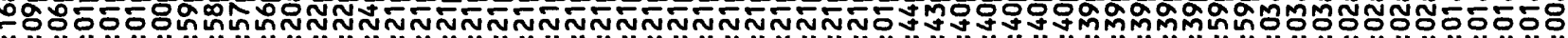

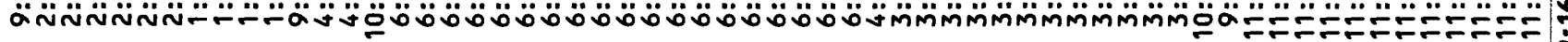

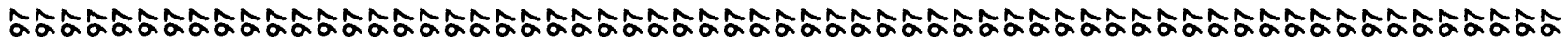

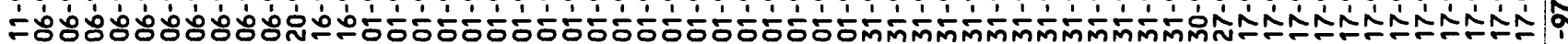

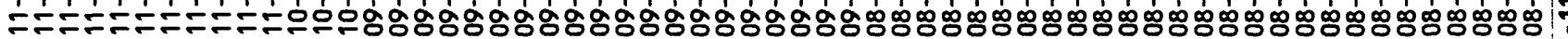

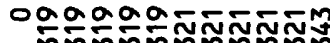

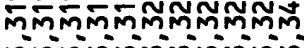

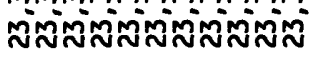
余食

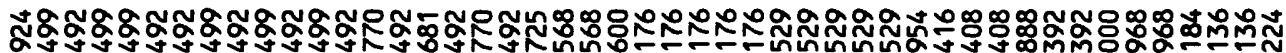
ininin 


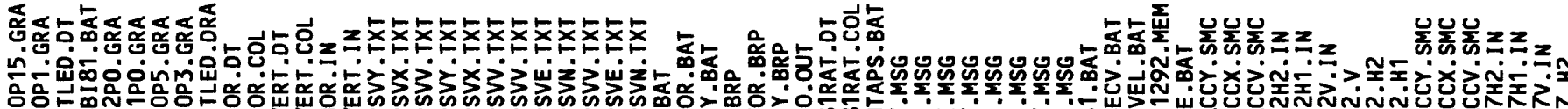

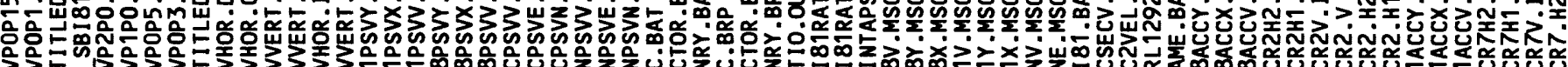
等

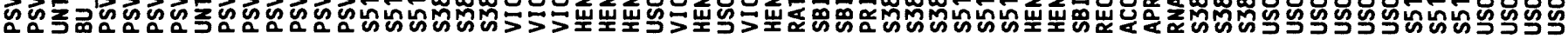

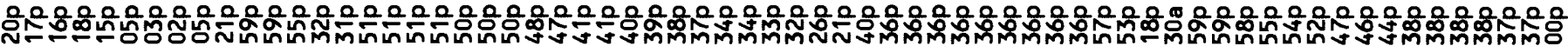

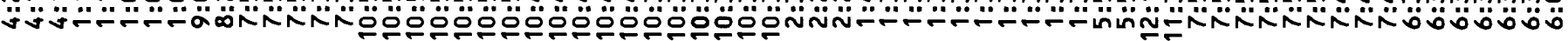

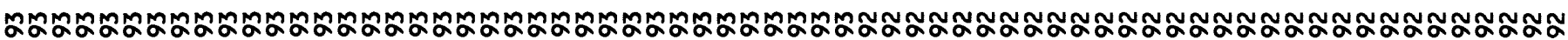

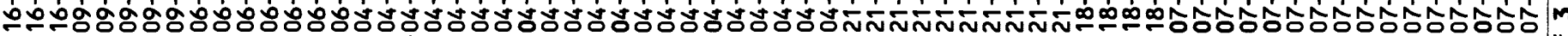

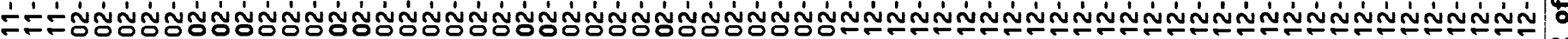

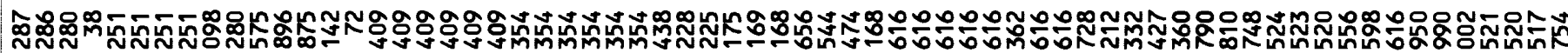

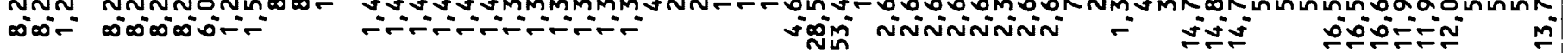

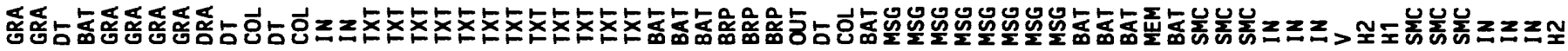

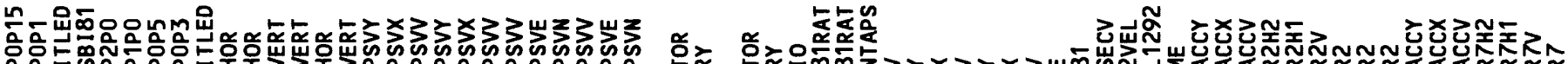

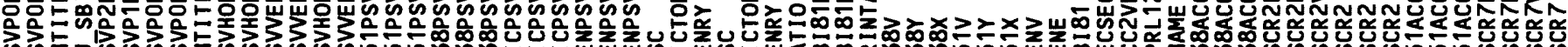

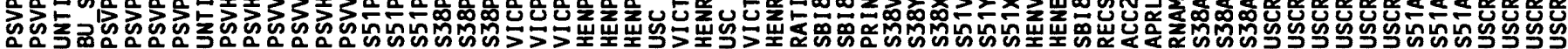

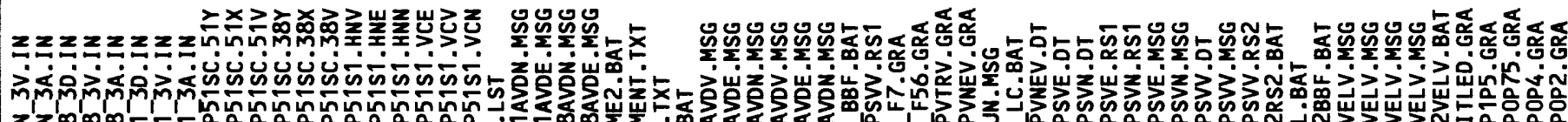

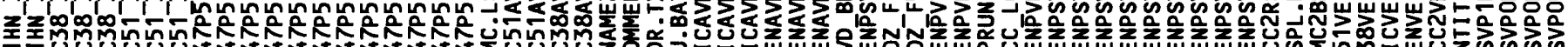

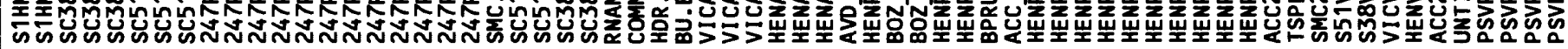

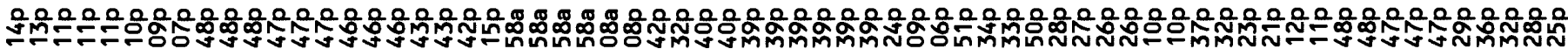

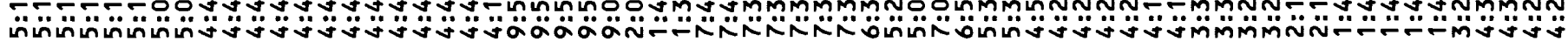

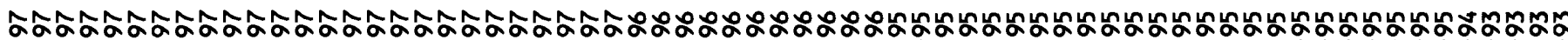

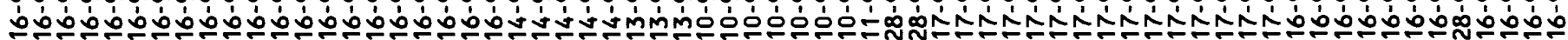

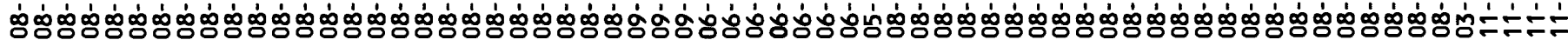

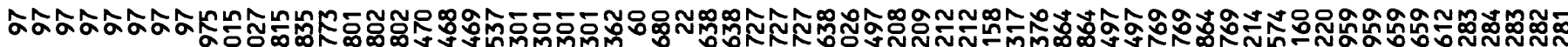

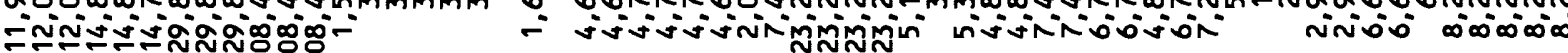

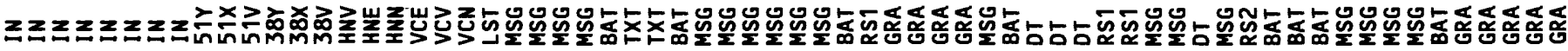

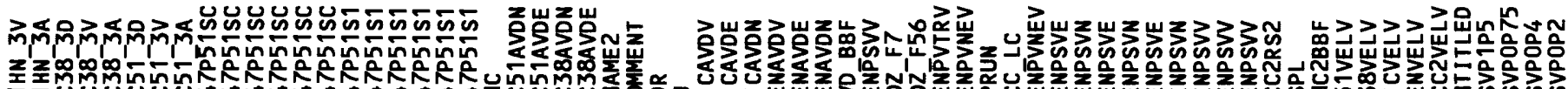

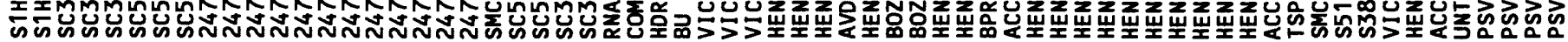




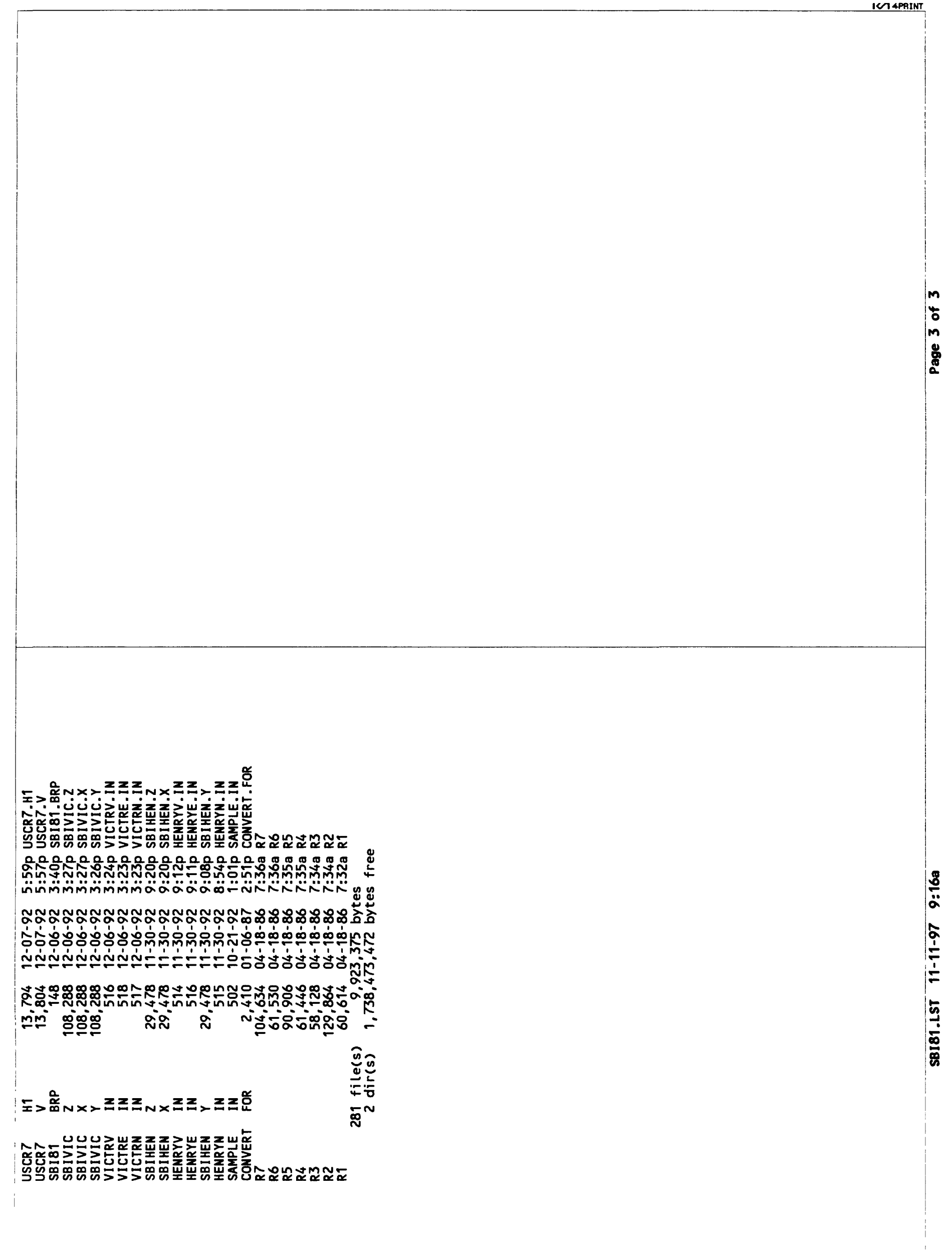


Wू⿹

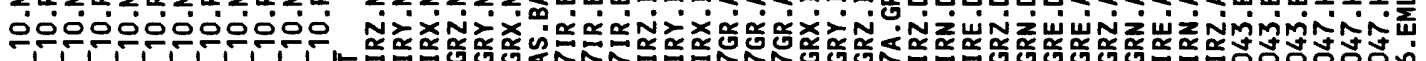

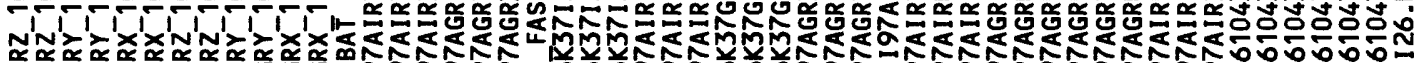

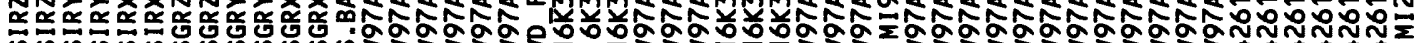

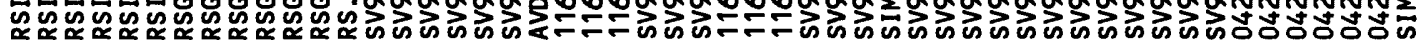

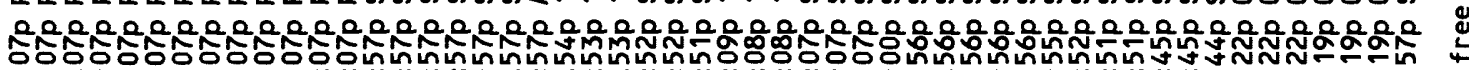

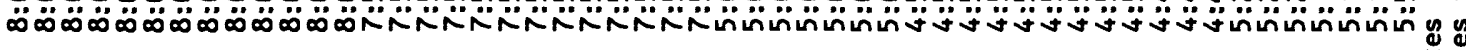

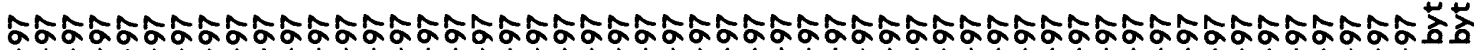

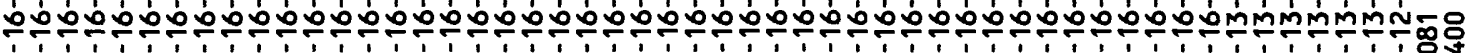

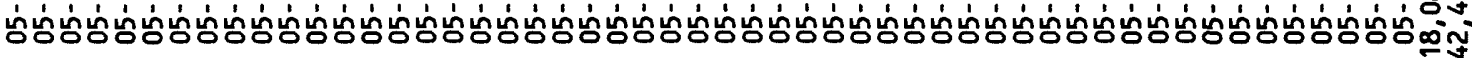
Mิสมี ninininininini-600-

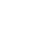
正

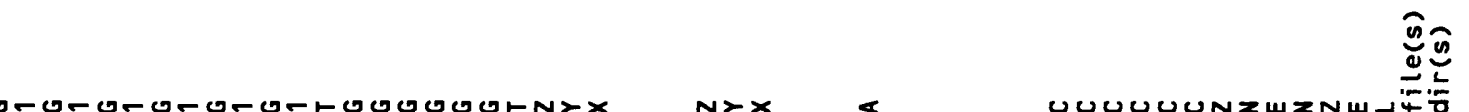

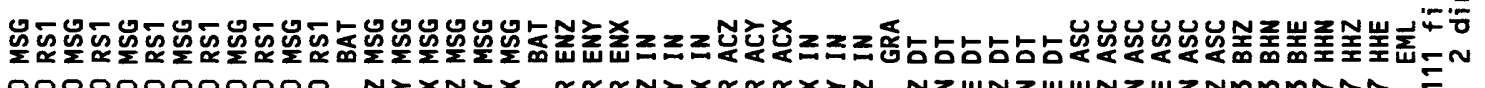

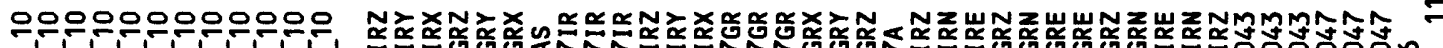

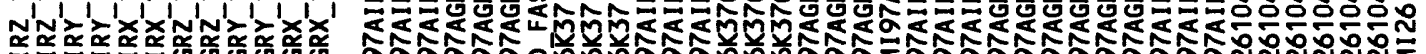

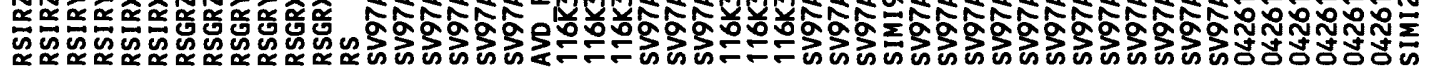

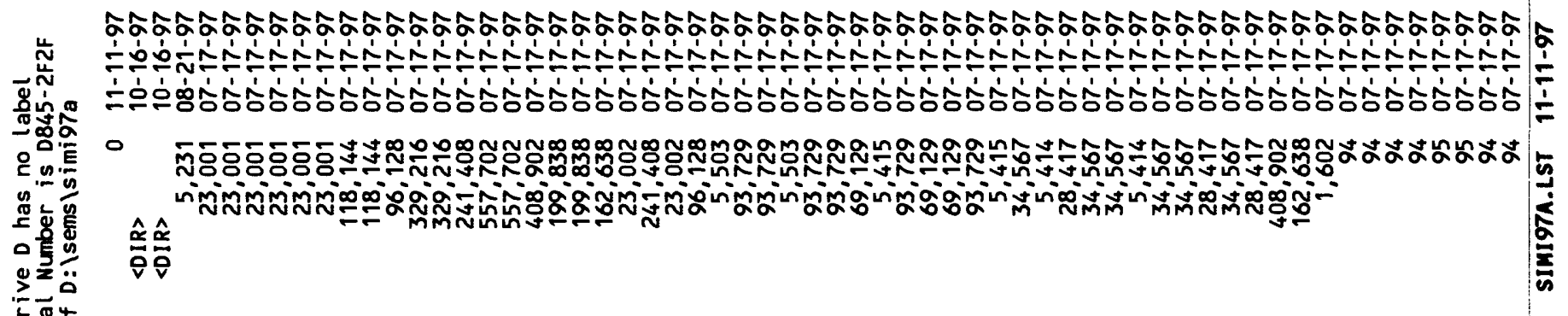

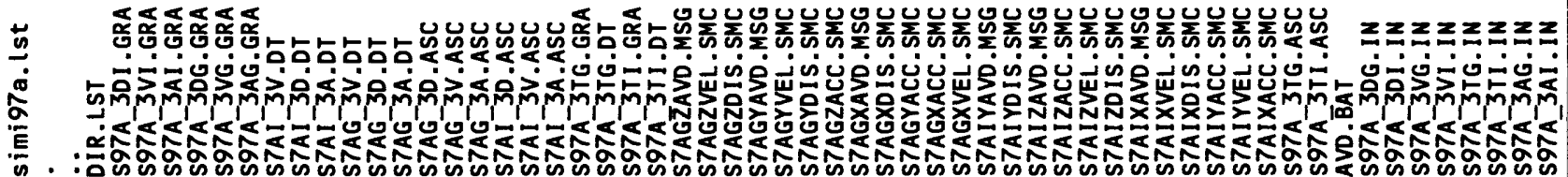

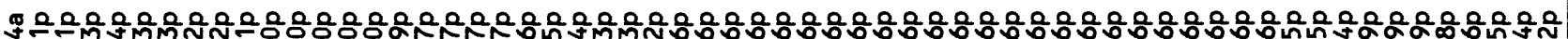

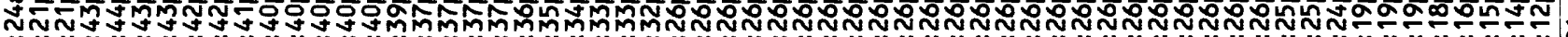

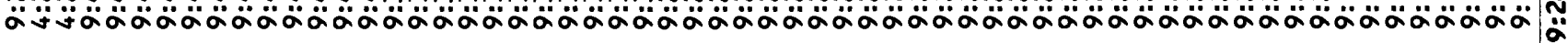

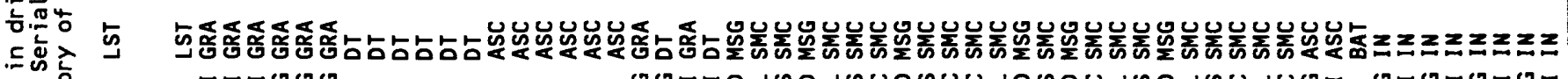

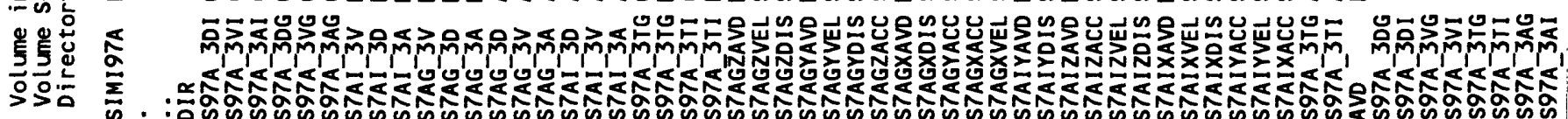



-

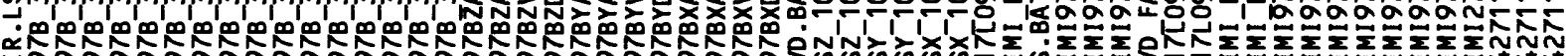

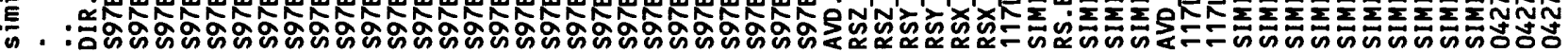

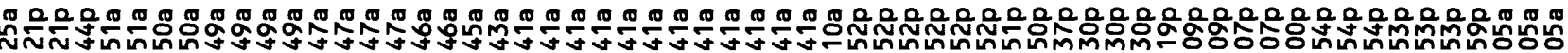

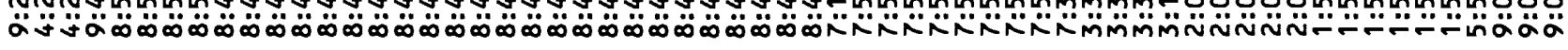

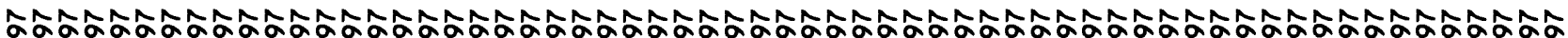

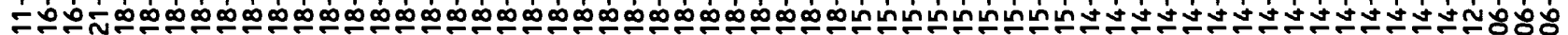

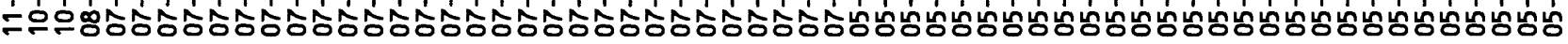

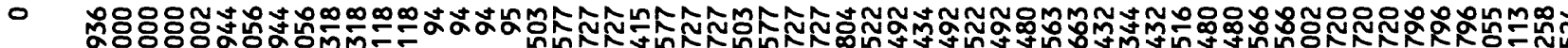
$\hat{\underline{\alpha}} \hat{\underline{\alpha}}$

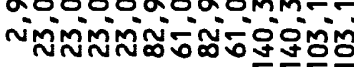

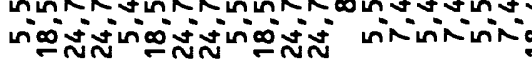

0.000

nio

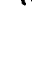

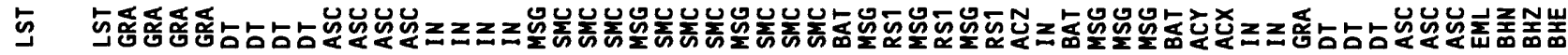




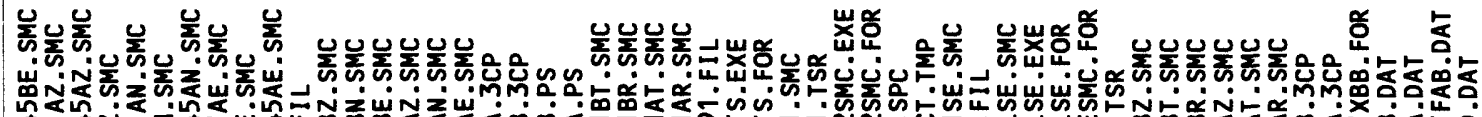
员 N

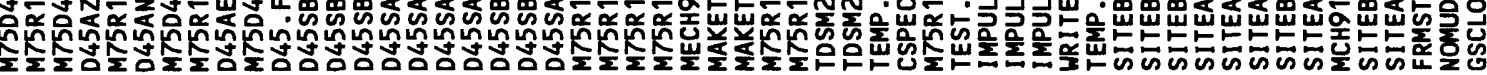

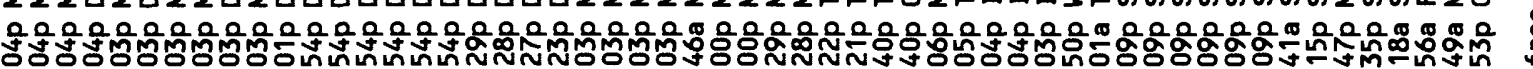

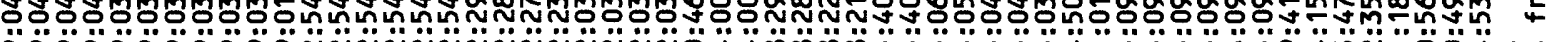

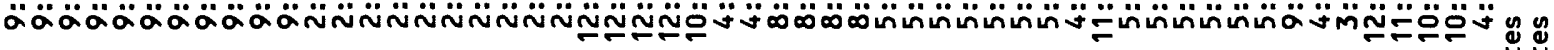

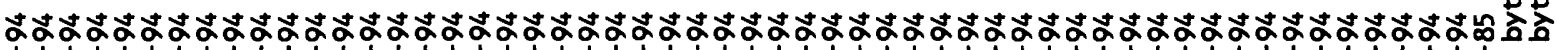

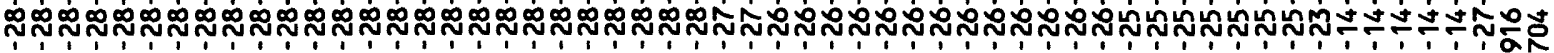

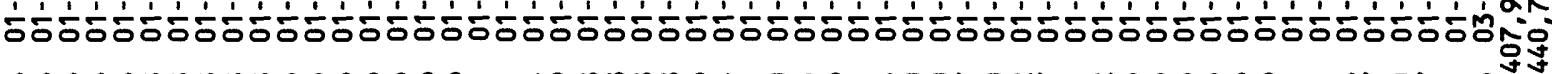

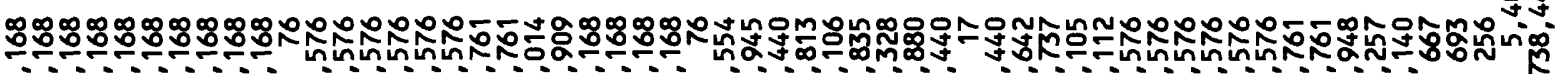

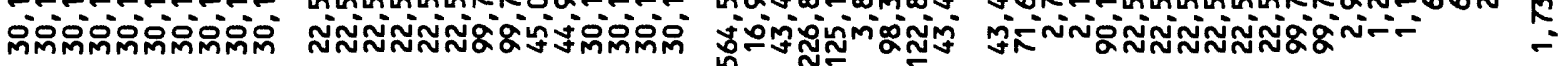

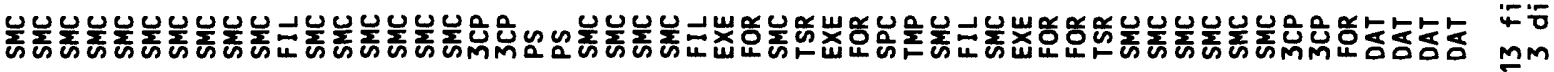

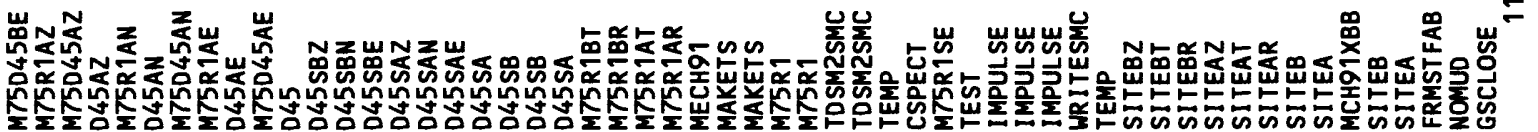

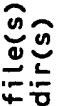

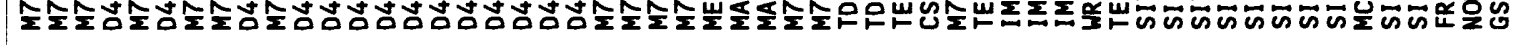

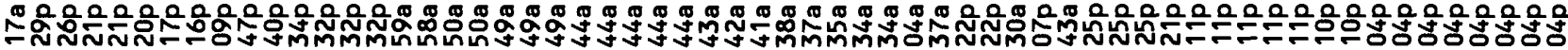

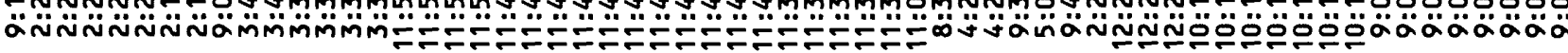

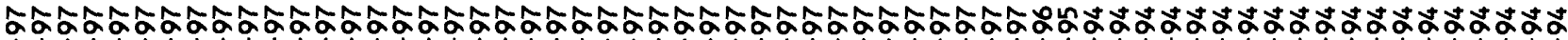

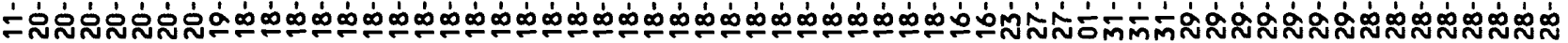

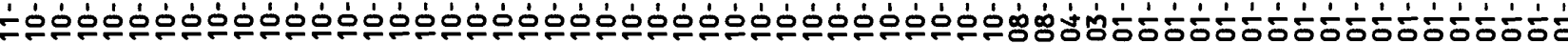

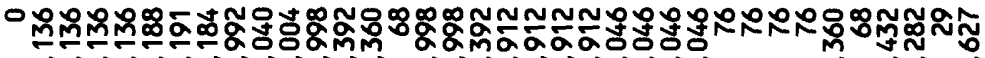

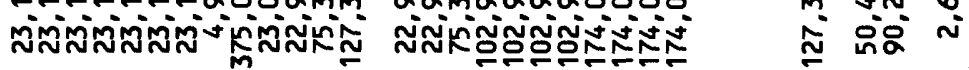

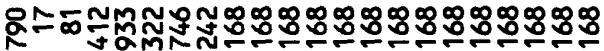

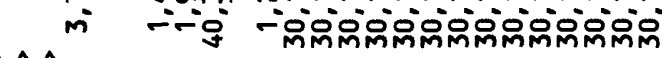

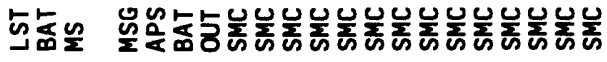

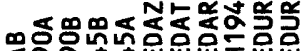




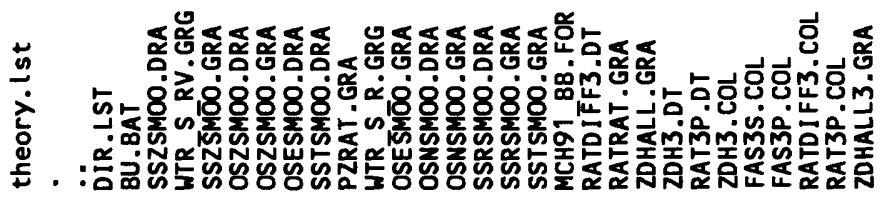

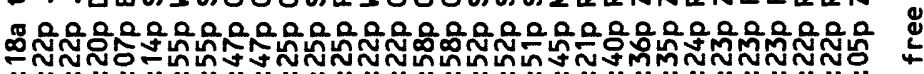

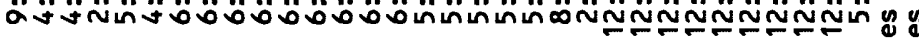

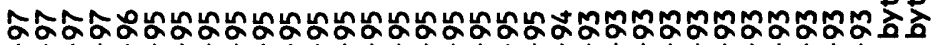

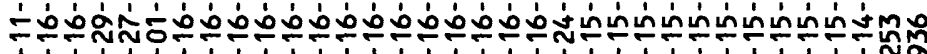

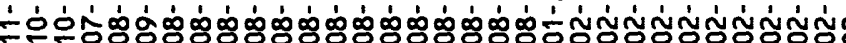

-

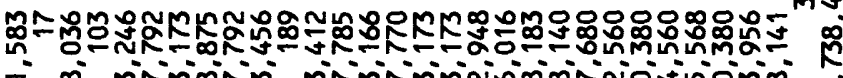
$\hat{\underline{\alpha}} \hat{\underline{\alpha}}$

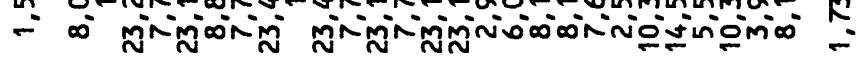
จิจे

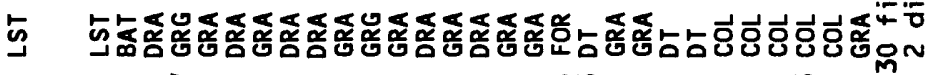

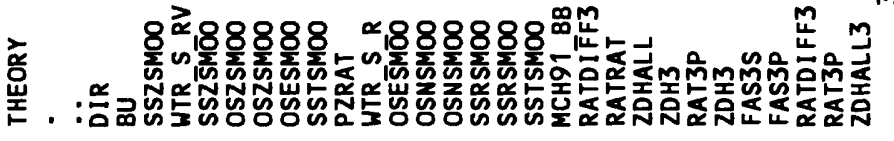




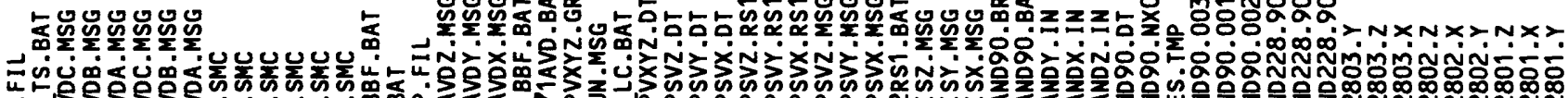

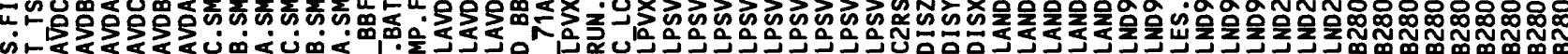

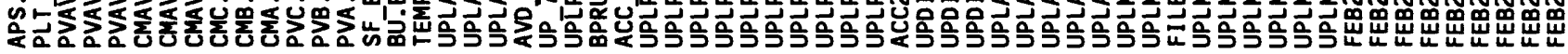

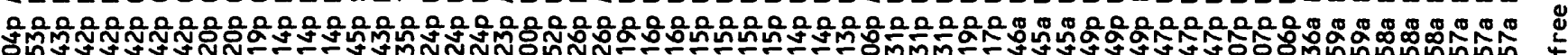

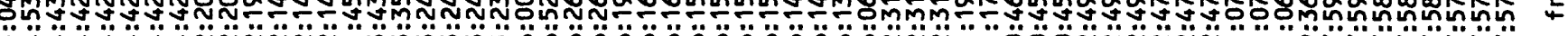

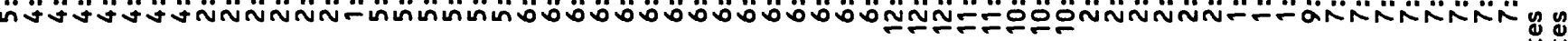

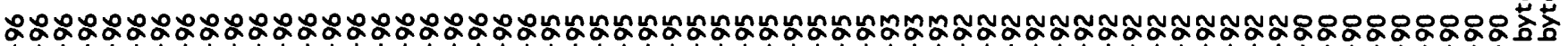
ஸ்

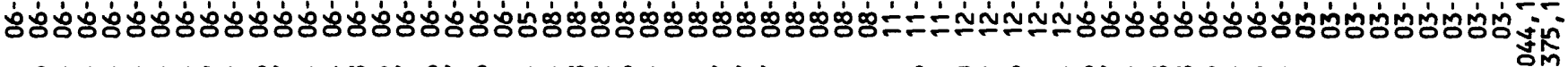

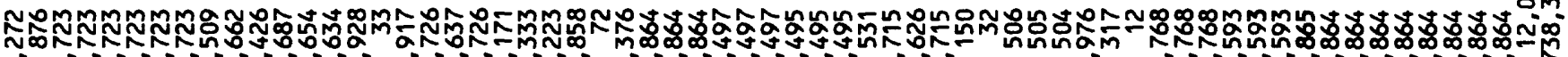

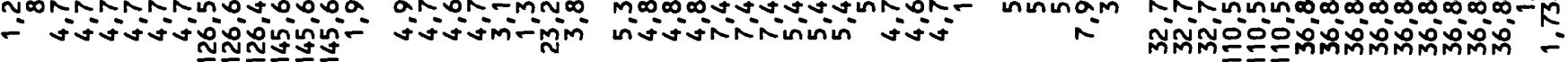

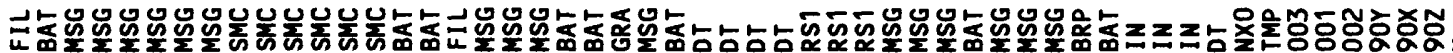

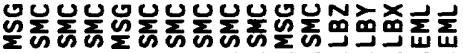
大t

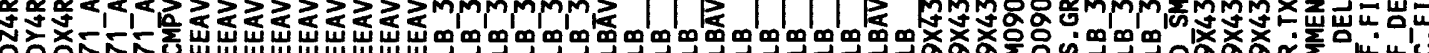

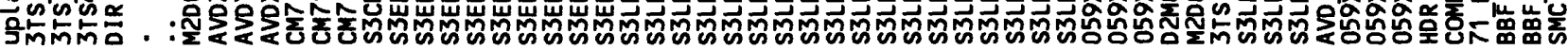

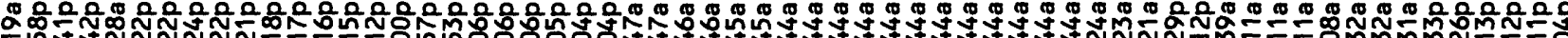

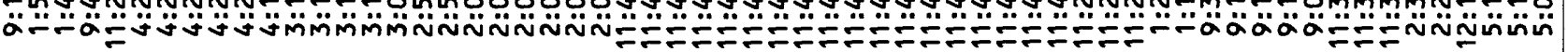

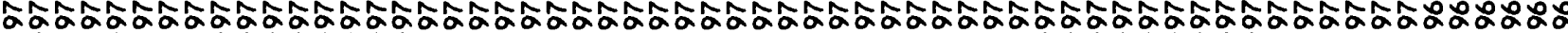

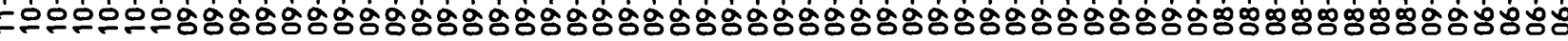

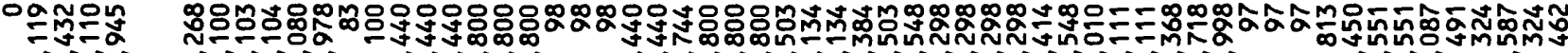

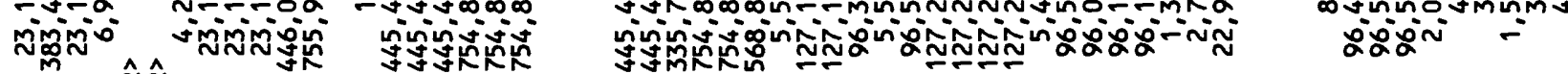

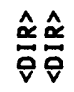

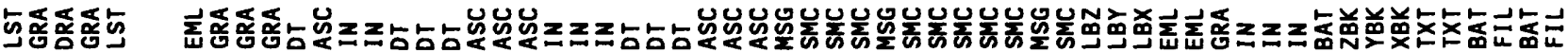




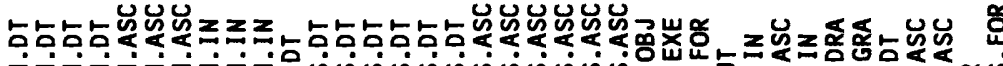

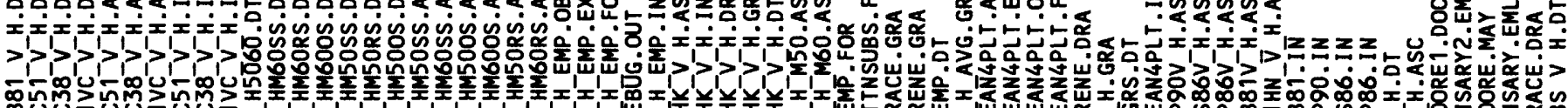

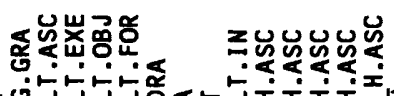

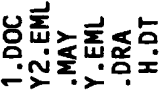

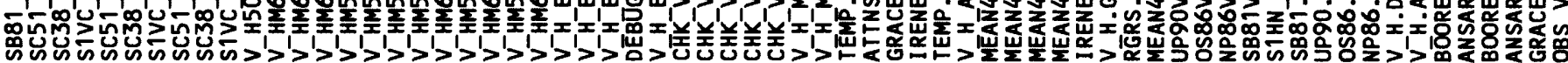

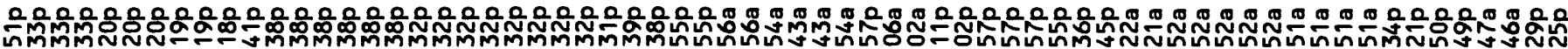

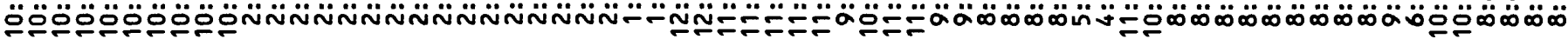

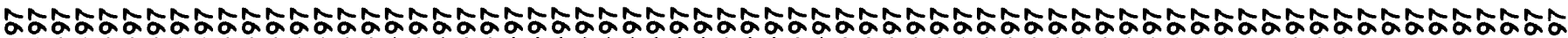

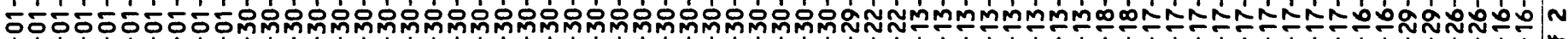

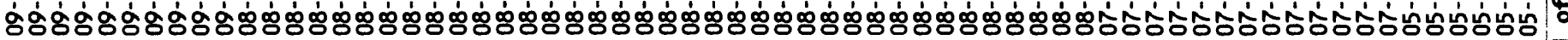

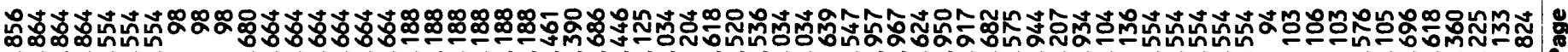

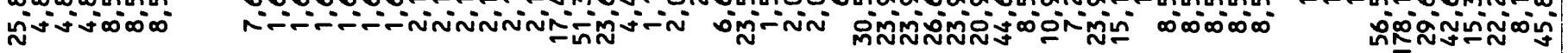

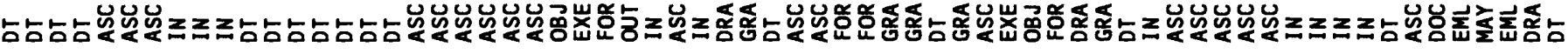

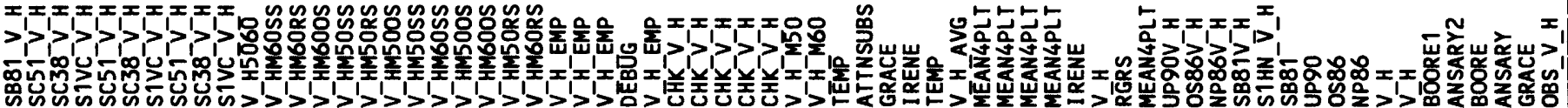

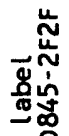

至

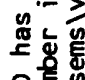

宩

$\gg \frac{5}{2}$

능.

ㄷ⿺ㅇ

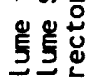

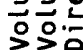

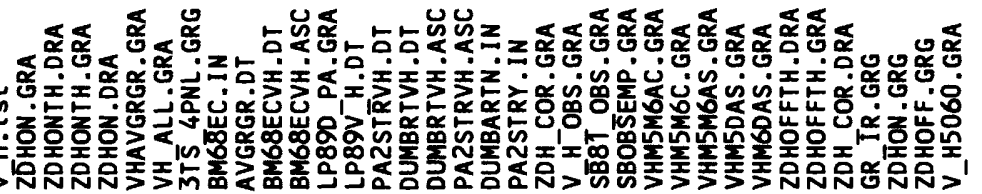

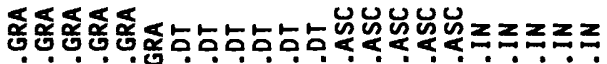

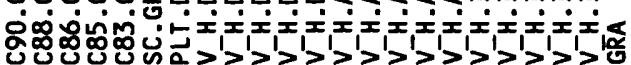
फै匕0

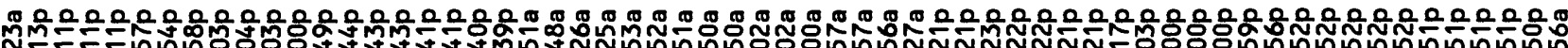

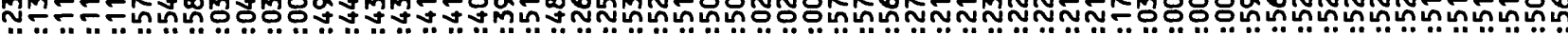

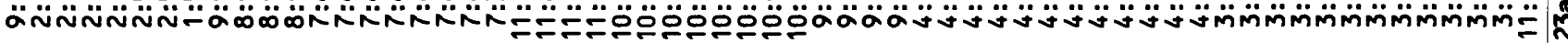

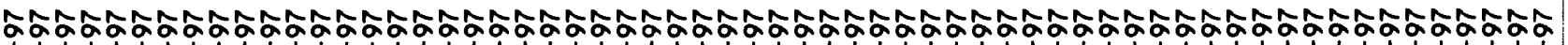

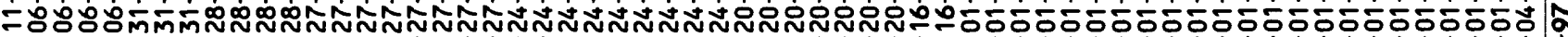

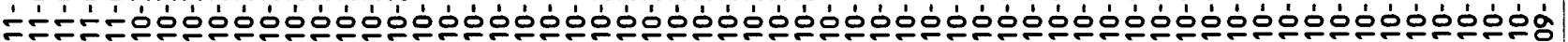

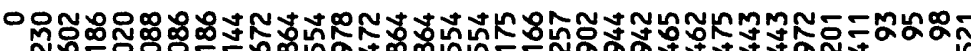
Non

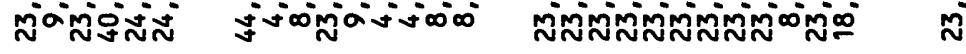

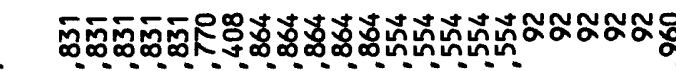
谷参

ninininiñ

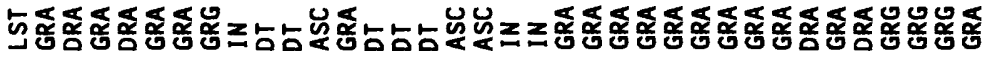

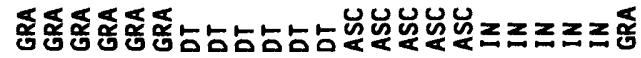

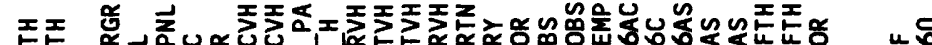

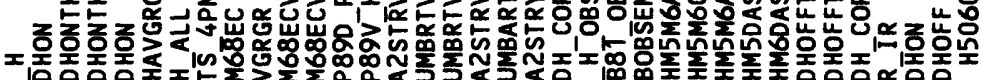

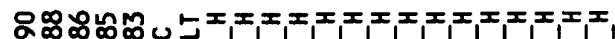
ơjo

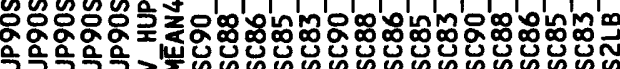




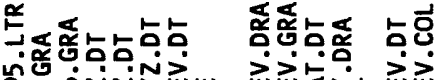

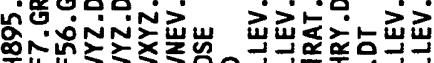

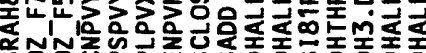

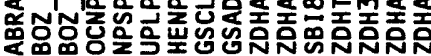

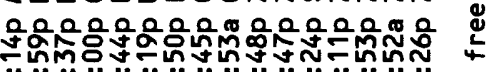

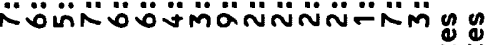

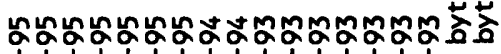

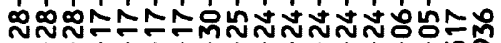

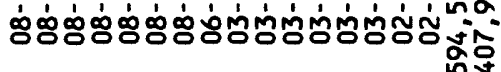

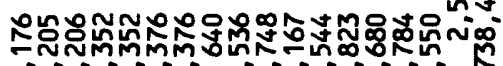

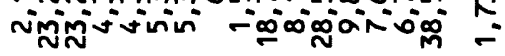

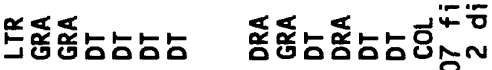

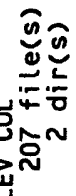

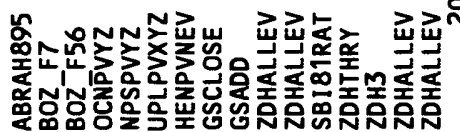

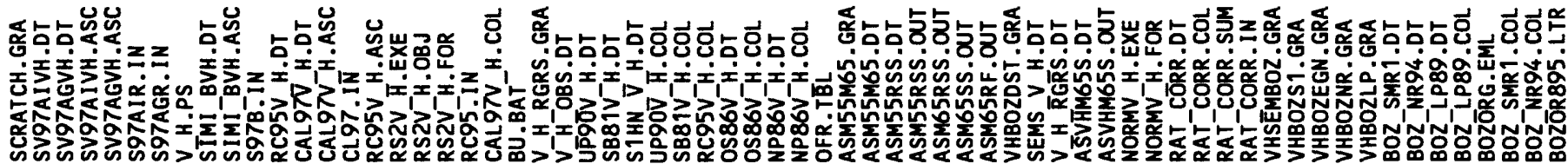

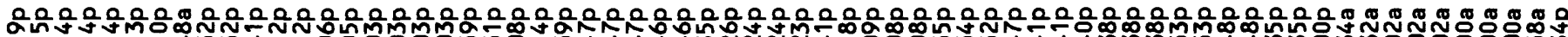

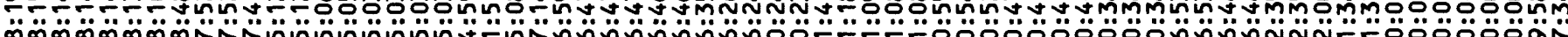

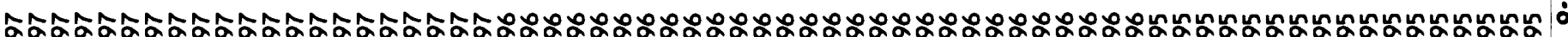

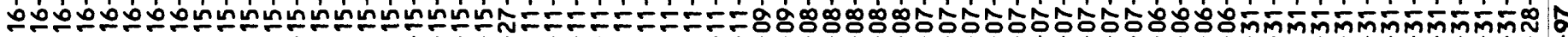

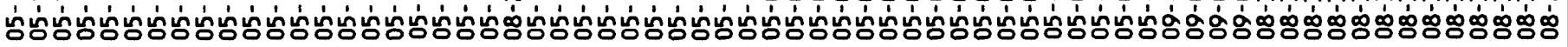

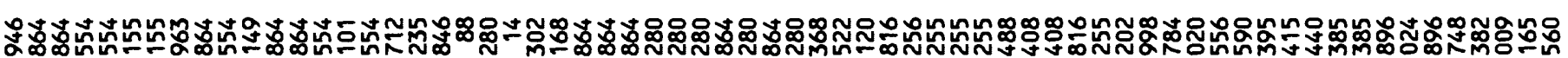

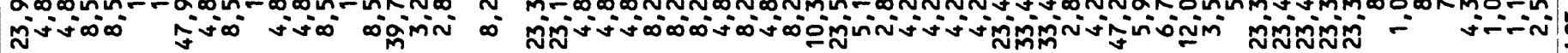

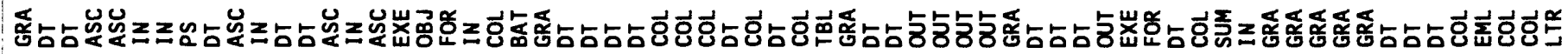

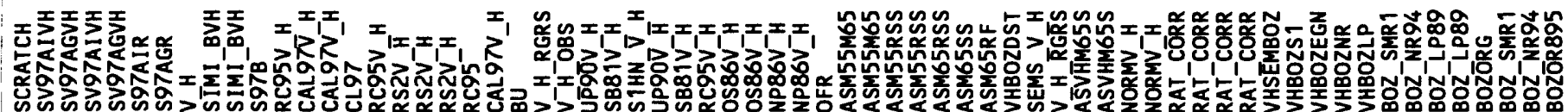




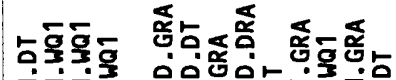

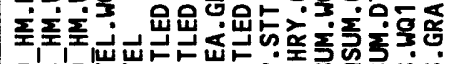

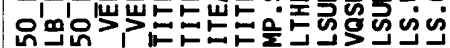

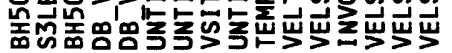

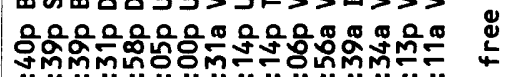

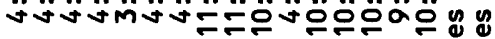

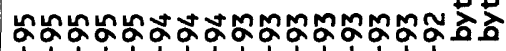

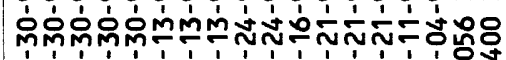

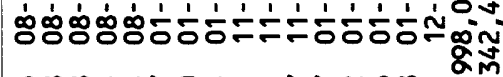

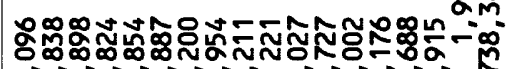

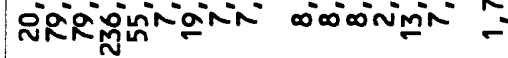

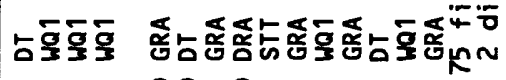

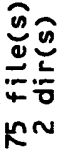

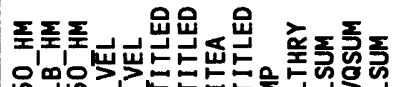

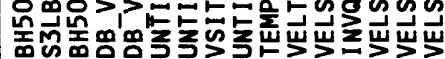

烍

용

空产

व

준

to.

崖莒

$>0$

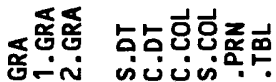

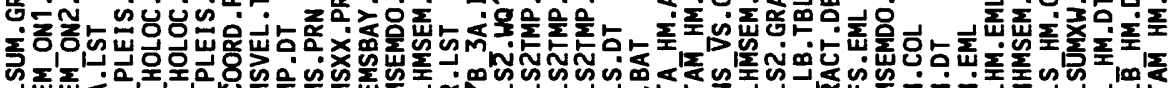

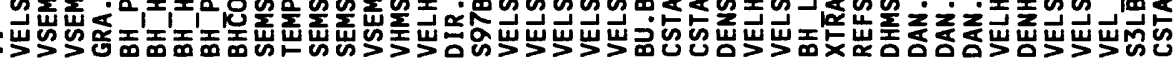

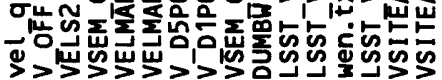

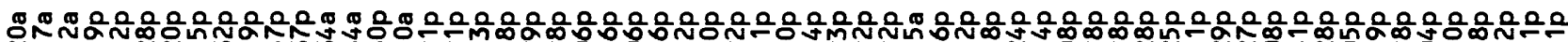

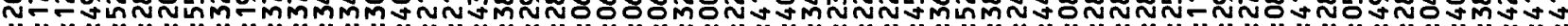

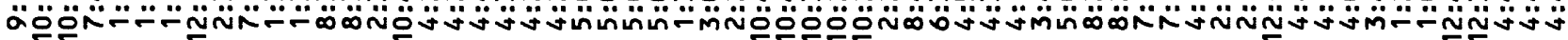

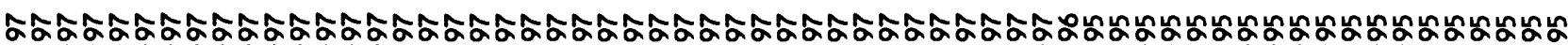

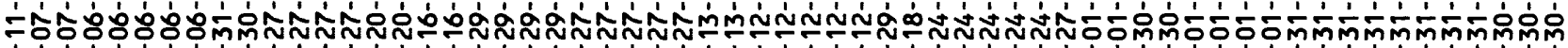

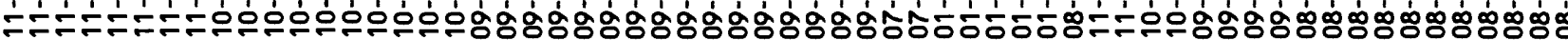

o

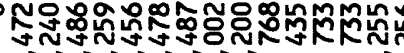

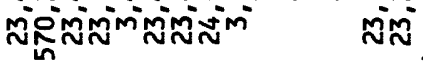
产产

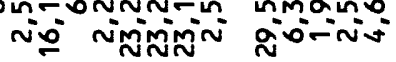

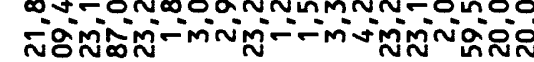

nimin-

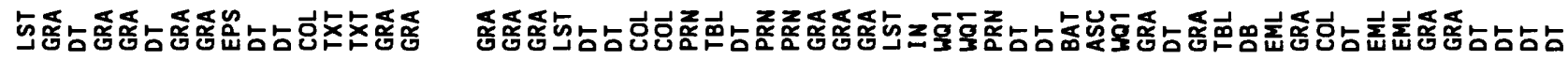

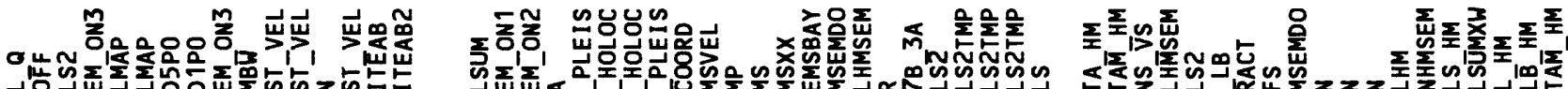

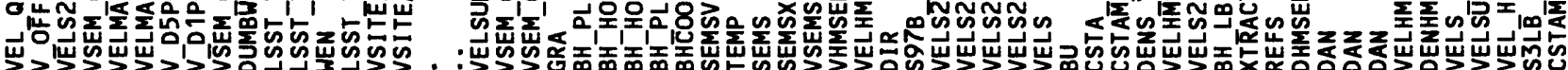




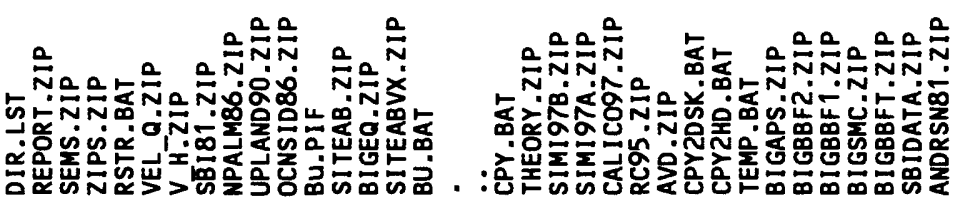

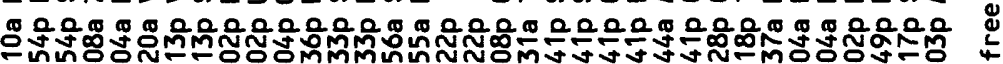

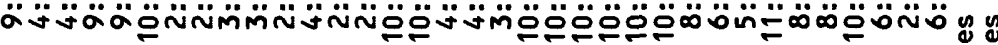

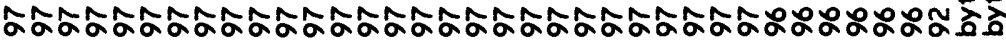

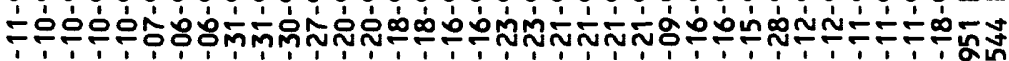

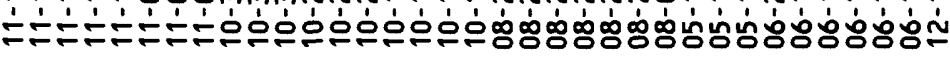

\section{OTNMmOMuN-}

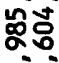

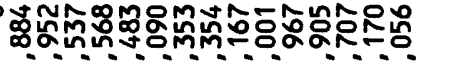

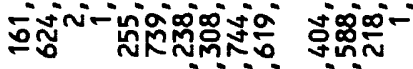
minm- $\because a^{-1}$ $\hat{a} \frac{\hat{a}}{\hat{v}} \hat{\frac{\hat{v}}{v}}$ ingîñ

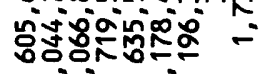

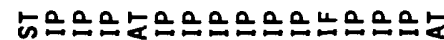

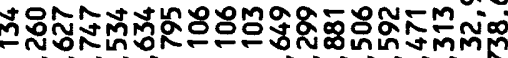

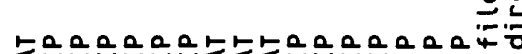




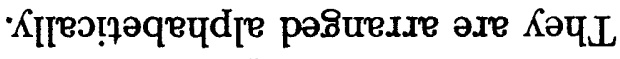

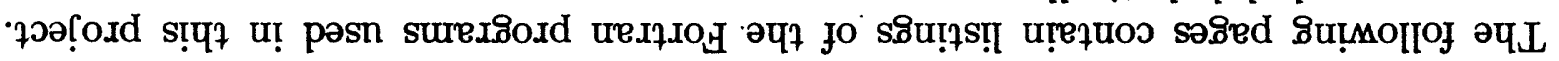

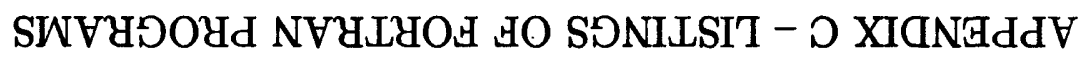



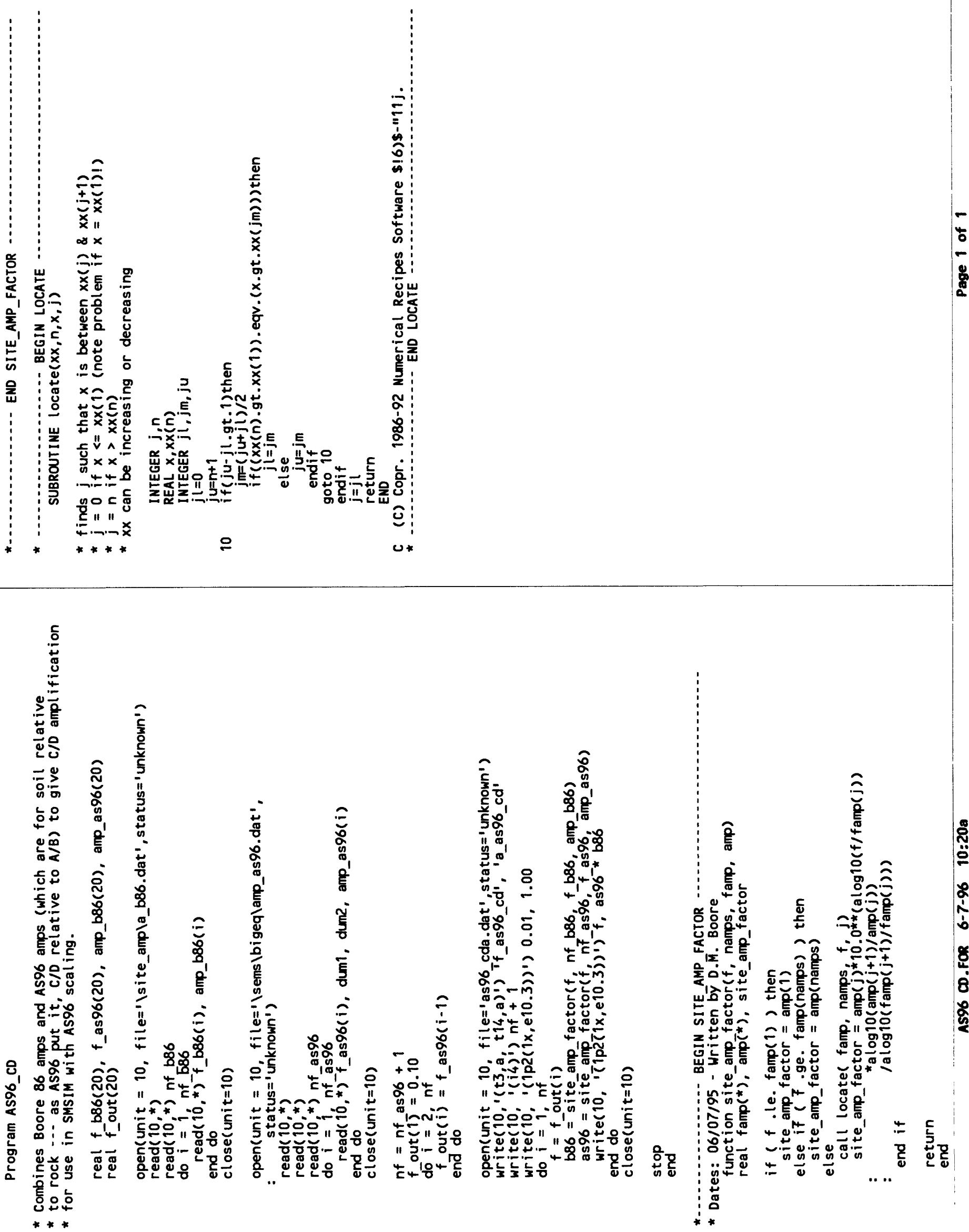


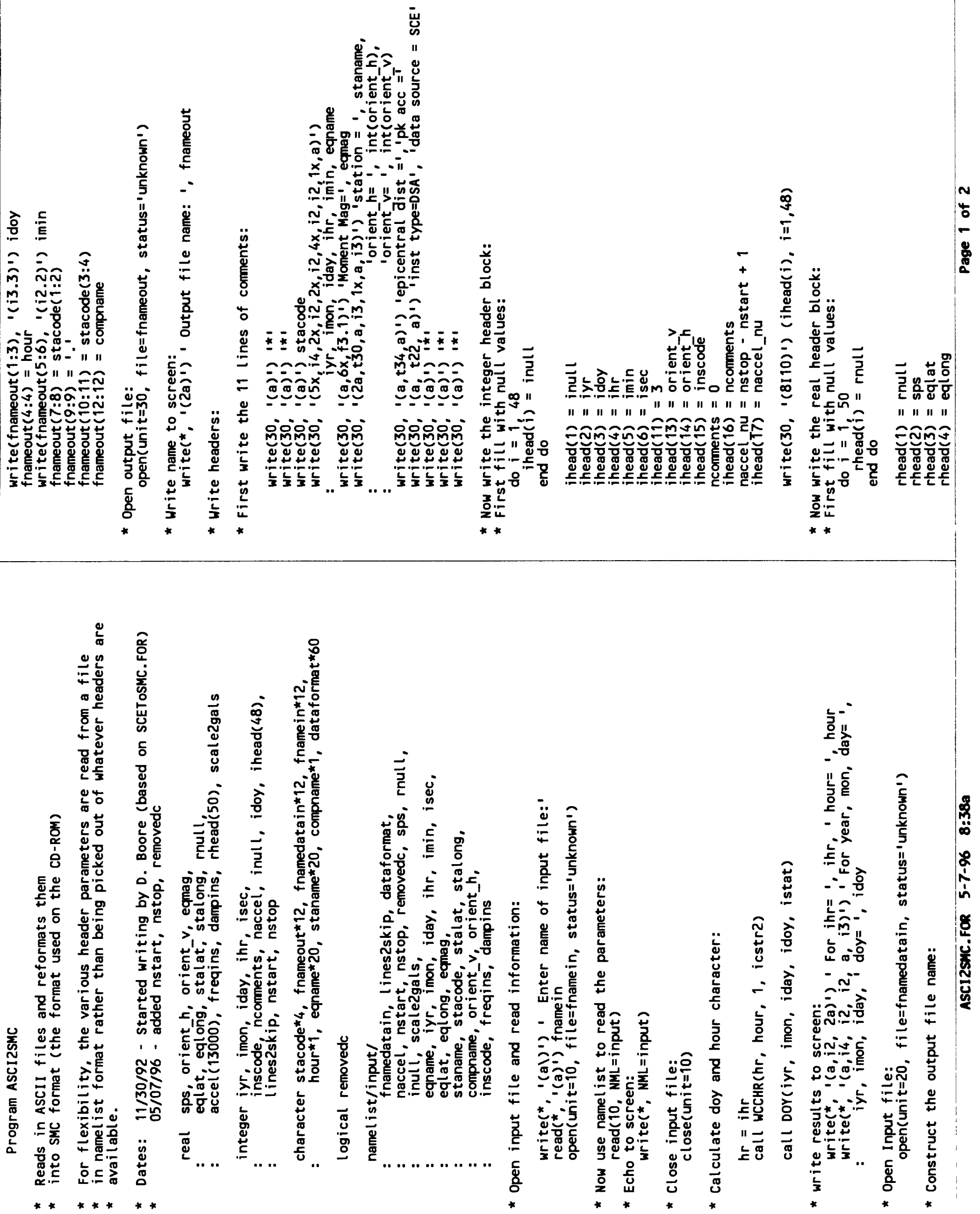




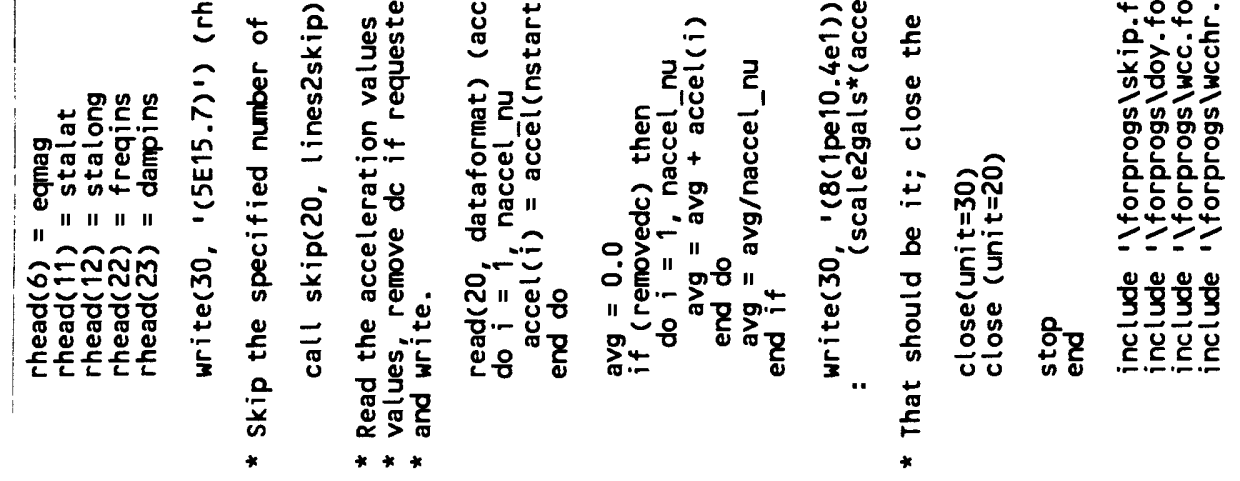



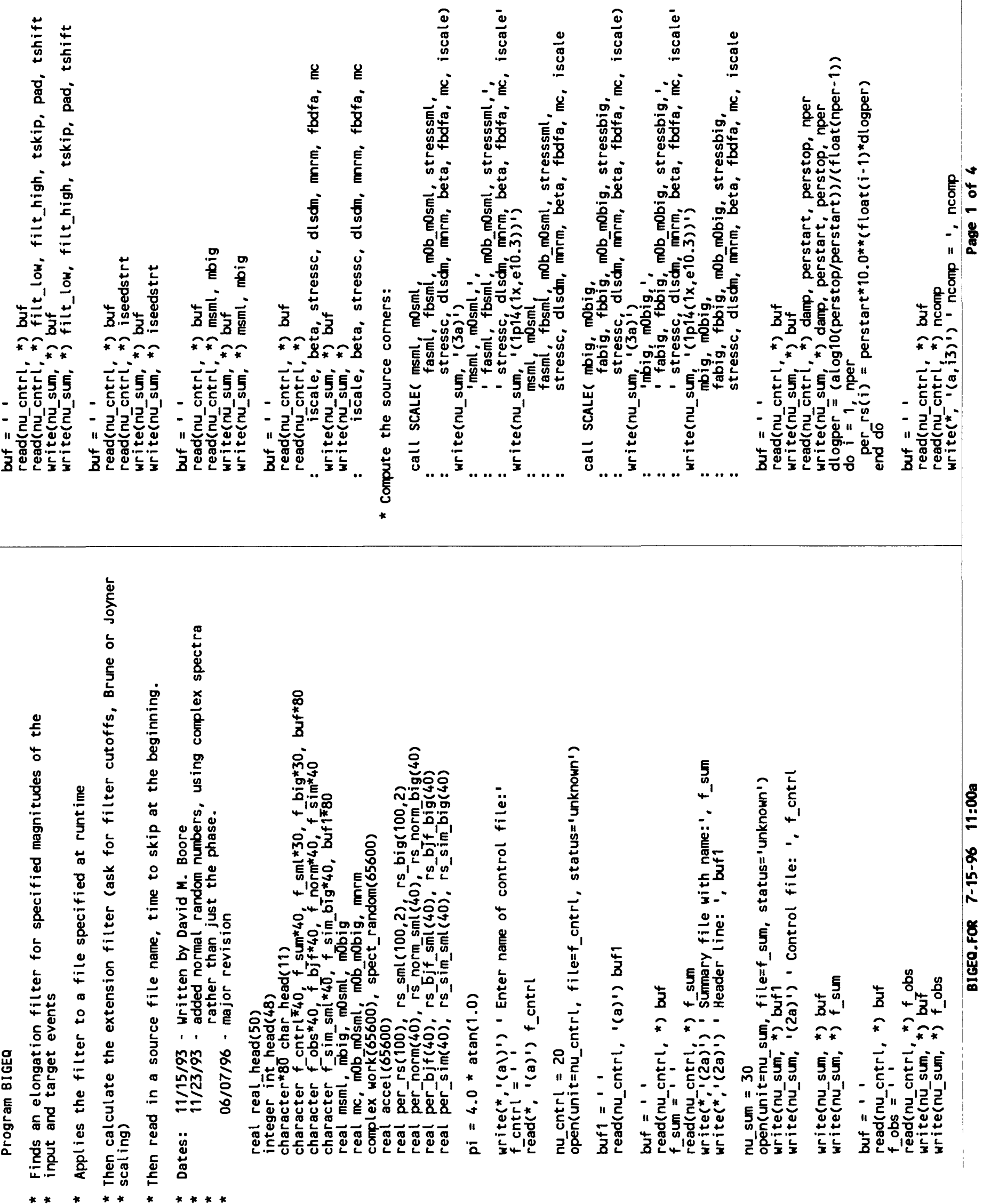

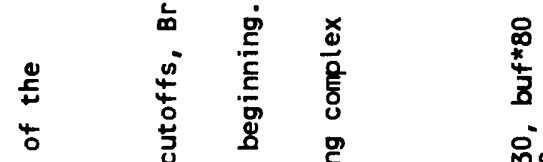

总 总

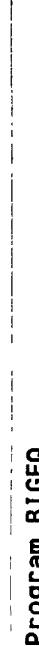



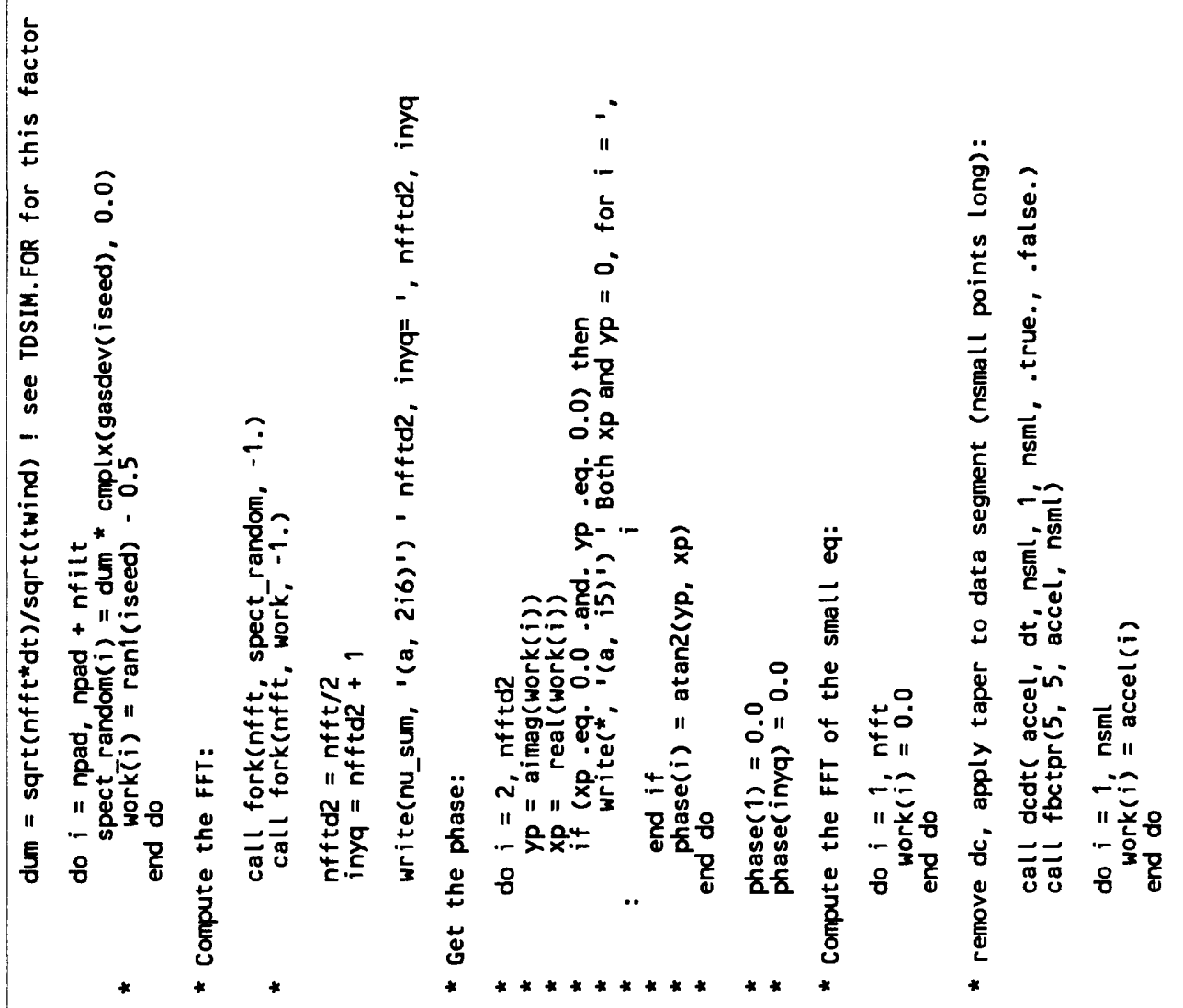


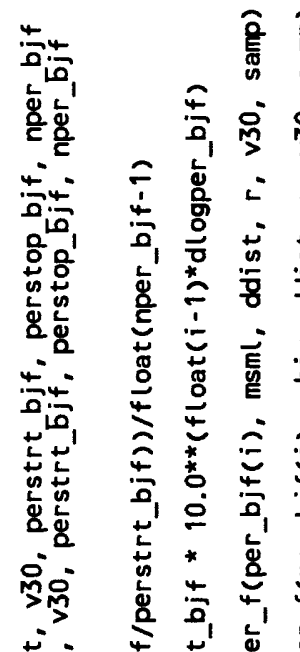

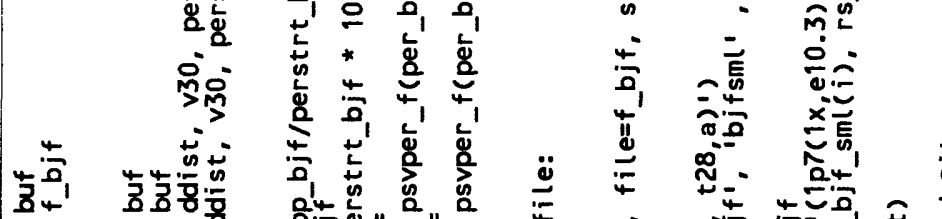

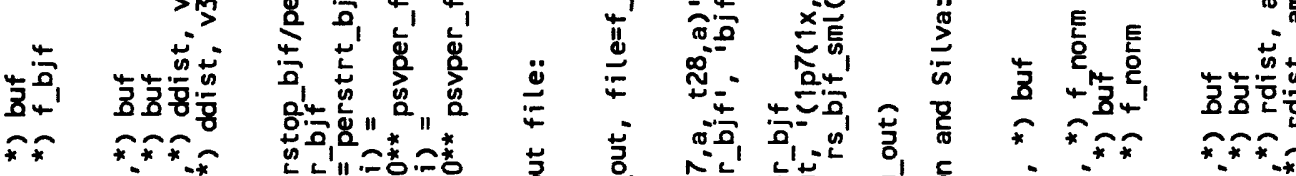

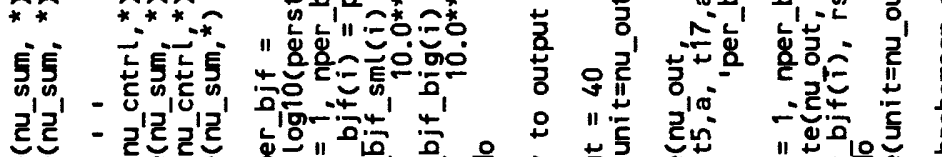

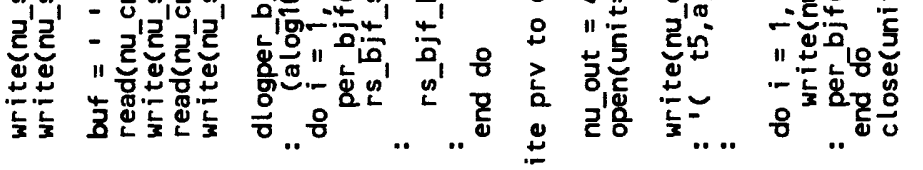

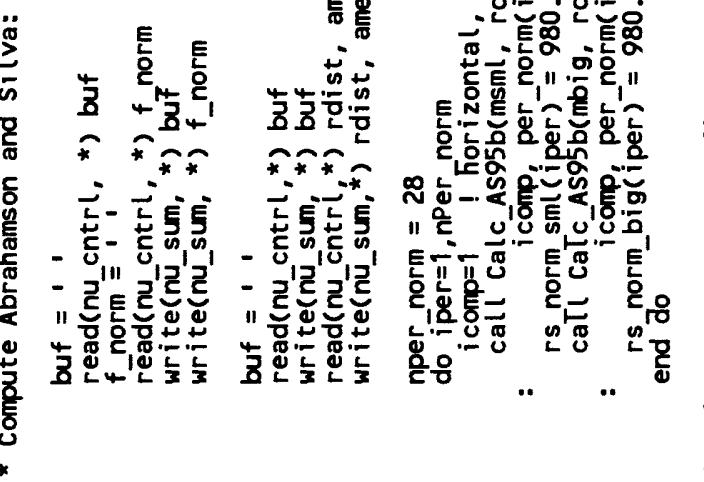

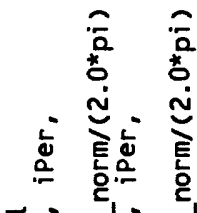

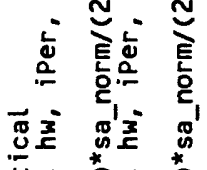

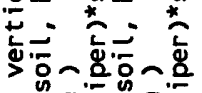

न-

至 "

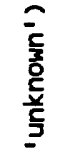

密热

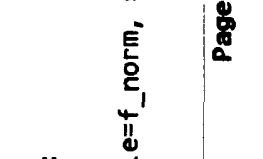



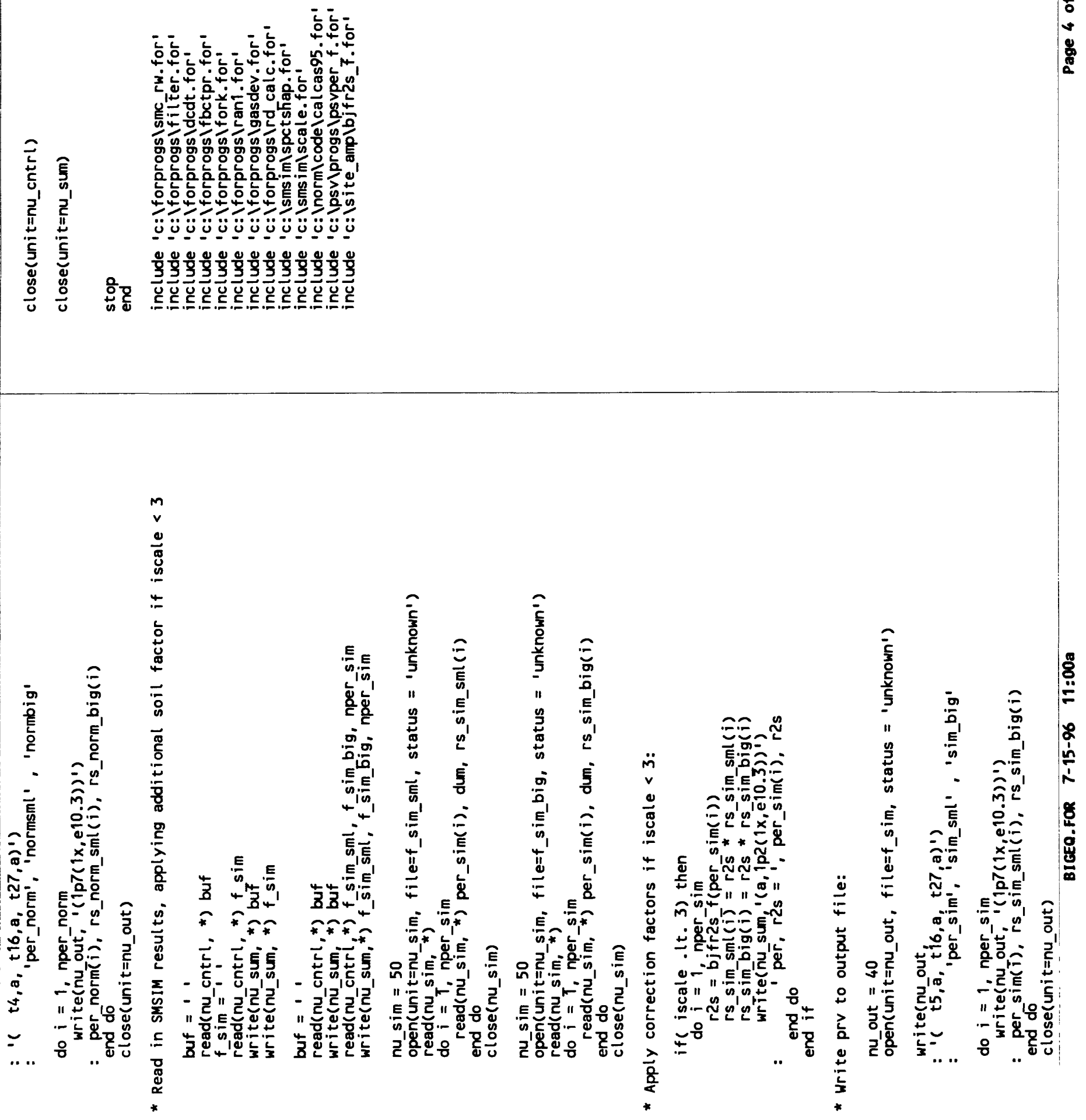


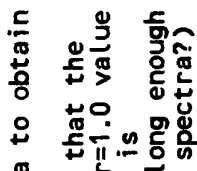

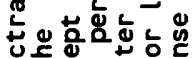

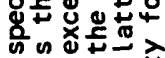

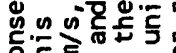

है

oNํ은

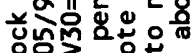

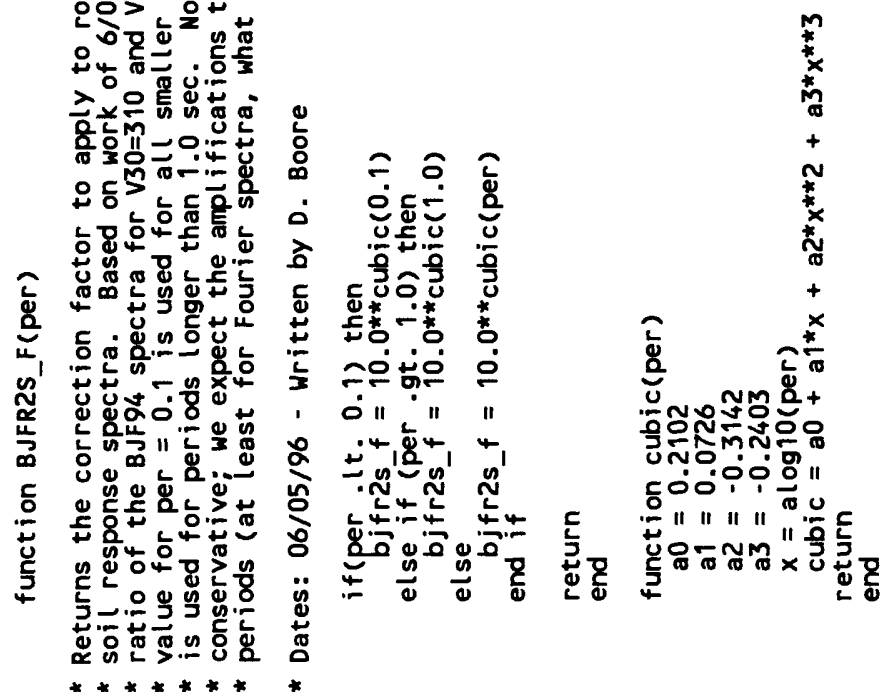



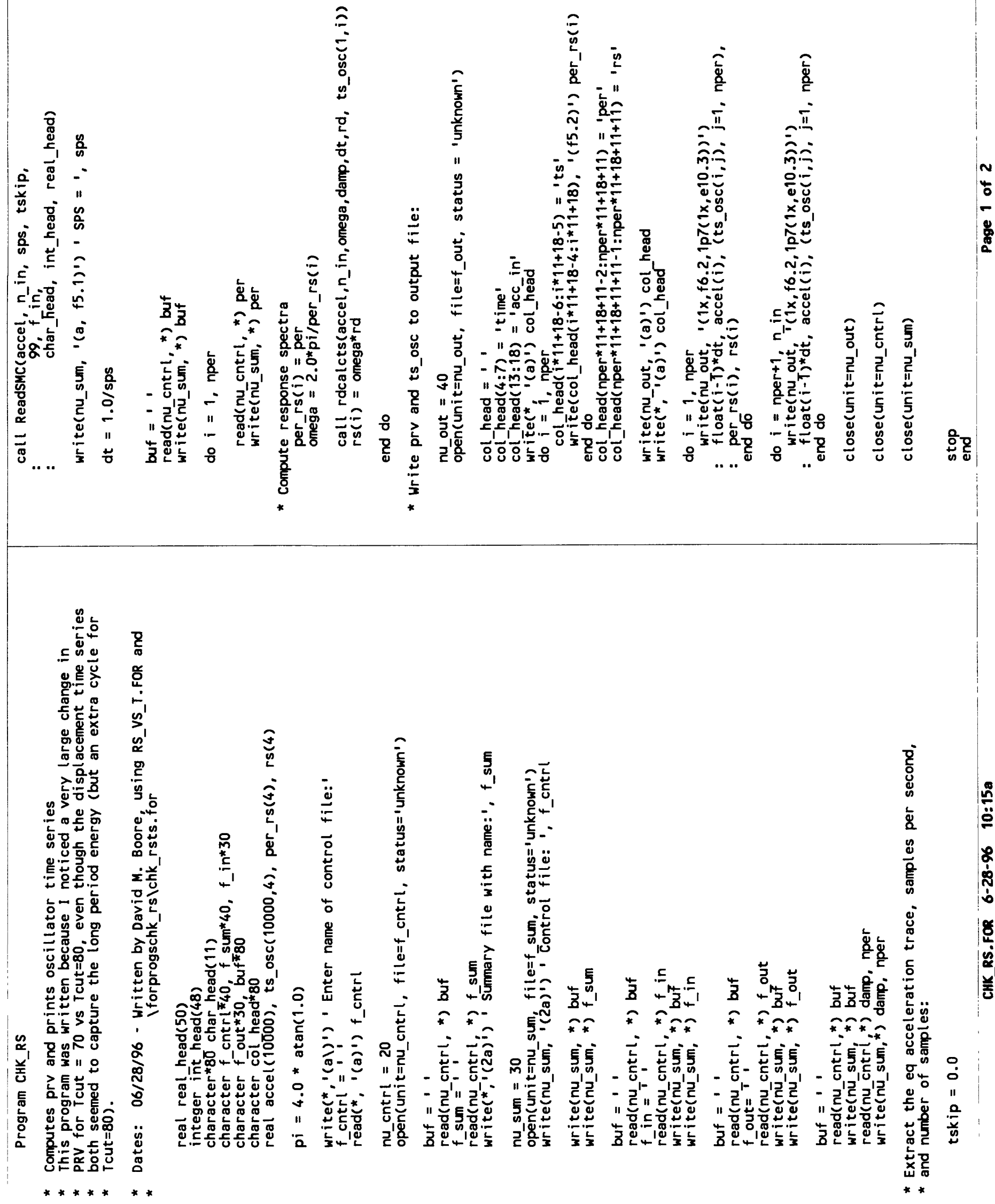
$\frac{0}{\frac{9}{2}}$

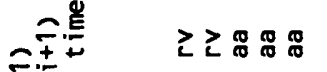

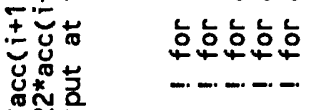

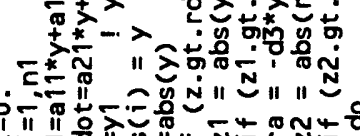

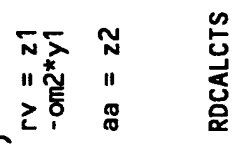

엥

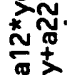

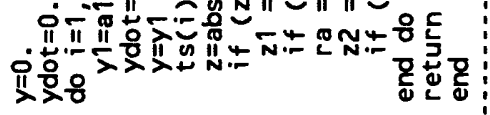

- i

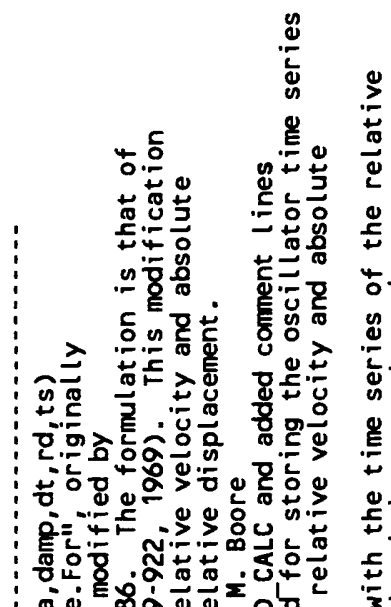

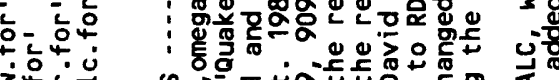

눈은

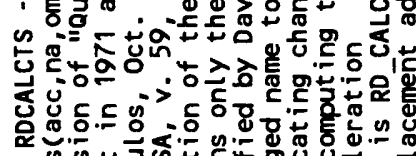

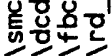

엉몽응

흔흔흔

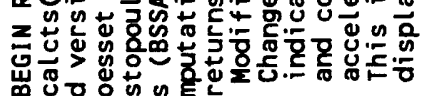

ن

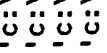

ะะํํํำ

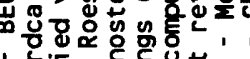

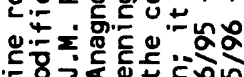

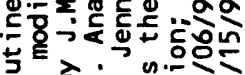

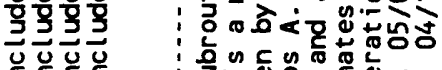

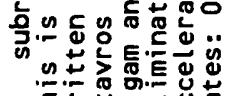




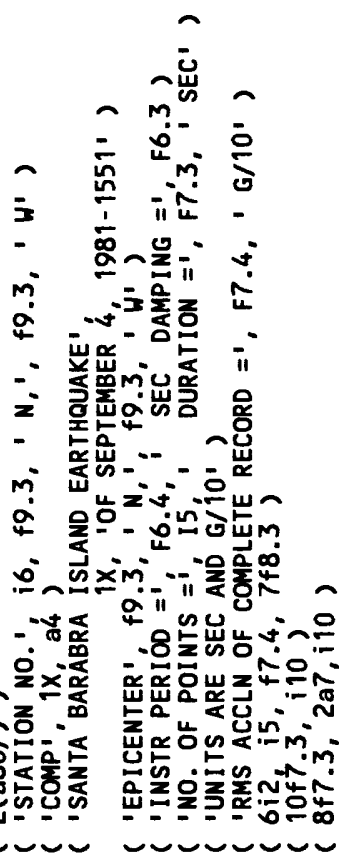

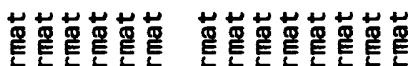

twant

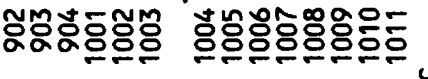

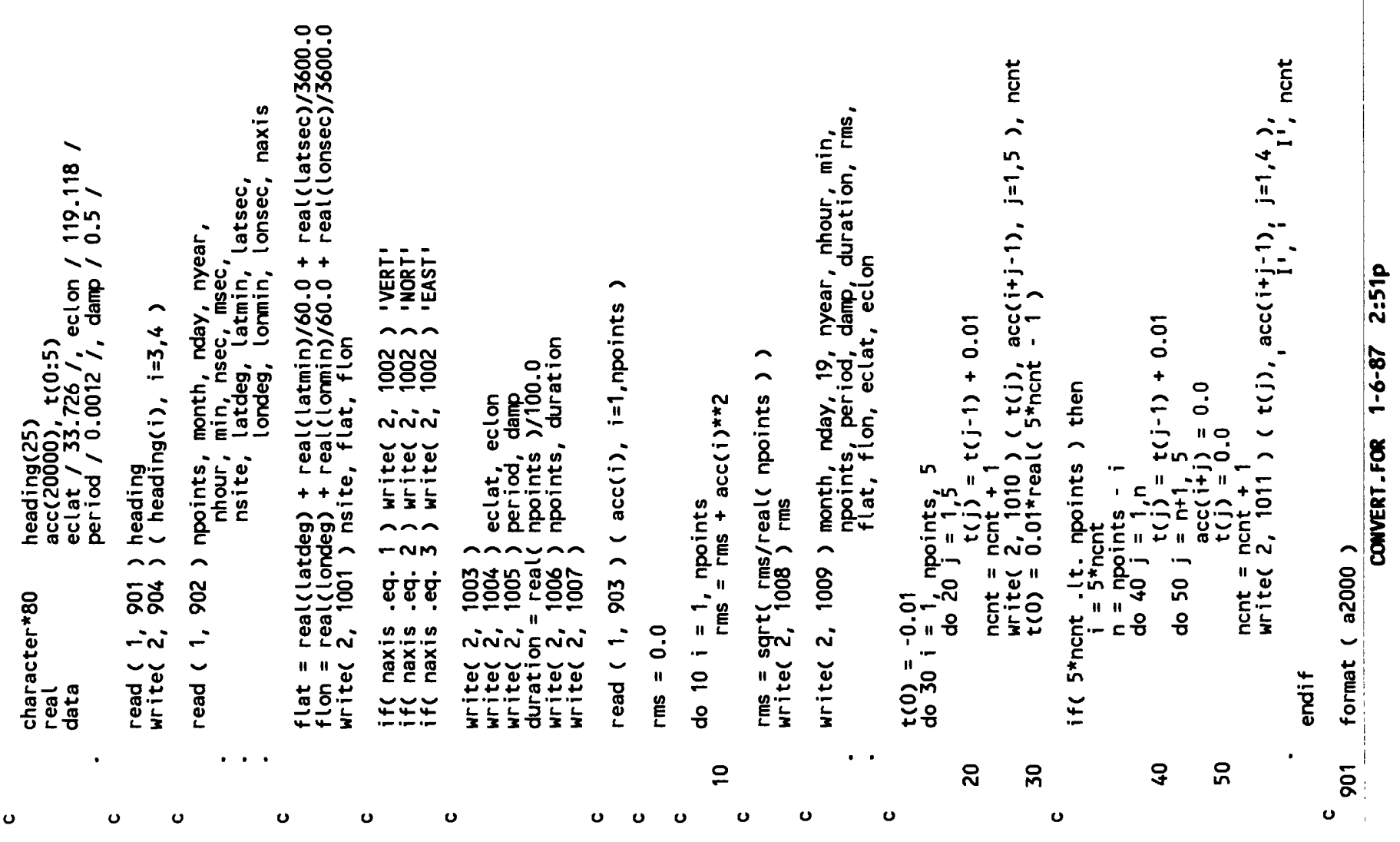




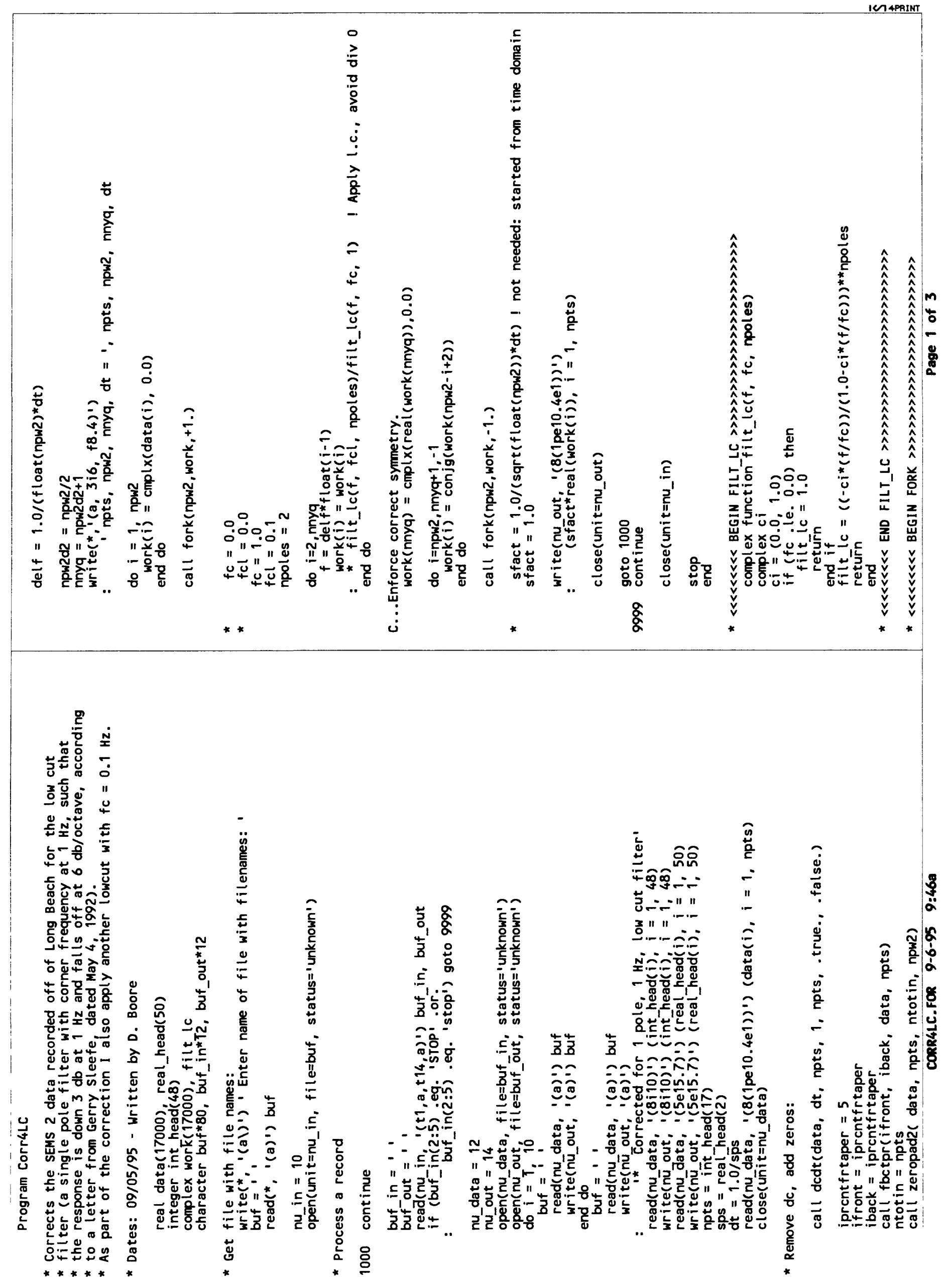




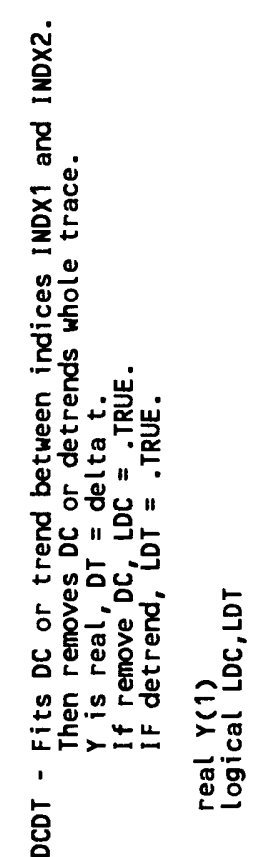

t000000 0

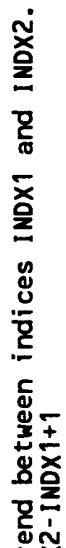

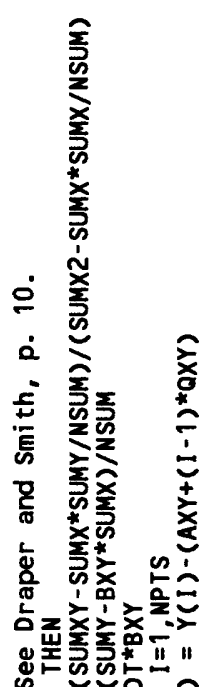

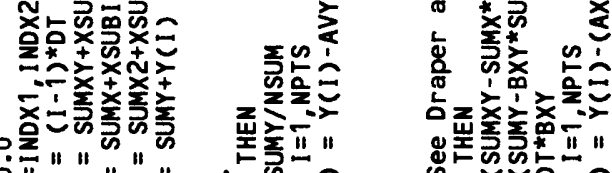

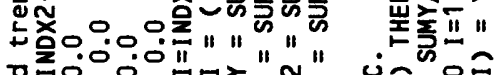
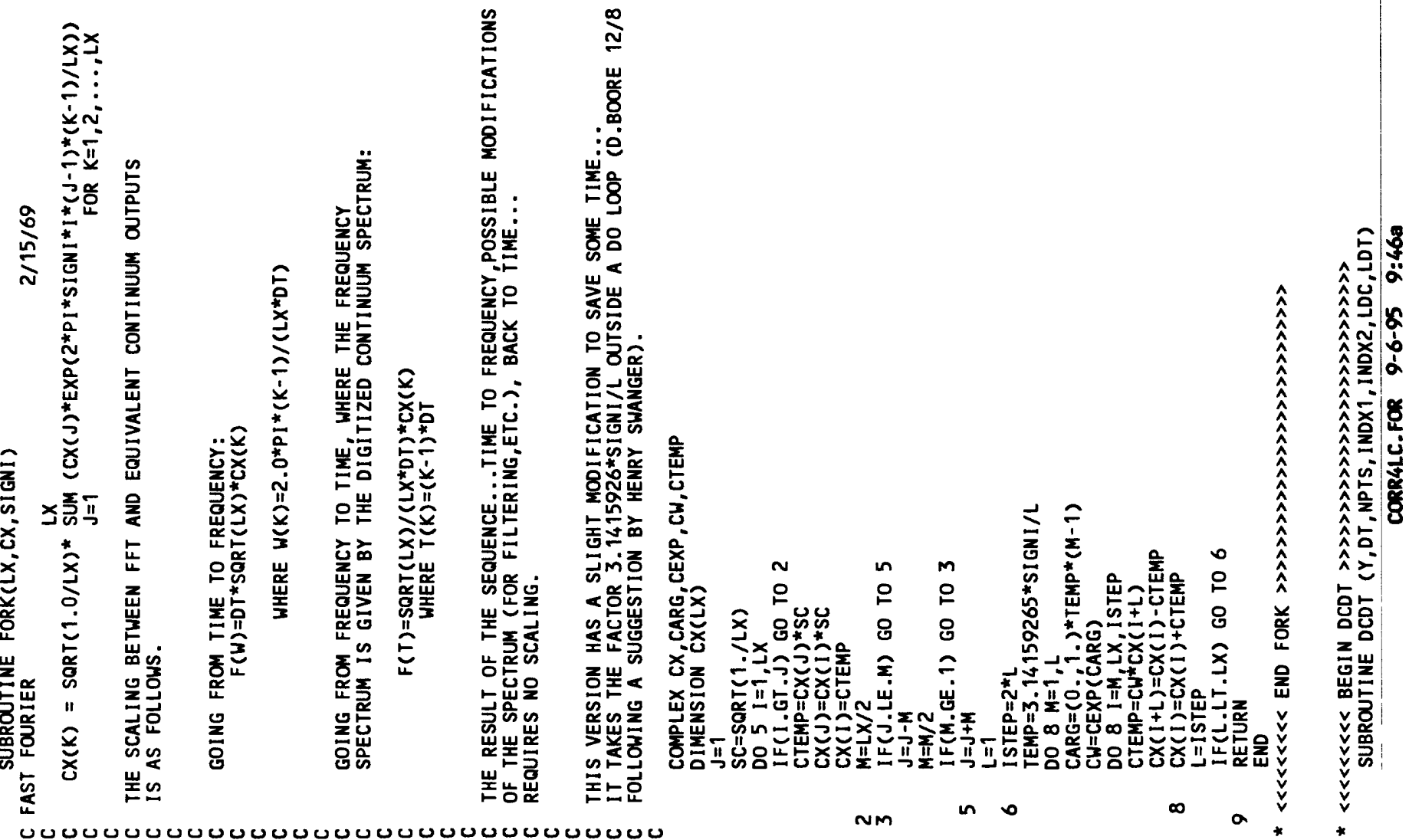


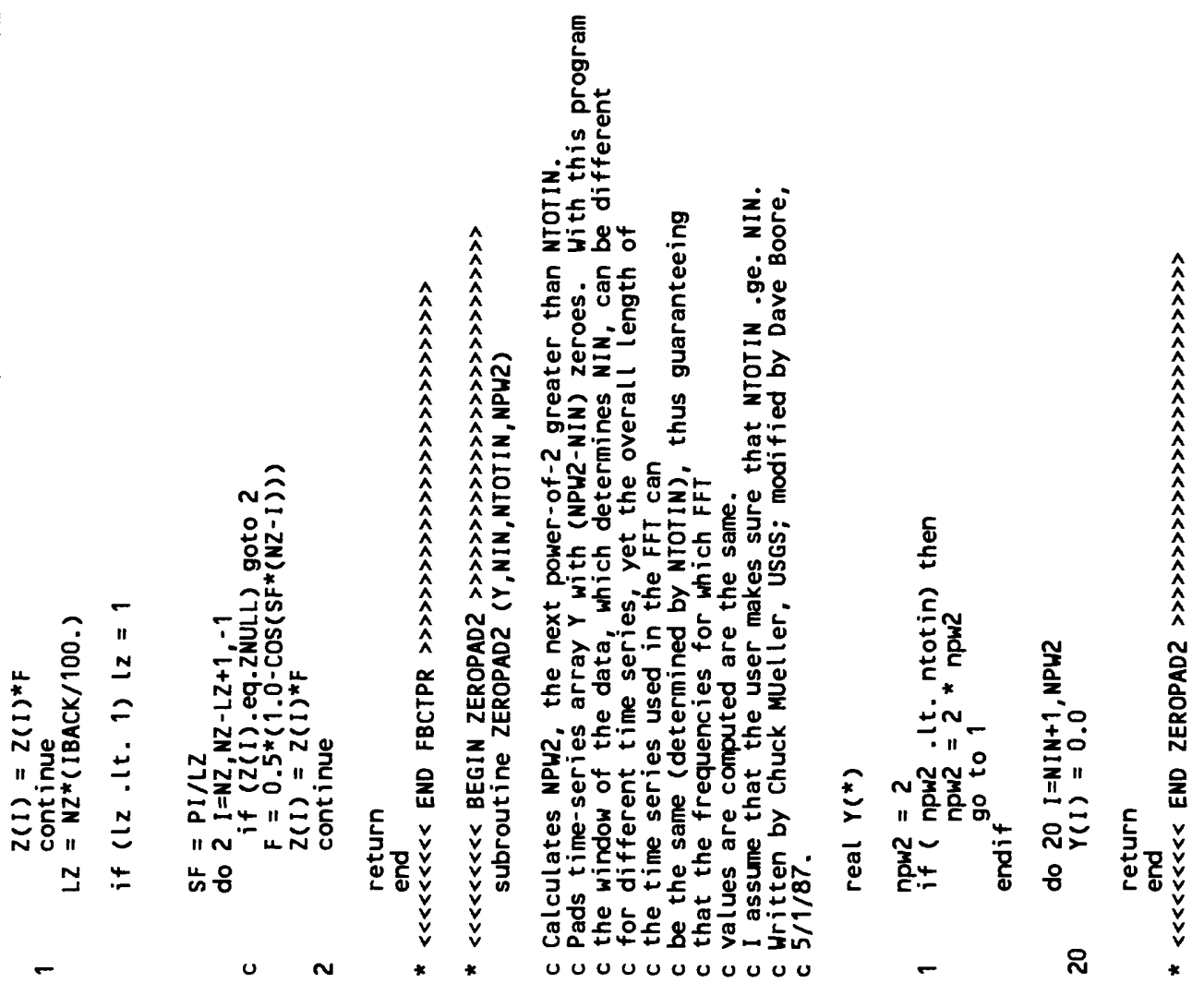



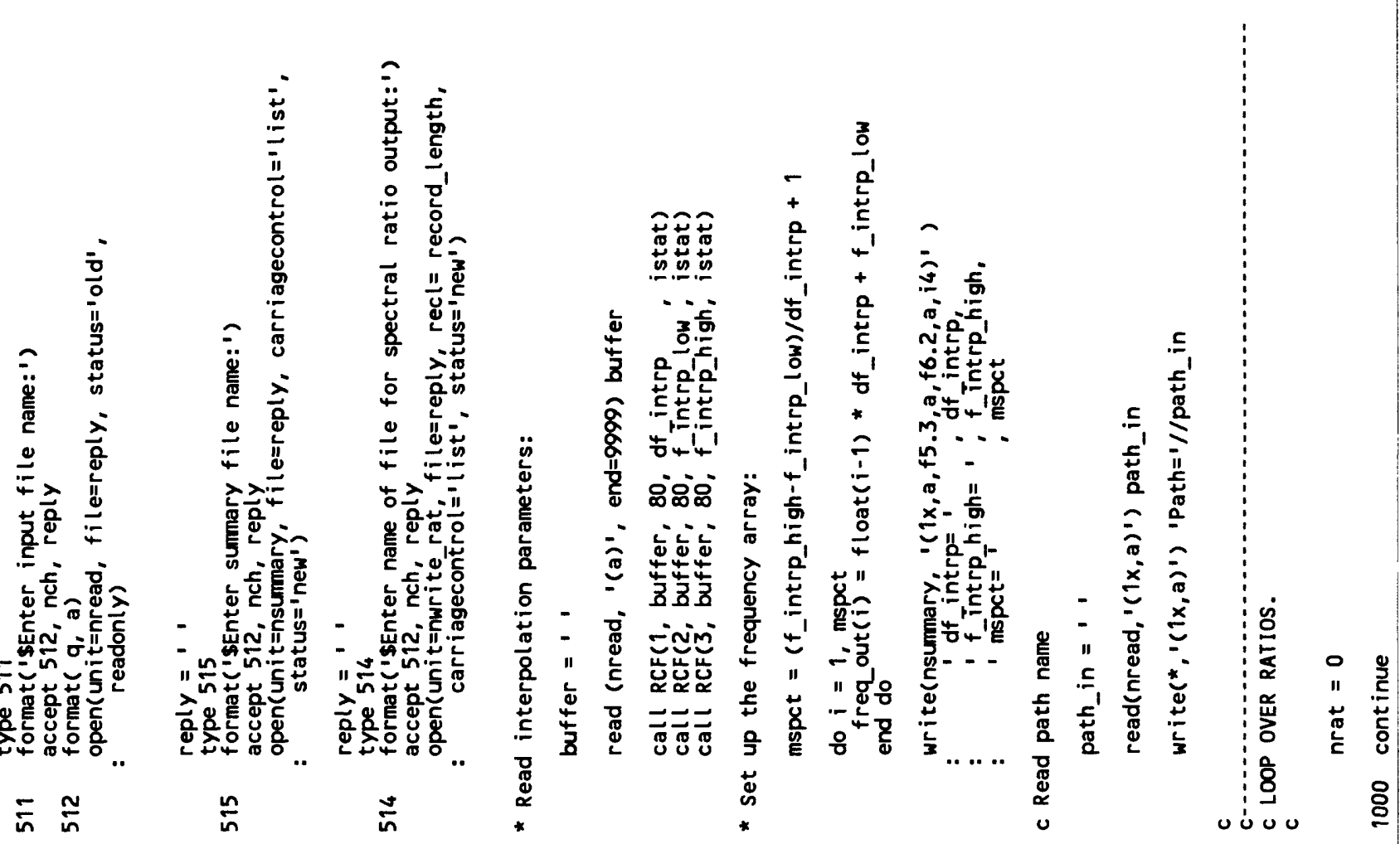

(2)

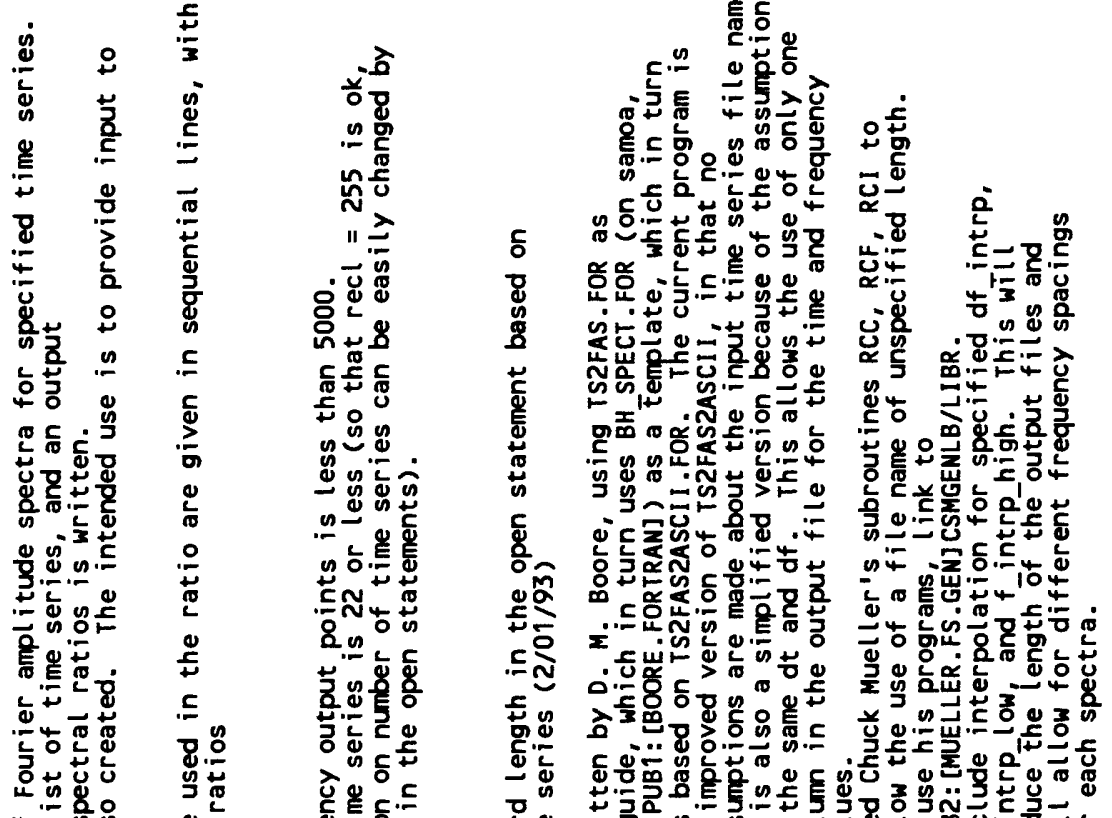

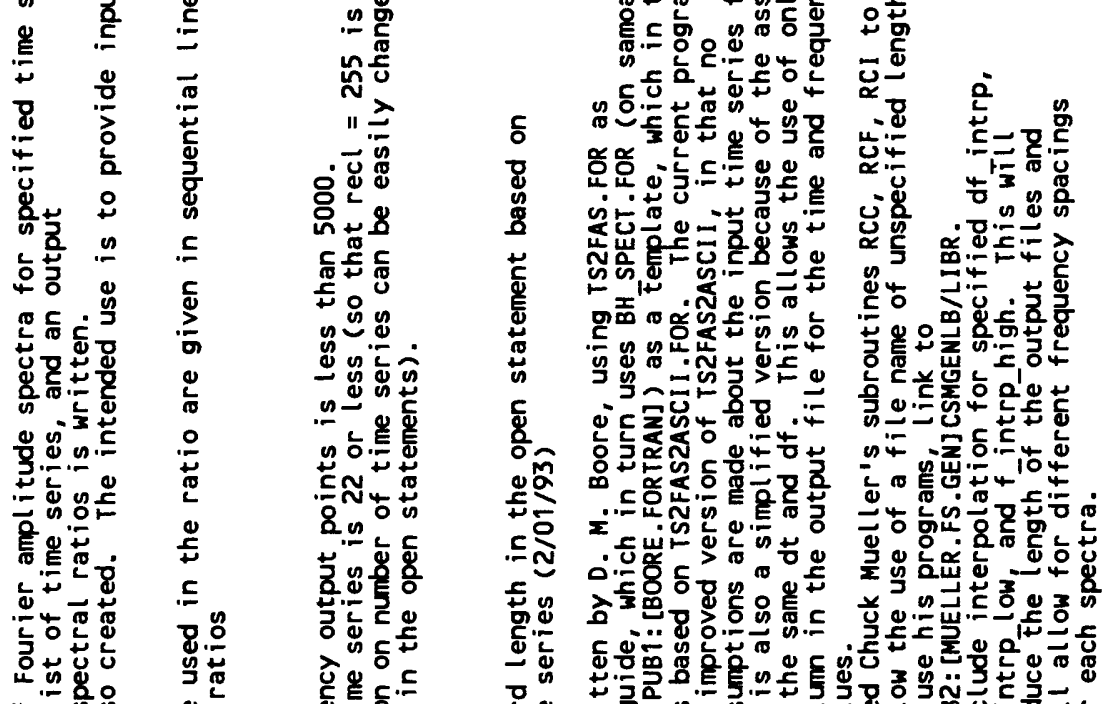

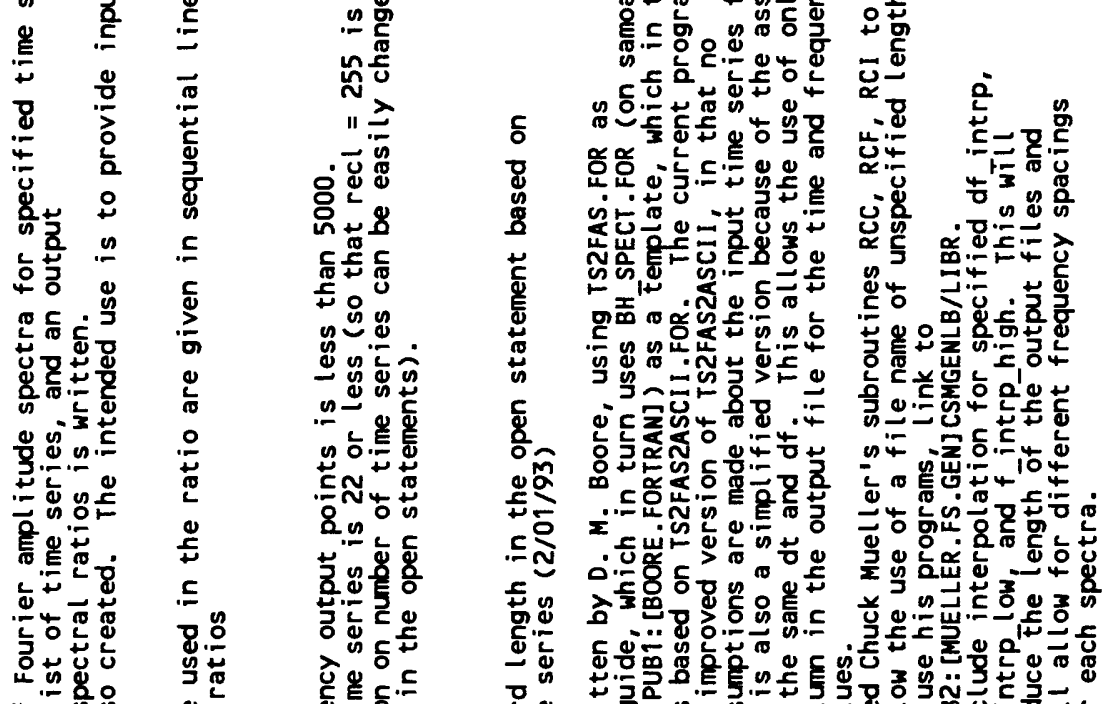

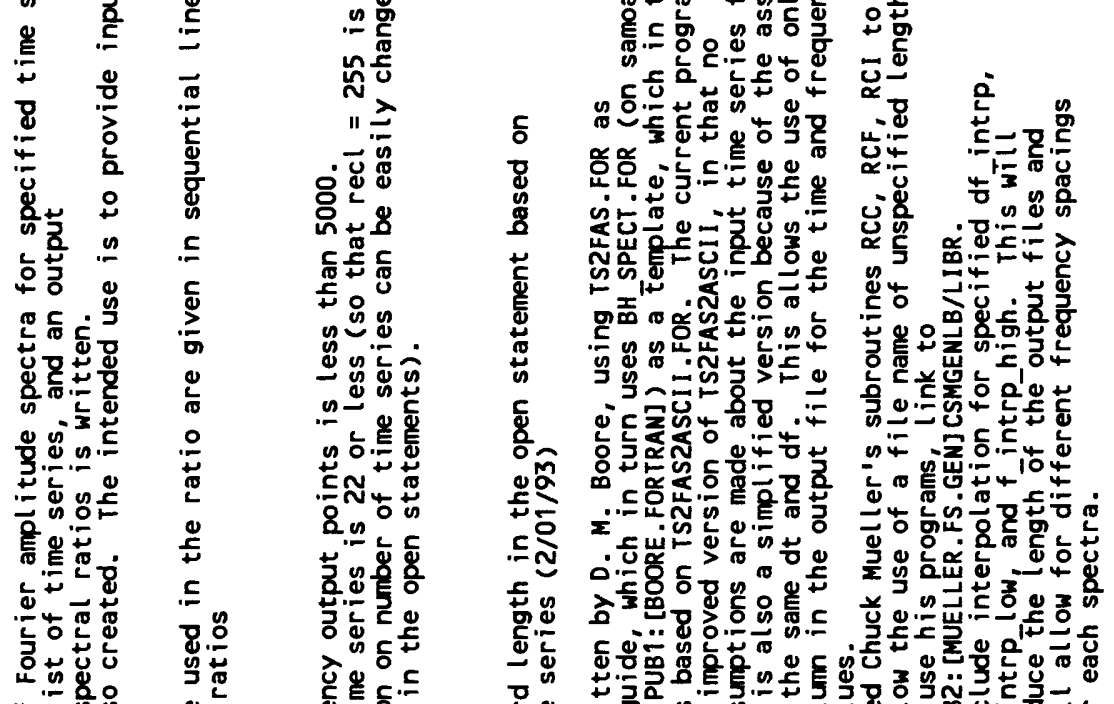

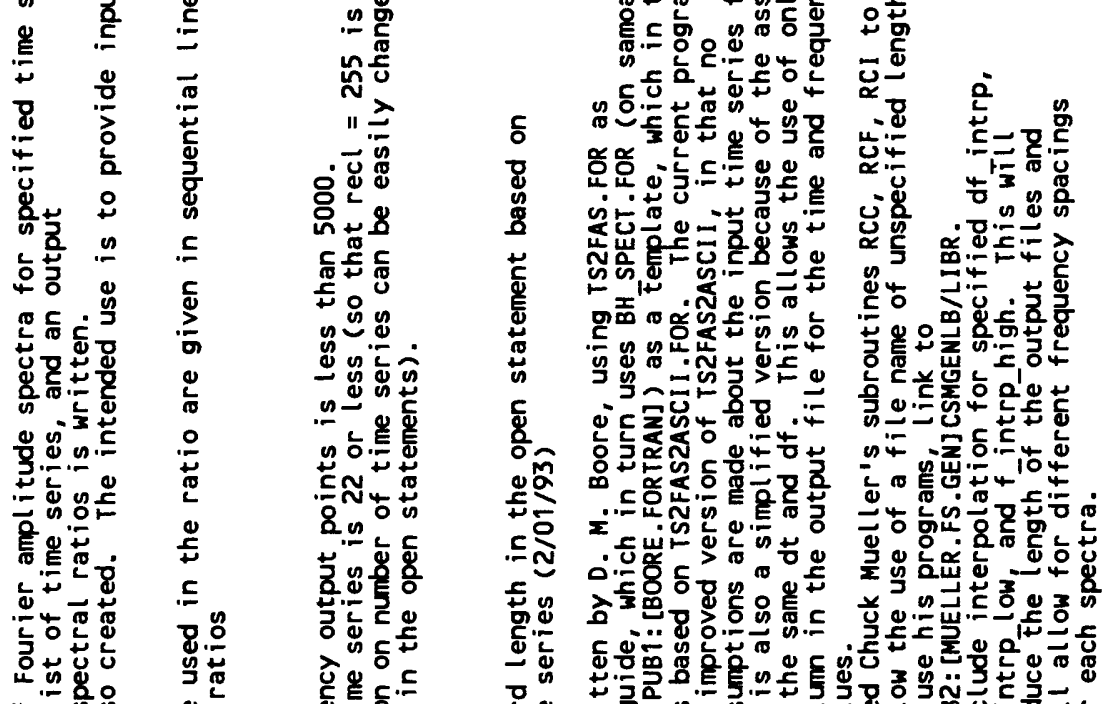

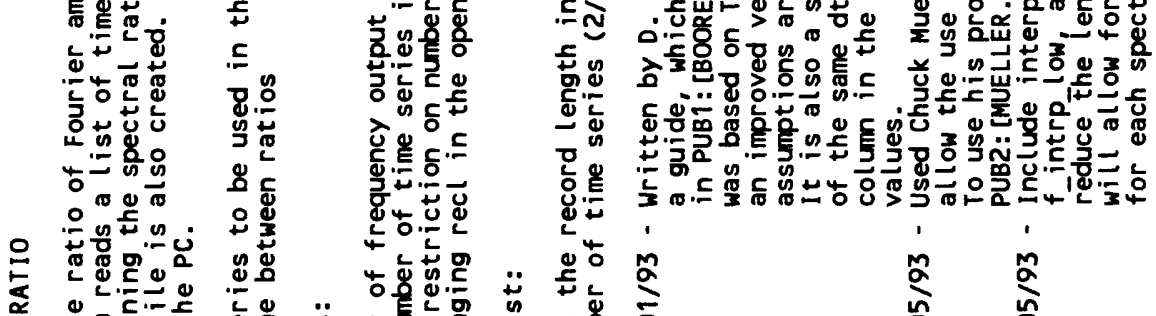

政

틍

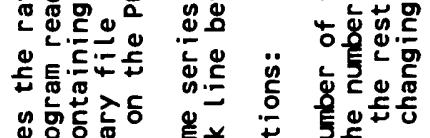

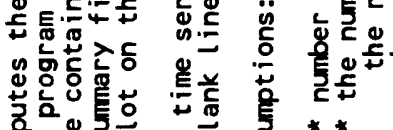

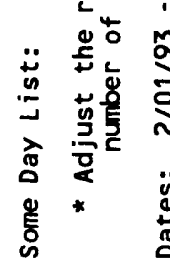
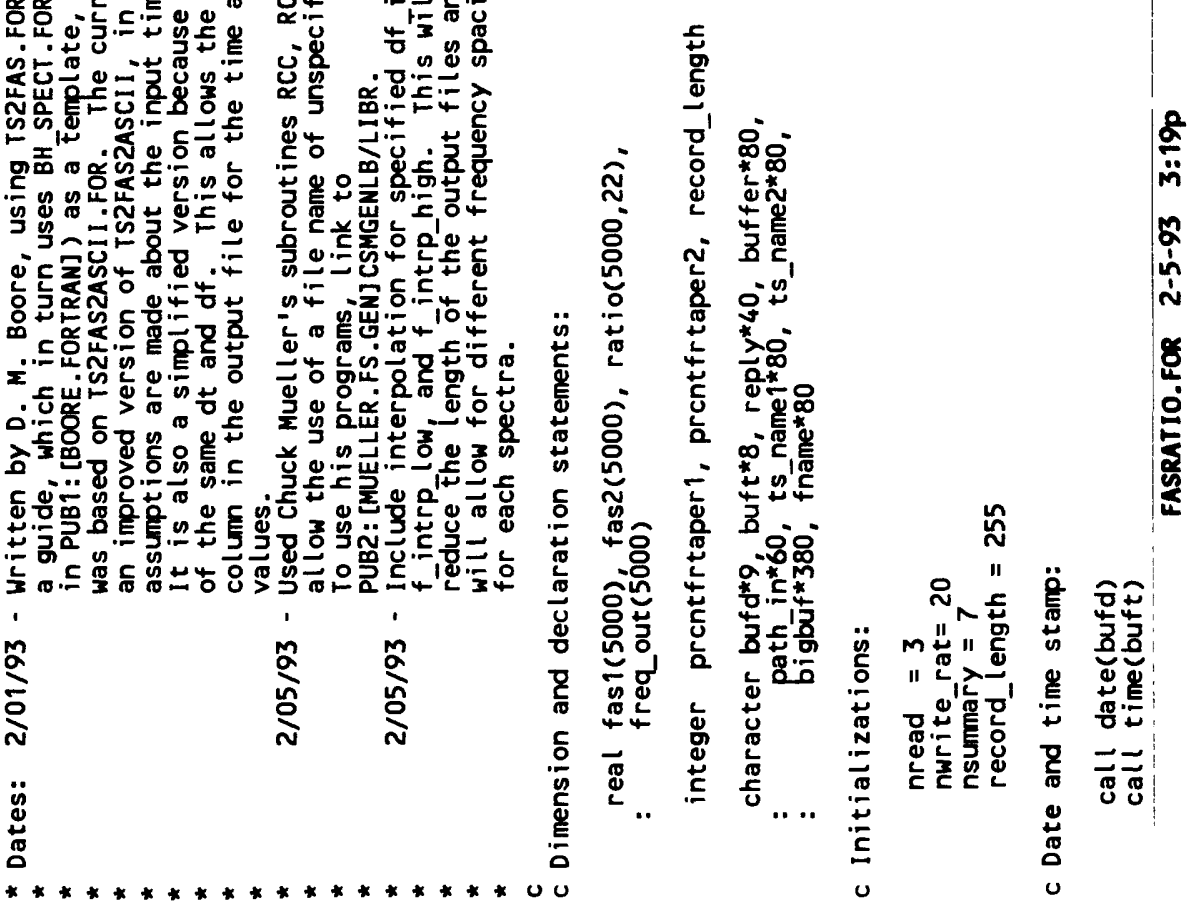

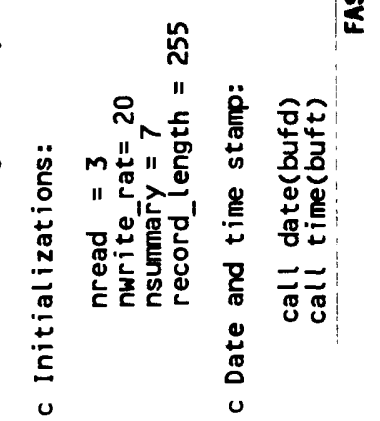




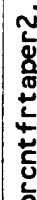

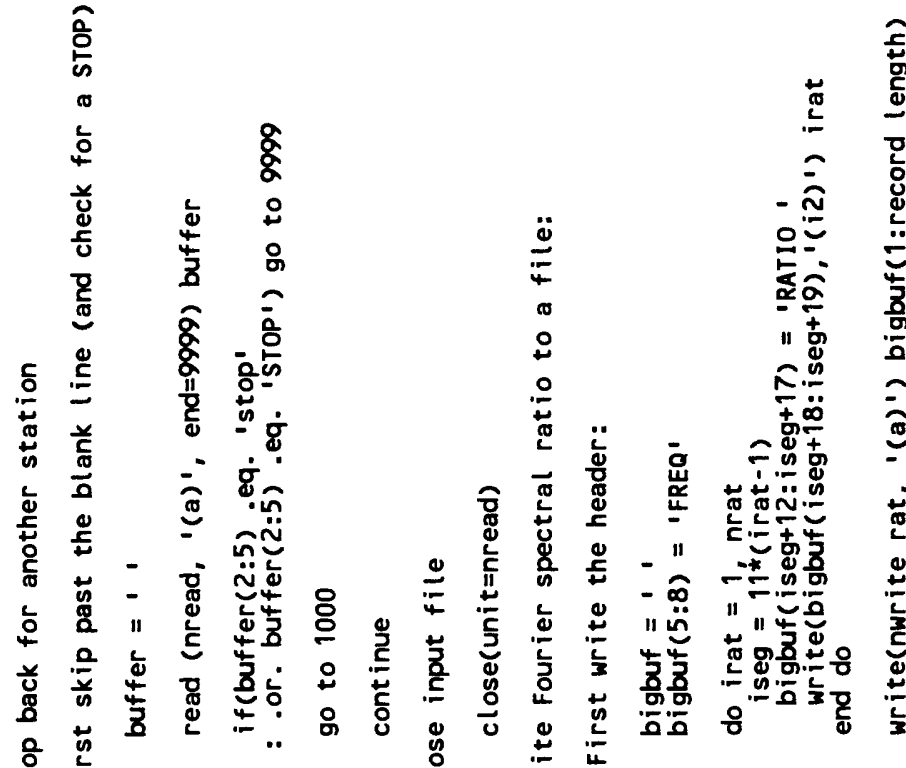

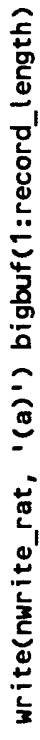
芩

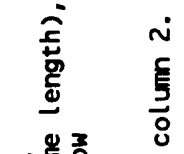

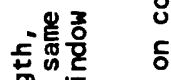

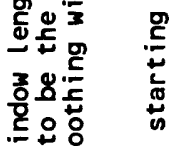

$\ddot{0}$

范言

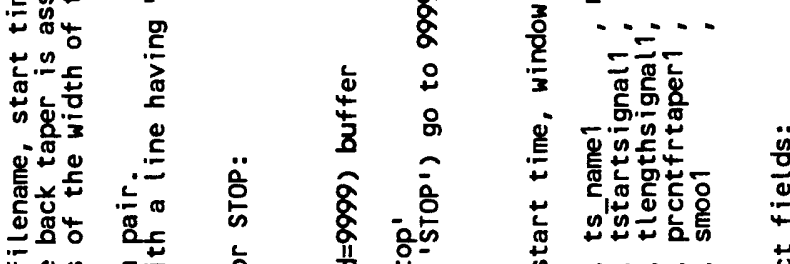

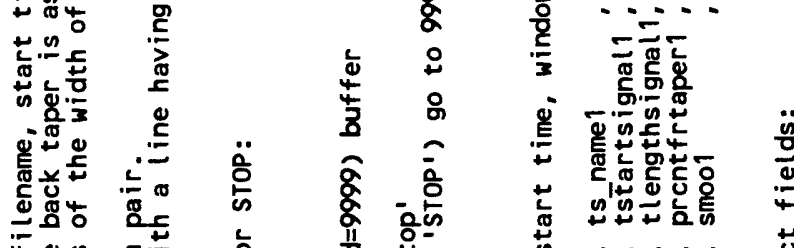

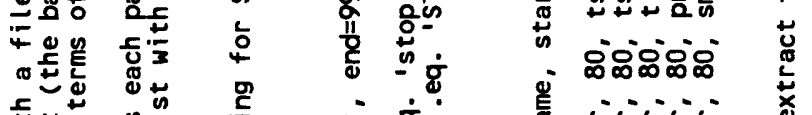

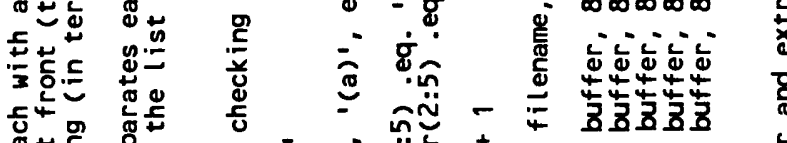

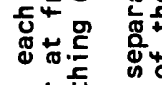

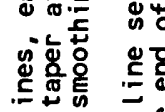

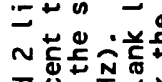

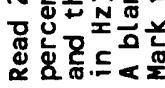

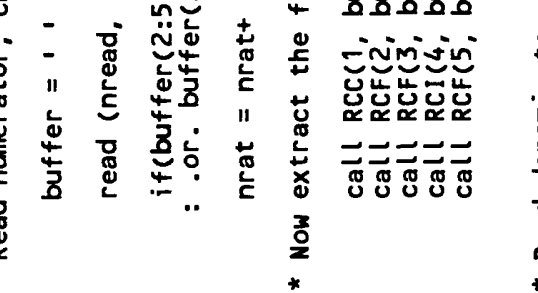

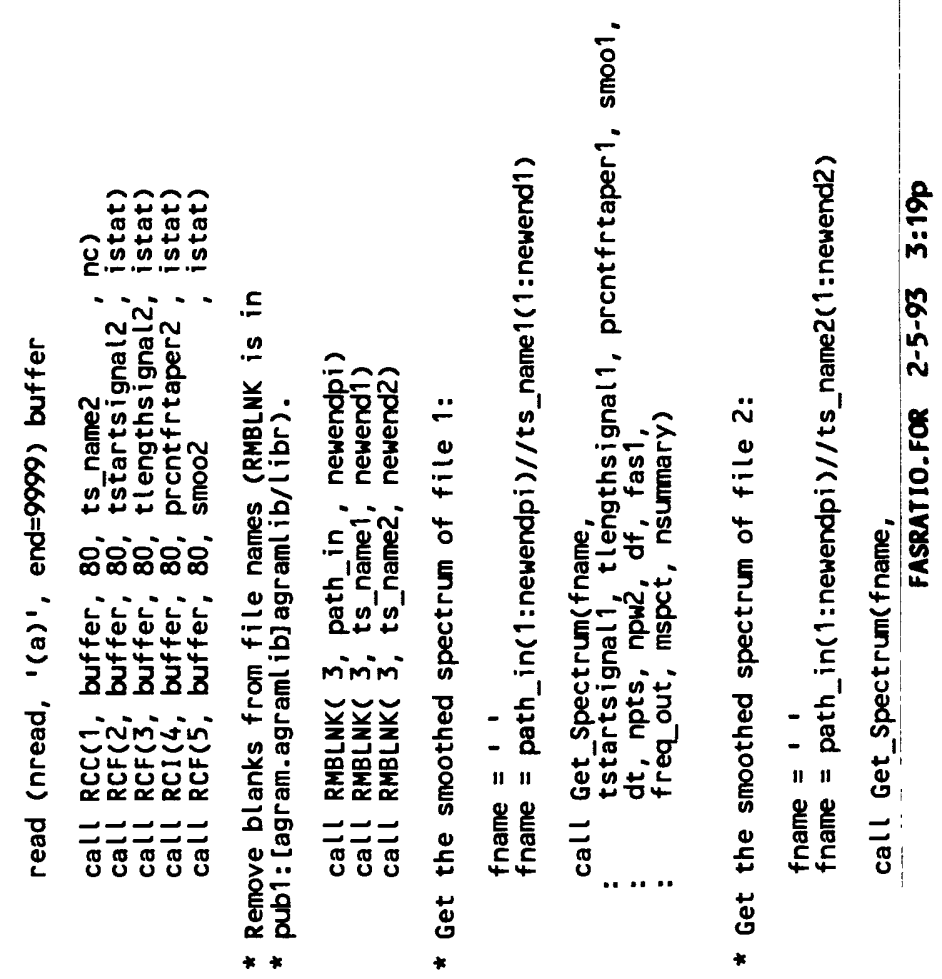




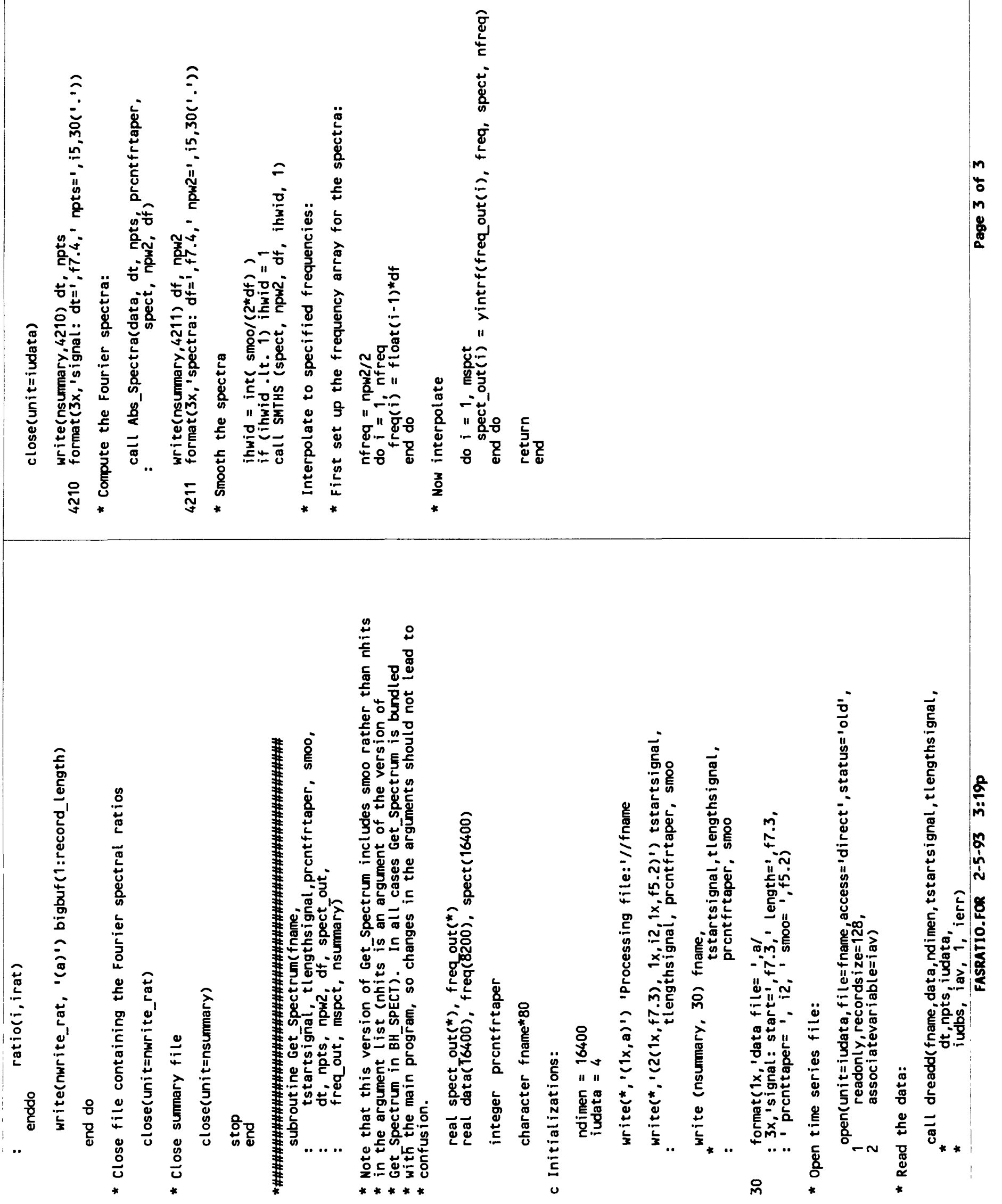




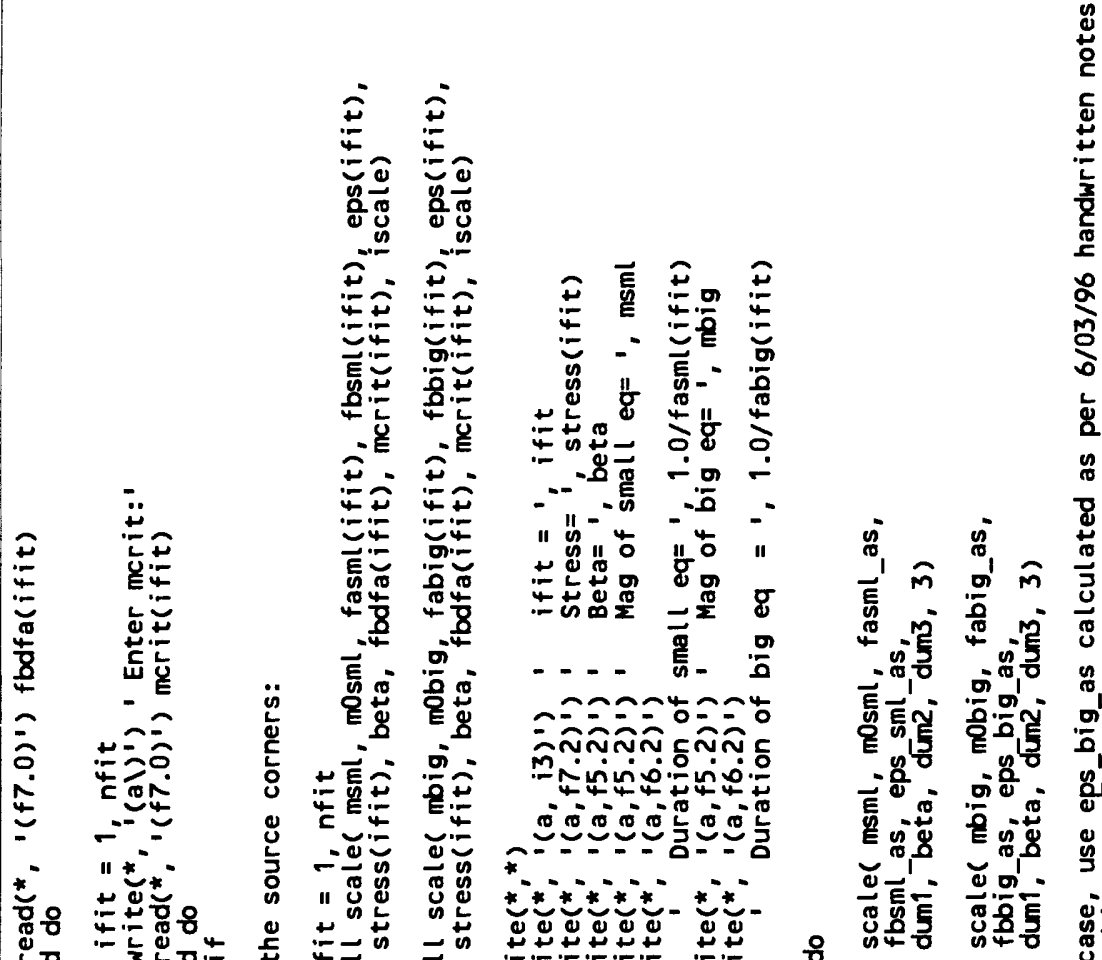

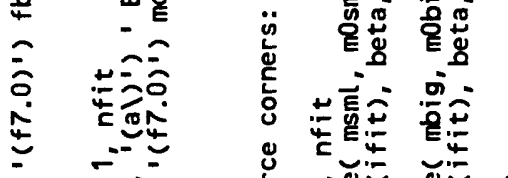

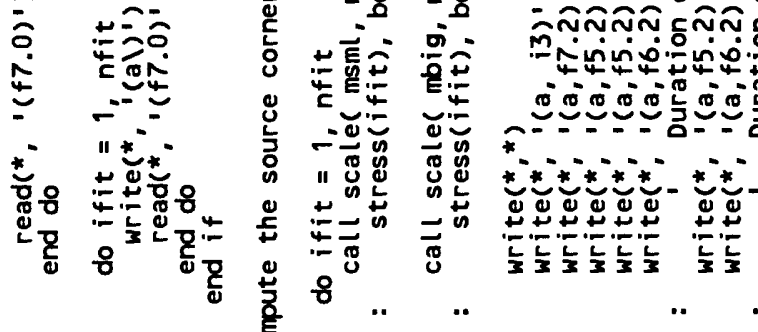

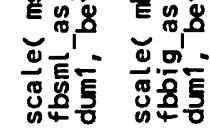

웅

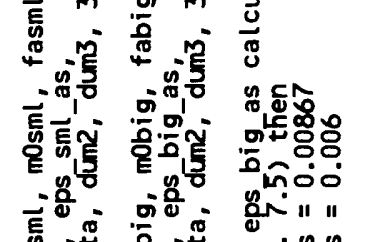

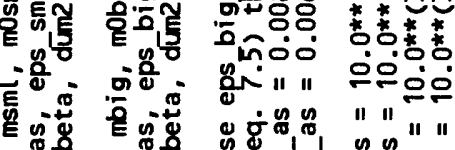

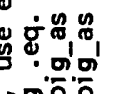

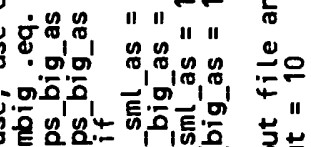

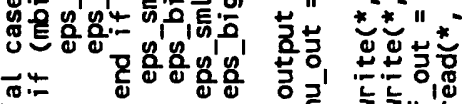

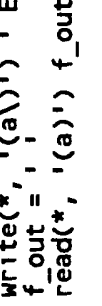

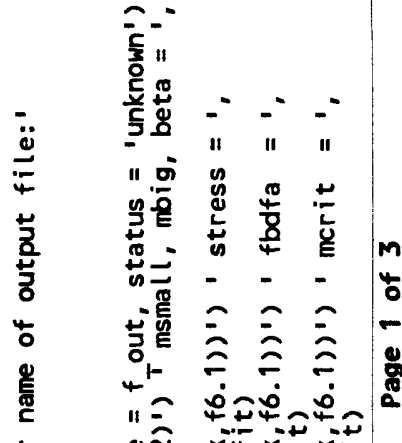

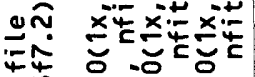
ว

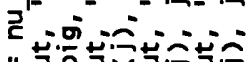
"

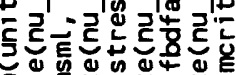

$\because$

\&

gू

\section{(5)}

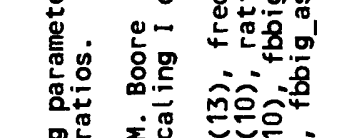

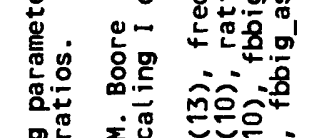

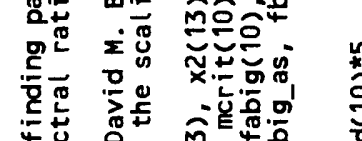

至

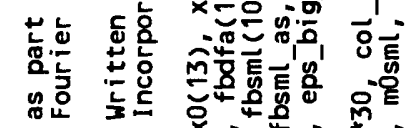

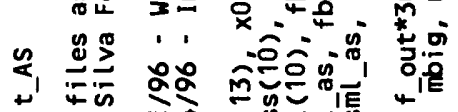

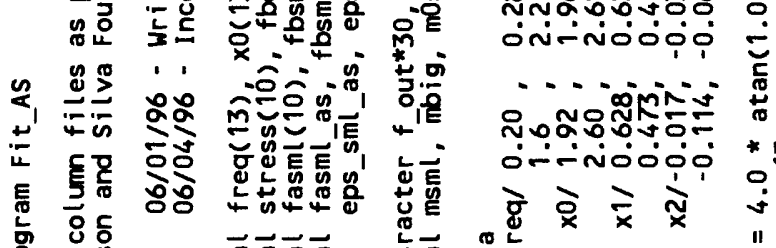

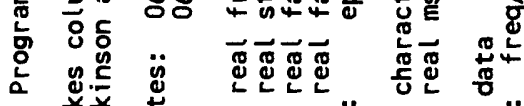

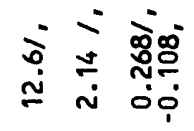

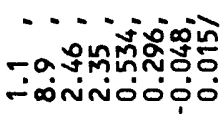

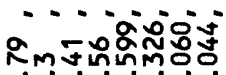

ธonniogọ

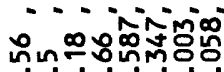

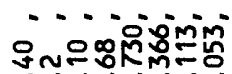

óminioiọ:

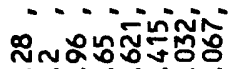

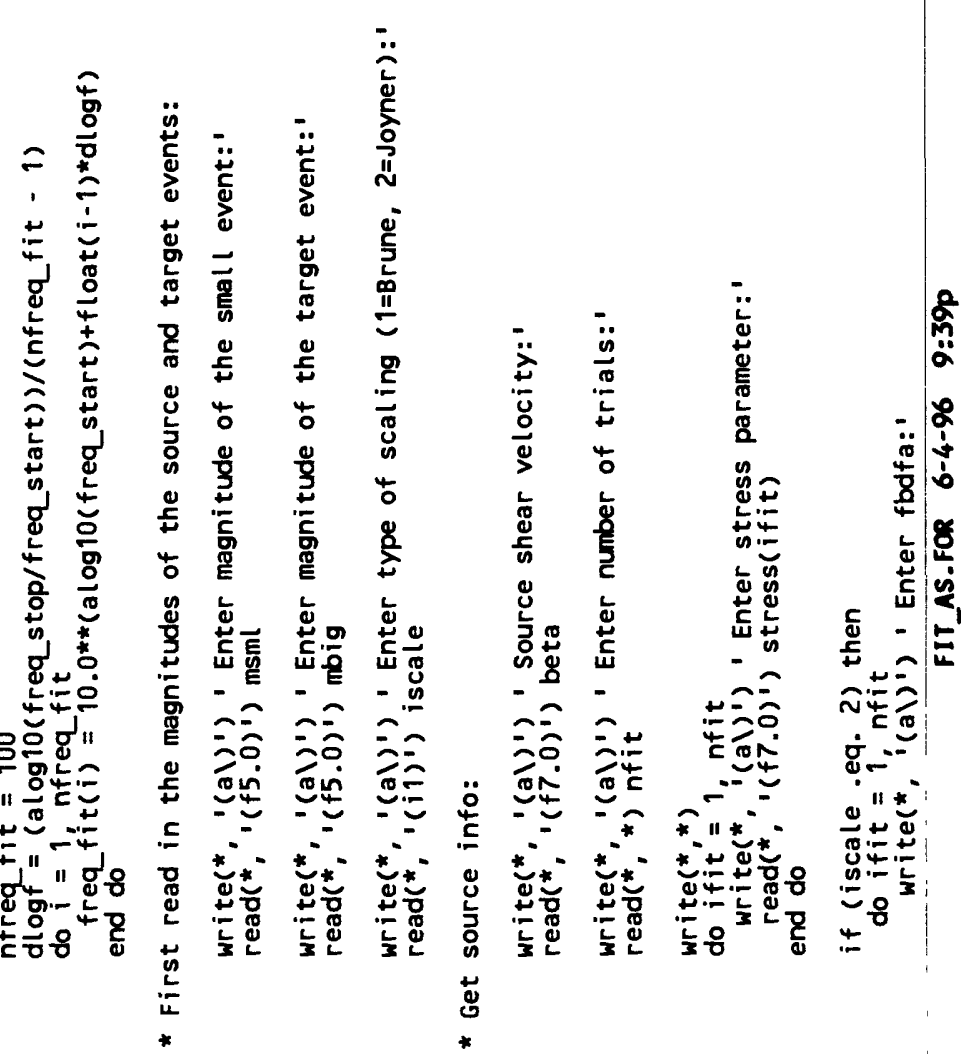




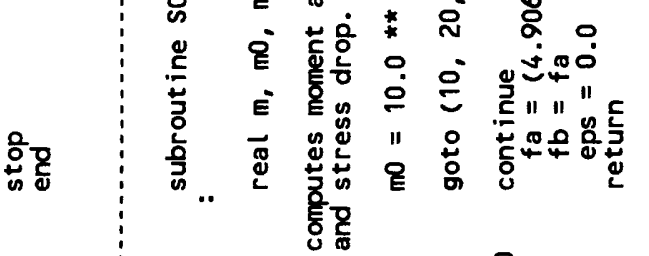
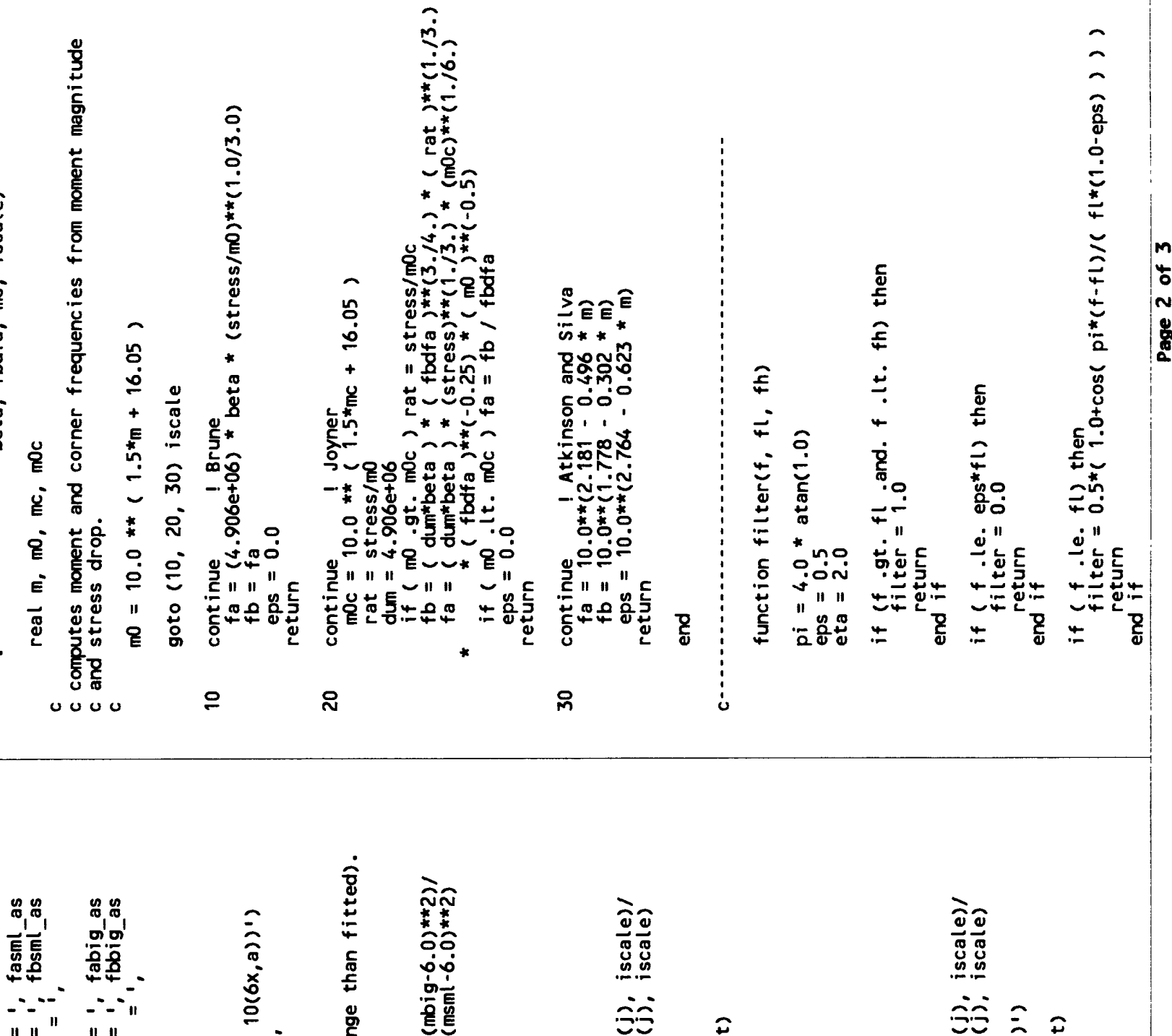

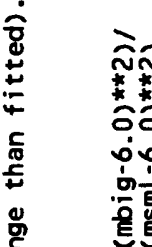
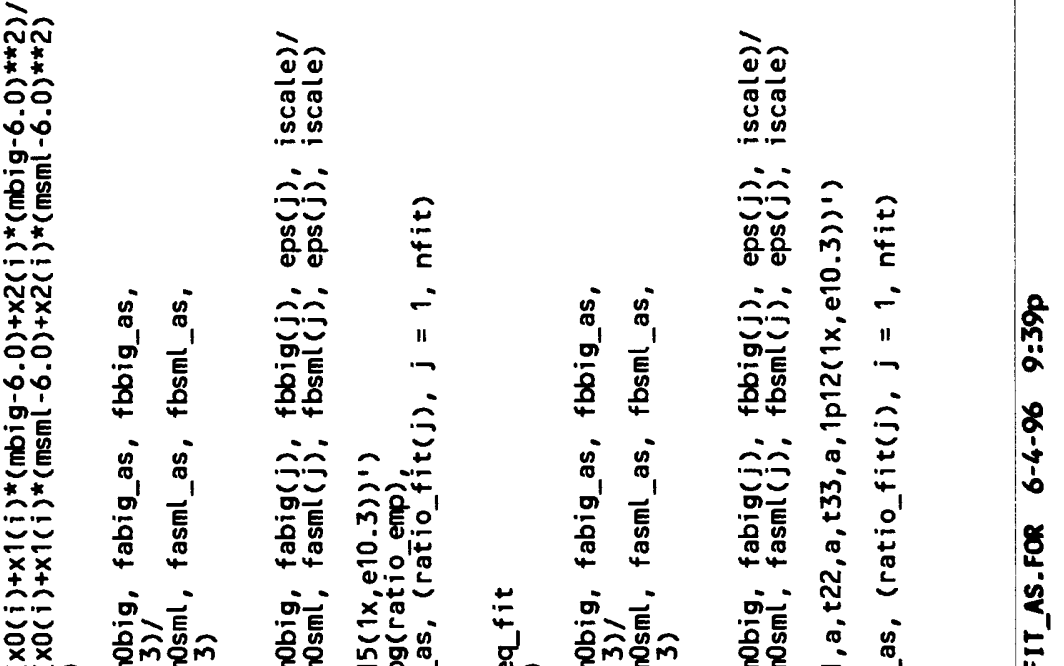

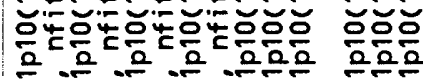

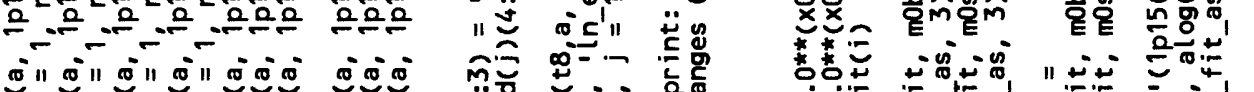

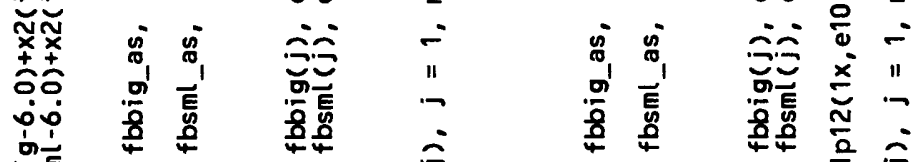

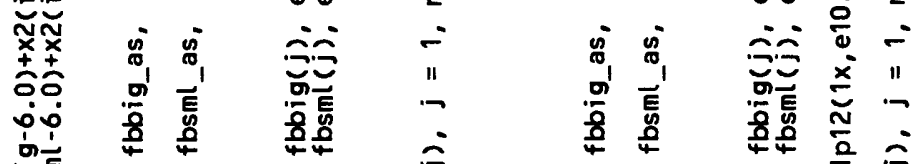

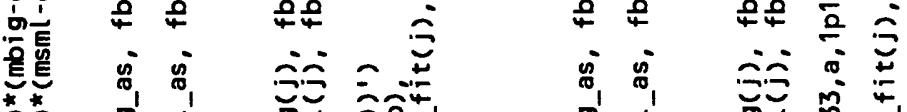

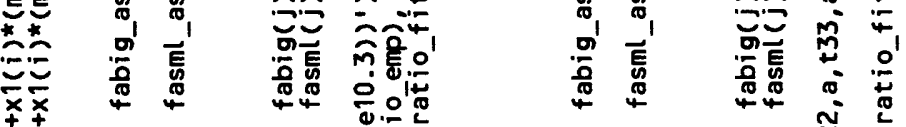

응 응 응 웅응 응응응

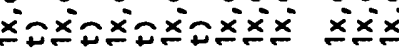

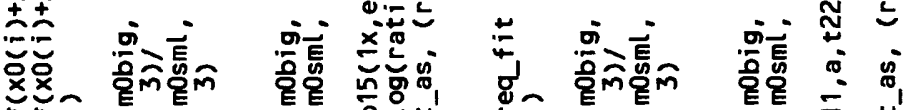

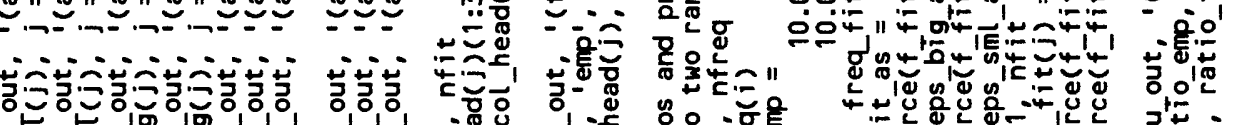

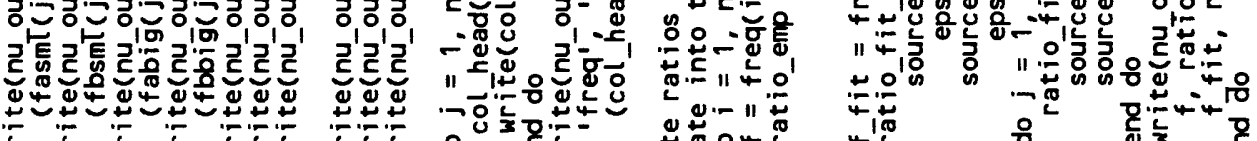

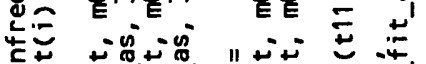

$\widehat{艹}$

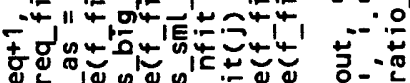

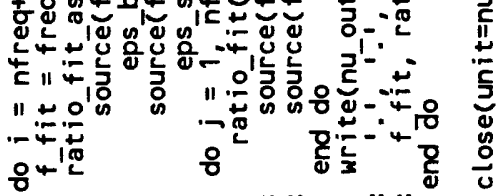




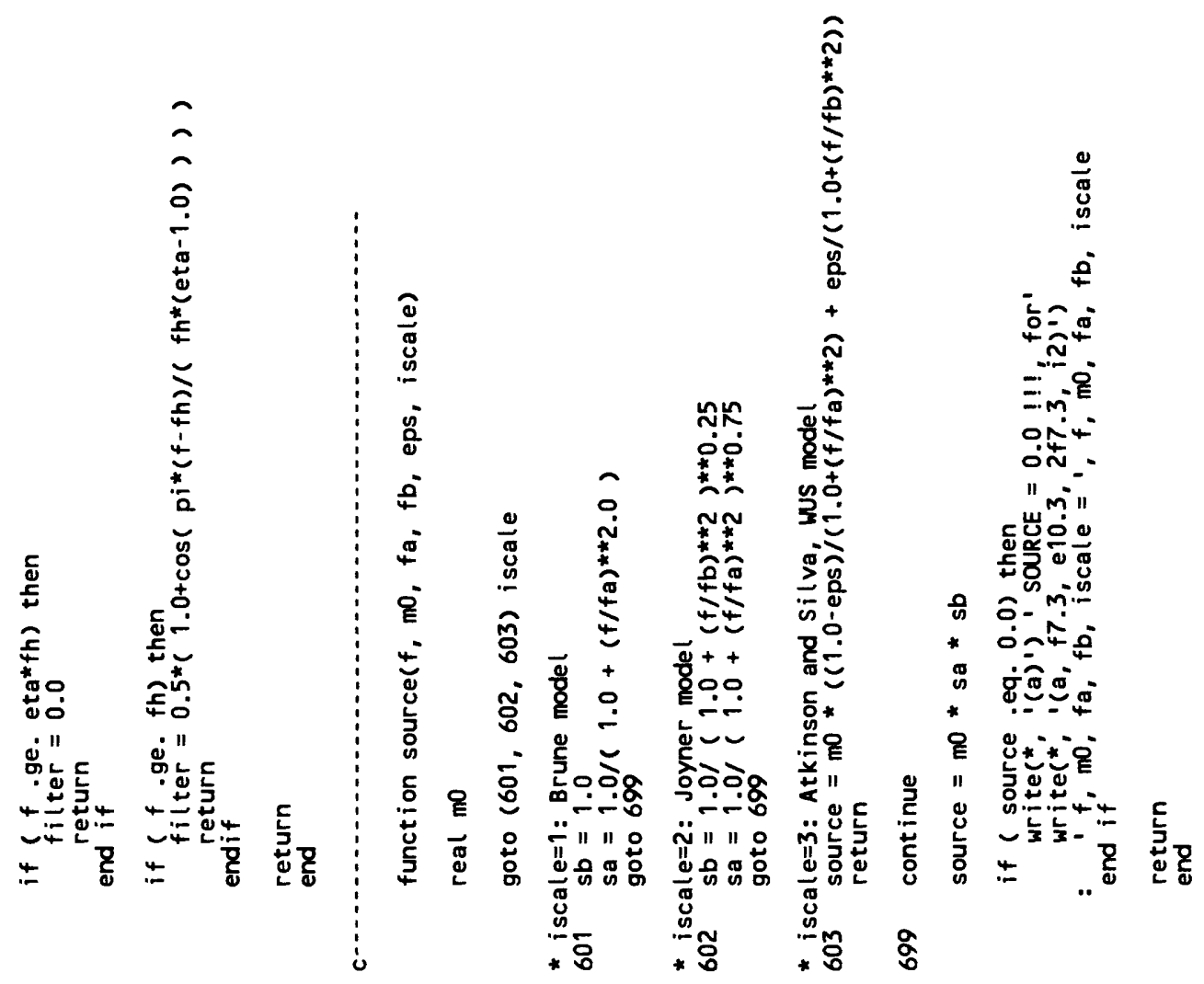




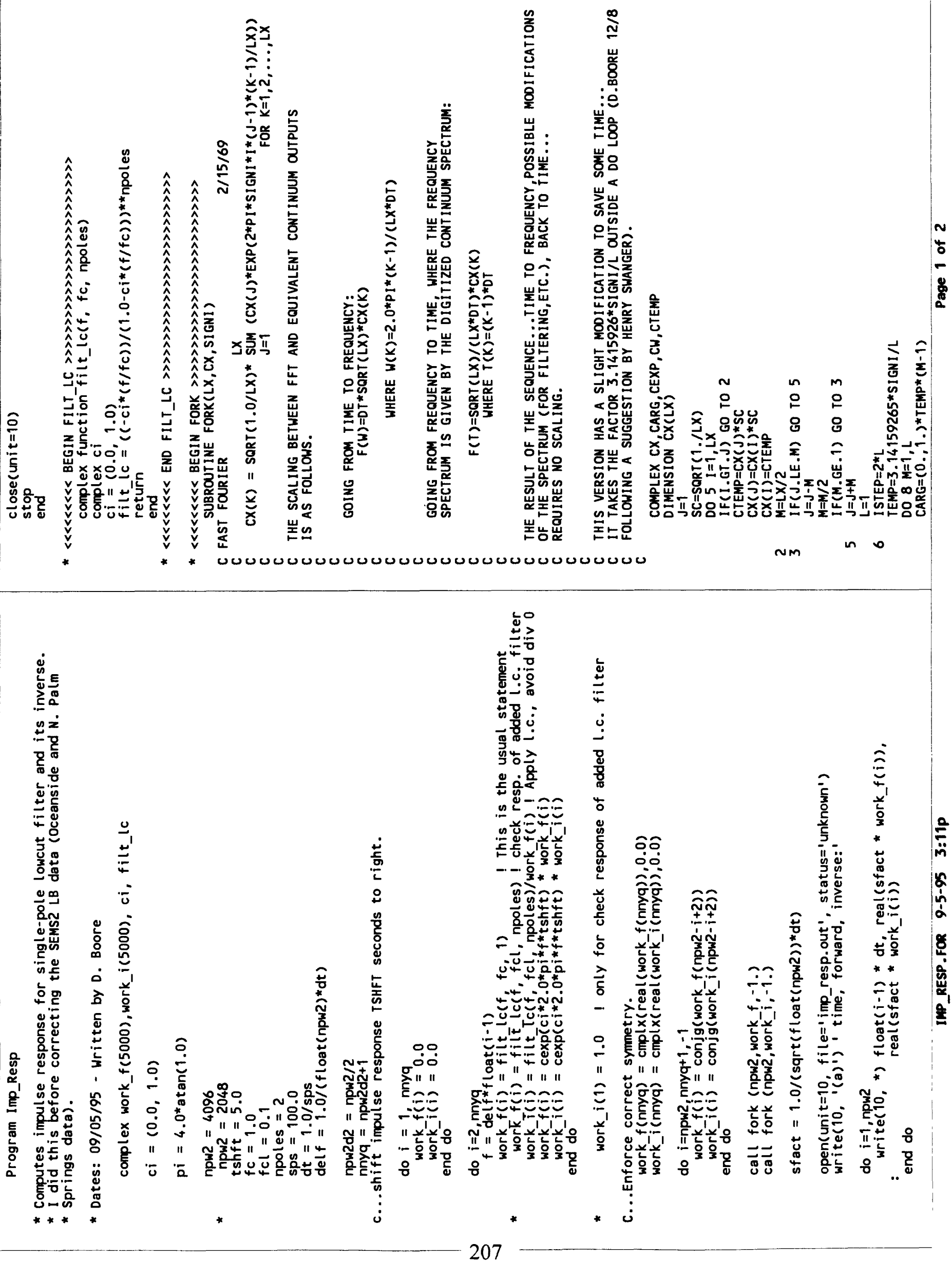




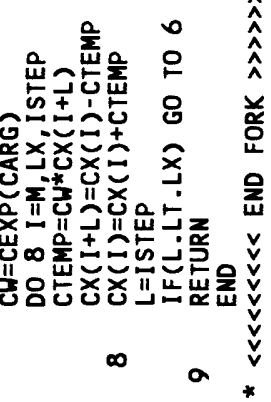




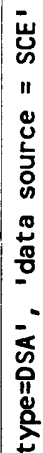

$\stackrel{\ddot{\underline{t}}}{=} \quad \frac{\ddot{0}}{0}$

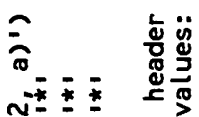

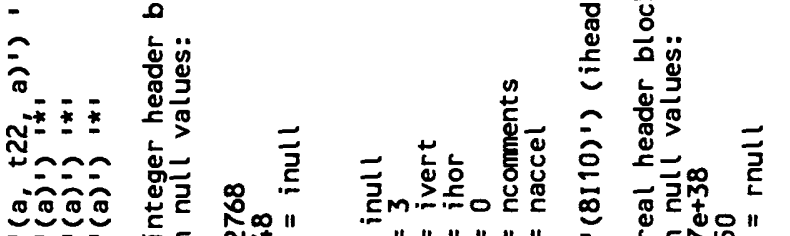

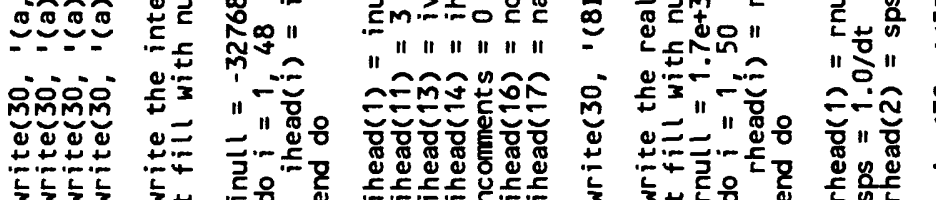

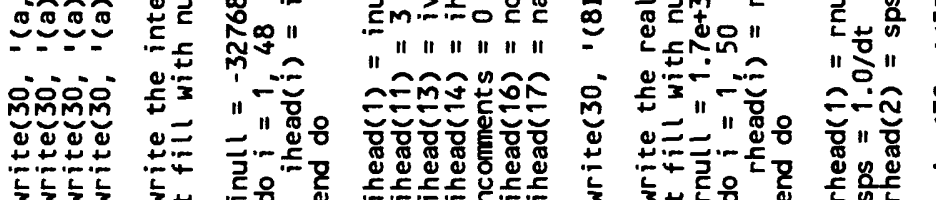

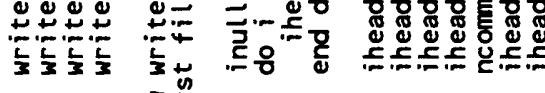
준해

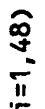
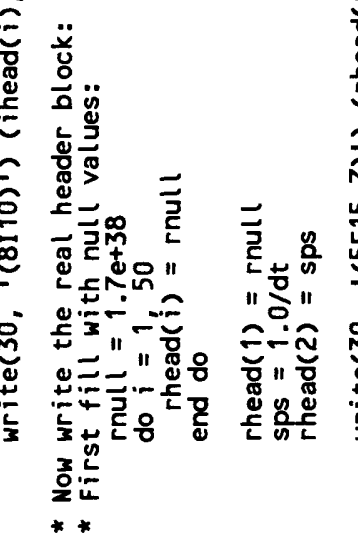

오ำ

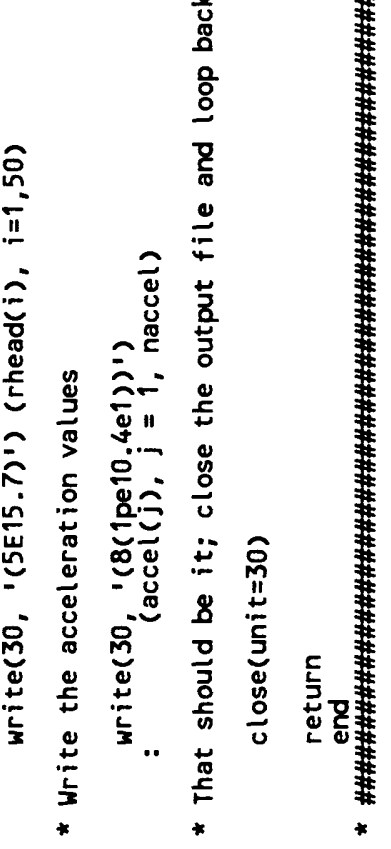

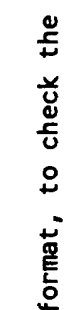

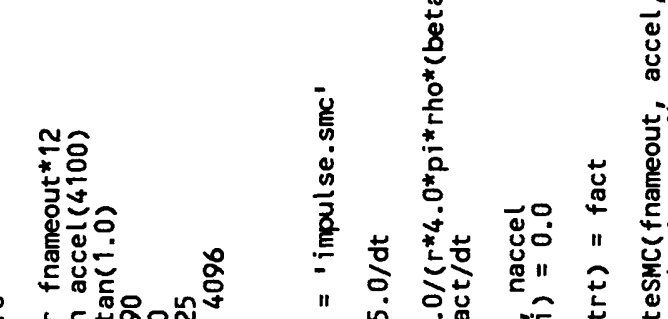

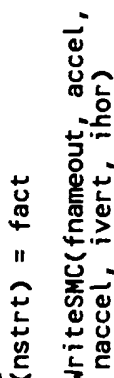

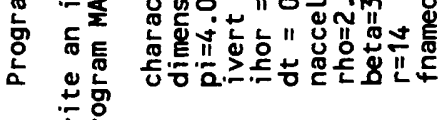

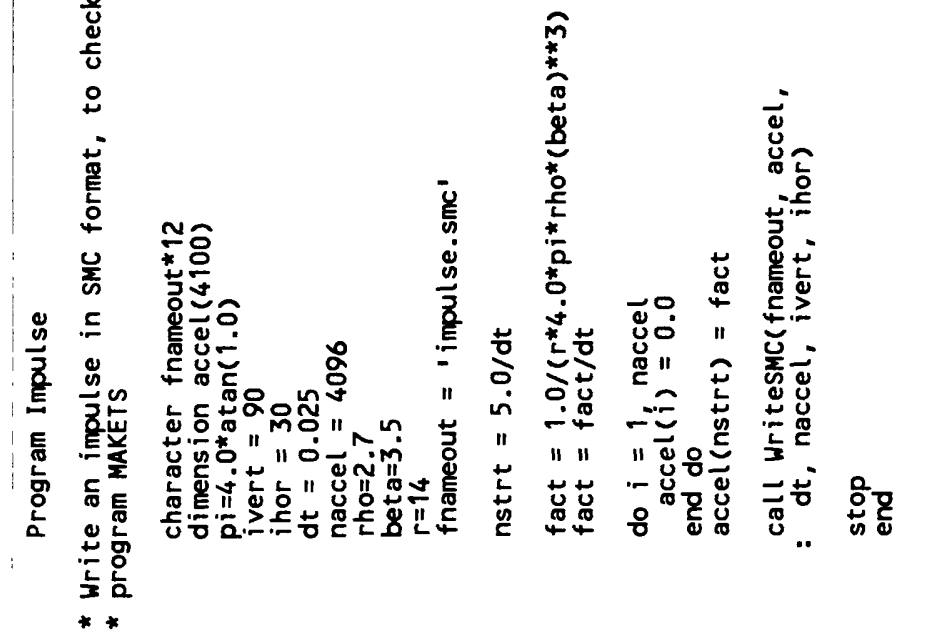

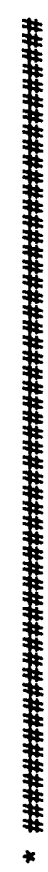

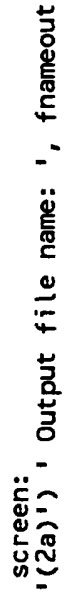
ij

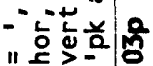
ᄃำ 政

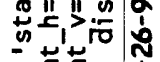
25

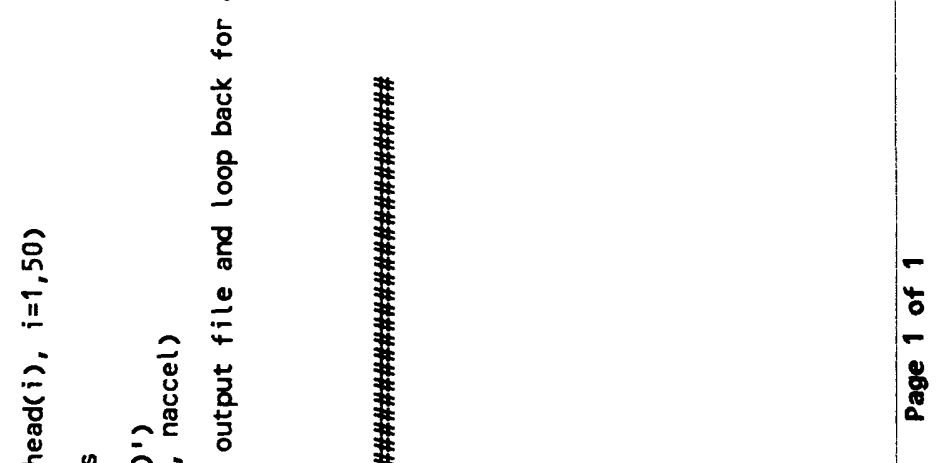

i Чٕ. 

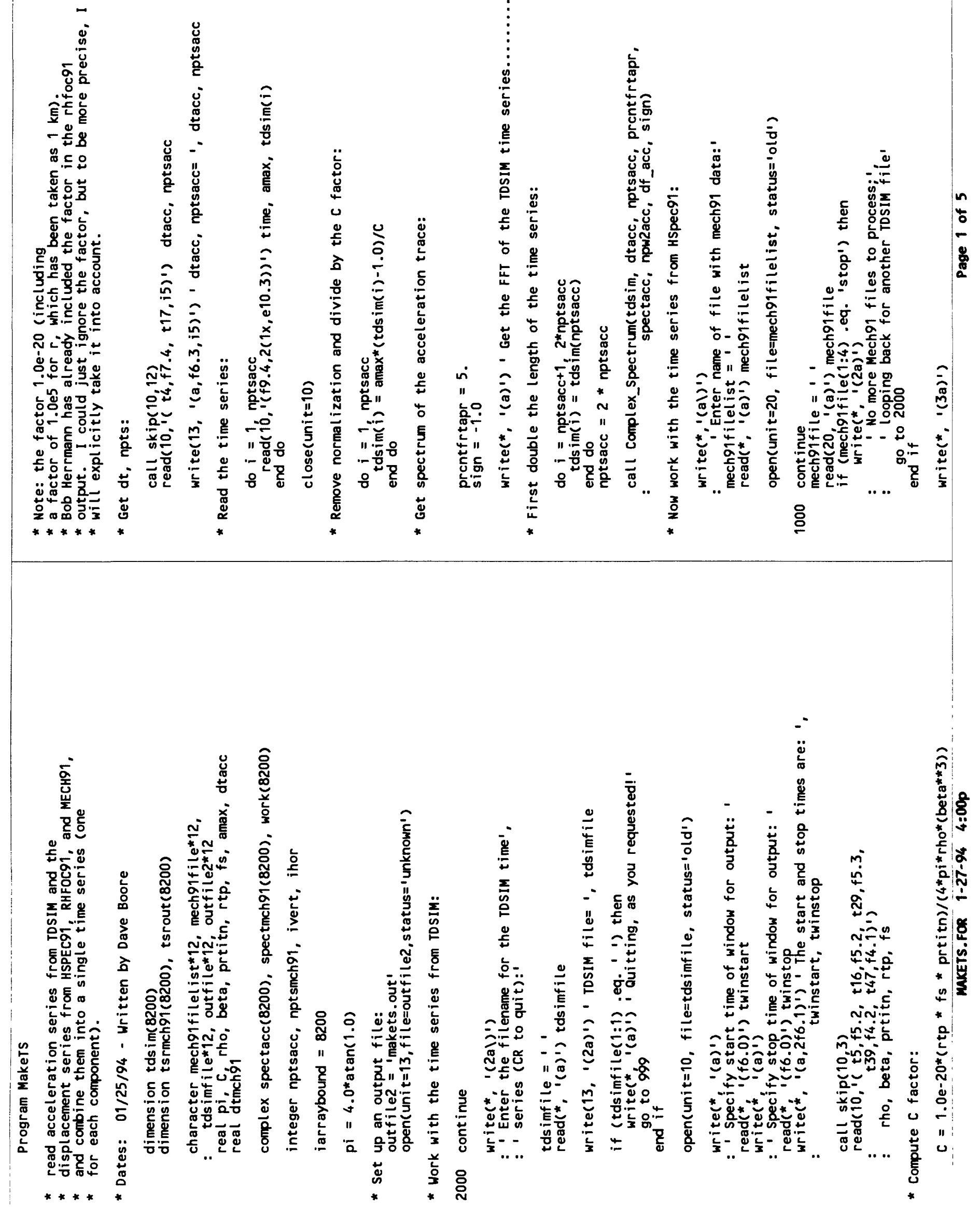
$\vdots \quad$ 毫

递容

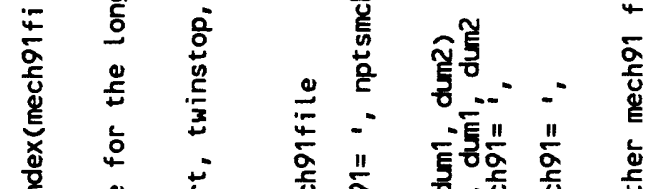

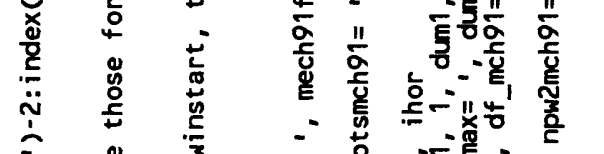

$\therefore$ :

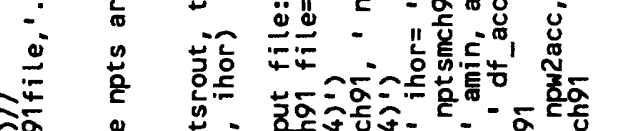

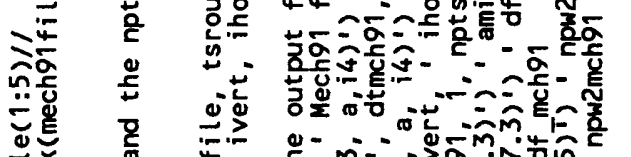

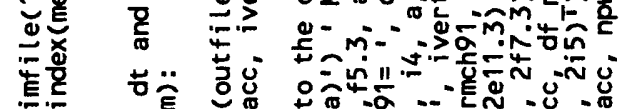

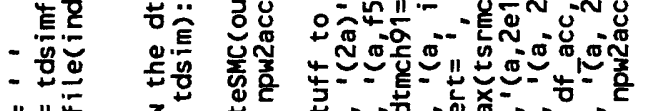

" " "L

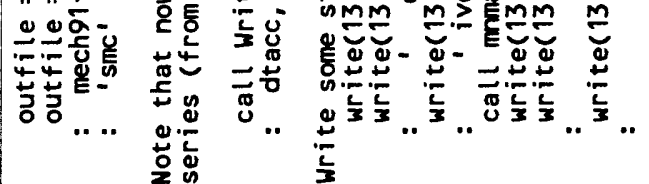
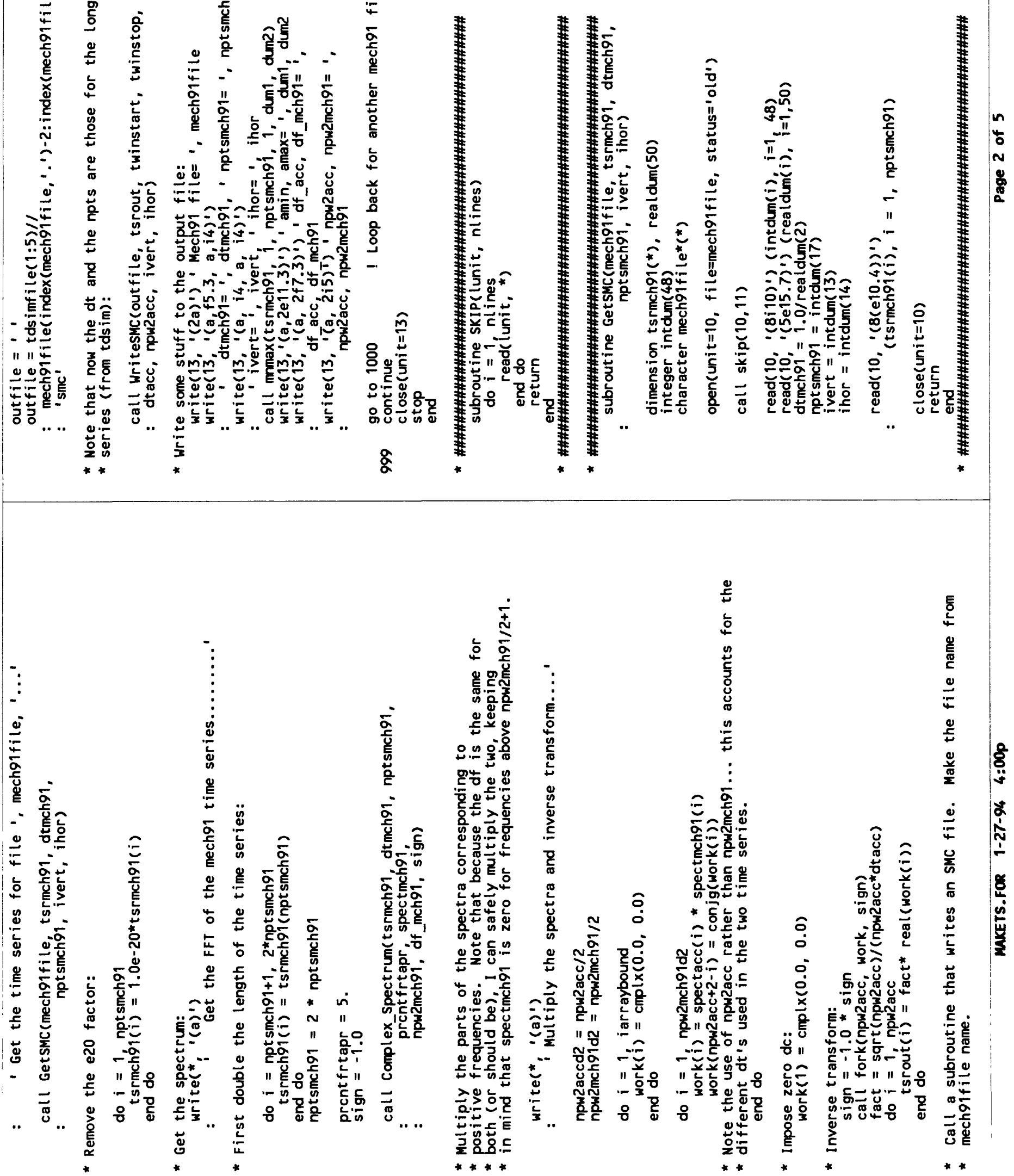


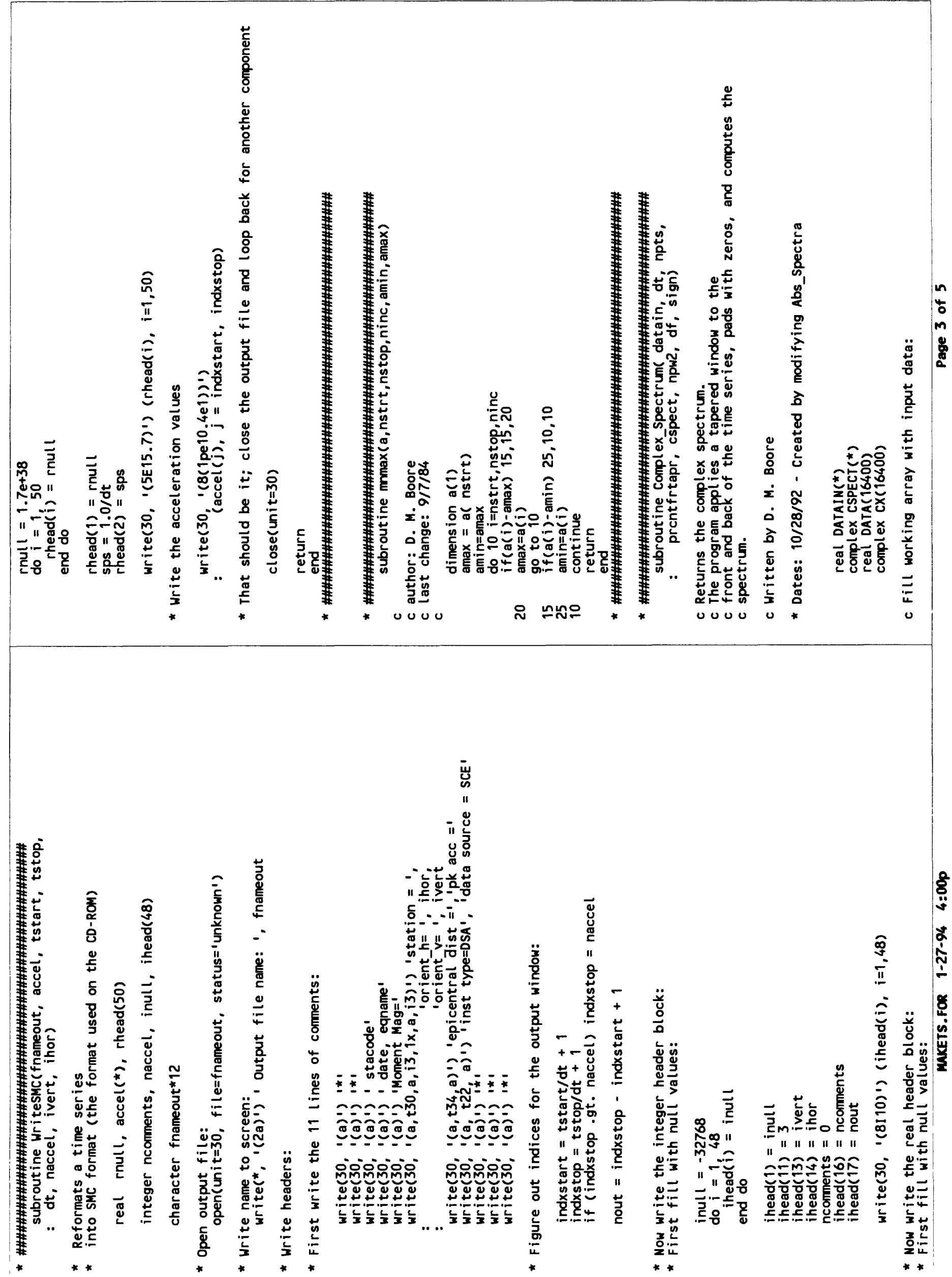



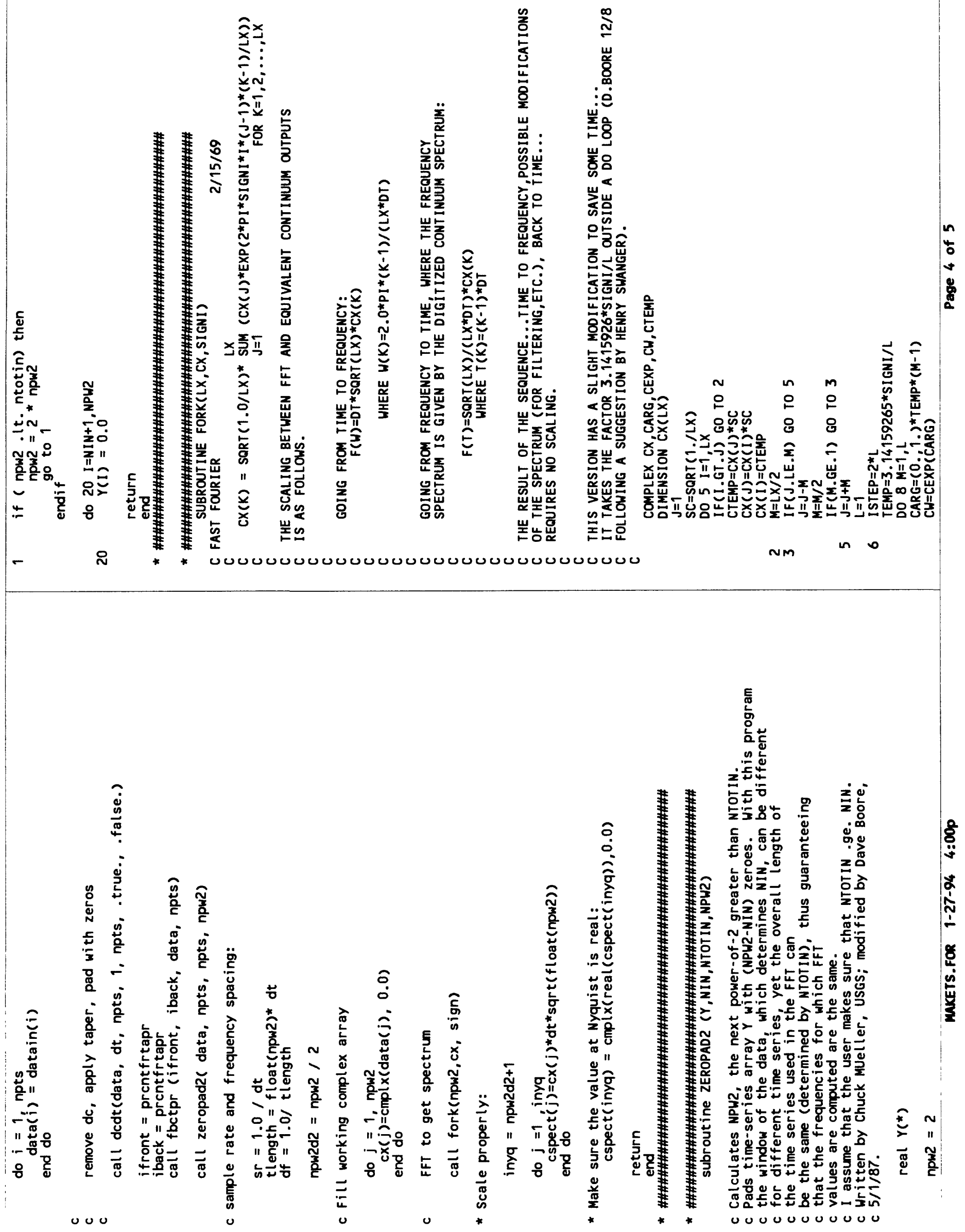

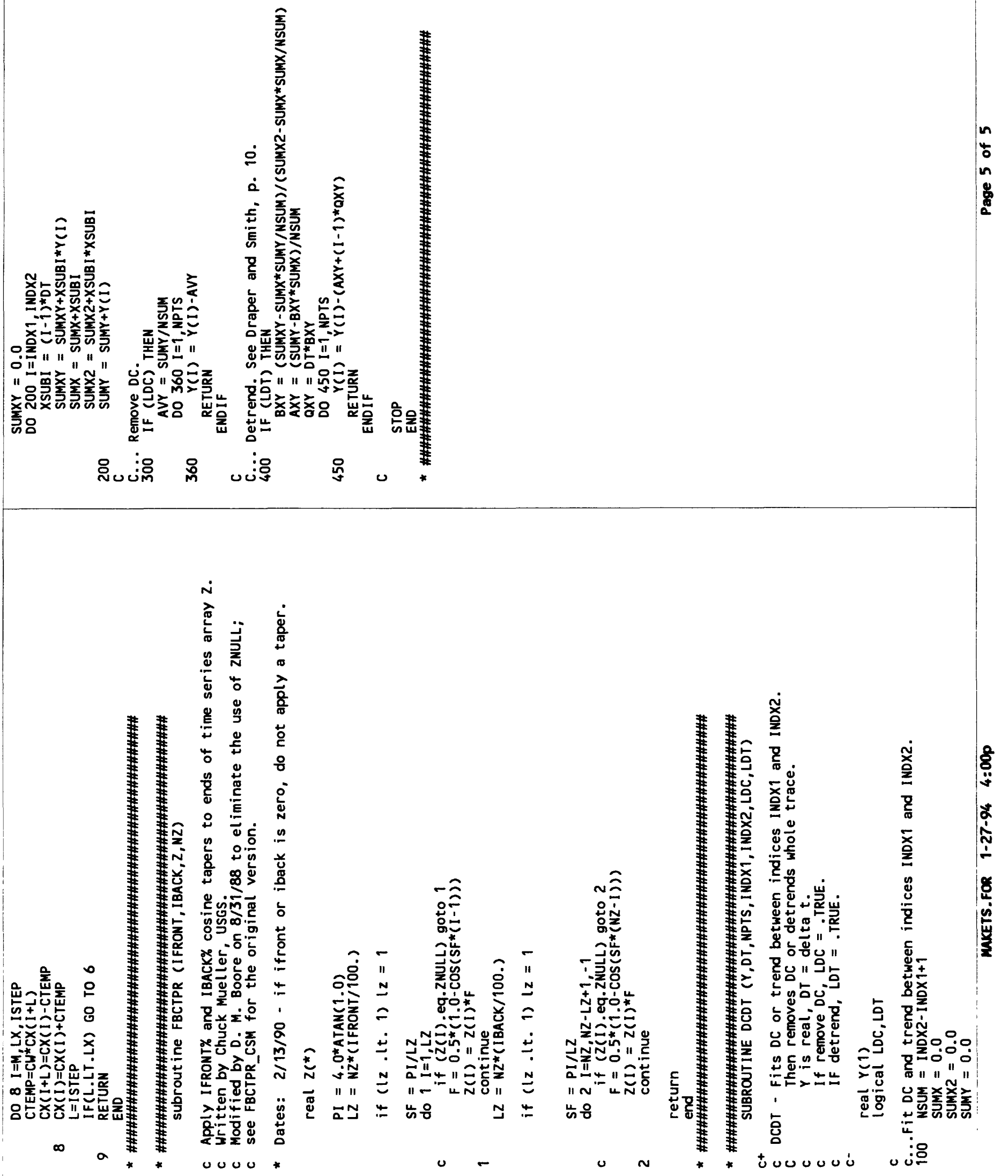


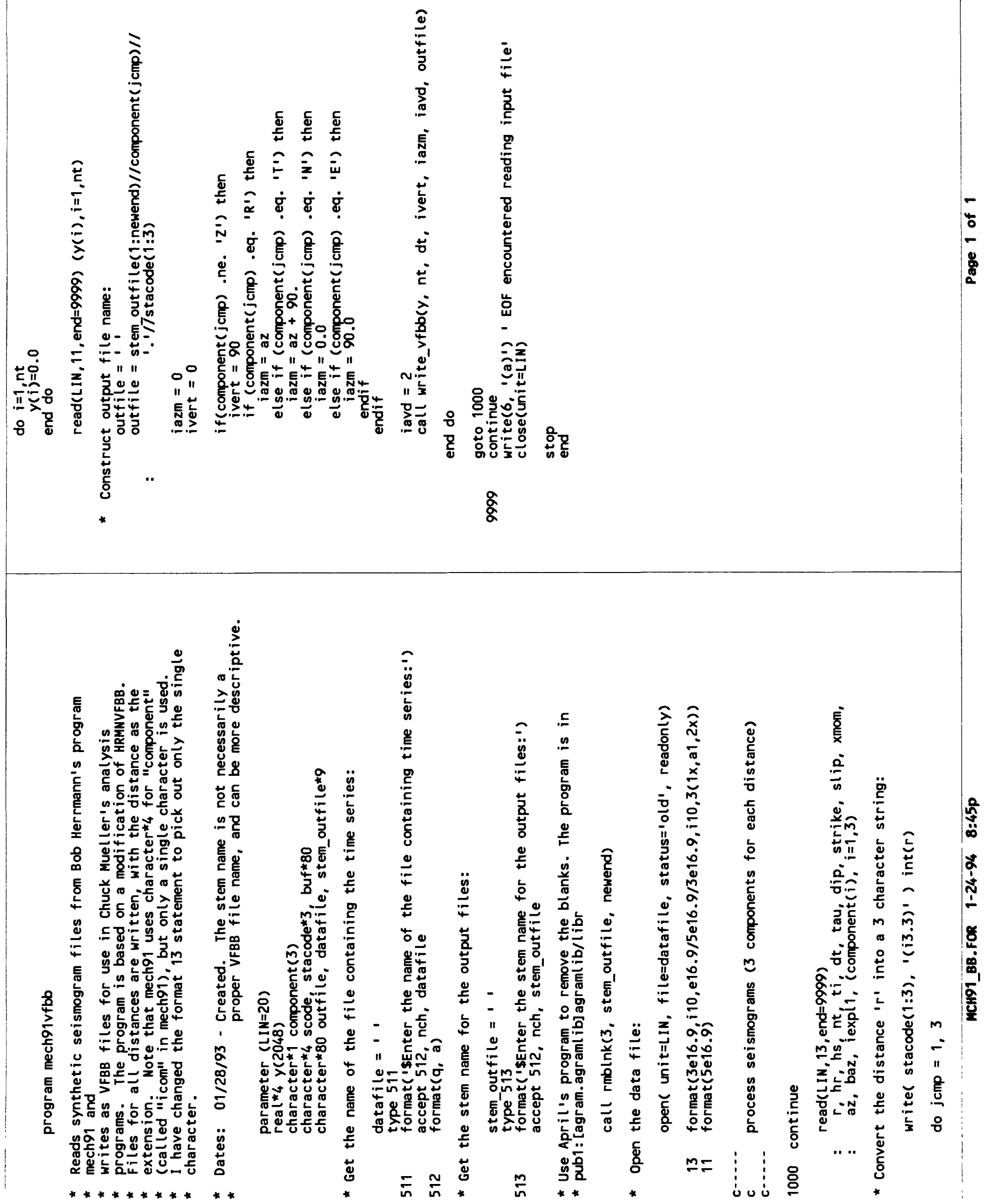




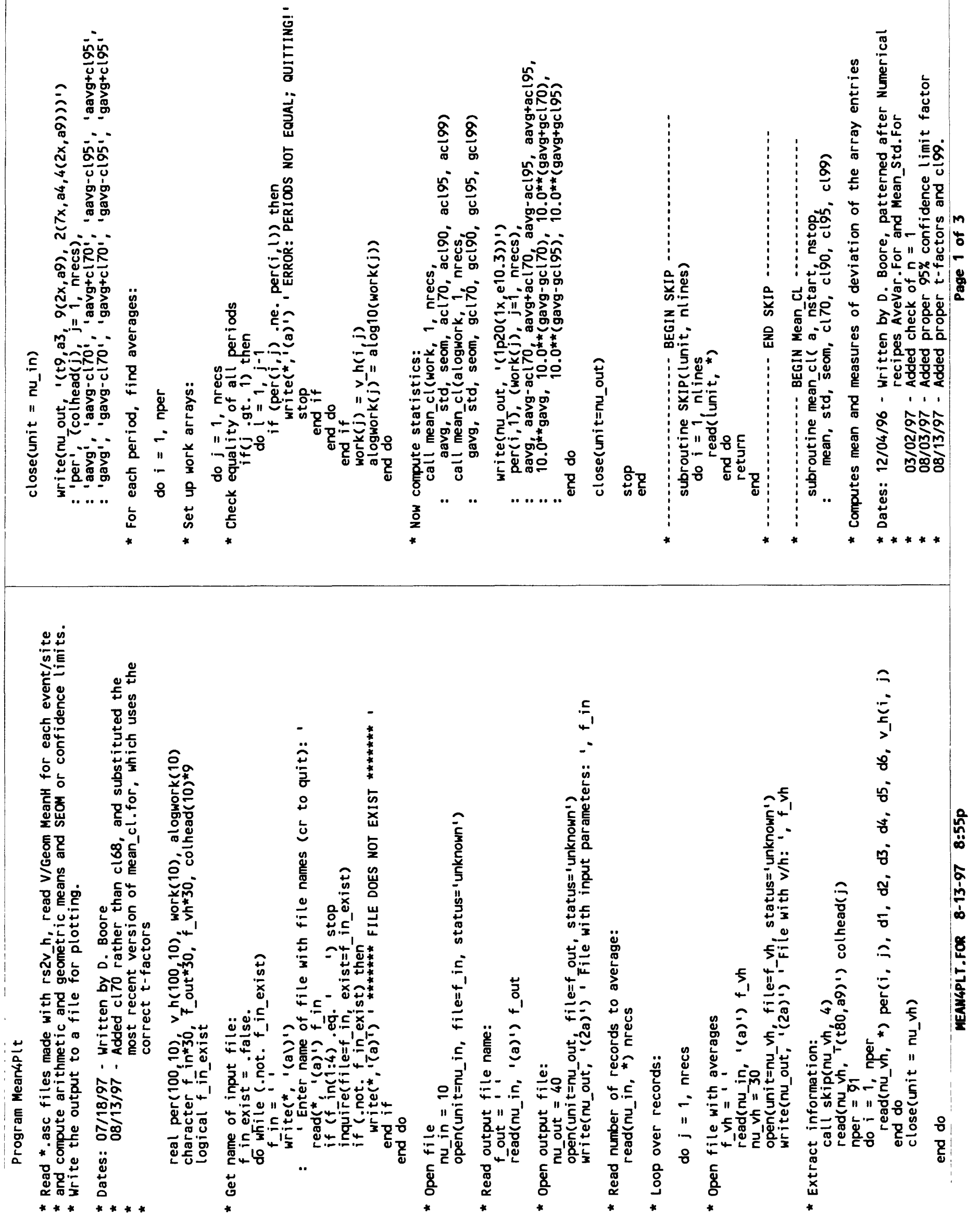




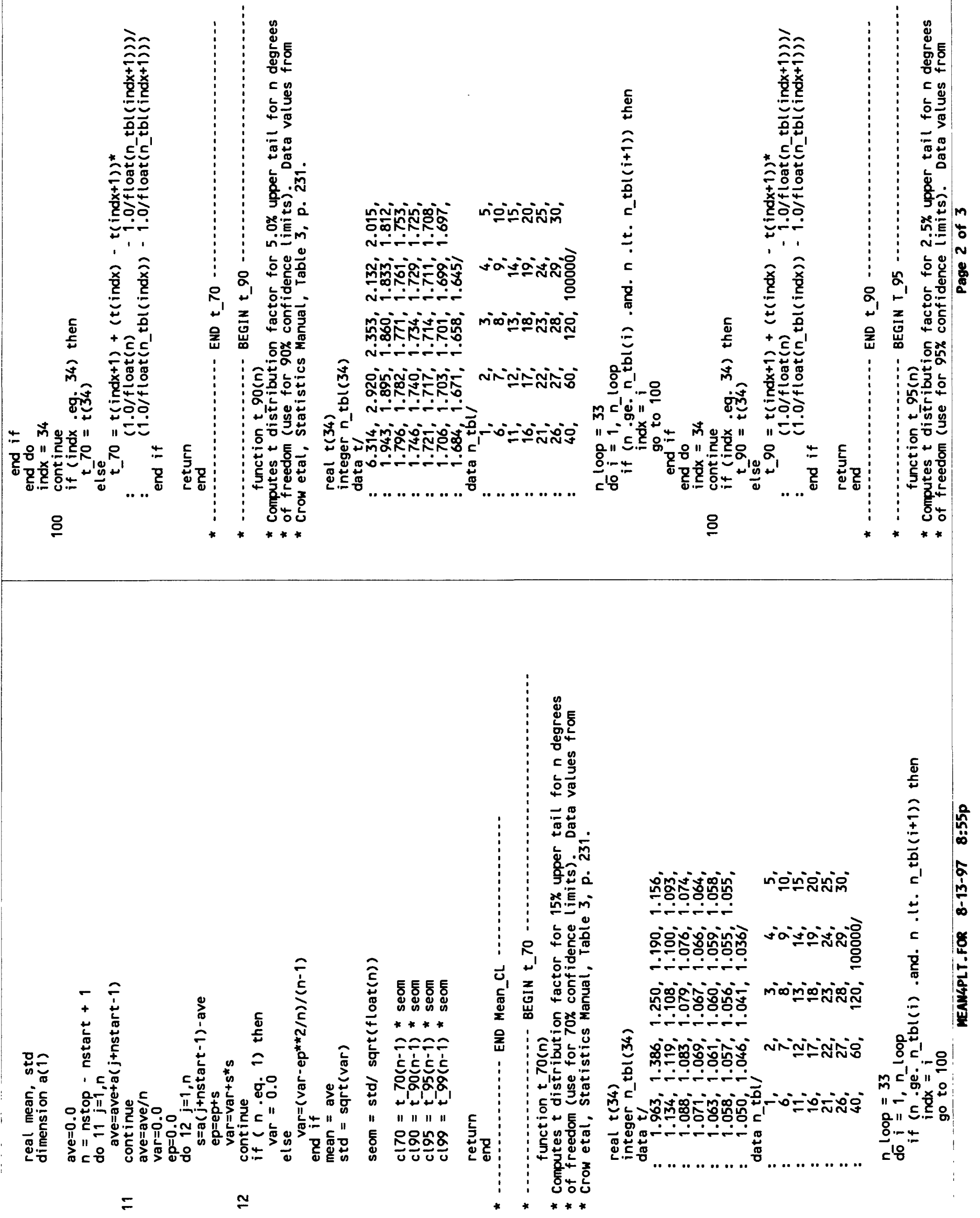




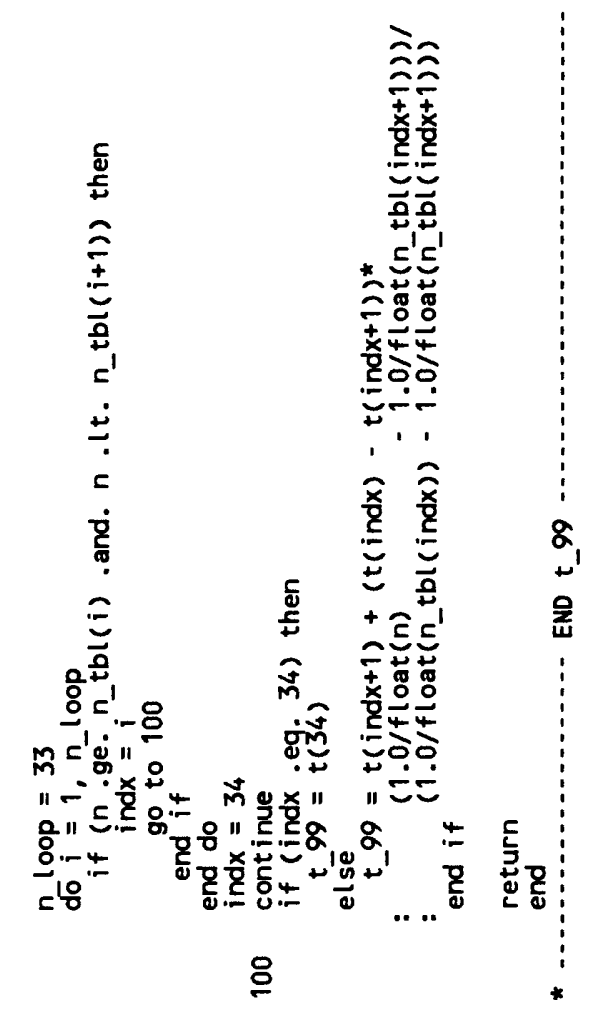

㐫

i

$\frac{2}{2}$

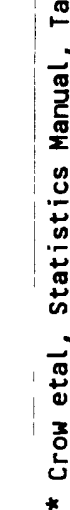

市

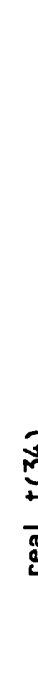

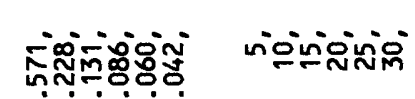 NंNiñNa

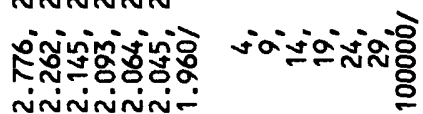

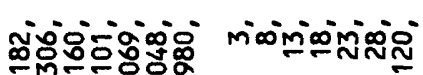

ले mininini-

P

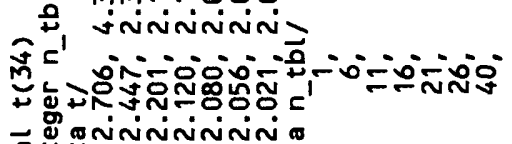

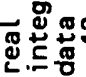
..

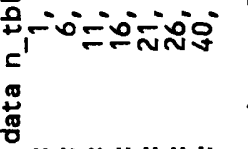




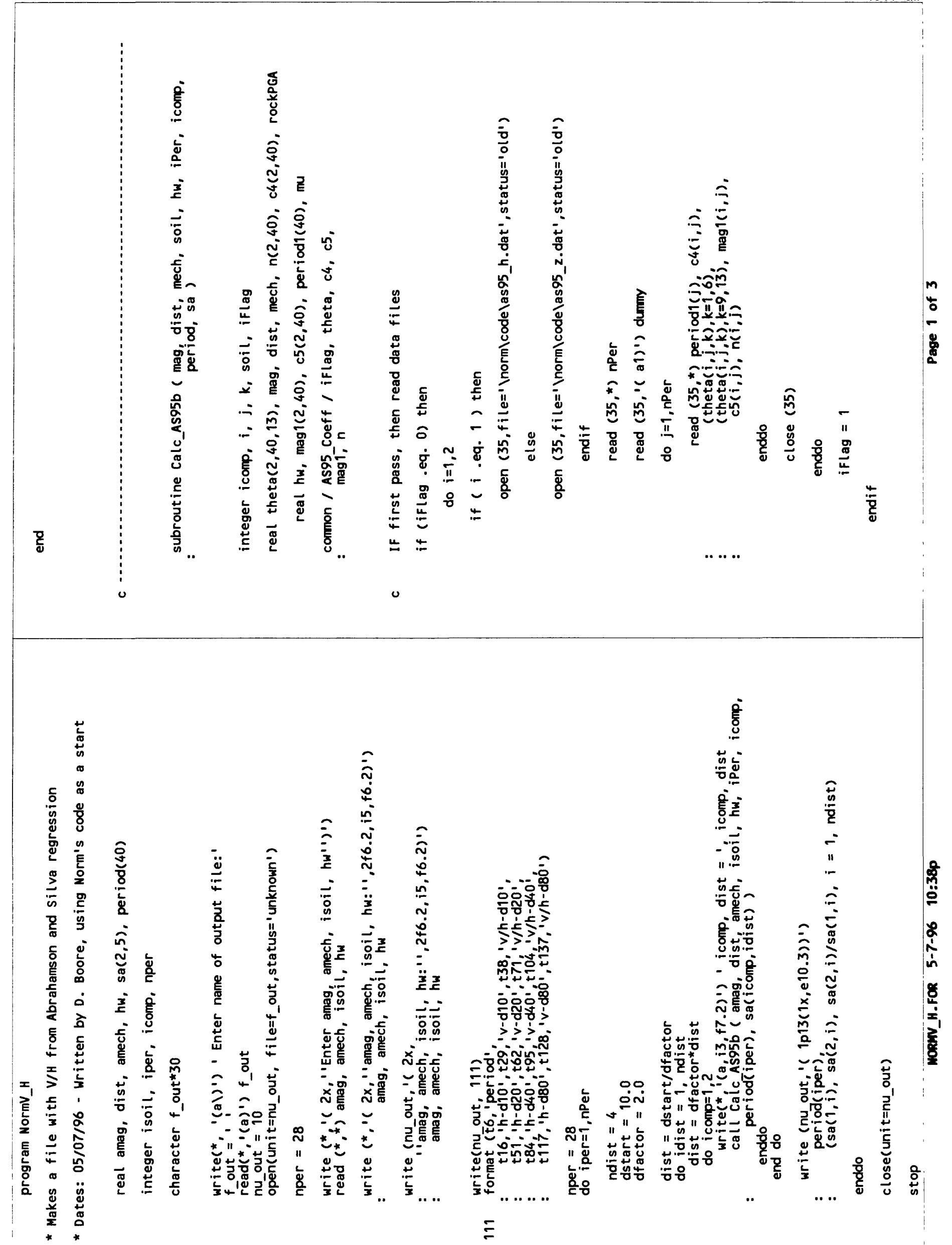




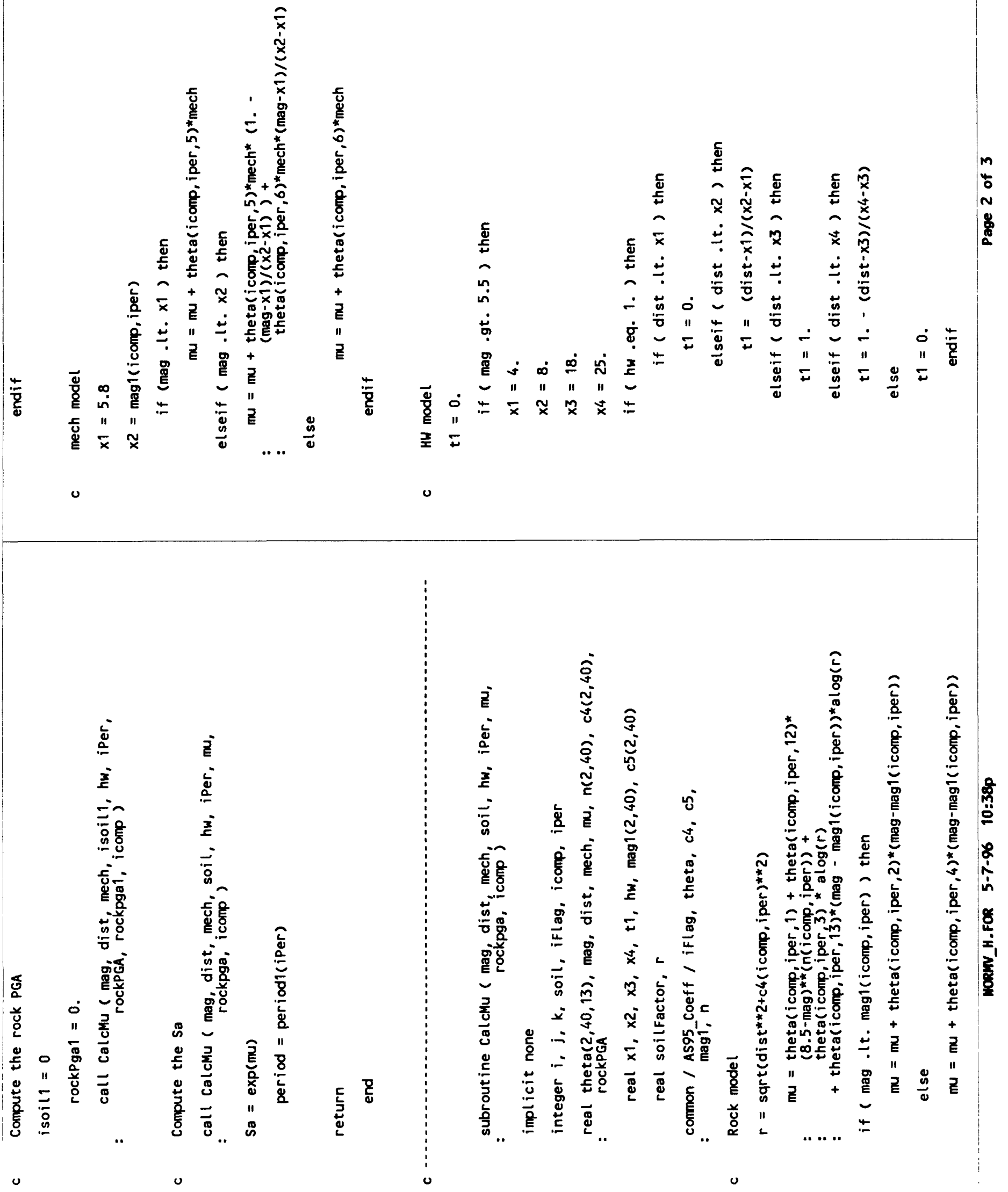




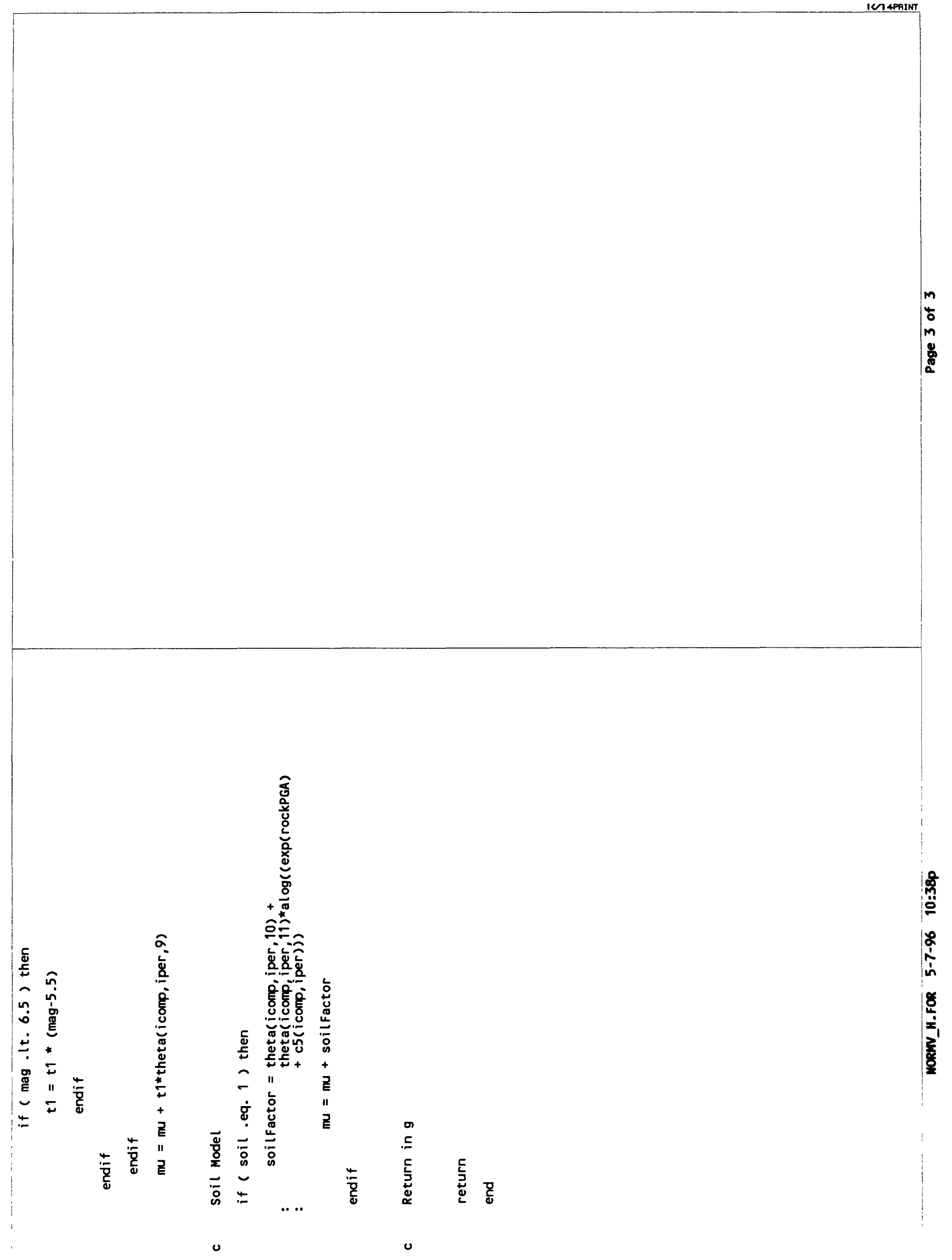




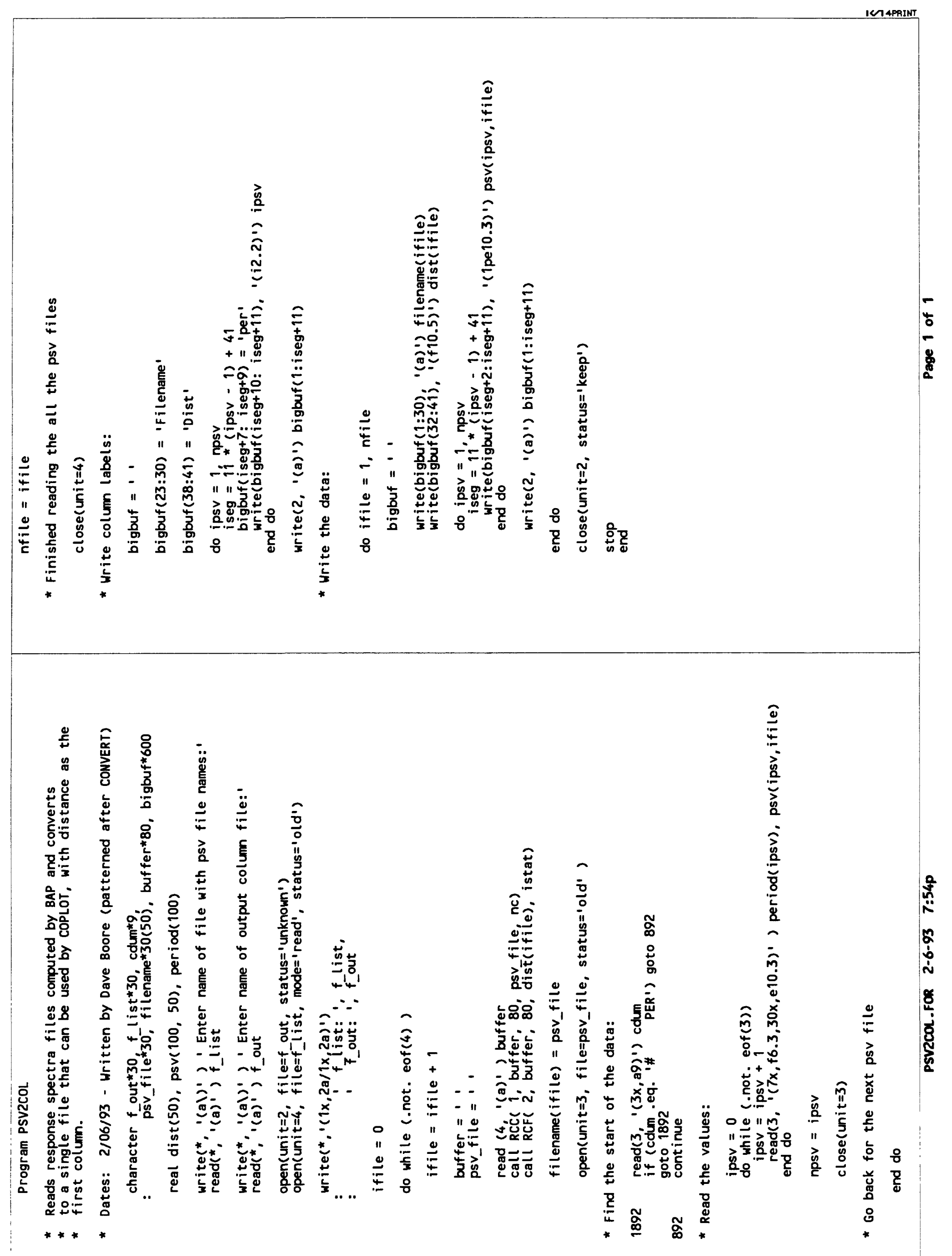




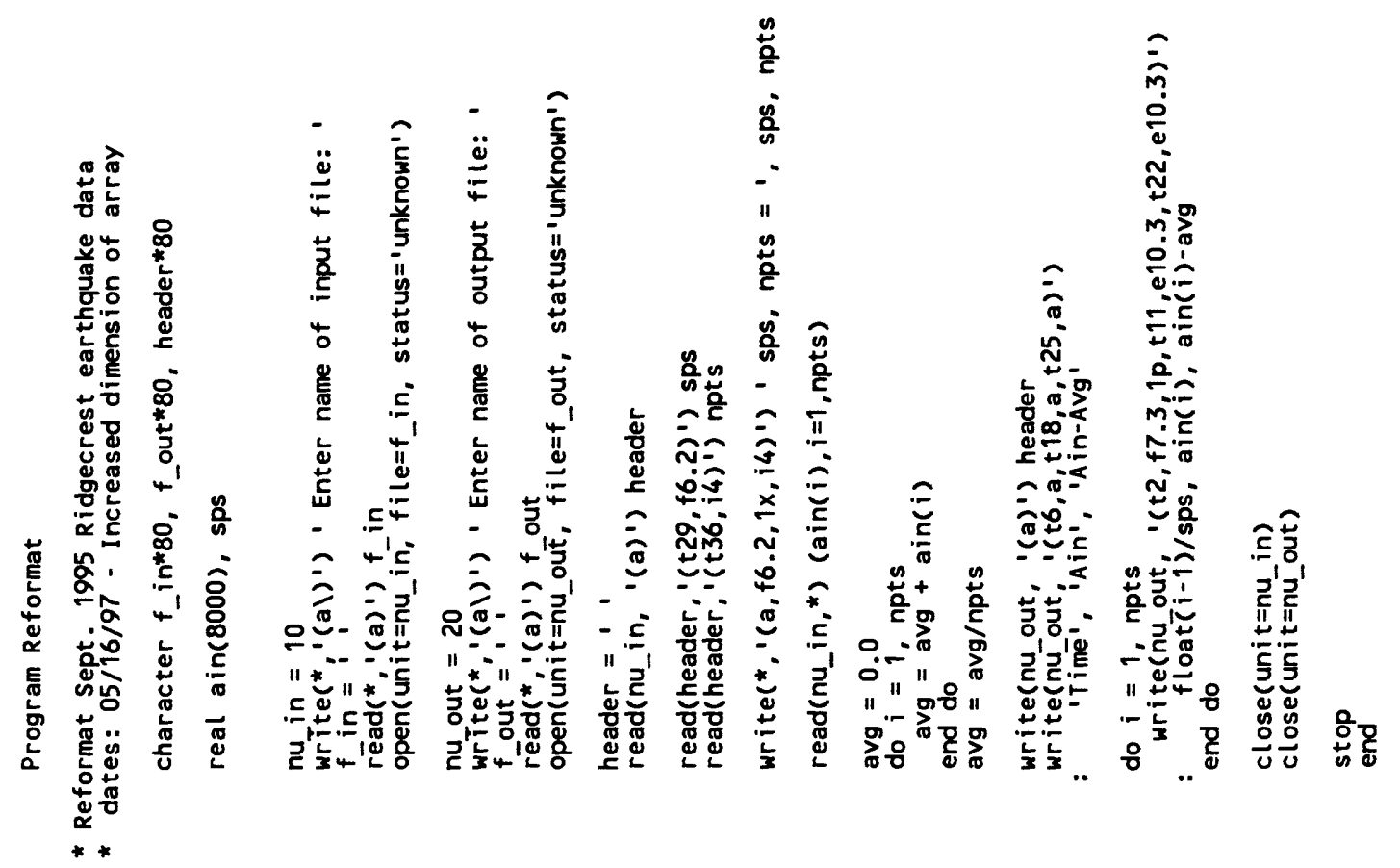




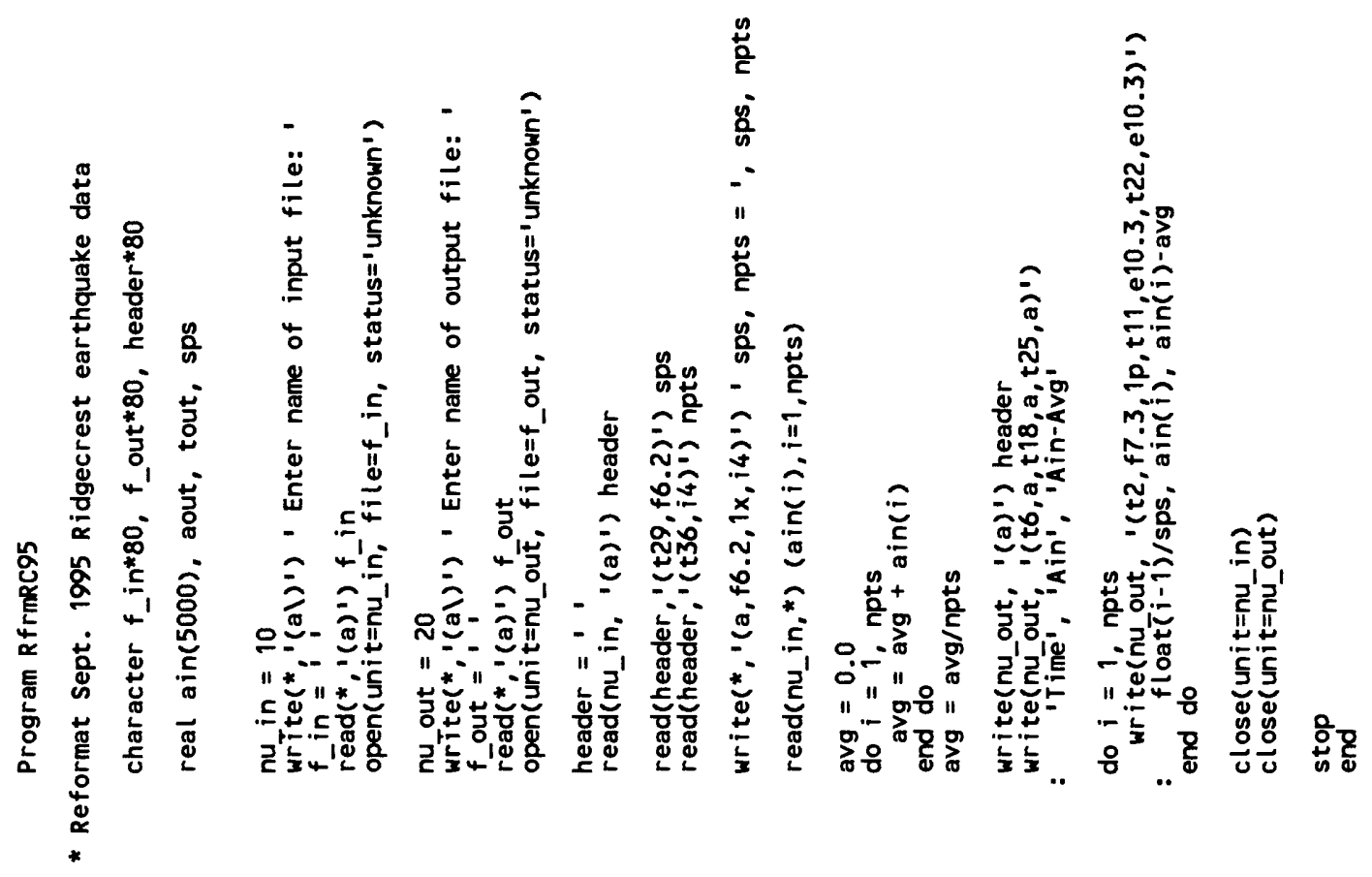




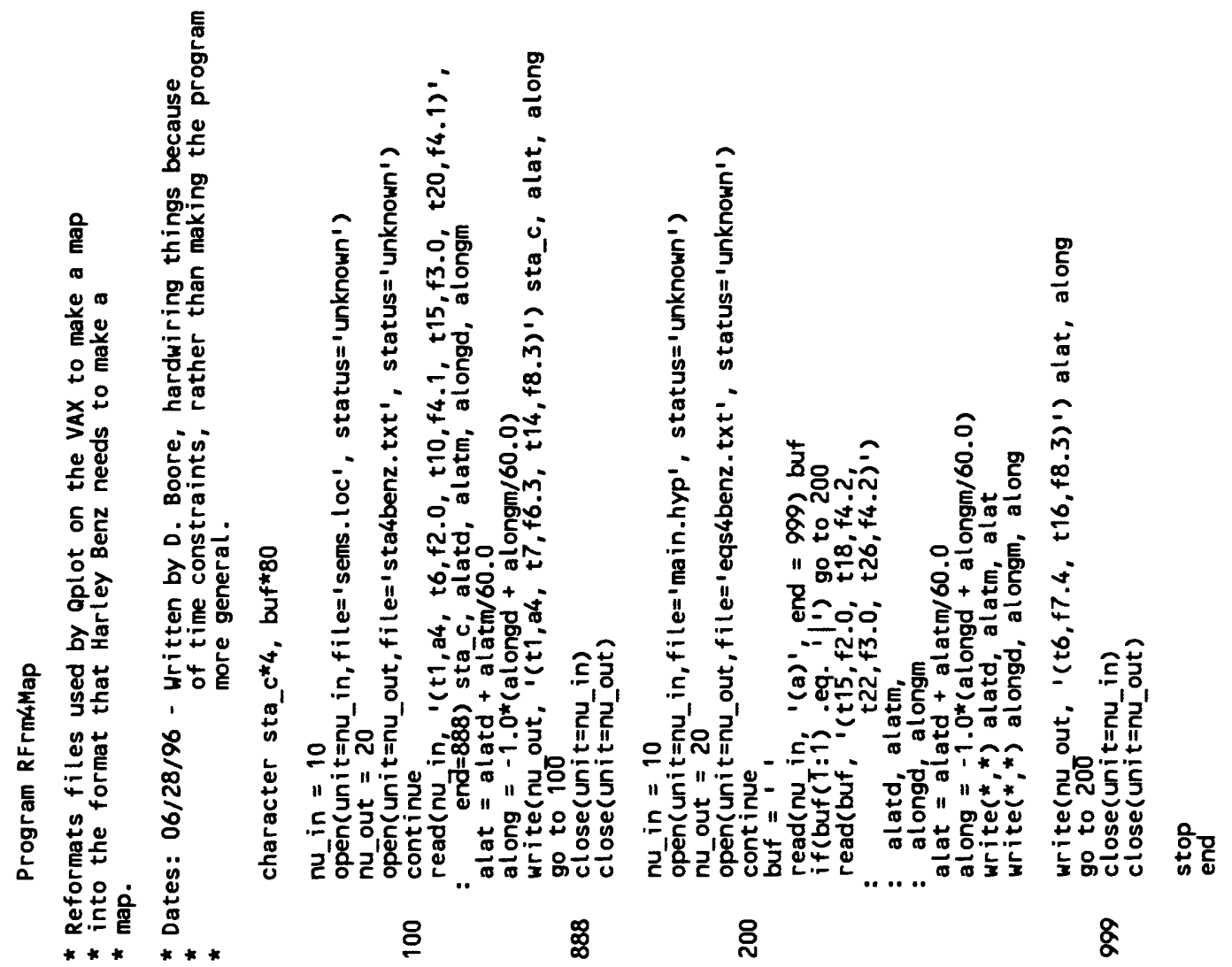




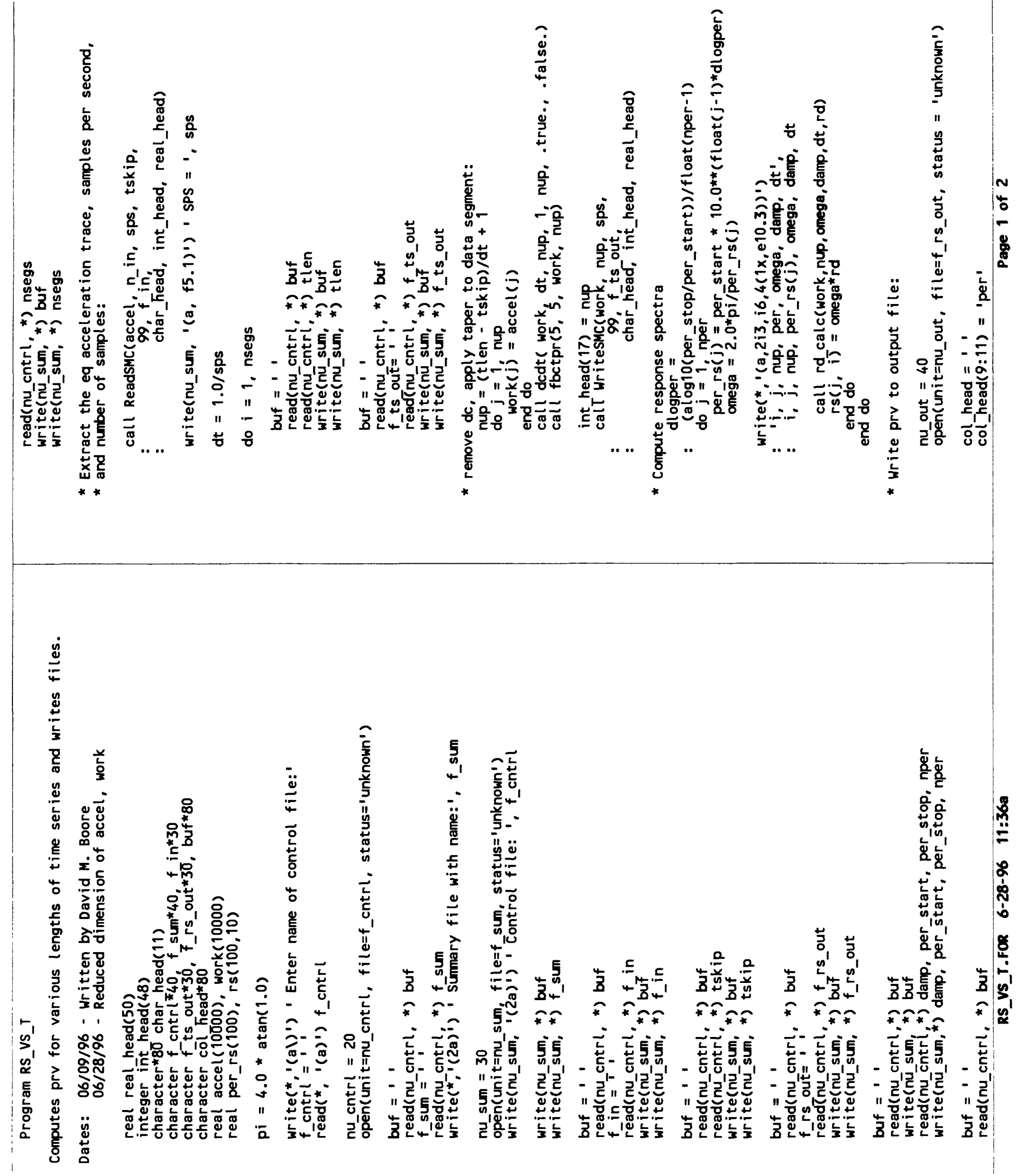




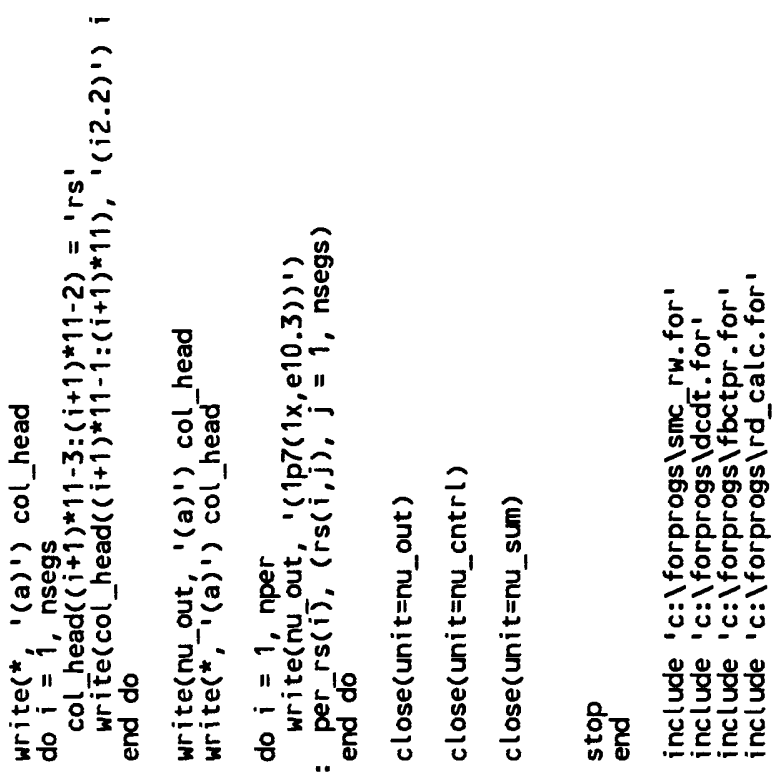



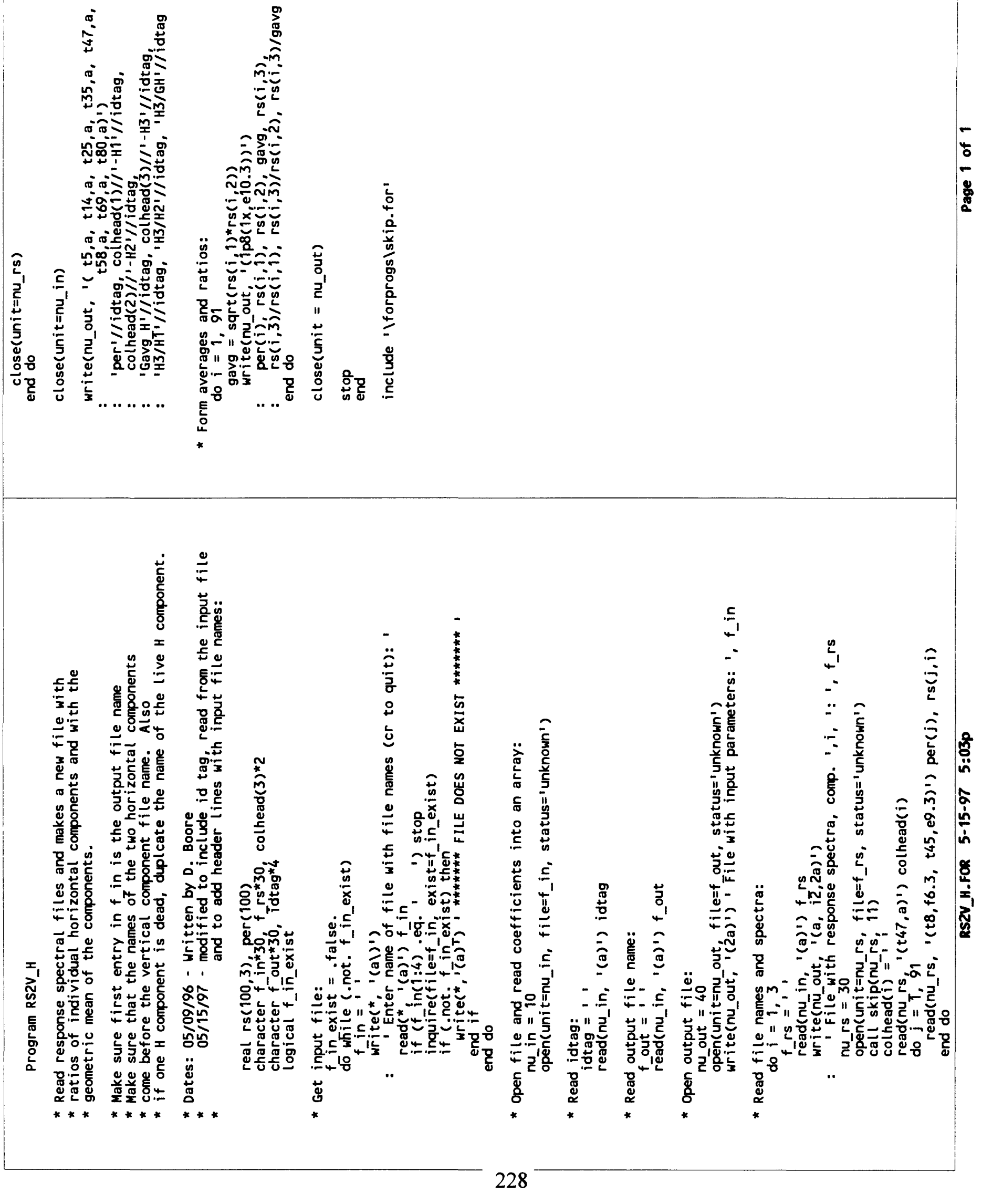


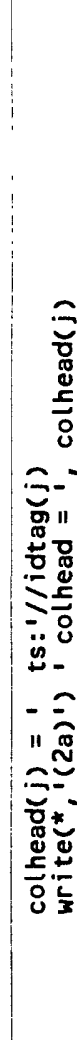

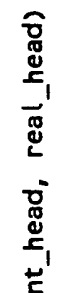

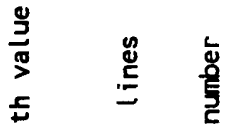

(2)
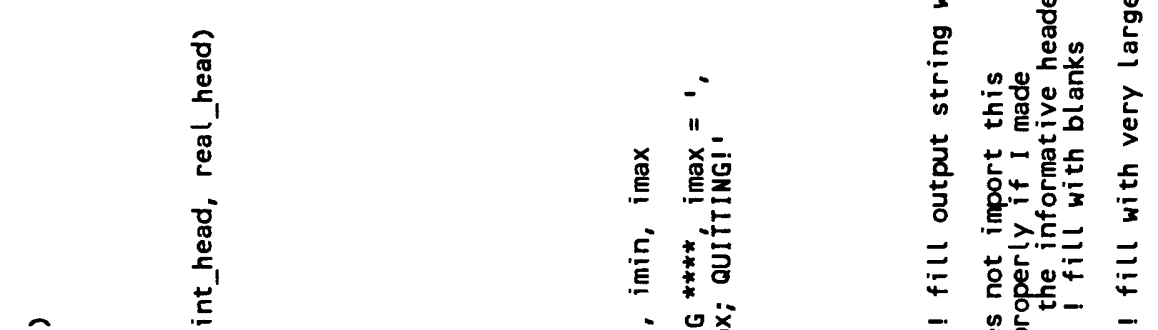

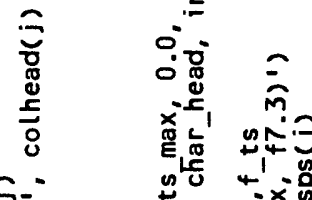

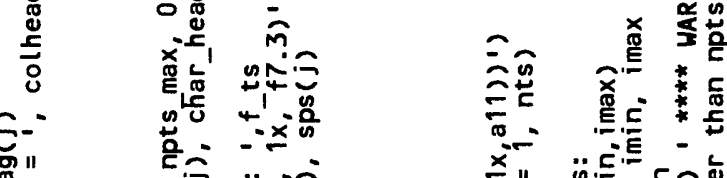

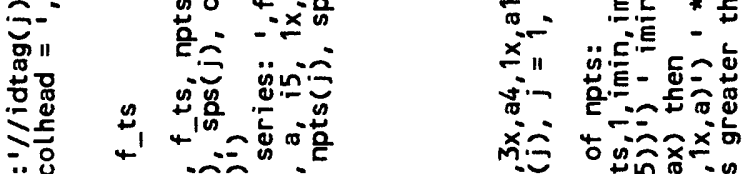

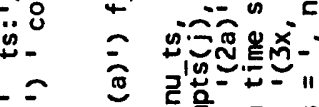

xis

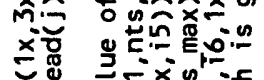

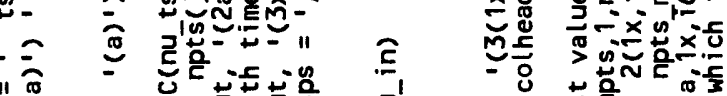

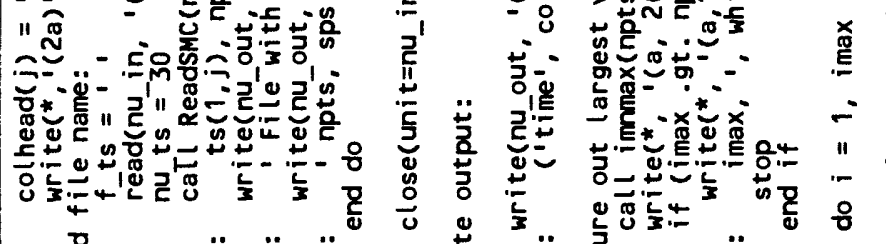

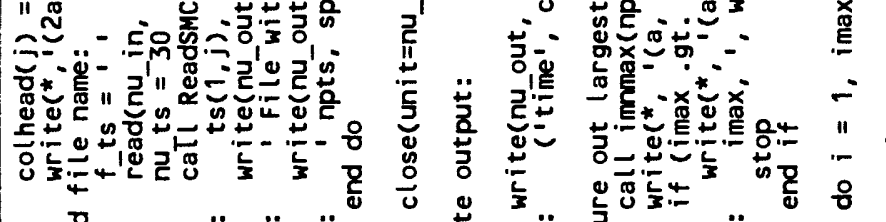

$\stackrel{?}{\stackrel{2}{2}}$

妾

.

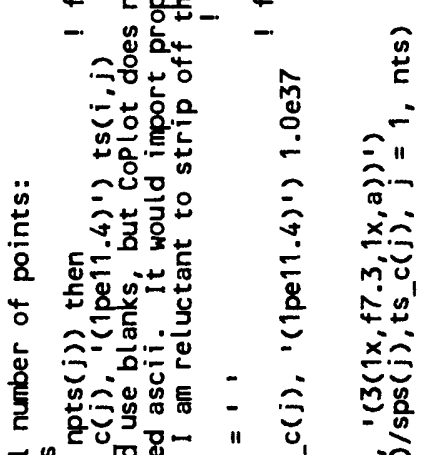

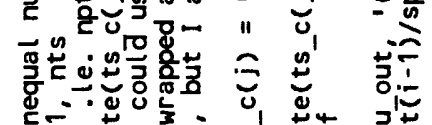

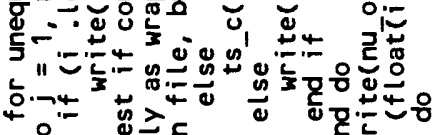

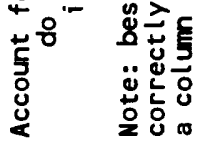

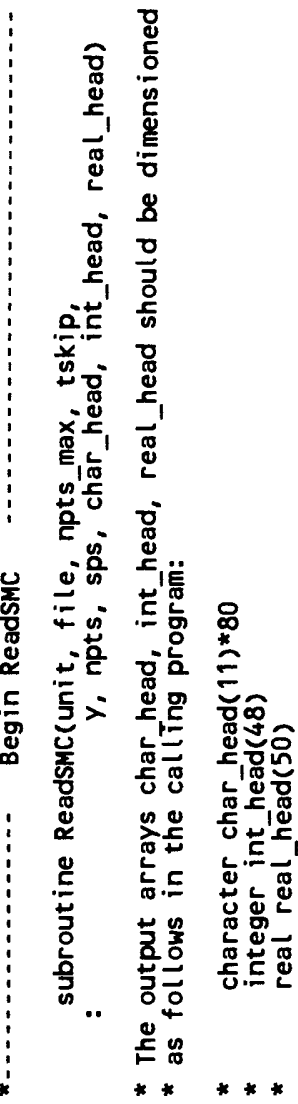

d

$\therefore \quad \begin{array}{rr}8 \\ 8 \\ 5\end{array}$

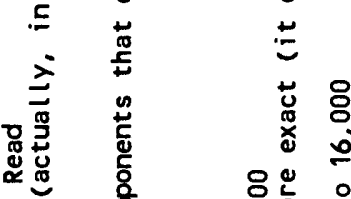

过 旁

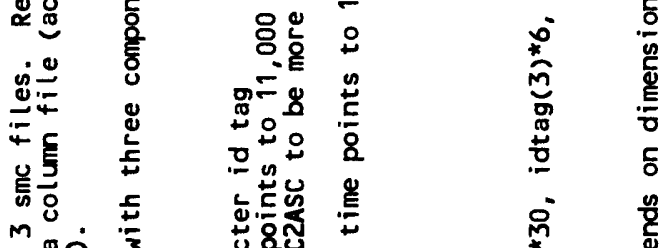

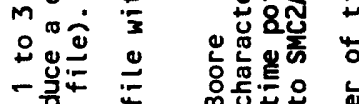

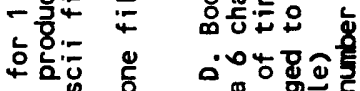

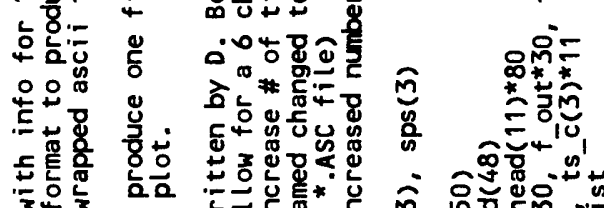

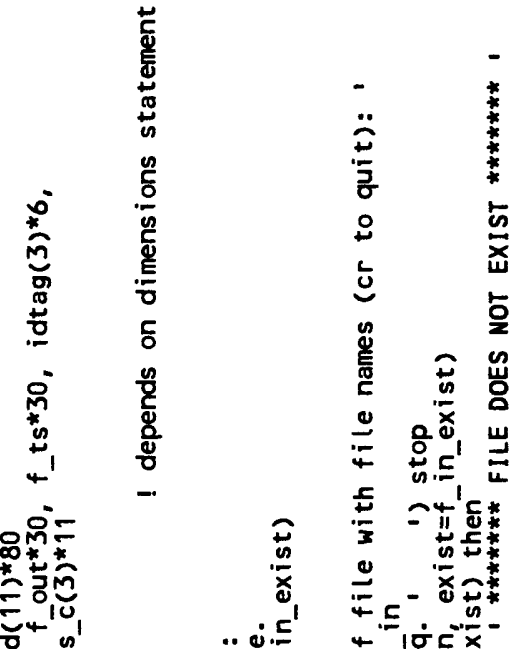

嵌

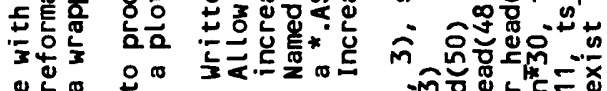

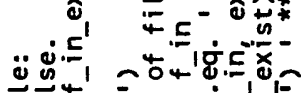

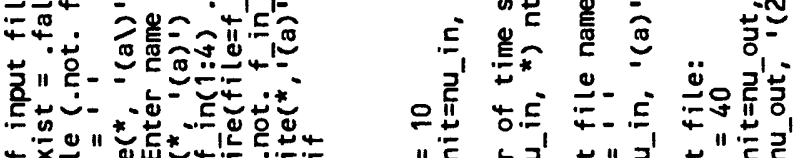

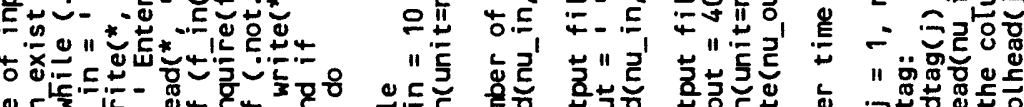

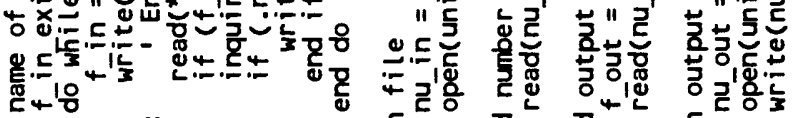
过

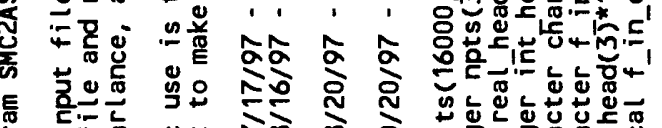

E

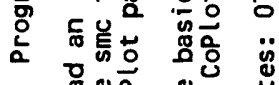

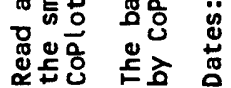

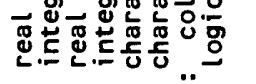

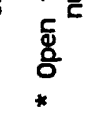

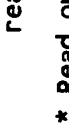


:

ํํ으
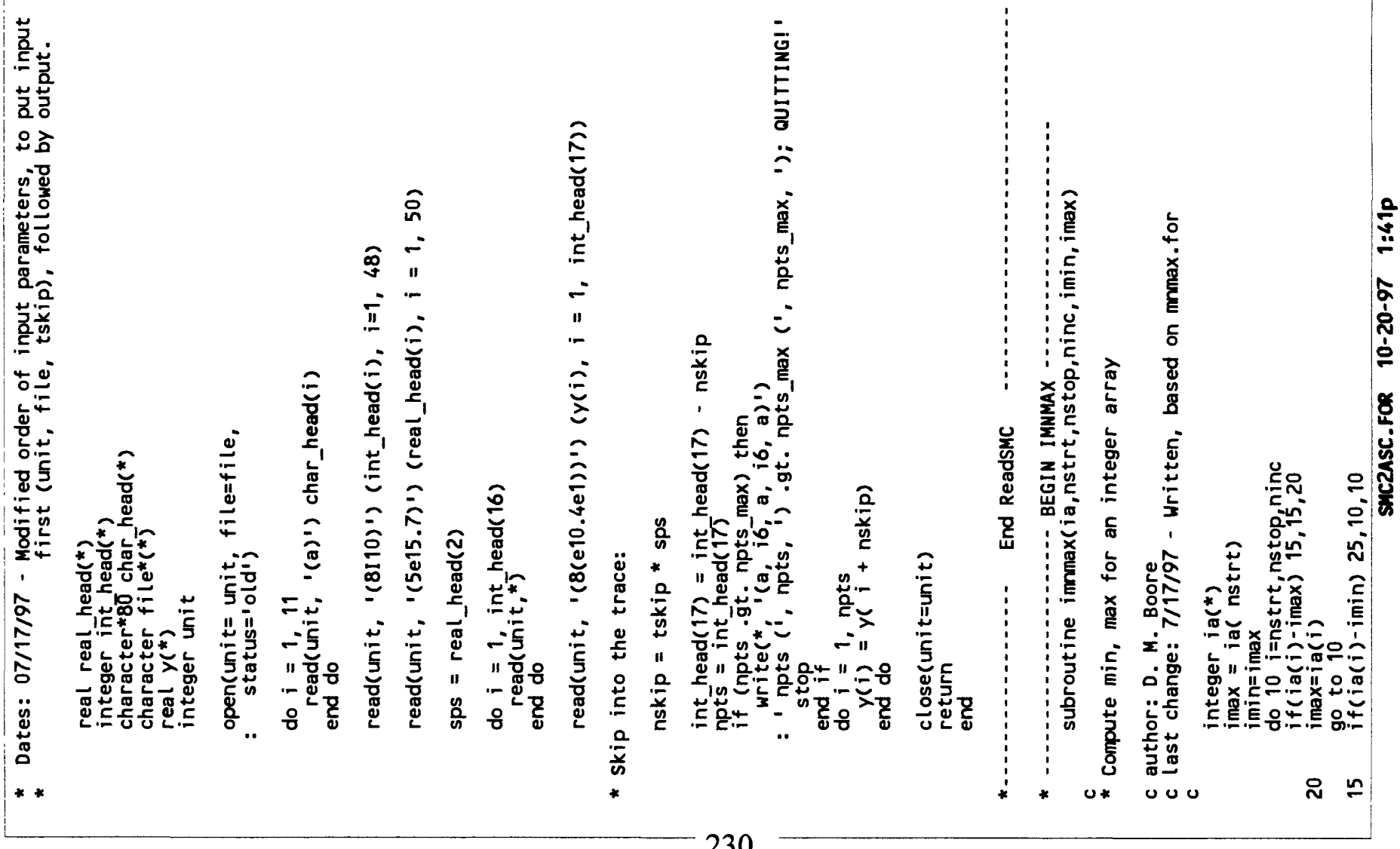


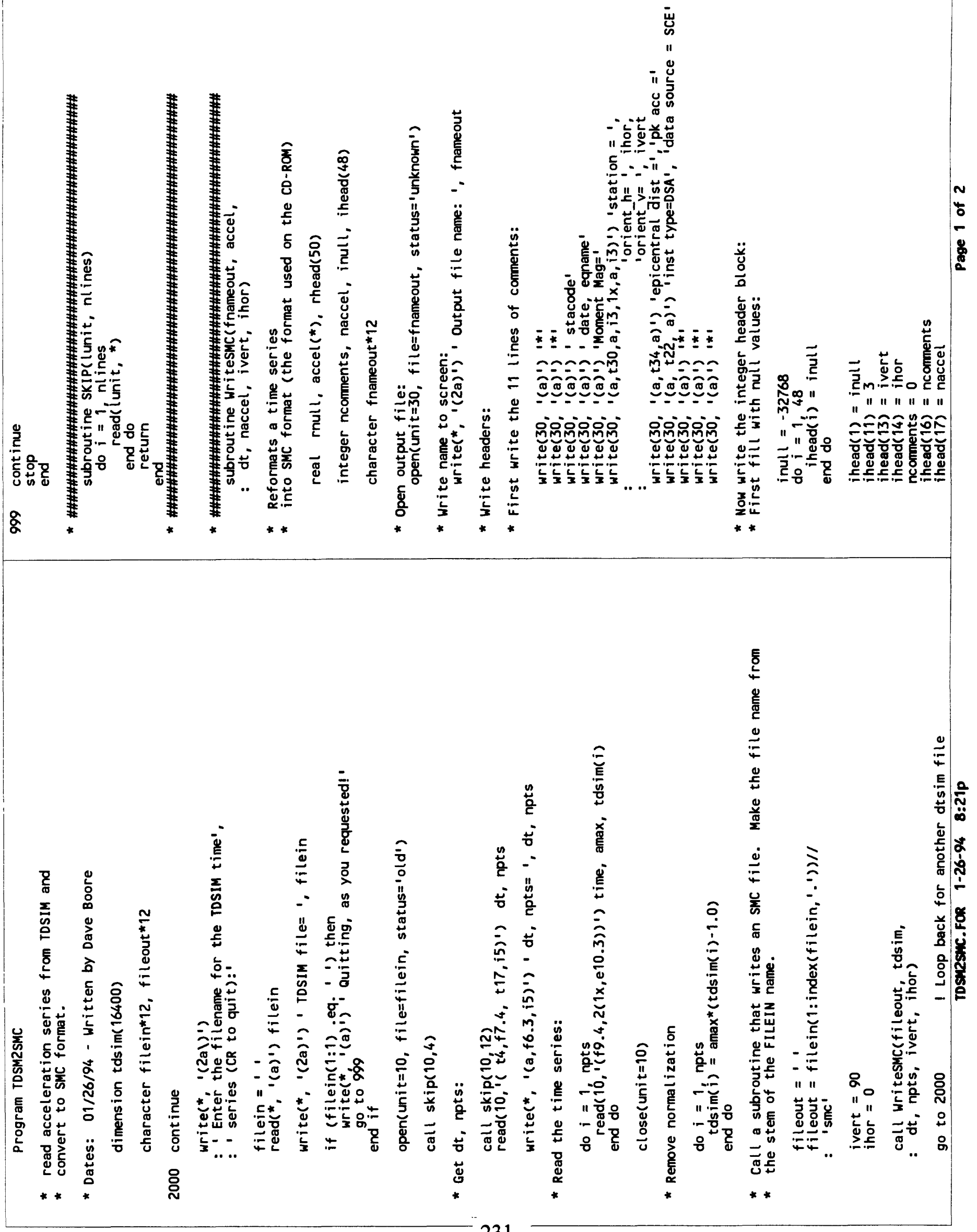




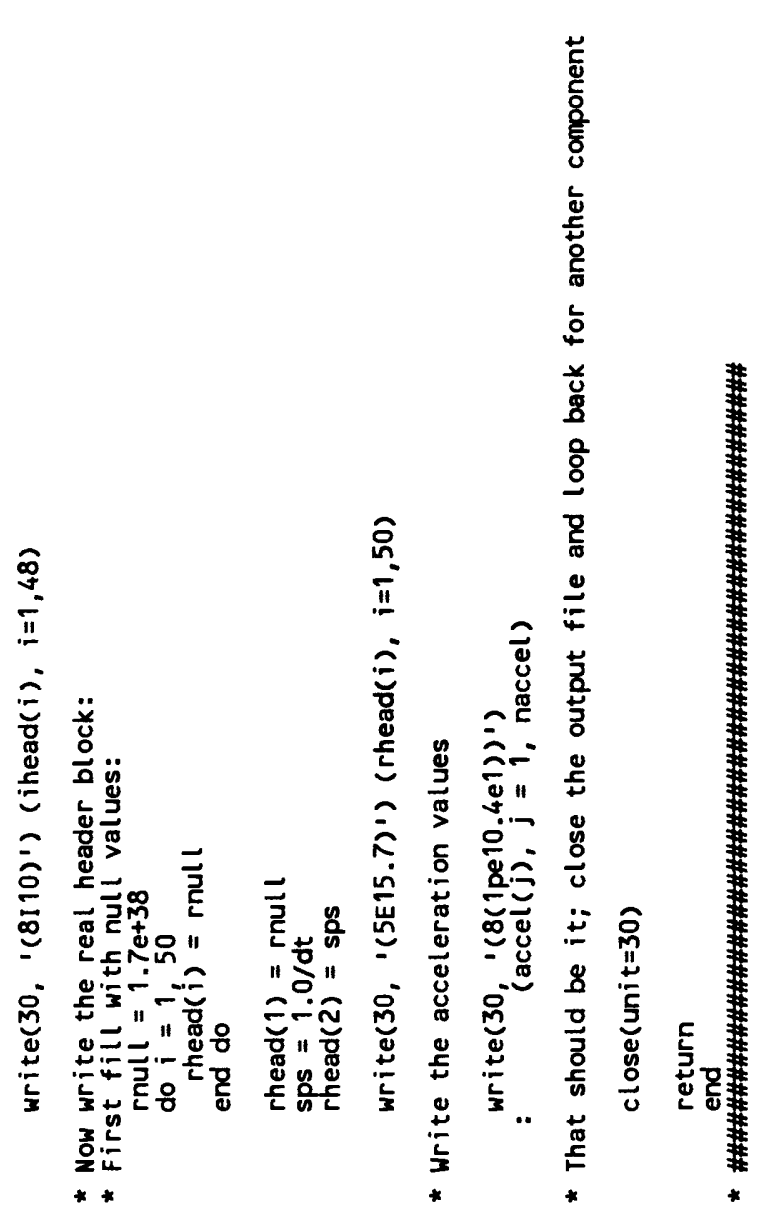




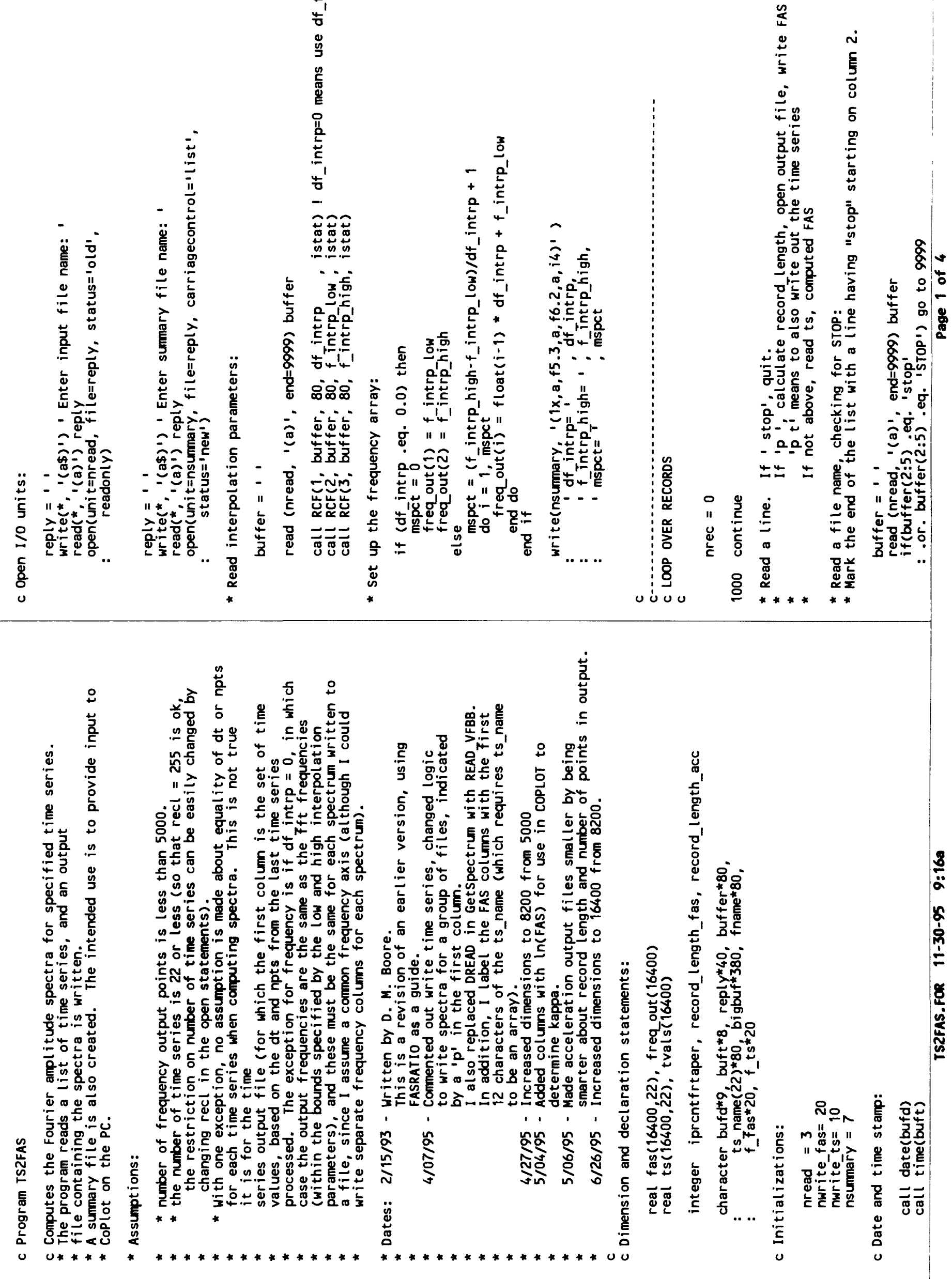




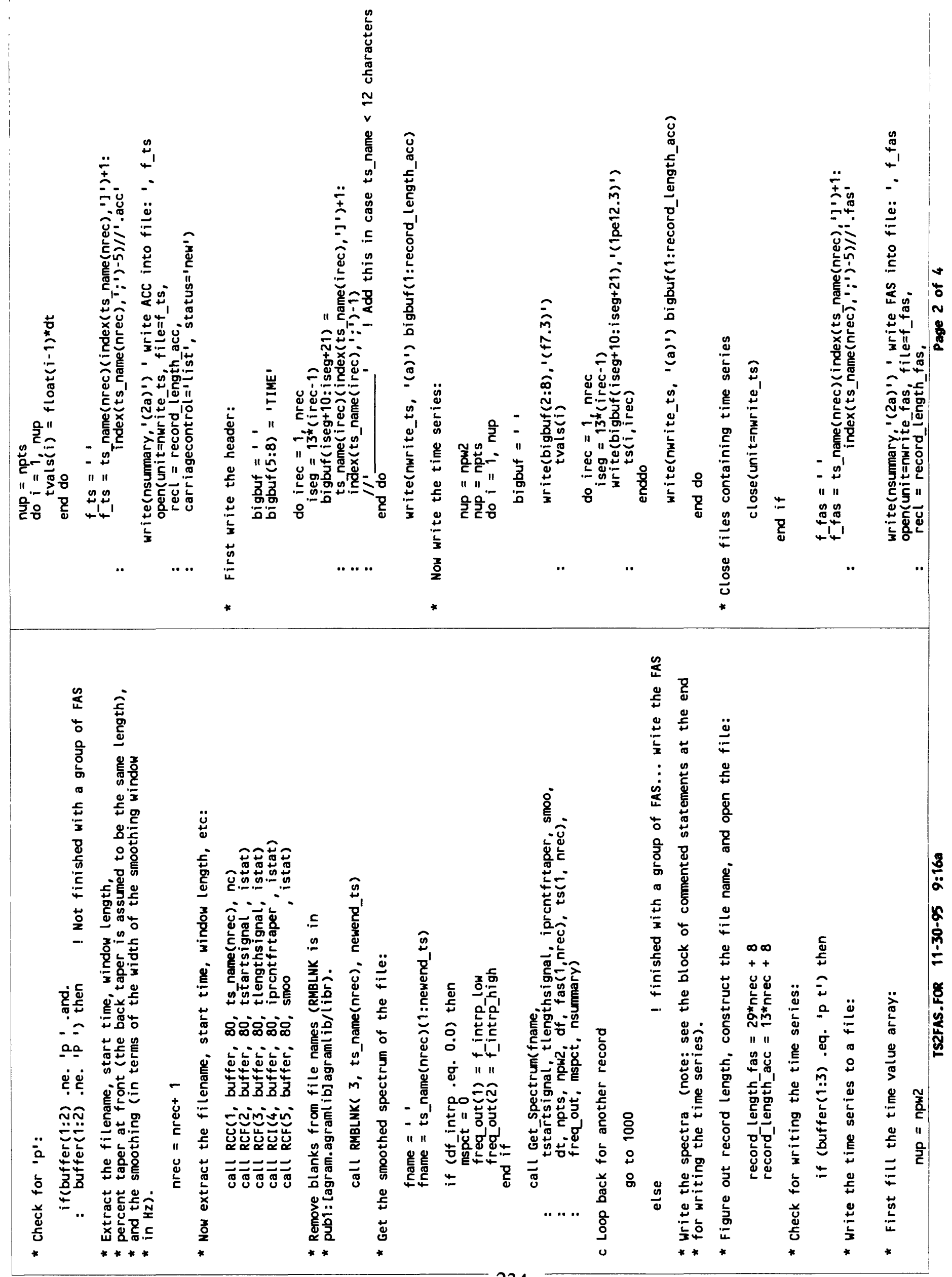



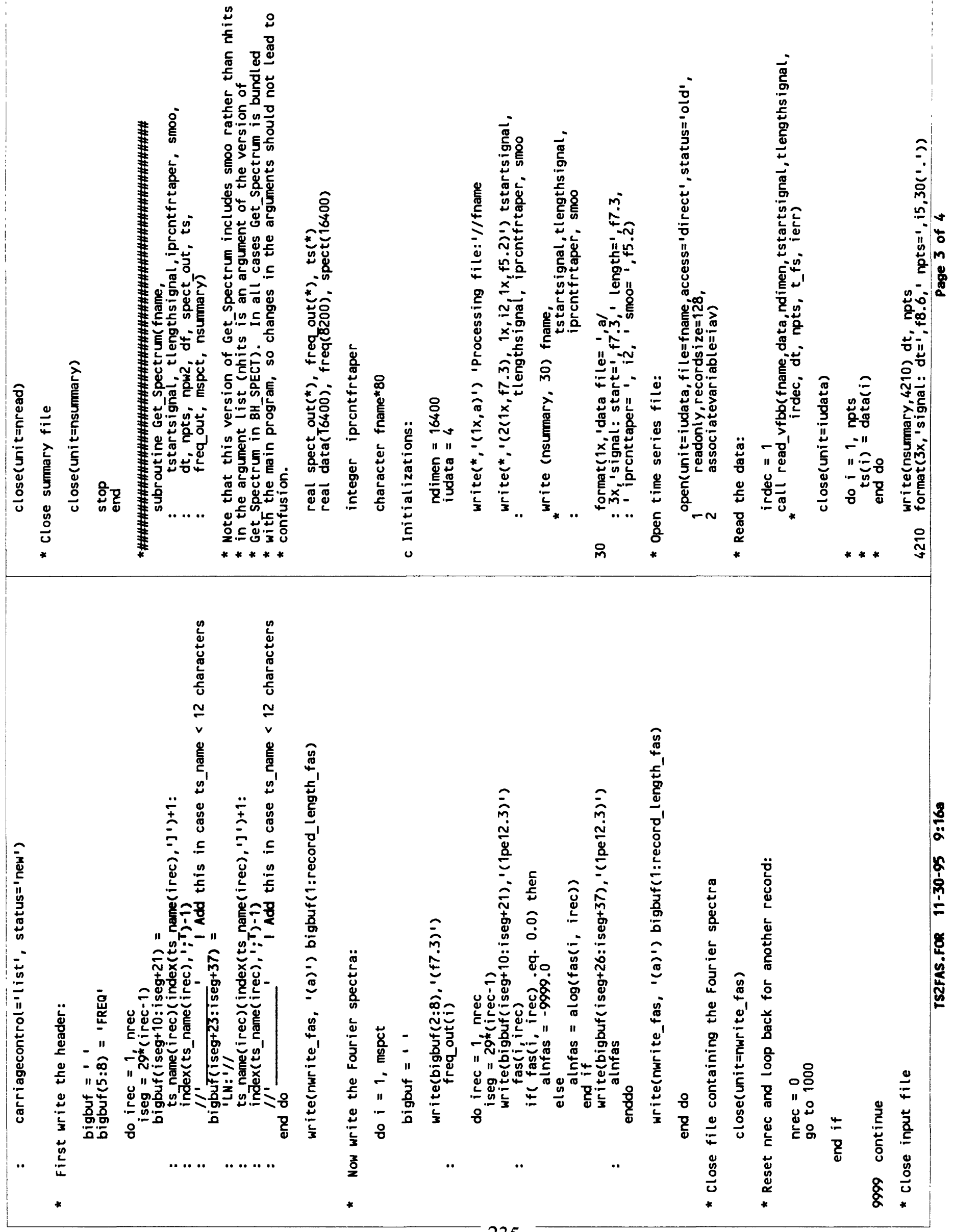

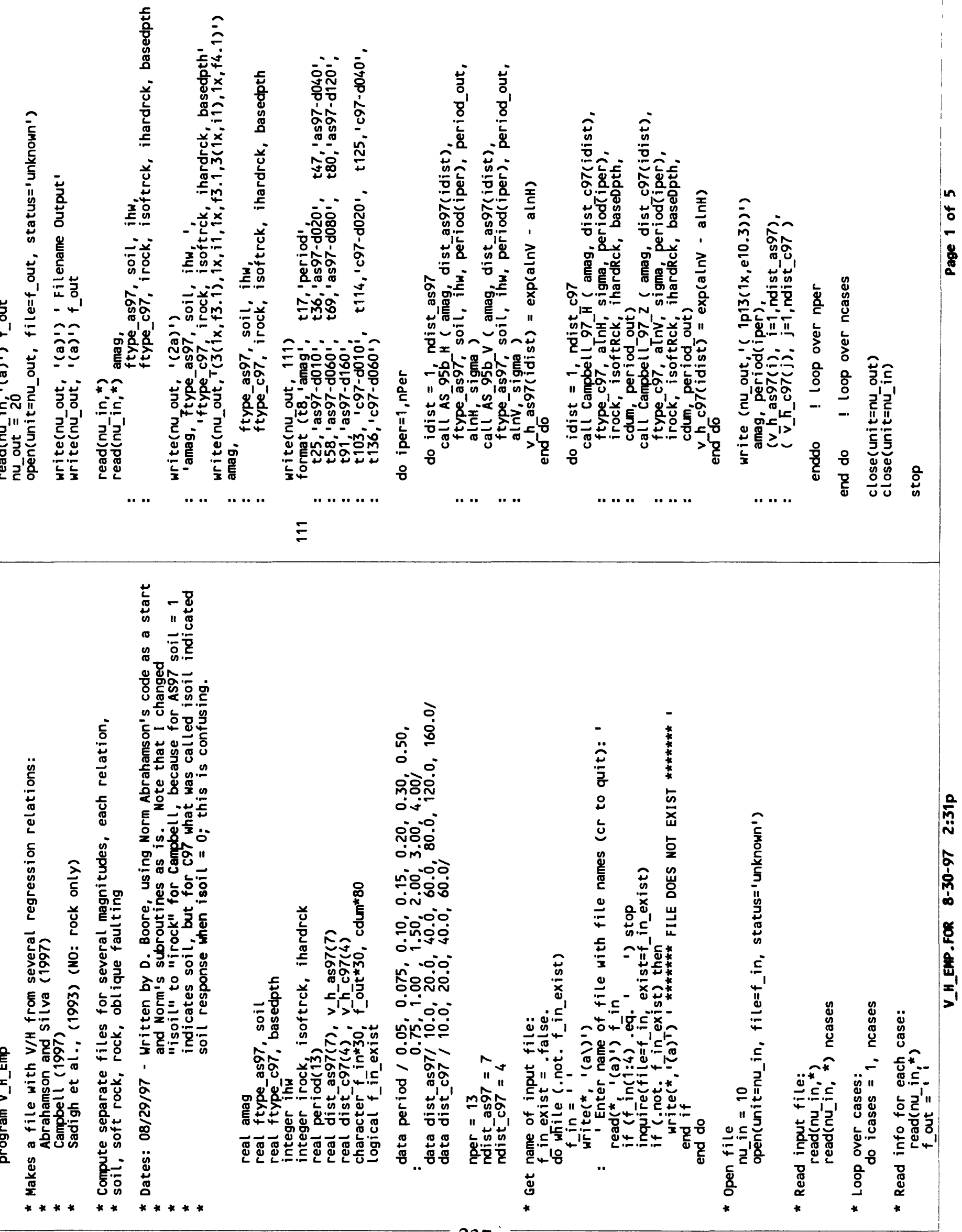
(1)

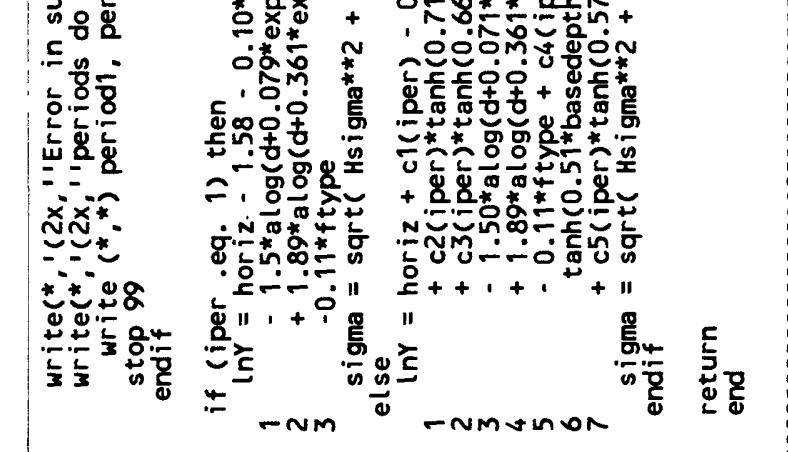

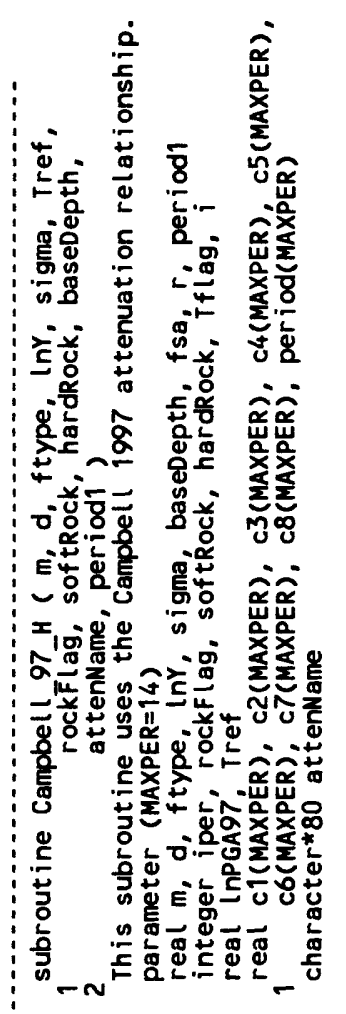

iุ

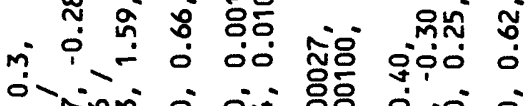

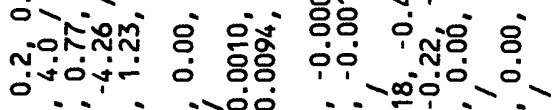
min 8.

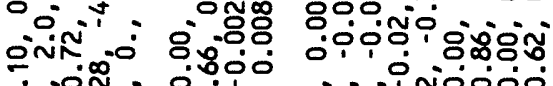

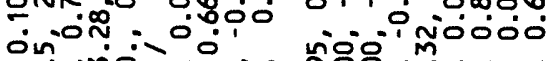
น

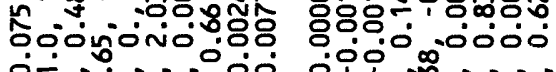

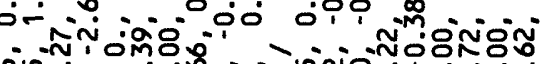

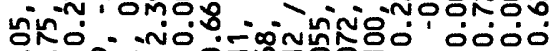
வ0 8in

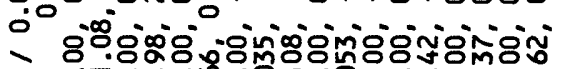
₹

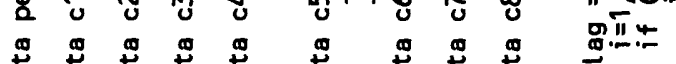

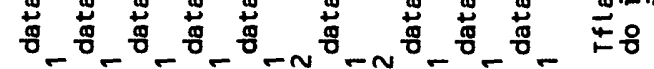
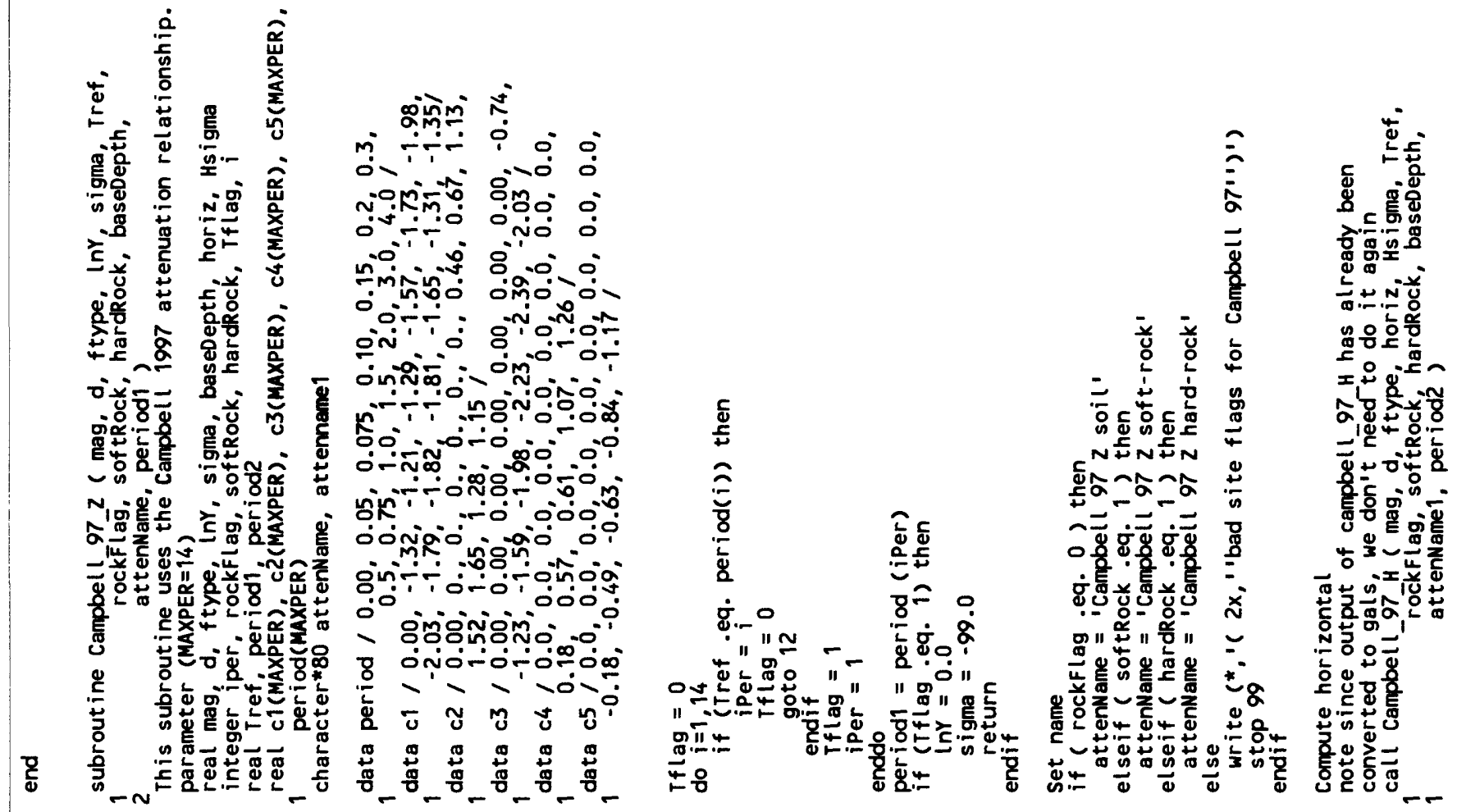


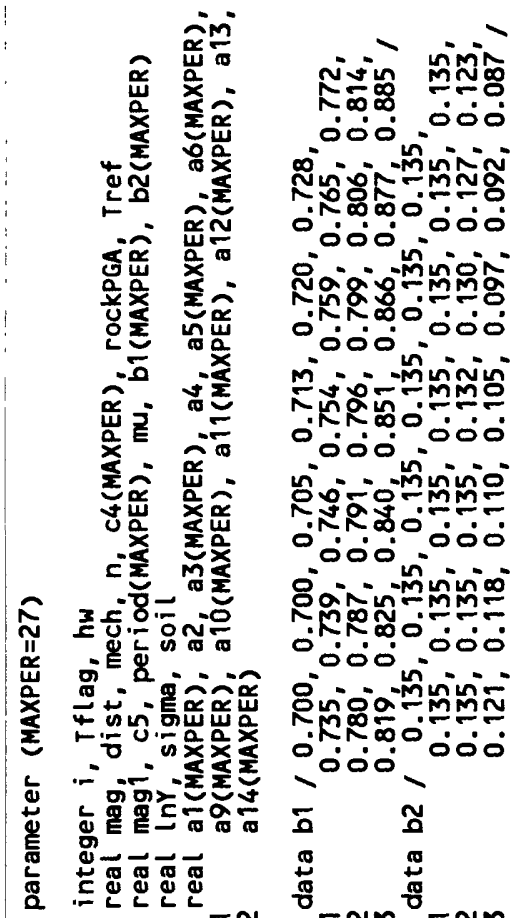

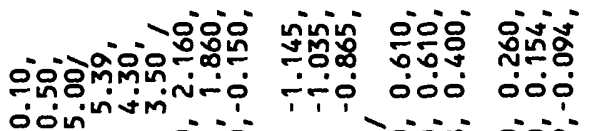

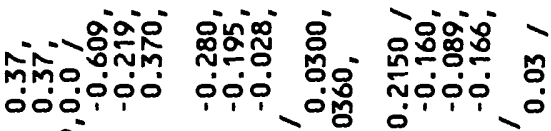
gion

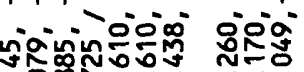

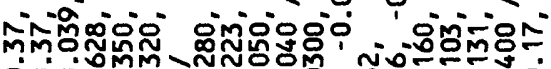
notonn 000 \%o O

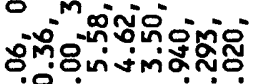
ond mon

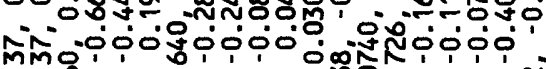
nimp 年 0 mino onm 8. Hnim

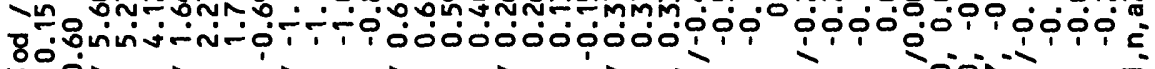

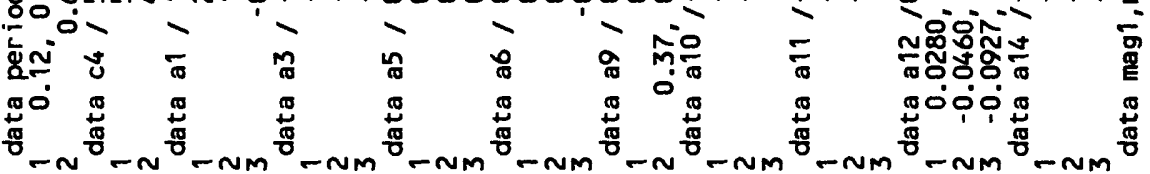

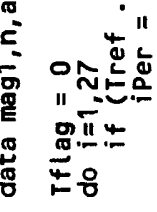




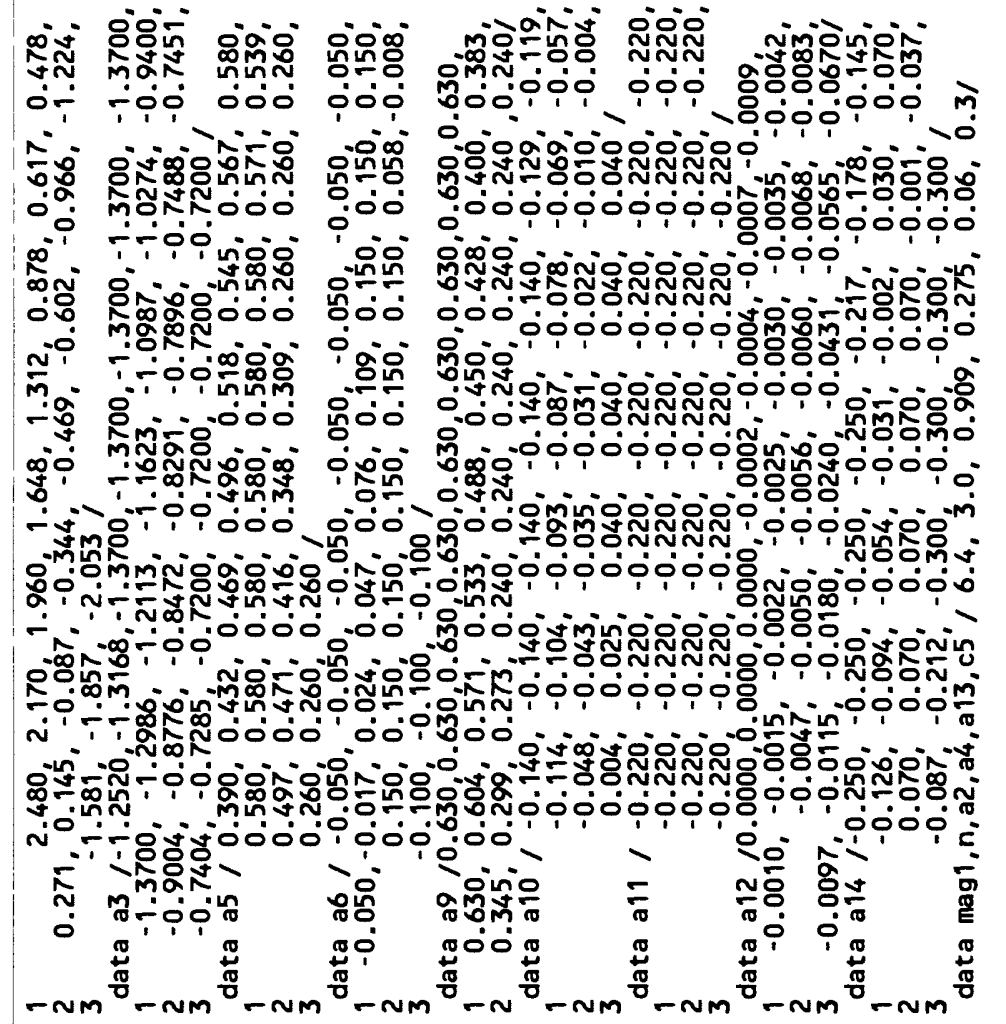

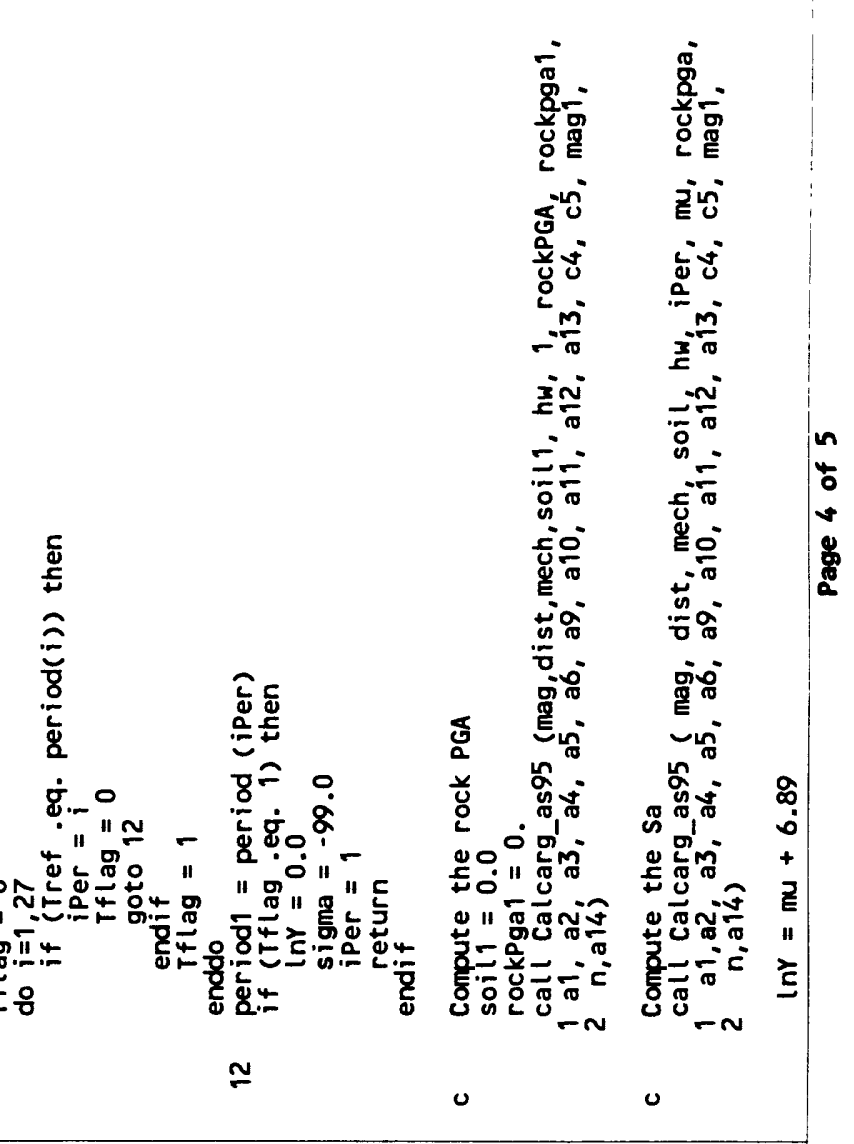

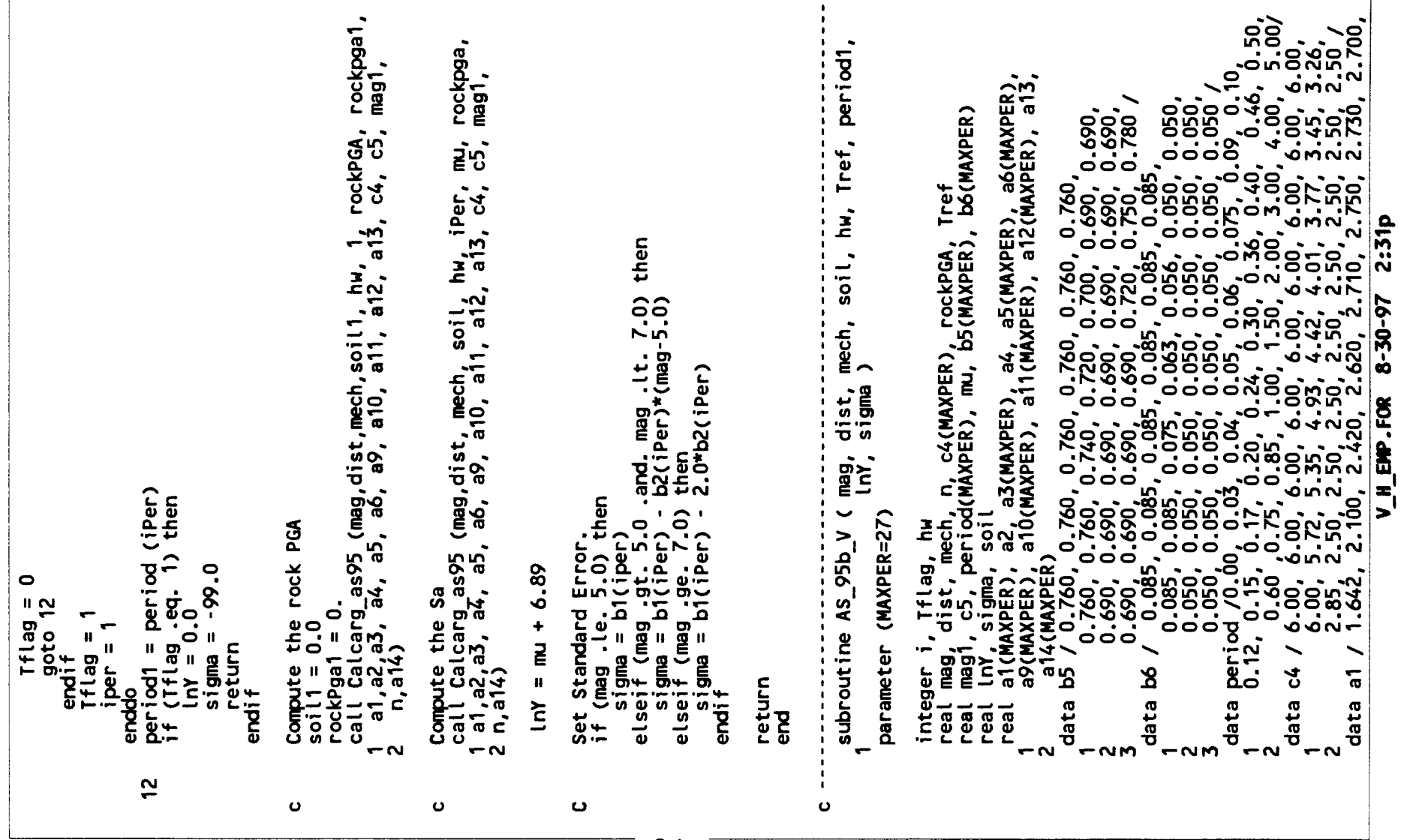




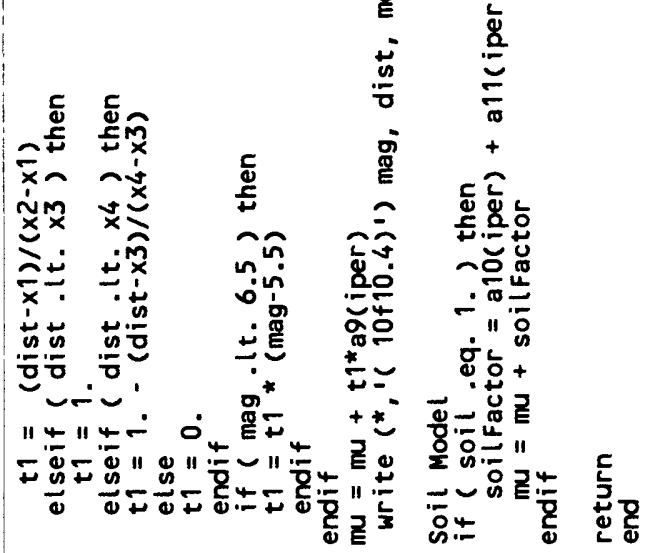

$\stackrel{5}{\frac{c}{5}}$

oิ으.

in

\pm 署

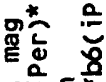

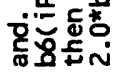

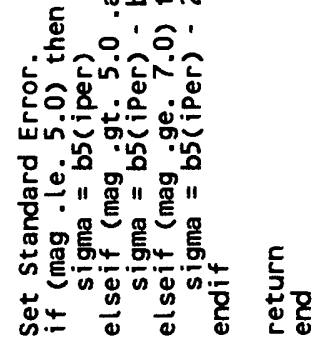

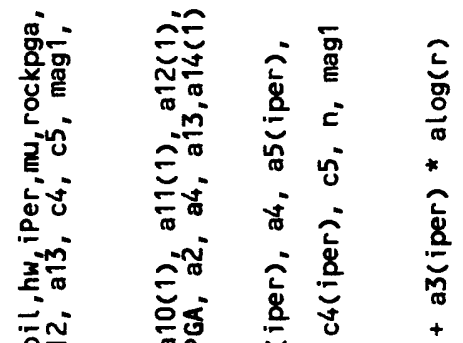

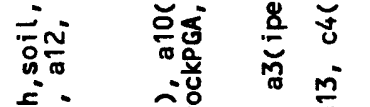

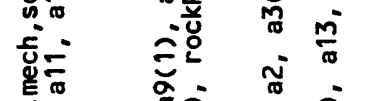

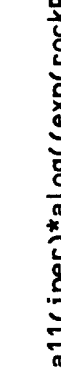

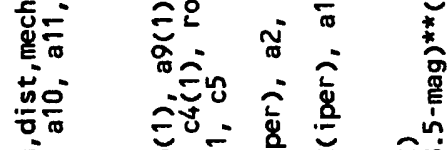

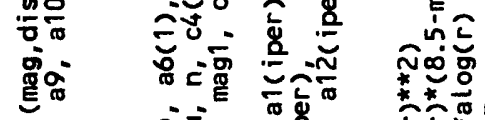

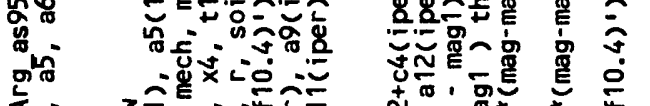

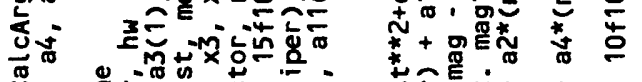

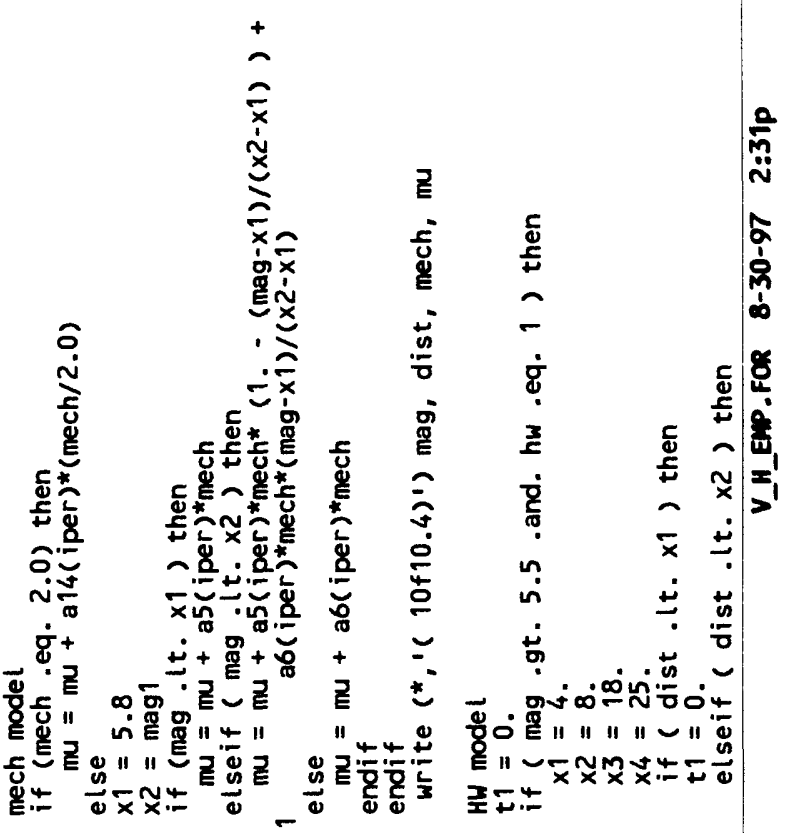

0 

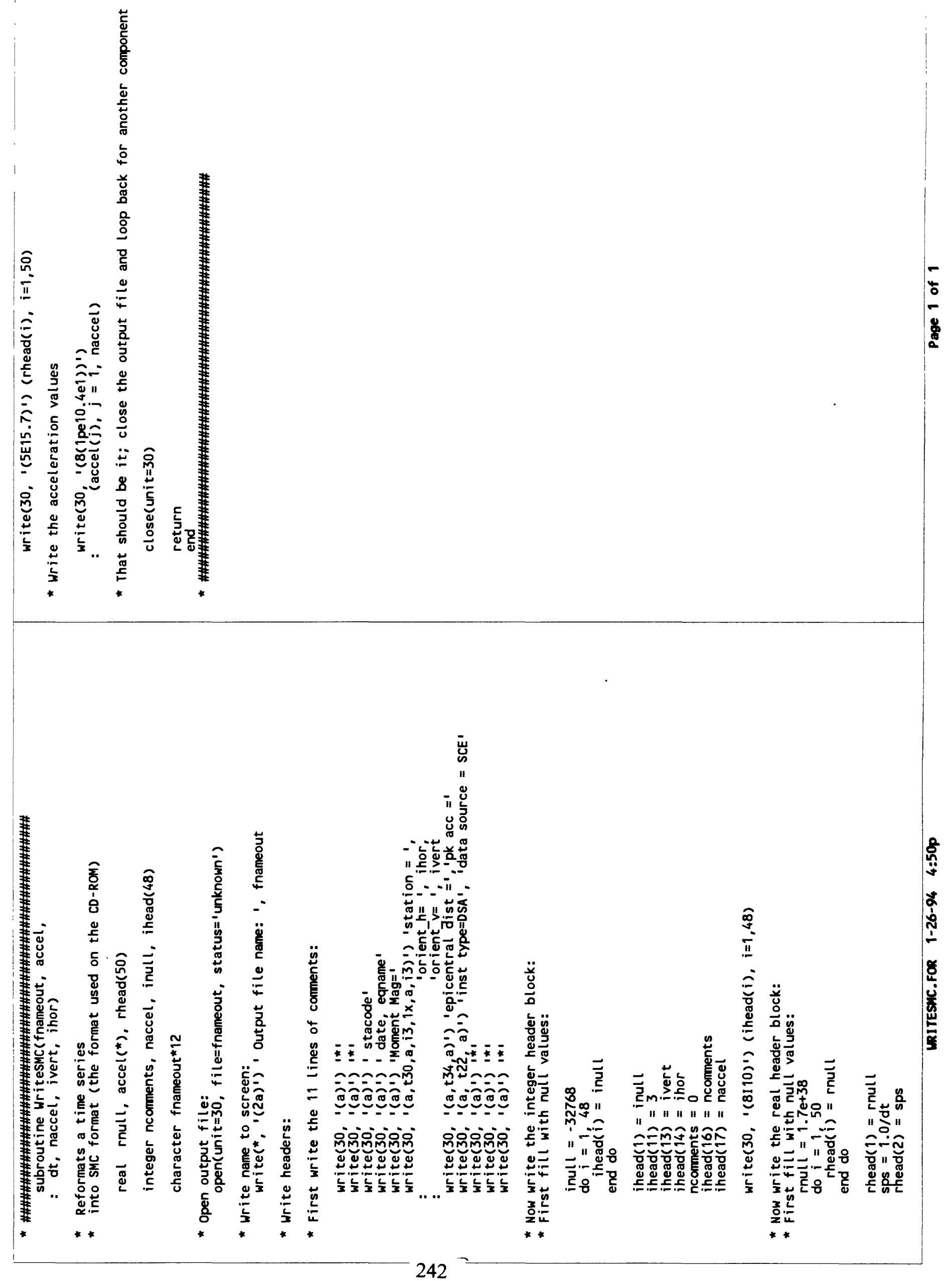


\section{REPRODUCED RROAS BEST AWARABLE COPY}

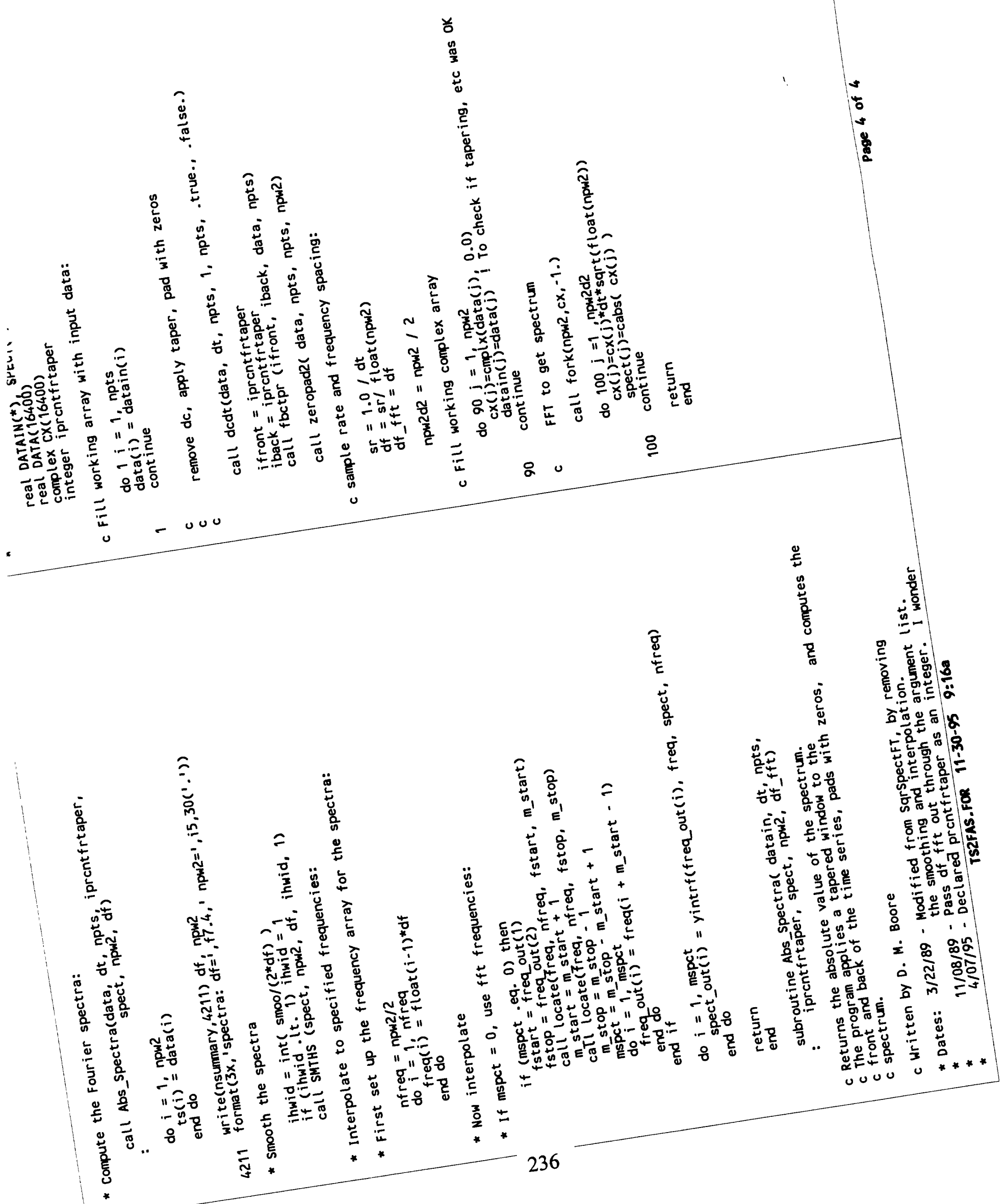

